University of Rhode Island

DigitalCommons@URI

Open Access Master's Theses

2013

\title{
A History of Sea Ice in the Cenzoic Arctic Ocean
}

Cristin Ashmankas

University of Rhode Island, igo2cea@gmail.com

Follow this and additional works at: https://digitalcommons.uri.edu/theses

\section{Recommended Citation}

Ashmankas, Cristin, "A History of Sea Ice in the Cenzoic Arctic Ocean" (2013). Open Access Master's

Theses. Paper 31.

https://digitalcommons.uri.edu/theses/31

This Thesis is brought to you for free and open access by DigitalCommons@URI. It has been accepted for inclusion in Open Access Master's Theses by an authorized administrator of DigitalCommons@URI. For more information, please contact digitalcommons-group@uri.edu. 


\section{A HISTORY OF SEA ICE IN THE CENOZOIC ARCTIC OCEAN BY CRISTIN ELIZABETH ASHMANKAS}

\section{A THESIS SUBMITTED IN PARTIAL FULFILLMENT OF THE REQUIREMENTS FOR THE DEGREE OF MASTER OF SCIENCE}

IN OCEANOGRAPHY 


\title{
MASTER OF SCIENCE THESIS
}

OF

\author{
CRISTIN E. ASHMANKAS
}

APPROVED:

Thesis Committee:

Major Professor

Kathryn Moran

Steve D'Hondt

Christopher Baxter

Nasser Zawia

$\overline{\text { DEAN OF THE GRADUATE SCHOOL }}$

UNIVERSITY OF RHODE ISLAND

2013 


\begin{abstract}
The body of this work focuses on the use and revelations of grain size distributions combined with age models and physical properties of sediments, expanding our understanding of the central Arctic Ocean in the Cenozoic Era. The Integrated Ocean Drilling Program's (IODP) Expedition 302, Arctic Coring Expedition (ACEX), recovered sediment cores from the Lomonosov Ridge, providing the most extensive geologic record of the region ever recovered. This record provides the first opportunity for scientists to directly determine the paleo- ice history of the region, one of high importance to understanding global climate.

Grain size distribution analyses reveal a more consistent ice presence than previously believed possible for the region. The implication suggests a simultaneous transition to a strong cryo-state occurring at both poles. This differs from the previous paradigm of the Antarctic's cryo-state strengthening millennia earlier than the Arctic. A simultaneous transition to a stronger cryo-state implies a global climatic driver, disavowing theories of current and continental shifts driving one pole than the other.

Due to the premiere opportunity to study the cryo-state of the central Arctic Ocean over a significant portion of the Cenozoic, proxies and analysis techniques needed to be developed and updated. A series of proxies for determining the type and intensity of the cryo-state are presented and employed in paleo- analyses. In addition, predictive relationships between grain size distributions and the physical properties of the sediments developed for these glacio-marine sediments allows more extensive analysis that can be used in the future to determine regions of interest nondestructively to the cores. This will be of significant benefit to future expeditions to
\end{abstract}


the region. Finally, the use of grain size to determine and remove the effects of paleocurrents was updated for the unique depositional environment. Interconnecting other elements of the global climate system to the central Arctic's cryo-state demonstrates the true interconnectedness of the global system. 


\section{ACKNOWLEDGEMENTS}

"The greatest glory of living lies not in never falling, but in rising every time you fall."

-Nelson Mandela

My deepest, sincerest thanks to everyone who has been there when I've fallen; ready to support me as I've risen.

My thanks to the advice and assistance provided by: Steve D'Hondt, Chris Baxter, John King, and Becky Robinson. It was with their push that I worked harder and went farther, gaining the knowledge and confidence I needed to pursue my own path. I would also like to thank Harold Bibb, Rob Pockalny, Meredith Clark, and Peter August for their invaluable support, aid, and direction along the way.

The research in this thesis was completed with the samples, data and work of the Integrated Ocean Drilling Program (IODP) and the ACEX scientists. I was supported with a series of funding from the U.S. National Science Foundation (NSF), University of Rhode Island, and the Discovery Channel. It is with such support that the next generation of science is able to progress.

To my graduate associates on bay campus, Meghan, Meghan, Oliver, Julie, Katy, Junsheng, and others, I owe all of you so many small kindnesses. I have been blessed to have so generous colleagues. To my friends, Gretchen, Andria, Rob, Kerri and the rest, thank you for my sanity, which would have been lost with out you. You were there each and every time I needed you. 
Thank you to my family who have agonized with me every step of the way. Your belief and pride in me has provided me the freedom and love to see my dreams through to wherever they may lead. Most children are talked out of their youthful dreams and fancies. You not only never questioned them, you encouraged them. I can't even begin to describe what kind of gift that is or the impact it has made. This thesis is as much yours as it is mine. 


\section{PREFACE}

Expedition 302, Arctic Coring Expedition (ACEX), of the Integrated Ocean Drilling Program (IODP) was the initial attempt at a mission specific platform expedition. It was successfully completed in the summer of 2004, retrieving $\sim 420 \mathrm{~m}$ of core from the Lomonosov Ridge, central Arctic Ocean, recovering a substantial portion of the Cenozoic Era. This was the first such extensive recovery of the region's sedimentary history. I have been investigating the sea ice history of those cores, looking predominantly at the $<2000 \mu \mathrm{m}$ grain size fractions.

The following thesis is presented in a manuscript format, comprising of three chapters outlining much of the research I have completed on the ACEX cores sediment samples. This work both answers some of the questions concerning the central Arctic's paleo- cryo-state as well as raising new avenues of investigation. It is my hope that the following chapters will provide a solid foundation for future Arctic cryo-state investigations, the importance of which cannot be understated to understanding the global climate system.

Chapter 1 of this thesis formulates proxies for various aspects of the cryostate, particularly the form of ice and intensity of the climate's frozen state. These proxies are utilized along with published age models to determine the ages of various climate states. There is particular focus on the different cryo-states present in the neogene and paleogene.

Chapter 2 of this thesis focuses on relationships between the grain size distributions and the non-destructive measurements of a multi-sensor core logger 
(MSCL) or the physical properties of the sediments. These relationships were utilized in the creation of predictive equations, translating the sediment's physical properties into cryo-state proxies. This permits us to investigate through the high- resolution nature of MSCL data, the precise timing of major cyro-state transitions. These transitions are compared to the transitions in the SST record. The methods formulated in this chapter are of particular interest to the conduction of future glaciomarine expeditions.

Chapter 3 of this thesis utilizes a method set forth by others for the investigation of paleo- current intensity. The method commonly referred to as 'sortible silt', uses the mean diameter of the silt fraction in a sample as a measure of current strength. Employing this method, I was able to minimize the winnowing effect of a sample, translating it to a distribution more similar to that found at the original time of deposition. This eliminates much of the high- frequency changes in samples' grain size distributions. It also provided a means of comparing transitions in current strength to those of cryo- state, demonstrating the inter-connected quality of the global system. This interconnected nature was particularly examined in the late Pleistocene. 


\section{TABLE OF CONTENTS}

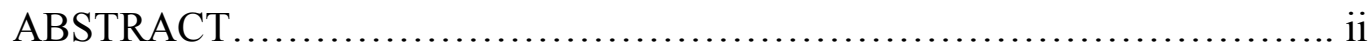

ACKNOWLEDGEMENTS $\ldots \ldots \ldots \ldots \ldots \ldots \ldots \ldots \ldots \ldots \ldots \ldots \ldots \ldots \ldots \ldots$ iv

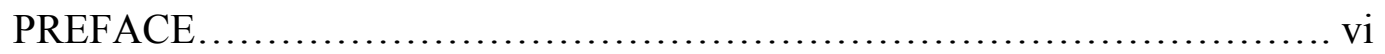

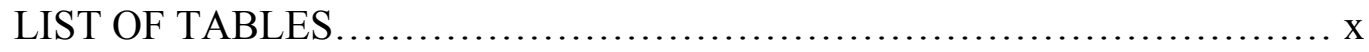

LIST OF FIGURES............................................... xi

CHAPTER 1. ARCTIC CORING EXPEDITION, IODP 302, GRAIN SIZE ANALYSES, REVEALING ARCTIC PALEO- CRYO ENVIRONMENTS
ABSTRACT. 2
INTRODUCTION. 3
METHODS.................................................. 5
RESULTS................................................ 12

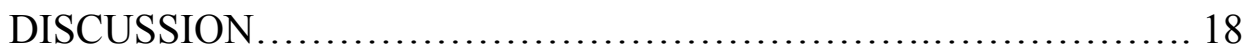
CONCLUSIONS .......................................... 21

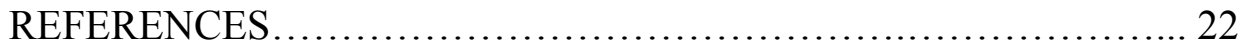
CHAPTER 2. PHYSICAL PROPERTIES AND GRAIN SIZE OF GLACIO- MARINE SEDIMENT AS PREDICTORS OF CRYO-STATES IN THE ARCTIC OCEAN
ABSTRACT.
INTRODUCTION 68
METHODS 69
RESULTS. 72
viii 
DISCUSSION. 75

CONCLUSIONS ............................................... 77

REFERENCES.............................................. 78

CHAPTER 3. LATE PLEISTOCENE CHANGES IN ICE AND CURRENTS FROM THE CENTRAL LOMONOSOV RIDGE, ARCTIC OCEAN
ABSTRACT. 102
INTRODUCTION 103
METHODS 105
RESULTS. 107

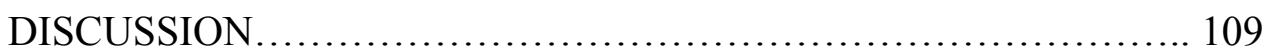
CONCLUSSIONS............................................. 110
REFERENCES................................................. 112

APPENDIX I: NEOGENE GRAIN SIZE DISTRIBUTIONS AND

STATISTICS.

APPENDIX II: PALEOGENE GRAIN SIZE DISTRIBUTIONS AND

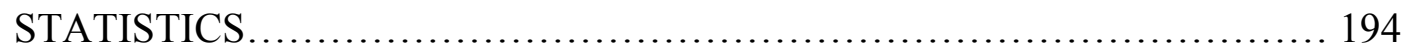

BIBLIOGRAPHY ......................................................... 246 


\section{LIST OF TABLES}

Table 1.1: $\quad$ Summary of grain size distribution methods employed in ice rafted debris studies........................................... 30

Table 1.2: $\quad$ Relationships and key to understanding studies results between grain size distributions, cryo- environments, and relative albedo..... 31

Table 1.3: List of samples that contained no ice rafted debris.............. 32

Table 1.4: $\quad$ List of samples containing anomalously high sand content..... 33

Table 1.5: Abbreviated list of principle components and corresponding variances............................................ 64

Table 2.1: $\quad$ Lists of grain size and MSCL data used in study.............. 80

Table 2.2: $\quad$ Abbreviated list of PCA correlation coefficients to sand percentages.......................................... 88

Table 2.3: $\quad$ Abbreviated list of PCA correlation coefficients to silt percentages............................................ 88

Table 2.4: Abbreviated list of PCA correlation coefficients to clay percentages........................................ 88

Table 2.5: Abbreviated list of PCA correlation coefficients to acoustic wave velocity percentages.................................. 88

Table 2.6: Abbreviated list of PCA correlation coefficients to bulk density percentages......................................... 88 


\section{LIST OF FIGURES}

Figure 1.1: Map displaying ocean circulation patterns in the Arctic Ocean.... 34

Figure 1.2: Bathymetric map of Arctic Ocean indicating the study site......... 35

Figure 1.3: Tertiary diagrams showing previous Arctic studies' grain size distribution findings......................................... 36

Figure 1.4: Ruddiman (1977a) graphs comparing IRD and sea level........... 37

Figure 1.5: Grain Size distribution graph for ACEX sample 302-2A-48X-3W-

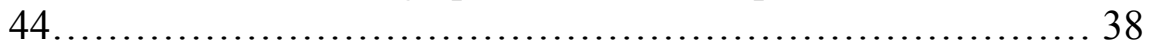

Figure 1.6: Madureira et al. (1997) graph showing the previous use of normalizing IRD samples................................................. 39

Figure 1.7: Map of Arctic Ocean illustrating sea ice transport movements.... 40

Figure 1.8: Grain size distributions for a previous study of McMurdo Sound, Antarctica................................................. 41

Figure 1.9: Grain Size distribution graph for ACEX sample 302-2A-56X-2W-

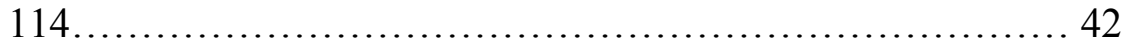

Figure 1.10: Map and seismic cross section of ACEX drill sites............. 43

Figure 1.11: Graph illustrating the site and depth coverage of the ACEX grain samples................................................ 44

Figure 1.12: Backman et al. (2007) age model for the ACEX cores........... 45

Figure 1.13: Tertiary graph comparing ACEX grain size distributions to 1991 ice samples 46

Figure 1.14: Tertiary graph comparing ACEX grain size distributions to 1991 ice samples

Figure 1.15: IRD analysis represented in terms of depth and lithological unit. ... 48

Figure 1.16: IRD analysis graphs for lithological unit $1 / 2 \ldots \ldots \ldots \ldots \ldots \ldots . \ldots 50$

Figure 1.17: IRD analysis graphs for lithological unit $1 / 3 \ldots \ldots \ldots \ldots \ldots \ldots . \ldots 52$ 
Figure 1.18: IRD analysis graphs for lithological units $1 / 4,1 / 5$, and $1 / 6 \ldots . .54$

Figure 1.19: IRD analysis graphs for lithological unit $2 \ldots \ldots \ldots \ldots \ldots \ldots \ldots$

Figure 1.20: IRD analysis graphs for lithological unit 3................ 57

Figure 1.21: IRD analysis represented in terms of sample age........... 58

Figure 1.22: IRD analysis graphs for samples deposited between $44.4 \mathrm{Ma}$ and 51 Ma.................................................. 59

Figure 1.23: IRD analysis graphs for samples deposited between 11.6 Ma and 18.2 Ma.................................................... 61

Figure 1.24: IRD analysis graphs for samples deposited between $0 \mathrm{Ma}$ and 9.4 Ma................................................. 62

Figure 1.25: IRD analysis graphs compared to global mean temperatures as

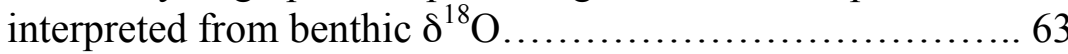

Figure 1.26: Graph comparing IBRD/SIRD to the percentage of Synedropsis.......................................... 65

Figure 2.1: Bathymetric map of Arctic Ocean indicating the study site... 90

Figure 2.2: $\quad$ Steurer and Underwood (2003) clay and bulk density correlation graphs.................................................. 91

Figure 2.3: $\quad$ ACEX sand \% and physical properties correlation graphs..... 92

Figure 2.4: $\quad$ Sand \%- color reflectance correlation coefficient graph....... 93

Figure 2.5: $\quad$ ACEX silt \% and physical properties correlation graphs...... 94

Figure 2.6: Silt \%-color reflectance correlation coefficient graph..........95

Figure 2.7: ACEX clay \% and physical properties correlation graphs...... 96

Figure 2.8: Clay \%- Color reflectance R-value graph.................. 97

Figure 2.9: Graphs comparing model predictions to measured values......98

Figure 2.10: Graphs of the predicted clay, silt, and sand percentages from the MSCL data set. 99 
Figure 2.11: Graphs comparing predicted and measured SST values to previously determined Arctic SST values. 100

Figure 3.1: Bathymetric map of the Lomonosov Ridge, Arctic Ocean indicating the ACEX, ARCTIC '91, and Arctic Ocean-96 coring sites..... 116

Figure 3.2: Graphs showing a comparison between the hydrometer method and Malvern method for sand................................ 117

Figure 3.3: Graphs showing a comparison between the hydrometer method and Malvern method for silt.................................. 118

Figure 3.4: Graphs showing the linear regression relationship between sand \% and mean silt size (SS) for the Quaternary ARCTIC '91 and ACEX samples............................................. 119

Figure 3.5: Graphs showing the ACEX Quaternary samples transformed sand \% and mean silt size (SS) with depth.................... 120

Figure 3.6: Graphs of bulk density, inclination, and magnetic susceptibility for ACEX, ARCTIC '91 and Arctic Ocean-96................ 121 
Chapter 1

“Arctic Coring Expedition, IODP 302, Grain Size Analyses, Revealing Arctic Paleo- Cryo Environments"

by

Cristin E. Ashmankas ${ }^{1,2}$

written for submission to Journal of Paleoceanography

${ }^{1}$ Graduate School of Oceanography, The University of Rhode Island, Narragansett, RI 02882.

${ }^{2}$ Assistant Professor, Natural Science and Mathematics Division, Lesley University, Cambridge, MA 02138. Email: cashmank@lesley.edu 


\section{Chapter 1. Arctic Coring Expedition, IODP 302, Grain Size Analyses, Revealing Arctic Paleo- Cryo Environments.}

\section{ABSTRACT}

Summer 2004 hosted an unprecedented event in Arctic research; the successful coring of Arctic sediments to obtain a paleo-ice record that extends through the Cenozoic Era. Low-resolution grain size analyses of samples taken during the Arctic Coring Expedition (ACEX), IODP 302, reveal five ice rafted debris (IRD) relationships, which we hypothesize to correspond to five distinct Arctic paleo-ice environments. This study defines IRD as the percentage of terrigenous grains $>63$ $\mu \mathrm{m}$. IRD is comprised of both sea-ice rafted debris (SIRD) and iceberg rafted debris (IBRD). IBRD is defined as the percentage of terrigenous grains $>250 \mu \mathrm{m}$. Grain size analyses were completed using a laser diffraction type analyzer (a Malvern Mastersizer 2000). The five relationships and their corresponding environments are: 1) low sand percentage and low coarse sand percentage, indicating a seasonally cold environment with little ice of glacial origin, 2) high sand percentage and low coarse sand percentage, an indication of a sea-ice dominated environment, 3) low sand percentage and high coarse sand percentage, indicative of conditions of considerable iceberg expulsion and low sea-ice production, 4) no sand present, corresponding to a warm ice-free Arctic climate, and 5) an extremely high coarse sand contribution, which supports a river ice dominated site. The earliest indication of IRD in the ACEX record occurs in the Eocene, a time much earlier than the intensification of Northern Hemisphere glaciation of $\sim 3$ Ma. Throughout the Neogene, IRD remains an important component of the sedimentary record. Differentiating modes of IRD in terms of SIRD 
and IBRD is an important step in reconstructing Arctic paleo-environments and the Arctic paleo- albedo contribution.

\section{INTRODUCTION}

The Arctic Ocean is a relatively shallow ocean basin roughly centered on the northern pole of the Earth, with water exchange between the Arctic and the Atlantic Ocean through both the Fram and Davis Straits and with the Pacific Ocean through the Bering Strait (Herman, 1974; Coachman and Aagaard, 1974; Aagaard, 1981) (Figure 1.1). This ocean has a major contributing influence on the Atlantic, Pacific Oceans, and global thermohaline circulation, and is strongly influenced by the Atlantic and Pacific intermediate and surface waters, and the production/dissolution of sea ice (Aagaard, 1981). The Arctic Ocean has two key roles in the Earth's climate system. It acts as a climate regulator by controlling solar insulation at high latitudes with changes of the ocean's albedo through the presence or absence of ice cover and by influencing thermohaline circulation (Singarayer et al., 2006; Dethloff et al., 2006; Curry et al., 1995; Holland and Bitz, 2003; Broecker, 1997; Holland et al., 2001, Rennermalm et al., 2006). It is this quality of the Arctic Ocean that makes it a dynamic location with global implications and of key importance to fully understanding global climate. One of the goals of the Integrated Ocean Drilling Program (IODP) Expedition 302, the Arctic Coring Expedition (ACEX), a multinational study funded through the National Science Foundation (NSF), the IODP, and others is to investigate the paleo sea ice dynamics of the Arctic Ocean's central region (Backman et al., 2004). 
Processes within the Arctic Ocean act as controlling mechanisms for heat and freshwater (Coachman and Aagaard, 1974; Aagaard, 1981; Aagaard and Carmack, 1989). The dominating presence of sea ice across the Arctic Ocean greatly increases the region's albedo and facilitates the redirection of solar radial heat/energy back into space (Singarayer et al., 2006; Dethloff et al., 2006; Curry et al., 1995; Holland and Bitz, 2003). The loss of heat feeds into the formation of ice in the region, sequestering freshwater and feeding back into strengthening the albedo. This strengthening albedo can be the result of exclusively sea ice, whose formation has only a temperature dependence. It can also be the result of continental glaciation, whose formation is dependent on both low temperatures and high humidity. Sea ice formation isolates much of the local sources of humidity needed for glacier formation. Alternatively, glacier formation sequesters water onto the continents, lowering sea level, raising salinities, and thus lowering the temperature required for sea ice production. This means that while at the climate extremes, there can exist no ice or an abundance of both forms of ice, it is likely that in periods of transition or average climate the production of one form of ice may negatively impact the production of the other. With open water having a much lower albedo than ice-free terrain, the greater presence of sea ice has a larger effect on the Earth's albedo than a greater presence of glaciers. Through its links to the global ocean system and its considerable effect on the global solar insolation, the Arctic Ocean is a key component of the global climate system.

Various authors had determined the transition to a perennially glaciated Northern Hemisphere as occurring roughly, 2.6-3.1 Ma (Shackleton et al., 1988; 
Maslin et al., 1998; Zachos et al., 2001). The presence of IRD in the North Atlantic and mid-latitude $\delta^{18} \mathrm{O}$ records are the evidence used for assigning the transition to the late Pliocene (Shackleton et al., 1988; Maslin et al., 1998; Knight et al., 2002; Raymo et al., 2006; Reeh, 2004; Ruddiman, 1977 a, b; Zachos et al., 2001). The advent of the ACEX's ability to retrieve deep cores from beneath the Arctic's ice-covered waters, allows us to redefine the paleoclimate transition to a cold Arctic without the reliance upon these external Arctic proxies.

The cores recovered during ACEX were from locations on the Lomonosov Ridge (Figure 1.2). The Lomonosov Ridge is a rifted portion of the Eurasian continent, separated $\sim 57$ Ma by the formation of the Gakkel Ridge (Backman et al., 2006). Subsequently, sediments have been captured on the ridge, providing a record for much of the Cenozoic Era. The sites cored were situated high on the Lomonosov Ridge, above the limit of the turbidite zone, providing for a usable ice rafted debris record. While this record proved to be incomplete with sediment record hiatuses from 9.4 to 11.6 Ma and 18.2 to 44.4 Ma (Backman et al., 2007), we are able to use it to distinguish periods of sea ice and or glacier intensity, subsequently inferring changes in the Arctic's albedo contribution.

\section{METHODS}

\section{Grain Size Analyses}

The initial step to determining the paleo-ice environment of the Cenozoic Arctic Ocean is to determine the grain size distribution of the cores. To accomplish this, each of the sediment samples was analyzed for the individual grain size 
distribution of terrigenous material. The samples were chemically cleaned of biological components in order to isolate the terrigenous portion of each sample. The cleaning process is adapted from a combination of the processes employed by Dr John King's lab (personal communication) and Mortlock and Froelich (1989). The process involved using acetic acid to rid the samples of biogenic carbonate, hydrogen peroxide to remove the lipids in each sample and sodium carbonate to eliminate the biogenic silicate. Approximately $20 \%$ of the samples were visually examined to ensure that only terrigenous material remained. The samples were then steeped in a solution of sodium hexametaphosphate for at least 48 hours to ensure that the clay particles were neutralized and no flocculation would occur, skewing the grain size results. Each of the biologically cleaned samples were then run on the Malvern Mastersizer 2000, a laser diffraction particle sizing system. The Mastersizer operates using both a red light laser and a blue light laser. By operating with lasers at two different wavelengths of light the Mastersizer increases the accuracy and precision of the results. The Mastersizer was set to analyze each sample in a general mode and not material specific, since each sample contained multiple mineral components, which could change from sample to sample. These data were then compiled into half phi size bins (phi being a scale of grain size equal to $-\log _{2}($ diameter of grain)). The Mastersizer sub-sampled each sediment sample three times, determined the grain size distribution and then averaged the three sub-samples. The averaged data set was then transferred into a Microsoft Excel worksheet.

The entire grain size distribution from clay through sand was collected with this method. The focus of this study is on the sand portion, using the finer sediments 
as a means of normalizing the sand contribution. The presence of any sand sized grain $(>63 \mu \mathrm{m})$ is indicative of a frozen environment, whether it is sea-ice or iceberg (Bischof, 2000; Lisitzin, 2002). The absence of any sand is suggestive of an Arctic environment where the climate was, on average, above freezing annually.

\section{Ice Rafted Debris and the Glacial Environment}

Ice rafted debris (IRD) present in sediment records reveals the presence of ice at a deep ocean location at some time in the geologic past (Jakobsson et al., 2001; Poore et al., 1993; Phillips and Grantz, 1997; Thiede et al., 1989; Gyllencreutz, 2005; Prins et al., 2002; Clark, 1996; Ruddiman, 1977a, b; Sakamoto et al., 2005; Lisitzin, 2002; Eldrett et al., 2007; Bischof and Darby, 1997: 1999; Darby et al., 2002; Bischof et al., 1996; Krissek et al., 1989; Norgaard-Pedersen et al., 1998; Heinrich, 1988; Hald et al., 2004; Nam et al., 1995; Bischof et al., 1999; Bischof, 2000; Winter et al., 1997). Ice is capable of rafting the complete range of sediment sizes from clay to boulder and releases them onto the seafloor in undifferentiated deposits, distinguishing them from turbidite deposits. However, the entire suite of sediment sizes is not useful when determining the cryo- history of an ocean basin. The fine component of sediments, clay and silts, may be corrupted by fluvial and eolian sources. Kotlyakov and Gordienko (1982) found at the Camp Century Station, a modern research station located on the Greenland ice sheet that the aerosol contribution to the site was 0.04 to $8 \mu \mathrm{m}$ in size and contributed $0.24 \%$ of the sediments entrained in the glacier core.

Ruddiman (1977a, b), in studies of ice rafted debris in the North Atlantic, determined that an insignificant portion of the coarse component of sediments, gravel to boulder, 
are included in 6 to $9 \mathrm{~cm}$ diameter cores, excluding them as a reliable indicator or the presence of ice. This leaves the sand component (63 $\mu \mathrm{m}$ to $2000 \mu \mathrm{m}$ ) as the reliably collected and uncorrupted component of sediments to be used in the determination of paleo- ice presence and subsequently -cryo environments (Ruddiman, 1977a,b; Ruddiman and Glover, 1972; Ruddiman and JOIDES, 1991; Smythe et al., 1985; Ruddiman and McIntyre, 1976, 1977, 1981, 1984; Ruddiman et al., 1986). A study by Vanney and Dangeard (1976), examining the sediment size ranges entrained in icebergs and iceberg-related deposits in Baffin Bay, determined that silt comprised 40$60 \%$, clay $20-40 \%$ (the higher values found at sites in current-protected depressions), and gravel/pebble $1-10 \%$. The combined contributions of silt and sand typically comprise $50-80 \%$ of both the icebergs and their deposits, showing cryo- sediments to be predominately laden with silt and sand size IRD. Nurnberg et al. (1994) studied the sand, silt, and clay fractions of sea ice and icebergs taken in the central Arctic Ocean region during a 1991 research cruise. The analyses showed similar ranges as the Vanney and Dangeard (1976) study (Figure 1.3). This also shows that when analyzing the sand component in its totality there is no significant difference in the sand percentage entrained in sea ice and icebergs, illustrating the need for a method to reliably determine the sea ice and iceberg contributions.

Ruddiman (1977 a, b) found that the sand fraction (63 $\mu \mathrm{m}$ to $2000 \mu \mathrm{m})$, representing ice rafted debris from sea ice and icebergs, increases during glacials and decreases during inter-glacials (Figure 1.4). In response to the Ruddiman (1977a, b) study, a number of more modern studies have adopted the use of $63 \mu \mathrm{m}$ to $2000 \mu \mathrm{m}$ for determining the Arctic's cryo- strength (Jakobsson et al., 2001; Poore et al., 1993; 
Phillips and Grantz, 1997; Thiede et al., 1989; Gyllencreutz, 2005; Prins et al., 2002;

Clark, 1996; Sakamoto et al., 2005; Lisitzin, 2002; and Eldrett et al., 2007). The 63 $\mu \mathrm{m}$ barrier for defining ice rafted debris is also supported by analyses of the individual grain size distributions of the ACEX core samples (Figure 1.5). All of the samples analyzed contained sediments for the entire silt range (4 to $63 \mu \mathrm{m}$ ), this included the samples that contained no sand contribution. In those samples, there is consistently sediment up to $63 \mu \mathrm{m}$ in size, but no larger.

Lisitzin (2002) and Madureira et al. (1997) employed the ratio of the number of ice rafted grains to total number of grains counted to normalize the IRD analysis (Figure 1.6). While this particular study looked at iceberg rafted debris (IBRD), by defining the ice rafted grains as those particles $>125 \mu \mathrm{m}$, the use of the ratio enhances small differences in the sand fraction percentages.

In this study of the ACEX cores, we employ a similar approach to Madureira et al. (1997). Instead of a grain point count, we use the $63 \mu \mathrm{m}$ to $2000 \mu \mathrm{m}$ sand fraction percentage in a ratio to the finer sediment (silt and clay) percentage to interpret glacials and inter-glacials or times of more intense cryo- environments and less intense cryo- environments.

\section{Sea Ice versus Iceberg Rafted Debris}

The occurrence of IRD permits us to study the possible ice environment at the time of deposition. This can be achieved with the stipulation that coarser sands characterize an environment dominated by icebergs and finer sands by sea-ice (Bischof et al., 1999; Bischof, 2000; Winter et al., 1997; Lisitzin, 2002). The 
understanding that icebergs carry coarser sand material led Bischof and Darby (1997, 1999), Darby et al. (2002), Bischof et al. (1996), and Krissek et al. (1989) to choose to utilize a minimum grain size of $250 \mu \mathrm{m}$ in their studies of iceberg rafted debris (IBRD). Icebergs carry a complete suite of sediment sizes. However, Kotlyakov and Gordienko (1982) determined at the Camp Century Station, Greenland (a location of Arctic iceberg origin) that sediments entrained in the glacier ice typically ranged from $2 \mu \mathrm{m}$ to $2000 \mu \mathrm{m}$, a silt- sand dominance. Ruddiman and McIntyre (1976) assigned sediments with $>2 \%$ of particles $>550 \mu \mathrm{m}$ as iceberg rafted debris (IBRD) after directly investigating the sediment load of Arctic icebergs. Lisitzin (2002) subsequently determined that IBRD samples have $\sim 2.9 \%$ in the $>500 \mu \mathrm{m}$ and $<1 \%$ in pebble or greater. Bellair et al. (1964) found the median diameter of sediments from icebergs calved from Adelie Land, Antarctica to be $35 \mu \mathrm{m}$, this value includes the silt and clay fraction. Mulholland (1976) found studying Massachusetts' glacial till that the statistical mode of sediments was $125-177 \mu \mathrm{m}$, this range of values is typically reduced in clay and silt, the finer fractions having been transported away. These mean values are larger than that of sea ice (Table 1.1).

Reimnitz et al. (1993a, b, 1998) compared in the Beaufort Sea sediments in sea ice to bottom sediments. They found that sea ice lacked coarse material, sand represented $<2 \%$ of any given sample, and that the samples were dominated by silt and clay. Due to the circulation pattern and direction of ice drift in the Arctic Ocean (Figure 1.7), the ACEX IODP 302 sites in the central Arctic Ocean, Lomonosov Ridge, typically are covered with sea ice originating from the Siberian shelf. Modern studies of the Siberian shelf sediments entrained in sea ice lack coarse-grained 
material and are characterized by fine-grained glacial material, rarely exceeding 250 $\mu \mathrm{m}$ in diameter (Lisitzin, 2002). Based on these earlier studies, recent studies, (Bischof et al., 1999; Bischof, 2000; Winter et al., 1997) have broken the sand size fraction into a $>63$ to $<250 \mu \mathrm{m}$ portion to represent sea ice and a $>250 \mu \mathrm{m}$ portion to represent glacial ice.

Additional studies of the granulometric composition of sea ice compared to icebergs supports the use of the coarser sand fraction to represent IBRD and the finer sand fraction to represent sea ice rafted debris (SIRD). Dreimanis and Vagners (1971) found that as one moves from a moraine (a region of sediment entrainment for icebergs) out over the continental shelf (a region of sediment entrainment for sea ice) less sand is present and more silt dominates. Lisitzin and Chernyshova (1970) and Lisitzin (1961a) working in the North Pacific and Bering Sea determined the coarse sand in cores to be glacial in origin and the fine sand-silt sediments (missing coarser sand material) were sea ice in origin.

Finally, these determinations have been further enforced through sediment trap studies in both the Arctic and Antarctic (Wefer et al., 1982, 1990; Honjo 1980; Lisitzin et al. 1994). By examining Antarctic grain distributions from the region around McMurdo Bay, we can more clearly see the grain size distribution differences for icebergs and sea ice (Figure 1.8). The grain size distributions of the icebergs are clearly skewed to the coarser sand fractions, while the sea ice is skewed to the finer sand fractions. One can distinguish in the bottom sediment samples, which sample sites are predominately influenced by sea ice and which are influenced by icebergs (Barrett and Treves, 1981). The use of $250 \mu \mathrm{m}$ as a division between sea ice and 
iceberg rafted debris is further supported by analysis of individual ACEX grain size distributions (Figure 1.9). A number of ACEX samples with significant percentages of fine sand (63 to $250 \mu \mathrm{m}$ ), have either no sand contribution or diminished sand contributions $>250 \mu \mathrm{m}$.

Goldstein (1983) presents and defines a term $\mathrm{R}$ which is the ratio of iceberg (I) to sea ice (SI) and claims iceberg material is distinguished by particles $>500 \mu \mathrm{m}$ and that Arctic Siberian sea ice is classified by finer material with $\sim 90 \%$ of particles being $<100 \mu \mathrm{m}$ in size. He subsequently found that samples from Alpha Ridge, Arctic Ocean, showed that around the white-pink layers, enriched in carbonates, corresponded to periods of greater iceberg presence as represented by high $\mathrm{R}$ values.

By dividing the sand sized particles into sea-ice dominated contribution (63$250 \mu \mathrm{m})$ and iceberg dominated contribution $(250 \mu \mathrm{m}-2000 \mu \mathrm{m})$ and by analyses of one contribution compared to the other, this study of central Arctic paleo- ice environments classifies the type of paleo-ice environment. These analyses are normalized and enhanced by using the R-value (I/SI).

\section{RESULTS}

The ACEX cores are the initial attempt of the Integrated Ocean Drilling Program (IODP) to utilize a mission specific platform, which allowed the coring ship to remain on site in a dense ice flow. This methodology allowed the recovery of multiple sediment cores, retrieving much of the present lithology. ACEX attempted core recovery at four sites on the Central Lomonosov Ridge, recovering $420 \mathrm{~m}$ of sediment (Figure 1.10). The four sites were chosen along a previously retrieved seismic line, AWI-91090. Sediments from these sites were used to create a composite 
record, representing the paleo-environments of the Cenozoic Central Arctic Ocean (Moran et al., 2006). The composite record was ultimately comprised of $\sim 67 \%$ of the sediment present at the sites. The majority of the recovered sediment (78\%) was from the upper $271 \mathrm{~m}$ of the $428 \mathrm{~m}$ sediment sequence. The recovered cores were visually sequestered into four lithologic units and numbered sequentially from shallowest to deepest. Samples from three of the sites (sites: 2, 3, 4) were used in this study, plotted using a common composite depth (Figure 1.11) and configured using the established age model (Figure 1.12).

Grain size analyses of the ACEX cores reveal similar classifications as those found in the modern ice rafting mechanisms (sea ice, iceberg). The ACEX grain size classifications from 18.2 Ma to present are similar to the distribution of the modern grain size classifications taken directly from central Arctic Ocean sea ice samples in 1991 (Figure 1.13). The similarities between the deposited material and the modern sea ice rafted debris suggests a common sea ice environment for the last 18.2 Ma. The samples are narrowly banded in the silt:clay ratio but vary significantly in the sand percentage. Due to the averaging nature of sedimentation, it is not surprising that the geological proxy does not show any of the potential 'extremes' shown by the modern sea ice measurements.

The ACEX grain size distributions from 44.4 to 50.4 Ma are comparable to the modern classification of grain size of the central Arctic Ocean sea ice and iceberg samples taken in 1991 (Figure 1.14). The similarities of the Paleocene deposited material to the modern combination of grain size directly taken from modern icebergs and sea ice indicate a cryo-environment in the Paleocene with significant contributions 
from both ice-rafting mechanisms. The samples are widely banded in the silt:clay ratio, while remaining in the silt and sandy silt classifications. The Eocene samples vary less significantly in the sand percentage than the Neogene samples. The ACEX cores yielded a single sample during the Eocene that has a silty sand classification and is similar to the river ice grain size distribution taken in the Laptev Sea in 1992

(Figure 1.14).

\section{Grain size and Lithology}

The ACEX record reveals the consistent presence of central Arctic ice through much of the Cenozoic by the regular occurrence of sand. The intensity and type of ice environment is indicated by changes in the grain size distributions and are fairly consistent within lithologic sub-units (Figure 1.15). ACEX lithology sub-units 1/1$1 / 4$ have low organic contributions $(<1 \% \mathrm{wt})$ and were defined by color and texture. Lithologic sub-unit $1 / 2$ is characterized by elevated coarse sand percentages. Lithologic sub-unit $1 / 3$ is comprised almost entirely of diminshed sand contributions. Lithologic sub-unit $1 / 4$ has a higher coarse sand contribution, while the unit directly below (Lithologic sub-unit 1/5), which incorporates a significant hiatus, has a more moderate coarse sand contributions. Lithologic sub-units $1 / 6,2$, and 3 are characterized by organic carbon rich sediments (1-3\%wt). Units $1 / 6,2$, and 3 are distinguished predominately by their microfossil assemblages rather than visual changes in color (Backman et al., 2006). Lithologic sub-units 1/6 and 2 are undifferentiated in their terrigenous grain size distributions, with lower sand values and coarse sand values that rapidly fluctuate between extremely high and low values. 
Finally, the few samples present in lithology unit 3 show an increase in sand deposition.

Closer analyses of the individual sub-units show samples that depart from the predominant grain size relationship, ice environment, and relative albedo contribution (Table 1.1). Lithologic sub-unit $1 / 2$ yielded 4 samples between 0 and $4 \mathrm{~m}$ that show significantly elevated sand contributions with decreased coarse sand contributions, which we interpret as being a vast sea ice environment (Figure 1.16). Sub-unit 1/2 also has 6 samples, which show elevated coarse sand components compared to the majority pf the unit, suggesting an iceberg influence. The majority of this unit is categorized as high sand and low coarse sand contributions compared to the rest of the sub-unit, which we interpret as a perennial sea ice environment. Lithologic sub-unit 1/3 has 6 points that show significantly elevated sand contributions with decreased coarse sand contributions, which we interpret as being a perennial sea ice environment (Figure 1.17). The majority of this unit is categorized as low sand and coarse sand contributions, which we interpret as being a seasonal sea ice presence. Lithologic unit 1/6 has 9 samples between 204 and 220 m that show no sand contributions, which we interpret as being an ice-free environment (Figure 1.18, Table 1.2). Unit 1/5 has 2 samples, which show elevated sand components with low coarse sand contributions, suggesting a vast sea ice environment. The majority of these units are categorized as alternating between low sand- low coarse sand contributions, which we interpret as being a sea ice environment, and low sand- high coarse sand contributions, which we interpret as being iceberg influenced (Figure 1.18). Lithologic unit 2 is categorized as alternating between low sand- low coarse sand contributions, which we interpret as a 
sea ice environment, and low sand- high coarse sand contributions, which we interpret as being iceberg influenced (Figure 1.19). Lithologic unit 3 has one sample that shows extremely elevated sand contributions with extremely coarse sand contributions, which with further investigation for this time period may prove to be a river ice environment (Figure 1.20, Table 1.3). The unit has two samples, which show low sand and coarse sand contributions, which we interpret as a sea ice environment. The unit also has one sample with an elevated coarse sand component, suggesting an iceberg influence.

\section{Grain Size and Age}

ACEX grain size distributions can be interpreted in the context of time. The ACEX age model as determined by Backman et al. (2007) defines two hiatuses of sediment retention in the cores. The earliest sedimentation in the ACEX cores (44.4$51 \mathrm{Ma}$ ), preceding the early, longer hiatus, shows a diminished sand component, and a widely varying coarse sand component. The calculated mass accumulation rates (MAR) for the percentage of IRD in this region of core ranges from 0.0 to $0.23 \mathrm{~g}^{*} \mathrm{ka}^{-}$ ${ }^{1} * \mathrm{~cm}^{-2}$, while the range of MAR for SIRD is 0.0 to $0.49 \mathrm{~g}^{*} \mathrm{ka}^{-1} * \mathrm{~cm}^{-2}$. Sedimentation between the hiatuses (11.6-18.2 Ma) shows again a relatively steady sand component, but with an increasing coarse sand component. MAR ranges for this region of core range from 0.01 to $0.11 \mathrm{~g}^{*} \mathrm{ka}^{-1} * \mathrm{~cm}^{-2}$ for IRD and 0.01 to $0.29 \mathrm{~g}^{*} \mathrm{ka}^{-1} * \mathrm{~cm}^{-2}$ for SIRD. Sedimentation from present to the more recent hiatus (0-9.4 Ma) shows a relatively consistent sand component, with a decreasing coarse sand component (Figure 1.21). IRD MAR values for these samples ranged from 0.04 to $0.24 \mathrm{~g}^{*} \mathrm{ka}^{-1} * \mathrm{~cm}^{-2}$, while SIRD ranged from 0.04 to $0.49 \mathrm{~g}^{*} \mathrm{ka}^{-1} * \mathrm{~cm}^{-2}$. The MAR ranges are consistent and similar to 
the values determined by St. John (2008). The general shape distribution is also similar t the one published in that study (St. John, 2008).

44.4- 51 Ma has one period that shows a significantly extreme of elevated sand contribution with a corresponding elevated coarse sand contribution, which may prove to be a river ice environment (Figure 1.22). The time range also has a period, which shows an elevated sand component with low coarse sand, suggesting an elevated sea ice environment. The time range has three periods with no sand contribution, corresponding to an ice-free environment. The majority of the time range is categorized as alternating between samples having low sand- low coarse sand contributions, indicating a sea ice environment, and low sand- high coarse sand contributions, interpreted as an elevated iceberg influence.

The time range from 11.6- 18.2 Ma has two periods that show significantly elevated sand contributions with decreased coarse sand contributions, a sea ice environment (Figure 1.23). The majority of the time range alternates between, low sand- elevated coarse sand components, suggesting an iceberg influence, and low sand- low coarse sand contributions, a diminished, but perennial sea ice environment. The switch between the two regimes took place around 14.5 Ma.

The time range of 0-9.4 Ma has six periods that show significantly elevated sand contributions with decreased coarse sand contributions, which we interpret as being a sea ice environment (Figure 1.24). This time range also contains samples, which show elevated coarse sand components, suggesting an iceberg influence. The majority of the time range is categorized as having low sand and coarse sand contributions, a diminished, but perennial sea ice environment. 


\section{Principle Component Analysis}

Principle Component Analysis (PCA) is a popular statistical regression model, commonly used to find variable relationships in seemingly unrelated and independent variables. After extensive use of PCA, it was found no statistically significant variables could be isolated from the ACEX grain size data set (Figure 1.25). There was a slight, non-significant, reliance on the variation in the data towards coarser grain sizes. This is due to the nature of grain size percentages skewing towards coarser grain sizes with the presence of only a few grains. The overall lack of significant variables is most likely a product of the inherent inter-dependence of grain size distributions. When a single grain size bin increases, all other bins naturally decrease. The lack of unrelated, independent variables makes grain size distributions poor candidates for PCA.

\section{DISCUSSION}

The interpretation of the overall grain size from the central Arctic Ocean supports a mid-Cenozoic transition to a perennial cyro-state. Diminished sand deposits between 44.4 and $51 \mathrm{Ma}$ is supportive of a seasonal ice presence (Figure 1.21). This interpretation is further supported by the presence of a sea ice dependant diatom Synedropsis in the core stratigraphy from 45.5 to 46.97 Ma (Stickley et al., 2009). The percentage of Synedropsis has a positive correlation with the IBRD/SIRD, in a relationship determined between IBRD/SIRD and the diatom sampling that were within a centimeter in the core (Figure 1.26). (Additional data are not available for this relationship determination at this time, due to sampling periodicity differences, 
SIRD differences in Stickley et al. (2009) from this study, and fundamental differences in methodology.) The relationship suggests that while the Arctic at this time was seasonally sea ice covered with occasional periods of iceberg presence, the icebergs appear at times of particularly strong seasonal sea ice (ergo strong Synedropsis deposition). Since the seasonal ice presence, supported by both studies, would have corresponded to the winter or dark season in the Northern Hemisphere, the sea ice in the Early Cenozoic would have a minimal effect on global albedo. Any albedo contribution would have likely been isolated to the spring season, when the waters had not warmed above freezing and the light had returned to the region. The albedo contribution drops to essentially non-existent during the time period from 44.6 to 45.3 Ma, a time period in the ACEX cores containing sand-free samples (Table 1.2). After the ACEX cores' major hiatus (18.6- $44.4 \mathrm{Ma}$ ), the sediment deposited in the late-Cenozoic supports the theory of a perennial ice environment (Figure 1.22, Figure 1.23). The year-round presence of sea ice in the central Arctic in the late Cenozoic would have contributed to the global albedo, particularly during the Northern Hemisphere's summer season, resulting in a cooler summer season further reducing summer ablation. The even greater contribution of ice in the Central Arctic during the earliest part of the Cenozoic would have enhanced these effects. While the transition from seasonal sea ice to perennial sea ice is not present in the sediments collected on IODP Expedition 302, we are able to limit the transition as some point during the hiatus, 18.6- 44.4 Ma.

While the exact strengthening of the transition to a perennial sea ice cover most likely occurred some time during the 18.6-44.4 Ma hiatus, we do have a 
transition from a mix of perennial ice and high iceberg influence (18.6-14.5 Ma) to a perennial sea ice with little to no iceberg influence (14.5 to 11.6 Ma) (Figure 1.21 and 1.23). This may indicate a switch at 14.5 Ma to a perennial sea ice cover of such extent as to make iceberg passage difficult. This strengthening of perennial sea ice extent would correspond to the initiation of North Atlantic Deep Water (NADW) formation, global increased cooling, and the expansion of the E. Antarctic Ice Sheet, all occurring at 14.5 Ma (Woodruff and Savin, 1989; Hodell and Woodruff, 1994; Pagani et al., 2000). The seemingly synchronicity of all these events suggests either a single global driver, or a domino effect between them (i.e strengthening of Arctic perennial sea ice leads to formation of NADW, which causes global cooling that leads to the ice sheet strengthening). Our interpreted timing of perennial sea ice and Middle Miocene Climate Transition (15-14 Ma) strengthening corresponds to the timing determined by other non-grain size distribution variables such as ice provenance and drift rates, ${ }^{10} \mathrm{Be} /{ }^{9} \mathrm{Be}$ ratios, and the presence of IRD at lower latitudes (Krylov et al., 2008; Darby, 2008; Haley et al., 2008a, 2008b; Frank et al., 2008, Knies and Gaina, 2008; O’Regan et al., 2010).

The timing of the central Arctic's cryo- state transition, being during the MidCenozoic Era, corresponds to the cryo-state transition of the Antarctic (Zachos, 2001). While the exact timing of the central Arctic's transition can not be determined with out more extensive coring efforts, the work completed in this study supports the theory of a simultaneous cryo-state transition in both polar regions. The glaciation of the Antarctic is associated with a benthic $\delta^{18} \mathrm{O}$ value transition from a value of 1 to a value of 2. The transition in the Arctic, being initially predominately sea ice would not 
impact the benthic $\delta^{18} \mathrm{O}$ value. However, using that as a proxy for global temperatures, it is likely that the Arctic transition is associated with a global temperature of $4-8^{\circ} \mathrm{C}$ (Figure 1.25).

Enhanced sand presence is typically interpreted as enhanced sea ice presence; contain an anomalous sample that is the exception to this rule. The sample from $\sim 50$ Ma has an extreme percentage of both sand and coarse sand when compared to the rest of the core. We have associated this with river ice, which is most likely seasonal. The river ice presence supports the theorized paleogeography and surface-water circulation proposed by Backman et al. (2006) for 50 Ma. They propose a strong riverine discharge close to the IODP Expedition 302 site.

\section{CONCLUSION}

Differentiating sea ice and iceberg contributions and cryo-state enhancements is essential for understanding the dynamics of the Arctic environment. From this study of sediments from the central Arctic Ocean, we can determine and date 5 cryostates. Once a cyro-state is determined, the relative albedo contribution can be theorized. The Early Cenozoic is dominated by ice- free, seasonal sea ice, and riverine ice cryo- states, or relatively low albedo contribution. The Late Cenozoic is dominated by perennial sea ice and iceberg/perennial sea ice cyro-states, or a relatively high albedo contribution. This transition from low albedo contribution in the Arctic to high takes place much earlier than previous studies had determined. We are now able to establish a transition point as having occurred at some point between 18.6 and 44.4 Ma. Additional, sediment retrieval in the central Arctic region is necessary to precisely date the transition. 


\section{REFERENCES}

Aagaard, K., 1981. On the Deep Circulation in the Arctic Ocean. Deep-Sea Research, Vol. 28, No. 3, pp. 251-268.

Aagaard, K., E.C. Carmack, 1989. The Role of Sea Ice and Other Fresh Water in the Arctic Circulation. Journal of Geophysical Research, Vol. 94, No. C10, pp. 14485-14498.

Backman, J., M. Jakobsson, M. Frank, F. Sangiorgi, H. Brinkhuis, C. Stickley, M. O’Regan, R. Lovlie, H. Palike, D. Spofforth, J. Gattacecca, K. Moran, and C. Heil, 2007. "Age Model and Core-Seismic Integration for the Cenozoic ACEX Sediments from the Lomonosov Ridge." Paleoceanography,

Backman, J., K. Moran, and D. Evans, 2004. "ACEX Arctic Coring Expedition: Paleoceanographic and tectonic evolution of the central Arctic Ocean." IODP Expedition 302 Scientific Prospectus, Edinburgh (Integrated Ocean Drilling Program Management International, Inc.).

Backman, J., K. Moran, D.B. McInroy, L.A. Mayer, 2006. Proceedings of the Integrated Ocean Drilling Program, 302, Edinburg (Integrated Ocean Drilling Program Management International, Inc.).

Barrett, L., and S.B. Treves, 1981. "Sedimentology and Petrology of Core from DVDP-15, Western McMurdo Sound." Antarctic Research Series, Vol. 33, pp. 281-314.

Bischof, J., 2000. Ice Drift, Ocean Circulation, and Climate Change. Springer, NY.

Bischof, J., D.L. Clark, and J.S. Vincent, 1996. "Origin of Ice-Rafted Debris: Pleistocene paleoceanography in the western Arctic Ocean." Paleoceanography, Vol. 11, No. 6, pp. 743-756.

Bischof, J.F. and D.A. Darby, 1997. "Mid- to Late Pleistocene Ice Drift in the Western Arctic Ocean: Evidence for a different circulation in the past." Science, Vol. 277, pp. 74-77.

Bischof, J.F. and D.A. Darby, 1999. "Quaternary Ice Transport in the Canadian Arctic and Extent of Late Wisconsinan Glaciation in the Queen Elizabeth Islands." Canadian Journal of Earth Science, Vol. 36, pp. 2007-2022.

Bischof, J.F., D.A. Darby, and C. Majer, 1999. "Very High Resolution Record of Late Pleistocene to Holocene Ice Rafting and Glacio-Fluvial Meltwater Discharge from the Northern Chukchi Sea." EOS, AGU, Vol. 80, No. 46. 
Broecker, W.S., 1997. "Thermohaline Circulation, the Achilles Heel of our Climate System: Will man-made CO2 upset the current balance?" Science, Vol. 278, pp. 1582-1588.

Clark, D.L., 1996. "The Pliocene Record in the Central Arctic." Marine Micropaleontology, Vol. 27, pp. 157-164.

Coachman, L.K. and K. Aagaard, 1974. Physical Oceanography of Arctic and Subarctic Seas. Marine Geology and Oceanography of the Arctic Seas, Springer-Veriag, NY.

Curry, J.A., J. Schramm, and E.E. Ebert, 1995. On the Sea-Ice Albedo Climate Feedback Mechanism. Journal of Climate, Vol. 8, pp. 240-247.

Darby, D.A., 2008. "Arctic Perennial Ice Cover Over the Last 14 Million Years." Paleoceanography, Vol. 23, PA1S07. doi:10.1029/2007PA001479.

Darby, D.A., J.F. Bischof, R.F. Spielhagen, S.A. Marshall, and S.W. Herman, 2002. "Arctic Ice Export Events and their Potential Impact on Global Climate during the Late Pleistocene." Paleoceanography, Vol. 17, No. 2.

Dethloff, K, et al., 2006. A Dynamical Link Between the Arctic and the Global Climate System. Geophysical Research Letters, Vol. 33, L03703.

Dreimanis A., and V.J. Vagners, 1971. "Bimodal Distribution of Rock and Mineral Fragments in Basal Tills." In: R.P. Goldthwait (ed) A Symposium on Till, Univ. Press, Ohio, pp. 237-250.

Eldrett, J.S., I.C. Harding, P.A. Wilson, E. Butler, and A.P. Roberts, 2007. "Continental Ice in Greenland during the Eocene and Oligocene." Nature.

Frank, M., Backman, J., Jakobsson, M., Moran, K., O’Regan, M., King, J., Haley, B.A., Kubik, P.W., Garbe-Scho"nberg, D., 2008. "Beryllium Isotopes in Central Arctic Ocean Sediments Over the Past 12.3 Million Years: Stratigraphic and paleoclimatic Implications." Paleoceanography, Vol. 23, PA1S02. doi:10.1029/2007PA001478.

Goldstein, R.H., 1983. "Stratigraphy and Sedimentology of Ice-Rafted and Turbidite Sediment, Canadian Basin, Arctic Ocean.” In: B Molnia (ed) Glacial Marine Sedimentation. Plenum Press, New York, pp. 367-401.

Gyllencreutz, R., 2005. "Late Glacial and Holocene Paleoceanography in the Skagerrak from High-Resolution Grain Size Records.” Paleogeography, Paleoclimatology, Paleoecology, Vol. 222, pp. 344-369. 
Hald, M., H. Ebbesen, M. Forwick, F. Goftliebsen, L. Khomenko, S. Korsun, L.R. Olsen, and T.O. Vorren, 2004. "Holocene Paleoceanography and Glacial History of the West Spitsbergen Area, Euro-Arctic Margin." Quaternary Science Reviews, Vol. 23, pp. 2075-2088.

Haley, A.B., Frank, M., Spielhagen, R.F., Eisenhauer, A., 2008a. "Influence of Brine Formation on Arctic Ocean Circulation Over the Past 15 Million Years." Nature Geoscience, Vol. 1, pp. 68-72.

Haley, B.A., Frank, M., Spielhagen, R.F., Fietzke, J., 2008b. "Radiogenic Isotope Record of Arctic Ocean Circulation and Weathering Inputs of the Past 15 Million Years." Paleoceanography, Vol. 23, PA1S13. doi:10.1029/2007PA001486.

Heinrich, H., 1988. "Origin and Consequences of Cyclic Ice Rafting in the Northeast Atlantic Ocean during the Past 130,000 Years." Quaternary Research, Vol. 29, pp. 142-152.

Herman, Y., 1974. Topography of the Arctic Ocean. Marine Geology and Oceanography of the Arctic Seas, Springer-Veriag, NY.

Hodell, D.A., Woodruff, F., 1994. "Variation in the Strontium Isotope Ratio of Seawater during the Miocene: stratigraphic and geochemical implications." Paleoceanography, Vol. 9, pp. 405-426.

Holland, M.M., et al., 2001. "The Role of Ice-Ocean Interactions in the Variability of the North Atlnatic Thermohaline Circulation." Journal of Climate, Vol. 14, pp. 656-675.

Holland, M.M., and C.M. Bitz, 2003. Polar Amplification of Climate Change in Coupled Models. Climate Dynamics, Vol. 21, pp. 221-232.

Honjo, S., 1980. "Material Fluxes and Mode of Sedimentation in Mesopelagic and Bathypelagic Zones.” Journal of Marine Research, Vol. 38, pp. 53-97.

Jakobsson, M., R. Lovlie, E.M. Arnold, J. Backman, L. Polyak, J.O. Knutsen, and E. Musatov, 2001. "Pleistocene Stratigraphy and Paleoenvironmental Variation from Lomonosov Ridge Sediments, Central Arctic Ocean." Global and Planetary Change, Vol. 31, pp. 1-22.

Knies, J., Gaina, C., 2008. "Middle Miocene Ice Sheet Expansion in the Arctic: views from the Barents Sea". Geochemistry, Geophysics, and Geosystems, Vol. 9, Q02015. doi:10.1029/2007GC001824. 
Knight, P.G., R.I. Waller, C.J. Patterson, A.P. Jones, and Z.P. Robinson, 2002. "Discharge of Debris from Ice at the Margin of the Greenland Ice Sheet." Journal of Glaciology, Vol. 48, No. 161, pp. 192-198.

Kotlyakov, V.M., and F.G. Gordienko, 1982. "Isotopic and Geochemical Glaciology." Gidrometeoizdat, Moscow.

Krissek, L.A., 1989. "Late Cenozoic Records of Ice-Rafting at ODP Sites 642, 643, and 644, Norwegian Sea: onset, chronology, and characteristics of glacial/interglacial fluctuations." Proceedings of ODP, Scientific Results, Edinburgh (Ocean Drilling Program Management International, Inc.).

Krylov, A.A., Andreeva, I.A., Vogt, C., Backman, J., Krupskaya, V.V., Grikurov, G.E., Moran, K., Shoji, H., 2008. "A Shift in Heavy and Clay Mineral Provenance Indicates a Middle Miocene Onset of a Perennial Sea Ice Cover in the Arctic Ocean." Paleoceanography, Vol. 23, PA1S06. doi:10.1029/2007PA001497.

Lisitzin, A.P., 2002. Sea-Ice and Iceberg Sedimentation in the Ocean. Springer, NY.

Lisitzin, A.P., 1961. "Ice-Rafted Deposits and Glacial Epochs on the Polar Areas and their Importance for Paleogeography." International Geography Congress in Stockholm, pp. 33-43.

Lisitzin, A.P., and V.I. Chernyshova, 1970. "Rock Material from Bottom Sediments of the North Pacific." In: The Pacific Ocean, Nauka, Moscow, pp. 237-296.

Lisitzin, A.P., V.P. Shevchenko, M.E. Vinogradov, O.V. Severina, V.V. Vavilova, I.N. Mitzkevich, 1994. "Particle Fluxes in the Kara Sea and Ob and Yenisei Estuaries." Oceanology, Vol. 34, pp. 748-759.

Madureira, L.A.S., S.A. Kreveld, G. Eglington, H. Maureen, G. Ganssen, J.E. Hinte, J.J. Ottens, 1997. "Late Quaternary High-Resolution Biomarker and other Sedimentary Climate Proxies in a Northeast Atlantic Core." Paleoceanography, Vol. 12, pp. 255-269.

Maslin, M.A., X.S. Li, M.F. Loutre, and A. Berger, 1998. The Contribution of Orbital Forcing to the Progressive Intensification of Northern Hemisphere Glaciation. Quaternary Science Reviews, Vol. 17, pp. 411-426.

Moran, K., J. Backman, H. Brinkhuis, S.C. Clemens, T. Cronin, G.R., Dickens, et al., 2006. "The Cenozoic Palaeoenvironment of the Arctic Ocean." Nature, Vol. 441, pp. 601-605. 
Mortlock, R.A., and P.N. Froelich, 1989. "A Simple Method for the Rapid Determination of Biogenic Opal in Pelagic Marine Sediments." Deep-Sea Research, Vol. 36, No. 9, pp. 1415-1426.

Mulholland, J.W., 1976. "Texture of Tills, Central Massachusetts." Journal of Sedimentary Petrology, Vol. 46, pp. 778-787.

Nam, S.I., R. Stein, H. Grobe, and H. Hubberten, 1995. "Late Quaternary GlacialInterglacial Changes in Sediment Composition at the East Greenland Continental Margin and their Paleoceanographic Implications." Marine Geology, Vol. 122, pp. 243-262.

Norgaard-Pedersen, N., R.F. Spielhagen, J. Thiede, and H. Kassens, 1998. “Central Arctic Surface Ocean Environment during the Past 80,000 Years."

Paleoceanography, Vol. 13, No. 2, pp. 193-204.

Nurnberg, D., I. Wollenburg, D. Dethleff, H. Eicken, H. Kassens, T. Letzig, E. Reimnnitz, and J. Thiede, 1994. "Sediments in the Arctic Sea Ice: Implications for entrainment, transport, and release." Marine Geology, Vol. 119, pp. 185-214.

Pagani, M., Arthur, M.A., Freeman, K.H., 2000. "Variations in Miocene Phytoplankton Growth Rates in the Southwest Atlantic: Evidence for changes in ocean circulation." Paleoceanography, Vol. 15, pp. 486-496.

Phillips, R.L., and A. Grantz, 1997. "Quaternary History of Sea Ice and Paleoclimate in the Amerasia Basin, Arctic Ocean, as Recorded in the Cyclical Strata of Northwind Ridge.” GSA Bulletin, Vol. 109, No. 9, pp. 1101-1115.

Prins, M.A., L.M. Bouwer, C.J. Beets, S.R. Troelstra, G.J. Weltje, R.W. Kruk, A. Kuijpers, and P.Z. Vroon, 2002. "Ocean Circulation and Iceberg Discharge in the Glacial North Atlantic: Inferences from unmixing of sediment size distributions." Geology, Vol. 30, No. 6, pp. 555-558.

Poore, R.Z., R.L. Phillips, and H.J. Rieck, 1993. "Paleoclimate Record for Northwind Ridge, Western Arctic Ocean." Paleoceanography, Vol. 8, No. 2, pp. 149159.

Raymo, M.E., L.E. Lisiecki, and K.H. Nisancioglu, 2006. "Pli-Peistocene Ice Volume, Antarctic Climate, and the Global $\delta^{18} \mathrm{O}$ Record." Science,

Reeh, N., 2004. "Holocene Climate and Fjord Glaciations in Northeast Greenland: implications for IRD deposition in the North Atlantic." Sedimentary Geology, Vol. 165, pp. 333-342. 
Reimnitz, E., M. McCormick, K. McDougall, and E. Brouwers, 1993a. "Sediment Export by Ice-Rafting from Coastal Polynya, Arctic, Alaska, USA.” Arctic and Alpine Research, Vol. 25, pp. 83-89.

Reimnitz, E., J.R. Clayton, E.W. Kempema, J.R. Payne, W.S. Wefer, 1993 b. "Interaction of Rising Frazil with Suspended Particles: Tank experiments with application to nature." Cold Regions Science and Technology, Vol. 21, pp. 117-135.

Reimnitz, E., M. McCormick, J. Bischof, D.A. Darby, 1998. "Comparing Sea-Ice Sediment Load with Beaufort Sea Shelf Deposits: Is entrainment selective?" Journal of Sedimentary Research, Vol. 68, pp. 777-787.

Rennermalm, A.K., E.F. Wood, S.J. Dery, A.J. Weaver, and M. Eby, 2006. Sensitivity of the Thermohaline Circulation to Arctic Runoff. Geophysical Research Letters, Vol. 33, L12703.

Ruddiman, W.F., 1977a. "Late Quaternary Deposition of Ice Rafted Sand in the Subpolar North Atlantic (Lat. $40^{\circ}$ to $65^{\circ} \mathrm{N}$ )." Geological Society of America Bulletin, Vol. 88, pp. 1813-1827.

Ruddiman, W.F., 1977b. "North Atlantic Ice Rafting: a major change at 75000 years before present." Science, Vol. 196, pp. 1208-1211.

Ruddiman, W.F., and L.K. Glover, 1972. "Vertical Mixing of Ice-Rafted Volcanic Ash in North Atlantic Sediments." Geological Society of America Bulletin, Vol. 83, pp. 2817-2836.

Ruddiman, W.F., and JOIDES NAAG-DPG, 1991. "North Atlantic-Arctic Gateways.” JOIDES Journal, Vol. 17, pp. 38-50.

Ruddiman, W.F., and A. McIntyre, 1976. "Northeast Atlantic Paleoclimatic Changes over the Past 60000 Years." Geological Society of America Mem, Vol. 145, pp. 111-146.

Ruddiman, W.F., and A. McIntyre, 1977. "Late Quaternary Surface Ocean Kinematics and Climatic Change in the High-Latitude North Atlantic." Journal of Geophysical Research, Vol, 82, pp. 3877-3887.

Ruddiman, W.F., and A. McIntyre, 1981. "The North Atlantic Ocean during the Last Deglaciation.” Palaeogeography Palaeoclimatology Palaeoecology, Vol. 35, pp. 145-214.

Ruddiman, W.F., and A. McIntyre, 1984. "Ice-Age Thermal Response and Climatic Role of the Surface Atlantic Ocean, $40^{\circ} \mathrm{N}$ to $63^{\circ} \mathrm{N}$." Geological Society of America Bulletin, Vol. 95, pp. 381-396. 
Ruddiman, W.F., N.J. Shackleton, and A. McIntyre, 1986. "North Atlantic SeaSurface Temperatures for the Last 1.1 Million Years." In: M. Smmaerhayes, N.J. Shackleton (eds) North Atlantic Palaeoceanography. Geological Society Special Publications, Vol. 21, pp. 155-173.

Sakamoto, T., M. Ikehara, K. Aoki, K. Iijima, N. Kimura, T. Nakatsuka, and M. Wakatsuchi, 2005. "Ice-Rafted Debris (IRD)- Based Sea-Ice Expansion Events during the Past 100 kyrs in the Okhotsk Sea." Deep-Sea Research, Vol. 52, pp. 2275-2301.

Shackleton, N.J., J. Imbrie, and N.G. Pisias, 1988. The Evolution of Oceanic OxygenIsotope Variability in the North Atlantic Over the Past Three Million Years. Phil. Trans. R. Soc. Lond. B, Vol. 318, pp. 679-688.

Singarayer, J.S., J.L. Bamber, and P.J. Valdes, 2006. Twenty-First Century Climate Impacts from a Declining Arctic Sea Ice Cover. Journal of Climate, Vol. 19, pp. 1109-1124.

Smythe, F.W., W.F. Ruddiman, and D.N. Lumsden, 1985. "Ice-Rafted Evidence of Long-term North Atlantic Circulation.” Marine Geology, Vol. 64, pp. 131141.

Stickley, C.E., K. St John, N. Koc, et al., 2009. "Evidence for Middle Eocene Arctic Sea Ice from Diatoms and Ice-Rafted Debris.” Nature, Vol. 460, pp. 376-390.

St. John, K., 2008. "Cenozoic Ice-Rafting History of the Central Arctic Ocean: Terrigenous Sands on the Lomonosov Ridge." Paleoceanography, Vol. 23.

Thiede, J., O. Eldholm, E. Taylor, 1989. "Variability of Cenozoic NorwegianGreenland Sea Paleoceanography and Northern Hemisphere Paleoclimate." Proceedings of ODP, Scientific Results, Vol. 104.

Vanney, J., and L. Dangeard, 1976. "Les deposits glacio-marins actuels et anciens." Rev Geogr Montr, Vol. 30, pp. 9-50.

Wefer, G., E. Suess, W. Balzer, et al., 1982. "Fluxes of Biogenic Components from Sediment Trap Deployment in Circumpolar waters of the Antarctic sector." In: U. Bleil and J. Thiede (eds) Geological History of the Polar Oceans: Arctic versus Antarctic, Kluwer Academic Publishing, Dordrecht, pp. 245-254.

Wefer, G., G. Fisher, D. Futterer, R. Gersonde, S. Honjo, D. Osterman, 1990. "Particle Sedimentation and Productivity in Atlantic waters of the Atlantic sector." In: U. Bleil and J. Thiede (eds) Geological History of the Polar Oceans: Arctic versus Antarctic, Kluwer Academic Publishing, Dordrecht, pp. 363-380. 
Woodruff, F., Savin, S.M., 1989. "Miocene Deepwater Oceanography." Paleoceanography, Vol. 4, pp. 87-140.

Woods Hole Oceanographic Institution, 2008. "Image: Arctic Ocean Circulation Primer." Polar Research, $<$ www.whoi.edu/page.do?pid $=12317 \&$ tid $=441 \&$ cid $=41043 \&$ ct $=61 \&$ article $=23$ 446>. (March 3, 2008).

Winter, B.L., C.M. Johnson, and D.L. Clark, 1997. "Strontium, Neodymium, and Lead Isotope Variations of Authigenic and Silicate Sediment Components from the Late Cenozoic Arctic Ocean: Implications for Sediment Provenance and the Source of Trace Metals in Seawater." GSA, Vol. 61, No. 19, pp. 41814200 .

Zachos, J., M. Pagani, L. Sloan, E. Thomas, and K. Billups, 2001. "Trends, Rhythms, and Aberrations in Global Climate 65 Ma to Present." Science, Vol. 292, pp. 686-693. 


\begin{tabular}{|c|c|c|c|c|}
\hline Study & $\begin{array}{l}\text { Defined size } \\
\text { range of Iceberg } \\
\text { Rafted Debris }\end{array}$ & $\begin{array}{c}\text { Size range of } \\
\text { debris in } \\
\text { lceberg material }\end{array}$ & $\begin{array}{c}\text { Size range of } \\
\text { debris in Sea Ice }\end{array}$ & $\begin{array}{l}\text { Defined size } \\
\text { range of Sea lce } \\
\text { Rafted Debris }\end{array}$ \\
\hline $\begin{array}{c}\text { Bischof and } \\
\text { Darby (1997, } \\
1999) \\
\end{array}$ & $>250 \mu \mathrm{m}$ & & & \\
\hline $\begin{array}{l}\text { Darby et al. } \\
\text { (2002) }\end{array}$ & $>250 \mu \mathrm{m}$ & & & \\
\hline $\begin{array}{l}\text { Bischof et al. } \\
\text { (1996) }\end{array}$ & $>250 \mu \mathrm{m}$ & & & \\
\hline $\begin{array}{c}\text { Krissek et al. } \\
(1989)\end{array}$ & $>250 \mu \mathrm{m}$ & & & \\
\hline $\begin{array}{l}\text { Kotlyakov and } \\
\text { Gordienko } \\
\text { (1982) }\end{array}$ & & $\begin{array}{c}2 \mu \mathrm{m} \text { to } 2000 \\
\mu \mathrm{m}\end{array}$ & & \\
\hline $\begin{array}{l}\text { Ruddiman and } \\
\text { Mclntyre (1976) }\end{array}$ & & $2 \%>550 \mu \mathrm{m}$ & & \\
\hline Lisitzin (2002) & $2.9 \%>500 \mu \mathrm{m}$ & & $<250 \mu \mathrm{m}$ & \\
\hline $\begin{array}{l}\text { Bellair et al. } \\
\quad(1964)\end{array}$ & & $\begin{array}{c}\text { average }=35 \\
\mu \mathrm{m}\end{array}$ & & \\
\hline $\begin{array}{l}\text { Mulholland } \\
\text { (1976) }\end{array}$ & & $\begin{array}{c}\text { mode }=125- \\
\quad 177 \mu \mathrm{m}\end{array}$ & & \\
\hline $\begin{array}{l}\text { Winter et al. } \\
\text { (I997) }\end{array}$ & & & & $>63-<250 \mu \mathrm{m}$ \\
\hline $\begin{array}{l}\text { Bischof et al. } \\
\text { (1999) }\end{array}$ & & & & $>63-<250 \mu \mathrm{m}$ \\
\hline Bischof (2000) & & & & $>63-<250 \mu \mathrm{m}$ \\
\hline
\end{tabular}

Table 1.1: A reference comparison of various studies cited in this paper, outlining the given size ranges for icebergs, sea ice, iceberg rafted debris (IBRD), and sea ice rafted debris (SIRD). 


\begin{tabular}{|c|c|c|c|}
\hline Ice Environment & $\begin{array}{c}\text { Sand vs. Fine Sediment } \\
\text { Ratio }\end{array}$ & $\begin{array}{c}\text { Coarse Sand vs. Fine } \\
\text { Sand Ratio }\end{array}$ & Relative Albedo \\
\hline Ice Free Arctic & Null Value & Null Value & Extremely Low \\
\hline River Deposit & Very High & Very High & Extremely Low \\
\hline Seasonal Sea Ice & Low & Low & Medium \\
\hline Iceberg Presence & Low & High & Low \\
\hline Perennial Sea Ice & High & Low & High \\
\hline
\end{tabular}

Table 1.2: Table outlining the 5 proposed central Arctic ice environments in this study, their criteria, the various color combinations are how they are identified through the remainder of this study, and their relative albedo contribution. 


\begin{tabular}{|c|c|c|}
\hline Sample ID & Depth (med) & Age (Ma) \\
\hline $302-2 A-47 X-3 W-114$ & 204.34 & 44.6609 \\
\hline $302-2 A-48 X-3 W-44$ & 210.09 & 44.8975 \\
\hline $302-2 A-48 X-4 W-50$ & 211.66 & $44.962 \mid$ \\
\hline $302-2 A-49 X-2 W-44$ & 212.91 & 45.0136 \\
\hline $302-2 A-49 X-2 W-114$ & $213.6 I$ & 45.0424 \\
\hline $302-2 A-49 X-3 W-44$ & $214.4 I$ & 45.0753 \\
\hline $302-2 A-49 X-4 W-114$ & 216.62 & 45.1663 \\
\hline $302-2 A-49 X-5 W-58$ & 217.57 & 45.2054 \\
\hline $302-2 A-50 X-I W-114$ & 219.02 & 45.2650 \\
\hline
\end{tabular}

Table 1.3: Table indicating samples containing no sand contribution to the grain size distribution. The sample identification, depths, and ages are provided. The 'no sand' samples are found in a narrow depth and age range. We maintain that these samples represent an ice-free environment. 


\begin{tabular}{|c|c|c|}
\hline Sample ID & Depth (mcd) & Age (Ma) \\
\hline $302-4 A-19 X-I$ W-44 & 320.97 & 50.25 I 2 \\
\hline
\end{tabular}

Table 1.4: Table indicating the sample containing an extremely high sand and coarse sand contribution to the grain size distribution. The sample identification, depth, and age are provided. We maintain that this sample represents a river ice environment. 


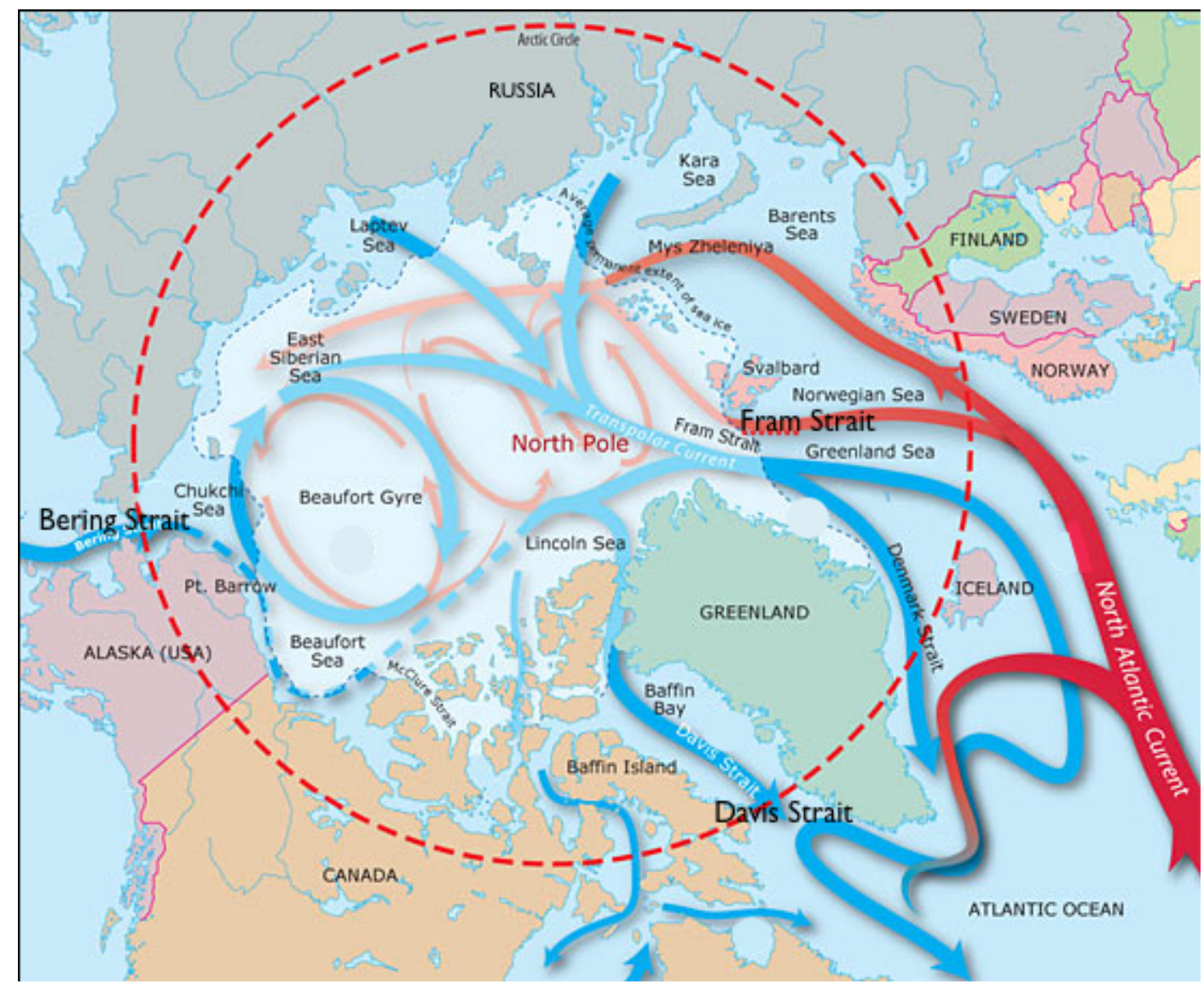

Figure 1.1: Map of the Arctic Ocean showing modern ocean circulation patterns. There is ocean water and heat exchange between the Atlantic and Arctic Oceans through the Fram and Davis Straits. Ocean water exchanges from the Pacific Ocean into the Arctic Ocean through the Bering Strait. The Arctic Ocean itself is roughly centered on the North Pole and is almost entirely contained within the Arctic Circle. (Woods Hole Oceanographic Institution, 2008) 


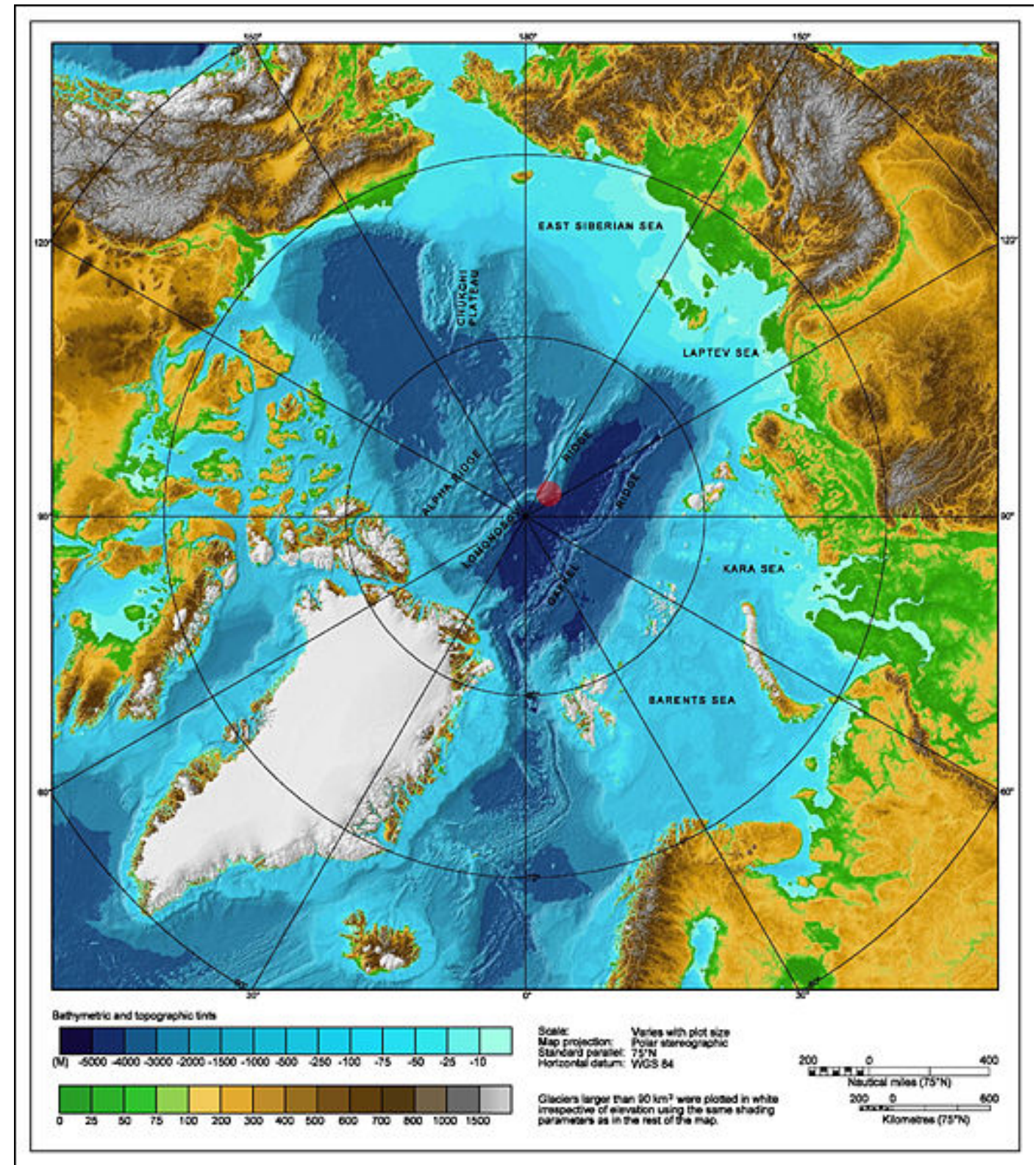

Figure 1.2: Bathymetric and topographic map of the Arctic. The IODP Expedition 302, ACEX, core sites were on the Lomonosov Ridge, central Arctic Ocean (red dot). The Lomonosov Ridge separated from the Barents/Kara shelf due to the formation of the Gakkel Ridge. By being elevated from the abyssal plain and separated from the continental shelf, the Lomonosov Ridge is an ideal setting for paleo- sea ice investigations of the Arctic. (IBCAO, 2008) 

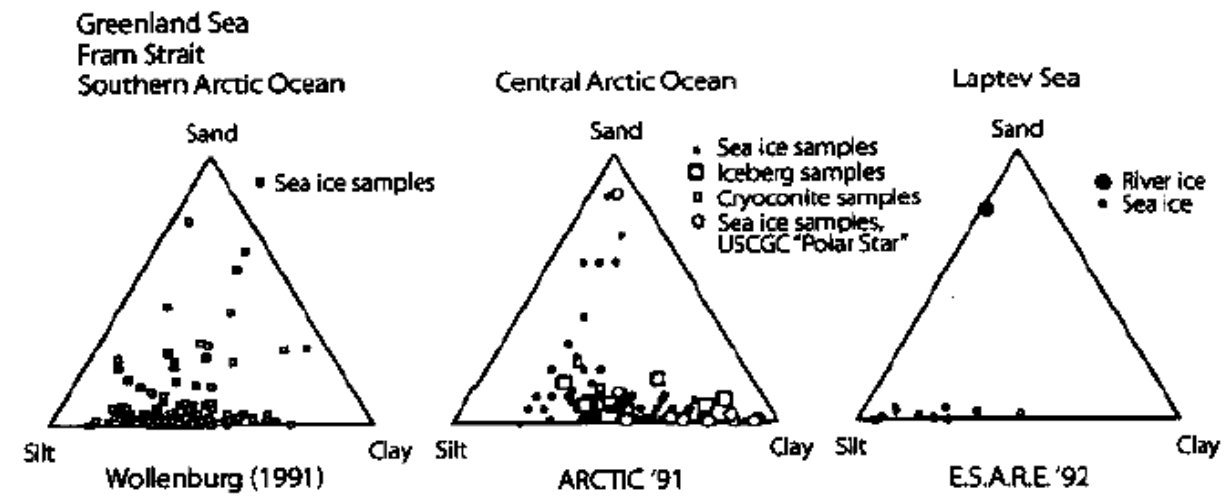

Figure 1.3: Tertiary diagrams taken from Lisitzin (2002) showing grain size distributions determined directly from sea ice, iceberg, and river ice samples on three different Arctic studies. The location of the ARCTIC '91 study (central diagram) is geographically the closest to the ACEX study. The sea ice samples show widely varying grain size distributions, while icebergs typically show lower sand contributions. 


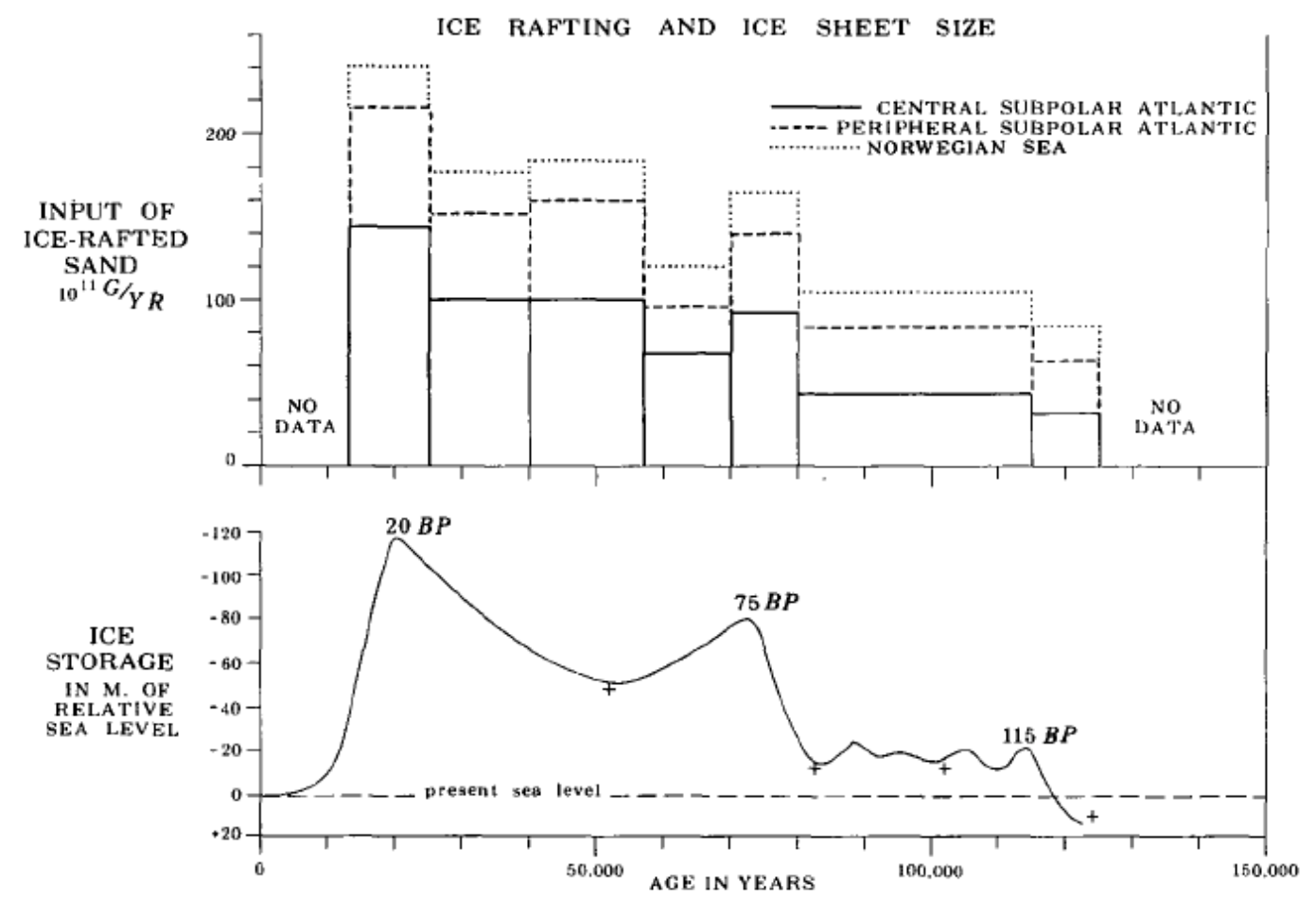

Figure 1.4: Upper graph shows variation in IRD input for the last 125,000 years at 3 locations. Lower graph shows the variation in sea level for the same time period. Sea level can be interpreted as a proxy for glacial ice extent. Periods of lower sea level, greater ice extent (glacial) correspond to periods of increased IRD deposition. (Ruddiman, 1977a) 


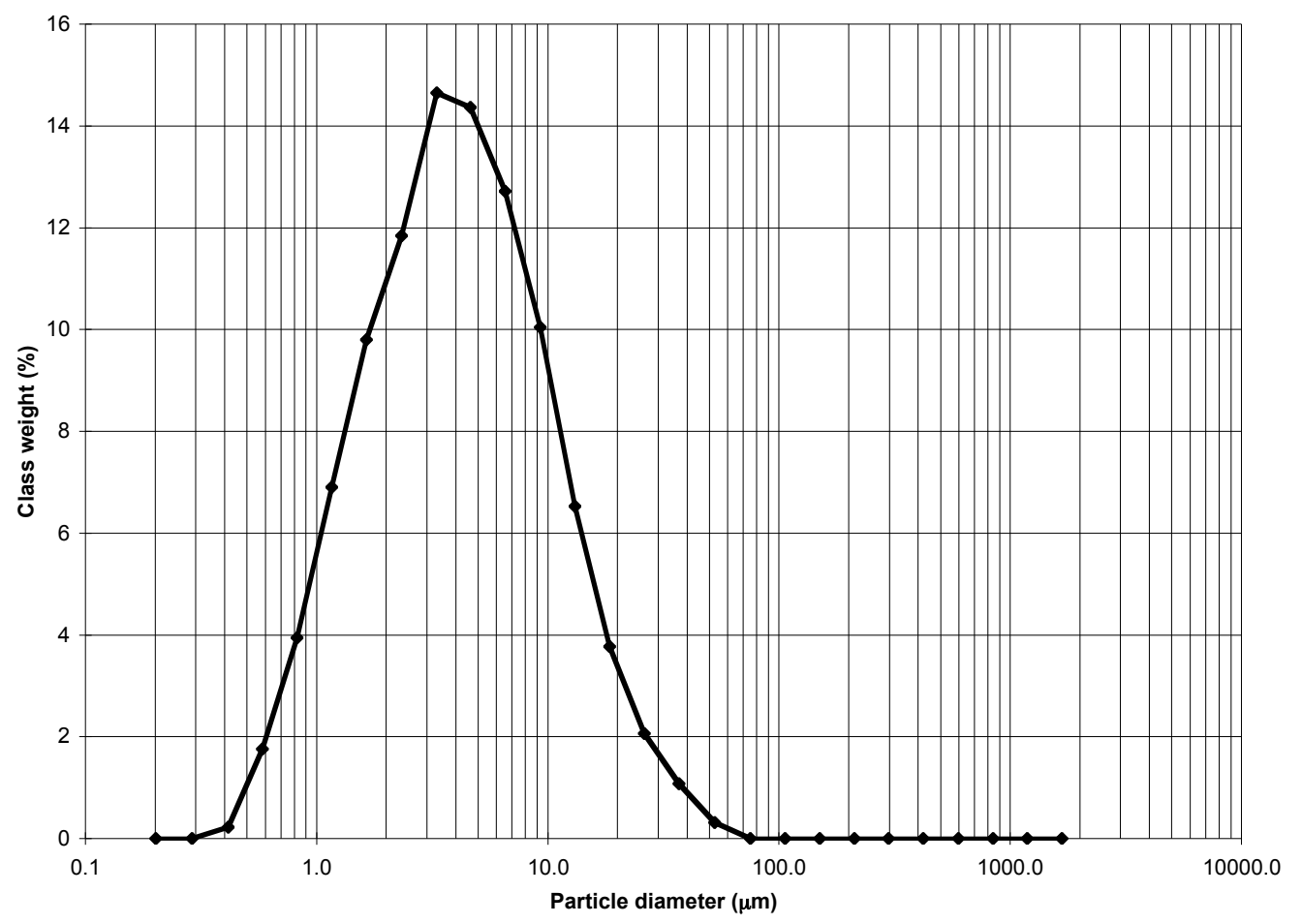

Figure 1.5: The grain size distribution of ACEX sample, 302-2A-48X-3W-44. This sample is an example showing a sediment range up to $63 \mu \mathrm{m}$ with no $>63 \mu \mathrm{m}$ contribution. No sand presence indicates no ice rafting contribution, and therefore representing an ice-free Arctic environment. Similar samples with no sand contribution also show sediment up to $63 \mu \mathrm{m}$ in size. 


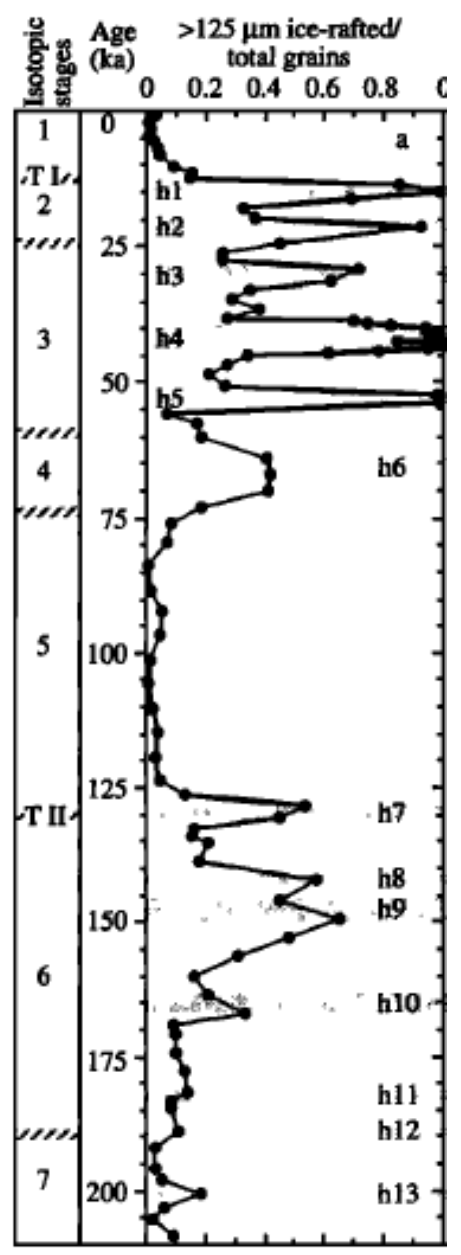

Figure 1.6: In the graph above, the IRD component was normalized and emphasized by plotting the ratio of IRD to finer sediments. (Madureira et al., 1997) 


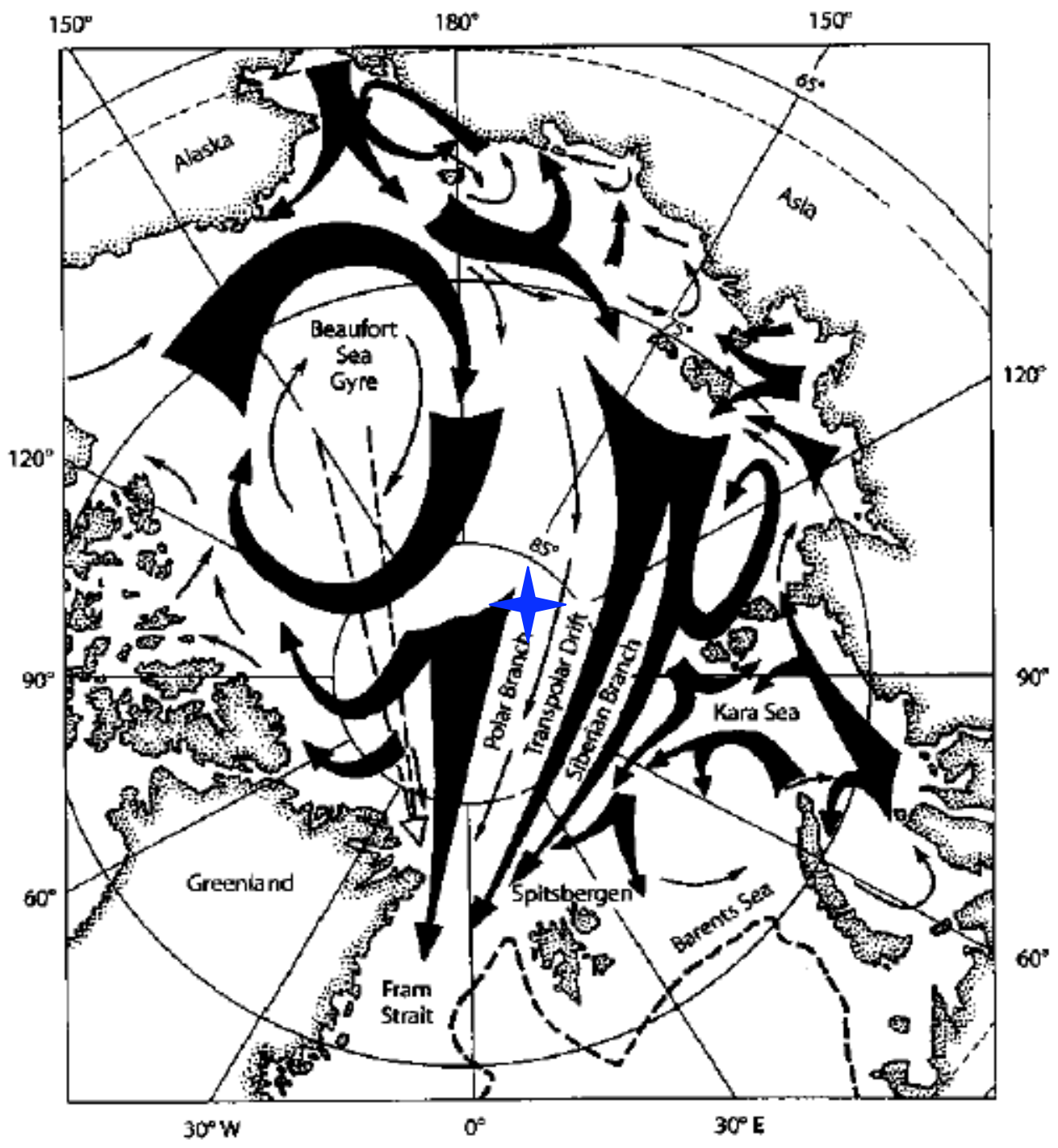

Figure 1.7: Map of Arctic Ocean showing circulation gyres and drift directions for sea ice transport (Lisitzin ,2002). The ACEX, IODP 302, site (indicated by a star) experiences deposition from Arctic ice in the Transpolar Drift. This sea ice originated and entrained sediment from the Siberian shelf. Siberian shelf sediments are typically fine sand, silt, and some clay. 


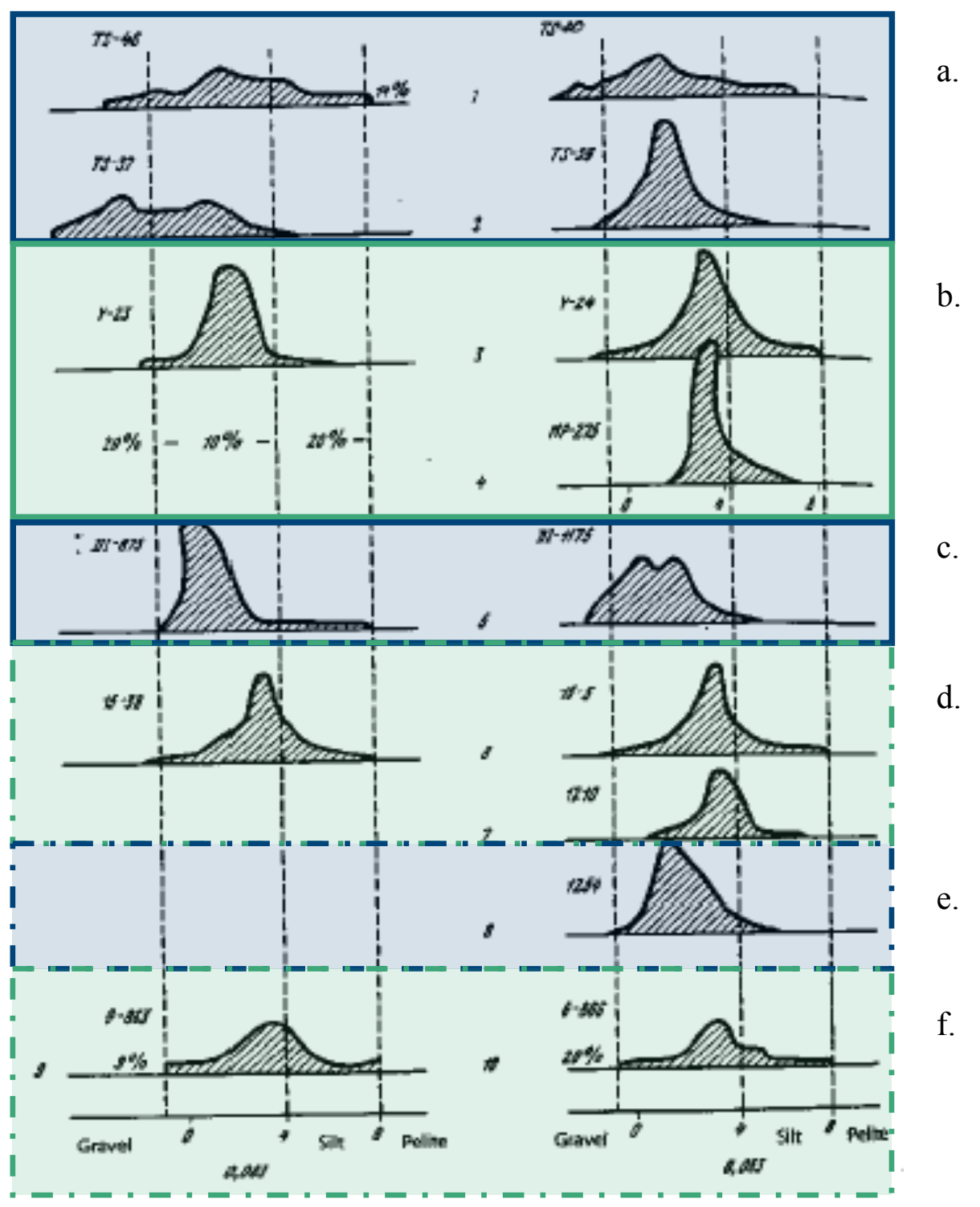

Figure 1.8: Grain size distributions for samples taken from the McMurdo Sound, Antarctica region (Barrett and Treves, 1981). Samples in boxes a and c are taken directly from glacial ice material. Samples in box $b$ are taken directly from sea ice. Samples in boxes $\mathrm{d}$, e, and $\mathrm{f}$ are from offshore cores. Box a and $\mathrm{c}$, representing iceberg material, show coarse sand averages. Box b, sea ice, shows fine sand averages. Employing the ratio of coarse sand to fine sand (I/SI), box $d$ and $f$ are interpreted as being a sea ice dominated depositional environment, and box e as iceberg dominated. This shows the I/SI is viable for determining ice environments even in Antarctica where the grain sizes are generally coarser and less distinctive between the two transport mechanisms than they are in the Arctic Ocean. 


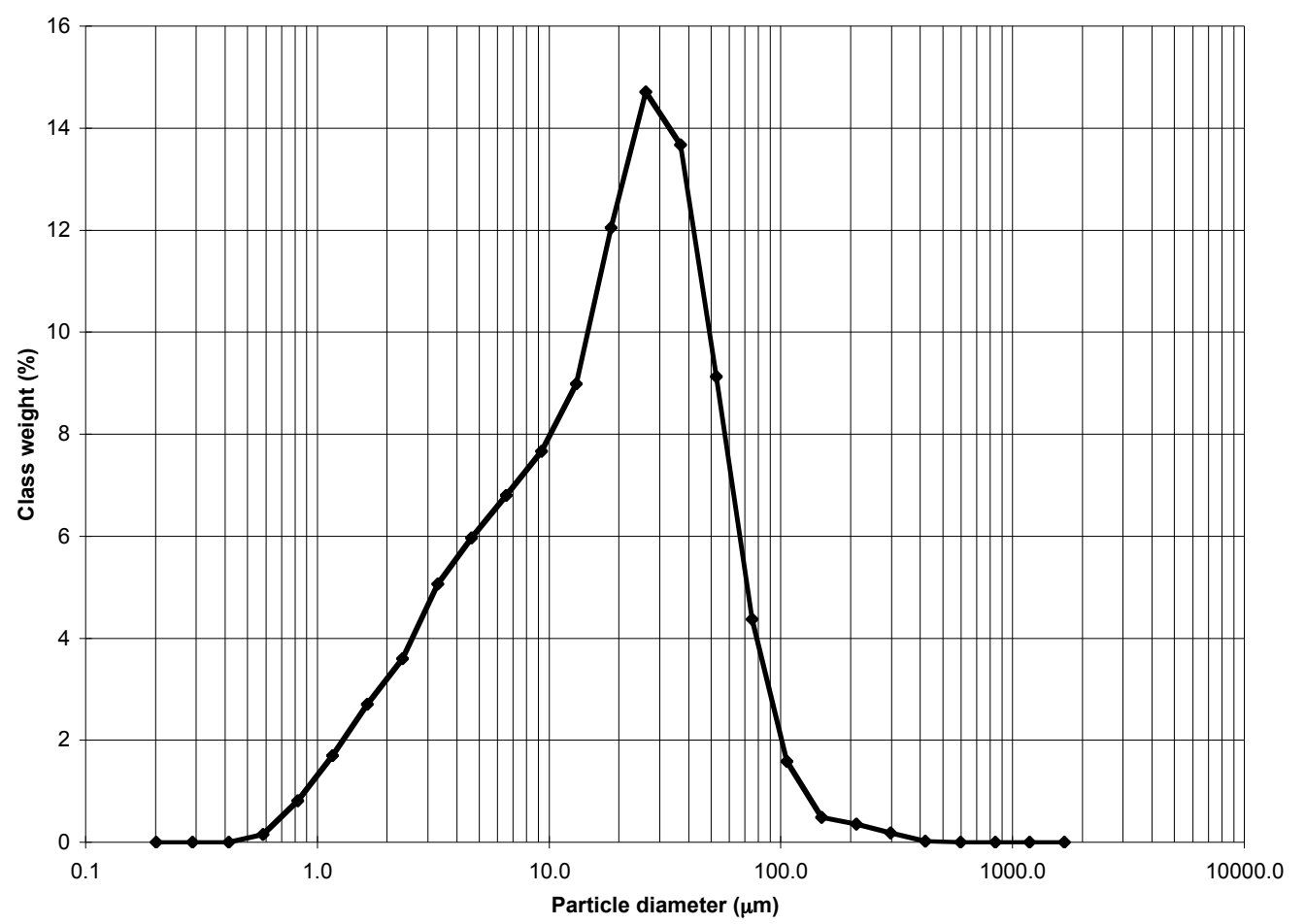

Figure 1.9: The grain size distribution of ACEX sample, 302-2A-56X-2W-114. This sample is an example showing a sediment range up to $250 \mu \mathrm{m}$ with no $>250 \mu \mathrm{m}$ contribution. No coarse sand presence indicates no iceberg rafting contribution, and therefore representing a sea ice environment. Similar samples with dominantly fine sand contributions also show sediment either not exceeding or considerably diminishing at $250 \mu \mathrm{m}$ in size. 


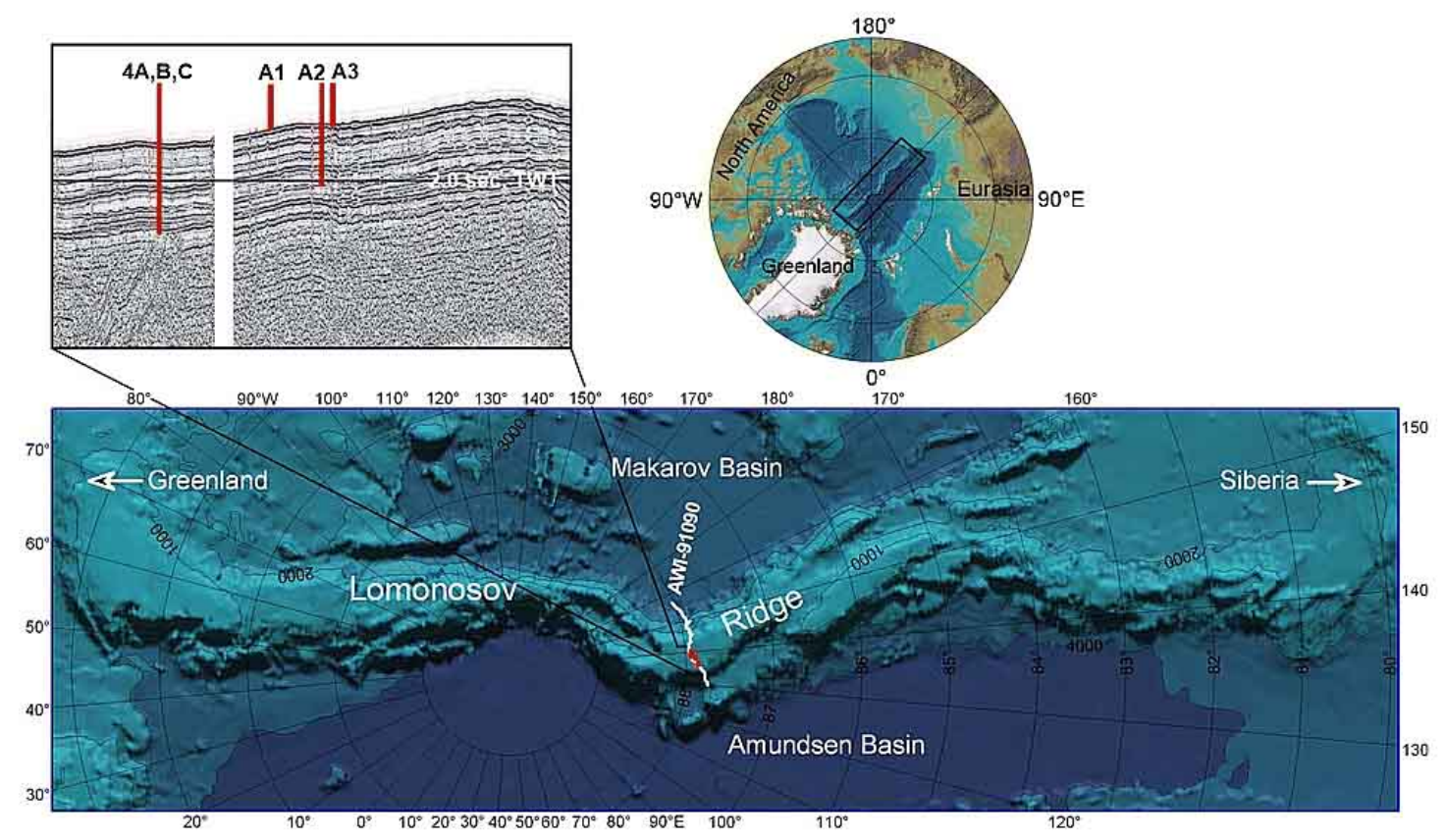

Figure 1.10: Bathymetric map showing the location of the four ACEX drill sites on the Lomonosov Ridge. Along with depth penetration of each site shown in the seismic reflection profile AWI-91090. Over $420 \mathrm{~m}$ of sediments from the Lomonosov Ridge were drilled. (Backman et al., 2007) 


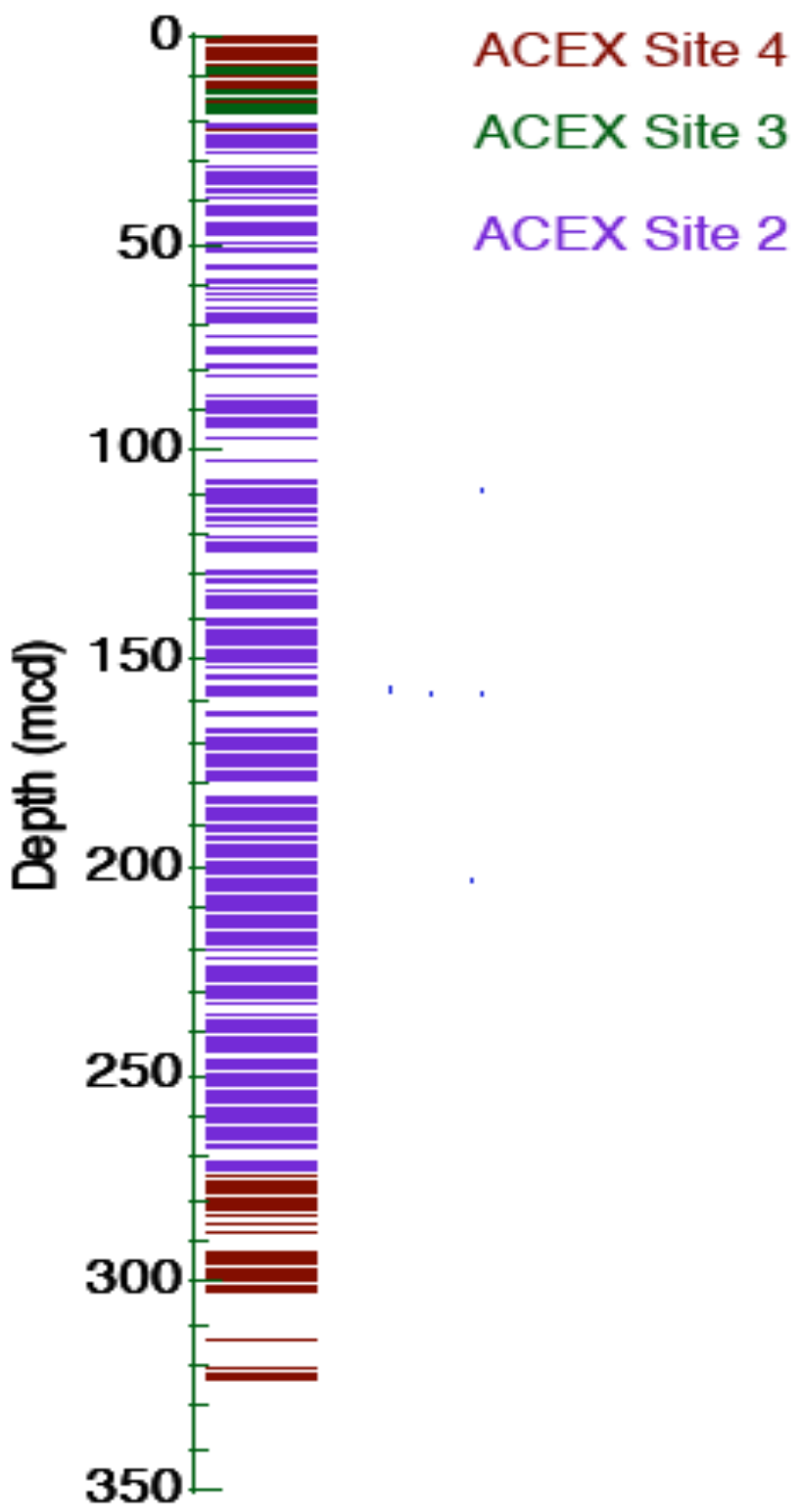

Figure 1.11: Samples for this study came from three of the four ACEX sites. The sample locations are plotted on the composite depth scale. Samples plotted in red came from cores taken at site 4. Samples plotted in green came from cores taken at site 3. Samples plotted in purple came from cores taken at site 2. The samples from the three sites combined make a more compete history of the central Arctic Ocean during the Cenozoic. Using the composite depth scale eliminates differences in accumulation rates between the three sites. 


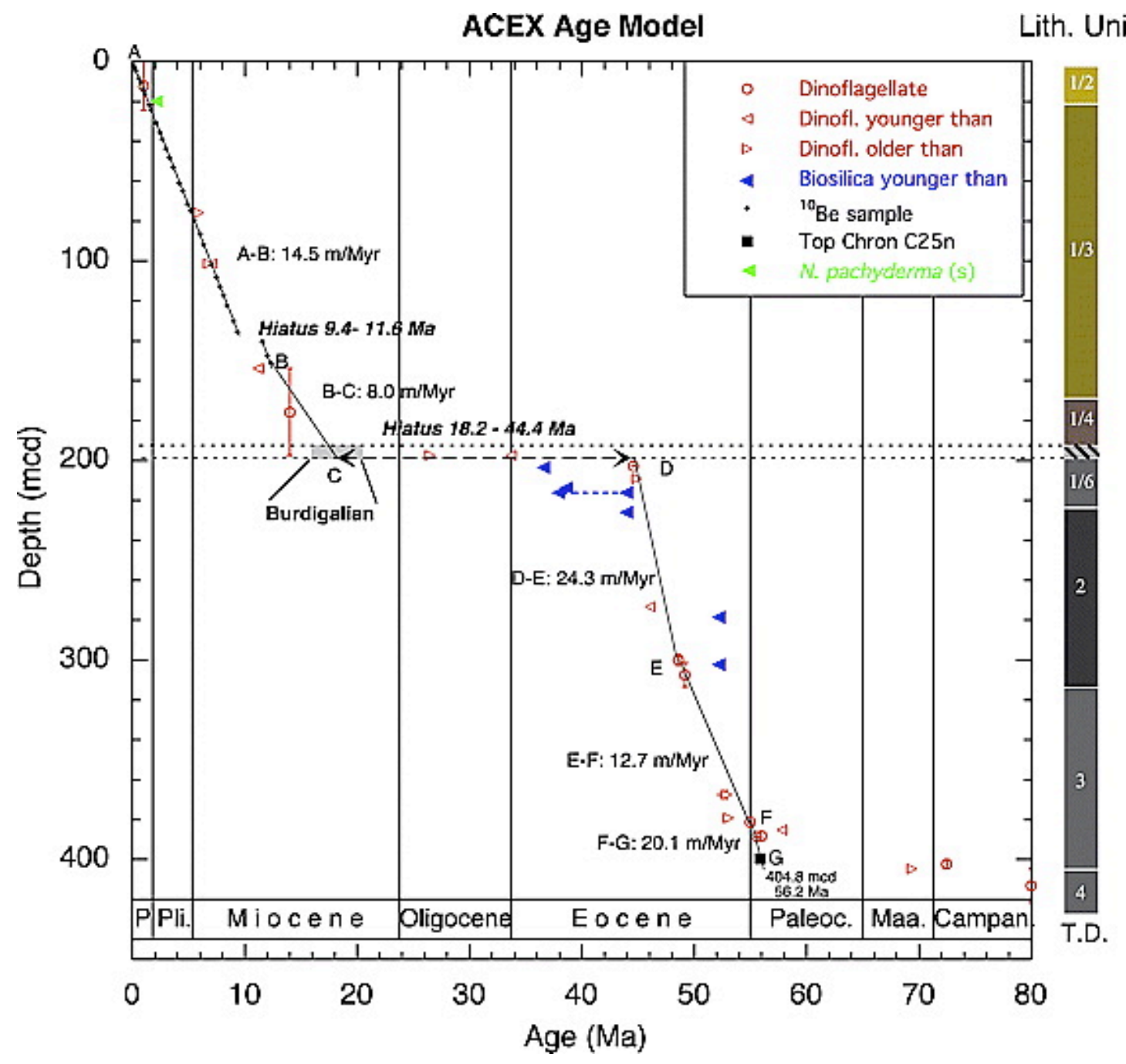

Figure 1.12: Age model for the ACEX cores as determined by Backman et al. (2007). Two hiatuses were found in the record, one from 9.4-11.6 Ma and the other from 18.244.4 Ma. This age model was applied to all samples used in this study. 


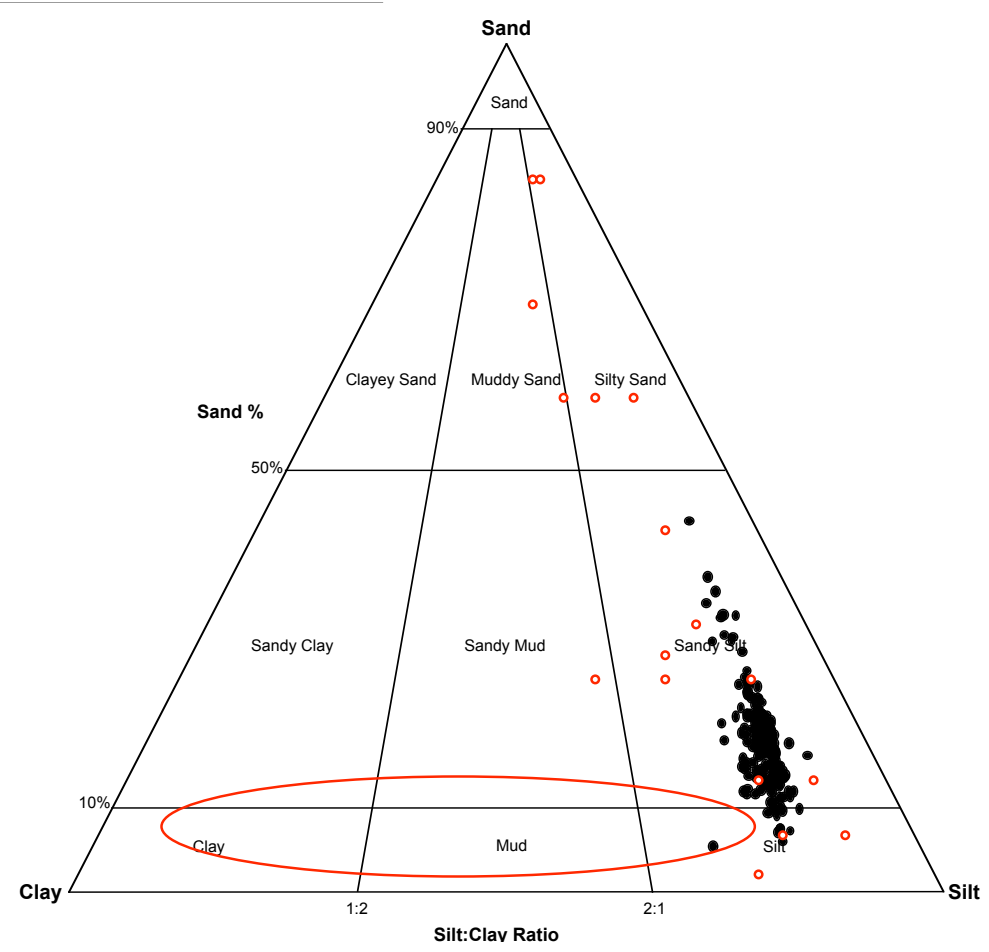

Figure 1.13: The ACEX grain size distributions from 18.2 Ma to present are plotted on a tertiary graph (solid black dots). This distribution compares to the distribution of the grain size of the central Arctic Ocean sea ice samples taken in 1991 (hallow red dots, large red oval represents region of many data points). The samples are narrowly banded in the silt:clay ratio but vary significantly in terms of the sand percentage. 


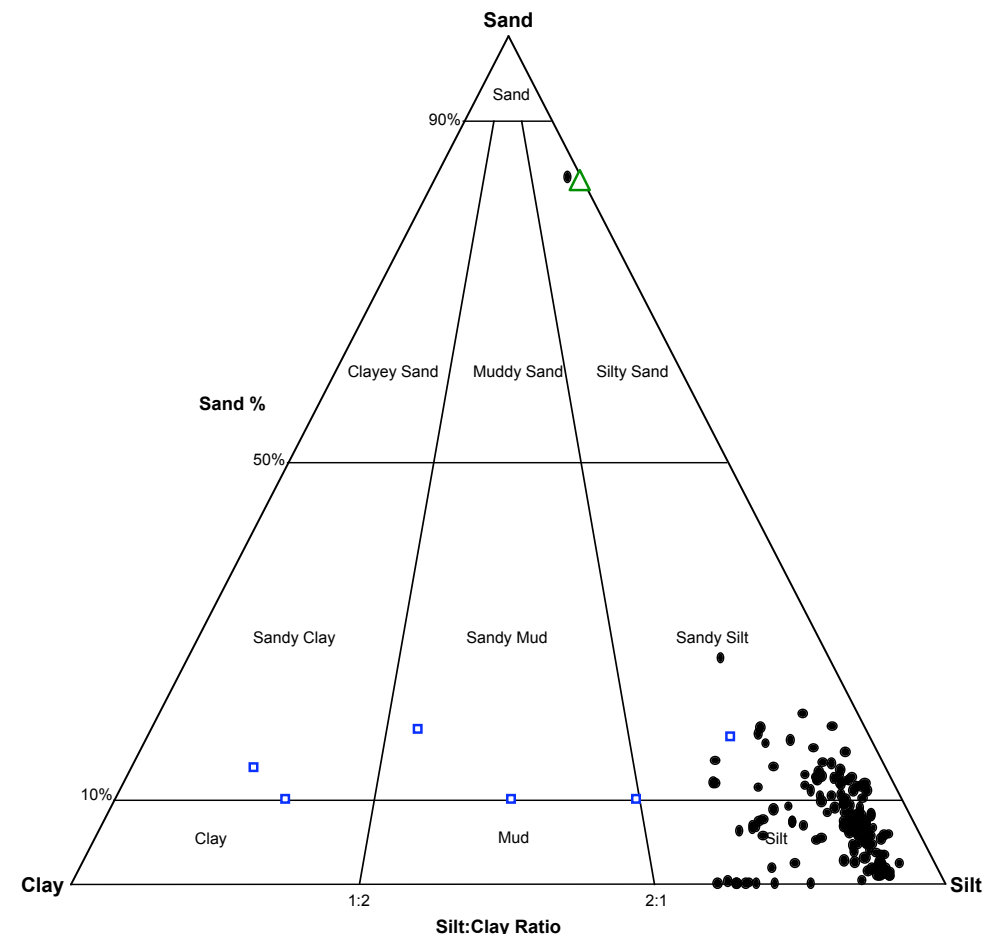

Figure 1.14: The ACEX grain size distributions from 44.4 to $50.4 \mathrm{Ma}$ are plotted on the tertiary graph above (solid black dots). This distribution compares to the distribution of the grain size of the central Arctic Ocean sea ice and iceberg samples taken in 1991 (square blue dots- icebergs). The samples are widely banded in the silt: clay ratio, while remaining in the silt and sandy silt distinctions. They vary more in the sand percentage than the direct iceberg samples. The notable outlier for this time range is a single sample, which has a silty-sand distinction and is comparable to the river ice grain size distribution taken in the Laptev Sea in 1992 (triangle green dotriver ice). 
Lith. Unit

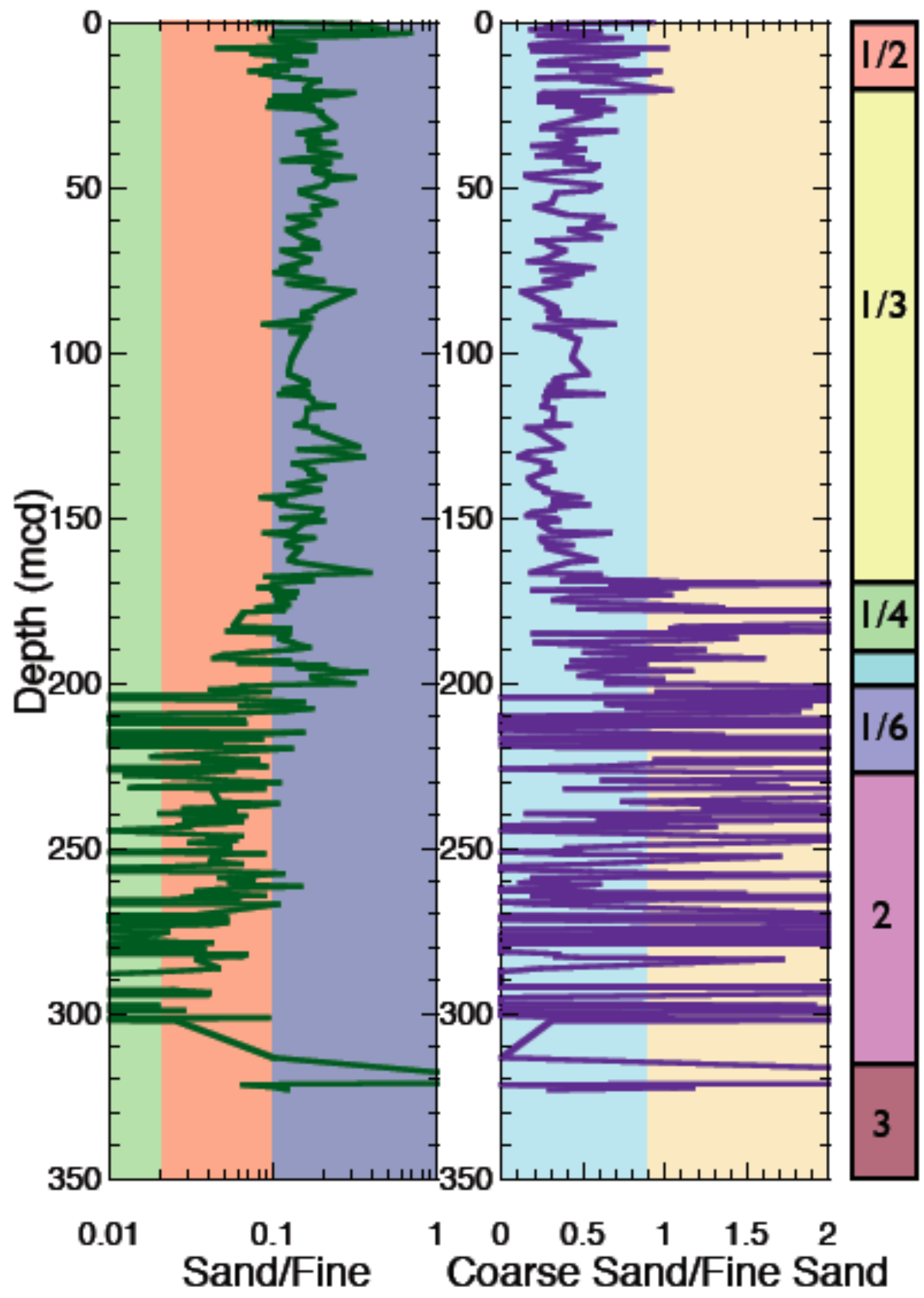


Figure 1.15: Grain size distributions of the ACEX cores are plotted here using the ratios of sand to fine sediments and coarse sand to fine sand. Changes in the grain size distributions correspond to changes in lithology. Unit $1 / 2$ is dominated by high coarse sand percentages. Unit $1 / 3$ is characterized by moderate sand contributions. Unit $1 / 4$ has significant coarse sand contributions, while the unit directly below, which incorporates a significant hiatus, returns to more moderate coarse sand levels. Units $1 / 6$ and 2 are undifferentiated in regard to grain size distribution, with low sand values and coarse sand values that fluctuate between extremely high and low values. The few samples from Unit 3 show an increase in sand deposition. 


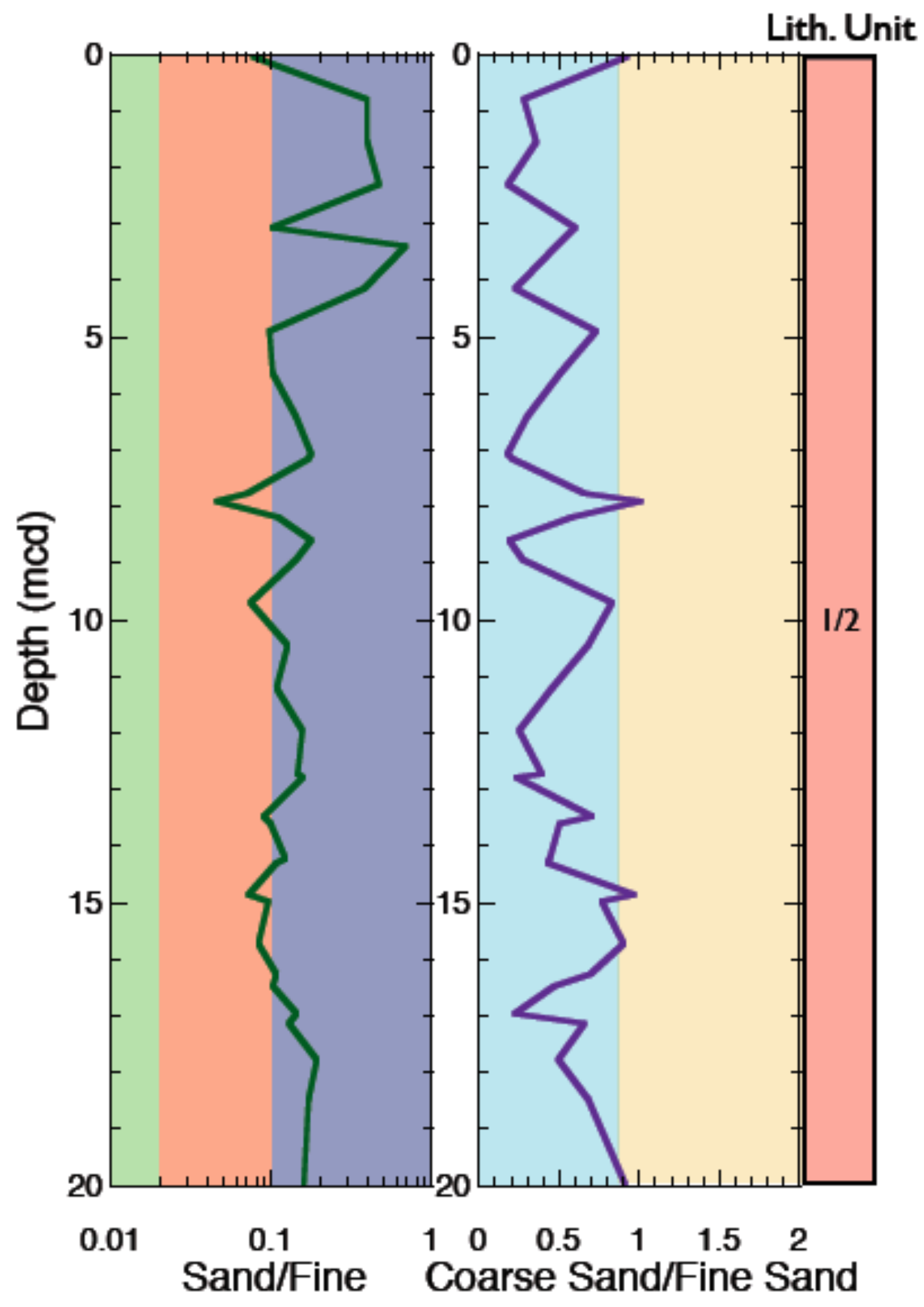


Figure 1.16: The plotted grain size distribution ratios are for the ACEX Lithology Unit $1 / 2$. Four samples show elevated sand percentages and decreased coarse sand contributions, indicative of a sea ice environment. Numerous samples show elevated coarse sand components, suggesting an iceberg influence. Overall this unit is categorized as low sand and coarse sand contributions. 
Lith. Unit

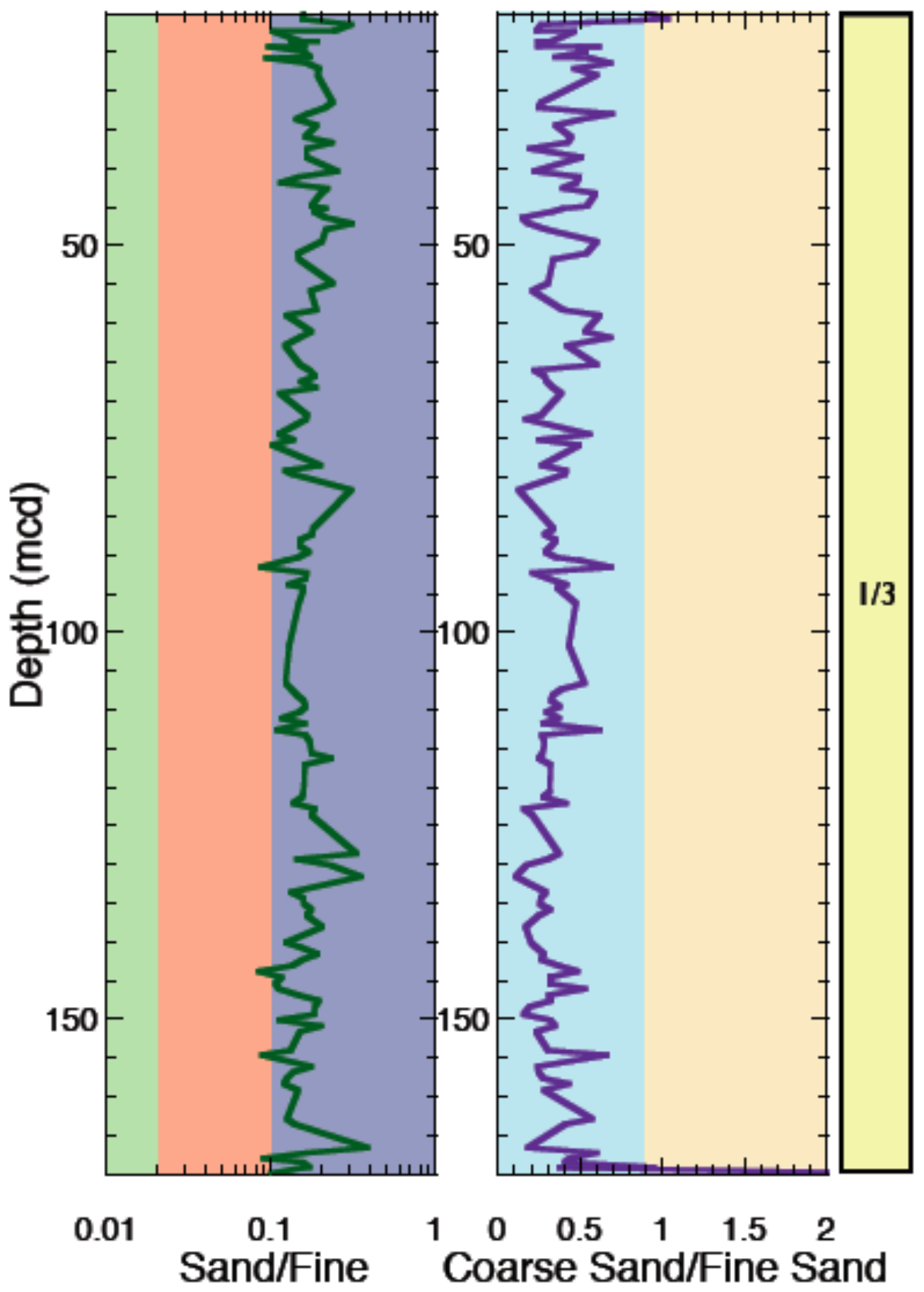


Figure 1.17: The plotted grain size distribution ratios are for the ACEX Lithology Unit $1 / 3$. Six samples show elevated sand with decreased coarse sand contributions, which we interpret as being a sea ice environment. The majority of this unit is categorized as low sand and coarse sand contributions, a diminshed sea ice presence. 
Lith. Unit

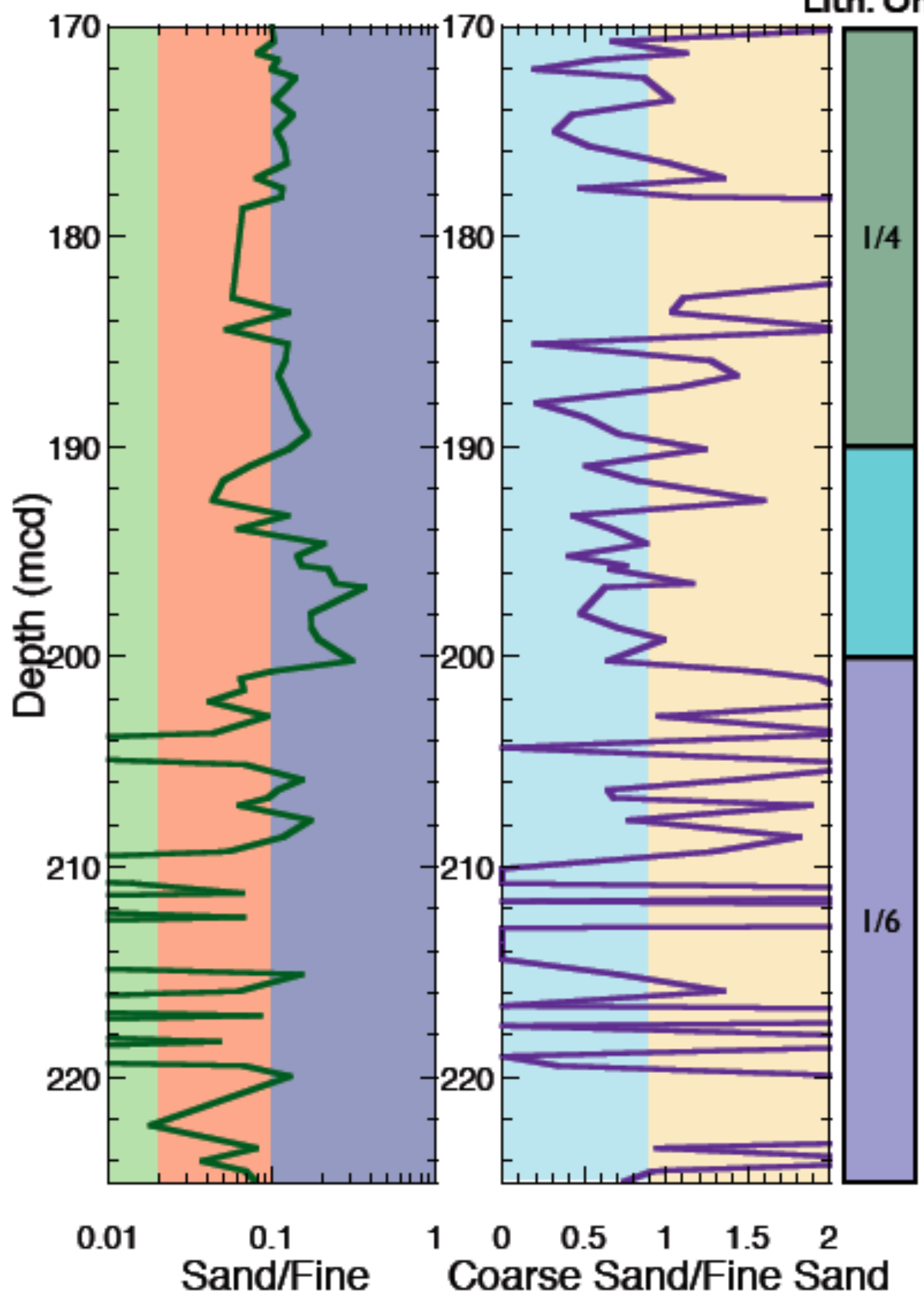


Figure 1.18: The plotted grain size distribution ratios are for the ACEX Lithology Units $1 / 4-1 / 6$. Unit $1 / 6$ has nine samples between 204 and $220 \mathrm{~m}$ with no sand, indicative of an ice-free environment (Table 1.2). Unit $1 / 5$ has two samples, with elevated sand and low coarse sand contributions, a sea ice environment. Most samples alternate between low sand- low coarse sand contributions, and low sand- high coarse sand contributions, going from sea ice to periods of iceberg influence. 


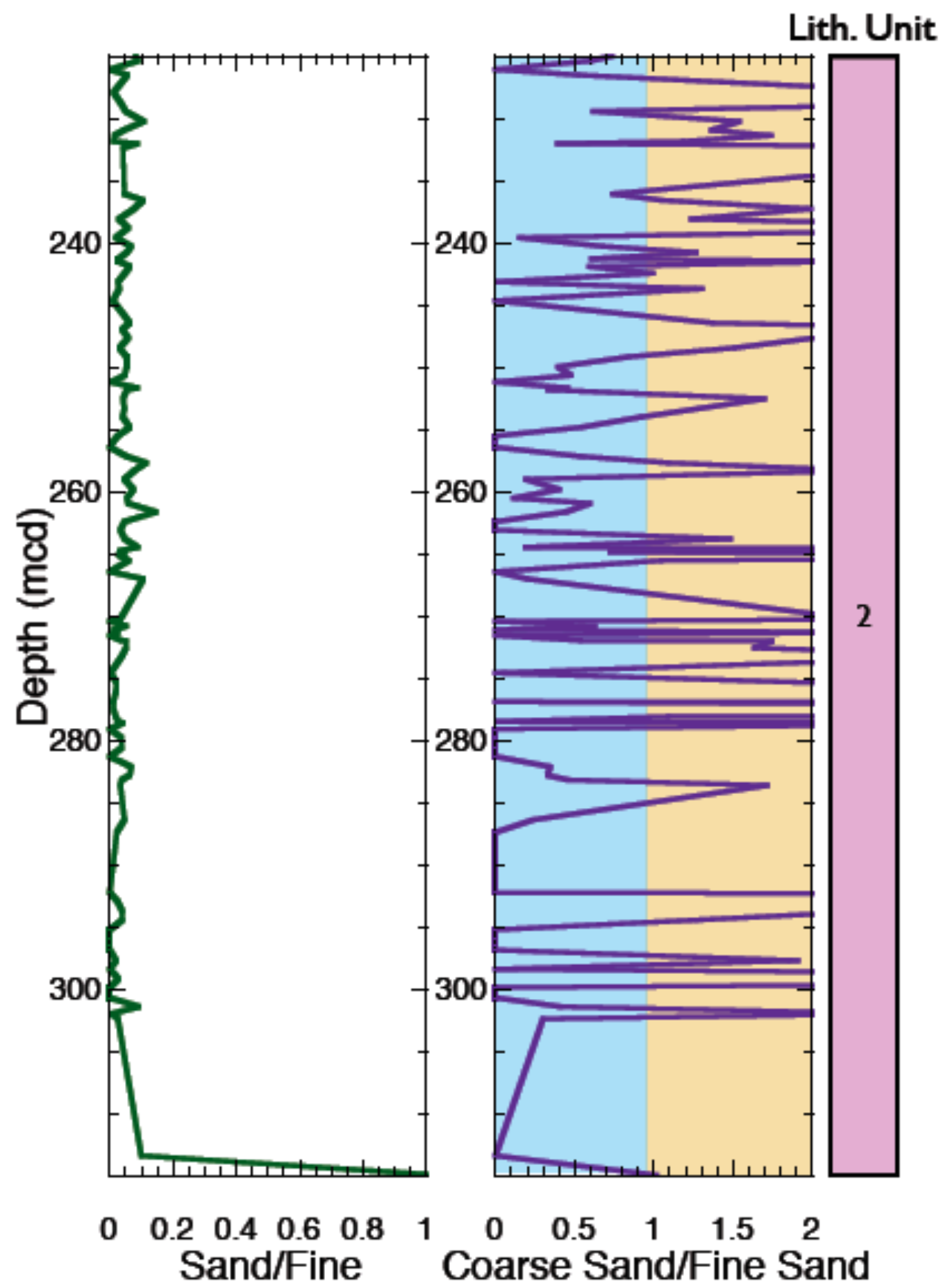

Figure 1.19: The plotted grain size distribution ratios are for the ACEX Lithology Unit 2. This region alternates between low sand- low coarse sand, and low sand- high coarse sand contributions, iceberg inclusions. 


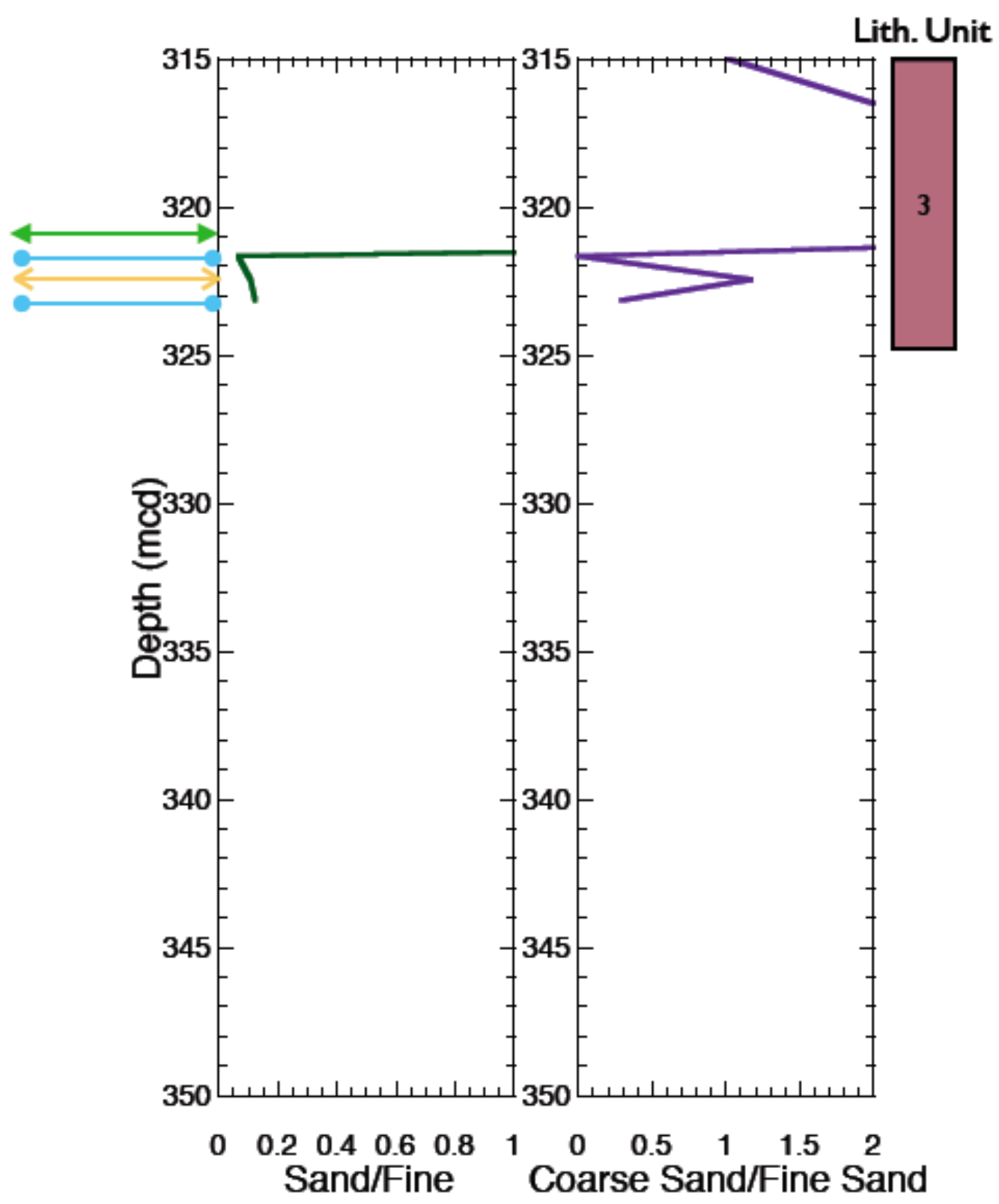

Figure 1.20: The plotted grain size distribution ratios are for the ACEX Lithology Unit 3. This unit has a sample that shows elevated sand with extremely coarse sand contributions. This may be a river ice environment (Table 1.3). There are two samples with low sand and coarse sand contributions, a seasonal sea ice presence. The sample with elevated coarse sand, suggests iceberg influence. 


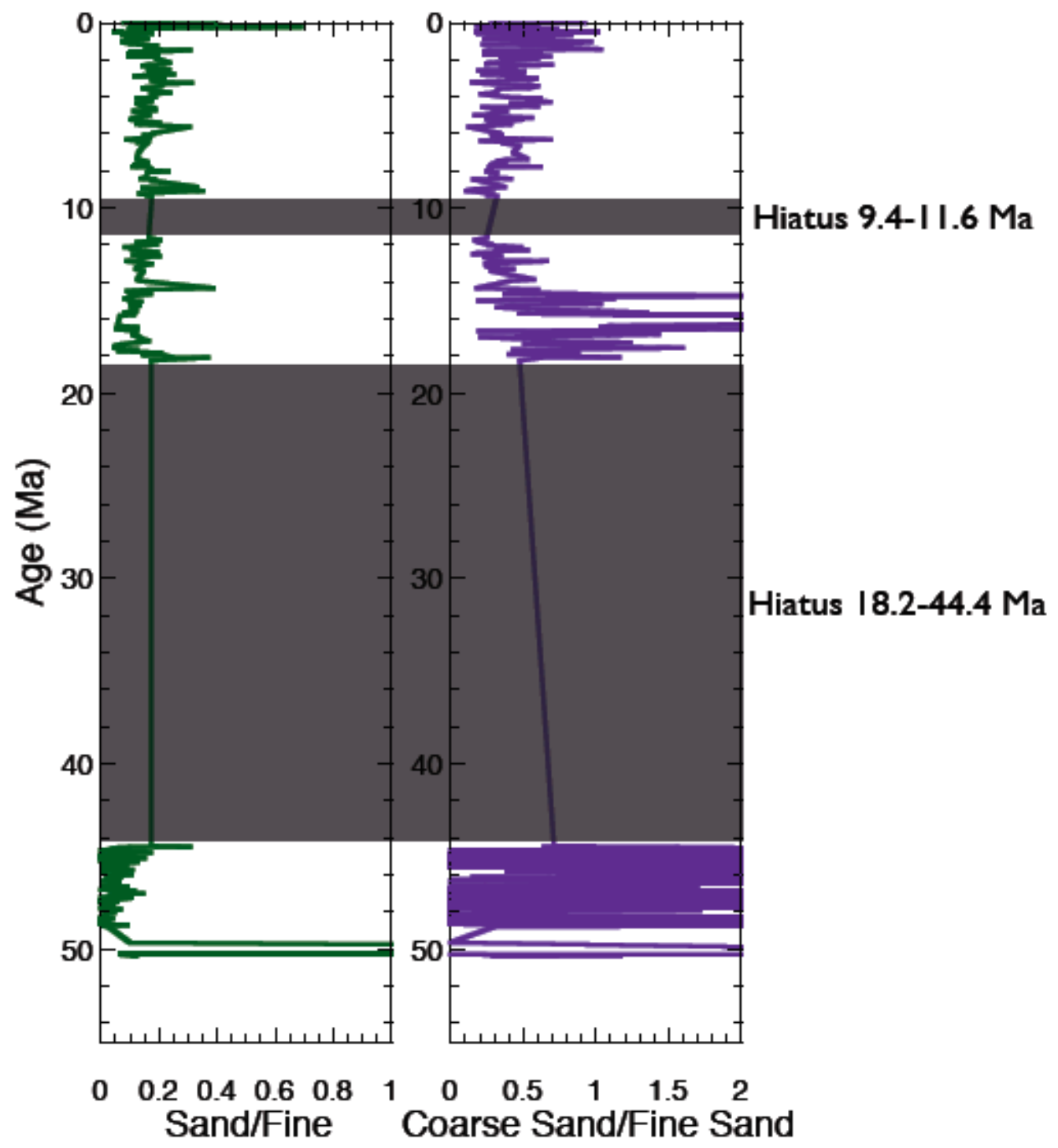

Figure 1.21: The ACEX grain size distribution ratios are plotted in time. The darkened portions of the graphs represent hiatuses in the deposition record. 0- 9.4 Ma shows a relatively steady sand component, with a decreasing coarse sand component. 11.6- 18.2 Ma shows again a relatively steady sand component, but with an increasing coarse sand component. 44.4- 51 Ma shows a diminished, but present sand component, and a widely varying coarse sand component. 


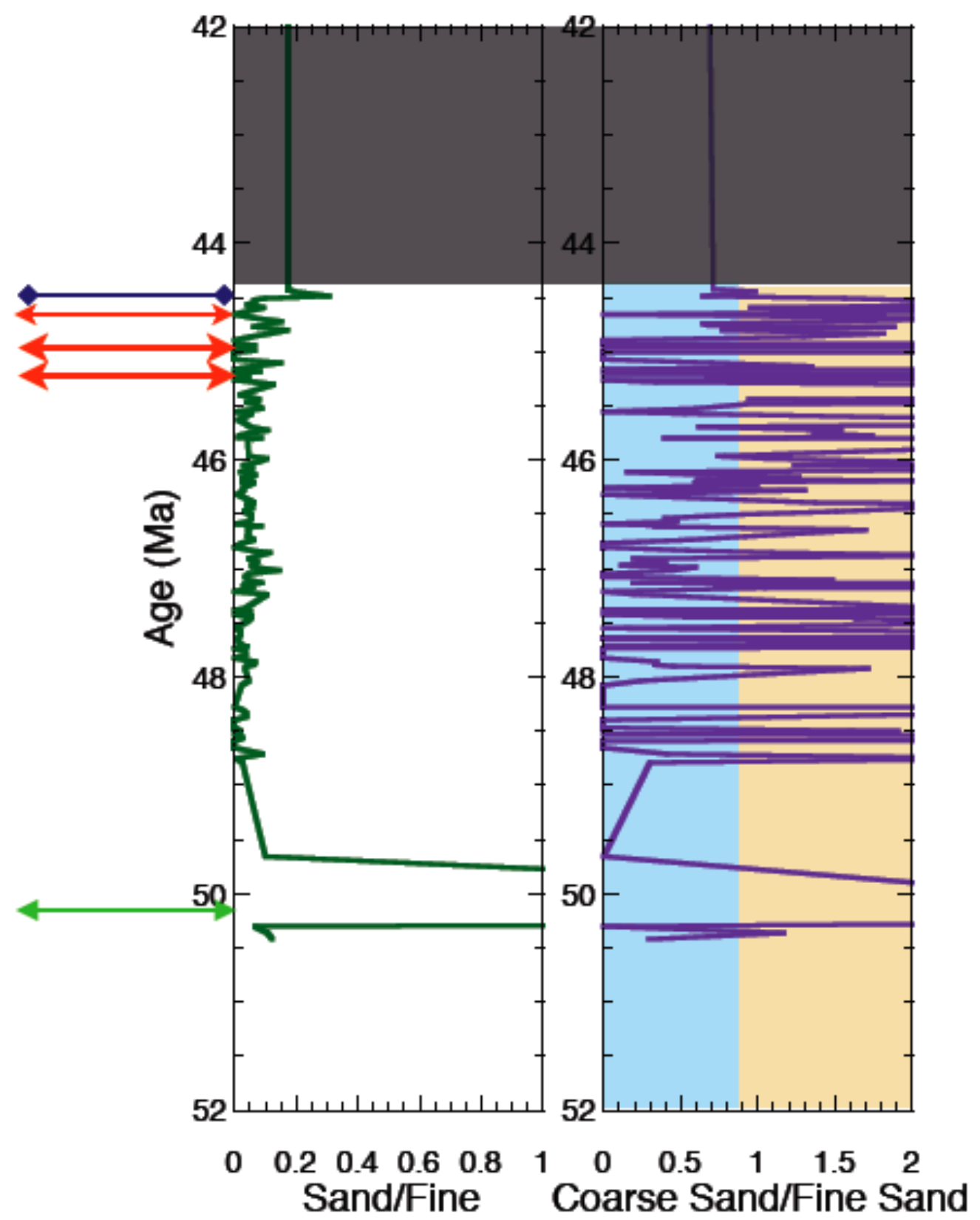


Figure 1.22: The plotted grain size distribution ratios are for the ACEX cores 44.4- 51 Ma. This time range has a period that shows a significantly extremely elevated sand contribution with a corresponding elevated coarse sand contribution, possibly a river ice environment (Table 1.3). This time has a period with elevated sand component, low coarse sand, a sea ice environment. The time range has three periods with no sand, an ice-free environment (Table 1.2). The majority of the time range is categorized as alternating between having low sand- low coarse sand contributions, seasonal sea ice, and low sand- high coarse sand contributions, iceberg influenced. 


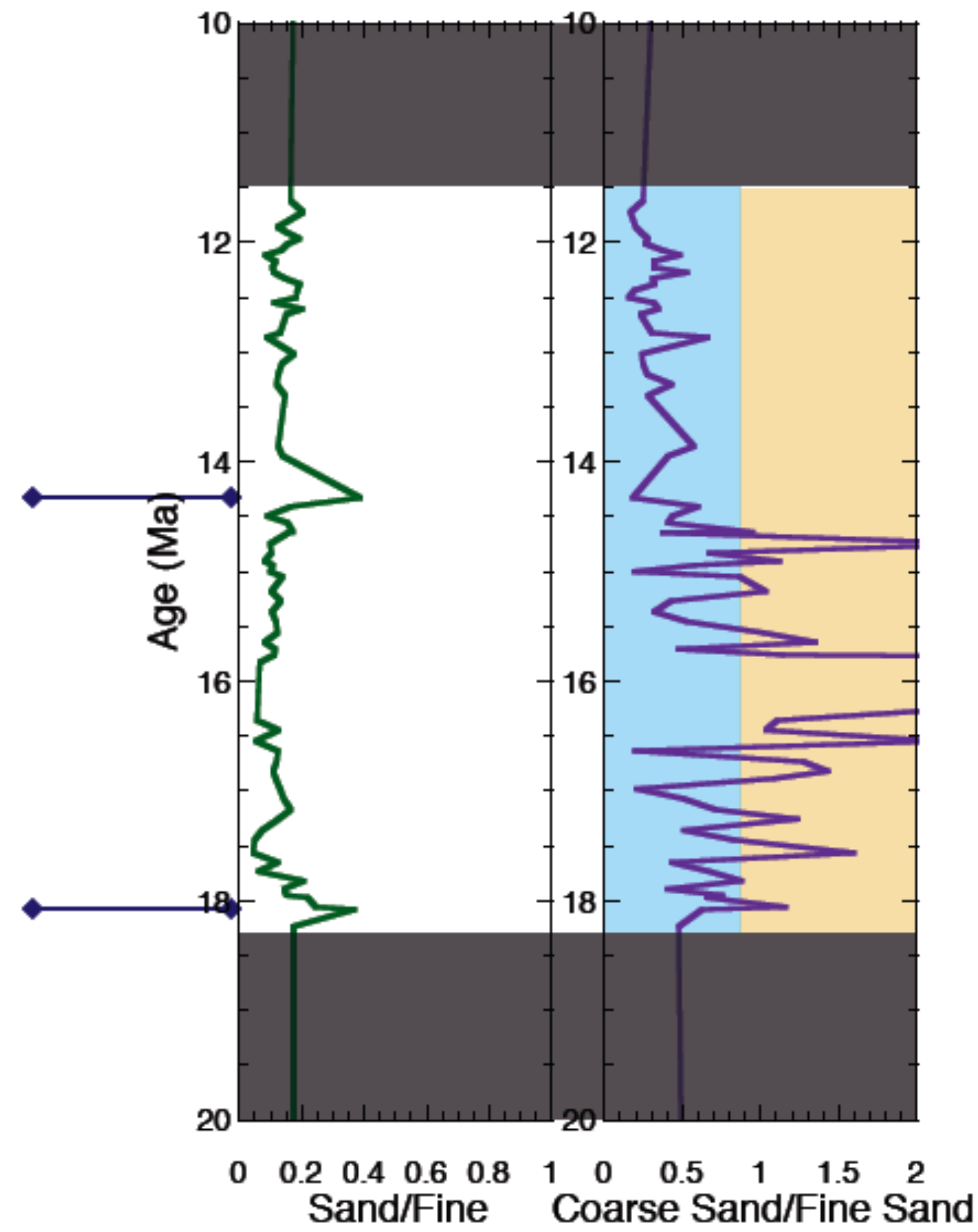

Figure 1.23: The plotted grain size distribution ratios are for the ACEX cores 11.618.2 Ma. This time range has two periods that have elevated sand, decreased coarse sand contributions, a sea ice environment. The majority of the time range alternates between, low sand- elevated coarse sand components, suggesting an iceberg influence, and low sand- low coarse sand contributions, diminished sea ice presence. 


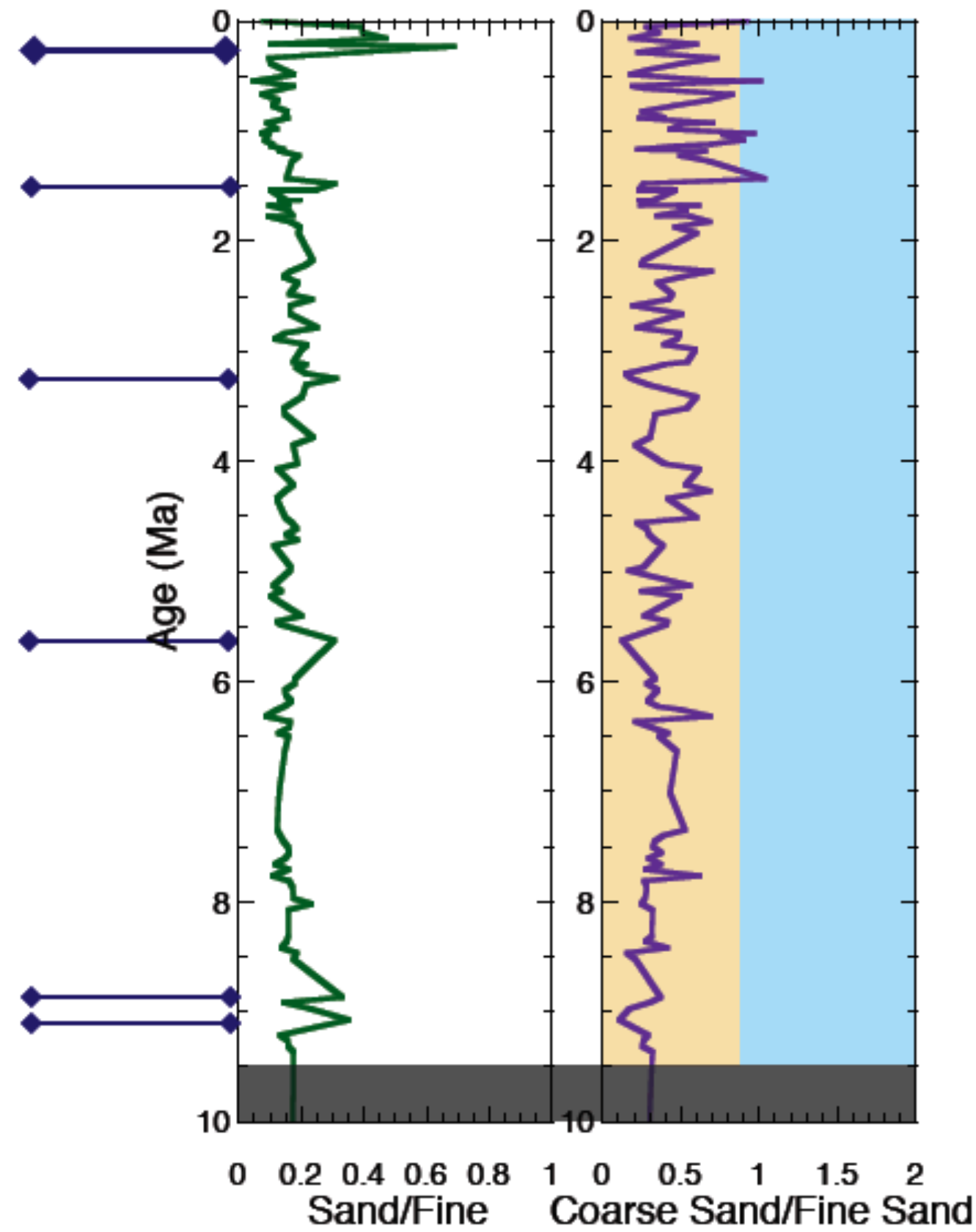

Figure 1.24: The plotted grain size distribution ratios are for the ACEX cores 0-9.4 Ma. This time range has six periods of elevated sand, decreased coarse sand contributions, a sea ice environment. The time range also has samples that display elevated coarse sand components, suggesting an iceberg influence. The majority of the time range is categorized as having low sand and coarse sand contributions, a seasonal sea ice presence. 


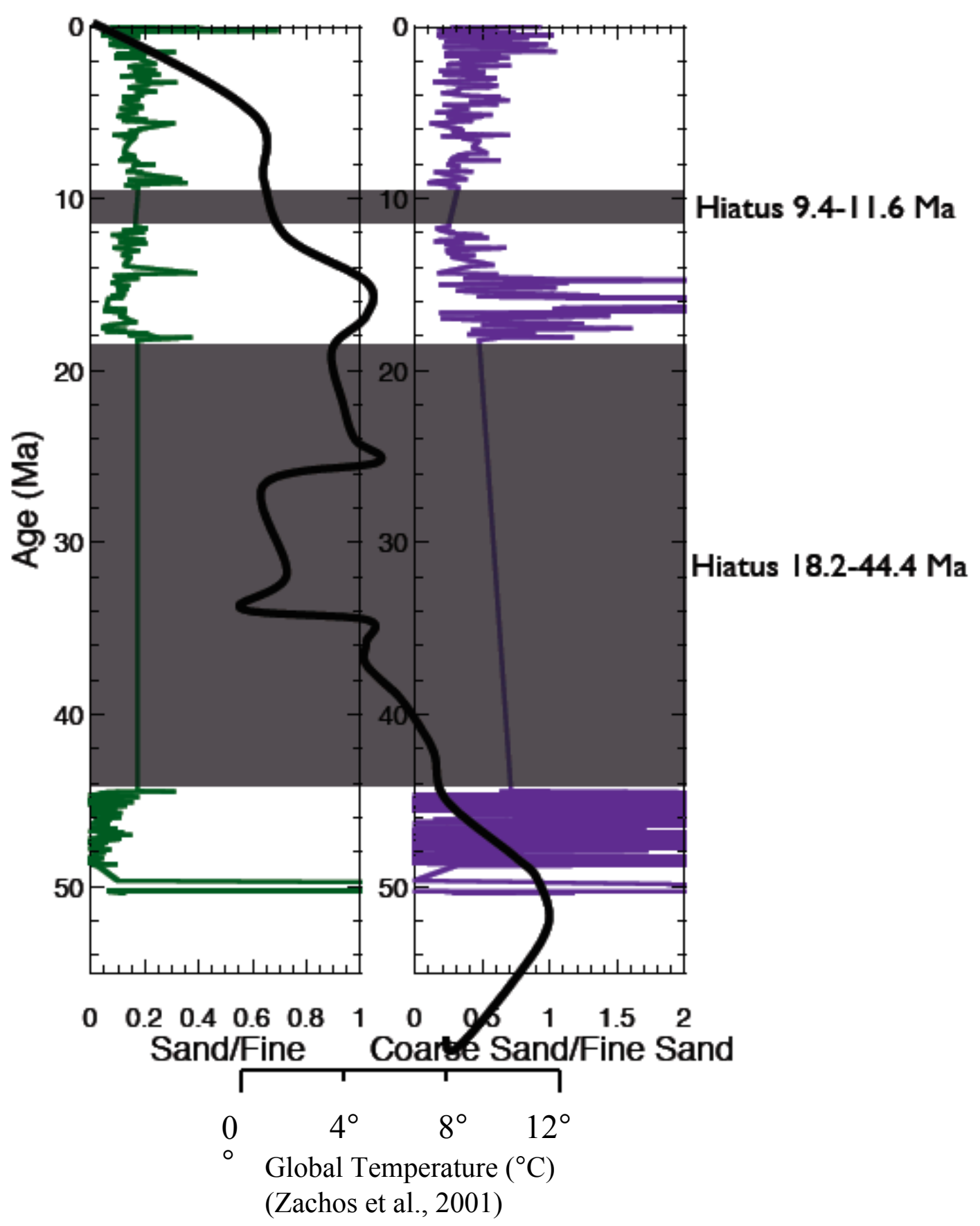

Figure 1.25: The solid black line superimposed on the grain size distributions of this study, is the global benthic $\delta^{18} \mathrm{O}$ compiled by Zachos et al. (2001) and interpreted as global mean temperature. There has been an overall decrease in global mean temperature for the Cenozoic Era. The transition from seasonal sea ice to perennial sea ice took place at a time when the global mean temperature was between $4^{\circ}$ and $8^{\circ}$ C. 


\begin{tabular}{|c|c|}
\hline Principle Component & Fraction of variance explained \\
\hline 1 & 0.439665 \\
\hline 2 & 0.247123 \\
\hline 3 & 0.139087 \\
\hline 4 & 0.0647166 \\
\hline 5 & 0.0466547 \\
\hline
\end{tabular}

Table 1.5: The first 5 principle components (components of greatest significance) for the ACEX grain size distribution data set. For statistically significant principle components, the fraction of variance explained by the first principle component needs to exceed 0.5. None of the principle components for the ACEX grain size data set meet the requirements of being statistically significant. The principle component analysis was completed using the Molegro Data Modeller software. 


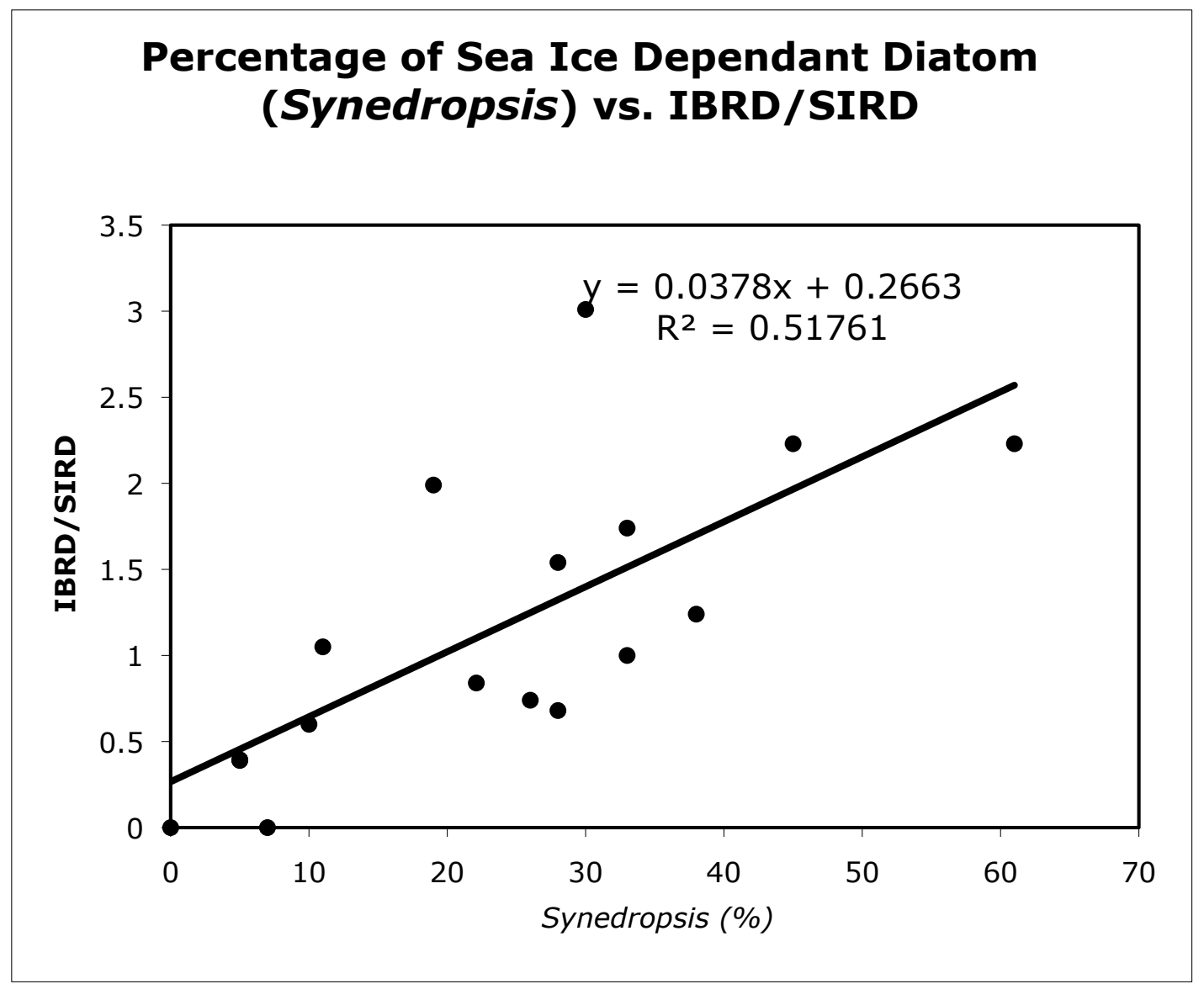

Figure 1.26: Samples of lithography unit 2 where both the determination of the percentage of sea ice dependant diatom, Synedropsis, and grain size profiles from this study were taken within 10 centimeters $( \pm 4,115 \mathrm{yrs})$ of each other graphed showing a positive correlation. This relationship suggests that at periods in unit 2 when icebergs were present there was also a strengthening in the presence of seasonal sea ice. The Synedropsis percentages were obtained from Stickley et al. (2009). 


\title{
Chapter 2
}

"Physical Properties and Grain Size of Glacio-marine Sediment as Predictors of Cryo-States in the Arctic Ocean"

by

\author{
Cristin E. Ashmankas ${ }^{3,4}$
}

written for submission to Geophysical Research Letters

\footnotetext{
${ }^{3}$ Graduate School of Oceanography, The University of Rhode Island, Narragansett, RI 02882 .

${ }^{4}$ Assistant Professor, Natural Science and Mathematics Division, Lesley University, Cambridge, MA 02138. Email: cashmank@lesley.edu
} 


\section{Chapter 2. Physical Properties and Grain Size of Glacio-marine Sediment as Predictors of Cryo-States in the Arctic Ocean}

\section{ABSTRACT}

We present the results of grain size analyses performed on glacio-marine sediment from IODP Expedition 302, Arctic Coring Expedition (ACEX), at the Lomonosov Ridge and the relationships to physical properties determined from nondestructive measurements. Analyses of the sand $(>63 \mu \mathrm{m})$, silt $(<63 \mu \mathrm{m},>4 \mu \mathrm{m})$, and clay $(<4 \mu \mathrm{m})$ fractions show varying relationships to the physical properties of acoustic compressional wave velocity, bulk density, and color reflectance. Sand percentages were found to have relationships to density, acoustic compressional wave velocity and color. Silt percentages were found to have relationships to color, and density. Clay percentages were also found to only have relationships to density, and color. Equally weighting these relationships can be utilized to predict a ratio of sand $(>63 \mu \mathrm{m})$ to fine grained material $(<63 \mu \mathrm{m})$ that shows regions of significant differences in grain size distributions. These differences in the ratio have been previously determined (Chapter 1 ) to indicate major changes in the cryo-state of the Arctic polar region. The prediction of the sand to fine-grained material ratio from the physical properties better resolves the ages of the climate transitions than is possible with the coarse resolution of the direct grain size analyses, permitting increased correlation with other high resolution factors. Utilizing the method we outline would aid future coring expeditions to high latitudes to determine nondestructively sections of core of particular climatic interest. 


\section{INTRODUCTION}

Physical properties of glacio- marine sediments are practically employed in determining grain size distributions. Grain size distributions have been linked in past studies to porosity, permeability, bulk density, and acoustic compressional wave velocity (Bachman, 1985; Boggs, 1995; Fetter, 2001; Hamilton, 1970; Hein, 1991; Schreiber, 1968; Steurer and Underwood, 2003; Moran et al., 2007). These physical properties, as well as gamma-ray attenuation, electrical resistivity, magnetic susceptibility, are measurements that can be completed in minimal time and at low cost, shipboard, and in a manner that does not destructively impact the core.

The nature of the physical properties obtained from a multi-sensor core track, while continuous; act as a smoothing filter to the contributions of grain size distribution changes. This reduces the potential for misinterpretation from aliasing inherent in discrete sampling at low frequency (Bendat and Piersol, 2000). This also highlights low frequency changes or modifications to the deposited grain size distributions.

Grain size distributions can be particularly helpful in the interpretation of highlatitude, paleo- cryo-climate in marine sediments (Chapter 1). The ability to predict low frequency modifications of grain size distributions in field would aid in reducing the cost and time associated in the analysis of such cores. To this end, we investigated the empirical relationships between the grain size distributions of the glacio- marine cores of Integrated Ocean Drilling Program (IODP) Expedition 302 and the physical properties of those cores. This was then extended out to the reinterpretation of other high- latitude, glacio- marine cores. Thus developing reliable, predictive, empirical 
equations that can be utilized for the interpretation of other such cores. IODP Expedition 302, Arctic Coring Expedition (ACEX), targeted the Lomonosov Ridge, central Arctic Ocean, for the interpretation of the dynamics of the deposited sediments found at that location and are used as the glacio- marine sediments that are the basis of this study.

\section{Geologic Setting}

The Lomonosov Ridge is a rifted section of the Eurasian continental shelf dividing the Arctic Basin. Drilling during ACEX focused on four sites, recovering sediments from three of the sites, penetrating $\sim 420 \mathrm{~m}$ (Figure 2.1). The sediments recovered at the three sites reveal much of the Cenozoic Era, with the noticeable exclusion of two depositional hiatuses.

Following the coring process, three major units of lithology were identified (Backman et al., 2004). The upper lithology unit was composed mainly of sandy silt, devoid of most biological deposition. The bottom two lithologies are composed mainly of clayey silt and are richly abundant in biological material. They are distinguished from each other by changes in biological components. The sites were influenced by drifting ice, as evidenced by the presence of sand for most of the recovered record.

\section{METHODS}

\section{Grain Size Analyses}

Samples were collected and sealed aboard ship and refrigerated until grain size analyses could be performed. Sediment samples were analyzed for the individual grain size distribution of terrigenous material. To isolate the terrigenous material, the 
samples were placed in a beaker and treated with acetic acid to rid the samples of biogenic carbonate, hydrogen peroxide to remove the lipids in each sample and sodium carbonate to eliminate the biogenic silicate (Dr John King, personal communication; Mortlock and Froelich, 1989). The samples were then dispersed using a solution of sodium hexametaphosphate for a minimum of 48 hours; further dispersion was achieved by exposing the samples to an ultrasonic bath for 10 minutes.

Grain size distributions from the samples were obtained on a Malvern Mastersizer 2000, a laser diffraction particle sizing system. The system determined the sand, silt, and clay fractions present in each sample. These data were compiled into half phi size bins (phi being a scale of grain size equal to $-\log _{2}$ (diameter of grain)). These data and the subsequent physical properties used in this study can be found in Table 2.1.

\section{Acoustic Compressional Wave Velocity}

Acoustic compressional wave velocity (Vp) was measured utilizing a Geotek Multi Sensor Core Track (MSCL) p-wave logger. A p-wave logger generates an ultrasonic wave pulse. The pulse's dominant frequency is $500 \mathrm{kHz}$. The pulse is transmitted through an unopened, undisturbed core. The p-wave logger records the travel time. The diameter of the core is divided by the travel time, determining the velocity. The p-wave velocity was corrected for transducer and core liner time delays and core diameter deviations (Schulthesis and McPhail, 1989). The data were then run through a detrending program to remove the influence of depth. 


\section{Bulk Density}

Bulk density was measured utilizing a gamma-ray attenuation porosity evaluator (GRAPE) on the MSCL (Evans, 1965). The measurement of bulk density in this matter is based on the concept of Compton scattering and attenuation. A parallel, monoenergetic beam of gamma rays produced from a sample of ${ }^{137} \mathrm{Cs}$ pass though the core and is detected on the opposite side by a scintillation counter. During passage gamma rays are absorbed and or scattered, loosing energy and direction. The energy loss and the attenuation are used to determine the bulk density (Boyce, 1976).

\section{Color Reflectance}

Color reflectance was measured utilizing a high-resolution color image camera on the MSCL. The image was then processed to determine both the percentage of color contribution from every 10-nm wavelengths (from $400 \mathrm{~nm}$ to $700 \mathrm{~nm}$ ) and the color coefficient for each of the red, green, blue (RGB) contributions.

\section{Approach}

We investigated correlation relationships between physical properties of sediments, determined nondestructively from core logging techniques, and grain size distributions, determined from discrete samples. From these relationships, we were able to formulate predictive empirical equations for grain size distributions, ultimately determining changes in cryo-state.

Principle component analysis (PCA), a multi-variable statistical regression model, was initially employed to determine possible relationships for this study. However, due to the often-strong correlation of the nondestructive physical properties of the cores to each other, correlations to a particular grain size were indistinguishable 
and mostly insignificant (Tables 2.2-2.6). PCA proved to be an analysis tool of limited usefulness for this data set due to its over-all interdependent nature. PCA requires a complete independent variable data set. It lacks usefulness for grain size and direct measurements of the physical properties of those grains analysis.

Ultimately, the relationships reported in this study were determined by direct one-toone comparison of various grain size ranges to their corresponding physical properties. This is a longer, but much more reflective, accurate, and revealing process that ensures no significant relationship is missed.

\section{RESULTS}

A previous study of grain size distributions and physical properties (Steurer and Underwood, 2003) compared clay fraction percentages and the physical properties of bulk density and porosity (Figure 2.2). Since porosity is calculated from the GRAPE-derived bulk density, assuming a specific gravity of 2.7 , any relationship that exists for bulk density also exists for porosity. Therefore, in this study, we ignored the porosity relationships as a redundancy, focusing only on the bulk density. Additional studies (Bachman, 1985; Hamilton, 1971) compared the grain size distribution in terms of median grain diameter to the physical properties of compressional wave velocity and impedance. Again, since the impedance is calculated by multiplying velocity and bulk density, any relationship that exists for either one, should also result in a relationship with impedance. Therefore, in this study, we ignored the impedance relationships as a redundancy, focusing on the velocity and bulk density only. Studies of color and glacial/interglacial cycles have been completed on similar Arctic 
sediments (Jakobsson et al., 2000; Jakobsson et al., 2001; Poore et al., 1993; Phillips and Grantz, 1997). The studies claimed that brown sediments, made so by additional Manganese content, were interglacial periods and contained an absence of larger grain size distributions. We found color relationships to grain size as well, however, the level of brown did not correspond to any of the size fractions.

In this study, we found relationships with physical properties for all three relevant categories of sediment (clay, silt, and sand). The Udden-Wentworth size classification system was employed for this study. This system defines sand as particles with diameters between $2000 \mu \mathrm{m}$ and $63 \mu \mathrm{m}$. Silt is defined as particles with diameters between $63 \mu \mathrm{m}$ and $4 \mu \mathrm{m}$. Clay is defined as all particles with diameters $<4$ $\mu \mathrm{m}$. Using the grain size distribution samples that had reliable MSCL data at the same location (with the exception of the one major outlier in grain size distributions), linear regressions were fit to the various datasets of sand, silt, clay, and fines. The best correlations are used in this study for prediction purposes.

Sand was found to have strong positive correlations to acoustic compressional wave velocity $(\mathrm{Vp} ; \mathrm{R}=0.79)$, bulk density $(\rho ; \mathrm{R}=0.67)$, and color reflectance at a $570 \mathrm{~nm}$ wavelength $(570 \lambda ; \mathrm{R}=0.55)$ (Figure 2.3). Multiple color reflectance $\lambda$ s were found to have correlating relationships with the percentage of sand. A $\lambda$ of $570 \mathrm{~nm}$ was chosen for prediction purposes since it produced the highest correlation coefficient (R) (Figure 2.4). Equally weighting all three relationships increases the accuracy of the predictive equation for sand:

Sand $\%=-25.6686+1 / 3 *(1.1 *[570 \lambda]+0.05 *[\mathrm{Vp}]+16 \rho)$ 
Silt was found to have strong negative correlations to bulk density $(\rho ; R=$ $0.82)$ and color reflectance at the $660 \mathrm{~nm}$ wavelength $(660 \lambda ; \mathrm{R}=0.73)$ (Figure 2.5). Again multiple color reflectance $\lambda \mathrm{s}$ were found to have a correlating relationship with the percentage of silt. A $\lambda$ of $660 \mathrm{~nm}$ was chosen for prediction purposes since it produced the highest correlation coefficient (R) (Figure 2.6). Equally weighing both relationships increases the accuracy of the predictive equation for silt:

Silt $\%=5^{*}\left(13-4 \rho+11^{*}[660 \lambda]^{\wedge}(-0.32)\right)$

Clay was found to have a positive correlation to bulk density $(\rho ; R=0.61)$ and a negative correlation to the green contribution on the RGB scale $(G ; R=0.57)$ (Figure 2.7). All three color contributions (red, green, and blue) were found to have a correlation to the percentage of silt. Green was chosen for prediction purposes since it produced the highest correlation coefficient (R) (Figure 2.8). Equally weighing both relationships increases the accuracy of the predictive equation for clay:

Clay $\%=44.5-0.24 *[\mathrm{G}]+24 \rho$

The predictive equations for silt and clay were added together, resulting in an equation for the prediction of the percentage of fine material in a sample $(<63 \mu \mathrm{m})$ :

Fines $\%=109.5+4 \rho+0.24 *[\mathrm{G}]+55^{*}[660 \lambda]^{\wedge}(-0.32)$ 
By combining the silt and clay percentages in this manner, we are able to increase the accuracy of the predictions (Figure 2.9) and employ the cryo-state ratio of sand percentages to fines percentages $(\mathrm{S} / \mathrm{F})$ established in previous studies (Chapter 1). Higher values of the $\mathrm{S} / \mathrm{F}$ ratio are indicative of a strong, perannial cyro-state with multi year sea ice (of some combination of frozen sea water and or icebergs). Lower values of the $\mathrm{S} / \mathrm{F}$ ration are indicative of a weak, seasonal cryo-state with a diminished sea ice presence (of either frozen sea water and or icebergs).

While the individual relationships inherently missed percentage changes present in the samples, compounding relationships decreased these occurrences (Figure 2.9). When the predictive equations are applied to the entire high-resolution MSCL dataset with quality data acquisition, the $\mathrm{S} / \mathrm{F}$ ratio eliminates the high frequency changes present in the physical samples and highlights the low frequency, major shifts in the central Arctic's cryo-state (Figure 2.10 and 2.11). The extended predicted S/F ratio matches the measured S/F ratio remarkably well. Major shifts in the predicted data occur at $\sim 220 \mathrm{mcd}$ or $44.5 \mathrm{Ma}, \sim 300 \mathrm{mcd}$ or $48.75 \mathrm{Ma}$, and $\sim 315 \mathrm{mcd}$ or $50 \mathrm{Ma}$. A drawback of this predictive approach is that short isolated points were no sand was present in the direct sample is missed in the smoothing effect of the prediction. Times between 45.5 and $48 \mathrm{Ma}$, when through direct grain size analyze there is an ice free Arctic Ocean are predicted as a weakened, seasonal sea ice presence, but not as ice free.

\section{DISSCUSSION}

By utilizing the predictive relationships outlined in this study to determine the S/F ratio, future central Arctic coring expeditions will be able to determine if the three 
cyro-state shifts found in the Expedition 302 cores are the only major shifts in the Arctic during the Cenozoic Era. Additionally, this can be used as a correlation feature between cores. If the uniqueness of the three cryo-state shifts persists with future exploration and research, it would indicate a fairly consistent cryo-state has existed in the central Arctic Ocean for the last 44.5 Ma. There was a weakened cryo-state previous to the $44.5 \mathrm{Ma}$ transition, with an excursion into a stronger cryo-state from 50 to $48.75 \mathrm{Ma}$ (Figure 2.11).

By comparing the timing and direction of the cryo-state transitions to the published paleogene temperature record of Weller and Stein (2007) for the same cores, we are able to determine a rough estimate for the Sea Surface Temperature that marks the boundary between a strong cryo-state and a weak cryo-state. Weller and Stein (2007) reported a warming of $\sim 7^{\circ} \mathrm{C}$ across the transition present at $44.5 \mathrm{Ma}$, a cooling of $\sim 10^{\circ} \mathrm{C}$ across the transition present at $48.75 \mathrm{Ma}$, and a warming of $\sim 4^{\circ} \mathrm{C}$ across the transition present at $50 \mathrm{Ma}$ (Figure 2.14). The transitions in cryo-state occur more rapidly than the warming and cooling periods, indicating a potential "tipping temperature" from one cryo-state to the other. This sea surface temperature appears to be in the 13 to $14^{\circ} \mathrm{C}$ range. This number can be refined with further SST work, both with increasing frequency of determination and increased accuracy. In addition to the significance of a "tipping temperature" to paleo- Arctic studies, this work can be of importance to the predictions of future Arctic cryo-states.

As of early August 2008, the SST $13^{\circ} \mathrm{C}$ isotherm was present south of Iceland in the North Atlantic and well south of the Artic Circle in the Pacific Ocean. SST temperatures at the present ice edge are $2-4^{\circ} \mathrm{C}$ (NCEP, 2008). There remains a 
significant amount of energy left to be added to the Arctic surface waters to raise the central Arctic Ocean to the $13-14^{\circ} \mathrm{C}$ "tipping temperature". A potential avenue of research for ocean modelers will be how and when that threshold of energy reaches the central Arctic Ocean and changes the cryo-state.

\section{CONCLUSIONS}

Correlations between the data acquired from the non-destructive Multi- Sensor Core Logger (MSCL) and grain size distributions were developed in this study for the central Arctic region. These correlations can be used to predict core locations that represent shifts in the Arctic's cryo-state. We show that by obtaining acoustic wave velocity, bulk density, and color reflectance from split glacio-marine cores and employing empirical relationships, major shifts in ice presence can be predicted. This prediction can aid in the sampling and study of the cores. The methods outlined in this study have the potential to be developed for additional sedimentary environments, broadening the use and reach of MSCL data.

The utilization of the techniques within the Arctic environment yielded noticeable sharp/fast transitions from one cryo-state to another. All the retrieved transitions from the ACEX cores are older than $44.4 \mathrm{Ma}$, indicating a reasonably stable cryo-state in the neogene. The possible Sea Surface Temperature associated with the shift from one cryo-state to another may exist around $14{ }^{\circ} \mathrm{C}$. This study opens multiple avenues for future research in both paleo- and predictive studies. 


\section{REFERENCES}

Bachman, R.T., 1985. "Acoustic and Physical Property Relationships in Marine Sediments." Journal of Accoust. Soc. Am., Vol. 78, No. 2, pp. 616-621.

Backman, J., K. Moran, and D. Evans, 2004. "ACEX Arctic Coring Expedition: Paleoceanographic and Tectonic Evolution of the Central Arctic Ocean." IODP Expedition 302 Scientific Prospectus, Edinburgh (Integrated Ocean Drilling Program Management International, Inc.).

Bendat, J.S., and A.G. Piersol, 2000. Random Data: Analysis and Measurement Procedures. John Wiley \& Sons Inc., NY.

Boggs, S., 1995. Principles of Sedimentology and Stratigraphy. Prentice-Hall Inc., NJ.

Boyce, R. E., 1976. "Definitions and Laboratory Techniques of Compressional Sound Velocity Parameters and Wet-Water Content, Wet-Bulk Density, and Porosity Parameters by Gravimetric and Gamma Ray Attenuation Techniques." Initial Report of the Deep Sea Drilling Program, Vol. 33, pp. 931-958.

Evans, H.B., 1965. "GRAPE-A Device for Continuous Determination of Material Density and Porosity." Transactions $6^{\text {th }}$ Annual SPWIA Logging Symposium, Dallas, TX. Vol. 2, pp. B1-B25.

Fetter, C.W., 2001. Applied Hydrogeology. Prentice-Hall Inc., NJ.

Hamilton, E.L., 1970. "Sound Velocity and Related Properties of Marine Sediments, North Pacific." Journal of Geophysical Research, Vol. 75, No. 23, pp. 44234446.

Hamilton, E.L., 1971. "Elastic Properties of Marine Sediments." Journal of Geophysical Research, Vol. 76, No. 2, pp. 579-604.

Hein, F.J., 991. "The Need for Grain Size Analyses in Marine Geotechnical Studies." In Syvitski, J.P.M. (Ed.), Principles, Methods, and Applications of Particle Size Analysis, Cambridge Univ. Press, NY.

Jakobsson, M., R. Lovlie, H. Al-Hanbali, et al., 2000. "Manganese and Color Cycles in Arctic Ocean Sediments Constrain Pleistocene Chronology." Geology, Vol. 28, No. 1, pp. 23-26.

Jakobsson, M., R. Lovlie, E. M. Arnold, et al., 2001. "Pleistocene Stratigraphy and Paleoenvironmental Variation from Lomonosov Ridge Sediments, Central Arctic Ocean." Global and Planetary Change, Vol. 31, pp. 1-22. 
Moran, K., V. Altmann, M. O’Regan, and C. Ashmankas, 2007. “Acoustic Compressional Wave Velocity as a Predictor of Glacio-marine Sediment Grain Size." Geotechnical Testing Journal, Vol. 30, No. 4.

Mortlock, R.A., and P.N. Froelich, 1989. "A Simple Method for the Rapid Determination of Biogenic Opal in Pelagic Marine Sediments." Deep-Sea Research, Vol. 36, No. 9, pp. 1415-1426.

NECP, 2008. "Real-time , Global, Sea Surface Temperature Experimental Analysis: Arctic SST." < polar.ncep.noaa.gov/sst/ophi > (July 30, 2008).

Phillips, R. L., and A. Grantz, 1997. "Quaternary History of Sea Ice and Paleoclimate in the Amerasia Basin, Arctic Ocean, as Recorded in the Cyclical Strata of Northwind Ridge.” GSA Bulletin, Vol. 109, no. 9, pp. 1101-1115.

Poore, R. Z., R. L. Phillips, and H. J. Rieck, 1993. "Paleoclimate Record for Northwind Ridge, Western Arctic Ocean". Paleoceanography, Vol. 8, No. 2, pp. 149-159.

Schreiber, B.C., 1968. "Sound Velocity in Deep Sea Sediments." Journal of Geophysical Research, Vol. 73, pp. 1259-1268.

Schultheiss, P.J., and S.D. McPhail, 1989. “An Automated P-Wave Logger for Recording Fine-Scale Compressional Wave Velocity Structures in Sediments." Proc. ODP Sci. Results, Vol. 108, pp. 407-413.

Steurer, J.F., and M.B. Underwood, 2003. "Data Report: The Relation Between Physical Properties and Grain-Size Variations in Hemipelagic Sediments from Nankai Trough." In Mikada, H., G.F. Moore, et al. (Eds.), Proc. ODP Sci. Results, Vol. 190/196.

Weller, P., and R. Stein, 2008. "Paleogene Biomarker Records from the Central Artic Ocean (IODP Exp. 302): Organic Carbon Sources, Anoxia, and Sea Surface Temperatures. "Paleoceanography, Vol. 23. 
Table 2.1: Grain size distributions and multi-sensor core logging data from IODP Exp. 302 (ACEX) used in this study. 


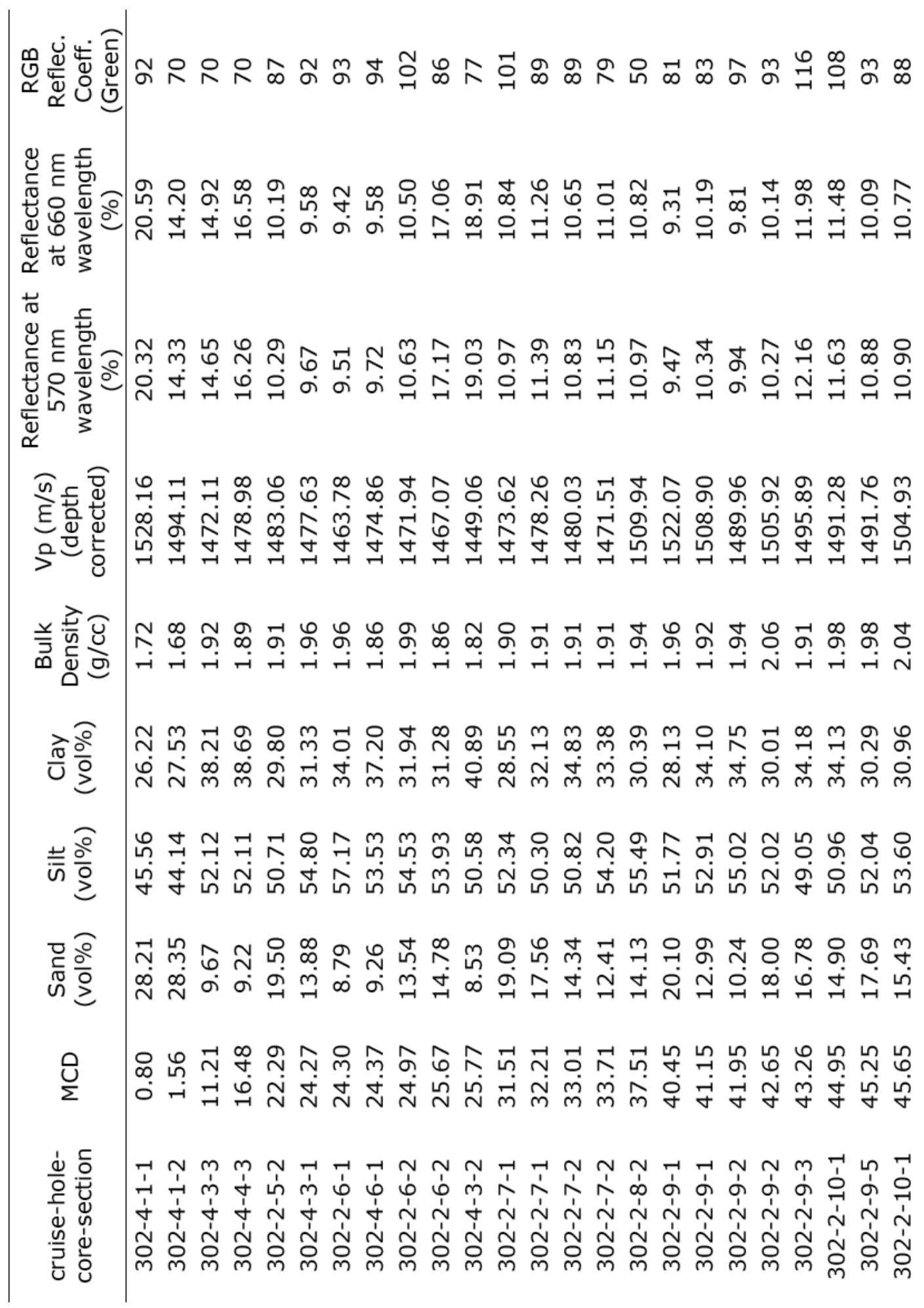


む

ஸ艹

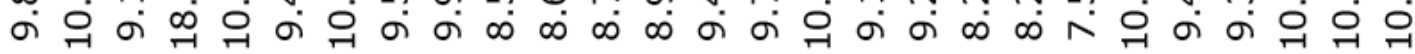

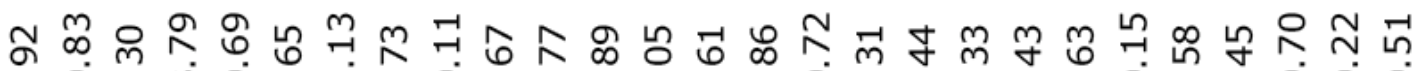

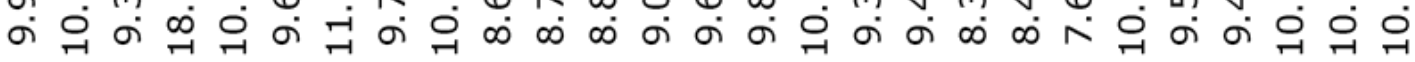

๙ सं வ்

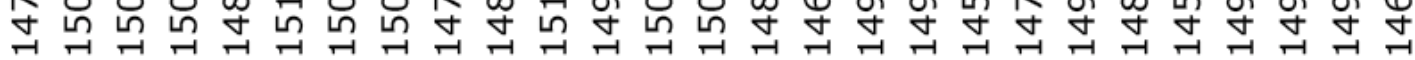

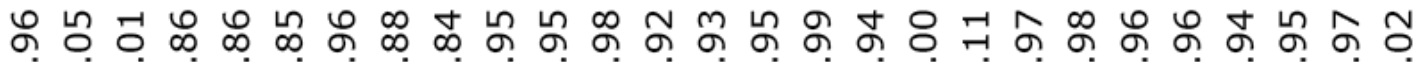
-i $\dot{\sim}$ N

ஸึ ₹

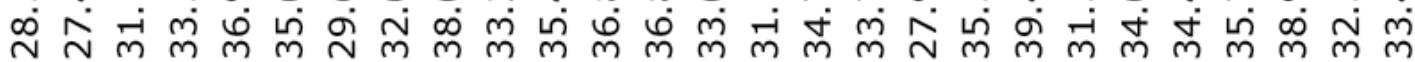

ம용ำ กึ \&

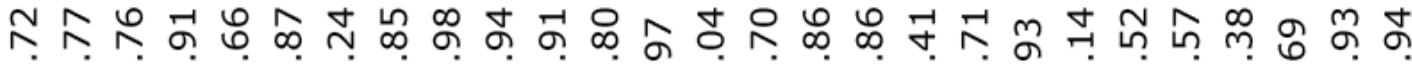
귁

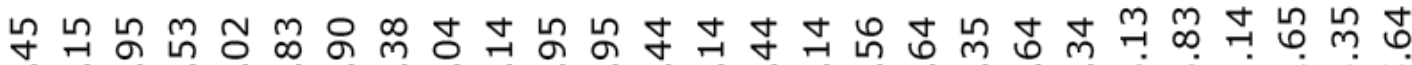

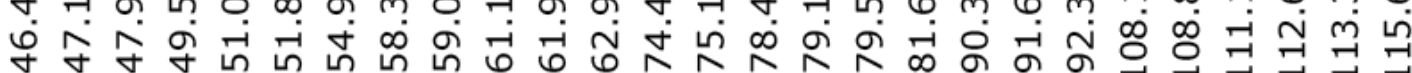

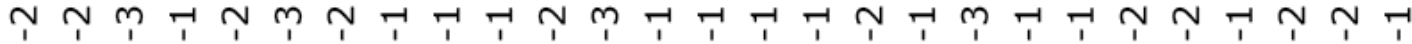

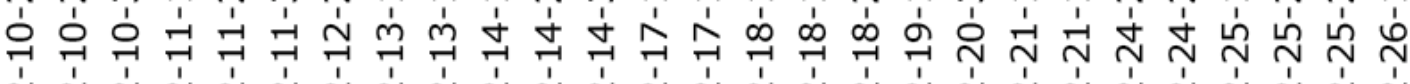

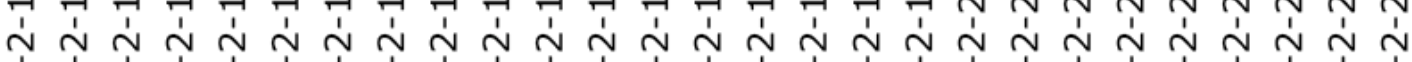

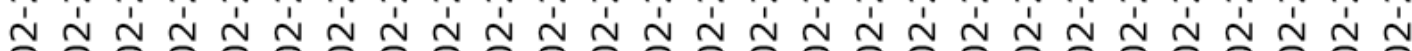

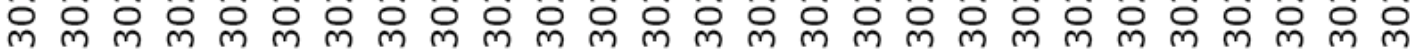




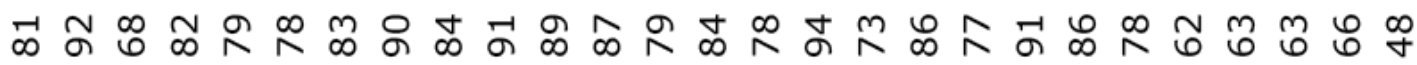

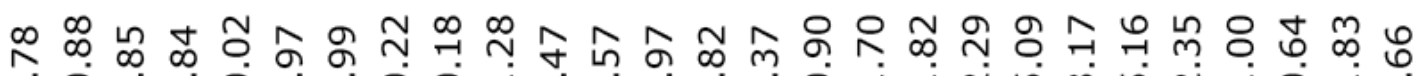
бં

๙ बiન

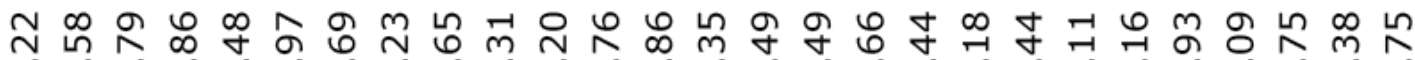
ஜ 文 亦

등 హ ง n

ํํㅇ 药

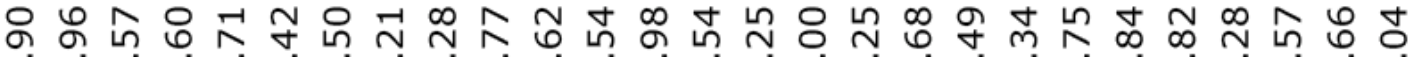

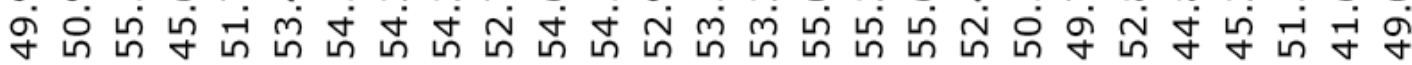

ఎ

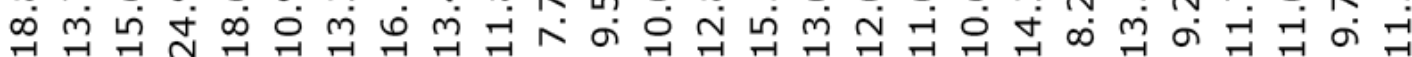

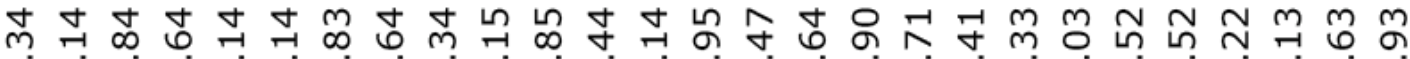

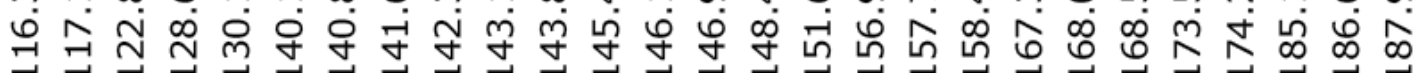

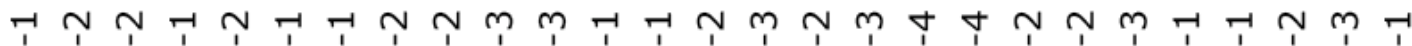

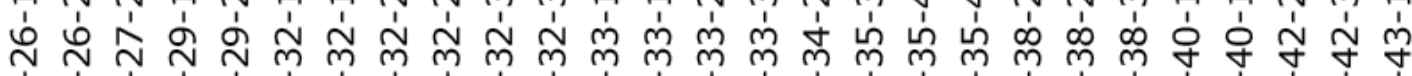

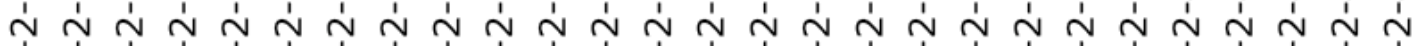

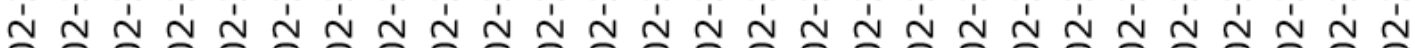

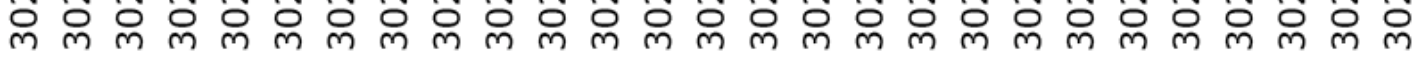




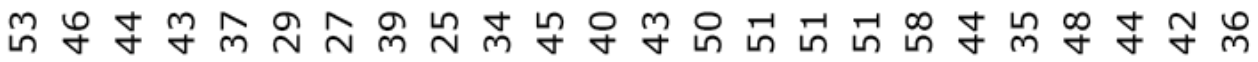

그 ت

बㄱำ

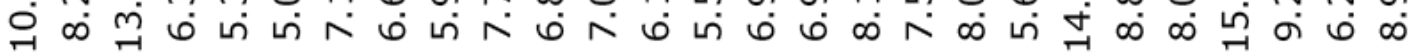

$\stackrel{\infty}{\wedge}$ ○ ด

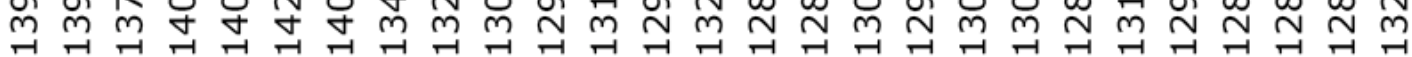

ᄋ

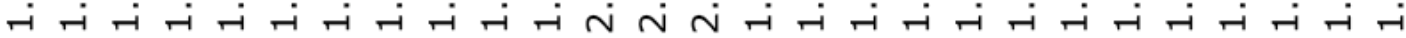

구 ம

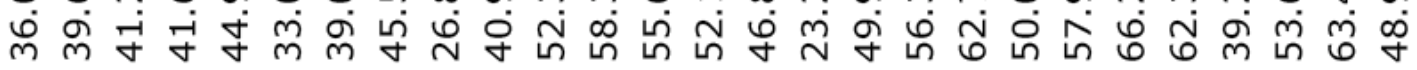

ㅁํ ำ ํำ ம்

북 걱

అִ œ

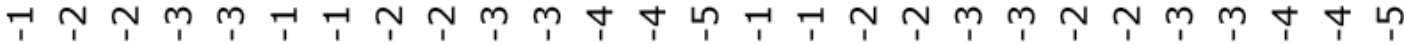

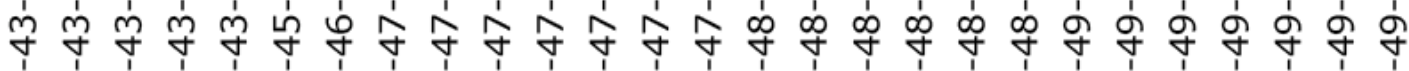

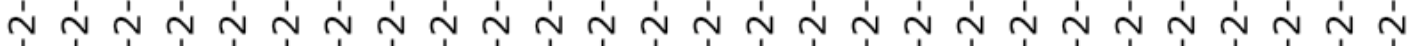

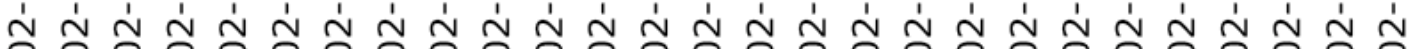

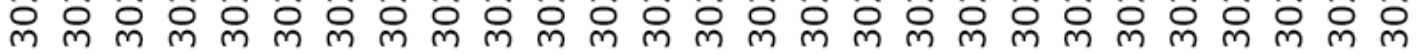




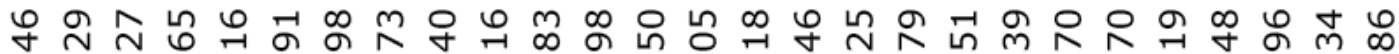

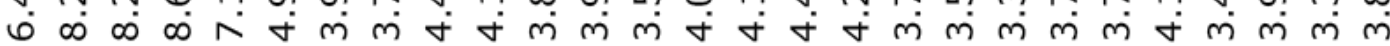

䎹

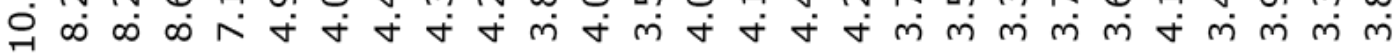

ஓ 어 m

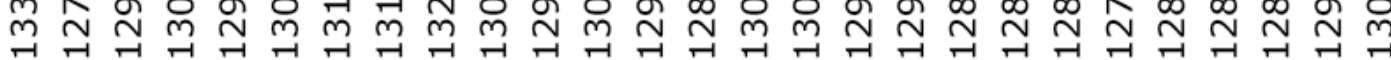

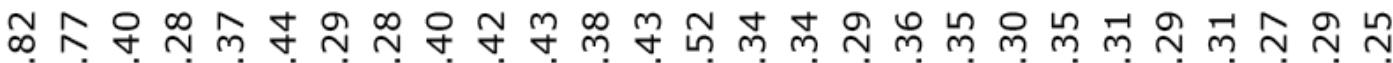
-i -

オ ஸे

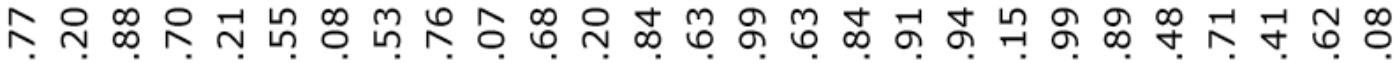

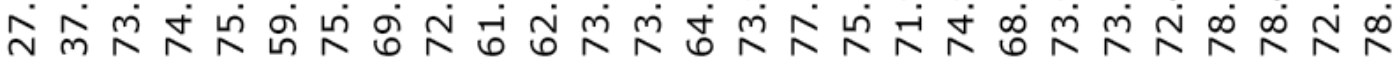

익 ல

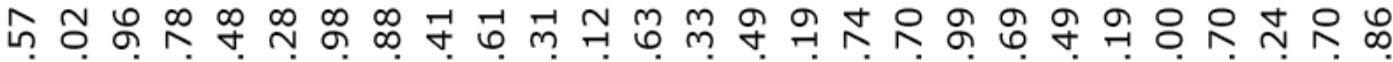

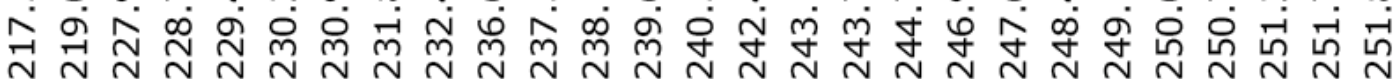

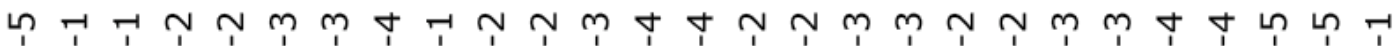

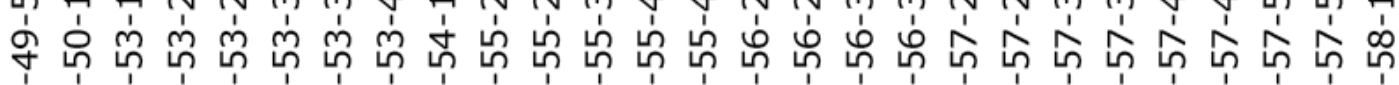

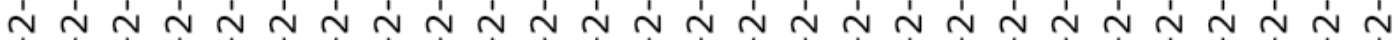

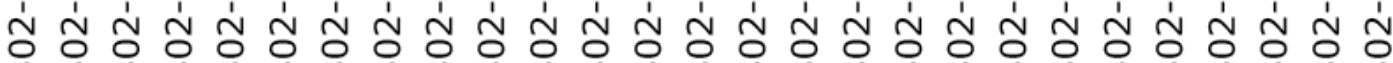

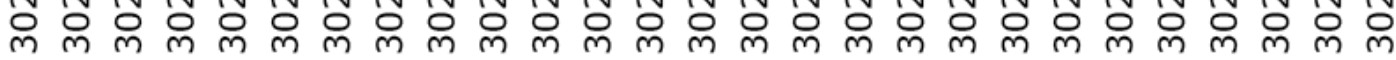


్ 유

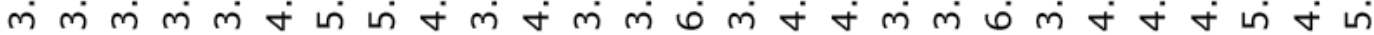

ิํำ

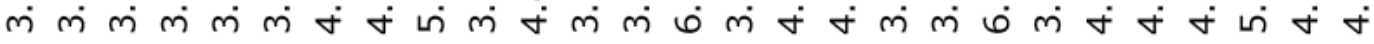

ஸ வ

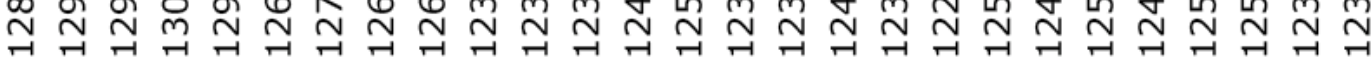

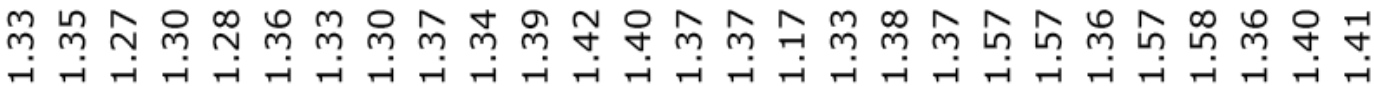

붕 依

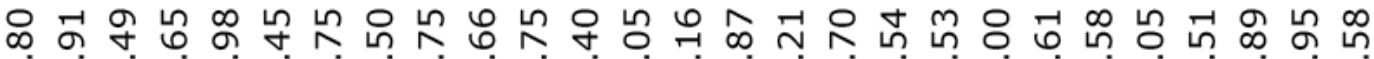
ம்

ก ำ ๙

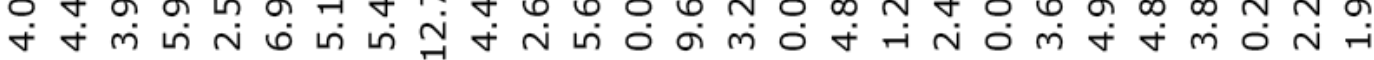

மீ กู่

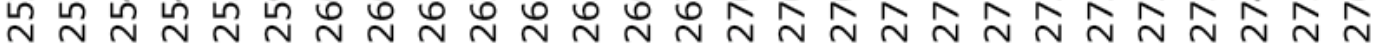

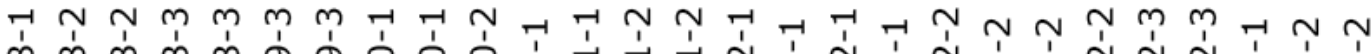

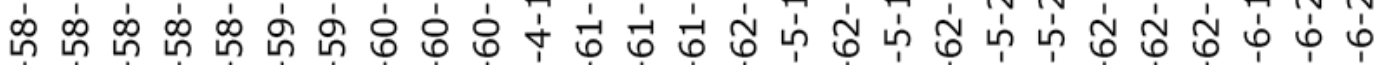
ஸ่

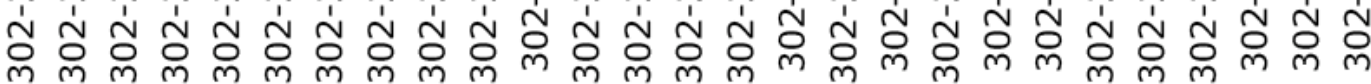




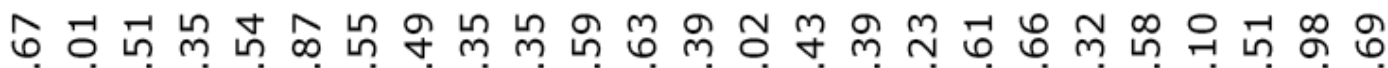

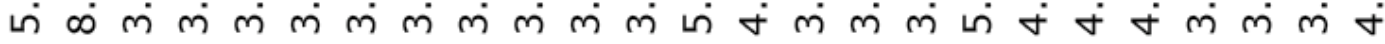

ํํ

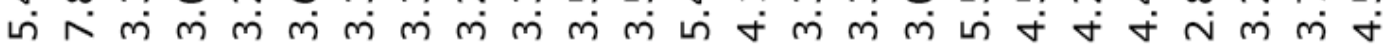

の ఫั

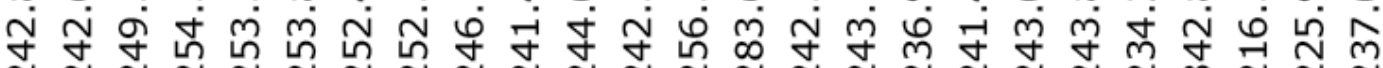

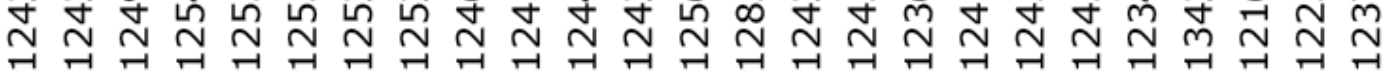

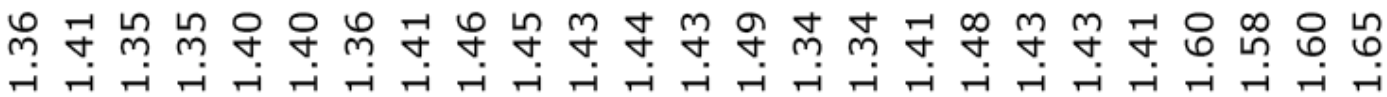

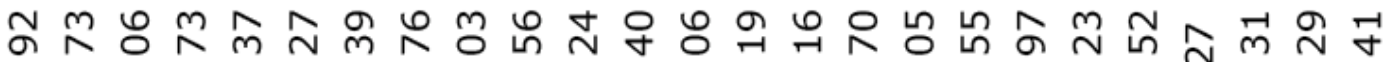

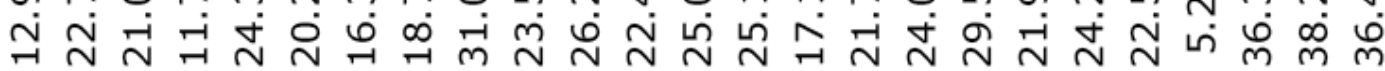

๖워ำ ம

广 น

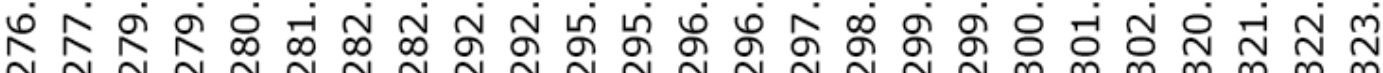

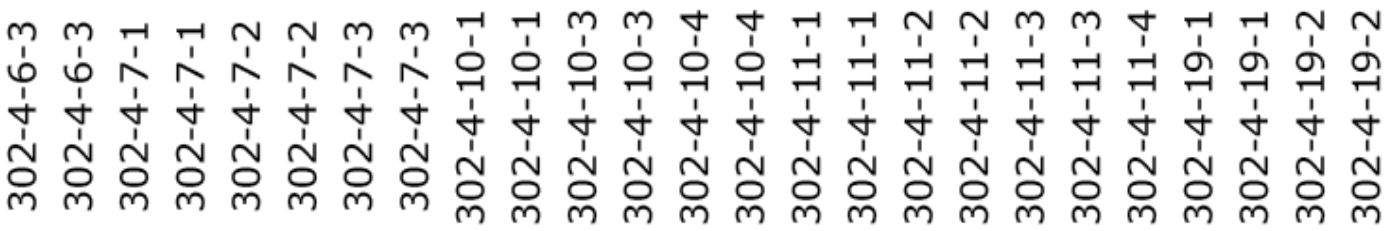


Table 2.2

\begin{tabular}{|l|l|}
\hline \multicolumn{1}{|c|}{ Sand } & \multicolumn{1}{c|}{ Correlation Coefficient } \\
\hline Acoustic Wave Velocity & 0.352 \\
\hline Bulk Density & 0.246 \\
\hline Color 570 & 0.245 \\
\hline Color 580 & 0.244 \\
\hline Color 590 & 0.202 \\
\hline
\end{tabular}

Table 2.3

\begin{tabular}{|l|l|}
\hline Silt & Correlation Coefficient \\
\hline Bulk Density & 0.626 \\
\hline Acoustic Wave Velocity & 0.316 \\
\hline Color 610 & 0.179 \\
\hline Color 620 & 0.103 \\
\hline RGB Reflectance (Green) & 0.023 \\
\hline
\end{tabular}

Table 2.4

\begin{tabular}{|l|l|}
\hline Clay & Correlation Coefficient \\
\hline Bulk Density & 0.368 \\
\hline Acoustic Wave Velocity & 0.069 \\
\hline RGB Reflectance (Green) & 0.031 \\
\hline RGB Reflectance (Red) & 0.027 \\
\hline Acoustic Wave Amplitude & 0.002 \\
\hline
\end{tabular}

Table 2.5

\begin{tabular}{|l|l|}
\hline Acoustic Wave Velocity & Correlation Coefficient \\
\hline Color 600 & 0.806 \\
\hline Color 610 & 0.803 \\
\hline Bulk Density & 0.658 \\
\hline Color 550 & 0.352 \\
\hline Color 540 & 0.316 \\
\hline
\end{tabular}

Table 2.6

\begin{tabular}{|l|l|}
\hline Bulk Density & Correlation Coefficient \\
\hline Acoustic Wave Velocity & 0.658 \\
\hline Resistivity & 0.615 \\
\hline Reflectance at 600 & 0.558 \\
\hline Reflectance at 610 & 0.557 \\
\hline Reflectance at 590 & 0.556 \\
\hline
\end{tabular}


Tables 2.2-2.6: The first principle components (components of greatest significance) for the ACEX MSCL data set and various grain size percentages were all statistically significant (explained more than 0.5 percent of the variance in the data set. For all of the principle component analyses (PCAs) run for each of the sediment sizes of sand, silt, and clay only the first principle component was significant. Once the existence between variables was established, the correlation coefficients were examined for each run. Tables 2.2-2.6 display the correlation coefficients for some of the variables. Too many of the variables qualified as being statistically significant to each other, diminishing the correlation to the grain size. Without any standout variables, this approach prohibited a narrowing down of the variables, which had statistically meaningful relationships with the grain size being analyzed. Tables 2.2-2.6 are the correlation coefficient for sand, silt, and clay respectively and various physical properties. Each of these show significantly lower correlation coefficients than the correlations the physical properties had to each other, examples of which are displayed in table 2.5 for acoustic wave velocity and table 2.6 for bulk density. The noticeable exception to this is the significantly strong correlation silt has with bulk density. The PCA was completed using the Molegro Data Modeller software. 


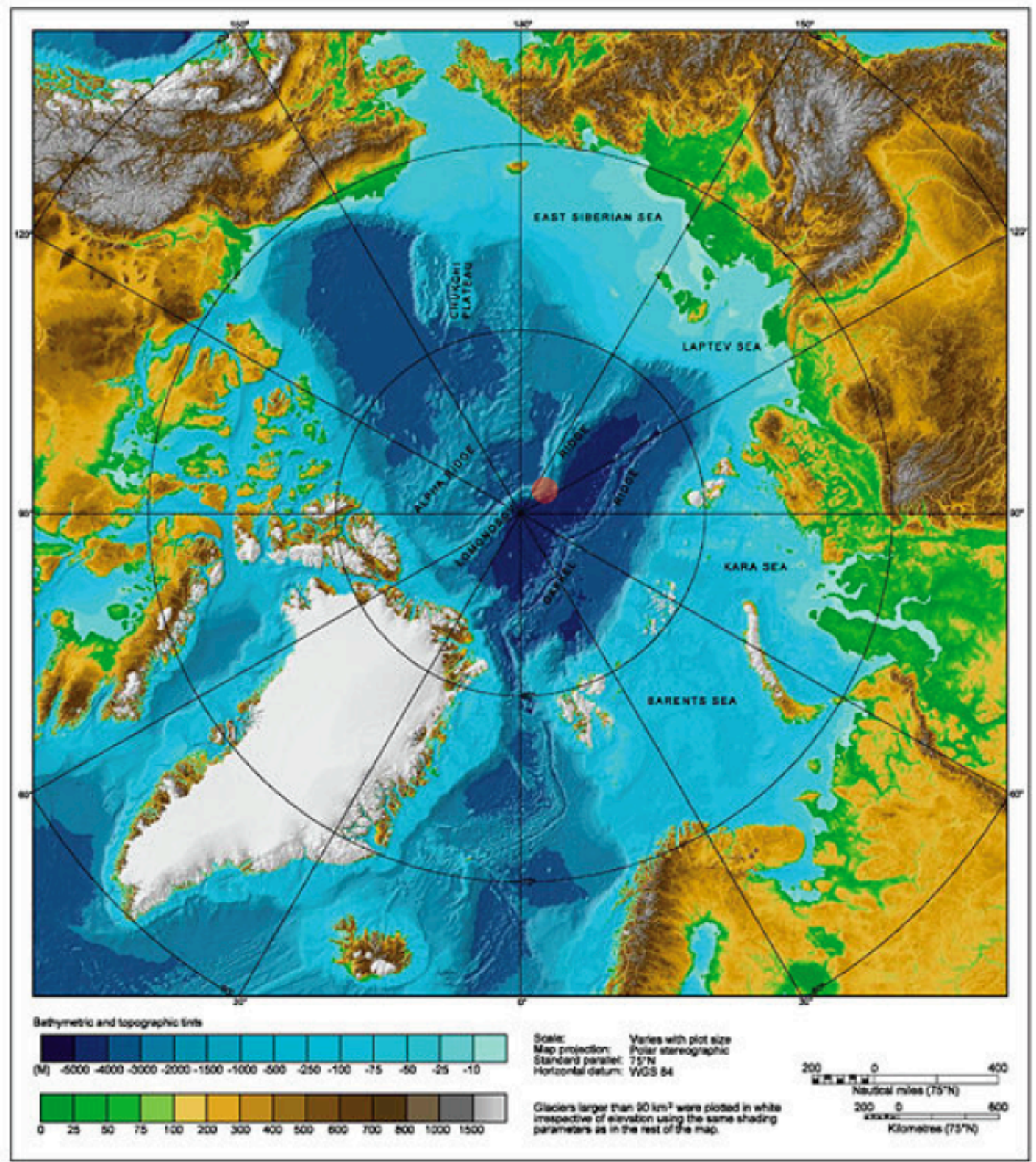

Figure 2.1: IODP Exp. 302 (ACEX) drill sites were located in the central Arctic Ocean, on the Lomonosov Ridge (red dot). These sediments were entirely from the Cenozoic Era and are primarily glacio-marine in origin. (IBCAO, 2008) 
Site 1173

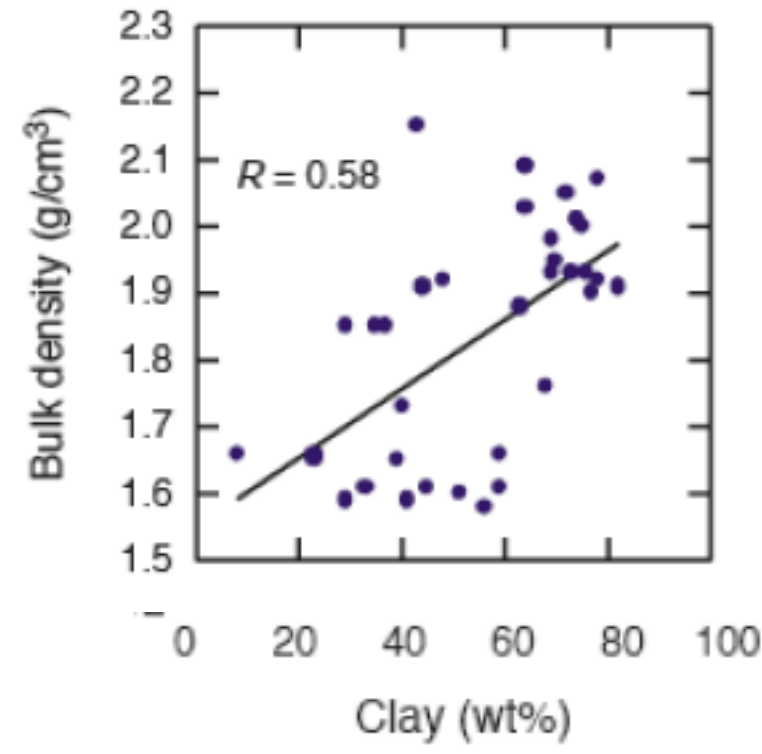

Site 1174

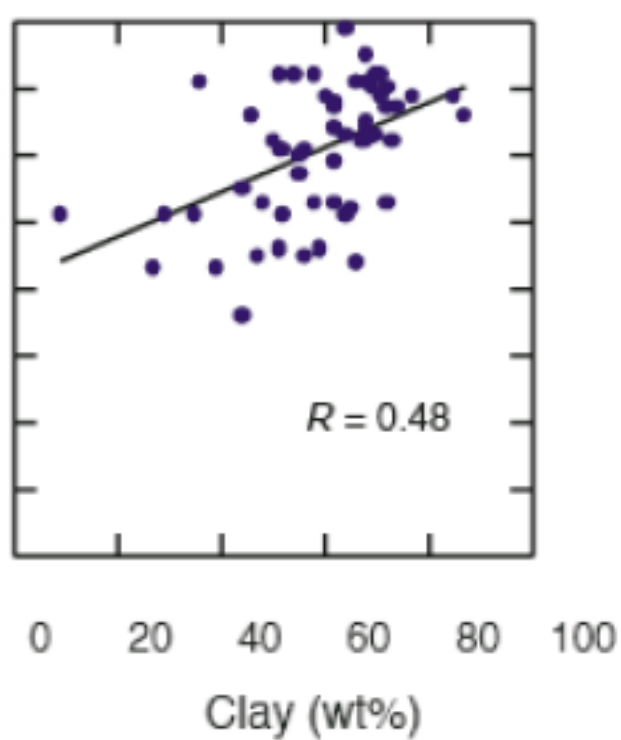

Figure 2.2: Steurer and Underwood (2003) found positive relationships between bulk density and percentage of clay by weight. Sites 1173 and 1174 were located at the Nankai Trench. While a vastly different depositional environment than the sediments analyzed in this study, the positive relationship is true in both studies. 

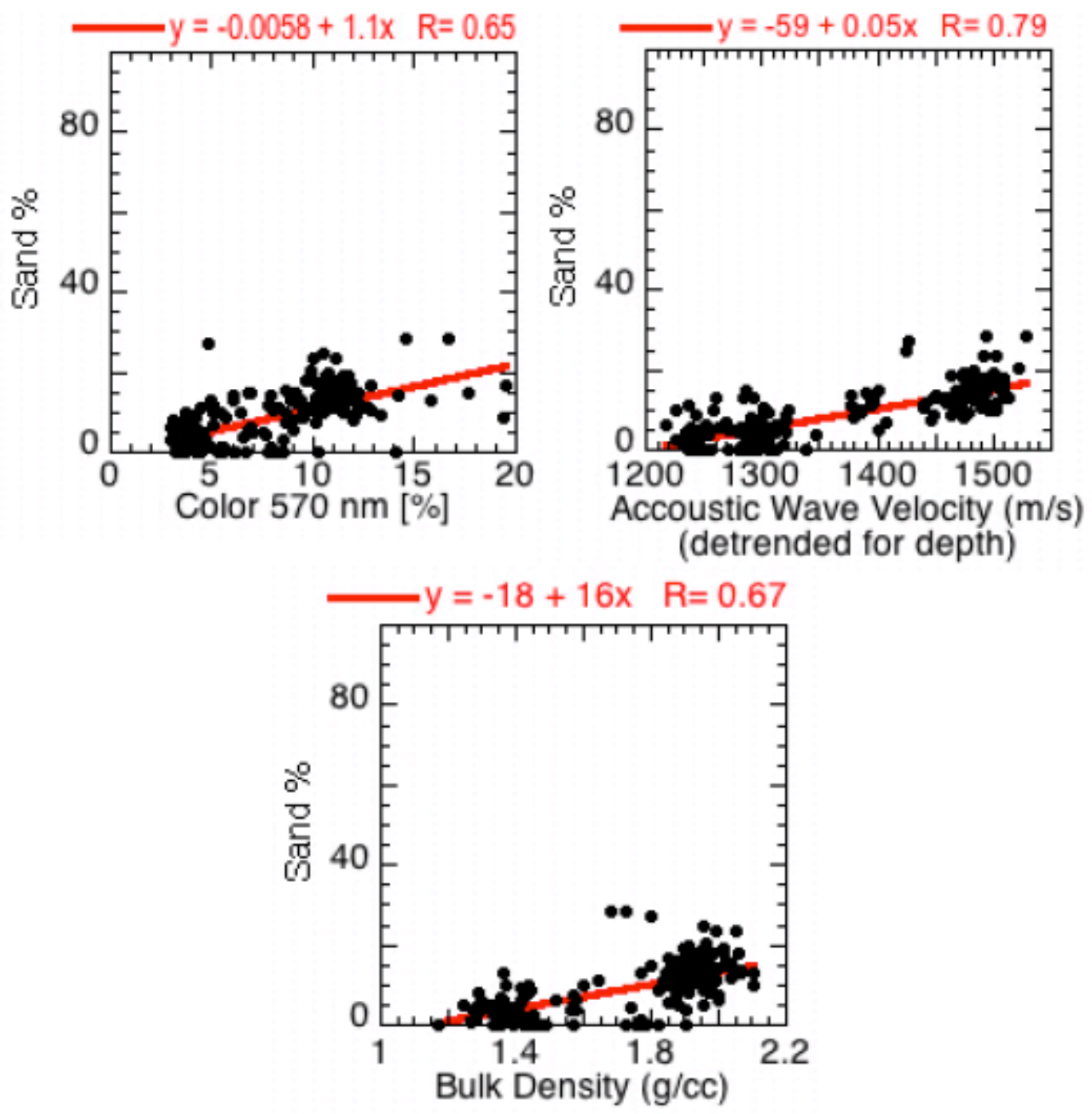

Figure 2.3: The three significant linear relationships between percentage of sand (\% volume) and the physical properties of the sediments are color reflectance at the 570 $\mathrm{nm}$ wavelength, acoustic wave velocity, and bulk density. The positive linear regressions are combined and used as a predictor of sand contributions. 


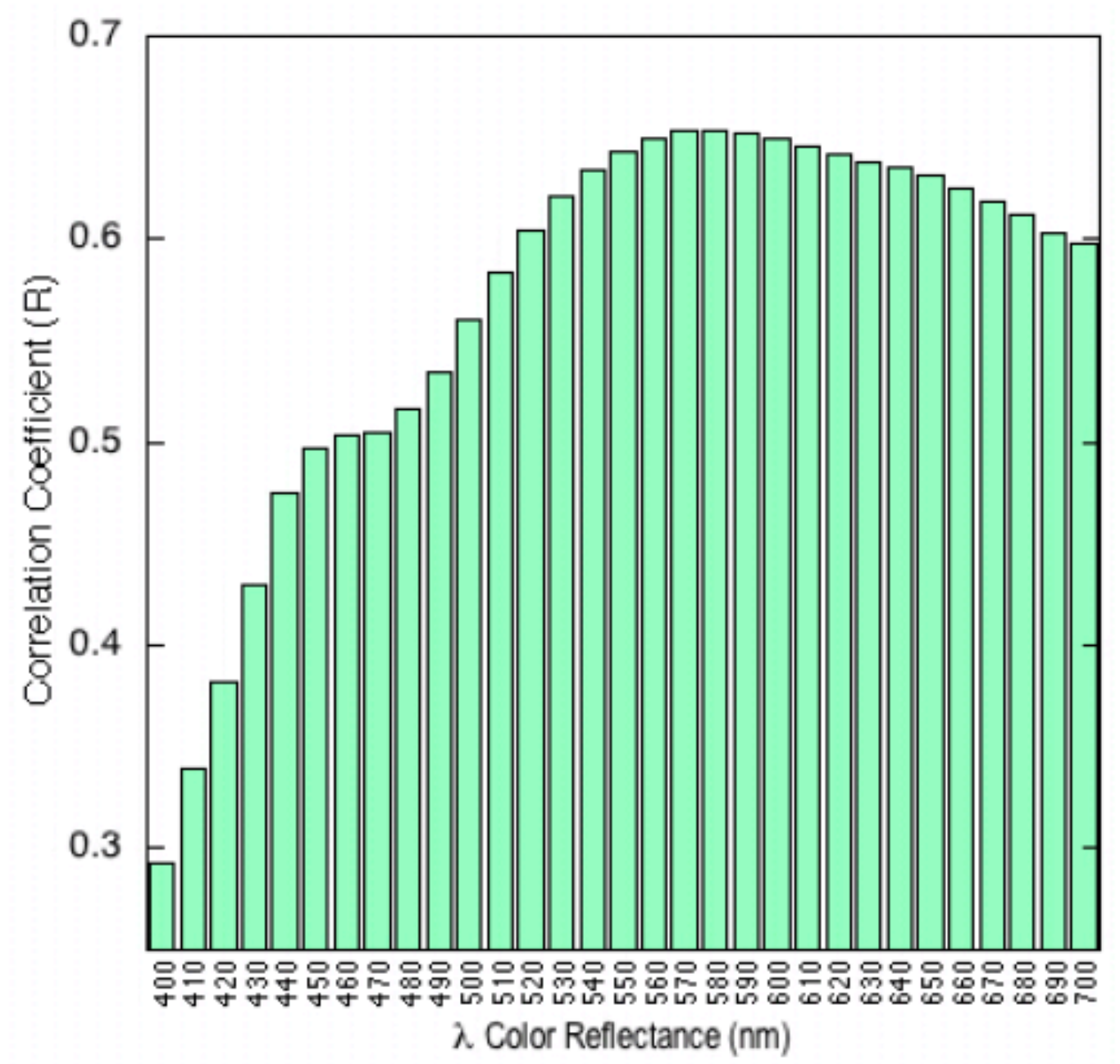

Figure 2.4: Multiple reflectance wavelengths were found to have significant relationships to the percentage of sand (\% volume). The wavelength of $570 \mathrm{~nm}$ was chosen to be used for prediction purposes since it had the greatest R-value of all the wavelengths. 

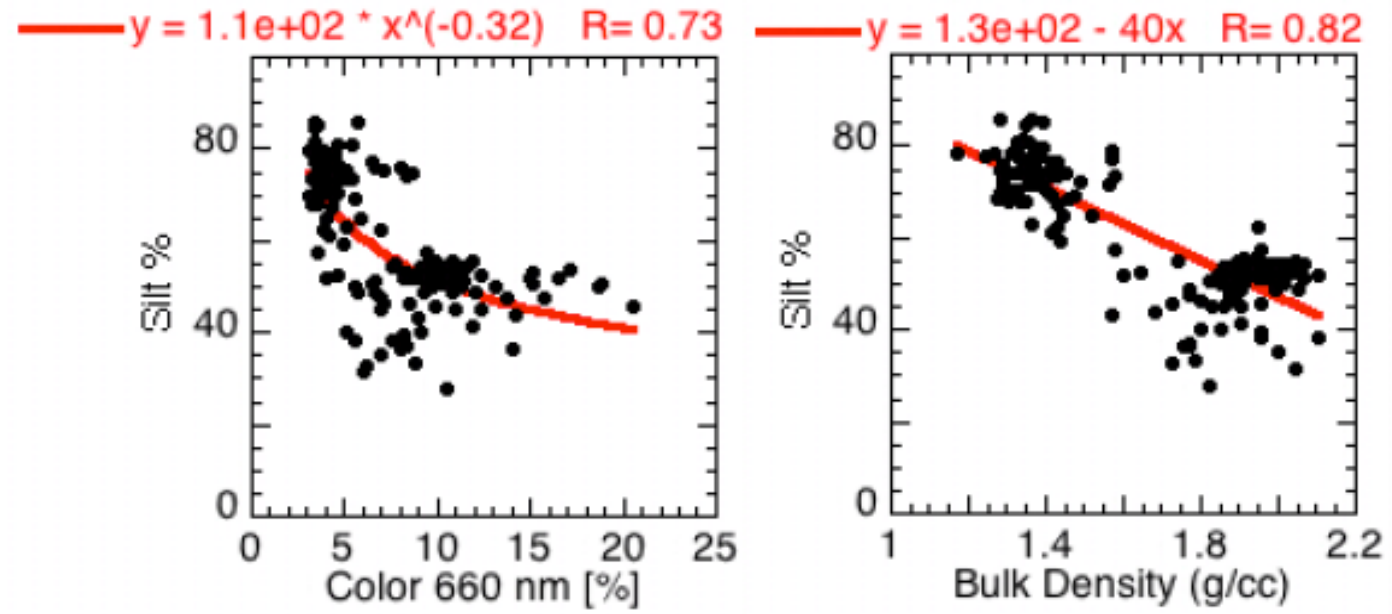

Figure 2.5: Percentage of silt (\% volume) has a power relationship with $660 \mathrm{~nm}$ wavelength color reflectance and a linear relationship to bulk density. These negative relationships are combined for the purpose of predicting the contribution of silt nondestructively. 


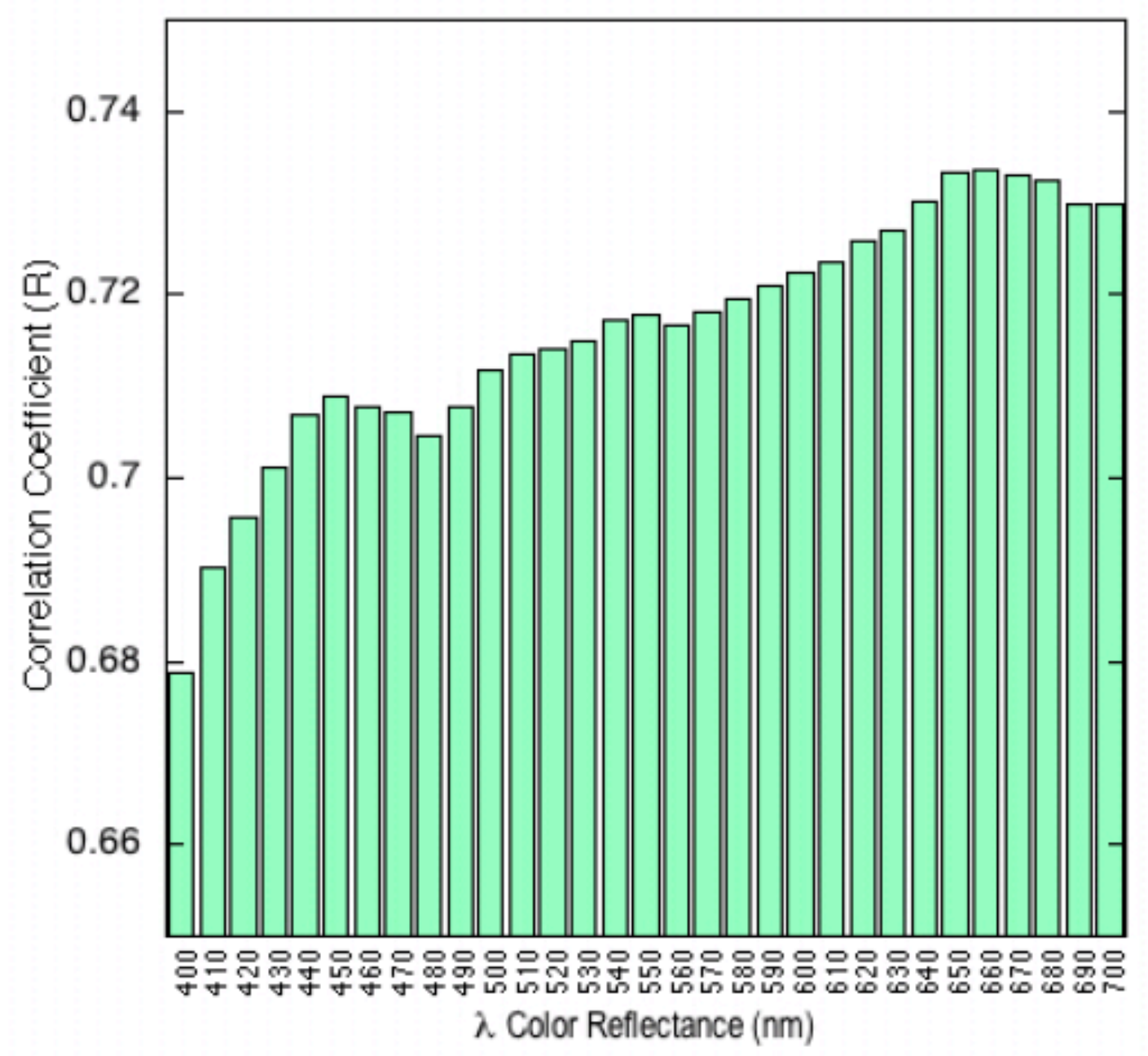

Figure 2.6: All of the color reflectance wavelengths had significant power relationship to the percentage of silt (\% volume). The wavelength of $660 \mathrm{~nm}$ was chosen for prediction purposes since it had the greatest R-value of all the wavelengths. 

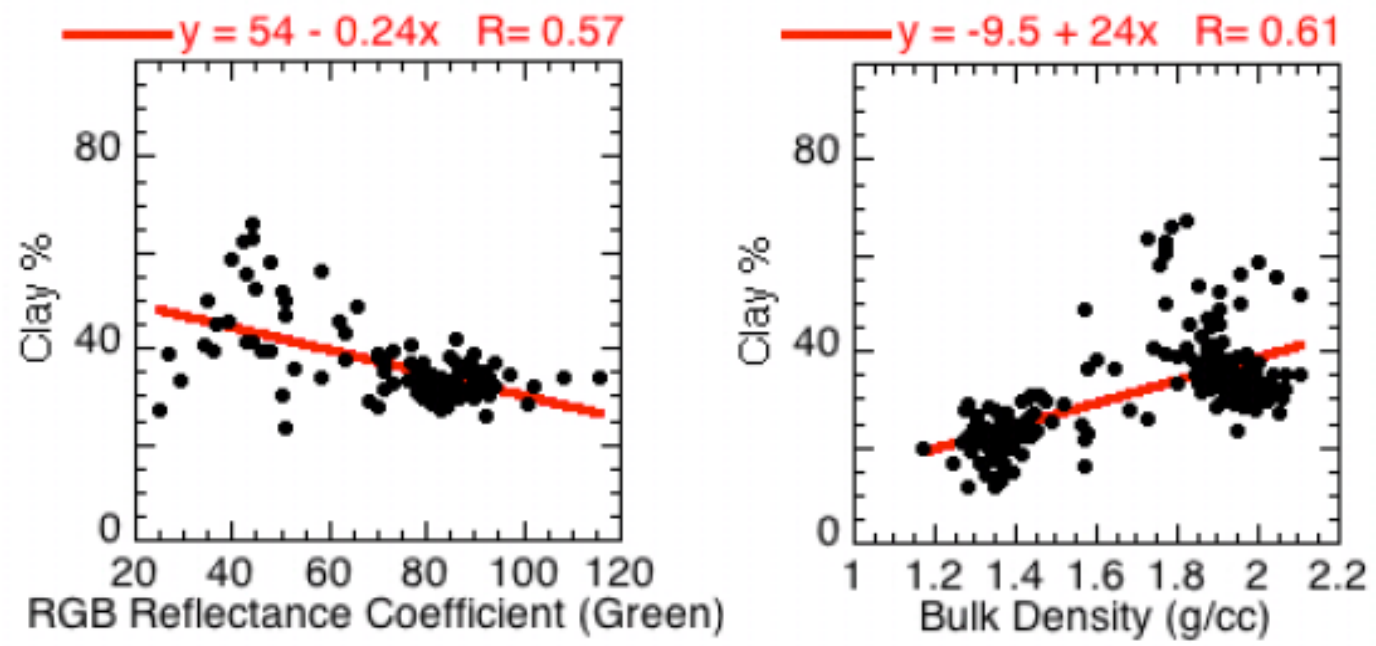

Figure 2.7: The percentage of clay (\% volume) has a negative linear relationship with RGB reflectance coefficient of green and a positive linear relationship bulk density. These relationships were combined to establish predicting equations. 


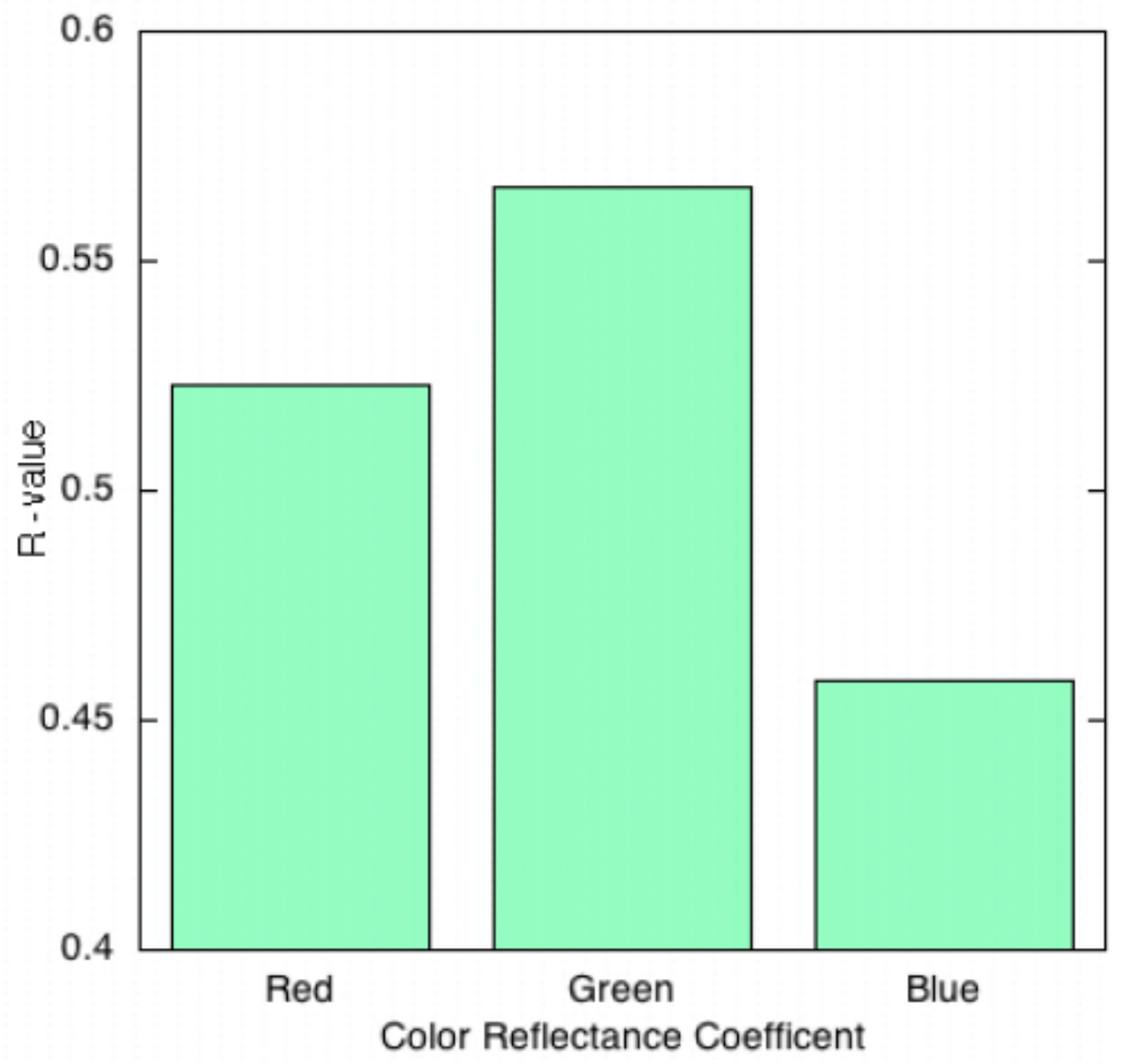

Figure 2.8: Of the three RGB color coefficients, green had the greatest R-value. Green was therefore chosen for the predicting equations. 

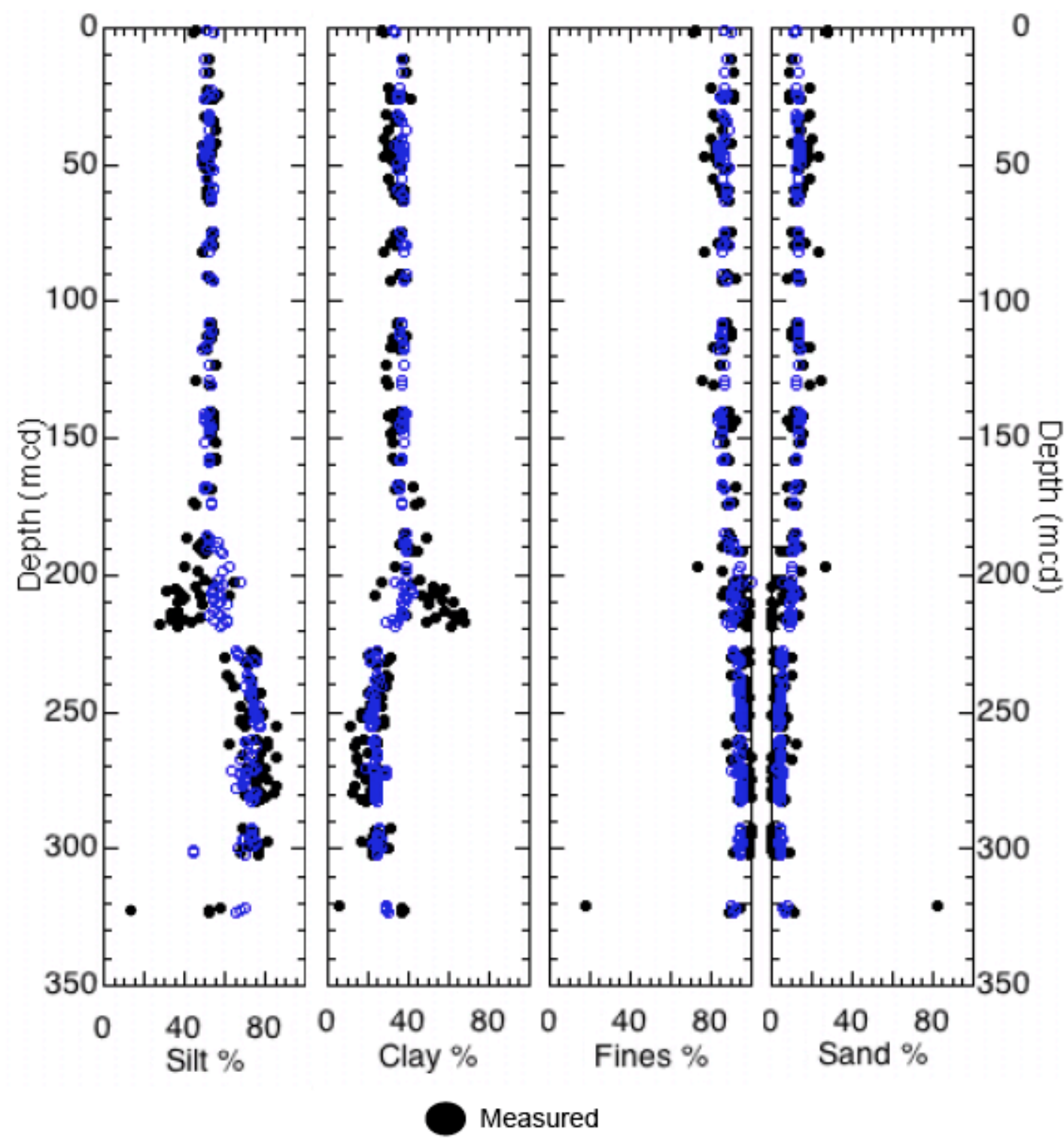

Predicted from physical properties

Figure 2.9: The four graphs show the measured percentages ( $\%$ volume) of silt, clay, fine material (silt + clay), and sand and compares to each locations predicted percentage. The predicted fine material eliminates much of the inaccuracy of the silt and clay predictions. 

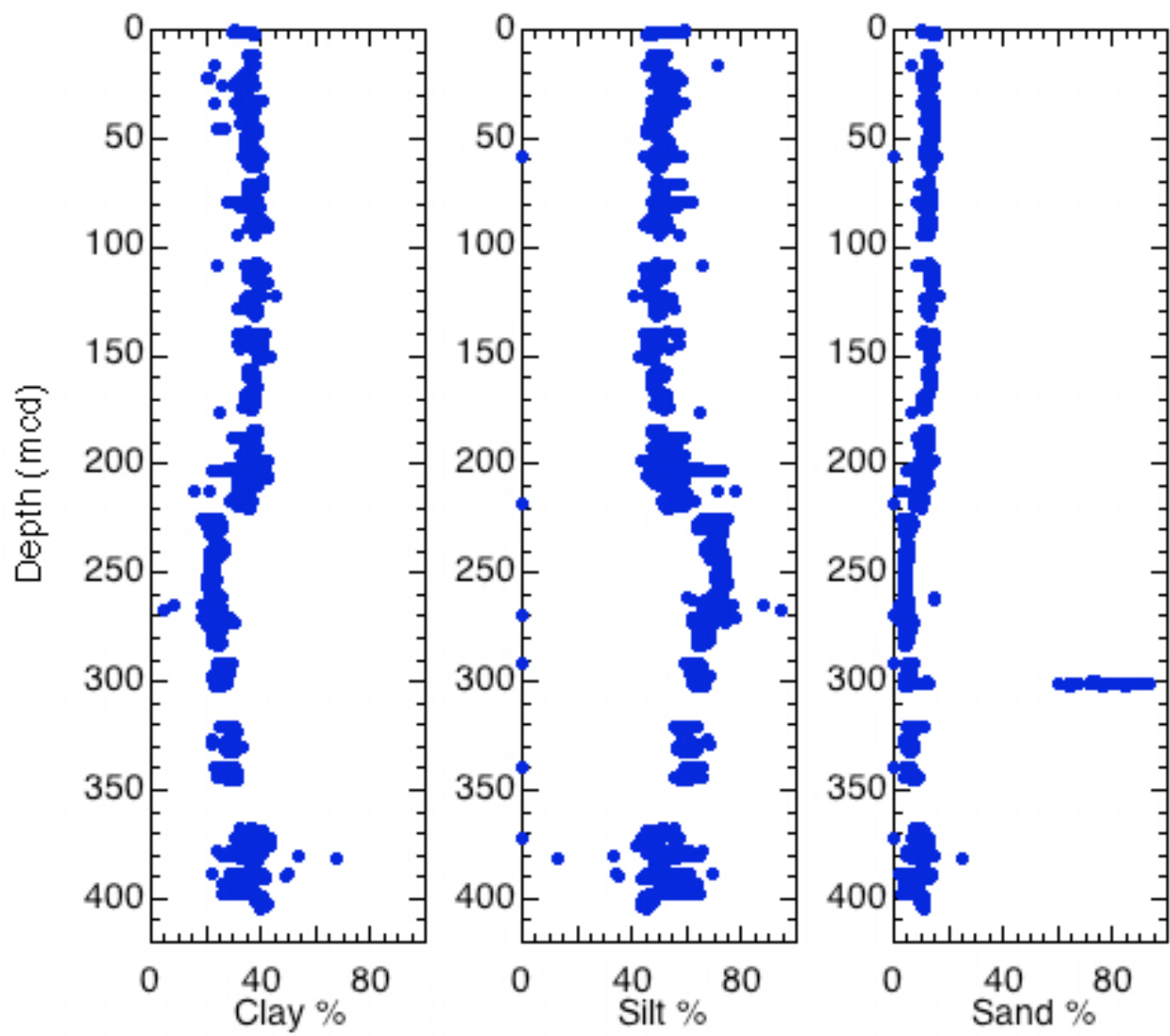

Figure 2.10: The graphs are of the predicted clay, silt, and sand percentages from the high-resolution MSCL data set. Clay, silt, and sand percentages all stay fairly consistent for the top 220 mcd of the ACEX cores. Below $220 \mathrm{mcd}$, clay percentages decrease (with increases with greater depth), silt percentages increase (with decreases with greater depth), and sand percentages decrease consistently with an exception at $\sim 300$ mcd when the sand percentages greatly increases. The changes in percentages above and below $220 \mathrm{mcd}$ are most likely indicative of a change in cryo-state from seasonal sea ice (lower cores) to perennial sea ice. The sharp change in sand percentages may correspond to a strong river influence at that time. 


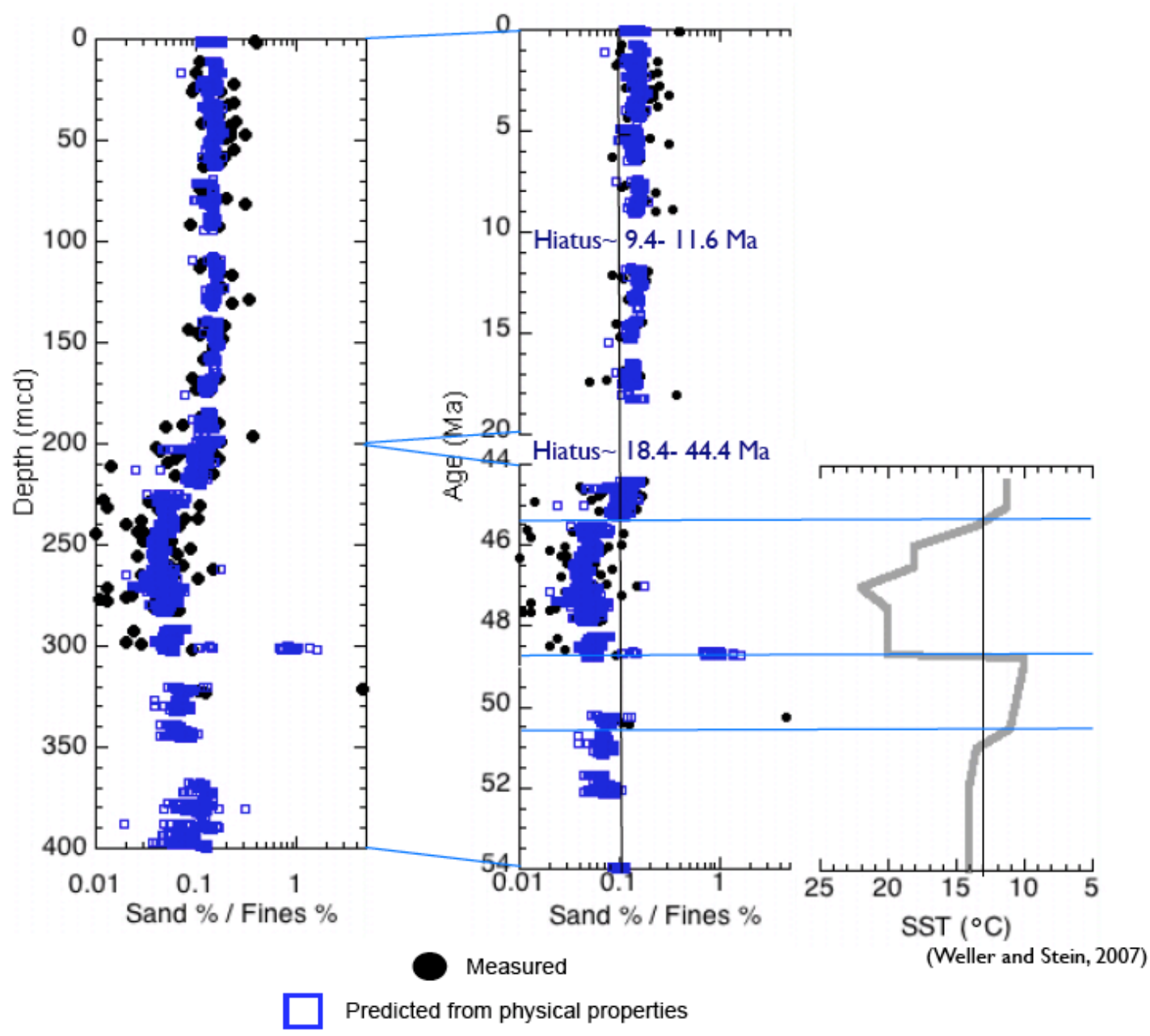

Figure 2.11: The graphs show the predicted sand to fine material ratio $(\mathrm{S} / \mathrm{F})$, which is a cryo-state proxy, for all the usable, high-resolution physical properties from the ACEX cores. These are compared to the measured ratio from discrete samples. The predicted ratio is fairly consistent until $\sim 220 \mathrm{~m}, 45.5 \mathrm{Ma}$. The cryo-state then weakens, with one possible excursion. This analysis of the cryo-state of the central Arctic Ocean correlates well with determined SST from the same cores. The use of highresolution in the prediction of $\mathrm{S} / \mathrm{F}$ in these graphs expands and extends the grain size analysis of the cores and helps improve confidence that the discrete samples are not being aliased due to sampling intervals. 


\section{Chapter 3}

"Late Pleistocene Changes in Ice and Currents from the Central Lomonosov Ridge, Arctic Ocean"

by

Cristin E. Ashmankas ${ }^{5,6}$

written for submission to Journal of Sedimentology

${ }^{5}$ Graduate School of Oceanography, The University of Rhode Island, Narragansett, RI 02882 .

${ }^{6}$ Assistant Professor, Natural Science and Mathematics Division, Lesley University, Cambridge, MA 02138. Email: cashmank@1esley.edu 


\title{
Chapter 3. Late Pleistocene Changes in Ice and Currents from the Central Lomonosov Ridge, Arctic Ocean
}

\begin{abstract}
The Arctic Coring Expedition (ACEX), a milestone research endeavor that took place during the summer of 2004, obtained a sediment core record from the central Lomonosov Ridge, Arctic Ocean. Grain size analyses of samples from the ACEX cores are complemented in the Holocene by high-resolution grain-size sampling taken from an ARCTIC '91 piston core and physical properties from Arctic Ocean-96 cores, both from locations near the ACEX site. This study is concerned with our ability to resolve and decouple paleo-currents from the paleo-ice climate. Relative paleo-current magnitudes can be ascertained using a measure of 'sortable silt' (SS), the mean of the silt fraction in a sample (McCave et al., 1995a,b). Paleo-ice climate can be estimated from the ice rafted debris (IRD), specifically the sand fraction percentage of a sample. The grain size analysis shows a linear relationship between SS and IRD. The linear relationship suggests that paleo-ice climate intensity can be overestimated with higher paleo-current speeds. Employing the linear relationship, the contribution of paleo-currents can be removed from the IRD record and the two paleo-indicators examined separately. The late Pleistocene has a strong paleo-ice climate and a strong, narrow range of paleo- bottom current speeds. There is a strong, noticeable change at the MIS 6 boundary ( $200 \mathrm{ka})$, where the ice climate was significantly strengthened to levels higher than at any other time in the Cenozoic record recovered from ACEX and the central Arctic Ocean, a strengthening not observed in the paleo-current speeds, which stay in the pre-MIS 6 range.
\end{abstract}




\section{INTRODUCTION}

The use of the silt fraction $(<63 \mu \mathrm{m})$ from grain-size distribution to obtain speeds of paleo- bottom currents is becoming a well-established practice (Prins et al., 2002; McCave et al., 1995a). Silt, which in most glacio- marine influenced regions is deposited from icebergs, bottom currents, and sea ice can not be separated into paleoclimate (IRD) influenced silt deposition and non- paleo-climate influenced deposition in most circumstances due to the multiple deposition mechanisms (McCave et al., 1995b). However, the Lomonosov Ridge, being significantly raised from the Arctic's abyssal plain, removes the influence of bottom-current silt deposition (Clark and Hansen, 1983). This unique bathymetric feature allows for both the interpretation of the paleo-current and-climate. For this reason, the coring study of the Arctic Coring Expedition (ACEX), which took place during the summer of 2004, along with the previous Arctic '91 and Arctic Ocean -96 were ideally suited for examining the paleocurrent and -ice climate of the late Pleistocene Arctic Ocean (Figure 3.1).

Aagaard (1981) showed bottom current speeds across the central Lomonosov Ridge that are sufficient for active sediment transport, particularly of the finer grain sizes. Previous studies of the central Lomonosov Ridge have noted that cores from the ridge show increased sand and suggest the effect of bottom currents in winnowing finer sediments from the site (Bjork et al., 2007; Darby et al., 1989, 1997). The measure of paleo-current speed is the mean size of the silt fraction, or 'sortable silt' (SS). Coarser SS sizes indicate stronger current speeds acting on the sediment in both the depositional process and post-deposition winnowing (McCave et al., 1995b; Hall et al., 2001). The work has been further developed by Prins (2002) and Moros et al 
(2002) to be used in examining the relationship between the IRD and SS components. The initial work of Prins (2002) and Moros et al. (2002) indicates that the intensity or percentage of IRD in a sample may be increased by the removal of fine-grained sediment by paleo-currents.

Ice Rafted Debris (IRD), commonly considered the sand fraction in glaciomarine sediments, has been well established as a paleo- ice climate indicator (Chapter 1 and 2). Jakobsson et al. (2001), Poore et al. (1993), Phillips and Grantz (1997), Gyllencreutz (2005), Prins et al. (2002), Clark (1996), Ruddiman (1977), and Sakamoto et al. (2005), have all employed a definition of IRD as being the $>63 \mu \mathrm{m}$ grain size component. The use of the $63 \mu \mathrm{m}$ minimum limit permits the most complete analysis of IRD, specifically including sediment deposited from sea ice along with icebergs.

A number of Arctic studies have evidence of mega-iceburgs originating from the grounded ice shelves of the Laurentide ice sheet (Polyak et al., 2007). These studies place the first erosional horizon of icebergs on the Lomonosov Ridge in MIS 6, $\sim 150$ ka (Jakobsson et al., 2001). The collapse of this ice sheet has a chronology of 14-34 ka (Darby et al., 2002). The timing of all this evidence of increased iceberg presence in the central Arctic Ocean correlates to the reconstruction of a massive northern Eurasian ice sheet (Svendsen et al., 2004). The work of this study, by decoupling the influence of winnowing on IRD fractions, provides further evidence for the strengthened paleo- ice climate at the MIS 6 boundary. 


\section{METHODS}

The sites used in this study can be interpreted to represent the paleo-climate of the central Cenozoic Arctic Ocean because the Lomonosov Ridge separated from the Eurasian shelf, limiting sedimentation influences to those from mid-ocean deposition. All of the core sections were run through a multi-sensor core logger (MSCL) to measure high resolution physical properties, including p-wave velocity, image/color analyses, gamma ray attenuation, magnetic susceptibility, and electrical resistivity. The initial step to determining the paleo-ice environment of the Cenozoic Arctic Ocean is to determine the grain size distribution of the cores. To accomplish this, each of the sediment samples taken from the cores was analyzed for its individual grain size distribution of terrigenous material. The samples were steeped in a solution of sodium hexametaphosphate for at least 48 hours to ensure that the clay particles were neutralized and that no flocculation occurred. Each of the sediment samples was run on the Malvern Mastersizer 2000, a laser diffraction particle sizing system. These data were then compiled into half phi size bins (phi being a scale of grain size equal to $\log _{2}$ (diameter of grain)).

The SS of each sample was obtained by determining the mean of each sample's silt component $(10-63 \mu \mathrm{m})$ as a proxy of the paleo-current intensity. Linear regression analysis was performed on the SS and sand \% (IRD) components. Once a relationship between the mean silt size and the percentage was established for each data set, the SS contribution to each sand percentage was removed, revealing paleo-ice presence to a greater accuracy. 
In addition, an examination of the ability of data from the Malvern Mastersizer 2000 to accurately and precisely determine silt and sand percentages was completed. For the ACEX sediment samples, 10 percent of the samples were compared for their grain size distribution percentages obtained from the Malvern Mastersizer 2000 to a more traditional procedure for determining grain size distributions. For the comparative procedure, samples were prepared in an identical fashion as the sample preparation for the Mastersizer and then hydrometer readings taken at set prescribed times to determine sand and silt percentages (Bouyoucos, 1962). The comparisons between silt and sand grain size distributions obtained by each process show no statistical difference (Figures 3.2-3.3). The small differences that do exist between the two methods ( $<3 \%$ of values) are within the range of error due to rounding differences, human error, and the possible discrepancy in comparing percent volume (Malvern Mastersizer 2000) and percent weight (hydrometer method). Differences in the percentages due to looking at either weight or volume, only exist if there is a difference in the mineral density of the sand, silt, and clay fractions. In addition, 10 percent of the samples were run 3 times on the Malvern Mastersizer 2000 with less than a $1 \%$ difference between the runs. It was suggested by McCave et al. (2006) that laser diffraction was not a reliable means of determining grain size distributions (they used a Malvern Mastersizer 2600 in the study, a previous generation to the 2000 series). Our methodology supports the analyzes of others that have not only demonstrated the accuracy and precision of laser diffraction in grain size distributions, but concluded it as the preferred method for grain size distributions of clay, silt, and sand (Jonkers et al., 2009; Wen et al., 2002; Sperazza et al., 2004; Goossens, 2008). 
In fact, the most comprehensive of the studies conducted by Goossens (2008), which examined and compared 10 of the most widely used and accepted methodologies for determining grain size distributions, found that McCave et al.'s (2006) preferred methodology involving the Sedigraph, grossly overestimates the silt fraction due to the nature and assumptions of the methodology.

\section{RESULTS}

\section{Sortable Silt- Sand Relationship}

Linear regression analysis, performed on both the ACEX and the ARCTIC '91 sediment distributions for the quaternary period, revealed a strong relationship between the mean silt fraction (SS) and the percentage of sand (IRD). The relationship determined for the ACEX quaternary samples is:

$$
\text { Sand } \%=204.65-37.572 * \text { SS }
$$

with an R-value of 0.94352 , showing highly strong correlation (Figure 3.4 ). The relationship for the ARCTIC '91 quaternary samples is:

$$
\text { Sand } \%=344.67-58.87 * \mathrm{SS}
$$

with an R-value of 0.79399 , showing strong correlation (Figure 3.4). The strength of the relationships supports the concept that the measure of the mean silt size (SS) is a proxy for paleo-current intensity for a particular depositional environment. The mechanism that is most likely responsible for both the increased sand presence and the larger mean silt size (lower phi value) is the winnowing of the deposited sediments by paleo-currents. These relationships are then used as projection transforms to reconfigure the sand percentage, as it would have been prior to the winnowing effects. 


\section{Changes in Ice and Current Velocities}

The transformed sand percentages for the quaternary period of the ACEX samples and the corresponding mean silt sizes (SS) show a dynamic environment in the central Arctic Ocean for the Quaternary period, particularly in the late Pleistocene epoch (Figure 3.5). While prior to MIS 6 in the late Pleistocene ( 200 ka), the sand percentage (IRD) is shown to be fairly consistent. This indicates a consistent ice intensity presence. Post-MIS 6 , the sand percentage increases by roughly $15 \%$. The implication is a significantly strengthened ice presence following the MIS 6 boundary. This alteration in ice intensity was expected from the physical property analysis for both the ACEX cores and other cores previously taken from the Lomonosov Ridge (Figure 3.6). The physical properties of the sediments all indicated that significant changes in depositional environment took place at the MIS 6 boundary. Bulk density, inclination, and magnetic susceptibility all showed sharp increases at the $\sim 200 \mathrm{ka}$ date. This transition corresponds to a time of global instability in the cryosphere as determined from global benthic $\delta^{18} \mathrm{O}$ data that shows a gradual increase in $\delta^{18} \mathrm{O}$ values from 4-1.5 Ma (strengthening cryosphere) followed by high frequency changes in the values from 1.5 Ma to present (Zachos et al., 2001; Lisiecki and Raymo, 2005; O’Regan et al., 2010).

While physical properties and sand percentage (IRD) show two distinct regimes pre- and post- MIS 6, the mean silt size (SS), a proxy for current intensity, shows no such pattern (Figure 3.5). Current intensity does vary over the Quaternary period, but with no pre/post MIS6 distinction. There is no discernable pattern in the paleo-current velocities as determined by the SS proxy. This indicates a decoupling 
between the climate of the Arctic as indicated by the sand \% (IRD) and the physical oceanography of the Arctic Ocean. This supports O'Regan et al. (2010) hypothesis that the increase in IRD at the start of MIS 6 is due to an increase in the amount of heat available for basal ice melt from the opening of the Bering and Fram Straits introducing lower-latitude water bodies to the Arctic.

\section{DISCUSSION}

The emerging use of the 'sortable silt' proxy for paleo-currents can be of significant use for raised, isolated, depositional features, such as the Lomonosov Ridge. Further development of the proxy through the analyses of additional samples from multiple sites of similar physical characteristics will lead to a clearer understanding of both paleo-physical and geological oceanography conditions. The use of such methods will prevent future misinterpretations of sand percentage (IRD) strengthening that may have been due to increased current velocities and not to changes in climate. The full potential of such methodologies will develop with time and data volume.

In its limited use, mean silt size (SS) provides intriguing glimpses of the paleoArctic, particularly in the ACEX cores' Quaternary samples. They clearly indicate that even with the effects of paleo-current winnowing on sediments, there was a distinct strengthening of the IRD presence in the late Pleistocene. The timing of the sand presence shift corresponds to the MIS 6 boundary and suggests a strengthened ice climate or as suggested by O'Regan et al. (2010) an increase in basal ice melt. The timing of strengthened ice climate observed in this study further support the theory of a pan-Arctic ice sheet (Mercer, 1970; Hughes et al., 1977; Grosswald and Hughes, 
1999). There is also a suggestion from the most recent sample and a sample taken at 3 MCD that the Arctic climate may have resumed an ice climate similar to the panArctic ice sheet recently and that there may have been previous decays and regrowths of the pan-Arctic ice sheet (Figure 3.5). Future high-resolution sampling of Arctic cores which date from the period, should reveal whether the pan-Arctic ice sheet was stable or if it was cyclical in nature and we have an unintended sampling bias in the ACEX grain size distribution data set.

Lack of a discernable pattern in the paleo-current intensity may also be a reflection of true Arctic dynamics or a symptom of too few samples. Either way, we have enough samples in this study to determine that while sediments are effected by paleo-currents, paleo-currents are unaffected by the Arctic climate as indicated by sand percentages (IRD). This suggests the paleo-current strengths are also independent of sea level, which is effected by ice volume and surface winds, effected by ice capping. Further investigations in paleo-current strengths along the Lomonosov Ridge may allow for paleo-current mapping. Once paleo-current dynamics in terms of both time and space are resolved, an understanding of the forces driving these currents may be determined.

\section{CONCLUSIONS}

Variations in ice intensity can be enhanced through the 'sortable silt' method of removing the winnowing contribution of paleo-currents. By employing the proxy of the mean silt size of a sample (SS) as a measure of relative current velocity, sand percentage variability can be reset to pre- winnowing patterns. By using these proxies and techniques on Quaternary period samples from the ACEX cores, we determine a 
consistent ice presence for the early and mid Pleistocene. This ice presence sharply intensified in the late Pleistocene, corresponding to MIS 6. Current velocities remained inconsistent and dynamic throughout the Quaternary era.

The strong correlative relationships between sand percentages (IRD) and mean silt fractions (SS) for the Lomonosov Ridge, show that the methods used in this study will be of further value in future coring endeavors of the ridge and similar depositional sites. The variability found in the paleo-current proxy (SS) suggests the need for highresolution grain size analyses in future cores to determine if there is a discernable pattern in Arctic Ocean current intensity. 


\section{REFERENCES}

Aagaard, K., 1981. "On the Deep Circulation in the Arctic Ocean." Deep-Sea Research, Vol. 28, pp. 251-268.

Bjork, G., Jakobsson, M., Rudels, B., et al., 2007. "Bathymetry and Deep-Water Exchange Across the Central Lomonosov Ridge at 88-89² N." Deep-Sea Research I, Vol. 54, pp. 1197-1208.

Bouyoucos, G.J., 1962. "Hydrometer Method Improved for Making Particle Size Analysis of Soils.” Agronomy Journal, Vol. 54, pp. 464-465.

Clark, D.L., 1996. "The Pliocene Record in the Central Arctic.” Marine Micropaleontology, Vol. 27, pp. 157-164.

Clark, D.L., Hansen, A., 1983. "Central Arctic Ocean Sediment Texture: a key to icetransport mechanism." In: B. Molnia (Ed.), Glacial-Marine Sedimentation, Plenum, New York, pp. 301-330.

Darby, D.A., Naidu, S.A., Mowatt, T.C., Jones, G.A., 1989. "Sediment Composition and Sedimentary Processes in the Arctic Ocean." In: Herman, Y. (Ed.), The Arctic Seas: Climatology, Oceanography, Geology, and Biology, Van Nostrand Reinhold Co., New York, pp. 657-720.

Darby, D.A., Bischof, J.F., Jones, G.A., 1997. "Radiocarbon Chronology of Depositional Regimes in the Western Arctic Ocean." Deep-Sea Research I, Vol. 44, pp. 1745-1757.

Darby, D.A., Bischof, J.F., Spielhagen, R.F., Marshall, S.A., Herman, S.W., 2002. "Arctic Ice Export Events and their Potential Impact on Global Climate during the Late Pleistocene." Paleoceanography, Vol. 17.

Frank, M., J. Backman, M. Jakobsson, K. Moran, M. O’Regan, J. King, B.A. Haley, P.W. Kubik, and D. Garbe-Schonberg, 2008. "Beryllium Isotopes in Central Arctic Ocean Sediments Over the Past 12.3 Million Years: Stratigraphic and Paleoclimatic Implications." Paleoceanography, Vol. 23.

Goossens, D., 2008. "Techniques to Measure Grain-Size Distributions of Loamy Sediments: a comparative study of ten instruments for wet analysis." Sedimentology, Vol. 55, pp. 65-96.

Grosswald, M.G., Hughes, T.J., 1999. "The Case for an Ice Shelf in the Pleistocene Arctic Ocean." Polar Geography, Vol. 23, pp. 23-54. 
Gyllencreutz, R., 2005. "Late Glacial and Holocene Paleoceanography in the Skagerrak from High-Resolution Grain Size Records." Paleogeography, Paleoclimatology, Paleoecology, Vol. 222, pp. 344-369.

Hall, I.R., McCave, I.N., Shackleton, N.J., Weedon, G.P., Harris, S.E., 2001. "Intensified Deep Pacific Inflow and Ventilation in Pleistocene Glacial Times.” Nature, Vol. 412, pp. 809-811.

Haley, B.A., M. Frank, R.F. Spielhagen, and J. Fietzke, 2008. "The Radiogenic Isotope Record of Arctic Ocean Circulation and Weathering Inputs of the Past 15 Million Years." Paleoceanography, Vol. 23.

Hughes, T.J., Denton, G.H., Grosswald, M.G., 1977. "Was There a Late Wurm Ice Sheet?" Nature, Vol. 266, pp. 596-602.

Jakobsson, M., Lovlie, R., Al-Hanbali, H., et al., 2000. "Manganese and Color Cycles in Arctic Ocean Sediments Constrain Pleistocene Chronology." Geology, Vol. 28, pp. 23-26.

Jakobsson, M., Lovlie, R., Arnlod, E.M., Backman, J., Polyak, L., Knutsen, J.-O., Musatov, E., 2001. "Pleistocene Stratigraphy and Paleoenvironmental Variation from the Lomonosov Ridge Sediments, Central Arctic Ocean." Global and Planetary Change, Vol. 31, pp. 1-22.

Jonkers, L., Prins, M.A., Brummer, G.-J.A., Koner, M., Lougheed, B.C., 2009. "Experimental Insights into Laser Diffraction Particle Sizing of Fine-Grained Sediments for Use in Paleoceanography." Sedimentology, Vol. 56, pp. 21922206.

Lisiecki, L.E., Raymo, M.E., 2005. “A Pliocene-Pleistocene Stack of 57 Globally Distributed Benthic $\delta 180$ Records.” Paleoceanography, Vol. 20, PA 1003. doi:10.1029/2004PA001071.

McCave, I.N., 2008. "Size Sorting During Transport and Deposition of fine Sediments: Sortable Silt and Flow Speed." In: M. Rebesco, A. Camerlenghi (eds) Contourites. Developments in Sedimentology, Vol. 57.

McCave, I.N., and I.R. Hall, 2006. "Size Sorting in Marine Muds:Processes, pitfalls, and prospects for paleoflow-speed proxies." Geochem. Geophys. Geosyst., Vol. 7.

McCave, I.N., I.R. Hall, and G.G. Bianchi, 2006. "Laser vs. Settling Velocity Differences in Silt Grainsize Measurements: estimation of palaeocurrent vigour." Sedimentology, Vol. 53, pp. 919-928. 
McCave, I.N., Manighetti, B., Robinson, S.G., 1995a. "Sortable Silt and Fine Sediment Size/Composition Slicing; Parameters for Paleocurrent Speed and Paleoceanography." Paleoceanography, Vol. 10, pp. 593-610.

McCave, I.N., Manighetti, B., Beveridge, N.A.S., 1995b. "Circulation in the Glacial North Atlantic Inferred from Grain Size Measurements." Nature, Vol. 374, pp. 149-152.

Mercer, J.H., 1970. "A Former Ice Sheet in the Arctic Ocean.” Palaeogeography, Palaeoclimatology, Palaeoecology, Vol. 8, pp. 19-27.

Moran, K., Altmann, V., O’Regan, M., Ashmankas, C., 2007. “Acoustic Compressional Wave Velocity as a Predictor of Glacio-Marine Sediment Grain Size." Geotechnical Testing Journal, Vol. 30.

Moros, M., Kuijpers, A., Snowball, I., Lassens, S., Backstrom, D., Gingele, F., McManus, J., 2002. "Were Glacial Iceberg Surges in the North Atlantic Triggered by Climatic Warming?” Marine Geology, Vol.192, pp. 393-417.

O’Regan, M., St. John, K., Moran, K., Backman, J., King, J., Haley, B.A., Jakobsson, M., Frank, M., Rohl, U., 2010. "Plio-Pleistocene Trends in Ice Rafted Debris on the Lomonosov Ridge.” Quaternary International, Vol. 219, pp. 168-176.

Phillips, R.L., Grantz, A., 1997. "Quaternary History of Sea Ice and Paleoclimate in the Amerasia Basin, Arctic Ocean, as Recorded in the Cyclical Strata of Northwind Ridge." GSA Bulletin, Vol. 109, pp. 1101-1115.

Polyak, L., Darby, D.A., Bischof, J.F., Jakobsson, M., 2007. "Stratigraphic Constraints on Late Pleistocene Glacial Erosion and Deglaciation of the Chukchi Margin, Arctic Ocean.” Quaternary Research, Vol. 67, pp. 234-245.

Poore, R.Z., Phillips, R.L., Rieck, H.J., 1993. "Paleoclimate Record for Northwind Ridge, Western Arctic Ocean.” Paleoceanography, Vol. 8, pp. 149-159.

Prins, M.A., Bouwer, L.M., Beets, C.J., Troelstra, S.R., Weltje, G.J., Kruk, R.W., Kuijpers, A., Vroon, P.Z., 2002. "Ocean Circulation and Iceberg Discharge in the Glacial North Atlantic: Inferences from unmixing of sediment size distributions." Geology, Vol. 30, pp. 555-558.

Ruddiman, W.F., 1977. "Late Quaternary Deposition of Ice-Rafted Sand in the Subpolar North Atlantic." GSA Bulletin, Vol. 88, pp. 1813-1827.

Sakamoto, T., Ikehara, M., Aoki, K., Iijima, K., Kimura, N., Nakatsuka, T., Wakatsuchi, M., 2005. "Ice-Rafted Debris (IRD)- Based Sea-Ice Expansion Events during the Past 100 kyrs in the Okhotsk Sea." Deep-Sea Research, Vol. 52, pp. 2275-2301. 
Sperazza, M., Moore, J.N., Hendrix, M.S., 2004. "High-Resolution Particle Analysis of Naturally Occurring Very Fine-Grained Sediment Through Laser Diffractometry.” Journal of Sedimentary Research, Vol. 74, pp. 736-743.

Svendsen, J.I., Alexanderson, H., Astakhov, V.I.,, et al., 2004. "Late Quaternary Ice Sheet History of Northern Euraisa." Quaternary Science Reviews, Vol. 23, pp. 1229-1271.

Wen, B., Aydin, A., Duzgoren-Aydin, N.S., 2002. "A Comparative Study of Particle Size Analyses by Sieve-Hydrometer and Laser Diffraction Methods." ASTM Geotechnical Testing Journal, Vol. 25, pp. 434-442.

Zachos, J.C., Pagani, M., Sloan, L., Thomas, E., Billups, K., 2001. “Trends, Rhythms, and Aberrations in Global Climate 65 Ma to Present." Science, Vol. 292, pp. 686-693. 


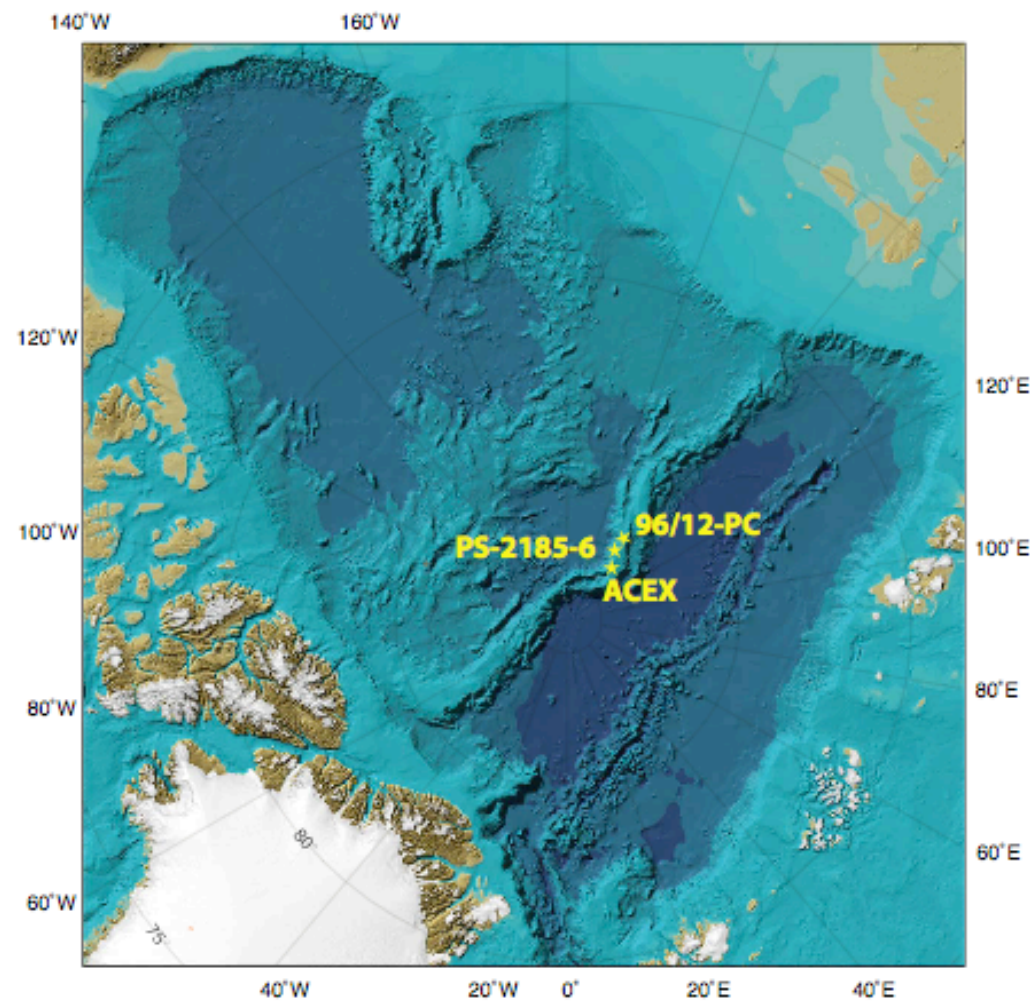

Figure 3.1: A map produced by the IBCAO of the bathymetry of the Arctic Ocean basin. The Lomonosov Ridge is the raised bathymetric feature fractioning the basin in two. The ridge provides a silt deposition site that is uninfluenced by bottom current deposition, while being affected by bottom current winnowing. This provides an ideal location for paleo-studies separating ice climate from bottom current speeds. The central Arctic Ocean coring locations of ACEX, ARCTIC '91, and Arctic Ocean-96 used in this study are identified on the map. PS-2185-6 is the site of the ARCTIC '91 study. 96/12-PC is the site of the Arctic Ocean-96 study. 

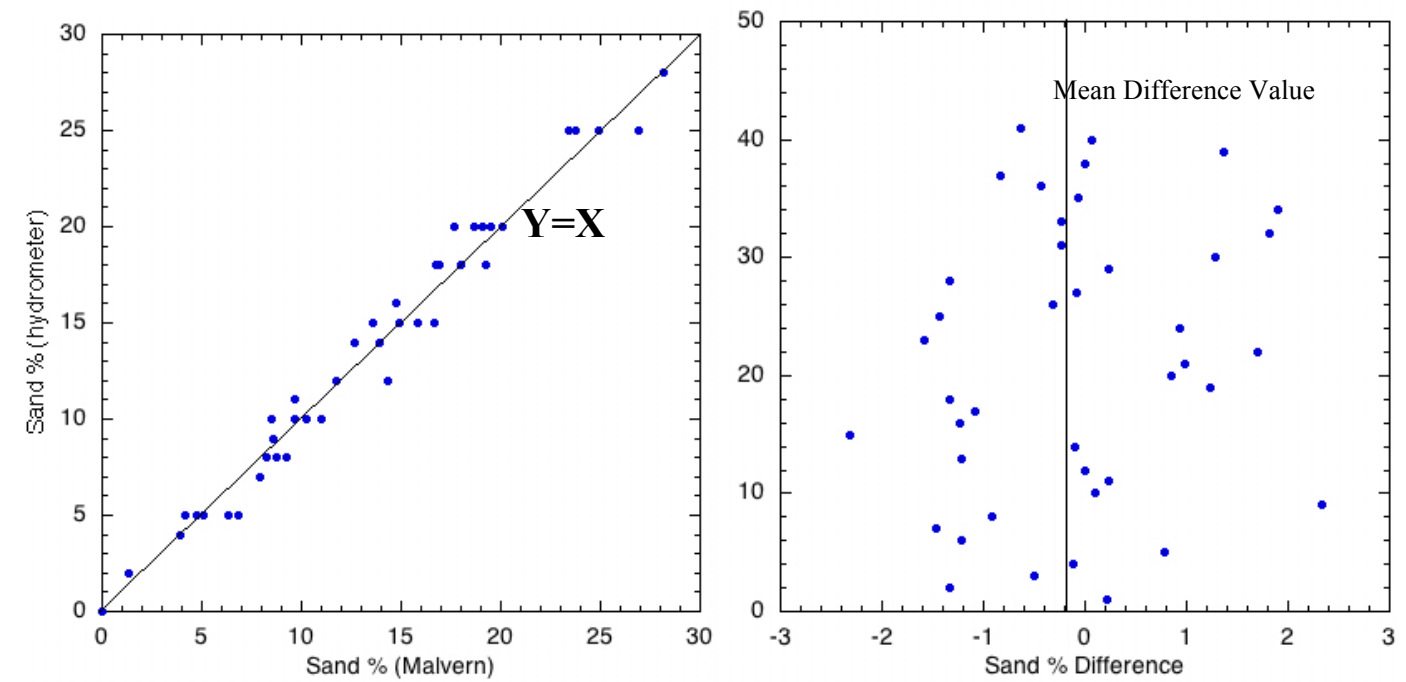

Figure 3.2: Graphs showing the comparison of sand percentages determined from the hydrometer method to the Malvern (laser diffraction) method. For the direct comparison graph (left) the $\mathrm{Y}=\mathrm{X}$ line is displayed for reference purposes to the ideal comparison. The graph on the right plots the difference in percentage between the two methods (Malvern - hydrometer) versus an arbitrary sample number. The mean difference in the methods $(\sim-0.2)$ is plotted as a vertical line for reference, suggesting an slight bias of the Malvern method to under estimate sand percentages. There is a good correlation between the two methods concerning the percentage of sand, with no sample with more than a 3\% difference between the methods. 

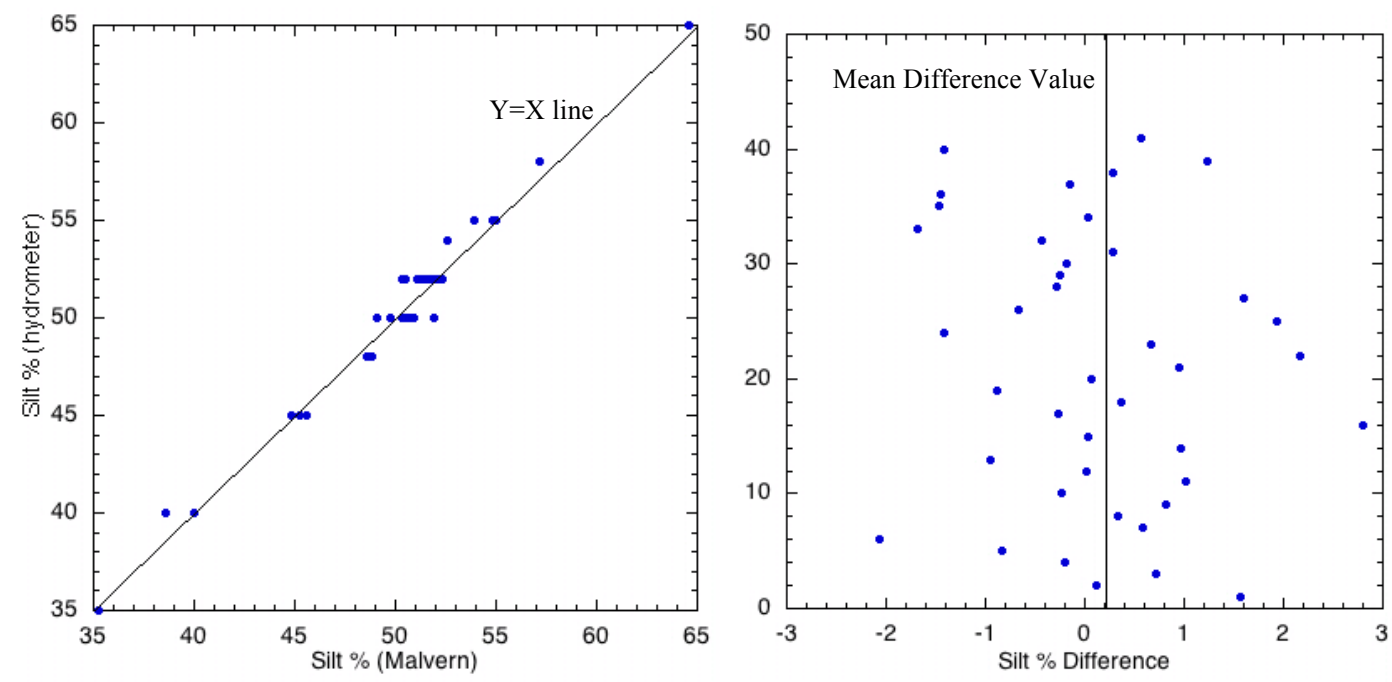

Figure 3.3: Graphs showing the comparison of silt percentages determined from the hydrometer method to the Malvern (laser diffraction) method. For the direct comparison graph (left) the $\mathrm{Y}=\mathrm{X}$ line is displayed for reference purposes to the ideal comparison. The graph on the right plots the difference in percentage between the two methods (Malvern - hydrometer) versus an arbitrary sample number. The mean difference in the methods $(\sim 0.2)$ is plotted as a vertical line for reference, suggesting an slight bias of the Malvern method to over estimate silt percentages. There is a good correlation between the two methods concerning the percentage of sand, with no sample with more than a 3\% difference between the methods. 

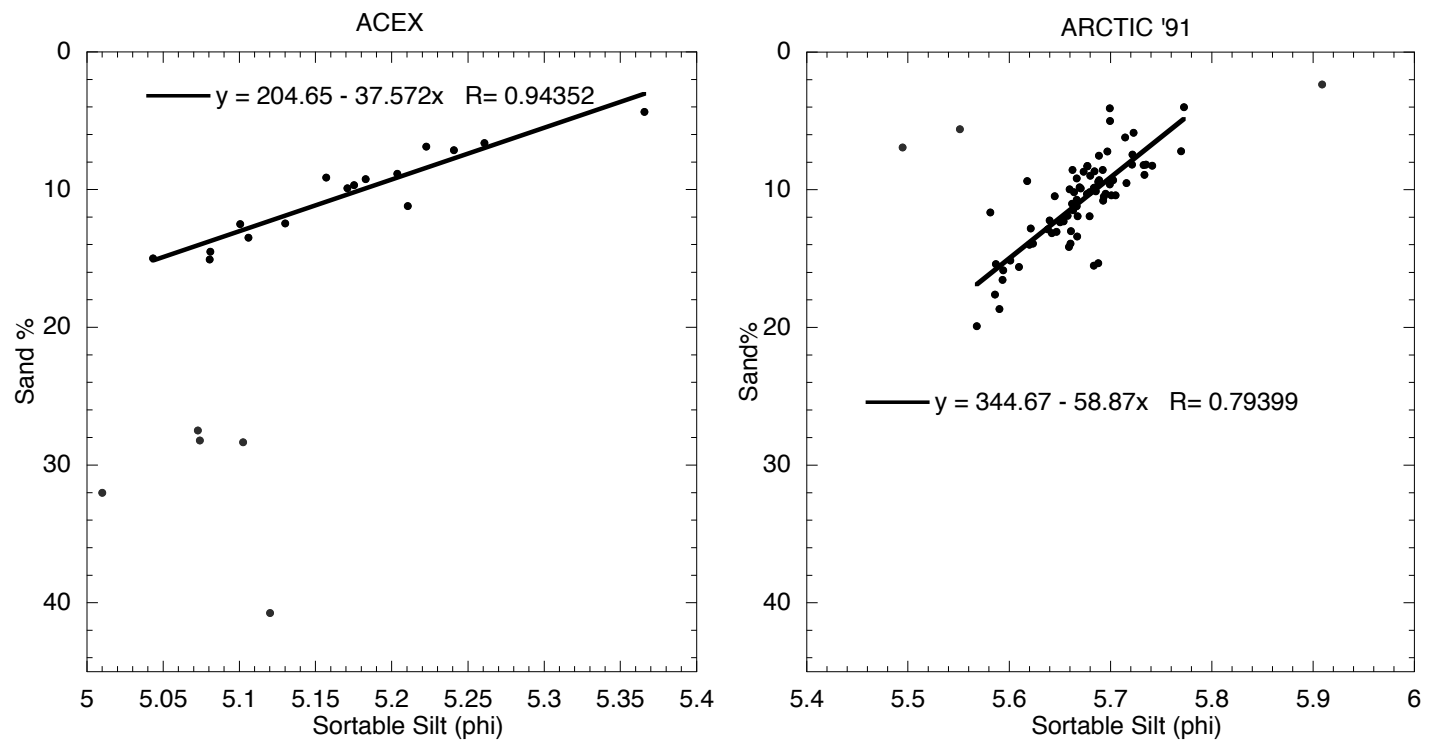

Figure 3.4: Graphs of sortable silt versus Sand \% (IRD) for sediment samples taken from the late Pleistocene of the ACEX and Arctic '91 cores. The sediments from both coring projects show a strong linear relationship between the two variables. Significant outliers from the line indicate significant changes in the paleo- ice environment, altering the depositional regime. Larger sortable silt values indicate finer mean silt fractions, corresponding to weaker current speeds over the Lomonosov Ridge. Using these linear relationships, the paleo- bottom current speeds and -ice climate can be decoupled. 


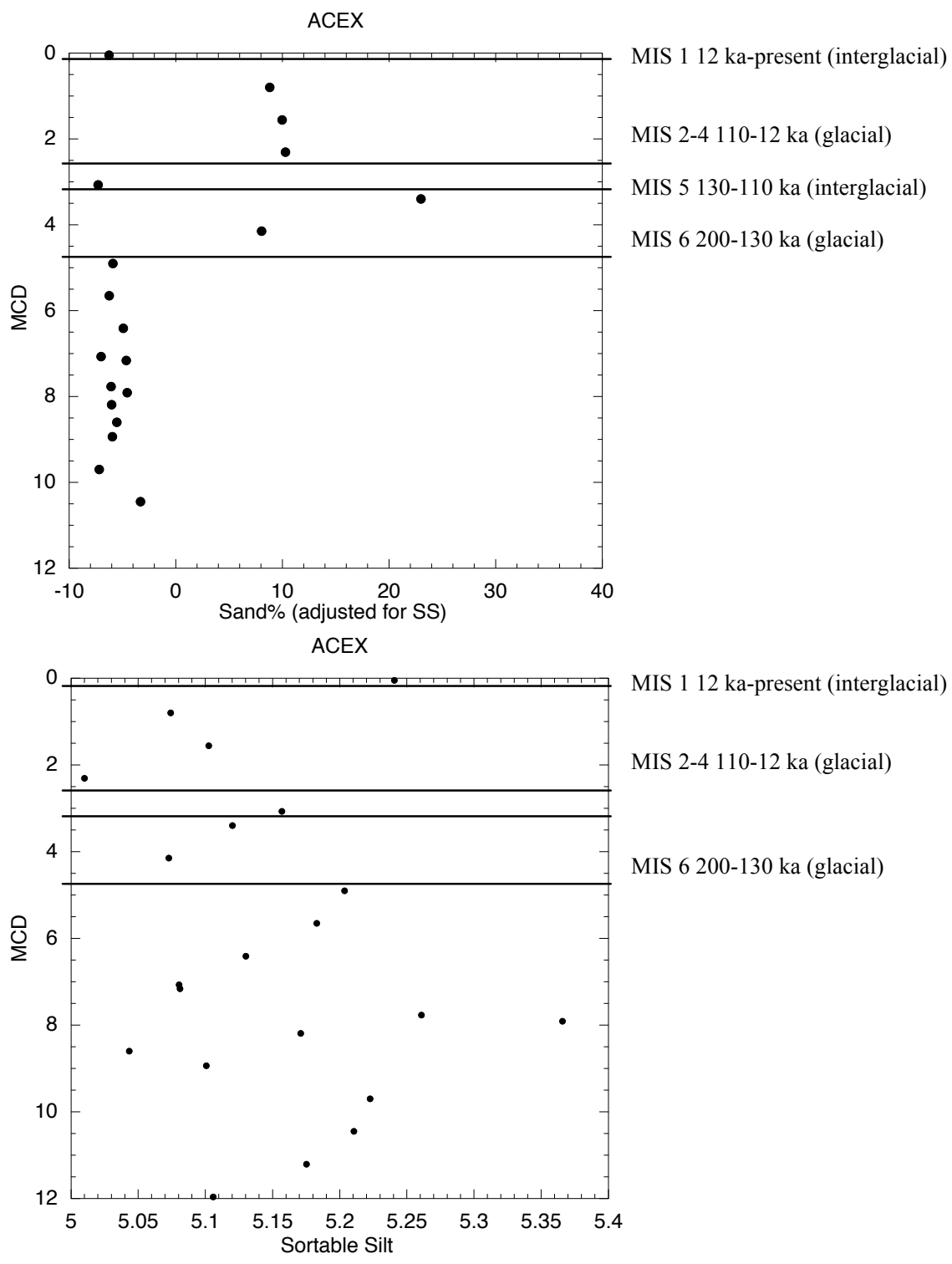

Figure 3.5: Graphs covering the late Pleistocene as gained from the ACEX core sediments. The boundary of MIS $6(\sim 200 \mathrm{ka})$ is found at $\sim 4.85 \mathrm{MCD}$. The graph of sand $\%$ after it has been decoupled from winnowing affects of paleo- bottom currents, as previously established in the linear relationship, shows a significant increase in sand $\%$ (IRD) after the MIS 6 boundary. This indicates a strengthening paleo- ice climate and corresponds to the presence of 'mega-iceburgs' in the central Arctic Ocean. The variation in the adjusted sand \% from the beginning of MIS 6 to present corresponds to marine isotope stages with interglacials showing decreased sand $\%$ and glacials increased sand \%. While paleo- bottom currents have varied over time for the $\sim 500 \mathrm{ka}$ shown in the graph of sortable silt, the range of current speeds has not deviated greatly and shows no significant strengthening or weakening after the MIS 6 boundary. The larger sortable silt phi sizes correspond to finer silt fractions, indicating weaker bottom current speeds. The two most recent interglacials do show possible current strengthening. 


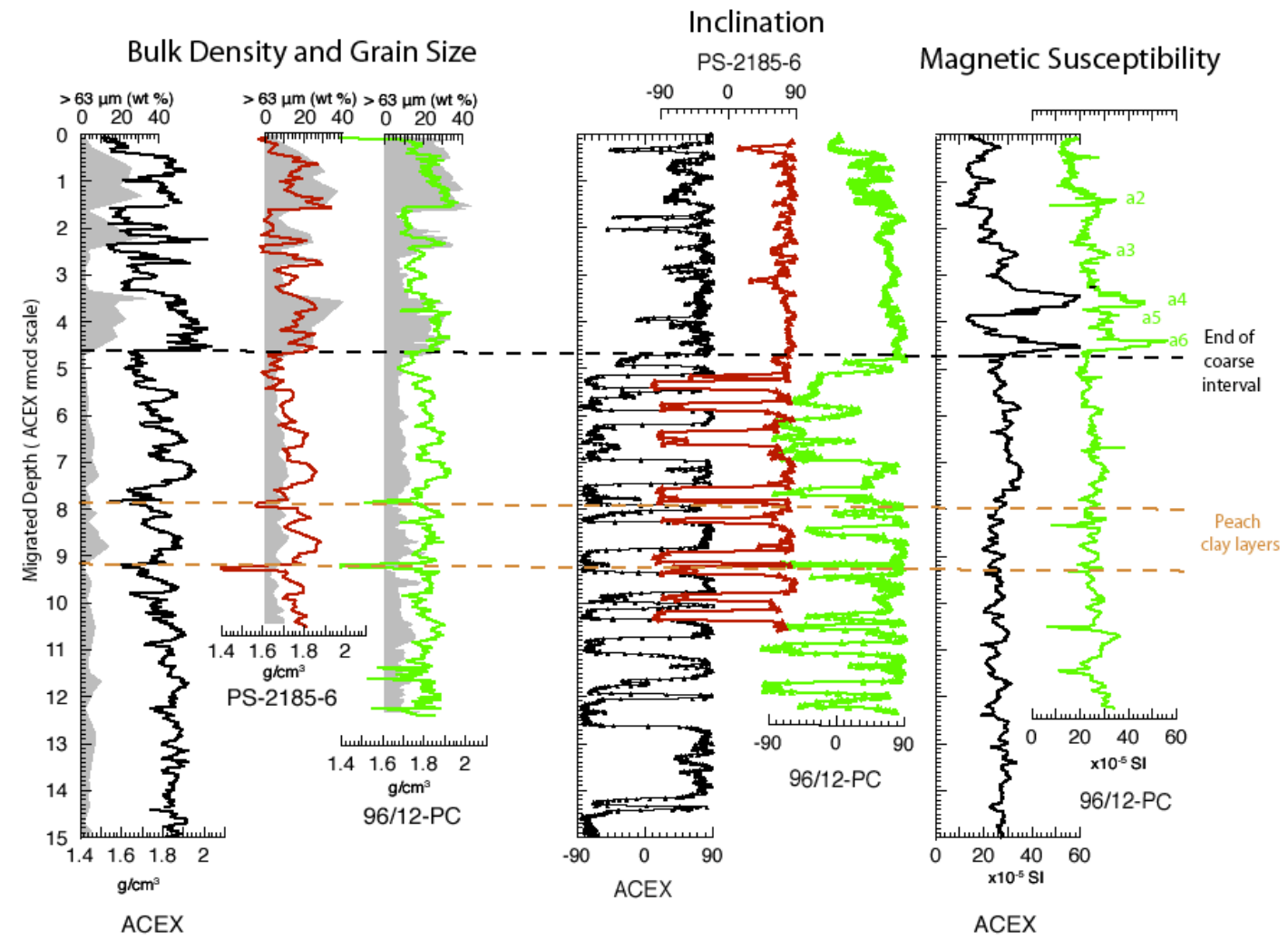

Figure 3.6: The graphs are of some of the physical properties of the ACEX cores and two previous studies of the Lomonosov Ridge, Arctic Ocean. Coring sites are shown on the Figure 3.1 map. The bulk density, inclination, and magnetic susceptibility of these studies all show a change in deposition occurring at $\sim 4.7$ on the migrated depth scale, a depth which corresponds to MIS 6. This change is more clearly visible in the transformed sand percentages in this study. Mean silt size (SS) shows no such change. 
APPENDIX I: Data and statistical variables for IODP Exp. 302, ACEX, samples taken from neogene sediments. Samples exclusively contained sand, silt, and clay. Sample identifications are the expedition-site-core-section. The samples are presented in descending order. 


\begin{tabular}{|c|c|c|}
\hline & $\begin{array}{l}\text { Sample ID: } \\
\text { ANALYST: }\end{array}$ & $\begin{array}{c}\text { 302-4-C-1-H-1 } \\
\text { Cristin Ashmankas }\end{array}$ \\
\hline & SAMPLE TYPE: & $\begin{array}{l}\text { Unimodal, Very Poorly } \\
\text { Sorted }\end{array}$ \\
\hline & TEXTURAL GROUP: & Mud \\
\hline & SEDIMENT NAME: & Fine Silt \\
\hline METHOD OF & MEAN & 49.36690952 \\
\hline MOMENTS & SORTING & 204.3603811 \\
\hline \multirow[t]{2}{*}{ Arithmetic $(\mathrm{mm})$} & SKEWNESS & 6.469754885 \\
\hline & KURTOSIS & 46.88074205 \\
\hline METHOD OF & MEAN & 7.64100207 \\
\hline MOMENTS & SORTING & 4.474920979 \\
\hline \multirow[t]{2}{*}{ Geometric $(\mathrm{mm})$} & SKEWNESS & 1.174749516 \\
\hline & KURTOSIS & 4.83101554 \\
\hline METHOD OF & MEAN & 6.983862503 \\
\hline MOMENTS & SORTING & 2.20651326 \\
\hline \multirow{2}{*}{ Logarithmic (f) } & SKEWNESS & -1.207156871 \\
\hline & KURTOSIS & 4.826836511 \\
\hline FOLK AND & MEAN & 7.050178415 \\
\hline WARD METHOD & SORTING & 4.13454464 \\
\hline \multirow[t]{2}{*}{$(\mathrm{mm})$} & SKEWNESS & 0.249468594 \\
\hline & KURTOSIS & 1.200840024 \\
\hline FOLK AND & MEAN & 7.148124517 \\
\hline WARD METHOD & SORTING & 2.047728446 \\
\hline \multirow[t]{2}{*}{ (f) } & SKEWNESS & -0.249468594 \\
\hline & KURTOSIS & 1.200840024 \\
\hline FOLK AND & MEAN: & Fine Silt \\
\hline WARD METHOD & SORTING: & Very Poorly Sorted \\
\hline \multirow[t]{33}{*}{ (Description) } & SKEWNESS: & Coarse Skewed \\
\hline & KURTOSIS: & Leptokurtic \\
\hline & MODE $1(\mathrm{~mm}):$ & 4.7 \\
\hline & MODE $2(\mathrm{~mm}):$ & \\
\hline & MODE 1 (f): & 7.754331413 \\
\hline & MODE 2 (f): & \\
\hline & $\mathrm{D} 10(\mathrm{~mm}):$ & 1.520351238 \\
\hline & $\mathrm{D} 50(\mathrm{~mm}):$ & 6.0080573 \\
\hline & D90 (mm): & 56.8317893 \\
\hline & $(\mathrm{D} 90 / \mathrm{D} 10)(\mathrm{mm}):$ & 37.38069723 \\
\hline & $(\mathrm{D} 90-\mathrm{D} 10)(\mathrm{mm}):$ & 55.31143806 \\
\hline & $(\mathrm{D} 75 / \mathrm{D} 25)(\mathrm{mm}):$ & 5.472098723 \\
\hline & $(\mathrm{D} 75-\mathrm{D} 25)(\mathrm{mm}):$ & 12.71296791 \\
\hline & D10 (f): & 4.137158052 \\
\hline & D50 (f): & 7.378885713 \\
\hline & D90 (f): & 9.361379625 \\
\hline & $(D 90 / D 10)(f):$ & 2.262756102 \\
\hline & $(D 90-D 10)(f):$ & 5.224221573 \\
\hline & $(D 75 / D 25)(f):$ & 1.408246023 \\
\hline & $(D 75-D 25)(f):$ & 2.452094258 \\
\hline & \% SAND: & 0.092973514 \\
\hline & \% MUD: & 0.907026486 \\
\hline & \% V COARSE SAND: & 0.021663056 \\
\hline & \% COARSE SAND: & 0.008431928 \\
\hline & $\%$ MEDIUM SAND: & 0.010031661 \\
\hline & $\%$ FINE SAND: & 0.016330612 \\
\hline & $\%$ V FINE SAND: & 0.036516257 \\
\hline & \% V COARSE SILT: & 0.057591605 \\
\hline & \% COARSE SILT: & 0.098564448 \\
\hline & \% MEDIUM SILT: & 0.168562812 \\
\hline & $\%$ FINE SILT: & 0.225825001 \\
\hline & $\%$ V FINE SILT: & 0.205324218 \\
\hline & \% CLAY: & 0.151158402 \\
\hline
\end{tabular}




\begin{tabular}{|c|c|c|}
\hline 302-4-C-1-H-1 & 302-4-C-1-H-2 & $302-4-\mathrm{C}-1-\mathrm{H}-2$ \\
\hline Cristin Ashmankas, & Cristin Ashmankas, & Cristin Ashmankas, \\
\hline $\begin{array}{l}\text { Bimodal, Very Poorly } \\
\text { Sorted }\end{array}$ & $\begin{array}{c}\text { Bimodal, Very Poorly } \\
\text { Sorted }\end{array}$ & $\begin{array}{c}\text { Bimodal, Very Poorly } \\
\text { Sorted }\end{array}$ \\
\hline Sandy Mud & Sandy Mud & Sandy Mud \\
\hline Fine Sandy Medium Silt & Fine Sandy Fine Silt & Fine Sandy Fine Silt \\
\hline 92.33996366 & 105.2323342 & 94.90165134 \\
\hline 172.3019746 & 228.2781555 & 178.8473685 \\
\hline 4.201910948 & 4.496879479 & 5.130996209 \\
\hline 29.42318937 & 27.64541096 & 39.93201769 \\
\hline 22.22836522 & 21.2832317 & 24.57791066 \\
\hline 6.118025196 & 6.512392595 & 6.10634554 \\
\hline 0.128310655 & 0.238456562 & -0.011054926 \\
\hline 1.984590606 & 2.068992395 & 1.927514307 \\
\hline 5.47882933 & 5.499666602 & 5.315607701 \\
\hline 2.615491539 & 2.714127979 & 2.614425535 \\
\hline-0.13154039 & -0.245680866 & 0.002846258 \\
\hline 1.988328047 & 2.071393536 & 1.938701065 \\
\hline 22.45133942 & 21.81369851 & 24.59678616 \\
\hline 6.530817962 & 6.869703164 & 6.306267767 \\
\hline 0.116712457 & 0.168868383 & 0.015787715 \\
\hline 0.75528595 & 0.754981323 & 0.718202463 \\
\hline 5.477054673 & 5.51862179 & 5.345386366 \\
\hline 2.707263696 & 2.780247762 & 2.656786429 \\
\hline-0.116712457 & -0.168868383 & -0.015787715 \\
\hline 0.75528595 & 0.754981323 & 0.718202463 \\
\hline Coarse Silt & Coarse Silt & Coarse Silt \\
\hline Very Poorly Sorted & Very Poorly Sorted & Very Poorly Sorted \\
\hline Coarse Skewed & Coarse Skewed & Symmetrical \\
\hline Platykurtic & Platykurtic & Platykurtic \\
\hline 9.4 & 9.4 & 215 \\
\hline 215 & 215 & 9.4 \\
\hline 6.754331413 & 6.754331413 & 2.236965594 \\
\hline 2.236965594 & 2.236965594 & 6.754331413 \\
\hline 2.168489233 & 2.096708015 & 2.250364648 \\
\hline 18.49915578 & 16.68555342 & 23.28006978 \\
\hline 270.8224202 & 295.7171223 & 250.2124551 \\
\hline 124.8899077 & 141.0387713 & 111.1875159 \\
\hline 268.653931 & 293.6204143 & 247.9620904 \\
\hline 21.31890603 & 23.3584567 & 22.80455626 \\
\hline 104.926868 & 108.5746915 & 120.5151553 \\
\hline 1.884580917 & 1.757710315 & 1.998774489 \\
\hline 5.756396756 & 5.905256652 & 5.424760807 \\
\hline 8.849094005 & 8.897658317 & 8.795625491 \\
\hline 4.695523512 & 5.06207322 & 4.400509182 \\
\hline 6.964513088 & 7.139948002 & 6.796851002 \\
\hline 2.386659767 & 2.44767684 & 2.509778588 \\
\hline 4.414061503 & 4.545873053 & 4.511250193 \\
\hline 0.328979141 & 0.324909855 & 0.374136545 \\
\hline 0.671020859 & 0.675090145 & 0.625863455 \\
\hline 0.007067609 & 0.022430343 & 0.011947013 \\
\hline 0.022069609 & 0.020763898 & 0.011047238 \\
\hline 0.082210961 & 0.080222637 & 0.077130717 \\
\hline 0.118415789 & 0.11255166 & 0.151662084 \\
\hline 0.099215172 & 0.088941317 & 0.122349492 \\
\hline 0.08762136 & 0.078020213 & 0.085260073 \\
\hline 0.112890465 & 0.108294702 & 0.102161461 \\
\hline 0.137668671 & 0.140116882 & 0.124122157 \\
\hline 0.136870991 & 0.142761295 & 0.127574628 \\
\hline 0.110600702 & 0.116339903 & 0.105750503 \\
\hline 0.085368671 & 0.08955715 & 0.080994633 \\
\hline
\end{tabular}




\begin{tabular}{|c|c|c|}
\hline $\begin{array}{c}\text { 302-4-C-1-H-3 } \\
\text { Cristin Ashmankas, }\end{array}$ & $\begin{array}{c}\text { 302-4-C-2-H-1 } \\
\text { Cristin Ashmankas, }\end{array}$ & $\begin{array}{c}302-4-\mathrm{C}-2-\mathrm{H}-1 \\
\text { Cristin Ashmankas, }\end{array}$ \\
\hline $\begin{array}{l}\text { Unimodal, Very Poorly } \\
\text { Sorted }\end{array}$ & $\begin{array}{c}\text { Bimodal, Very Poorly } \\
\text { Sorted }\end{array}$ & $\begin{array}{l}\text { Trimodal, Very Poorly } \\
\text { Sorted }\end{array}$ \\
\hline Sandy Mud & Sandy Mud & Sandy Mud \\
\hline Very Fine Sandy Fine Silt & Medium Sandy Medium Sil & Fine Sandy Medium Silt \\
\hline 55.0519548 & 138.3480623 & 86.68912036 \\
\hline 207.9441421 & 181.2225702 & 161.0614094 \\
\hline 6.350507922 & 1.525974789 & 4.873520794 \\
\hline 45.21027651 & 4.949705609 & 39.58508177 \\
\hline 9.761820052 & 35.85874746 & 23.74420207 \\
\hline 4.771020313 & 6.972303159 & 5.614953235 \\
\hline 0.804251489 & -0.156661269 & 0.046449373 \\
\hline 3.745719669 & 1.733944741 & 2.084072117 \\
\hline 6.627140809 & 4.801531094 & 5.378010919 \\
\hline 2.292126939 & 2.8016353 & 2.492239256 \\
\hline-0.840734115 & 0.156661269 & -0.054200547 \\
\hline 3.776486354 & 1.733944741 & 2.091836302 \\
\hline 9.429477341 & 35.30227864 & 24.23951115 \\
\hline 4.576579464 & 7.206534167 & 5.995267563 \\
\hline 0.184175601 & -0.032091566 & 0.060685641 \\
\hline 0.992324791 & 0.671600427 & 0.790513238 \\
\hline 6.728606478 & 4.824094882 & 5.366495586 \\
\hline 2.194269731 & 2.849305592 & 2.583824141 \\
\hline-0.184175601 & 0.032091566 & -0.060685641 \\
\hline 0.992324791 & 0.671600427 & 0.790513238 \\
\hline Medium Silt & Very Coarse Silt & Coarse Silt \\
\hline Very Poorly Sorted & Very Poorly Sorted & Very Poorly Sorted \\
\hline Coarse Skewed & Symmetrical & Symmetrical \\
\hline Mesokurtic & Platykurtic & Platykurtic \\
\hline 4.7 & 302.5 & 9.4 \\
\hline & 9.4 & 215 \\
\hline 7.754331413 & 1.747054535 & 6.754331413 \\
\hline & 6.754331413 & 2.236965594 \\
\hline 1.604188914 & 2.55701715 & 2.45994288 \\
\hline 8.030388446 & 34.85965456 & 21.57917001 \\
\hline 82.65857942 & 406.9160232 & 247.5246445 \\
\hline 51.52671155 & 159.1369941 & 100.6221106 \\
\hline 81.05439051 & 404.3590061 & 245.0647016 \\
\hline 7.784846857 & 33.76287441 & 16.78812465 \\
\hline 21.84563024 & 224.011565 & 97.8842648 \\
\hline 3.59669162 & 1.297197004 & 2.014355922 \\
\hline 6.960314509 & 4.842297917 & 5.534216814 \\
\hline 9.283940237 & 8.611322448 & 8.667159468 \\
\hline 2.581244437 & 6.638407598 & 4.302695155 \\
\hline 5.687248617 & 7.314125444 & 6.652803546 \\
\hline 1.55670931 & 3.400669526 & 2.246675034 \\
\hline 2.960668659 & 5.077365828 & 4.069369175 \\
\hline 0.128553537 & 0.440961421 & 0.327874525 \\
\hline 0.871446463 & 0.559038579 & 0.672125475 \\
\hline 0.022734849 & 0.0001 & 0.007066431 \\
\hline 0.008867258 & 0.05115 & 0.014499517 \\
\hline 0.005933729 & 0.17865 & 0.076630779 \\
\hline 0.02520168 & 0.13915 & 0.120495983 \\
\hline 0.065816021 & 0.071911421 & 0.109181814 \\
\hline 0.08575708 & 0.071008992 & 0.105231985 \\
\hline 0.124396308 & 0.097137373 & 0.130691598 \\
\hline 0.168412478 & 0.118460873 & 0.142281904 \\
\hline 0.190315123 & 0.113277482 & 0.126080834 \\
\hline 0.168078537 & 0.089722173 & 0.095449921 \\
\hline 0.134486937 & 0.069431687 & 0.072389233 \\
\hline
\end{tabular}




\begin{tabular}{|c|c|c|}
\hline $\begin{array}{c}\text { 302-4-C-2-H-2 } \\
\text { Cristin Ashmankas, }\end{array}$ & $\begin{array}{c}\text { 302-4-C-2-H-2 } \\
\text { Cristin Ashmankas, }\end{array}$ & $\begin{array}{c}\text { 302-4-C-2-H-3 } \\
\text { Cristin Ashmankas, }\end{array}$ \\
\hline $\begin{array}{l}\text { Unimodal, Very Poorly } \\
\text { Sorted }\end{array}$ & $\begin{array}{l}\text { Unimodal, Very Poorly } \\
\text { Sorted }\end{array}$ & $\begin{array}{l}\text { Unimodal, Very Poorly } \\
\text { Sorted }\end{array}$ \\
\hline Sandy Mud & Sandy Mud & Sandy Mud \\
\hline Very Fine Sandy Fine Silt & Very Fine Sandy Fine Silt & Very Fine Sandy Fine Silt \\
\hline 57.47639901 & 54.77045138 & 57.16564748 \\
\hline 224.9020751 & 210.5975862 & 191.069294 \\
\hline 5.904668035 & 6.393406287 & 6.574711446 \\
\hline 38.83438898 & 45.33570893 & 50.11798035 \\
\hline 8.313261954 & 9.603109769 & 11.49459294 \\
\hline 4.874041581 & 4.748896525 & 4.978759736 \\
\hline 1.05342518 & 0.822360583 & 0.609925243 \\
\hline 4.280752375 & 3.810461376 & 3.091681122 \\
\hline 6.853910009 & 6.650123129 & 6.407689549 \\
\hline 2.331572081 & 2.286551045 & 2.337615088 \\
\hline-1.079293592 & -0.859618669 & -0.63387582 \\
\hline 4.262047669 & 3.840409416 & 3.12392308 \\
\hline 7.824758403 & 9.227873282 & 11.37411901 \\
\hline 4.569956772 & 4.559145945 & 5.003443479 \\
\hline 0.255948006 & 0.185824905 & 0.186913638 \\
\hline 1.109196613 & 1.016187481 & 0.949823568 \\
\hline 6.997738077 & 6.759786092 & 6.458101384 \\
\hline 2.192180519 & 2.188763593 & 2.322921331 \\
\hline-0.255948006 & -0.185824905 & -0.186913638 \\
\hline 1.109196613 & 1.016187481 & 0.949823568 \\
\hline Medium Silt & Medium Silt & Medium Silt \\
\hline Very Poorly Sorted & Very Poorly Sorted & Very Poorly Sorted \\
\hline Coarse Skewed & Coarse Skewed & Coarse Skewed \\
\hline Mesokurtic & Mesokurtic & Mesokurtic \\
\hline 3.35 & 4.7 & 4.7 \\
\hline 8.241333809 & 7.754331413 & 7.754331413 \\
\hline 1.481105269 & 1.591882302 & 1.708617673 \\
\hline 6.396187458 & 7.911986688 & 9.355975124 \\
\hline 76.6950044 & 82.86093438 & 111.8123857 \\
\hline 51.78227775 & 52.05217387 & 65.44026055 \\
\hline 75.21389913 & 81.26905208 & 110.103768 \\
\hline 6.740060672 & 7.520170948 & 9.21558231 \\
\hline 16.25087689 & 20.86550276 & 29.07922984 \\
\hline 3.70472358 & 3.593164101 & 3.160848087 \\
\hline 7.288572063 & 6.981744286 & 6.739896259 \\
\hline 9.399110102 & 9.295050612 & 9.192954674 \\
\hline 2.537061105 & 2.586870611 & 2.908382314 \\
\hline 5.694386521 & 5.701886511 & 6.032106587 \\
\hline 1.481956166 & 1.541348329 & 1.648840623 \\
\hline 2.752761578 & 2.910765457 & 3.204075329 \\
\hline 0.114873975 & 0.126128756 & 0.166257888 \\
\hline 0.885126025 & 0.873871244 & 0.833742112 \\
\hline 0.026893725 & 0.02390239 & 0.018099397 \\
\hline 0.008864598 & 0.00610061 & 0.007399753 \\
\hline 0.005898624 & 0.00540054 & 0.012499583 \\
\hline 0.025227447 & 0.029936327 & 0.049365021 \\
\hline 0.047989581 & 0.060788888 & 0.078894134 \\
\hline 0.064818958 & 0.081751512 & 0.089658351 \\
\hline 0.103904996 & 0.124535455 & 0.124890297 \\
\hline 0.159159252 & 0.170913374 & 0.164539192 \\
\hline 0.206594608 & 0.192358731 & 0.180013359 \\
\hline 0.194283701 & 0.16832016 & 0.153498995 \\
\hline 0.15636451 & 0.135992013 & 0.121141918 \\
\hline
\end{tabular}




\begin{tabular}{|c|c|c|}
\hline $\begin{array}{c}302-3-\mathrm{A}-1-\mathrm{H}-3 \\
\text { Cristin Ashmankas. }\end{array}$ & $\frac{302-4-\mathrm{C}-2-\mathrm{H}-3}{\text { Cristin Ashmankas }}$ & $\frac{302-3-\mathrm{A}-1-\mathrm{H}-3}{\text { Cristin }}$ \\
\hline $\begin{array}{c}\text { Bimodal, Very Poorly } \\
\text { Sorted }\end{array}$ & $\begin{array}{c}\text { Bimodal, Very Poorly } \\
\text { Sorted }\end{array}$ & Unimodal, Poorly Sorted \\
\hline Sandy Mud & Sandy Mud & Mud \\
\hline Very Fine Sandy Fine Silt & Very Fine Sandy Fine Silt & Fine Silt \\
\hline 57.8401145 & 59.59132141 & 45.038319 \\
\hline 170.4603 & 188.3723836 & 192.5850721 \\
\hline 6.990858 & 6.802515775 & 7.016581812 \\
\hline 58.83002586 & 53.529977 & 54.2031639 \\
\hline 13.81872119 & 13.22490129 & 8.089600694 \\
\hline 5.005573968 & 5.042143083 & 4.292971205 \\
\hline 0.374917658 & 0.437808476 & 0.996358967 \\
\hline 2.644315655 & 2.779167841 & 4.571307541 \\
\hline 6.153647174 & 6.201735268 & 6.90885199 \\
\hline 2.335508036 & 2.354565259 & 2.139481041 \\
\hline-0.392775407 & -0.464986277 & -1.039596332 \\
\hline 2.673461873 & 2.819180776 & 4.617816772 \\
\hline 13.88365124 & 13.3049467 & 7.550738103 \\
\hline 5.126657799 & 5.123988611 & 3.970945616 \\
\hline 0.131382564 & 0.144623889 & 0.1753284 \\
\hline 0.870263202 & 0.877059911 & 1.079905126 \\
\hline 6.17046916 & 6.231893459 & 7.049166606 \\
\hline 2.358018602 & 2.357267269 & 1.989482603 \\
\hline-0.131382564 & -0.144623889 & -0.1753284 \\
\hline 0.870263202 & 0.877059911 & 1.079905126 \\
\hline Medium Silt & Medium Silt & Fine Silt \\
\hline Very Poorly Sorted & Very Poorly Sorted & Poorly Sorted \\
\hline Coarse Skewed & Coarse Skewed & Coarse Skewed \\
\hline Platykurtic & Platykurtic & Mesokurtic \\
\hline 6.65 & 6.65 & 4.7 \\
\hline 107.5 & 107.5 & \\
\hline 7.254331413 & 7.254331413 & 7.754331413 \\
\hline 3.236965594 & 3.236965594 & \\
\hline 1.871704266 & 1.826905463 & 1.551038644 \\
\hline 11.8355974 & 11.20994369 & 6.76682399 \\
\hline 127.7940093 & 123.5093686 & 55.58486274 \\
\hline 68.27681681 & 67.60577989 & 35.83718751 \\
\hline 125.922305 & 121.6824632 & 54.03382409 \\
\hline 11.0533894 & 10.9042057 & 5.91960645 \\
\hline 40.94366215 & 38.89973367 & 14.7582603 \\
\hline 2.968107887 & 3.017307615 & 4.169164138 \\
\hline 6.400723661 & 6.479077159 & 7.207305421 \\
\hline 9.061431781 & 9.096382304 & 9.332549653 \\
\hline 3.052932078 & 3.014734811 & 2.238470193 \\
\hline 6.093323894 & 6.079074689 & 5.163385515 \\
\hline 1.774893771 & 1.758320521 & 1.441158342 \\
\hline 3.466416919 & 3.446812778 & 2.565501265 \\
\hline 0.202220186 & 0.195854638 & 0.090395019 \\
\hline 0.797779814 & 0.804145362 & 0.909604981 \\
\hline 0.013566214 & 0.01829878 & 0.019568624 \\
\hline 0.0059998 & 0.00419972 & 0.006333967 \\
\hline 0.015466151 & 0.013365776 & 0.00270027 \\
\hline 0.067431086 & 0.062429171 & 0.019168584 \\
\hline 0.099756935 & 0.097561191 & 0.042623575 \\
\hline 0.105851042 & 0.102948224 & 0.06584981 \\
\hline 0.131826507 & 0.129218217 & 0.118835553 \\
\hline 0.156538576 & 0.157226791 & 0.181377622 \\
\hline 0.163297973 & 0.166053112 & 0.213341887 \\
\hline 0.134363714 & 0.139156981 & 0.186539473 \\
\hline 0.105902002 & 0.109542037 & 0.143660636 \\
\hline
\end{tabular}




\begin{tabular}{|c|c|c|}
\hline $\begin{array}{c}\text { 302-4-C-2-H-4 } \\
\text { Cristin Ashmankas, }\end{array}$ & $\begin{array}{c}\text { 302-4-C-3-H-1 } \\
\text { Cristin Ashmankas, }\end{array}$ & $\begin{array}{c}\text { 302-3-A-1-H-CC } \\
\text { Cristin Ashmankas, }\end{array}$ \\
\hline Unimodal, Poorly Sorted & $\begin{array}{c}\text { Unimodal, Very Poorly } \\
\text { Sorted }\end{array}$ & $\begin{array}{c}\text { Bimodal, Very Poorly } \\
\text { Sorted }\end{array}$ \\
\hline Mud & Sandy Mud & Sandy Mud \\
\hline Fine Silt & Very Fine Sandy Fine Silt & Very Fine Sandy Fine Silt \\
\hline 36.71471681 & 58.92352752 & 58.80228192 \\
\hline 177.4364134 & 221.846489 & 179.8512113 \\
\hline 7.801261242 & 5.954462299 & 6.806558929 \\
\hline 65.97874816 & 39.68728563 & 54.39222353 \\
\hline 7.02335757 & 9.241653535 & 13.50560578 \\
\hline 3.847463425 & 4.912573561 & 5.052487387 \\
\hline 1.105225295 & 0.944236292 & 0.396865805 \\
\hline 5.481221861 & 3.937433013 & 2.676058407 \\
\hline 7.118408612 & 6.703148211 & 6.183058935 \\
\hline 1.982528787 & 2.337571606 & 2.351098573 \\
\hline-1.164684861 & -0.971590496 & -0.41652059 \\
\hline 5.566496151 & 3.936382581 & 2.707574616 \\
\hline 6.515503653 & 8.883532113 & 13.55120035 \\
\hline 3.47619822 & 4.705729355 & 5.112457686 \\
\hline 0.125861058 & 0.247361975 & 0.138525379 \\
\hline 1.078702235 & 1.075228283 & 0.836473066 \\
\hline 7.26190758 & 6.814650875 & 6.20543554 \\
\hline 1.79751035 & 2.234418348 & 2.354016998 \\
\hline-0.125861058 & -0.247361975 & -0.138525379 \\
\hline 1.078702235 & 1.075228283 & 0.836473066 \\
\hline Fine Silt & Medium Silt & Medium Silt \\
\hline Poorly Sorted & Very Poorly Sorted & Very Poorly Sorted \\
\hline Coarse Skewed & Coarse Skewed & Coarse Skewed \\
\hline Mesokurtic & Mesokurtic & Platykurtic \\
\hline 4.7 & 4.7 & 6.65 \\
\hline & & 107.5 \\
\hline 7.754331413 & 7.754331413 & 7.254331413 \\
\hline & & 3.236965594 \\
\hline 1.50780015 & 1.578929644 & 1.829007867 \\
\hline 6.176962343 & 7.155751442 & 11.32886611 \\
\hline 35.40783328 & 88.98175228 & 122.1021384 \\
\hline 23.48310769 & 56.3557424 & 66.75867318 \\
\hline 33.90003313 & 87.40282264 & 120.2731306 \\
\hline 5.05745503 & 7.150065927 & 11.76959439 \\
\hline 11.63426631 & 18.86846581 & 42.43949497 \\
\hline 4.819787626 & 3.490346681 & 3.033839628 \\
\hline 7.338886749 & 7.126681009 & 6.463852718 \\
\hline 9.373339065 & 9.306837398 & 9.094723004 \\
\hline 1.944761842 & 2.666450714 & 2.997759974 \\
\hline 4.553551438 & 5.816490717 & 6.060883376 \\
\hline 1.38286667 & 1.51500662 & 1.802869816 \\
\hline 2.338411587 & 2.837956544 & 3.556992697 \\
\hline 0.059244192 & 0.130798954 & 0.206261524 \\
\hline 0.940755808 & 0.869201046 & 0.793738476 \\
\hline 0.016734449 & 0.026069274 & 0.015666144 \\
\hline 0.004933662 & 0.008367503 & 0.007099763 \\
\hline 0.001033402 & 0.00720072 & 0.008233059 \\
\hline 0.009867324 & 0.030769744 & 0.065164495 \\
\hline 0.026675354 & 0.058391714 & 0.110098063 \\
\hline 0.05219443 & 0.07064122 & 0.102920218 \\
\hline 0.119517384 & 0.108209294 & 0.123367427 \\
\hline 0.193520731 & 0.165280049 & 0.153656789 \\
\hline 0.226037019 & 0.203422574 & 0.165887018 \\
\hline 0.197607277 & 0.182362345 & 0.138529324 \\
\hline 0.151878967 & 0.139285565 & 0.1093777 \\
\hline
\end{tabular}




\begin{tabular}{|c|c|c|}
\hline $302-4-\mathrm{C}-3-\mathrm{H}-1$ & $302-4-\mathrm{C}-3-\mathrm{H}-2$ & $302-4-\mathrm{C}-3-\mathrm{H}-2$ \\
\hline Cristin Ashmankas, & Cristin Ashmankas, & Cristin Ashmankas, \\
\hline $\begin{array}{l}\text { Bimodal, Very Poorly } \\
\text { Sorted }\end{array}$ & $\begin{array}{l}\text { Unimodal, Very Poorly } \\
\text { Sorted }\end{array}$ & $\begin{array}{l}\text { Unimodal, Very Poorly } \\
\text { Sorted }\end{array}$ \\
\hline Sandy Mud & Mud & Sandy Mud \\
\hline Very Fine Sandy Fine Silt & Fine Silt & Very Fine Sandy Fine Silt \\
\hline 57.22002117 & 49.98322229 & 65.6725685 \\
\hline 196.4684113 & 207.7410735 & 224.5584796 \\
\hline 6.61954541 & 6.514375888 & 5.457132844 \\
\hline 49.69523382 & 46.74329302 & 34.60355418 \\
\hline 11.59685611 & 8.352898491 & 10.19922126 \\
\hline 4.935471722 & 4.454880499 & 5.183390057 \\
\hline 0.593233648 & 1.017508581 & 0.883207965 \\
\hline 3.102828148 & 4.518176741 & 3.656317853 \\
\hline 6.388933282 & 6.854678291 & 6.572876508 \\
\hline 2.328561517 & 2.197924354 & 2.402582877 \\
\hline-0.622477668 & -1.057983073 & -0.899486425 \\
\hline 3.142215787 & 4.539853501 & 3.648348712 \\
\hline 11.61507689 & 7.860341575 & 9.635952507 \\
\hline 4.924836188 & 4.111423264 & 5.115219457 \\
\hline 0.180039434 & 0.198019969 & 0.241081303 \\
\hline 0.913046117 & 1.052972199 & 1.114725917 \\
\hline 6.427857485 & 6.991192278 & 6.697357002 \\
\hline 2.300075738 & 2.039637902 & 2.354796137 \\
\hline-0.180039434 & -0.198019969 & -0.241081303 \\
\hline 0.913046117 & 1.052972199 & 1.114725917 \\
\hline Medium Silt & Medium Silt & Medium Silt \\
\hline Very Poorly Sorted & Very Poorly Sorted & Very Poorly Sorted \\
\hline Coarse Skewed & Coarse Skewed & Coarse Skewed \\
\hline Mesokurtic & Mesokurtic & Leptokurtic \\
\hline 4.7 & 4.7 & 4.7 \\
\hline \multicolumn{3}{|l|}{107.5} \\
\hline 7.754331413 & 7.754331413 & 7.754331413 \\
\hline \multicolumn{3}{|l|}{3.236965594} \\
\hline 1.736058558 & 1.566961009 & 1.601316114 \\
\hline 9.474428376 & 6.811374743 & 7.952026114 \\
\hline 109.3014549 & 59.40044478 & 105.6166187 \\
\hline 62.95954384 & 37.90805543 & 65.95613306 \\
\hline 107.5653963 & 57.83348377 & 104.0153026 \\
\hline 9.506095277 & 6.350467049 & 7.733857328 \\
\hline 30.59273703 & 16.08823103 & 21.51762762 \\
\hline 3.19361549 & 4.073382456 & 3.243091235 \\
\hline 6.721745381 & 7.197838277 & 6.97446179 \\
\hline 9.169968673 & 9.317815004 & 9.286526148 \\
\hline 2.871343999 & 2.287488372 & 2.863479771 \\
\hline 5.976353183 & 5.244432547 & 6.043434913 \\
\hline 1.667072956 & 1.466997886 & 1.552803733 \\
\hline 3.248852861 & 2.6668627 & 2.95118815 \\
\hline 0.171028279 & 0.095210641 & 0.141616988 \\
\hline 0.828971721 & 0.904789359 & 0.858383012 \\
\hline 0.020131991 & 0.023031798 & 0.0244 \\
\hline 0.005932938 & 0.006832878 & 0.0149 \\
\hline 0.006499567 & 0.004466369 & 0.014966667 \\
\hline 0.050196654 & 0.01679888 & 0.033166667 \\
\hline 0.08826713 & 0.044080716 & 0.054183655 \\
\hline 0.091317686 & 0.07443967 & 0.073011605 \\
\hline 0.12238685 & 0.118327257 & 0.119294674 \\
\hline 0.163794368 & 0.171560158 & 0.170723094 \\
\hline 0.180905746 & 0.210251931 & 0.190308801 \\
\hline 0.152299502 & 0.188336216 & 0.169861998 \\
\hline 0.118267569 & 0.141874128 & 0.13518284 \\
\hline
\end{tabular}




\begin{tabular}{|c|c|c|}
\hline $\begin{array}{c}\text { 302-4-C-3-H-3 } \\
\text { Cristin Ashmankas, }\end{array}$ & $\begin{array}{c}\text { 302-4-C-3-H-3 } \\
\text { Cristin Ashmankas, }\end{array}$ & $\begin{array}{c}\text { 302-4-C-4-H-1 } \\
\text { Cristin Ashmankas, }\end{array}$ \\
\hline $\begin{array}{l}\text { Unimodal, Very Poorly } \\
\text { Sorted }\end{array}$ & $\begin{array}{l}\text { Bimodal, Very Poorly } \\
\text { Sorted }\end{array}$ & $\begin{array}{l}\text { Unimodal, Very Poorly } \\
\text { Sorted }\end{array}$ \\
\hline Sandy Mud & Sandy Mud & Sandy Mud \\
\hline Very Fine Sandy Fine Silt & Very Fine Sandy Fine Silt & Very Fine Sandy Fine Silt \\
\hline 54.82864055 & 58.94971333 & 63.53195903 \\
\hline 202.0973882 & 194.8252303 & 214.6770528 \\
\hline 6.436303114 & 6.586088369 & 5.939069062 \\
\hline 46.66152543 & 49.8488854 & 40.45231533 \\
\hline 10.27597616 & 11.9953131 & 11.26151232 \\
\hline 4.74295273 & 5.048714278 & 5.160235874 \\
\hline 0.753786987 & 0.564507077 & 0.705758989 \\
\hline 3.618483791 & 2.970508383 & 3.244549666 \\
\hline 6.563058024 & 6.34052566 & 6.424282834 \\
\hline 2.275192775 & 2.359897936 & 2.397071172 \\
\hline-0.785530996 & -0.590958125 & -0.72972965 \\
\hline 3.651669571 & 3.006255814 & 3.261115215 \\
\hline 9.896572287 & 12.02710045 & 11.10545345 \\
\hline 4.587167073 & 5.105622056 & 5.135049501 \\
\hline 0.172484092 & 0.186614548 & 0.215531185 \\
\hline 0.994429262 & 0.913204398 & 0.976783929 \\
\hline 6.658855356 & 6.377567317 & 6.492587889 \\
\hline 2.197603454 & 2.352086746 & 2.360378184 \\
\hline-0.172484092 & -0.186614548 & -0.215531185 \\
\hline 0.994429262 & 0.913204398 & 0.976783929 \\
\hline Medium Silt & Medium Silt & Medium Silt \\
\hline Very Poorly Sorted & Very Poorly Sorted & Very Poorly Sorted \\
\hline Coarse Skewed & Coarse Skewed & Coarse Skewed \\
\hline Mesokurtic & Mesokurtic & Mesokurtic \\
\hline 4.7 & 4.7 & 4.7 \\
\hline & 107.5 & \\
\hline 7.754331413 & 7.754331413 & 7.754331413 \\
\hline & 3.236965594 & \\
\hline 1.666777927 & 1.742509792 & 1.68364999 \\
\hline 8.557305685 & 9.740663899 & 8.905574642 \\
\hline 87.06130322 & 118.8808734 & 116.6993045 \\
\hline 52.23329504 & 68.22393417 & 69.31328079 \\
\hline 85.39452529 & 117.1383636 & 115.0156545 \\
\hline 7.824387674 & 10.05611487 & 9.157210446 \\
\hline 22.98472744 & 32.78939199 & 27.95233111 \\
\hline 3.521824574 & 3.072411475 & 3.099132132 \\
\hline 6.868627657 & 6.681764179 & 6.811075579 \\
\hline 9.228722385 & 9.164617521 & 9.214192034 \\
\hline 2.620437842 & 2.982874395 & 2.973152367 \\
\hline 5.706897811 & 6.092206046 & 6.115059902 \\
\hline 1.565770698 & 1.696723187 & 1.639742253 \\
\hline 2.967977853 & 3.330001129 & 3.194908178 \\
\hline 0.132779793 & 0.179534502 & 0.165920085 \\
\hline 0.867220207 & 0.820465498 & 0.834079915 \\
\hline 0.021065964 & 0.019633333 & 0.02370237 \\
\hline 0.007966401 & 0.005333333 & 0.008767543 \\
\hline 0.006399787 & 0.011966667 & 0.012867953 \\
\hline 0.03269891 & 0.056766667 & 0.047438077 \\
\hline 0.064648731 & 0.085834502 & 0.073144141 \\
\hline 0.088158713 & 0.091746996 & 0.084619647 \\
\hline 0.130818897 & 0.122245962 & 0.119994242 \\
\hline 0.17207274 & 0.16077832 & 0.162152973 \\
\hline 0.187011262 & 0.176983852 & 0.183289915 \\
\hline 0.162697085 & 0.151103204 & 0.159751624 \\
\hline 0.12646151 & 0.117607164 & 0.124271514 \\
\hline
\end{tabular}




\begin{tabular}{|c|c|c|}
\hline $\begin{array}{c}\text { 302-3-A-2-H-2 } \\
\text { Cristin Ashmankas. }\end{array}$ & $\frac{\text { 302-4-C-4-H-1 }}{\text { Cristin Ashmankas. }}$ & $\begin{array}{c}\text { 302-3-A-2-H-3 } \\
\text { Cristin Ashmankas. }\end{array}$ \\
\hline $\begin{array}{l}\text { Unimodal, Very Poorly } \\
\text { Sorted }\end{array}$ & $\begin{array}{l}\text { Unimodal, Very Poorly } \\
\text { Sorted }\end{array}$ & $\begin{array}{l}\text { Unimodal, Very Poorly } \\
\text { Sorted }\end{array}$ \\
\hline Sandy Mud & Sandy Mud & Sandy Mud \\
\hline Very Fine Sandy Fine Silt & Very Fine Sandy Fine Silt & Very Fine Sandy Fine Silt \\
\hline 57.50915519 & 56.01081241 & 54.51014465 \\
\hline 178.046783 & 219.3656382 & 202.8680599 \\
\hline 6.80100816 & 6.120814588 & 6.374478447 \\
\hline 54.67119516 & 41.41418794 & 45.63326603 \\
\hline 13.1569865 & 9.49323275 & 10.34451964 \\
\hline 4.979777123 & 4.624910771 & 4.663797946 \\
\hline 0.422093651 & 0.903255404 & 0.748133542 \\
\hline 2.775005663 & 4.198408558 & 3.728015976 \\
\hline 6.222781288 & 6.664731987 & 6.557788901 \\
\hline 2.329693837 & 2.250921262 & 2.248031126 \\
\hline-0.441388214 & -0.942854766 & -0.779145729 \\
\hline 2.805502483 & 4.210919565 & 3.759557812 \\
\hline 13.01880056 & 8.962845709 & 9.832467031 \\
\hline 5.024486347 & 4.343564796 & 4.457981037 \\
\hline 0.128581155 & 0.1647364 & 0.147440245 \\
\hline 0.874774113 & 1.065126184 & 0.99901537 \\
\hline 6.263259652 & 6.801827423 & 6.668230841 \\
\hline 2.328976117 & 2.118879559 & 2.15639048 \\
\hline-0.128581155 & -0.1647364 & -0.147440245 \\
\hline 0.874774113 & 1.065126184 & 0.99901537 \\
\hline Medium Silt & Medium Silt & Medium Silt \\
\hline Very Poorly Sorted & Very Poorly Sorted & Very Poorly Sorted \\
\hline Coarse Skewed & Coarse Skewed & Coarse Skewed \\
\hline Platykurtic & Mesokurtic & Mesokurtic \\
\hline 6.65 & 6.65 & 6.65 \\
\hline 7.254331413 & 7.254331413 & 7.254331413 \\
\hline 1.809890418 & 1.634320662 & 1.678445063 \\
\hline 11.25084444 & 8.027879438 & 8.791724417 \\
\hline 116.4085273 & 71.60449245 & 80.48705677 \\
\hline 64.31799747 & 43.8130008 & 47.95334595 \\
\hline 114.5986369 & 69.97017179 & 78.8086117 \\
\hline 10.75037296 & 6.738005191 & 7.586872061 \\
\hline 38.10256404 & 18.98559852 & 22.81576573 \\
\hline 3.102731351 & 3.803806085 & 3.63509939 \\
\hline 6.473822902 & 6.960765334 & 6.82963812 \\
\hline 9.109881935 & 9.25709321 & 9.218658968 \\
\hline 2.936084664 & 2.433639624 & 2.536012906 \\
\hline 6.007150584 & 5.453287125 & 5.583559578 \\
\hline 1.749230672 & 1.501591404 & 1.556867317 \\
\hline 3.426314807 & 2.75232154 & 2.923505209 \\
\hline 0.188581318 & 0.11091987 & 0.124003204 \\
\hline 0.811418682 & 0.88908013 & 0.875996796 \\
\hline 0.014932836 & 0.025869254 & 0.020963871 \\
\hline 0.007699743 & 0.00750075 & 0.008765498 \\
\hline 0.011966268 & 0.00410041 & 0.004266098 \\
\hline 0.055531482 & 0.023235657 & 0.029662712 \\
\hline 0.098450989 & 0.0502138 & 0.060345025 \\
\hline 0.110282267 & 0.081163863 & 0.09407781 \\
\hline 0.131005499 & 0.133074485 & 0.138493885 \\
\hline 0.155069784 & 0.18244491 & 0.174828353 \\
\hline 0.165155727 & 0.197745966 & 0.187935398 \\
\hline 0.138926136 & 0.16463737 & 0.156260593 \\
\hline 0.110979269 & 0.130013536 & 0.124400757 \\
\hline
\end{tabular}




\begin{tabular}{|c|c|c|}
\hline$\frac{302-4-\mathrm{C}-4-\mathrm{H}-2}{\text { Cristin Ashmankas, }}$ & $\begin{array}{c}\text { 302-3-A-2-H-3 } \\
\text { Cristin Ashmankas, }\end{array}$ & $\begin{array}{c}\text { 302-3-A-2-H-CC } \\
\text { Cristin Ashmankas, }\end{array}$ \\
\hline $\begin{array}{c}\text { Unimodal, Very Poorly } \\
\text { Sorted }\end{array}$ & $\begin{array}{c}\text { Unimodal, Very Poorly } \\
\text { Sorted }\end{array}$ & $\begin{array}{c}\text { Unimodal, Very Poorly } \\
\text { Sorted }\end{array}$ \\
\hline Sandy Mud & Sandy Mud & Mud \\
\hline Very Fine Sandy Fine Silt & Very Fine Sandy Fine Silt & Fine Silt \\
\hline 60.0290278 & 54.225003 & 51.75378275 \\
\hline 214.0564784 & 202.303739 & 209.8967804 \\
\hline 6.108227932 & 6.575543368 & 6.248617829 \\
\hline 41.9654812 & 48.26809305 & 43.29858377 \\
\hline 10.90688967 & 10.29006225 & 8.768341921 \\
\hline 4.960851515 & 4.745144603 & 4.452334541 \\
\hline 0.697339491 & 0.721015187 & 0.99098151 \\
\hline 3.422443132 & 3.559388993 & 4.519963069 \\
\hline 6.469782473 & 6.556428141 & 6.792955406 \\
\hline 2.342311283 & 2.27903474 & 2.18871758 \\
\hline-0.72807156 & -0.757296865 & -1.025430522 \\
\hline 3.448390468 & 3.600761457 & 4.535682097 \\
\hline 10.6329755 & 10.00422475 & 8.21678345 \\
\hline 4.834865456 & 4.616688446 & 4.059544531 \\
\hline 0.173379212 & 0.16900408 & 0.169616675 \\
\hline 0.960717825 & 0.975269042 & 1.034536576 \\
\hline 6.555310817 & 6.643246815 & 6.927210539 \\
\hline 2.273475743 & 2.206858376 & 2.02131787 \\
\hline-0.173379212 & -0.16900408 & -0.169616675 \\
\hline 0.960717825 & 0.975269042 & 1.034536576 \\
\hline Medium Silt & Medium Silt & Medium Silt \\
\hline Very Poorly Sorted & Very Poorly Sorted & Very Poorly Sorted \\
\hline Coarse Skewed & Coarse Skewed & Coarse Skewed \\
\hline Mesokurtic & Mesokurtic & Mesokurtic \\
\hline 4.7 & 4.7 & 4.7 \\
\hline 7.754331413 & 7.754331413 & 7.754331413 \\
\hline 1.658884447 & 1.649160417 & 1.607910711 \\
\hline 9.01057775 & 8.597192913 & 7.277976765 \\
\hline 98.0364264 & 87.36476309 & 59.34753156 \\
\hline 59.0978031 & 52.97529712 & 36.9097184 \\
\hline 96.37754196 & 85.71560267 & 57.73962085 \\
\hline 8.774440568 & 8.073510966 & 6.373810326 \\
\hline 26.72059519 & 23.84418121 & 16.92726071 \\
\hline 3.350538293 & 3.516804676 & 4.074668165 \\
\hline 6.794164671 & 6.861918605 & 7.102246839 \\
\hline 9.235570889 & 9.244052545 & 9.28059699 \\
\hline 2.756443914 & 2.628537379 & 2.277632586 \\
\hline 5.885032596 & 5.727247869 & 5.205928826 \\
\hline 1.620292788 & 1.57952219 & 1.473929645 \\
\hline 3.133307146 & 3.013196202 & 2.672156088 \\
\hline 0.14994616 & 0.135402757 & 0.094823951 \\
\hline 0.85005384 & 0.864597243 & 0.905176049 \\
\hline 0.024100803 & 0.021734058 & 0.022598493 \\
\hline 0.00810027 & 0.006133538 & 0.010232651 \\
\hline 0.006266876 & 0.005666856 & 0.000999933 \\
\hline 0.03690123 & 0.0330011 & 0.015065662 \\
\hline 0.074576981 & 0.068867206 & 0.04592721 \\
\hline 0.094193017 & 0.091227732 & 0.079456479 \\
\hline 0.127223281 & 0.128724914 & 0.126111011 \\
\hline 0.164552335 & 0.169479933 & 0.178530552 \\
\hline 0.181687735 & 0.186788526 & 0.20847891 \\
\hline 0.155874878 & 0.160277973 & 0.177781585 \\
\hline 0.126522594 & 0.128098165 & 0.134817512 \\
\hline
\end{tabular}




\begin{tabular}{|c|c|c|}
\hline $\begin{array}{c}\text { 302-4-C-4-H-2 } \\
\text { Cristin Ashmankas, }\end{array}$ & $\begin{array}{c}\text { 302-4-C-4-H-3 } \\
\text { Cristin Ashmankas, }\end{array}$ & $\begin{array}{c}\text { 302-3-A-3-H-2 } \\
\text { Cristin Ashmankas, }\end{array}$ \\
\hline $\begin{array}{l}\text { Unimodal, Very Poorly } \\
\text { Sorted }\end{array}$ & $\begin{array}{l}\text { Unimodal, Very Poorly } \\
\text { Sorted }\end{array}$ & $\begin{array}{l}\text { Unimodal, Very Poorly } \\
\text { Sorted }\end{array}$ \\
\hline Sandy Mud & Sandy Mud & Sandy Mud \\
\hline Very Fine Sandy Fine Silt & Very Fine Sandy Fine Silt & Very Fine Sandy Fine Silt \\
\hline 60.00855917 & 55.7055555 & 62.32564208 \\
\hline 229.188982 & 220.7733318 & 229.0000835 \\
\hline 5.785088169 & 5.932698758 & 5.614937586 \\
\hline 37.17793695 & 39.14435108 & 35.51443594 \\
\hline 9.481339402 & 8.693820532 & 9.567591995 \\
\hline 4.79715562 & 4.636338563 & 4.985212266 \\
\hline 0.940975691 & 1.030311025 & 0.927969815 \\
\hline 4.141538956 & 4.480437328 & 3.939957696 \\
\hline 6.664220628 & 6.799286977 & 6.658470435 \\
\hline 2.304461472 & 2.251315107 & 2.353439397 \\
\hline-0.972976272 & -1.060227847 & -0.950900337 \\
\hline 4.134513463 & 4.474622816 & 3.931047026 \\
\hline 8.95081268 & 8.0966778 & 9.007311651 \\
\hline 4.497895092 & 4.260503466 & 4.72869886 \\
\hline 0.1966416 & 0.195765719 & 0.222884556 \\
\hline 1.058025771 & 1.082733233 & 1.063079529 \\
\hline 6.803765608 & 6.948454217 & 6.794687705 \\
\hline 2.169250012 & 2.091023924 & 2.241443269 \\
\hline-0.1966416 & -0.195765719 & -0.222884556 \\
\hline 1.058025771 & 1.082733233 & 1.063079529 \\
\hline Medium Silt & Medium Silt & Medium Silt \\
\hline Very Poorly Sorted & Very Poorly Sorted & Very Poorly Sorted \\
\hline Coarse Skewed & Coarse Skewed & Coarse Skewed \\
\hline Mesokurtic & Mesokurtic & Mesokurtic \\
\hline 4.7 & 4.7 & 4.7 \\
\hline 7.754331413 & 7.754331413 & 7.754331413 \\
\hline 1.613566853 & 1.561631791 & 1.573509568 \\
\hline 7.724794842 & 7.07367202 & 7.527885588 \\
\hline 77.39513508 & 64.88817356 & 86.78781255 \\
\hline 47.9652485 & 41.55151933 & 55.15556711 \\
\hline 75.78156823 & 63.32654177 & 85.21430298 \\
\hline 7.084946831 & 6.429612195 & 7.487654231 \\
\hline 19.48369621 & 16.60111932 & 20.24849966 \\
\hline 3.691613306 & 3.945900631 & 3.526363728 \\
\hline 7.016287667 & 7.143324956 & 7.053539583 \\
\hline 9.275530932 & 9.322729956 & 9.311798334 \\
\hline 2.512595487 & 2.362636779 & 2.640623331 \\
\hline 5.583917626 & 5.376829325 & 5.785434606 \\
\hline 1.517158093 & 1.473606821 & 1.535964865 \\
\hline 2.824757027 & 2.684731723 & 2.904513815 \\
\hline 0.118189504 & 0.102855536 & 0.127648806 \\
\hline 0.881810496 & 0.897144464 & 0.872351194 \\
\hline 0.0281 & 0.025233333 & 0.027029729 \\
\hline 0.009 & 0.0108 & 0.011731769 \\
\hline 0.004333333 & 0.0018 & 0.005132649 \\
\hline 0.023233333 & 0.019 & 0.028696174 \\
\hline 0.053522838 & 0.046022203 & 0.055058484 \\
\hline 0.080244287 & 0.071903332 & 0.077692775 \\
\hline 0.124614269 & 0.119730911 & 0.11818151 \\
\hline 0.173788674 & 0.176168645 & 0.166129464 \\
\hline 0.197568636 & 0.207489393 & 0.197092721 \\
\hline 0.171977276 & 0.180351197 & 0.174083212 \\
\hline 0.133617353 & 0.141500986 & 0.139171512 \\
\hline
\end{tabular}




\begin{tabular}{|c|c|c|}
\hline 302-4-C-4-H-3 & 302-3-A-3-H-2 & 302-4-C-5-X-1 \\
\hline Cristin Ashmankas, & Cristin Ashmankas, & Cristin Ashmankas, \\
\hline $\begin{array}{c}\text { Unimodal, Very Poorly } \\
\text { Sorted }\end{array}$ & $\begin{array}{l}\text { Unimodal, Very Poorly } \\
\text { Sorted }\end{array}$ & $\begin{array}{l}\text { Unimodal, Very Poorly } \\
\text { Sorted }\end{array}$ \\
\hline Sandy Mud & Sandy Mud & Sandy Mud \\
\hline Very Fine Sandy Fine Silt & Very Fine Sandy Fine Silt & Very Fine Sandy Fine Silt \\
\hline 54.20884719 & 55.21434416 & 64.3335421 \\
\hline 205.7651768 & 174.6541936 & 228.0061677 \\
\hline 6.493172985 & 7.070831896 & 5.562994651 \\
\hline 46.87354597 & 58.03890715 & 35.6895928 \\
\hline 10.037578 & 13.42046345 & 8.890221467 \\
\hline 4.703255669 & 4.854361184 & 5.259039697 \\
\hline 0.767042026 & 0.336886598 & 1.038413161 \\
\hline 3.703108216 & 2.774119506 & 3.888401873 \\
\hline 6.591281472 & 6.194832872 & 6.757095913 \\
\hline 2.2678569 & 2.292450426 & 2.43693002 \\
\hline-0.804110704 & -0.358972741 & -1.052065052 \\
\hline 3.740791314 & 2.810900945 & 3.856075466 \\
\hline 9.673337245 & 13.2849458 & 8.407599385 \\
\hline 4.530061087 & 4.845042117 & 5.132939157 \\
\hline 0.171122714 & 0.067228098 & 0.311129914 \\
\hline 0.988067974 & 0.844749801 & 1.198967849 \\
\hline 6.691770588 & 6.234063848 & 6.894090357 \\
\hline 2.179530505 & 2.276509207 & 2.35978516 \\
\hline-0.171122714 & -0.067228098 & -0.311129914 \\
\hline 0.988067974 & 0.844749801 & 1.198967849 \\
\hline Medium Silt & Medium Silt & Medium Silt \\
\hline Very Poorly Sorted & Very Poorly Sorted & Very Poorly Sorted \\
\hline Coarse Skewed & Symmetrical & Very Coarse Skewed \\
\hline Mesokurtic & Platykurtic & Leptokurtic \\
\hline 4.7 & 6.65 & 4.7 \\
\hline 7.754331413 & 7.254331413 & 7.754331413 \\
\hline 1.647910839 & 1.809883221 & 1.507403846 \\
\hline 8.373890892 & 12.25120937 & 6.462099458 \\
\hline 83.11221718 & 106.5990947 & 111.6516665 \\
\hline 50.43489926 & 58.89832749 & 74.06884811 \\
\hline 81.46430634 & 104.7892114 & 110.1442627 \\
\hline 7.784641588 & 10.83719622 & 6.90518152 \\
\hline 22.57985588 & 39.60655047 & 16.99864354 \\
\hline 3.588795626 & 3.229732909 & 3.162923309 \\
\hline 6.899886164 & 6.350932019 & 7.273781329 \\
\hline 9.245146097 & 9.109887671 & 9.373718306 \\
\hline 2.576113844 & 2.8206319 & 2.963624909 \\
\hline 5.656350471 & 5.880154762 & 6.210794996 \\
\hline 1.561740256 & 1.760863506 & 1.493155534 \\
\hline 2.960630618 & 3.437919649 & 2.78767934 \\
\hline 0.128244311 & 0.186750548 & 0.137166546 \\
\hline 0.871755689 & 0.813249452 & 0.862833454 \\
\hline 0.022562906 & 0.014637237 & 0.026464902 \\
\hline 0.006265622 & 0.007835423 & 0.01109926 \\
\hline 0.004965839 & 0.004734596 & 0.020031998 \\
\hline 0.030428262 & 0.048646306 & 0.035230985 \\
\hline 0.064021682 & 0.110896987 & 0.044339401 \\
\hline 0.089645367 & 0.124329654 & 0.055903457 \\
\hline 0.130059295 & 0.137213751 & 0.094527357 \\
\hline 0.170114461 & 0.152169981 & 0.157332692 \\
\hline 0.189244548 & 0.156312542 & 0.209323579 \\
\hline 0.164012045 & 0.132488905 & 0.193925259 \\
\hline 0.128679973 & 0.110734619 & 0.151821109 \\
\hline
\end{tabular}




\begin{tabular}{|c|c|c|}
\hline $302-3-\mathrm{A}-3-\mathrm{H}-3$ & 302-3-A-3-H-3 & $302-2-A-5-X-1$ \\
\hline Cristin Ashmankas, & Cristin Ashmankas, & Cristin Ashmankas, \\
\hline $\begin{array}{l}\text { Bimodal, Very Poorly } \\
\text { Sorted }\end{array}$ & $\begin{array}{l}\text { Bimodal, Very Poorly } \\
\text { Sorted }\end{array}$ & $\begin{array}{l}\text { Bimodal, Very Poorly } \\
\text { Sorted }\end{array}$ \\
\hline Sandy Mud & Sandy Mud & Sandy Mud \\
\hline Very Fine Sandy Fine Silt & Very Fine Sandy Fine Silt & Very Fine Sandy Fine Silt \\
\hline 85.8520282 & 86.28624725 & 91.83171566 \\
\hline 261.7317647 & 267.9362292 & 289.807729 \\
\hline 4.785874343 & 4.589283547 & 4.340125012 \\
\hline 26.35953768 & 24.39545201 & 21.61723388 \\
\hline 14.01731698 & 12.28170751 & 12.03713953 \\
\hline 5.77297517 & 5.922617082 & 5.888018676 \\
\hline 0.565874904 & 0.710107872 & 0.809929855 \\
\hline 2.948475198 & 3.132036321 & 3.408778268 \\
\hline 6.083888455 & 6.27956415 & 6.281707575 \\
\hline 2.561823493 & 2.601141006 & 2.607123163 \\
\hline-0.584712437 & -0.720846897 & -0.819583068 \\
\hline 2.938217275 & 3.103749768 & 3.336745672 \\
\hline 13.81260181 & 11.86750199 & 11.45702368 \\
\hline 6.237142003 & 6.507666967 & 6.456538527 \\
\hline 0.19621467 & 0.257345467 & 0.261787109 \\
\hline 1.000599152 & 1.079721877 & 1.169253046 \\
\hline 6.177871091 & 6.396839898 & 6.447623882 \\
\hline 2.640885106 & 2.702140422 & 2.690760916 \\
\hline-0.19621467 & -0.257345467 & -0.261787109 \\
\hline 1.000599152 & 1.079721877 & 1.169253046 \\
\hline Medium Silt & Medium Silt & Medium Silt \\
\hline Very Poorly Sorted & Very Poorly Sorted & Very Poorly Sorted \\
\hline Coarse Skewed & Coarse Skewed & Coarse Skewed \\
\hline Mesokurtic & Mesokurtic & Leptokurtic \\
\hline 4.7 & 4.7 & 4.7 \\
\hline 1200 & 1200 & 1200 \\
\hline 7.754331413 & 7.754331413 & 7.754331413 \\
\hline-0.242713414 & -0.242713414 & -0.242713414 \\
\hline 1.736436495 & 1.579200045 & 1.626234494 \\
\hline 11.70406494 & 9.528515269 & 9.517449331 \\
\hline 148.2239515 & 143.1627973 & 136.6189271 \\
\hline 85.3609976 & 90.65526416 & 84.00936494 \\
\hline 146.487515 & 141.5835972 & 134.9926926 \\
\hline 12.403464 & 11.58317644 & 10.33733502 \\
\hline 43.6485374 & 35.46792243 & 31.8990747 \\
\hline 2.754149504 & 2.804271457 & 2.871770727 \\
\hline 6.416846511 & 6.713532853 & 6.7152093 \\
\hline 9.169654635 & 9.306590348 & 9.264248983 \\
\hline 3.329396107 & 3.318719493 & 3.225970965 \\
\hline 6.415505132 & 6.502318892 & 6.392478256 \\
\hline 1.826235792 & 1.753978313 & 1.698611058 \\
\hline 3.632671183 & 3.533959032 & 3.3697924 \\
\hline 0.210855447 & 0.187549778 & 0.171495728 \\
\hline 0.789144553 & 0.812450222 & 0.828504272 \\
\hline 0.03660366 & 0.037307461 & 0.045690862 \\
\hline 0.01460146 & 0.018403681 & 0.018196361 \\
\hline 0.00970097 & 0.0105021 & 0.00979804 \\
\hline 0.055405541 & 0.043908782 & 0.030993801 \\
\hline 0.094543816 & 0.077427753 & 0.066816663 \\
\hline 0.10322596 & 0.093361908 & 0.096939575 \\
\hline 0.126555696 & 0.116882804 & 0.124382899 \\
\hline 0.148265452 & 0.147152108 & 0.153397588 \\
\hline 0.156609606 & 0.168002858 & 0.17094159 \\
\hline 0.137092836 & 0.151408284 & 0.152652642 \\
\hline 0.117395003 & 0.135642259 & 0.130189978 \\
\hline
\end{tabular}




\begin{tabular}{|c|c|c|}
\hline $302-2-A-5-X-1$ & $302-2-A-5-X-2$ & $302-4-A-2-X-2$ \\
\hline Cristin Ashmankas, & Cristin Ashmankas, & Cristin Ashmankas, \\
\hline $\begin{array}{l}\text { Trimodal, Very Poorly } \\
\text { Sorted }\end{array}$ & $\begin{array}{l}\text { Bimodal, Very Poorly } \\
\text { Sorted }\end{array}$ & $\begin{array}{l}\text { Unimodal, Very Poorly } \\
\text { Sorted }\end{array}$ \\
\hline Sandy Mud & Sandy Mud & Sandy Mud \\
\hline Fine Sandy Medium Silt & Very Fine Sandy Fine Silt & Very Fine Sandy Fine Silt \\
\hline 86.6341875 & 72.52290881 & 53.90889717 \\
\hline 203.7479528 & 190.2238061 & 201.0177917 \\
\hline 5.194011186 & 5.963583704 & 6.452820568 \\
\hline 35.38838587 & 44.68724233 & 46.74588726 \\
\hline 19.65379173 & 16.41665616 & 10.1280803 \\
\hline 5.773278615 & 5.461905799 & 4.708476608 \\
\hline 0.235022891 & 0.322119949 & 0.755631444 \\
\hline 2.270798665 & 2.427346376 & 3.657522619 \\
\hline 5.63516485 & 5.894482311 & 6.588129356 \\
\hline 2.538339804 & 2.462342414 & 2.262244013 \\
\hline-0.246863884 & -0.338432658 & -0.785616631 \\
\hline 2.28136972 & 2.447335809 & 3.69060703 \\
\hline 19.99338127 & 16.51179616 & 9.746891813 \\
\hline 6.040401947 & 5.619711714 & 4.528507764 \\
\hline 0.101768779 & 0.13953796 & 0.172554501 \\
\hline 0.810327256 & 0.833234666 & 0.982333891 \\
\hline 5.644333709 & 5.920359124 & 6.680842054 \\
\hline 2.594644554 & 2.490496123 & 2.179035731 \\
\hline-0.101768779 & -0.13953796 & -0.172554501 \\
\hline 0.810327256 & 0.833234666 & 0.982333891 \\
\hline Coarse Silt & Coarse Silt & Medium Silt \\
\hline Very Poorly Sorted & Very Poorly Sorted & Very Poorly Sorted \\
\hline Coarse Skewed & Coarse Skewed & Coarse Skewed \\
\hline Platykurtic & Platykurtic & Mesokurtic \\
\hline 9.4 & 6.65 & 4.7 \\
\hline 107.5 & 107.5 & \\
\hline 6.754331413 & 7.254331413 & 7.754331413 \\
\hline 3.236965594 & 3.236965594 & \\
\hline 2.139700922 & 2.012406608 & 1.651223089 \\
\hline 17.33913826 & 13.8289274 & 8.372250357 \\
\hline 222.8012306 & 173.8047594 & 83.64329716 \\
\hline 104.127277 & 86.36662132 & 50.65535828 \\
\hline 220.6615297 & 171.7923528 & 81.99207407 \\
\hline 16.20449541 & 13.99106016 & 7.806207911 \\
\hline 75.49106217 & 57.58985881 & 22.81483243 \\
\hline 2.166170894 & 2.524460506 & 3.579606257 \\
\hline 5.84982399 & 6.176166927 & 6.900168831 \\
\hline 8.868375127 & 8.956862453 & 9.242249236 \\
\hline 4.094033002 & 3.548030335 & 2.581917835 \\
\hline 6.702204234 & 6.432401947 & 5.662642979 \\
\hline 2.105254237 & 1.948985518 & 1.564033084 \\
\hline 4.018322192 & 3.806433381 & 2.964621888 \\
\hline 0.284752121 & 0.248880701 & 0.129827307 \\
\hline 0.715247879 & 0.751119299 & 0.870172693 \\
\hline 0.0179 & 0.016398907 & 0.020646903 \\
\hline 0.0138 & 0.009832678 & 0.008448733 \\
\hline 0.0514 & 0.033031131 & 0.003749438 \\
\hline 0.101 & 0.083461103 & 0.030445433 \\
\hline 0.100652121 & 0.106156883 & 0.066536801 \\
\hline 0.106538245 & 0.103861072 & 0.090152081 \\
\hline 0.128603605 & 0.122495876 & 0.128246978 \\
\hline 0.139078107 & 0.147530387 & 0.169876934 \\
\hline 0.138610248 & 0.155357396 & 0.19129592 \\
\hline 0.115783097 & 0.126626422 & 0.162639575 \\
\hline 0.086634578 & 0.095248145 & 0.127961206 \\
\hline
\end{tabular}




\begin{tabular}{|c|c|c|}
\hline $\begin{array}{c}\text { 302-2-A-6-X-1 } \\
\text { Cristin Ashmankas, }\end{array}$ & $\frac{302-4-C-6-X-1}{\text { Cristin Ashmankas, }}$ & $\begin{array}{c}302-4-\mathrm{A}-2-\mathrm{X}-3 \\
\text { Cristin Ashmankas, }\end{array}$ \\
\hline $\begin{array}{l}\text { Unimodal, Very Poorly } \\
\text { Sorted }\end{array}$ & $\begin{array}{l}\text { Unimodal, Very Poorly } \\
\text { Sorted }\end{array}$ & $\begin{array}{l}\text { Unimodal, Very Poorly } \\
\text { Sorted }\end{array}$ \\
\hline Sandy Mud & Sandy Mud & Sandy Mud \\
\hline Very Fine Sandy Fine Silt & Very Fine Sandy Fine Silt & Very Fine Sandy Fine Silt \\
\hline 61.95497567 & 62.72473318 & 56.26468548 \\
\hline 203.6352946 & 174.5232326 & 190.8372938 \\
\hline 6.275568216 & 6.517327159 & 6.528577614 \\
\hline 45.26784036 & 53.1706772 & 49.33084237 \\
\hline 12.57526997 & 14.52546412 & 11.45319581 \\
\hline 5.029223088 & 5.165056799 & 4.835874538 \\
\hline 0.546398492 & 0.391553046 & 0.646897939 \\
\hline 3.05290265 & 2.581639408 & 3.241288341 \\
\hline 6.268420788 & 6.078033934 & 6.416545556 \\
\hline 2.355371872 & 2.381499421 & 2.293806984 \\
\hline-0.575469009 & -0.408693561 & -0.670589829 \\
\hline 3.085398897 & 2.606643175 & 3.271746462 \\
\hline 12.42655545 & 14.52688894 & 11.20895718 \\
\hline 5.023964637 & 5.2892548 & 4.786073293 \\
\hline 0.153158599 & 0.150453497 & 0.183680891 \\
\hline 0.931418268 & 0.872332957 & 0.971874287 \\
\hline 6.330429743 & 6.105130419 & 6.479204126 \\
\hline 2.328826309 & 2.403064476 & 2.25884249 \\
\hline-0.153158599 & -0.150453497 & -0.183680891 \\
\hline 0.931418268 & 0.872332957 & 0.971874287 \\
\hline Medium Silt & Medium Silt & Medium Silt \\
\hline Very Poorly Sorted & Very Poorly Sorted & Very Poorly Sorted \\
\hline Coarse Skewed & Coarse Skewed & Coarse Skewed \\
\hline Mesokurtic & Platykurtic & Mesokurtic \\
\hline 6.65 & 6.65 & 6.65 \\
\hline 7.254331413 & 7.254331413 & 7.254331413 \\
\hline 1.80023552 & 1.946709252 & 1.780888409 \\
\hline 10.63145239 & 12.19916182 & 9.365245616 \\
\hline 115.6252138 & 145.4973882 & 104.8295976 \\
\hline 64.22782603 & 74.74017399 & 58.86365316 \\
\hline 113.8249783 & 143.550679 & 103.0487092 \\
\hline 9.746182376 & 11.69228152 & 8.44571313 \\
\hline 33.61360064 & 44.30554815 & 27.16367492 \\
\hline 3.112472062 & 2.780934839 & 3.25388199 \\
\hline 6.555517489 & 6.357074163 & 6.738467453 \\
\hline 9.117598622 & 9.004746856 & 9.133187165 \\
\hline 2.929375249 & 3.238028712 & 2.80685876 \\
\hline 6.00512656 & 6.223812017 & 5.879305176 \\
\hline 1.693204382 & 1.812267969 & 1.6131461 \\
\hline 3.284837219 & 3.547484566 & 3.078219245 \\
\hline 0.175609943 & 0.21233127 & 0.156310144 \\
\hline 0.824390057 & 0.78766873 & 0.843689856 \\
\hline 0.021333333 & 0.013399107 & 0.017734516 \\
\hline 0.007366667 & 0.008666089 & 0.008567238 \\
\hline 0.013 & 0.027198187 & 0.010634042 \\
\hline 0.0491 & 0.066628891 & 0.04440296 \\
\hline 0.084809943 & 0.096438997 & 0.074971388 \\
\hline 0.103084552 & 0.106825127 & 0.09149139 \\
\hline 0.13400983 & 0.128568646 & 0.129831692 \\
\hline 0.162935875 & 0.15326458 & 0.16935488 \\
\hline 0.170568064 & 0.162850531 & 0.185765543 \\
\hline 0.141970566 & 0.135659832 & 0.153197512 \\
\hline 0.111821171 & 0.100500012 & 0.114048838 \\
\hline
\end{tabular}




\begin{tabular}{|c|c|c|}
\hline $\begin{array}{c}\text { 302-4-A-3-X-1 } \\
\text { Cristin Ashmankas, }\end{array}$ & $\begin{array}{c}\text { 302-2-A-6-X-1 } \\
\text { Cristin Ashmankas, }\end{array}$ & $\begin{array}{c}\text { 302-4-C-6-X-1 } \\
\text { Cristin Ashmankas, }\end{array}$ \\
\hline $\begin{array}{c}\text { Unimodal, Very Poorly } \\
\text { Sorted }\end{array}$ & $\begin{array}{c}\text { Unimodal, Very Poorly } \\
\text { Sorted }\end{array}$ & $\begin{array}{c}\text { Unimodal, Very Poorly } \\
\text { Sorted }\end{array}$ \\
\hline Sandy Mud & Sandy Mud & Sandy Mud \\
\hline Very Fine Sandy Fine Silt & ery Fine Sandy Medium S & Very Fine Sandy Fine Silt \\
\hline 57.38449267 & 54.24183105 & 54.3304305 \\
\hline 169.7224077 & 189.3556851 & 199.6083858 \\
\hline 6.858126518 & 6.39855573 & 6.478032238 \\
\hline 57.50276839 & 47.75335127 & 47.39859756 \\
\hline 13.72430474 & 11.25663969 & 10.49053412 \\
\hline 4.867219575 & 4.565680154 & 4.676775147 \\
\hline 0.436154052 & 0.69387812 & 0.734973088 \\
\hline 2.79397724 & 3.674626529 & 3.641129305 \\
\hline 6.16420182 & 6.445167398 & 6.535237111 \\
\hline 2.295041512 & 2.20955788 & 2.253265827 \\
\hline-0.45474561 & -0.719967555 & -0.767576871 \\
\hline 2.822087016 & 3.703098437 & 3.67651711 \\
\hline 13.62418863 & 10.46276526 & 10.0263529 \\
\hline 4.945281398 & 4.407323701 & 4.510120126 \\
\hline 0.142086944 & 0.11247415 & 0.152913255 \\
\hline 0.924423115 & 1.061930993 & 0.997031948 \\
\hline 6.197685875 & 6.57859199 & 6.640059271 \\
\hline 2.306052616 & 2.139902861 & 2.17316586 \\
\hline-0.142086944 & -0.11247415 & -0.152913255 \\
\hline 0.924423115 & 1.061930993 & 0.997031948 \\
\hline Medium Silt & Medium Silt & Medium Silt \\
\hline Very Poorly Sorted & Very Poorly Sorted & Very Poorly Sorted \\
\hline Coarse Skewed & Coarse Skewed & Coarse Skewed \\
\hline Mesokurtic & Mesokurtic & Mesokurtic \\
\hline 9.4 & 9.4 & 4.7 \\
\hline 6.754331413 & 6.754331413 & 7.754331413 \\
\hline 1.972406402 & 1.821607794 & 1.706216897 \\
\hline 11.74546037 & 10.03015929 & 8.930977155 \\
\hline 123.5769208 & 77.46353819 & 83.3631207 \\
\hline 62.65286946 & 42.52481707 & 48.85845456 \\
\hline 121.6045144 & 75.6419304 & 81.65690381 \\
\hline 9.633605086 & 7.127033207 & 7.724325127 \\
\hline 36.43776406 & 23.53572431 & 23.30161769 \\
\hline 3.016518763 & 3.690338791 & 3.584446904 \\
\hline 6.411752928 & 6.639511672 & 6.806966253 \\
\hline 8.985827444 & 9.100571916 & 9.194983229 \\
\hline 2.97887338 & 2.466053236 & 2.565244646 \\
\hline 5.96930868 & 5.410233125 & 5.610536325 \\
\hline 1.707328391 & 1.545821838 & 1.564652358 \\
\hline 3.268075784 & 2.833301646 & 2.949408891 \\
\hline 0.18575656 & 0.117623136 & 0.127893064 \\
\hline 0.81424344 & 0.882376864 & 0.872106936 \\
\hline 0.012866667 & 0.016604981 & 0.020366667 \\
\hline 0.007566667 & 0.011603481 & 0.008133333 \\
\hline 0.020566667 & 0.013904171 & 0.007566667 \\
\hline 0.0576 & 0.027008102 & 0.030466667 \\
\hline 0.08715656 & 0.0485024 & 0.06135973 \\
\hline 0.108557659 & 0.103632689 & 0.093797455 \\
\hline 0.140277839 & 0.161861318 & 0.138761996 \\
\hline 0.165310771 & 0.184718618 & 0.174693536 \\
\hline 0.168581262 & 0.178184664 & 0.183861232 \\
\hline 0.133149611 & 0.143856193 & 0.159101624 \\
\hline 0.098366297 & 0.110123382 & 0.121891092 \\
\hline
\end{tabular}




\begin{tabular}{|c|c|c|}
\hline $\begin{array}{c}\text { 302-2-A-6-X-2 } \\
\text { Cristin Ashmankas, }\end{array}$ & $\begin{array}{c}\text { 302-2-A-6-X-2 } \\
\text { Cristin Ashmankas, }\end{array}$ & $\begin{array}{c}\text { 302-4-A-3-X-2 } \\
\text { Cristin Ashmankas, }\end{array}$ \\
\hline $\begin{array}{l}\text { Bimodal, Very Poorly } \\
\text { Sorted }\end{array}$ & $\begin{array}{l}\text { Unimodal, Very Poorly } \\
\text { Sorted }\end{array}$ & $\begin{array}{l}\text { Unimodal, Very Poorly } \\
\text { Sorted }\end{array}$ \\
\hline Sandy Mud & Sandy Mud & Sandy Mud \\
\hline ery Fine Sandy Medium S & ery Fine Sandy Medium S & Very Fine Sandy Fine Silt \\
\hline 76.08885611 & 69.27433943 & 52.3520429 \\
\hline 242.8913614 & 212.2814669 & 199.5646497 \\
\hline 5.212742117 & 5.767523594 & 6.458121005 \\
\hline 31.12447682 & 39.07312449 & 46.95879727 \\
\hline 13.58819995 & 14.01137804 & 9.431140116 \\
\hline 5.289752349 & 5.167061274 & 4.667986575 \\
\hline 0.600827231 & 0.522946718 & 0.842794455 \\
\hline 3.190405017 & 2.96144397 & 3.852457497 \\
\hline 6.137727195 & 6.114400178 & 6.693138486 \\
\hline 2.434489002 & 2.390107555 & 2.250006571 \\
\hline-0.628787748 & -0.546558819 & -0.870648337 \\
\hline 3.192397855 & 2.980418768 & 3.880914025 \\
\hline 13.26199783 & 13.92964598 & 8.941914909 \\
\hline 5.296570252 & 5.180103193 & 4.437482841 \\
\hline 0.154234842 & 0.150292722 & 0.19430859 \\
\hline 0.987036656 & 0.948320264 & 1.009959203 \\
\hline 6.236558065 & 6.165697597 & 6.805200467 \\
\hline 2.405058457 & 2.372980838 & 2.149741541 \\
\hline-0.154234842 & -0.150292722 & -0.19430859 \\
\hline 0.987036656 & 0.948320264 & 1.009959203 \\
\hline Medium Silt & Medium Silt & Medium Silt \\
\hline Very Poorly Sorted & Very Poorly Sorted & Very Poorly Sorted \\
\hline Coarse Skewed & Coarse Skewed & Coarse Skewed \\
\hline Mesokurtic & Mesokurtic & Mesokurtic \\
\hline 9.4 & 9.4 & 4.7 \\
\hline 1200 & & \\
\hline 6.754331413 & 6.754331413 & 7.754331413 \\
\hline-0.242713414 & & \\
\hline 1.869525715 & 1.943986984 & 1.604423998 \\
\hline 11.68341415 & 11.95257934 & 7.616762528 \\
\hline 123.1215951 & 138.8272721 & 76.47904085 \\
\hline 65.8571284 & 71.41368393 & 47.66759969 \\
\hline 121.2520693 & 136.8832851 & 74.87461685 \\
\hline 9.893317026 & 9.831948573 & 7.369315204 \\
\hline 36.26349807 & 37.0326164 & 20.18479643 \\
\hline 3.021844268 & 2.848637087 & 3.70879176 \\
\hline 6.419394266 & 6.386534208 & 7.036606368 \\
\hline 9.063111969 & 9.006765725 & 9.283728835 \\
\hline 2.999198889 & 3.161780686 & 2.503167995 \\
\hline 6.041267702 & 6.158128638 & 5.574937075 \\
\hline 1.713889467 & 1.71679396 & 1.531628592 \\
\hline 3.306454308 & 3.29747737 & 2.881530563 \\
\hline 0.182771581 & 0.191406885 & 0.118374141 \\
\hline 0.817228419 & 0.808593115 & 0.881625859 \\
\hline 0.03109689 & 0.02240224 & 0.019967332 \\
\hline 0.01269873 & 0.01020102 & 0.009166972 \\
\hline 0.01149885 & 0.01890189 & 0.005000167 \\
\hline 0.0429957 & 0.058105811 & 0.026200873 \\
\hline 0.08448141 & 0.081795923 & 0.058038796 \\
\hline 0.110827498 & 0.104006142 & 0.084189491 \\
\hline 0.140117051 & 0.14218185 & 0.123536861 \\
\hline 0.163135243 & 0.165672782 & 0.1668344 \\
\hline 0.16310139 & 0.163138206 & 0.197722175 \\
\hline 0.133985644 & 0.132915852 & 0.174383173 \\
\hline 0.106061593 & 0.100678283 & 0.134959759 \\
\hline
\end{tabular}




\begin{tabular}{|c|c|c|}
\hline $302-2-A-6-X-3$ & $302-2-A-6-X-3$ & $302-2-A-6-X-4$ \\
\hline Cristin Ashmankas, & Cristin Ashmankas, & Cristin Ashmankas, \\
\hline $\begin{array}{c}\text { Bimodal, Very Poorly } \\
\text { Sorted }\end{array}$ & $\begin{array}{c}\text { Bimodal, Very Poorly } \\
\text { Sorted }\end{array}$ & $\begin{array}{l}\text { Bimodal, Very Poorly } \\
\text { Sorted }\end{array}$ \\
\hline Sandy Mud & Sandy Mud & Sandy Mud \\
\hline Very Fine Sandy Fine Silt & Very Fine Sandy Fine Silt & Very Fine Sandy Fine Silt \\
\hline 84.09688731 & 84.10180604 & 89.71565437 \\
\hline 271.219425 & 250.2093489 & 268.6675401 \\
\hline 4.836702795 & 4.89207584 & 4.600769162 \\
\hline 26.47184459 & 27.93944008 & 24.59954167 \\
\hline 12.84923618 & 14.47020509 & 14.12772749 \\
\hline 5.626341795 & 5.714326476 & 5.840590797 \\
\hline 0.682586552 & 0.538038632 & 0.611011266 \\
\hline 3.235865422 & 2.87584215 & 2.986052035 \\
\hline 6.170567965 & 6.05095817 & 6.068605575 \\
\hline 2.54727409 & 2.540565935 & 2.5797633 \\
\hline-0.709589229 & -0.555543226 & -0.627235266 \\
\hline 3.194391944 & 2.873412465 & 2.964221464 \\
\hline 12.7082187 & 14.23384654 & 13.81846147 \\
\hline 6.19057664 & 5.915286631 & 6.364873089 \\
\hline 0.222768314 & 0.175931087 & 0.220136859 \\
\hline 1.092336192 & 0.954331909 & 1.047177159 \\
\hline 6.298094367 & 6.134530603 & 6.177259193 \\
\hline 2.6300738 & 2.564448077 & 2.670131748 \\
\hline-0.222768314 & -0.175931087 & -0.220136859 \\
\hline 1.092336192 & 0.954331909 & 1.047177159 \\
\hline Medium Silt & Medium Silt & Medium Silt \\
\hline Very Poorly Sorted & Very Poorly Sorted & Very Poorly Sorted \\
\hline Coarse Skewed & Coarse Skewed & Coarse Skewed \\
\hline Mesokurtic & Mesokurtic & Mesokurtic \\
\hline 4.7 & 6.65 & 6.65 \\
\hline 1700 & 1200 & 1200 \\
\hline 7.754331413 & 7.254331413 & 7.254331413 \\
\hline-0.742713414 & -0.242713414 & -0.242713414 \\
\hline 1.745829817 & 1.795706426 & 1.778658797 \\
\hline 10.84080894 & 12.04472111 & 11.52490942 \\
\hline 138.3046404 & 156.8381678 & 161.2130901 \\
\hline 79.22000133 & 87.34065076 & 90.63744569 \\
\hline 136.5588106 & 155.0424614 & 159.4344313 \\
\hline 10.80033388 & 12.16582604 & 11.88078895 \\
\hline 36.26707528 & 44.22853858 & 42.17932944 \\
\hline 2.854078532 & 2.672651401 & 2.632959203 \\
\hline 6.527383775 & 6.375455201 & 6.439100777 \\
\hline 9.161871352 & 9.121232777 & 9.134994502 \\
\hline 3.210097848 & 3.412803021 & 3.46947818 \\
\hline 6.30779282 & 6.448581375 & 6.502035299 \\
\hline 1.739071528 & 1.82392039 & 1.804094315 \\
\hline 3.433004007 & 3.604762376 & 3.570558738 \\
\hline 0.185495833 & 0.212609244 & 0.206884105 \\
\hline 0.814504167 & 0.787390756 & 0.793115895 \\
\hline 0.04219578 & 0.032209663 & 0.038192362 \\
\hline 0.01129887 & 0.015104531 & 0.016796641 \\
\hline 0.01239876 & 0.016304891 & 0.015596881 \\
\hline 0.04109589 & 0.057917375 & 0.050689862 \\
\hline 0.078506532 & 0.091072783 & 0.08560836 \\
\hline 0.103986227 & 0.105201695 & 0.103292391 \\
\hline 0.131955327 & 0.128413173 & 0.126529202 \\
\hline 0.153837105 & 0.149295414 & 0.150912059 \\
\hline 0.162073545 & 0.157643101 & 0.160661347 \\
\hline 0.145463157 & 0.134827146 & 0.138060365 \\
\hline 0.117188806 & 0.112010228 & 0.113660532 \\
\hline
\end{tabular}




\begin{tabular}{|c|c|c|}
\hline $\begin{array}{c}\text { 302-2-A-7-X-1 } \\
\text { Cristin Ashmankas, }\end{array}$ & $\begin{array}{c}\text { 302-2-A-7-X-1 } \\
\text { Cristin Ashmankas, }\end{array}$ & $\begin{array}{c}\text { 302-2-A-7-X-2 } \\
\text { Cristin Ashmankas, }\end{array}$ \\
\hline $\begin{array}{c}\text { Bimodal, Very Poorly } \\
\text { Sorted }\end{array}$ & $\begin{array}{c}\text { Bimodal, Very Poorly } \\
\text { Sorted }\end{array}$ & $\begin{array}{c}\text { Bimodal, Very Poorly } \\
\text { Sorted }\end{array}$ \\
\hline Sandy Mud & Sandy Mud & Sandy Mud \\
\hline Very Fine Sandy Fine Silt & Very Fine Sandy Fine Silt & Very Fine Sandy Fine Silt \\
\hline 79.5504781 & 69.10304933 & 87.23502 \\
\hline 223.2105209 & 196.6291866 & 273.6091518 \\
\hline 5.503740214 & 6.028714685 & 4.572383802 \\
\hline 35.70524761 & 44.11865127 & 24.00509614 \\
\hline 16.97014704 & 14.54456762 & 12.83672045 \\
\hline 5.502300406 & 5.386032533 & 5.712595395 \\
\hline 0.31765232 & 0.444983912 & 0.727607307 \\
\hline 2.586147256 & 2.611672502 & 3.266312838 \\
\hline 5.828027901 & 6.067498957 & 6.207831987 \\
\hline 2.478680779 & 2.445452055 & 2.551909465 \\
\hline-0.341113385 & -0.46231904 & -0.743011922 \\
\hline 2.60626742 & 2.63189011 & 3.23016816 \\
\hline 16.99423779 & 14.73568748 & 12.48855926 \\
\hline 5.542194416 & 5.52401587 & 6.306211895 \\
\hline 0.08628214 & 0.183986938 & 0.254527812 \\
\hline 0.844374725 & 0.868219289 & 1.126791302 \\
\hline 5.878810533 & 6.08454182 & 6.32324914 \\
\hline 2.47045732 & 2.465717464 & 2.656773647 \\
\hline-0.08628214 & -0.183986938 & -0.254527812 \\
\hline 0.844374725 & 0.868219289 & 1.126791302 \\
\hline Coarse Silt & Medium Silt & Medium Silt \\
\hline Very Poorly Sorted & Very Poorly Sorted & Very Poorly Sorted \\
\hline Symmetrical & Coarse Skewed & Coarse Skewed \\
\hline Platykurtic & Platykurtic & Leptokurtic \\
\hline 9.4 & 6.65 & 6.65 \\
\hline 107.5 & 107.5 & 1200 \\
\hline 6.754331413 & 7.254331413 & 7.254331413 \\
\hline 3.236965594 & 3.236965594 & -0.242713414 \\
\hline 2.017714595 & 1.912040045 & 1.731081772 \\
\hline 15.37677952 & 11.67176618 & 10.18651111 \\
\hline 164.5005478 & 160.7390133 & 137.8700499 \\
\hline 81.52815476 & 84.06676091 & 79.64386899 \\
\hline 162.4828332 & 158.8269733 & 136.1389681 \\
\hline 13.4822698 & 12.34538295 & 10.42207223 \\
\hline 57.81056498 & 46.30982885 & 34.81721374 \\
\hline 2.603835707 & 2.637207963 & 2.858619007 \\
\hline 6.02310281 & 6.420833303 & 6.617196178 \\
\hline 8.953062164 & 9.030671546 & 9.174110409 \\
\hline 3.438412854 & 3.424330455 & 3.209280561 \\
\hline 6.349226458 & 6.393463582 & 6.315491402 \\
\hline 1.937933686 & 1.841144981 & 1.719708198 \\
\hline 3.752991496 & 3.625899684 & 3.381570253 \\
\hline 0.249848603 & 0.22216336 & 0.185833071 \\
\hline 0.750151397 & 0.77783664 & 0.814166929 \\
\hline 0.025705141 & 0.0184 & 0.03980398 \\
\hline 0.00940188 & 0.008333333 & 0.0170017 \\
\hline 0.020804161 & 0.026633333 & 0.00780078 \\
\hline 0.079715943 & 0.076333333 & 0.04270427 \\
\hline 0.114221477 & 0.09246336 & 0.07852234 \\
\hline 0.116141567 & 0.094158046 & 0.094720672 \\
\hline 0.130798967 & 0.121876757 & 0.125477571 \\
\hline 0.143497957 & 0.155488878 & 0.158038481 \\
\hline 0.14493877 & 0.166829917 & 0.17280517 \\
\hline 0.119712138 & 0.136541668 & 0.144918444 \\
\hline 0.095062 & 0.102941 .373 & 0.118206592 \\
\hline
\end{tabular}




\begin{tabular}{|c|c|c|}
\hline 302-2-A-7-X-2 & $\begin{array}{c}302-2-\mathrm{A}-7-\mathrm{X}-3 \\
\text { Cristin }\end{array}$ & $\frac{302-2-A-8-X-1}{\text { Cristin }}$ \\
\hline cristin Asnmankas, & cristin Asnmankas, & Cristin Ashmankas, \\
\hline $\begin{array}{c}\text { Unimodal, Very Poorly } \\
\text { Sorted }\end{array}$ & $\begin{array}{c}\text { Unimodal, Very Poorly } \\
\text { Sorted }\end{array}$ & $\begin{array}{c}\text { Unimodal, Very Poorly } \\
\text { Sorted }\end{array}$ \\
\hline Sandy Mud & Sandy Mud & Sandy Mud \\
\hline Very Fine Sandy Fine Silt & Very Fine Sandy Fine Silt & Very Fine Sandy Fine Silt \\
\hline 68.5259711 & 75.0213261 & 71.65526903 \\
\hline 225.9282114 & 226.3804777 & 226.3328236 \\
\hline 5.602261577 & 5.48054292 & 5.485839988 \\
\hline 35.96980929 & 34.93815606 & 34.87250946 \\
\hline 12.68493746 & 14.75460607 & 13.39090672 \\
\hline 5.09522346 & 5.392857592 & 5.24496696 \\
\hline 0.633988863 & 0.454009798 & 0.584405569 \\
\hline 3.27213263 & 2.833661823 & 3.081251352 \\
\hline 6.245922488 & 6.030884251 & 6.171771956 \\
\hline 2.379067244 & 2.453828315 & 2.416611376 \\
\hline-0.66351973 & -0.477918915 & -0.608896067 \\
\hline 3.285886393 & 2.850547943 & 3.093340742 \\
\hline 12.31819983 & 14.65589966 & 13.1303787 \\
\hline 4.994776937 & 5.399784322 & 5.213763304 \\
\hline 0.156902985 & 0.120682301 & 0.171831308 \\
\hline 0.970711843 & 0.896561727 & 0.948824176 \\
\hline 6.343064752 & 6.092374659 & 6.250947663 \\
\hline 2.32042025 & 2.432901784 & 2.382325088 \\
\hline-0.156902985 & -0.120682301 & -0.171831308 \\
\hline 0.970711843 & 0.896561727 & 0.948824176 \\
\hline Medium Silt & Medium Silt & Medium Silt \\
\hline Very Poorly Sorted & Very Poorly Sorted & Very Poorly Sorted \\
\hline Coarse Skewed & Coarse Skewed & Coarse Skewed \\
\hline Mesokurtic & Platykurtic & Mesokurtic \\
\hline 6.65 & 9.4 & 6.65 \\
\hline 7.254331413 & 6.754331413 & 7.254331413 \\
\hline 1.845860804 & 1.878161484 & 1.872137361 \\
\hline 10.74279935 & 12.91563161 & 11.07279897 \\
\hline 113.1504264 & 142.5542828 & 124.8011285 \\
\hline 61.29954444 & 75.90097232 & 66.66237804 \\
\hline 111.3045656 & 140.6761214 & 122.9289911 \\
\hline 9.252849672 & 11.61213212 & 10.13204439 \\
\hline 32.2615834 & 44.4324801 & 36.57019958 \\
\hline 3.143686074 & 2.810416711 & 3.002297115 \\
\hline 6.540486211 & 6.274737993 & 6.496836239 \\
\hline 9.081490521 & 9.056463173 & 9.061097994 \\
\hline 2.888803242 & 3.222462753 & 3.018055058 \\
\hline 5.937804447 & 6.246046462 & 6.058800878 \\
\hline 1.670260026 & 1.810935103 & 1.72261664 \\
\hline 3.209897752 & 3.537560987 & 3.340853397 \\
\hline 0.167840046 & 0.211459719 & 0.186464107 \\
\hline 0.832159954 & 0.788540281 & 0.813535893 \\
\hline 0.02640264 & 0.026292112 & 0.0260026 \\
\hline 0.01190119 & 0.011196641 & 0.01260126 \\
\hline 0.01080108 & 0.014895531 & 0.01340134 \\
\hline 0.04040404 & 0.060981705 & 0.04780478 \\
\hline 0.078331095 & 0.098093729 & 0.086654126 \\
\hline 0.106547942 & 0.112369278 & 0.105669234 \\
\hline 0.139613845 & 0.135807985 & 0.132187691 \\
\hline 0.164760114 & 0.151419174 & 0.160547117 \\
\hline 0.171419937 & 0.154260709 & 0.171215724 \\
\hline 0.141720944 & 0.129350504 & 0.138028472 \\
\hline 0.108097172 & 0.105332632 & 0.105887656 \\
\hline
\end{tabular}




\begin{tabular}{|c|c|c|}
\hline $\begin{array}{c}\text { 302-2-A-8-X-1 } \\
\text { Cristin Ashmankas }\end{array}$ & $\begin{array}{c}\text { 302-2-A-8-X-2 } \\
\text { Cristin Ashmankas, }\end{array}$ & $\begin{array}{c}\text { 302-2-A-8-X-3 } \\
\text { Cristin Ashmankas, }\end{array}$ \\
\hline $\begin{array}{l}\text { Trimodal, Very Poorly } \\
\text { Sorted }\end{array}$ & $\begin{array}{l}\text { Unimodal, Very Poorly } \\
\text { Sorted }\end{array}$ & $\begin{array}{l}\text { Bimodal, Very Poorly } \\
\text { Sorted }\end{array}$ \\
\hline Sandy Mud & Sandy Mud & Sandy Mud \\
\hline Very Fine Sandy Fine Silt & Very Fine Sandy Fine Silt & Very Fine Sandy Fine Silt \\
\hline 91.6820027 & 57.66341377 & 76.34648144 \\
\hline 257.6503323 & 179.6049321 & 239.1107587 \\
\hline 4.662474476 & 7.076388939 & 5.204300486 \\
\hline 25.66913885 & 57.97763803 & 31.26602062 \\
\hline 15.97739366 & 14.15220882 & 13.83596227 \\
\hline 5.983577184 & 4.814420241 & 5.337933651 \\
\hline 0.447619167 & 0.367003389 & 0.575132509 \\
\hline 2.657752572 & 2.777445763 & 3.094698357 \\
\hline 5.906030063 & 6.109279712 & 6.118611188 \\
\hline 2.603749384 & 2.284214357 & 2.443504064 \\
\hline-0.461887593 & -0.396130185 & -0.599667792 \\
\hline 2.655538095 & 2.821478388 & 3.09964644 \\
\hline 15.71331008 & 14.23416336 & 13.49972456 \\
\hline 6.387426601 & 4.831397677 & 5.356547264 \\
\hline 0.171939686 & 0.106934066 & 0.161044805 \\
\hline 0.928997699 & 0.858919619 & 0.965385249 \\
\hline 5.991869067 & 6.134498492 & 6.210926218 \\
\hline 2.675234808 & 2.272440607 & 2.421303365 \\
\hline-0.171939686 & -0.106934066 & -0.161044805 \\
\hline 0.928997699 & 0.858919619 & 0.965385249 \\
\hline Coarse Silt & Medium Silt & Medium Silt \\
\hline Very Poorly Sorted & Very Poorly Sorted & Very Poorly Sorted \\
\hline Coarse Skewed & Coarse Skewed & Coarse Skewed \\
\hline Mesokurtic & Platykurtic & Mesokurtic \\
\hline 4.7 & 9.4 & 6.65 \\
\hline 107.5 & & 1200 \\
\hline 7.754331413 & 6.754331413 & 7.254331413 \\
\hline 3.236965594 & & -0.242713414 \\
\hline 1.824888617 & 2.008626312 & 1.872426963 \\
\hline 13.40530038 & 12.49875185 & 11.68874702 \\
\hline 173.8216332 & 117.4035188 & 125.2080836 \\
\hline 95.25054381 & 58.44965692 & 66.86940856 \\
\hline 171.9967446 & 115.3948925 & 123.3356566 \\
\hline 14.76665423 & 10.4385176 & 10.424524 \\
\hline 56.64947473 & 41.13817158 & 38.53946723 \\
\hline 2.524320449 & 3.090452445 & 2.997600388 \\
\hline 6.221052643 & 6.322072158 & 6.418735902 \\
\hline 9.097975873 & 8.959575097 & 9.06087484 \\
\hline 3.604128737 & 2.899114371 & 3.02270939 \\
\hline 6.573655424 & 5.869122652 & 6.063274452 \\
\hline 1.961303663 & 1.759034027 & 1.742945415 \\
\hline 3.884271077 & 3.383844941 & 3.381909604 \\
\hline 0.24581 & 0.198902427 & 0.1908782 \\
\hline 0.75419 & 0.801097573 & 0.8091218 \\
\hline 0.03390339 & 0.016365576 & 0.029408823 \\
\hline 0.01770177 & 0.005032998 & 0.014204261 \\
\hline 0.01730173 & 0.008932738 & 0.011503451 \\
\hline 0.069706971 & 0.059929338 & 0.045013504 \\
\hline 0.107196138 & 0.108641778 & 0.090748161 \\
\hline 0.104986547 & 0.114677125 & 0.111361553 \\
\hline 0.119663102 & 0.136292452 & 0.133966913 \\
\hline 0.140162313 & 0.161832073 & 0.159387262 \\
\hline 0.150705755 & 0.1636733 & 0.165158398 \\
\hline 0.129295787 & 0.129137619 & 0.13344639 \\
\hline 0.109376497 & 0.095485003 & 0.105801284 \\
\hline
\end{tabular}




\begin{tabular}{|c|c|c|}
\hline $302-2-A-9-X-1$ & $302-2-A-9-X-1$ & $302-2-A-9-X-2$ \\
\hline Cristin Ashmankas, & Cristin Ashmankas, & Cristin Ashmankas, \\
\hline $\begin{array}{c}\text { Bimodal, Very Poorly } \\
\text { Sorted }\end{array}$ & $\begin{array}{c}\text { Unimodal, Very Poorly } \\
\text { Sorted }\end{array}$ & $\begin{array}{c}\text { Unimodal, Very Poorly } \\
\text { Sorted }\end{array}$ \\
\hline Sandy Mud & Sandy Mud & Sandy Mud \\
\hline Very Fine Sandy Fine Silt & Very Fine Sandy Fine Silt & Very Fine Sandy Fine Silt \\
\hline 75.2958955 & 68.0956995 & 57.11235126 \\
\hline 198.5215139 & 219.7964266 & 201.5287364 \\
\hline 5.816627837 & 5.551754068 & 6.382170159 \\
\hline 41.50105573 & 36.07061838 & 46.48627842 \\
\hline 17.49422158 & 12.28940592 & 11.34131872 \\
\hline 5.429419722 & 5.109097564 & 4.696354404 \\
\hline 0.258860958 & 0.716280838 & 0.710168218 \\
\hline 2.440640146 & 3.325472443 & 3.5552873 \\
\hline 5.803094051 & 6.299601828 & 6.419087042 \\
\hline 2.452391884 & 2.379595014 & 2.259573636 \\
\hline-0.275822531 & -0.739233734 & -0.7442348 \\
\hline 2.460219776 & 3.331765858 & 3.58786726 \\
\hline 17.41668009 & 11.95950505 & 10.90639808 \\
\hline 5.495430569 & 5.080730438 & 4.580596003 \\
\hline 0.08695888 & 0.205581641 & 0.164441145 \\
\hline 0.814759673 & 1.049430575 & 1.030527119 \\
\hline 5.843386541 & 6.385698506 & 6.518681471 \\
\hline 2.458232521 & 2.345035923 & 2.195535326 \\
\hline-0.08695888 & -0.205581641 & -0.164441145 \\
\hline 0.814759673 & 1.049430575 & 1.030527119 \\
\hline Coarse Silt & Medium Silt & Medium Silt \\
\hline Very Poorly Sorted & Very Poorly Sorted & Very Poorly Sorted \\
\hline Symmetrical & Coarse Skewed & Coarse Skewed \\
\hline Platykurtic & Mesokurtic & Mesokurtic \\
\hline 9.4 & 9.4 & 6.65 \\
\hline \multicolumn{3}{|l|}{107.5} \\
\hline 6.754331413 & 6.754331413 & 7.254331413 \\
\hline \multicolumn{3}{|l|}{3.236965594} \\
\hline 2.063105221 & 1.860670141 & 1.843840032 \\
\hline 15.55348606 & 9.951941324 & 9.611791409 \\
\hline 166.4039613 & 124.3264428 & 92.71348729 \\
\hline 80.65704048 & 66.81809962 & 50.28282588 \\
\hline 164.3408561 & 122.4657727 & 90.86964726 \\
\hline 14.19774091 & 8.251087333 & 7.545113709 \\
\hline 62.45921275 & 28.00977617 & 24.89101803 \\
\hline 2.587238317 & 3.007794921 & 3.431076963 \\
\hline 6.006618216 & 6.650806305 & 6.700978945 \\
\hline 8.920966882 & 9.069961967 & 9.083070789 \\
\hline 3.448065384 & 3.015485499 & 2.647294388 \\
\hline 6.333728565 & 6.062167046 & 5.651993826 \\
\hline 1.98254892 & 1.61240279 & 1.569096622 \\
\hline 3.827589487 & 3.044584251 & 2.915542643 \\
\hline 0.262067555 & 0.165099054 & 0.138063683 \\
\hline 0.737932445 & 0.834900946 & 0.861936317 \\
\hline 0.0184 & 0.0238 & 0.02069793 \\
\hline 0.0107 & 0.0137 & 0.00806586 \\
\hline 0.0245 & 0.0165 & 0.01253208 \\
\hline 0.0872 & 0.0455 & 0.0343299 \\
\hline 0.121267555 & 0.065599054 & 0.062437912 \\
\hline 0.111329692 & 0.087672505 & 0.096035689 \\
\hline 0.12570045 & 0.134387011 & 0.142174419 \\
\hline 0.144257147 & 0.178109635 & 0.180233951 \\
\hline 0.146611645 & 0.182018632 & 0.1868928 \\
\hline 0.11819495 & 0.145721047 & 0.148214345 \\
\hline 0.091838561 & 0.106992116 & 0.108385113 \\
\hline
\end{tabular}




\begin{tabular}{|c|c|c|}
\hline $302-2-A-9-X-2$ & $302-2-A-9-X-3$ & $302-2-A-10-X-1$ \\
\hline Cristin Ashmankas, & Cristin Ashmankas, & Cristin Ashmankas, \\
\hline $\begin{array}{l}\text { Bimodal, Very Poorly } \\
\text { Sorted }\end{array}$ & $\begin{array}{l}\text { Bimodal, Very Poorly } \\
\text { Sorted }\end{array}$ & $\begin{array}{l}\text { Bimodal, Very Poorly } \\
\text { Sorted }\end{array}$ \\
\hline Sandy Mud & Sandy Mud & Sandy Mud \\
\hline Very Fine Sandy Fine Silt & Very Fine Sandy Fine Silt & Very Fine Sandy Fine Silt \\
\hline 83.90004899 & 91.00421608 & 81.11429693 \\
\hline 238.1522131 & 265.8862042 & 251.7342512 \\
\hline 5.072943012 & 4.529427899 & 4.914930157 \\
\hline 30.51450343 & 24.22861745 & 28.00451113 \\
\hline 16.01738729 & 13.88421337 & 13.1671029 \\
\hline 5.675919352 & 5.99765985 & 5.584452632 \\
\hline 0.418869391 & 0.634205973 & 0.663799726 \\
\hline 2.695839011 & 2.922242005 & 3.116662365 \\
\hline 5.906433138 & 6.101653712 & 6.184127519 \\
\hline 2.526730142 & 2.614898625 & 2.512413245 \\
\hline-0.438752569 & -0.645120829 & -0.681825555 \\
\hline 2.703937476 & 2.899568975 & 3.104335702 \\
\hline 15.943566 & 13.70968694 & 12.93170563 \\
\hline 5.818687999 & 6.505181952 & 5.795107448 \\
\hline 0.126876337 & 0.243027925 & 0.2233963 \\
\hline 0.90766927 & 1.042998168 & 1.020292454 \\
\hline 5.970881846 & 6.188660562 & 6.272943617 \\
\hline 2.54069389 & 2.70158941 & 2.534835411 \\
\hline-0.126876337 & -0.243027925 & -0.2233963 \\
\hline 0.90766927 & 1.042998168 & 1.020292454 \\
\hline Coarse Silt & Medium Silt & Medium Silt \\
\hline Very Poorly Sorted & Very Poorly Sorted & Very Poorly Sorted \\
\hline Coarse Skewed & Coarse Skewed & Coarse Skewed \\
\hline Mesokurtic & Mesokurtic & Mesokurtic \\
\hline 9.4 & 4.7 & 6.65 \\
\hline 1200 & 1200 & 1200 \\
\hline 6.754331413 & 7.754331413 & 7.254331413 \\
\hline-0.242713414 & -0.242713414 & -0.242713414 \\
\hline 1.902350082 & 1.726713534 & 1.780480329 \\
\hline 14.06474528 & 10.85460479 & 10.47129642 \\
\hline 170.3637127 & 183.662474 & 144.8223773 \\
\hline 89.55434351 & 106.3653411 & 81.33893702 \\
\hline 168.4613626 & 181.9357605 & 143.041897 \\
\hline 12.84662211 & 11.85864722 & 10.50891013 \\
\hline 51.36373309 & 40.51108653 & 36.10949945 \\
\hline 2.553310019 & 2.44487121 & 2.787643556 \\
\hline 6.151772765 & 6.52554899 & 6.57741612 \\
\hline 9.038001521 & 9.177755528 & 9.133517788 \\
\hline 3.5397196 & 3.753880978 & 3.276429573 \\
\hline 6.484691501 & 6.732884318 & 6.345874232 \\
\hline 1.884096662 & 1.793133639 & 1.730230896 \\
\hline 3.683317162 & 3.567867538 & 3.393541151 \\
\hline 0.232257919 & 0.207460443 & 0.191229171 \\
\hline 0.767742081 & 0.792539557 & 0.808770829 \\
\hline 0.028691393 & 0.03619638 & 0.03280328 \\
\hline 0.014295711 & 0.01879812 & 0.01520152 \\
\hline 0.023193042 & 0.02219778 & 0.01420142 \\
\hline 0.067179846 & 0.055594441 & 0.04990499 \\
\hline 0.098897927 & 0.074673722 & 0.07911796 \\
\hline 0.112467103 & 0.092942084 & 0.094525092 \\
\hline 0.133612871 & 0.123851812 & 0.126175311 \\
\hline 0.146427658 & 0.151121074 & 0.159139057 \\
\hline 0.147166098 & 0.164070551 & 0.172309312 \\
\hline 0.124543586 & 0.141974221 & 0.143020794 \\
\hline 0.103524765 & 0.118579815 & 0.113601263 \\
\hline
\end{tabular}




\begin{tabular}{|c|c|c|}
\hline 302-2-A-9-X-5 & 302-2-A-10-X-1 & 302-2-A-10-X-2 \\
\hline $\begin{array}{c}\text { Bimodal, Very Poorly } \\
\text { Sorted }\end{array}$ & $\begin{array}{c}\text { Bimodal, Very Poorly } \\
\text { Sorted }\end{array}$ & $\begin{array}{c}\text { Bimodal, Very Poorly } \\
\text { Sorted }\end{array}$ \\
\hline Sandy Mud & Sandy Mud & Sandy Mud \\
\hline Very Fine Sandy Fine Silt & Very Fine Sandy Fine Silt & Very Fine Sandy Fine Silt \\
\hline 84.53965157 & 68.92612461 & 61.06718511 \\
\hline 244.3538177 & 204.2158086 & 153.7813023 \\
\hline 5.012033392 & 5.799017386 & 7.042427304 \\
\hline 29.46019905 & 40.2234194 & 63.92992388 \\
\hline 15.78382794 & 14.41742668 & 16.79680604 \\
\hline 5.657296589 & 5.192440082 & 5.007972753 \\
\hline 0.448045357 & 0.481880561 & 0.182564339 \\
\hline 2.75221969 & 2.848027623 & 2.352154856 \\
\hline 5.923633548 & 6.080162093 & 5.880722082 \\
\hline 2.524006699 & 2.393191498 & 2.330041477 \\
\hline-0.468975621 & -0.501914423 & -0.194247159 \\
\hline 2.757654624 & 2.8670099 & 2.371046036 \\
\hline 15.69092644 & 14.36517504 & 16.74691253 \\
\hline 5.756446956 & 5.234293837 & 5.136050028 \\
\hline 0.138707301 & 0.150514637 & 0.049889621 \\
\hline 0.90657107 & 0.924938618 & 0.806912275 \\
\hline 5.993925654 & 6.121280618 & 5.899961046 \\
\hline 2.525178614 & 2.387994915 & 2.360659255 \\
\hline-0.138707301 & -0.150514637 & -0.049889621 \\
\hline 0.90657107 & 0.924938618 & 0.806912275 \\
\hline Coarse Silt & Medium Silt & Coarse Silt \\
\hline Very Poorly Sorted & Very Poorly Sorted & Very Poorly Sorted \\
\hline Coarse Skewed & Coarse Skewed & Symmetrical \\
\hline Mesokurtic & Mesokurtic & Platykurtic \\
\hline 9.4 & 9.4 & 4.7 \\
\hline 1200 & 107.5 & 107.5 \\
\hline 6.754331413 & 6.754331413 & 7.754331413 \\
\hline-0.242713414 & 3.236965594 & 3.236965594 \\
\hline 1.923687223 & 1.962945208 & 2.103165292 \\
\hline 13.6512191 & 12.20799617 & 15.74313694 \\
\hline 164.2478236 & 140.8817328 & 142.5166855 \\
\hline 85.38177183 & 71.77058853 & 67.76295046 \\
\hline 162.3241363 & 138.9187876 & 140.4135202 \\
\hline 12.76571538 & 10.38858587 & 12.93780002 \\
\hline 50.70719294 & 39.91443452 & 55.58763584 \\
\hline 2.606053841 & 2.827443535 & 2.810797259 \\
\hline 6.194826395 & 6.356029775 & 5.989133152 \\
\hline 9.021910038 & 8.992764381 & 8.893222046 \\
\hline 3.461904698 & 3.180528371 & 3.163950021 \\
\hline 6.415856196 & 6.165320846 & 6.082424787 \\
\hline 1.878159576 & 1.750273898 & 1.911297025 \\
\hline 3.674202483 & 3.376927378 & 3.693520413 \\
\hline 0.230285979 & 0.201532316 & 0.243323033 \\
\hline 0.769714021 & 0.798467684 & 0.756676967 \\
\hline 0.030893821 & 0.01970197 & 0.00963237 \\
\hline 0.013797241 & 0.01230123 & 0.00683265 \\
\hline 0.018996201 & 0.01950195 & 0.02143119 \\
\hline 0.065586883 & 0.060206021 & 0.079425391 \\
\hline 0.101011834 & 0.089821145 & 0.126001432 \\
\hline 0.111599312 & 0.104202385 & 0.126695469 \\
\hline 0.130308651 & 0.138271064 & 0.131424548 \\
\hline 0.147728998 & 0.162467338 & 0.139727541 \\
\hline 0.15137578 & 0.163133082 & 0.146044765 \\
\hline 0.126663651 & 0.131220108 & 0.124376012 \\
\hline 0.102037628 & 0.099173707 & 0.088408632 \\
\hline
\end{tabular}




\begin{tabular}{|c|c|c|}
\hline $302-2-A-10-X-2$ & $302-2-A-10-X-3$ & $302-2-A-11-X-1$ \\
\hline Cristin Ashmankas, & Cristin Ashmankas, & Cristin Ashmankas, \\
\hline $\begin{array}{l}\text { Bimodal, Very Poorly } \\
\text { Sorted }\end{array}$ & $\begin{array}{l}\text { Bimodal, Very Poorly } \\
\text { Sorted }\end{array}$ & $\begin{array}{l}\text { Trimodal, Very Poorly } \\
\text { Sorted }\end{array}$ \\
\hline Sandy Mud & Sandy Mud & Sandy Mud \\
\hline Very Fine Sandy Fine Silt & Very Fine Sandy Fine Silt & Very Fine Sandy Fine Silt \\
\hline 82.3099715 & 77.12486251 & 92.27739978 \\
\hline 203.0287071 & 222.097451 & 270.1002555 \\
\hline 5.612873969 & 5.467958483 & 4.472334812 \\
\hline 39.16564197 & 35.2049519 & 23.53256415 \\
\hline 19.44935712 & 15.62872705 & 14.0691125 \\
\hline 5.663190801 & 5.553707777 & 5.979349543 \\
\hline 0.174716376 & 0.376249622 & 0.632182609 \\
\hline 2.256207295 & 2.618496174 & 2.950334056 \\
\hline 5.648253309 & 5.953817889 & 6.079592738 \\
\hline 2.511396536 & 2.491801143 & 2.611287758 \\
\hline-0.189404322 & -0.395555362 & -0.643816639 \\
\hline 2.273275816 & 2.636140044 & 2.925006034 \\
\hline 19.31290244 & 15.51411948 & 13.9082189 \\
\hline 5.725011775 & 5.559570353 & 6.585284263 \\
\hline 0.055258063 & 0.10347536 & 0.243419805 \\
\hline 0.766690077 & 0.836247847 & 1.060654892 \\
\hline 5.694291193 & 6.010274372 & 6.167918511 \\
\hline 2.51727866 & 2.474973395 & 2.719245718 \\
\hline-0.055258063 & -0.10347536 & -0.243419805 \\
\hline 0.766690077 & 0.836247847 & 1.060654892 \\
\hline Coarse Silt & Medium Silt & Medium Silt \\
\hline Very Poorly Sorted & Very Poorly Sorted & Very Poorly Sorted \\
\hline Symmetrical & Coarse Skewed & Coarse Skewed \\
\hline Platykurtic & Platykurtic & Mesokurtic \\
\hline 107.5 & 4.7 & 6.65 \\
\hline 6.65 & 107.5 & 107.5 \\
\hline 3.236965594 & 7.754331413 & 7.254331413 \\
\hline 7.254331413 & 3.236965594 & 3.236965594 \\
\hline 2.10898322 & 1.880443886 & 1.742420373 \\
\hline 17.82559943 & 13.80264225 & 11.0893221 \\
\hline 185.8626204 & 153.2130833 & 176.1558446 \\
\hline 88.12901813 & 81.47708335 & 101.0983614 \\
\hline 183.7536372 & 151.3326394 & 174.4134242 \\
\hline 17.21643233 & 13.79938431 & 11.83871937 \\
\hline 79.06372109 & 52.96506936 & 41.56611341 \\
\hline 2.427691442 & 2.706388597 & 2.505075753 \\
\hline 5.809905598 & 6.17891172 & 6.494685015 \\
\hline 8.889236669 & 9.054711029 & 9.164691557 \\
\hline 3.661600694 & 3.345680306 & 3.65844887 \\
\hline 6.461545227 & 6.348322432 & 6.659615804 \\
\hline 2.1486088 & 1.916772461 & 1.799223836 \\
\hline 4.105714306 & 3.786531995 & 3.565441123 \\
\hline 0.301764433 & 0.235459548 & 0.211009007 \\
\hline 0.698235567 & 0.764540452 & 0.788990993 \\
\hline 0.01940194 & 0.02479752 & 0.037688693 \\
\hline 0.01020102 & 0.01159884 & 0.019594122 \\
\hline 0.02960296 & 0.01629837 & 0.018194542 \\
\hline 0.109410941 & 0.071692831 & 0.055183445 \\
\hline 0.133147571 & 0.111071987 & 0.080348205 \\
\hline 0.106160763 & 0.114347672 & 0.090578956 \\
\hline 0.114652707 & 0.126247064 & 0.124274057 \\
\hline 0.132268976 & 0.138453549 & 0.156983501 \\
\hline 0.13971071 & 0.147969366 & 0.16305807 \\
\hline 0.116796755 & 0.132261571 & 0.137249085 \\
\hline 0.088645655 & 0.10526123 & 0.116847324 \\
\hline
\end{tabular}




\begin{tabular}{|c|c|c|}
\hline $302-2-A-11-X-2$ & $302-2-A-11-X-3$ & $302-2-A-12-X-2$ \\
\hline Cristin Ashmankas, & Cristin Ashmankas, & Cristin Ashmankas, \\
\hline $\begin{array}{c}\text { Unimodal, Very Poorly } \\
\text { Sorted }\end{array}$ & $\begin{array}{c}\text { Unimodal, Very Poorly } \\
\text { Sorted }\end{array}$ & $\begin{array}{c}\text { Trimodal, Very Poorly } \\
\text { Sorted }\end{array}$ \\
\hline Sandy Mud & Sandy Mud & Sandy Mud \\
\hline Very Fine Sandy Fine Silt & Very Fine Sandy Fine Silt & Very Fine Sandy Fine Silt \\
\hline 70.01045141 & 60.45144762 & 82.96069193 \\
\hline 233.8942214 & 194.9380139 & 234.2295697 \\
\hline 5.360648362 & 6.187082378 & 5.21781364 \\
\hline 32.99613226 & 45.06019087 & 32.06547081 \\
\hline 11.42673231 & 12.13744858 & 16.51732705 \\
\hline 5.233038254 & 4.971046607 & 5.615697464 \\
\hline 0.789075481 & 0.639057526 & 0.392745459 \\
\hline 3.434810115 & 3.119869475 & 2.617173836 \\
\hline 6.398635198 & 6.333165923 & 5.863076661 \\
\hline 2.419334805 & 2.331911601 & 2.510109744 \\
\hline-0.809703171 & -0.659146177 & -0.413869211 \\
\hline 3.42916171 & 3.142401113 & 2.629450545 \\
\hline 11.16035353 & 11.89912864 & 16.47142712 \\
\hline 5.166146021 & 4.953570769 & 5.649824462 \\
\hline 0.234125355 & 0.196759847 & 0.135066239 \\
\hline 1.026715088 & 0.963520091 & 0.845789525 \\
\hline 6.485473461 & 6.393000259 & 5.923890631 \\
\hline 2.369088422 & 2.308468863 & 2.498206044 \\
\hline-0.234125355 & -0.196759847 & -0.135066239 \\
\hline 1.026715088 & 0.963520091 & 0.845789525 \\
\hline Medium Silt & Medium Silt & Coarse Silt \\
\hline Very Poorly Sorted & Very Poorly Sorted & Very Poorly Sorted \\
\hline Coarse Skewed & Coarse Skewed & Coarse Skewed \\
\hline Mesokurtic & Mesokurtic & Platykurtic \\
\hline 6.65 & 4.7 & 6.65 \\
\hline & & 107.5 \\
\hline 7.254331413 & 7.754331413 & 7.254331413 \\
\hline & & 3.236965594 \\
\hline 1.735009741 & 1.842434069 & 2.012670252 \\
\hline 8.889779339 & 9.772982092 & 14.07432375 \\
\hline 117.1675994 & 117.758941 & 167.4052976 \\
\hline 67.53137843 & 63.91487378 & 83.17572014 \\
\hline 115.4325897 & 115.9165069 & 165.3926274 \\
\hline 8.632267893 & 8.977544858 & 13.98963559 \\
\hline 26.96278755 & 29.85804124 & 57.83943751 \\
\hline 3.093354421 & 3.086091492 & 2.578582911 \\
\hline 6.813636676 & 6.676985437 & 6.150790585 \\
\hline 9.170840522 & 9.084171291 & 8.956673458 \\
\hline 2.964691165 & 2.943584567 & 3.473486704 \\
\hline 6.077486101 & 5.998079798 & 6.378090547 \\
\hline 1.617592823 & 1.646800361 & 1.950429858 \\
\hline 3.109739638 & 3.166320957 & 3.806286477 \\
\hline 0.164046265 & 0.16839707 & 0.249491548 \\
\hline 0.835953735 & 0.83160293 & 0.750508452 \\
\hline 0.027894421 & 0.018066064 & 0.02829717 \\
\hline 0.013397321 & 0.010399653 & 0.01179882 \\
\hline 0.01009798 & 0.01439952 & 0.01939806 \\
\hline 0.042091582 & 0.050764975 & 0.077992201 \\
\hline 0.070564962 & 0.074766858 & 0.112005297 \\
\hline 0.082379219 & 0.092068559 & 0.107311303 \\
\hline 0.11919769 & 0.129531285 & 0.122253927 \\
\hline 0.168151318 & 0.167076322 & 0.145827658 \\
\hline 0.190241457 & 0.182213907 & 0.153984602 \\
\hline 0.157290888 & 0.151977754 & 0.125886877 \\
\hline 0.118693163 & 0.108735103 & 0.095244085 \\
\hline
\end{tabular}




\begin{tabular}{|c|c|c|}
\hline $\begin{array}{c}302-2-\mathrm{A}-12-\mathrm{X}-3 \\
\text { Cristin Ashmankas. }\end{array}$ & $\begin{array}{c}\text { 302-2-A-13-X-1 } \\
\text { Cristin Ashmankas }\end{array}$ & 302-2-A-13-X-1 \\
\hline $\begin{array}{l}\text { Unimodal, Very Poorly } \\
\text { Sorted }\end{array}$ & $\begin{array}{l}\text { Unimodal, Very Poorly } \\
\text { Sorted }\end{array}$ & $\begin{array}{c}\text { Unimodal, Very Poorly } \\
\text { Sorted }\end{array}$ \\
\hline Sandy Mud & Sandy Mud & Sandy Mud \\
\hline Very Fine Sandy Fine Silt & Very Fine Sandy Fine Silt & Very Fine Sandy Fine Silt \\
\hline 59.3519974 & 76.68924235 & 62.96633142 \\
\hline 171.5094087 & 233.0573958 & 216.1898889 \\
\hline 6.732366816 & 5.299574052 & 5.704915645 \\
\hline 54.95195388 & 32.6800378 & 37.78594656 \\
\hline 14.75569641 & 14.29065715 & 10.63742176 \\
\hline 4.875828114 & 5.439151823 & 4.995983993 \\
\hline 0.360317723 & 0.528217711 & 0.847202998 \\
\hline 2.690214553 & 2.897284302 & 3.647919472 \\
\hline 6.062648622 & 6.073961152 & 6.510855295 \\
\hline 2.29513223 & 2.468349756 & 2.349872493 \\
\hline-0.376734486 & -0.55057961 & -0.869082127 \\
\hline 2.714766346 & 2.90691197 & 3.650417241 \\
\hline 14.68673724 & 14.16137562 & 10.07285332 \\
\hline 4.930377559 & 5.464210232 & 4.889732359 \\
\hline 0.105750025 & 0.170002813 & 0.22353732 \\
\hline 0.868309559 & 0.907652454 & 1.092984045 \\
\hline 6.089342263 & 6.141894776 & 6.633383779 \\
\hline 2.30169813 & 2.450012991 & 2.289755501 \\
\hline-0.105750025 & -0.170002813 & -0.22353732 \\
\hline 0.868309559 & 0.907652454 & 1.092984045 \\
\hline Medium Silt & Medium Silt & Medium Silt \\
\hline Very Poorly Sorted & Very Poorly Sorted & Very Poorly Sorted \\
\hline Coarse Skewed & Coarse Skewed & Coarse Skewed \\
\hline Platykurtic & Mesokurtic & Mesokurtic \\
\hline 9.4 & 6.65 & 4.7 \\
\hline 6.754331413 & 7.254331413 & 7.754331413 \\
\hline 2.043100063 & 1.890767253 & 1.713202964 \\
\hline 13.04363694 & 11.80276599 & 8.454616271 \\
\hline 124.34805 & 141.6136697 & 102.8061054 \\
\hline 60.86243756 & 74.89746264 & 60.00812958 \\
\hline 122.30495 & 139.7229024 & 101.0929025 \\
\hline 10.5907469 & 11.66426052 & 7.553887983 \\
\hline 42.27540471 & 43.43981946 & 22.4976911 \\
\hline 3.007544211 & 2.819967562 & 3.282002149 \\
\hline 6.260509999 & 6.404731193 & 6.886045008 \\
\hline 8.935024421 & 9.046812501 & 9.189088206 \\
\hline 2.970870516 & 3.208126442 & 2.799842227 \\
\hline 5.92748021 & 6.226844939 & 5.907086057 \\
\hline 1.770136213 & 1.806279386 & 1.553634968 \\
\hline 3.404732433 & 3.544022942 & 2.91721939 \\
\hline 0.203412677 & 0.2101986 & 0.140015153 \\
\hline 0.796587323 & 0.7898014 & 0.859984847 \\
\hline 0.013102621 & 0.027805561 & 0.022901527 \\
\hline 0.00880176 & 0.013202641 & 0.013167545 \\
\hline 0.014102821 & 0.013602721 & 0.015434362 \\
\hline 0.063212643 & 0.057711542 & 0.034135609 \\
\hline 0.104192833 & 0.097876136 & 0.05437611 \\
\hline 0.116238408 & 0.103921104 & 0.079597652 \\
\hline 0.140303668 & 0.126159994 & 0.126652906 \\
\hline 0.158192977 & 0.155163026 & 0.175004533 \\
\hline 0.159343514 & 0.164431955 & 0.194127799 \\
\hline 0.129829972 & 0.135630453 & 0.163264279 \\
\hline 0.092678784 & 0.104494868 & 0.121337678 \\
\hline
\end{tabular}




\begin{tabular}{|c|c|c|}
\hline $\begin{array}{c}\text { 302-2-A-14-X-1 } \\
\text { Cristin Ashmankas, }\end{array}$ & $\begin{array}{c}\text { 302-2-A-14-X-2 } \\
\text { Cristin Ashmankas, }\end{array}$ & $\begin{array}{c}\text { 302-2-A-14-X-3 } \\
\text { Cristin Ashmankas, }\end{array}$ \\
\hline $\begin{array}{c}\text { Bimodal, Very Poorly } \\
\text { Sorted }\end{array}$ & $\begin{array}{c}\text { Bimodal, Very Poorly } \\
\text { Sorted }\end{array}$ & $\begin{array}{l}\text { Unimodal, Very Poorly } \\
\text { Sorted }\end{array}$ \\
\hline Sandy Mud & Sandy Mud & Sandy Mud \\
\hline Very Fine Sandy Fine Silt & Very Fine Sandy Fine Silt & Very Fine Sandy Fine Silt \\
\hline 81.70394271 & 78.17444189 & 57.49548662 \\
\hline 253.9843309 & 254.3011009 & 202.2340812 \\
\hline 4.941765335 & 4.936668209 & 6.289696783 \\
\hline 28.08740482 & 27.92099372 & 45.08802356 \\
\hline 13.7003143 & 12.10579277 & 11.01649567 \\
\hline 5.571558575 & 5.497103262 & 4.834614937 \\
\hline 0.601091537 & 0.718076629 & 0.707085484 \\
\hline 3.052822336 & 3.339146016 & 3.425999178 \\
\hline 6.120897037 & 6.303368074 & 6.464331661 \\
\hline 2.510395959 & 2.49406746 & 2.299573579 \\
\hline-0.622879355 & -0.737719838 & -0.735355107 \\
\hline 3.045542372 & 3.321058926 & 3.455322554 \\
\hline 13.41495452 & 11.69076562 & 10.72465236 \\
\hline 5.788621383 & 5.797048102 & 4.715930524 \\
\hline 0.194132907 & 0.21480594 & 0.182889535 \\
\hline 0.986674457 & 1.082612947 & 0.973667047 \\
\hline 6.220014027 & 6.418486776 & 6.542925306 \\
\hline 2.533219797 & 2.535318457 & 2.237542464 \\
\hline-0.194132907 & -0.21480594 & -0.182889535 \\
\hline 0.986674457 & 1.082612947 & 0.973667047 \\
\hline Medium Silt & Medium Silt & Medium Silt \\
\hline Very Poorly Sorted & Very Poorly Sorted & Very Poorly Sorted \\
\hline Coarse Skewed & Coarse Skewed & Coarse Skewed \\
\hline Mesokurtic & Mesokurtic & Mesokurtic \\
\hline 4.7 & 6.65 & 4.7 \\
\hline 1200 & 1200 & \\
\hline 7.754331413 & 7.254331413 & 7.754331413 \\
\hline-0.242713414 & -0.242713414 & \\
\hline 1.803115225 & 1.658101515 & 1.742884428 \\
\hline 11.30748676 & 9.906746845 & 9.03092305 \\
\hline 136.8982206 & 119.2430374 & 97.52265647 \\
\hline 75.92316826 & 71.91540227 & 55.95474659 \\
\hline 135.0951054 & 117.5849359 & 95.77977204 \\
\hline 11.3465168 & 9.783761993 & 8.303369159 \\
\hline 40.21828392 & 31.35198143 & 25.82267687 \\
\hline 2.8688244 & 3.068023065 & 3.358118765 \\
\hline 6.466577883 & 6.657372898 & 6.790910832 \\
\hline 9.115292692 & 9.236251948 & 9.164307379 \\
\hline 3.177361672 & 3.010489737 & 2.729000378 \\
\hline 6.246468292 & 6.168228884 & 5.806188614 \\
\hline 1.778204559 & 1.679867728 & 1.599930664 \\
\hline 3.504177576 & 3.290389308 & 3.05369684 \\
\hline 0.199025635 & 0.171053138 & 0.147958254 \\
\hline 0.800974365 & 0.828946862 & 0.852041746 \\
\hline 0.034093181 & 0.033706741 & 0.02069793 \\
\hline 0.014497101 & 0.015803161 & 0.00936573 \\
\hline 0.0104979 & 0.00840168 & 0.00746592 \\
\hline 0.048590282 & 0.037207441 & 0.0376629 \\
\hline 0.09134717 & 0.075934114 & 0.072765773 \\
\hline 0.105735889 & 0.095316649 & 0.091606627 \\
\hline 0.127243251 & 0.129487518 & 0.128775022 \\
\hline 0.153007447 & 0.162461225 & 0.169191629 \\
\hline 0.16385931 & 0.17053597 & 0.186696342 \\
\hline 0.139566189 & 0.145420715 & 0.15779829 \\
\hline 0.111 .562279 & 0.125724785 & 0.117973836 \\
\hline
\end{tabular}




\begin{tabular}{|c|c|c|}
\hline $302-2-A-15-X-1$ & $302-2-A-15-X-1$ & $302-2-A-15-X-2$ \\
\hline Cristin Ashmankas, & Cristin Ashmankas, & Cristin Ashmankas, \\
\hline $\begin{array}{c}\text { Bimodal, Very Poorly } \\
\text { Sorted }\end{array}$ & $\begin{array}{c}\text { Bimodal, Very Poorly } \\
\text { Sorted }\end{array}$ & $\begin{array}{c}\text { Unimodal, Very Poorly } \\
\text { Sorted }\end{array}$ \\
\hline Sandy Mud & Sandy Mud & Sandy Mud \\
\hline Very Fine Sandy Fine Silt & Very Fine Sandy Fine Silt & Very Fine Sandy Fine Silt \\
\hline 76.46873863 & 59.25025682 & 70.17527731 \\
\hline 247.6690791 & 179.2743863 & 217.3122366 \\
\hline 5.06863079 & 6.789054512 & 5.887566785 \\
\hline 29.4164158 & 54.84872835 & 39.74153569 \\
\hline 12.58688265 & 13.81467313 & 14.69197562 \\
\hline 5.424187056 & 4.943540689 & 5.199934049 \\
\hline 0.652860787 & 0.428992122 & 0.428841321 \\
\hline 3.263087967 & 2.760608996 & 2.8302772 \\
\hline 6.253142921 & 6.147427232 & 6.036346566 \\
\hline 2.470531219 & 2.320959314 & 2.402198559 \\
\hline-0.674559009 & -0.451810665 & -0.458613135 \\
\hline 3.257258393 & 2.794155003 & 2.858897137 \\
\hline 12.13330334 & 13.84665354 & 14.72907562 \\
\hline 5.462948731 & 5.022879437 & 5.164090615 \\
\hline 0.165667153 & 0.137510464 & 0.111664034 \\
\hline 1.011996401 & 0.890140887 & 0.862925742 \\
\hline 6.364883806 & 6.174318842 & 6.085189299 \\
\hline 2.449679884 & 2.328514647 & 2.368514316 \\
\hline-0.165667153 & -0.137510464 & -0.111664034 \\
\hline 1.011996401 & 0.890140887 & 0.862925742 \\
\hline Medium Silt & Medium Silt & Medium Silt \\
\hline Very Poorly Sorted & Very Poorly Sorted & Very Poorly Sorted \\
\hline Coarse Skewed & Coarse Skewed & Coarse Skewed \\
\hline Mesokurtic & Platykurtic & Platykurtic \\
\hline 9.4 & 9.4 & 9.4 \\
\hline 1200 & 107.5 & \\
\hline 6.754331413 & 6.754331413 & 6.754331413 \\
\hline-0.242713414 & 3.236965594 & \\
\hline 1.687281288 & 1.949616149 & 1.952866444 \\
\hline 10.63800138 & 11.87788028 & 12.96895919 \\
\hline 119.5333497 & 125.2785385 & 132.0499185 \\
\hline 70.84375945 & 64.25805332 & 67.61850965 \\
\hline 117.8460684 & 123.3289223 & 130.097052 \\
\hline 9.884459806 & 10.37617459 & 11.55026115 \\
\hline 32.9648833 & 38.77102839 & 44.91546685 \\
\hline 3.06451491 & 2.996788808 & 2.920844684 \\
\hline 6.554629061 & 6.395578793 & 6.268793487 \\
\hline 9.211083778 & 9.002594178 & 9.000190998 \\
\hline 3.00572327 & 3.004080286 & 3.081365828 \\
\hline 6.146568868 & 6.00580537 & 6.079346314 \\
\hline 1.693044402 & 1.742999135 & 1.812207989 \\
\hline 3.305162124 & 3.375202755 & 3.529853566 \\
\hline 0.172868237 & 0.195302807 & 0.212298192 \\
\hline 0.827131763 & 0.804697193 & 0.787701808 \\
\hline 0.03179682 & 0.015498967 & 0.02496417 \\
\hline 0.01449855 & 0.006466236 & 0.00769923 \\
\hline 0.00859914 & 0.016532231 & 0.01076559 \\
\hline 0.04039596 & 0.061729218 & 0.062493751 \\
\hline 0.077577766 & 0.095076156 & 0.106375451 \\
\hline 0.102910606 & 0.106107679 & 0.112946347 \\
\hline 0.137344004 & 0.136958403 & 0.134817506 \\
\hline 0.161134512 & 0.160973693 & 0.153112228 \\
\hline 0.164193362 & 0.164030317 & 0.156090291 \\
\hline 0.139373806 & 0.13632501 & 0.130713507 \\
\hline 0.122175472 & 0.100302091 & 0.100021929 \\
\hline
\end{tabular}




\begin{tabular}{|c|c|c|}
\hline $\begin{array}{c}\text { 302-2-A-15-X-2 } \\
\text { Cristin Ashmankas. }\end{array}$ & $\begin{array}{c}\text { 302-2-A-15-X-3 } \\
\text { Cristin Ashmankas. }\end{array}$ & $\begin{array}{c}302-2-A-15-X-3 \\
\text { Cristin Ashmankas }\end{array}$ \\
\hline $\begin{array}{l}\text { Unimodal, Very Poorly } \\
\text { Sorted }\end{array}$ & $\begin{array}{l}\text { Unimodal, Very Poorly } \\
\text { Sorted }\end{array}$ & $\begin{array}{l}\text { Unimodal, Very Poorly } \\
\text { Sorted }\end{array}$ \\
\hline Sandy Mud & Sandy Mud & Sandy Mud \\
\hline Very Fine Sandy Fine Silt & Very Fine Sandy Fine Silt & Very Fine Sandy Fine Silt \\
\hline 60.62938404 & 74.21127358 & 54.51888737 \\
\hline 196.261429 & 227.1814013 & 191.8645729 \\
\hline 6.401795987 & 5.528180306 & 6.568880245 \\
\hline 47.48339133 & 35.23159378 & 49.16405477 \\
\hline 12.91824671 & 14.77353728 & 11.40163873 \\
\hline 4.917317046 & 5.311797314 & 4.668590461 \\
\hline 0.540594507 & 0.460958767 & 0.644214977 \\
\hline 3.03787789 & 2.862816279 & 3.381158169 \\
\hline 6.236246286 & 6.028683144 & 6.422725548 \\
\hline 2.31892807 & 2.43229475 & 2.243773449 \\
\hline-0.567968815 & -0.486717886 & -0.672272371 \\
\hline 3.07081474 & 2.881509435 & 3.418106936 \\
\hline 12.77325357 & 14.70550927 & 11.07200201 \\
\hline 4.910367742 & 5.243494461 & 4.535094885 \\
\hline 0.151279764 & 0.120003114 & 0.149356287 \\
\hline 0.935344062 & 0.870197901 & 0.943376255 \\
\hline 6.290730139 & 6.087499442 & 6.49694008 \\
\hline 2.295831073 & 2.390528598 & 2.181132736 \\
\hline-0.151279764 & -0.120003114 & -0.149356287 \\
\hline 0.935344062 & 0.870197901 & 0.943376255 \\
\hline Medium Silt & Medium Silt & Medium Silt \\
\hline Very Poorly Sorted & Very Poorly Sorted & Very Poorly Sorted \\
\hline Coarse Skewed & Coarse Skewed & Coarse Skewed \\
\hline Mesokurtic & Platykurtic & Mesokurtic \\
\hline 9.4 & 9.4 & 4.7 \\
\hline 6.754331413 & 6.754331413 & 7.754331413 \\
\hline 1.897345563 & 1.936291132 & 1.817501549 \\
\hline 10.97204639 & 12.86321632 & 9.650879949 \\
\hline 117.5179804 & 135.0699104 & 91.34563997 \\
\hline 61.93810065 & 69.7570258 & 50.25890625 \\
\hline 115.6206349 & 133.1336193 & 89.52813842 \\
\hline 9.331319674 & 11.68946268 & 8.28914735 \\
\hline 33.2748959 & 45.1863417 & 26.96325379 \\
\hline 3.089046587 & 2.888221774 & 3.452520321 \\
\hline 6.510023563 & 6.28060477 & 6.695123794 \\
\hline 9.041801824 & 9.012488399 & 9.103827691 \\
\hline 2.927052594 & 3.120428105 & 2.636864332 \\
\hline 5.952755238 & 6.124266625 & 5.65130737 \\
\hline 1.678920894 & 1.817510363 & 1.606920282 \\
\hline 3.222081127 & 3.547136711 & 3.051223709 \\
\hline 0.175340501 & 0.213518117 & 0.144577005 \\
\hline 0.824659499 & 0.786481883 & 0.855422995 \\
\hline 0.019332045 & 0.026735116 & 0.018199393 \\
\hline 0.007632824 & 0.010900727 & 0.009566348 \\
\hline 0.012665822 & 0.010167344 & 0.004399853 \\
\hline 0.053129791 & 0.060370691 & 0.035498817 \\
\hline 0.082580019 & 0.105344239 & 0.076912594 \\
\hline 0.103142003 & 0.111564104 & 0.102103151 \\
\hline 0.139779963 & 0.133459504 & 0.137866994 \\
\hline 0.166266664 & 0.15263492 & 0.169690054 \\
\hline 0.170895904 & 0.156548428 & 0.182083683 \\
\hline 0.140465161 & 0.131068696 & 0.152774762 \\
\hline 0.104109804 & 0.10120623 & 0.110904353 \\
\hline
\end{tabular}




\begin{tabular}{|c|c|c|}
\hline$\frac{302-2-A-16-X-2}{\text { Cristin Ashmankas }}$ & 302-2-A-16-X-3 & 302-2-A-17-X-1 \\
\hline $\begin{array}{c}\text { Unimodal, Very Poorly } \\
\text { Sorted }\end{array}$ & $\begin{array}{c}\text { Bimodal, Very Poorly } \\
\text { Sorted }\end{array}$ & $\begin{array}{l}\text { Unimodal, Very Poorly } \\
\text { Sorted }\end{array}$ \\
\hline Sandy Mud & Sandy Mud & Sandy Mud \\
\hline Very Fine Sandy Fine Silt & Very Fine Sandy Fine Silt & Very Fine Sandy Fine Silt \\
\hline 61.00329561 & 53.94366109 & 58.67080672 \\
\hline 188.0355279 & 161.1590696 & 207.9550123 \\
\hline 6.520351182 & 7.422870517 & 6.079508233 \\
\hline 50.28649349 & 66.01525379 & 42.16351488 \\
\hline 13.42097496 & 13.59582238 & 10.90502167 \\
\hline 5.032016825 & 4.844618 & 4.807344402 \\
\hline 0.468375333 & 0.356416135 & 0.751497311 \\
\hline 2.829263547 & 2.639334285 & 3.583019741 \\
\hline 6.185481914 & 6.180430359 & 6.478333329 \\
\hline 2.348796655 & 2.287107289 & 2.292199125 \\
\hline-0.491529318 & -0.374435066 & -0.779617148 \\
\hline 2.860654289 & 2.671353348 & 3.605635041 \\
\hline 13.34466803 & 13.61836689 & 10.46186281 \\
\hline 5.091965627 & 4.911698743 & 4.634870634 \\
\hline 0.144845418 & 0.12121589 & 0.178618604 \\
\hline 0.905905797 & 0.843768468 & 0.990984469 \\
\hline 6.227592773 & 6.198302483 & 6.578716433 \\
\hline 2.34822268 & 2.296222076 & 2.212529072 \\
\hline-0.144845418 & -0.12121589 & -0.178618604 \\
\hline 0.905905797 & 0.843768468 & 0.990984469 \\
\hline Medium Silt & Medium Silt & Medium Silt \\
\hline Very Poorly Sorted & Very Poorly Sorted & Very Poorly Sorted \\
\hline Coarse Skewed & Coarse Skewed & Coarse Skewed \\
\hline Mesokurtic & Platykurtic & Mesokurtic \\
\hline \multirow[t]{2}{*}{6.65} & 6.65 & 4.7 \\
\hline & 107.5 & \\
\hline \multirow[t]{2}{*}{7.254331413} & 7.254331413 & 7.754331413 \\
\hline & 3.236965594 & \\
\hline 1.875919963 & 1.910288849 & 1.752385391 \\
\hline 11.43088628 & 11.71876438 & 8.986622513 \\
\hline 125.1806905 & 117.0815945 & 89.72129551 \\
\hline 66.73029392 & 61.28999526 & 51.19952266 \\
\hline 123.3047705 & 115.1713056 & 87.96891012 \\
\hline 10.32960141 & 10.97299608 & 8.050364674 \\
\hline 37.21759806 & 40.52582478 & 24.97352189 \\
\hline 2.997916056 & 3.094413797 & 3.478405738 \\
\hline 6.450918924 & 6.415035728 & 6.798005282 \\
\hline 9.058186009 & 9.031993485 & 9.156464192 \\
\hline 3.021494211 & 2.918805977 & 2.632373818 \\
\hline 6.060269953 & 5.937579688 & 5.678058455 \\
\hline 1.732173813 & 1.770172814 & 1.586320173 \\
\hline 3.368712681 & 3.455885589 & 3.009054137 \\
\hline 0.189242149 & 0.197134433 & 0.138247418 \\
\hline 0.810757851 & 0.802865567 & 0.861752582 \\
\hline 0.017167239 & 0.011932538 & 0.02160144 \\
\hline 0.007466916 & 0.006232918 & 0.011167411 \\
\hline 0.017367246 & 0.009466036 & 0.00810054 \\
\hline 0.058135271 & 0.062229185 & 0.030068671 \\
\hline 0.089105478 & 0.107273757 & 0.067309355 \\
\hline 0.105987568 & 0.111256474 & 0.095694324 \\
\hline 0.136054252 & 0.130131334 & 0.132520191 \\
\hline 0.158156674 & 0.155362112 & 0.169924379 \\
\hline 0.165569391 & 0.16551702 & 0.18815856 \\
\hline 0.13927073 & 0.137494657 & 0.158394728 \\
\hline 0.105719236 & 0.10310397 & 0.117060399 \\
\hline
\end{tabular}




\begin{tabular}{|c|c|c|}
\hline $\begin{array}{c}\text { 302-2-A-17-X-1 } \\
\text { Cristin Ashmankas, }\end{array}$ & $\begin{array}{c}\text { 302-2-A-17-X-2 } \\
\text { Cristin Ashmankas, }\end{array}$ & $\begin{array}{c}\text { 302-2-A-18-X-1 } \\
\text { Cristin Ashmankas, }\end{array}$ \\
\hline $\begin{array}{l}\text { Unimodal, Very Poorly } \\
\text { Sorted }\end{array}$ & $\begin{array}{l}\text { Unimodal, Very Poorly } \\
\text { Sorted }\end{array}$ & $\begin{array}{l}\text { Bimodal, Very Poorly } \\
\text { Sorted }\end{array}$ \\
\hline Sandy Mud & Sandy Mud & Sandy Mud \\
\hline Very Fine Sandy Fine Silt & Very Fine Sandy Fine Silt & Very Fine Sandy Fine Silt \\
\hline 52.96364792 & 54.74322872 & 67.54835111 \\
\hline 167.3944671 & 200.7356381 & 190.7655071 \\
\hline 7.155163039 & 6.4450314 & 6.050861673 \\
\hline 60.85983455 & 46.77083968 & 44.88056388 \\
\hline 12.69172408 & 10.72310679 & 14.80849169 \\
\hline 4.735811298 & 4.672064599 & 5.267079577 \\
\hline 0.458231731 & 0.707719925 & 0.417267254 \\
\hline 2.909899798 & 3.596852735 & 2.642970105 \\
\hline 6.28136657 & 6.504928514 & 6.048203391 \\
\hline 2.254428155 & 2.250378061 & 2.410135459 \\
\hline-0.475671395 & -0.739962093 & -0.433440698 \\
\hline 2.939124982 & 3.633015653 & 2.662636101 \\
\hline 12.48680776 & 10.34391376 & 14.84331857 \\
\hline 4.736238739 & 4.488691734 & 5.370374423 \\
\hline 0.130542996 & 0.15147571 & 0.154989476 \\
\hline 0.904128619 & 0.964230242 & 0.881218549 \\
\hline 6.323451489 & 6.595074038 & 6.074042514 \\
\hline 2.243741805 & 2.166295021 & 2.425022677 \\
\hline-0.130542996 & -0.15147571 & -0.154989476 \\
\hline 0.904128619 & 0.964230242 & 0.881218549 \\
\hline Medium Silt & Medium Silt & Medium Silt \\
\hline Very Poorly Sorted & Very Poorly Sorted & Very Poorly Sorted \\
\hline Coarse Skewed & Coarse Skewed & Coarse Skewed \\
\hline Mesokurtic & Mesokurtic & Platykurtic \\
\hline 6.65 & 6.65 & 6.65 \\
\hline & & 107.5 \\
\hline 7.254331413 & 7.254331413 & 7.254331413 \\
\hline & & 3.236965594 \\
\hline 1.879592539 & 1.731987615 & 1.950196525 \\
\hline 10.88653733 & 9.063401939 & 12.33785759 \\
\hline 106.0603333 & 83.91540261 & 151.1668147 \\
\hline 56.42730064 & 48.45034796 & 77.51363145 \\
\hline 104.1807408 & 82.183415 & 149.2166182 \\
\hline 9.381143967 & 7.965231586 & 11.69515694 \\
\hline 33.31822303 & 24.70994842 & 45.15405849 \\
\hline 3.237042908 & 3.574920549 & 2.725786632 \\
\hline 6.521311039 & 6.785731619 & 6.340764291 \\
\hline 9.055364338 & 9.173355671 & 9.00216477 \\
\hline 2.797418693 & 2.566030642 & 3.302593337 \\
\hline 5.818321431 & 5.598435122 & 6.276378138 \\
\hline 1.6806771 & 1.581844269 & 1.817465652 \\
\hline 3.22976386 & 2.993716308 & 3.547839316 \\
\hline 0.169845202 & 0.132555143 & 0.216625671 \\
\hline 0.830154798 & 0.867444857 & 0.783374329 \\
\hline 0.012499167 & 0.020468031 & 0.016463923 \\
\hline 0.007766149 & 0.009067271 & 0.010464923 \\
\hline 0.011532564 & 0.004400293 & 0.024895851 \\
\hline 0.047763482 & 0.028601907 & 0.06902183 \\
\hline 0.09028384 & 0.07001764 & 0.095779145 \\
\hline 0.109821626 & 0.099278507 & 0.103263368 \\
\hline 0.138169165 & 0.135621828 & 0.129420265 \\
\hline 0.16429547 & 0.171328976 & 0.155779994 \\
\hline 0.172190384 & 0.186632888 & 0.162977029 \\
\hline 0.140269763 & 0.155726712 & 0.131685558 \\
\hline 0.10540839 & 0.118855945 & 0.100248114 \\
\hline
\end{tabular}




\begin{tabular}{|c|c|c|}
\hline $\begin{array}{c}\text { 302-2-A-18-X-1 } \\
\text { Cristin Ashmankas, }\end{array}$ & $\begin{array}{c}\text { 302-2-A-18-X-2 } \\
\text { Cristin Ashmankas, }\end{array}$ & $\begin{array}{c}\text { 302-2-A-19-X-1 } \\
\text { Cristin Ashmankas, }\end{array}$ \\
\hline $\begin{array}{l}\text { Unimodal, Very Poorly } \\
\text { Sorted }\end{array}$ & $\begin{array}{l}\text { Unimodal, Very Poorly } \\
\text { Sorted }\end{array}$ & $\begin{array}{l}\text { Bimodal, Very Poorly } \\
\text { Sorted }\end{array}$ \\
\hline Sandy Mud & Sandy Mud & Sandy Mud \\
\hline Very Fine Sandy Fine Silt & Very Fine Sandy Fine Silt & Very Fine Sandy Fine Silt \\
\hline 56.56953502 & 62.12649857 & 72.80472332 \\
\hline 185.9243925 & 208.4555134 & 171.8625894 \\
\hline 6.259224589 & 6.156538851 & 6.422451328 \\
\hline 46.15429164 & 43.24151537 & 53.25833948 \\
\hline 11.84488948 & 12.49645515 & 18.85759613 \\
\hline 4.800434961 & 4.965462819 & 5.503863436 \\
\hline 0.617012429 & 0.561603441 & 0.113952252 \\
\hline 3.239944083 & 3.15540559 & 2.163967211 \\
\hline 6.374345641 & 6.274504708 & 5.704127322 \\
\hline 2.278773906 & 2.33898744 & 2.46776269 \\
\hline-0.637000842 & -0.593908933 & -0.126400388 \\
\hline 3.265495603 & 3.188772083 & 2.182980257 \\
\hline 11.35925185 & 12.21119935 & 18.86663071 \\
\hline 4.699576214 & 4.879684933 & 5.597537141 \\
\hline 0.155608395 & 0.139291368 & 0.039908977 \\
\hline 0.960846395 & 0.920450133 & 0.746225158 \\
\hline 6.459988371 & 6.355651285 & 5.728019387 \\
\hline 2.232530667 & 2.286788 & 2.484792196 \\
\hline-0.155608395 & -0.139291368 & -0.039908977 \\
\hline 0.960846395 & 0.920450133 & 0.746225158 \\
\hline Medium Silt & Medium Silt & Coarse Silt \\
\hline Very Poorly Sorted & Very Poorly Sorted & Very Poorly Sorted \\
\hline Coarse Skewed & Coarse Skewed & Symmetrical \\
\hline Mesokurtic & Mesokurtic & Platykurtic \\
\hline \multirow[t]{2}{*}{6.65} & 6.65 & 107.5 \\
\hline & & 4.7 \\
\hline \multirow[t]{2}{*}{7.254331413} & 7.254331413 & 3.236965594 \\
\hline & & 7.754331413 \\
\hline 1.817207228 & 1.817361933 & 2.0618497 \\
\hline 9.917163253 & 10.69229194 & 17.53535492 \\
\hline 98.66183278 & 105.89025 & 176.3827889 \\
\hline 54.29311047 & 58.26591175 & 85.54590029 \\
\hline 96.84462555 & 104.072888 & 174.3209392 \\
\hline 8.61982785 & 9.688142395 & 17.28824328 \\
\hline 28.66148771 & 33.49145524 & 77.49089647 \\
\hline 3.341364102 & 3.239358338 & 2.503218303 \\
\hline 6.65585678 & 6.547285055 & 5.833589559 \\
\hline 9.104061336 & 9.10393852 & 8.921845114 \\
\hline 2.724654081 & 2.810414153 & 3.56414984 \\
\hline 5.762697234 & 5.864580182 & 6.418626811 \\
\hline 1.628210691 & 1.690764389 & 2.140918072 \\
\hline 3.107659057 & 3.27622007 & 4.111719374 \\
\hline 0.149752344 & 0.168015656 & 0.298270132 \\
\hline 0.850247656 & 0.831984344 & 0.701729868 \\
\hline 0.015966134 & 0.0224985 & 0.013100437 \\
\hline 0.012699577 & 0.0089994 & 0.005866862 \\
\hline 0.01019966 & 0.009532698 & 0.029934331 \\
\hline 0.0389987 & 0.039964002 & 0.114370479 \\
\hline 0.071888272 & 0.087021055 & 0.134998023 \\
\hline 0.106370922 & 0.112363052 & 0.10605573 \\
\hline 0.136896633 & 0.135399917 & 0.115516024 \\
\hline 0.167786546 & 0.160162102 & 0.130532667 \\
\hline 0.179954768 & 0.170948749 & 0.139329283 \\
\hline 0.148543279 & 0.142662351 & 0.118452033 \\
\hline 0.110695507 & 0.110448173 & 0.091844131 \\
\hline
\end{tabular}




\begin{tabular}{|c|c|c|}
\hline 302-2-A-20-X-1 & 302-2-A-20-X-1 & $302-2-A-20-X-2$ \\
\hline Cristin Ashmankas, & Cristin Ashmankas, & Cristin Ashmankas, \\
\hline $\begin{array}{c}\text { Bimodal, Very Poorly } \\
\text { Sorted }\end{array}$ & $\begin{array}{c}\text { Unimodal, Very Poorly } \\
\text { Sorted }\end{array}$ & $\begin{array}{c}\text { Unimodal, Very Poorly } \\
\text { Sorted }\end{array}$ \\
\hline Sandy Mud & Sandy Mud & Sandy Mud \\
\hline Very Fine Sandy Fine Silt & Very Fine Sandy Fine Silt & Very Fine Sandy Fine Silt \\
\hline 67.07341044 & 63.54088555 & 62.16406714 \\
\hline 201.3275307 & 186.3375019 & 201.5771528 \\
\hline 5.867110845 & 6.294032808 & 6.203482204 \\
\hline 41.27318498 & 47.97815925 & 44.6384912 \\
\hline 13.39678481 & 14.03571269 & 12.52668381 \\
\hline 5.298889284 & 5.166516926 & 5.089718947 \\
\hline 0.527795931 & 0.427241813 & 0.540618697 \\
\hline 2.804794309 & 2.695949274 & 2.9988628 \\
\hline 6.186094958 & 6.124196204 & 6.279651591 \\
\hline 2.423831617 & 2.384062847 & 2.369464651 \\
\hline-0.545783468 & -0.446125212 & -0.5650869 \\
\hline 2.823950769 & 2.721631471 & 3.027457302 \\
\hline 13.27095233 & 13.8983475 & 12.29059197 \\
\hline 5.349414796 & 5.228632943 & 5.078719905 \\
\hline 0.190146186 & 0.146254066 & 0.157826651 \\
\hline 0.890592853 & 0.873111377 & 0.912079517 \\
\hline 6.235584287 & 6.168942832 & 6.346301786 \\
\hline 2.419381075 & 2.386433795 & 2.34446491 \\
\hline-0.190146186 & -0.146254066 & -0.157826651 \\
\hline 0.890592853 & 0.873111377 & 0.912079517 \\
\hline Medium Silt & Medium Silt & Medium Silt \\
\hline Very Poorly Sorted & Very Poorly Sorted & Very Poorly Sorted \\
\hline Coarse Skewed & Coarse Skewed & Coarse Skewed \\
\hline Platykurtic & Platykurtic & Mesokurtic \\
\hline 4.7 & 6.65 & 4.7 \\
\hline \multicolumn{3}{|l|}{107.5} \\
\hline 7.754331413 & 7.254331413 & 7.754331413 \\
\hline \multicolumn{3}{|l|}{3.236965594} \\
\hline 1.832074201 & 1.884140275 & 1.762693186 \\
\hline 10.67506113 & 11.78255051 & 10.43217561 \\
\hline 135.3230728 & 131.3932168 & 114.1605929 \\
\hline 73.86331446 & 69.7364302 & 64.76486878 \\
\hline 133.4909986 & 129.5090765 & 112.3978997 \\
\hline 11.43668366 & 11.56360202 & 10.29671927 \\
\hline 39.98150117 & 42.61256346 & 34.8595653 \\
\hline 2.885520253 & 2.928037297 & 3.130863362 \\
\hline 6.549611858 & 6.407204323 & 6.582816129 \\
\hline 9.09230635 & 9.051877906 & 9.148002903 \\
\hline 3.151011101 & 3.091448977 & 2.921878678 \\
\hline 6.206786097 & 6.12384061 & 6.017139541 \\
\hline 1.779076506 & 1.798608867 & 1.71654462 \\
\hline 3.515596863 & 3.531518958 & 3.364112836 \\
\hline 0.201702451 & 0.205258016 & 0.177935818 \\
\hline 0.798297549 & 0.794741984 & 0.822064182 \\
\hline 0.018932071 & 0.015931209 & 0.020167339 \\
\hline 0.012932471 & 0.010565258 & 0.009333644 \\
\hline 0.018365442 & 0.019397414 & 0.01290043 \\
\hline 0.057429505 & 0.059025463 & 0.046534884 \\
\hline 0.094042961 & 0.100338672 & 0.08899952 \\
\hline 0.097051944 & 0.108968588 & 0.105760488 \\
\hline 0.120586361 & 0.126940946 & 0.128338522 \\
\hline 0.154575158 & 0.152117145 & 0.157167616 \\
\hline 0.171436606 & 0.164334818 & 0.171160106 \\
\hline 0.145260741 & 0.137350019 & 0.144340016 \\
\hline 0.109386741 & 0.105030468 & 0.115297434 \\
\hline
\end{tabular}




\begin{tabular}{|c|c|c|}
\hline $302-2-A-20-X-2$ & $302-2-A-20-X-3$ & $302-2-A-20-X-3$ \\
\hline Cristin Ashmankas, & Cristin Ashmankas, & Cristin Ashmankas, \\
\hline $\begin{array}{c}\text { Unimodal, Very Poorly } \\
\text { Sorted }\end{array}$ & $\begin{array}{c}\text { Bimodal, Very Poorly } \\
\text { Sorted }\end{array}$ & $\begin{array}{c}\text { Unimodal, Very Poorly } \\
\text { Sorted }\end{array}$ \\
\hline Sandy Mud & Sandy Mud & Sandy Mud \\
\hline Very Fine Sandy Fine Silt & Very Fine Sandy Fine Silt & Very Fine Sandy Fine Silt \\
\hline 60.99604697 & 64.52266208 & 61.22298117 \\
\hline 194.8396619 & 205.1146174 & 201.0864438 \\
\hline 6.257187324 & 6.131271798 & 6.223769732 \\
\hline 45.79977057 & 43.35051216 & 44.8931854 \\
\hline 12.74376588 & 13.08906223 & 12.12599159 \\
\hline 5.012057139 & 5.216407771 & 5.039186628 \\
\hline 0.534879432 & 0.486117929 & 0.603924914 \\
\hline 2.979743207 & 2.835747764 & 3.070840739 \\
\hline 6.263835984 & 6.213971734 & 6.326222519 \\
\hline 2.342190076 & 2.404769984 & 2.356172458 \\
\hline-0.555287486 & -0.509905625 & -0.628462945 \\
\hline 3.005422146 & 2.864867307 & 3.098636637 \\
\hline 12.52456777 & 13.01098948 & 11.92312091 \\
\hline 4.990075531 & 5.196915972 & 5.014420451 \\
\hline 0.157562052 & 0.154804643 & 0.188701526 \\
\hline 0.904655177 & 0.848528208 & 0.920699223 \\
\hline 6.319095374 & 6.264125507 & 6.390094276 \\
\hline 2.319061653 & 2.377655733 & 2.326082969 \\
\hline-0.157562052 & -0.154804643 & -0.188701526 \\
\hline 0.904655177 & 0.848528208 & 0.920699223 \\
\hline Medium Silt & Medium Silt & Medium Silt \\
\hline Very Poorly Sorted & Very Poorly Sorted & Very Poorly Sorted \\
\hline Coarse Skewed & Coarse Skewed & Coarse Skewed \\
\hline Mesokurtic & Platykurtic & Mesokurtic \\
\hline \multirow[t]{2}{*}{4.7} & 4.7 & 4.7 \\
\hline & 76.5 & \\
\hline \multirow[t]{2}{*}{7.754331413} & 7.754331413 & 7.754331413 \\
\hline & 3.731217775 & \\
\hline 1.829288518 & 1.774858844 & 1.795038624 \\
\hline 10.60210716 & 10.79720807 & 9.794700881 \\
\hline 114.2357923 & 120.7807701 & 113.3683999 \\
\hline 62.44820932 & 68.05091597 & 63.15652401 \\
\hline 112.4065038 & 119.0059112 & 111.5733613 \\
\hline 10.11106777 & 11.91160109 & 9.91674709 \\
\hline 34.87210485 & 41.01712138 & 32.70411856 \\
\hline 3.129913349 & 3.049537318 & 3.140909532 \\
\hline 6.559505162 & 6.53319788 & 6.67378285 \\
\hline 9.094501647 & 9.138079994 & 9.121769398 \\
\hline 2.905672021 & 2.996546374 & 2.904180876 \\
\hline 5.964588298 & 6.088542676 & 5.980859866 \\
\hline 1.711464436 & 1.797633433 & 1.692290975 \\
\hline 3.337863455 & 3.574295441 & 3.309866963 \\
\hline 0.179339483 & 0.200574293 & 0.173291444 \\
\hline 0.820660517 & 0.799425707 & 0.826708556 \\
\hline 0.018099397 & 0.021332622 & 0.020133333 \\
\hline 0.010266324 & 0.009233026 & 0.009166667 \\
\hline 0.011532949 & 0.007899737 & 0.0128 \\
\hline 0.048698377 & 0.056298123 & 0.046433333 \\
\hline 0.090742436 & 0.105810785 & 0.08475811 \\
\hline 0.104319868 & 0.102985771 & 0.099533938 \\
\hline 0.130240803 & 0.119830973 & 0.124003475 \\
\hline 0.159993172 & 0.151087879 & 0.15811538 \\
\hline 0.171252108 & 0.166475198 & 0.179237321 \\
\hline 0.14526389 & 0.144787519 & 0.152976322 \\
\hline 0.109590676 & 0.114258367 & 0.11284212 \\
\hline
\end{tabular}




\begin{tabular}{|c|c|c|}
\hline $\begin{array}{c}302-2-\mathrm{A}-20-\mathrm{X}-4 \\
\text { Cristin Ashmankas }\end{array}$ & $\frac{302-2-\mathrm{A}-21-\mathrm{X}-1}{\text { Cristin Ashmankas }}$ & $\frac{302-2-A-21-X-1}{\text { Cristin Ashmankas }}$ \\
\hline $\begin{array}{l}\text { Unimodal, Very Poorly } \\
\text { Sorted }\end{array}$ & $\begin{array}{l}\text { Unimodal, Very Poorly } \\
\text { Sorted }\end{array}$ & $\begin{array}{l}\text { Unimodal, Very Poorly } \\
\text { Sorted }\end{array}$ \\
\hline Sandy Mud & Sandy Mud & Sandy Mud \\
\hline Very Fine Sandy Fine Silt & Very Fine Sandy Fine Silt & Very Fine Sandy Fine Silt \\
\hline 62.2010513 & 52.29759393 & 56.24744641 \\
\hline 218.8475072 & 199.3599309 & 160.6879333 \\
\hline 5.912135058 & 6.368225338 & 6.890927831 \\
\hline 39.51612819 & 45.8357815 & 58.76484579 \\
\hline 11.07989683 & 9.627738205 & 14.04567833 \\
\hline 4.967737525 & 4.543475769 & 4.881481685 \\
\hline 0.742342233 & 0.870173767 & 0.369621615 \\
\hline 3.475220623 & 4.026699537 & 2.650635868 \\
\hline 6.446084481 & 6.664700316 & 6.139777326 \\
\hline 2.344432583 & 2.209999555 & 2.294407647 \\
\hline-0.771298509 & -0.899258075 & -0.381395208 \\
\hline 3.492638475 & 4.053291269 & 2.670309466 \\
\hline 10.76804341 & 9.090662388 & 13.91405941 \\
\hline 4.829599444 & 4.266930963 & 4.947700166 \\
\hline 0.198053797 & 0.177552048 & 0.117400678 \\
\hline 0.972098145 & 1.022008853 & 0.864953159 \\
\hline 6.537100059 & 6.781398865 & 6.167312804 \\
\hline 2.27190354 & 2.093198768 & 2.306758075 \\
\hline-0.198053797 & -0.177552048 & -0.117400678 \\
\hline 0.972098145 & 1.022008853 & 0.864953159 \\
\hline Medium Silt & Medium Silt & Medium Silt \\
\hline Very Poorly Sorted & Very Poorly Sorted & Very Poorly Sorted \\
\hline Coarse Skewed & Coarse Skewed & Coarse Skewed \\
\hline Mesokurtic & Mesokurtic & Platykurtic \\
\hline 4.7 & 4.7 & 6.65 \\
\hline 7.754331413 & 7.754331413 & 7.254331413 \\
\hline 1.734605842 & 1.686601332 & 1.95751807 \\
\hline 8.931343449 & 7.933002039 & 12.21609149 \\
\hline 99.60287995 & 71.14082808 & 120.0852498 \\
\hline 57.4210449 & 42.17999045 & 61.34566607 \\
\hline 97.86827411 & 69.45422675 & 118.1277318 \\
\hline 8.675837178 & 6.910728001 & 10.76261242 \\
\hline 26.8768197 & 19.66618443 & 40.47685002 \\
\hline 3.327668732 & 3.813178422 & 3.05786914 \\
\hline 6.806907083 & 6.977917365 & 6.355073418 \\
\hline 9.171176411 & 9.211665286 & 8.996758659 \\
\hline 2.756036477 & 2.415744627 & 2.942166014 \\
\hline 5.843507679 & 5.398486863 & 5.938889519 \\
\hline 1.618352994 & 1.51240558 & 1.764133503 \\
\hline 3.117002978 & 2.788837697 & 3.427956402 \\
\hline 0.151276852 & 0.111596894 & 0.196277057 \\
\hline 0.848723148 & 0.888403106 & 0.803722943 \\
\hline 0.024965834 & 0.019535287 & 0.010767026 \\
\hline 0.009399687 & 0.011234457 & 0.009033634 \\
\hline 0.007633079 & 0.00430043 & 0.015433848 \\
\hline 0.035532149 & 0.021468814 & 0.059001967 \\
\hline 0.073746103 & 0.055057907 & 0.102040582 \\
\hline 0.094186984 & 0.086377949 & 0.11488362 \\
\hline 0.124348036 & 0.129530452 & 0.135461485 \\
\hline 0.164097955 & 0.176674561 & 0.155659075 \\
\hline 0.187428745 & 0.200989356 & 0.161604455 \\
\hline 0.15977607 & 0.170142119 & 0.13650162 \\
\hline 0.118885359 & 0.124688669 & 0.099612688 \\
\hline
\end{tabular}




\begin{tabular}{|c|c|c|}
\hline 302-2-A-21-X-2 & 302-2-A-21-X-2 & $302-2-A-21-X-3$ \\
\hline & Cristin Ashmankas, & Cristin Ashmankas, \\
\hline $\begin{array}{l}\text { Unimodal, Very Poorly } \\
\text { Sorted }\end{array}$ & $\begin{array}{c}\text { Unimodal, Very Poorly } \\
\text { Sorted }\end{array}$ & $\begin{array}{c}\text { Unimodal, Very Poorly } \\
\text { Sorted }\end{array}$ \\
\hline Sandy Mud & Sandy Mud & Sandy Mud \\
\hline Very Fine Sandy Fine Silt & Very Fine Sandy Fine Silt & Very Fine Sandy Fine Silt \\
\hline 63.10853626 & 60.25789067 & 64.82924509 \\
\hline 194.9494712 & 207.3951107 & 205.6997321 \\
\hline 6.238265965 & 6.254305451 & 5.975410906 \\
\hline 45.83404103 & 44.31651288 & 41.72529036 \\
\hline 13.68834727 & 12.03505196 & 12.83518264 \\
\hline 5.052068181 & 4.886268735 & 5.148795495 \\
\hline 0.463699037 & 0.606787958 & 0.562825042 \\
\hline 2.859855784 & 3.242269453 & 2.976266813 \\
\hline 6.157026516 & 6.331435597 & 6.244217467 \\
\hline 2.354079694 & 2.315640381 & 2.385561303 \\
\hline-0.486280417 & -0.638885409 & -0.585232312 \\
\hline 2.888065032 & 3.276542825 & 2.999277547 \\
\hline 13.50294735 & 11.74601975 & 12.62276928 \\
\hline 5.04389794 & 4.763322109 & 5.132766738 \\
\hline 0.13477644 & 0.151636802 & 0.175706925 \\
\hline 0.885217654 & 0.91427372 & 0.909093161 \\
\hline 6.210581844 & 6.411684221 & 6.307827735 \\
\hline 2.334539084 & 2.251968111 & 2.359736698 \\
\hline-0.13477644 & -0.151636802 & -0.175706925 \\
\hline 0.885217654 & 0.91427372 & 0.909093161 \\
\hline Medium Silt & Medium Silt & Medium Silt \\
\hline Very Poorly Sorted & Very Poorly Sorted & Very Poorly Sorted \\
\hline Coarse Skewed & Coarse Skewed & Coarse Skewed \\
\hline Platykurtic & Mesokurtic & Mesokurtic \\
\hline 6.65 & 4.7 & 4.7 \\
\hline 7.254331413 & 7.754331413 & 7.754331413 \\
\hline 1.90075089 & 1.816366391 & 1.821242675 \\
\hline 11.69731708 & 10.13276595 & 10.47566899 \\
\hline 119.424793 & 100.5335632 & 120.5830269 \\
\hline 62.8303233 & 55.3487246 & 66.20920351 \\
\hline 117.5240421 & 98.71719677 & 118.7617843 \\
\hline 10.74021051 & 9.409077032 & 10.47878877 \\
\hline 39.41681936 & 31.57100083 & 35.90817032 \\
\hline 3.065825719 & 3.314250869 & 3.051901245 \\
\hline 6.417678522 & 6.624828148 & 6.57681381 \\
\hline 9.039214818 & 9.104729037 & 9.100861115 \\
\hline 2.948378559 & 2.747145403 & 2.982030015 \\
\hline 5.973389099 & 5.790478168 & 6.04895987 \\
\hline 1.757054481 & 1.670527127 & 1.728144293 \\
\hline 3.424950366 & 3.234053211 & 3.389400062 \\
\hline 0.192936193 & 0.161295778 & 0.184443186 \\
\hline 0.807063807 & 0.838704222 & 0.815556814 \\
\hline 0.018198787 & 0.022333333 & 0.020735407 \\
\hline 0.010432638 & 0.007833333 & 0.011067773 \\
\hline 0.013599093 & 0.008666667 & 0.013468013 \\
\hline 0.051496567 & 0.036566667 & 0.050238357 \\
\hline 0.099209108 & 0.085895778 & 0.088933635 \\
\hline 0.112200956 & 0.108819511 & 0.102769632 \\
\hline 0.132247022 & 0.131929976 & 0.126653388 \\
\hline 0.15646592 & 0.16202687 & 0.155909904 \\
\hline 0.164520192 & 0.176253003 & 0.172829655 \\
\hline 0.137824467 & 0.148840412 & 0.147052293 \\
\hline 0.103805251 & 0.110834449 & 0.110341942 \\
\hline
\end{tabular}




\begin{tabular}{|c|c|c|}
\hline $\begin{array}{c}\text { 302-2-A-22-X-1 } \\
\text { Cristin Ashmankas, }\end{array}$ & $\begin{array}{c}\text { 302-2-A-23-X-2 } \\
\text { Cristin Ashmankas, }\end{array}$ & $\begin{array}{c}\text { 302-2-A-24-X-1 } \\
\text { Cristin Ashmankas, }\end{array}$ \\
\hline $\begin{array}{c}\text { Unimodal, Very Poorly } \\
\text { Sorted }\end{array}$ & $\begin{array}{c}\text { Unimodal, Very Poorly } \\
\text { Sorted }\end{array}$ & $\begin{array}{c}\text { Unimodal, Very Poorly } \\
\text { Sorted }\end{array}$ \\
\hline Sandy Mud & Sandy Mud & Sandy Mud \\
\hline Very Fine Sandy Fine Silt & Very Fine Sandy Fine Silt & Very Fine Sandy Fine Silt \\
\hline 65.6079979 & 59.24503917 & 61.20845978 \\
\hline 212.1236634 & 197.9159262 & 212.7182871 \\
\hline 5.683788714 & 6.158725314 & 5.945212943 \\
\hline 38.00489168 & 44.19684754 & 40.47713625 \\
\hline 11.73376035 & 11.68274537 & 10.95159408 \\
\hline 5.176733097 & 4.899718082 & 4.957904264 \\
\hline 0.716130394 & 0.661938879 & 0.763879604 \\
\hline 3.224008711 & 3.275584409 & 3.472870263 \\
\hline 6.375654222 & 6.386917615 & 6.469528805 \\
\hline 2.394274603 & 2.312780928 & 2.337760668 \\
\hline-0.734017327 & -0.684251603 & -0.788965569 \\
\hline 3.23403917 & 3.29942746 & 3.489331399 \\
\hline 11.40654668 & 11.32316341 & 10.5679005 \\
\hline 5.15403921 & 4.820857592 & 4.839168636 \\
\hline 0.227562462 & 0.181995783 & 0.213958003 \\
\hline 0.994286037 & 0.97009829 & 0.988264902 \\
\hline 6.453994107 & 6.464579123 & 6.564167402 \\
\hline 2.365703513 & 2.269289813 & 2.274759215 \\
\hline-0.227562462 & -0.181995783 & -0.213958003 \\
\hline 0.994286037 & 0.97009829 & 0.988264902 \\
\hline Medium Silt & Medium Silt & Medium Silt \\
\hline Very Poorly Sorted & Very Poorly Sorted & Very Poorly Sorted \\
\hline Coarse Skewed & Coarse Skewed & Coarse Skewed \\
\hline Mesokurtic & Mesokurtic & Mesokurtic \\
\hline 4.7 & 6.65 & 4.7 \\
\hline 7.754331413 & 7.254331413 & 7.754331413 \\
\hline 1.764351681 & 1.796806586 & 1.738657198 \\
\hline 9.124883967 & 9.550729294 & 8.677250887 \\
\hline 119.2146561 & 103.3783214 & 99.09162948 \\
\hline 67.56853376 & 57.53447378 & 56.99319542 \\
\hline 117.4503044 & 101.5815148 & 97.35297228 \\
\hline 9.112118223 & 8.688849445 & 8.533738405 \\
\hline 28.858432 & 28.28865357 & 26.07983625 \\
\hline 3.068366485 & 3.273994413 & 3.335092995 \\
\hline 6.775978071 & 6.710173383 & 6.848546242 \\
\hline 9.146646129 & 9.120349164 & 9.167810772 \\
\hline 2.980949692 & 2.785694786 & 2.748892095 \\
\hline 6.078279644 & 5.846354751 & 5.832717777 \\
\hline 1.644367551 & 1.627947941 & 1.608760336 \\
\hline 3.187786465 & 3.119165152 & 3.093177886 \\
\hline 0.167064556 & 0.156328637 & 0.148562428 \\
\hline 0.832935444 & 0.843671363 & 0.851437572 \\
\hline 0.021399287 & 0.018669156 & 0.022667422 \\
\hline 0.013666211 & 0.011734898 & 0.011000367 \\
\hline 0.016332789 & 0.011368182 & 0.01050035 \\
\hline 0.043831872 & 0.038838512 & 0.034101137 \\
\hline 0.071834397 & 0.075717889 & 0.070293152 \\
\hline 0.087931377 & 0.097069981 & 0.092368538 \\
\hline 0.121620524 & 0.130228648 & 0.12257683 \\
\hline 0.162363592 & 0.16790226 & 0.163071024 \\
\hline 0.18665993 & 0.18344475 & 0.190930643 \\
\hline 0.158444769 & 0.152404134 & 0.16372336 \\
\hline 0.11591525 & 0.11262159 & 0.118767176 \\
\hline
\end{tabular}




\begin{tabular}{|c|c|c|}
\hline $\begin{array}{c}\text { 302-2-A-24-X-1 } \\
\text { Cristin Ashmankas, }\end{array}$ & $\begin{array}{c}\text { 302-2-A-24-X-2 } \\
\text { Cristin Ashmankas, }\end{array}$ & $\begin{array}{c}\text { 302-2-A-24-X-2 } \\
\text { Cristin Ashmankas, }\end{array}$ \\
\hline $\begin{array}{c}\text { Unimodal, Very Poorly } \\
\text { Sorted }\end{array}$ & $\begin{array}{c}\text { Unimodal, Very Poorly } \\
\text { Sorted }\end{array}$ & $\begin{array}{c}\text { Unimodal, Very Poorly } \\
\text { Sorted }\end{array}$ \\
\hline Sandy Mud & Sandy Mud & Sandy Mud \\
\hline Very Fine Sandy Fine Silt & Very Fine Sandy Fine Silt & Very Fine Sandy Fine Silt \\
\hline 59.37352631 & 58.2890047 & 63.26354326 \\
\hline 196.9078825 & 183.5737903 & 203.4042368 \\
\hline 6.296700201 & 6.363264117 & 6.154509921 \\
\hline 45.94424609 & 48.24093322 & 43.85322127 \\
\hline 12.14597875 & 12.58135038 & 12.77109491 \\
\hline 4.928791977 & 4.911458456 & 5.114288382 \\
\hline 0.580410873 & 0.55146462 & 0.540249827 \\
\hline 3.133451313 & 2.993050355 & 2.947101117 \\
\hline 6.329497161 & 6.288984508 & 6.251436439 \\
\hline 2.321222292 & 2.309648472 & 2.376068498 \\
\hline-0.604502958 & -0.568900145 & -0.564078972 \\
\hline 3.162623192 & 3.017080776 & 2.974752944 \\
\hline 11.81283513 & 12.3061309 & 12.60848593 \\
\hline 4.856413401 & 4.890463349 & 5.091232547 \\
\hline 0.15527327 & 0.167802935 & 0.169575012 \\
\hline 0.925411551 & 0.916138539 & 0.88730168 \\
\hline 6.40350093 & 6.344478947 & 6.309461147 \\
\hline 2.279891236 & 2.28997116 & 2.348014964 \\
\hline-0.15527327 & -0.167802935 & -0.169575012 \\
\hline 0.925411551 & 0.916138539 & 0.88730168 \\
\hline Medium Silt & Medium Silt & Medium Silt \\
\hline Very Poorly Sorted & Very Poorly Sorted & Very Poorly Sorted \\
\hline Coarse Skewed & Coarse Skewed & Coarse Skewed \\
\hline Mesokurtic & Mesokurtic & Platykurtic \\
\hline 4.7 & 6.65 & 4.7 \\
\hline 7.754331413 & 7.254331413 & 7.754331413 \\
\hline 1.795488146 & 1.862447707 & 1.812297435 \\
\hline 10.15898886 & 10.34862453 & 10.45977559 \\
\hline 104.7441216 & 110.8639264 & 117.8591595 \\
\hline 58.33740635 & 59.5259271 & 65.03301127 \\
\hline 102.9486334 & 109.0014787 & 116.0468621 \\
\hline 9.485402229 & 9.650103299 & 10.75689557 \\
\hline 31.75200523 & 33.30101837 & 36.7409341 \\
\hline 3.255058816 & 3.173138086 & 3.084864212 \\
\hline 6.621099374 & 6.594417162 & 6.579004291 \\
\hline 9.121408157 & 9.068584366 & 9.107964534 \\
\hline 2.802225297 & 2.857923015 & 2.952468539 \\
\hline 5.866349341 & 5.89544628 & 6.023100322 \\
\hline 1.673903347 & 1.688468572 & 1.740901858 \\
\hline 3.245708953 & 3.270544386 & 3.427189873 \\
\hline 0.164074966 & 0.173332283 & 0.186252789 \\
\hline 0.835925034 & 0.826667717 & 0.813747211 \\
\hline 0.01883145 & 0.015132829 & 0.020670112 \\
\hline 0.01016565 & 0.011899603 & 0.009234872 \\
\hline 0.01076559 & 0.012399587 & 0.011268545 \\
\hline 0.04036263 & 0.046065131 & 0.05104184 \\
\hline 0.083949645 & 0.087835133 & 0.09403742 \\
\hline 0.106625486 & 0.103798539 & 0.104080461 \\
\hline 0.132503252 & 0.130003046 & 0.12466617 \\
\hline 0.16101496 & 0.162483928 & 0.15348625 \\
\hline 0.175367868 & 0.176848816 & 0.17263509 \\
\hline 0.147858859 & 0.146608847 & 0.147761818 \\
\hline 0.112554609 & 0.106924541 & 0.1111117422 \\
\hline
\end{tabular}




\begin{tabular}{|c|c|c|}
\hline $302-2-A-24-X-3$ & $302-2-A-24-X-3$ & $302-2-A-25-X-1$ \\
\hline Cristin Ashmankas, & Cristin Ashmankas, & Cristin Ashmankas, \\
\hline $\begin{array}{c}\text { Unimodal, Very Poorly } \\
\text { Sorted }\end{array}$ & $\begin{array}{c}\text { Unimodal, Very Poorly } \\
\text { Sorted }\end{array}$ & $\begin{array}{c}\text { Unimodal, Very Poorly } \\
\text { Sorted }\end{array}$ \\
\hline Sandy Mud & Sandy Mud & Sandy Mud \\
\hline Very Fine Sandy Fine Silt & Very Fine Sandy Fine Silt & Very Fine Sandy Fine Silt \\
\hline 64.19759488 & 57.62330917 & 55.16658475 \\
\hline 198.141659 & 185.0424116 & 194.9388519 \\
\hline 5.908332459 & 6.605324497 & 6.603848057 \\
\hline 41.96914928 & 51.52625484 & 49.34496093 \\
\hline 12.29661888 & 11.98437198 & 11.40248152 \\
\hline 5.240969627 & 5.010986821 & 4.755115677 \\
\hline 0.61936506 & 0.573568598 & 0.608759015 \\
\hline 2.953372444 & 2.953975652 & 3.291896458 \\
\hline 6.315444995 & 6.352140142 & 6.419129823 \\
\hline 2.406775015 & 2.343222735 & 2.272231909 \\
\hline-0.634537892 & -0.594172259 & -0.638410669 \\
\hline 2.969057462 & 2.983656302 & 3.331698374 \\
\hline 12.0861704 & 11.83118468 & 11.14021787 \\
\hline 5.289775143 & 5.052367176 & 4.634702688 \\
\hline 0.219541464 & 0.194103566 & 0.148675114 \\
\hline 0.93803462 & 0.92011479 & 0.916487608 \\
\hline 6.370499002 & 6.401261649 & 6.488078742 \\
\hline 2.403206398 & 2.336959489 & 2.212476794 \\
\hline-0.219541464 & -0.194103566 & -0.148675114 \\
\hline 0.93803462 & 0.92011479 & 0.916487608 \\
\hline Medium Silt & Medium Silt & Medium Silt \\
\hline Very Poorly Sorted & Very Poorly Sorted & Very Poorly Sorted \\
\hline Coarse Skewed & Coarse Skewed & Coarse Skewed \\
\hline Mesokurtic & Mesokurtic & Mesokurtic \\
\hline 4.7 & 4.7 & 4.7 \\
\hline 7.754331413 & 7.754331413 & 7.754331413 \\
\hline 1.764913765 & 1.766305711 & 1.763356265 \\
\hline 9.534484926 & 9.607349369 & 9.602538359 \\
\hline 127.9303071 & 115.7309014 & 93.0936881 \\
\hline 72.48530188 & 65.52144436 & 52.79346547 \\
\hline 126.1653933 & 113.9645957 & 91.33033184 \\
\hline 10.28351115 & 9.940208319 & 8.915873819 \\
\hline 33.41027578 & 32.29478633 & 28.79383296 \\
\hline 2.966570011 & 3.111153964 & 3.425172836 \\
\hline 6.712629282 & 6.701645833 & 6.702368463 \\
\hline 9.14618659 & 9.145049219 & 9.147460301 \\
\hline 3.083084692 & 2.939439618 & 2.67065656 \\
\hline 6.179616579 & 6.033895255 & 5.722287465 \\
\hline 1.706955327 & 1.690325208 & 1.638106972 \\
\hline 3.36226103 & 3.313276087 & 3.156376199 \\
\hline 0.18235997 & 0.174378159 & 0.150545461 \\
\hline 0.81764003 & 0.825621841 & 0.849454539 \\
\hline 0.017776778 & 0.0163 & 0.0192 \\
\hline 0.013026303 & 0.008133333 & 0.0083 \\
\hline 0.019851985 & 0.0158 & 0.0043 \\
\hline 0.051280128 & 0.050666667 & 0.0355 \\
\hline 0.080424776 & 0.083478159 & 0.083245461 \\
\hline 0.091055559 & 0.095852115 & 0.105414401 \\
\hline 0.118404851 & 0.122368044 & 0.131917806 \\
\hline 0.156421667 & 0.157612896 & 0.163672212 \\
\hline 0.180932693 & 0.180034837 & 0.180681368 \\
\hline 0.155100106 & 0.154208583 & 0.152111146 \\
\hline 0.115725154 & 0.115545366 & 0.115657607 \\
\hline
\end{tabular}




\begin{tabular}{|c|c|c|}
\hline $\begin{array}{c}\text { 302-2-A-25-X-1 } \\
\text { Cristin Ashmankas, }\end{array}$ & $\begin{array}{c}\text { 302-2-A-25-X-2 } \\
\text { Cristin Ashmankas, }\end{array}$ & $\begin{array}{c}\text { 302-2-A-25-X-2 } \\
\text { Cristin Ashmankas, }\end{array}$ \\
\hline $\begin{array}{l}\text { Unimodal, Very Poorly } \\
\text { Sorted }\end{array}$ & $\begin{array}{l}\text { Unimodal, Very Poorly } \\
\text { Sorted }\end{array}$ & $\begin{array}{l}\text { Unimodal, Very Poorly } \\
\text { Sorted }\end{array}$ \\
\hline Sandy Mud & Sandy Mud & Sandy Mud \\
\hline Very Fine Sandy Fine Silt & Very Fine Sandy Fine Silt & Very Fine Sandy Fine Silt \\
\hline 60.09948675 & 58.521988 & 60.3359379 \\
\hline 185.3935034 & 213.8418623 & 186.5443825 \\
\hline 6.5521595 & 6.028300497 & 6.595505798 \\
\hline 50.75914085 & 41.2441135 & 51.26552364 \\
\hline 13.40771791 & 10.08491416 & 13.51714478 \\
\hline 5.026111673 & 4.78338094 & 5.012158488 \\
\hline 0.440391961 & 0.881756547 & 0.438768058 \\
\hline 2.798178004 & 3.86809282 & 2.80419472 \\
\hline 6.190900118 & 6.583157236 & 6.17584425 \\
\hline 2.345083669 & 2.292658076 & 2.342648314 \\
\hline-0.46160224 & -0.911680896 & -0.462433778 \\
\hline 2.828775351 & 3.878740884 & 2.837689834 \\
\hline 13.24064423 & 9.527727498 & 13.40381316 \\
\hline 5.052409763 & 4.598113766 & 5.04540956 \\
\hline 0.132613605 & 0.214381901 & 0.13394442 \\
\hline 0.878611069 & 1.074052907 & 0.883552535 \\
\hline 6.238882871 & 6.713652133 & 6.221212708 \\
\hline 2.33697165 & 2.201042162 & 2.334971384 \\
\hline-0.132613605 & -0.214381901 & -0.13394442 \\
\hline 0.878611069 & 1.074052907 & 0.883552535 \\
\hline Medium Silt & Medium Silt & Medium Silt \\
\hline Very Poorly Sorted & Very Poorly Sorted & Very Poorly Sorted \\
\hline Coarse Skewed & Coarse Skewed & Coarse Skewed \\
\hline Platykurtic & Mesokurtic & Platykurtic \\
\hline 4.7 & 4.7 & 6.65 \\
\hline 7.754331413 & 7.754331413 & 7.254331413 \\
\hline 1.849705961 & 1.715222237 & 1.876469033 \\
\hline 11.45714737 & 8.101143584 & 11.57734257 \\
\hline 118.6337065 & 86.65420573 & 120.0356112 \\
\hline 64.1365217 & 50.52068698 & 63.96887404 \\
\hline 116.7840006 & 84.93898349 & 118.1591422 \\
\hline 10.84249001 & 7.199918375 & 10.71769982 \\
\hline 38.86825281 & 20.96312593 & 38.99498475 \\
\hline 3.075414125 & 3.528586418 & 3.058465618 \\
\hline 6.447608307 & 6.947658707 & 6.43255205 \\
\hline 9.078488334 & 9.18738877 & 9.057763803 \\
\hline 2.951956376 & 2.603702356 & 2.96153854 \\
\hline 6.00307421 & 5.658802352 & 5.999298184 \\
\hline 1.756462624 & 1.531312792 & 1.753850654 \\
\hline 3.438624209 & 2.847980551 & 3.42192341 \\
\hline 0.19087355 & 0.127193204 & 0.191976688 \\
\hline 0.80912645 & 0.872806796 & 0.808023312 \\
\hline 0.016330612 & 0.023466667 & 0.016867791 \\
\hline 0.00869855 & 0.0098 & 0.00780052 \\
\hline 0.013997667 & 0.010966667 & 0.014900993 \\
\hline 0.053824363 & 0.0295 & 0.05490366 \\
\hline 0.098022359 & 0.053459871 & 0.097503723 \\
\hline 0.111994013 & 0.081644869 & 0.11146617 \\
\hline 0.131510585 & 0.126640527 & 0.132300453 \\
\hline 0.153453104 & 0.174322163 & 0.155387641 \\
\hline 0.164761982 & 0.20009933 & 0.165271785 \\
\hline 0.13964102 & 0.168661172 & 0.137977755 \\
\hline 0.107765745 & 0.121438736 & 0.105619507 \\
\hline
\end{tabular}




\begin{tabular}{|c|c|c|}
\hline$\frac{302-2-A-25-X-3}{}$ & $\begin{array}{c}\text { 302-2-A-26-X-1 } \\
\text { Cristin Ashmankas }\end{array}$ & $\frac{302-2-\mathrm{A}-26-\mathrm{X}-1}{}$ \\
\hline $\begin{array}{c}\text { Bimodal, Very Poorly } \\
\text { Sorted }\end{array}$ & $\begin{array}{l}\text { Unimodal, Very Poorly } \\
\text { Sorted }\end{array}$ & $\begin{array}{c}\text { Bimodal, Very Poorly } \\
\text { Sorted }\end{array}$ \\
\hline Sandy Mud & Sandy Mud & Sandy Mud \\
\hline Very Fine Sandy Fine Silt & Very Fine Sandy Fine Silt & Very Fine Sandy Fine Silt \\
\hline 64.79503683 & 62.15660293 & 70.97934596 \\
\hline 201.447541 & 184.5785954 & 186.2809513 \\
\hline 6.012099196 & 6.399835004 & 5.994418782 \\
\hline 42.58328677 & 49.64800999 & 45.58560994 \\
\hline 12.60262855 & 13.42836142 & 15.84001924 \\
\hline 5.283727125 & 5.159942348 & 5.503658342 \\
\hline 0.568710808 & 0.477226381 & 0.337090278 \\
\hline 2.85502696 & 2.738509514 & 2.406562463 \\
\hline 6.279903989 & 6.189667326 & 5.948721681 \\
\hline 2.41801482 & 2.38221957 & 2.472950359 \\
\hline-0.584057787 & -0.49482774 & -0.351734979 \\
\hline 2.872766823 & 2.762818904 & 2.426053539 \\
\hline 12.4689701 & 13.33295661 & 15.83108528 \\
\hline 5.310386417 & 5.256624449 & 5.662604596 \\
\hline 0.207541543 & 0.174110962 & 0.147642096 \\
\hline 0.890781894 & 0.8977375 & 0.831349499 \\
\hline 6.325513882 & 6.228859454 & 5.981096029 \\
\hline 2.408816844 & 2.394136668 & 2.501465794 \\
\hline-0.207541543 & -0.174110962 & -0.147642096 \\
\hline 0.890781894 & 0.8977375 & 0.831349499 \\
\hline Medium Silt & Medium Silt & Coarse Silt \\
\hline Very Poorly Sorted & Very Poorly Sorted & Very Poorly Sorted \\
\hline Coarse Skewed & Coarse Skewed & Coarse Skewed \\
\hline Platykurtic & Platykurtic & Platykurtic \\
\hline 4.7 & 4.7 & 4.7 \\
\hline 107.5 & & 107.5 \\
\hline 7.754331413 & 7.754331413 & 7.754331413 \\
\hline 3.236965594 & & 3.236965594 \\
\hline 1.762134453 & 1.848272838 & 1.943594179 \\
\hline 9.79265147 & 10.94824669 & 13.19440642 \\
\hline 132.4864767 & 134.7687437 & 170.5054418 \\
\hline 75.18522577 & 72.91604406 & 87.72687408 \\
\hline 130.7243422 & 132.9204709 & 168.5618477 \\
\hline 11.18822919 & 10.95922754 & 14.31183892 \\
\hline 36.73628896 & 38.84494898 & 55.74699267 \\
\hline 2.916082988 & 2.891442157 & 2.55211031 \\
\hline 6.674084746 & 6.513156342 & 6.243929741 \\
\hline 9.148460277 & 9.079606544 & 9.007057268 \\
\hline 3.137242772 & 3.140165375 & 3.529258603 \\
\hline 6.232377289 & 6.188164387 & 6.454946958 \\
\hline 1.752208944 & 1.759456192 & 1.945492451 \\
\hline 3.483909807 & 3.454074209 & 3.83913715 \\
\hline 0.191727604 & 0.196936846 & 0.243655715 \\
\hline 0.808272396 & 0.803063154 & 0.756344285 \\
\hline 0.019365376 & 0.015635939 & 0.015267685 \\
\hline 0.009532698 & 0.00870145 & 0.010567371 \\
\hline 0.015732285 & 0.022503751 & 0.033668911 \\
\hline 0.061095927 & 0.060410068 & 0.078271885 \\
\hline 0.08600132 & 0.089685637 & 0.105879863 \\
\hline 0.094901145 & 0.100984214 & 0.106416858 \\
\hline 0.116227389 & 0.126340672 & 0.117510591 \\
\hline 0.149668032 & 0.155655762 & 0.141078924 \\
\hline 0.177276798 & 0.169714933 & 0.157223475 \\
\hline 0.154260952 & 0.142428413 & 0.133404404 \\
\hline 0.115938079 & 0.10793916 & 0.100710033 \\
\hline
\end{tabular}




\begin{tabular}{|c|c|c|}
\hline $\begin{array}{c}\text { 302-2-A-26-X-2 } \\
\text { Cristin Ashmankas, }\end{array}$ & $\begin{array}{c}\text { 302-2-A-27-X-1 } \\
\text { Cristin Ashmankas, }\end{array}$ & $\begin{array}{c}\text { 302-2-A-27-X-1 } \\
\text { Cristin Ashmankas, }\end{array}$ \\
\hline $\begin{array}{c}\text { Bimodal, Very Poorly } \\
\text { Sorted }\end{array}$ & $\begin{array}{l}\text { Unimodal, Very Poorly } \\
\text { Sorted }\end{array}$ & $\begin{array}{l}\text { Unimodal, Very Poorly } \\
\text { Sorted }\end{array}$ \\
\hline Sandy Mud & Sandy Mud & Sandy Mud \\
\hline Very Fine Sandy Fine Silt & Very Fine Sandy Fine Silt & Very Fine Sandy Fine Silt \\
\hline 62.63947665 & 65.05542262 & 58.4795956 \\
\hline 202.5596161 & 207.2456418 & 182.9461777 \\
\hline 6.216768708 & 6.128858505 & 6.526079311 \\
\hline 45.00440993 & 43.07700687 & 50.68106748 \\
\hline 12.22671078 & 14.01734944 & 12.50258646 \\
\hline 5.103454005 & 5.002091816 & 5.024687431 \\
\hline 0.62198034 & 0.454280151 & 0.525053333 \\
\hline 3.041328927 & 2.953493814 & 2.888380194 \\
\hline 6.30963673 & 6.116119146 & 6.297043243 \\
\hline 2.376682876 & 2.342571127 & 2.342994575 \\
\hline-0.646892877 & -0.482117786 & -0.541981052 \\
\hline 3.066969652 & 2.984136681 & 2.913045859 \\
\hline 12.18683315 & 13.87054797 & 12.31026961 \\
\hline 5.141624424 & 4.932486889 & 5.069051912 \\
\hline 0.208687021 & 0.108166787 & 0.169756467 \\
\hline 0.949907726 & 0.885248629 & 0.912564432 \\
\hline 6.358532911 & 6.171831406 & 6.343993831 \\
\hline 2.362224231 & 2.302315216 & 2.341715939 \\
\hline-0.208687021 & -0.108166787 & -0.169756467 \\
\hline 0.949907726 & 0.885248629 & 0.912564432 \\
\hline Medium Silt & Medium Silt & Medium Silt \\
\hline Very Poorly Sorted & Very Poorly Sorted & Very Poorly Sorted \\
\hline Coarse Skewed & Coarse Skewed & Coarse Skewed \\
\hline Mesokurtic & Platykurtic & Mesokurtic \\
\hline 4.7 & 9.4 & 4.7 \\
\hline 107.5 & & \\
\hline 7.754331413 & 6.754331413 & 7.754331413 \\
\hline 3.236965594 & & \\
\hline 1.810998176 & 1.949164185 & 1.78972212 \\
\hline 9.736440077 & 12.38203757 & 10.27724637 \\
\hline 126.5915043 & 116.5266914 & 118.9582962 \\
\hline 69.90150844 & 59.78290196 & 66.46746715 \\
\hline 124.7805061 & 114.5775272 & 117.1685741 \\
\hline 9.586339947 & 10.41347816 & 10.13812316 \\
\hline 31.87880305 & 39.73162296 & 33.97312056 \\
\hline 2.981747508 & 3.101267641 & 3.071472206 \\
\hline 6.682389907 & 6.335607448 & 6.604402421 \\
\hline 9.108999191 & 9.002928665 & 9.126048679 \\
\hline 3.054919696 & 2.902983459 & 2.971229452 \\
\hline 6.127251684 & 5.901661024 & 6.054576474 \\
\hline 1.67763133 & 1.749876426 & 1.706547967 \\
\hline 3.260980101 & 3.380380113 & 3.34171869 \\
\hline 0.178364936 & 0.192156443 & 0.178512316 \\
\hline 0.821635064 & 0.807843557 & 0.821487684 \\
\hline 0.020800693 & 0.02189781 & 0.015435906 \\
\hline 0.007266909 & 0.00816585 & 0.008768128 \\
\hline 0.0180006 & 0.00979902 & 0.0156026 \\
\hline 0.055035168 & 0.050294971 & 0.054275713 \\
\hline 0.077261566 & 0.101998793 & 0.084429969 \\
\hline 0.089664181 & 0.118158701 & 0.100299442 \\
\hline 0.123541157 & 0.138507083 & 0.128574127 \\
\hline 0.163911372 & 0.15777346 & 0.158457316 \\
\hline 0.181855494 & 0.161225595 & 0.172145877 \\
\hline 0.151321454 & 0.131855933 & 0.148856138 \\
\hline 0.1111341406 & 0.100322784 & 0.113154783 \\
\hline
\end{tabular}




\begin{tabular}{|c|c|c|}
\hline$\frac{302-2-A-27-X-2}{}$ & 302-2-A-27-X-2 & 302-2-A-27-X-3 \\
\hline $\begin{array}{l}\text { Unimodal, Very Poorly } \\
\text { Sorted }\end{array}$ & $\begin{array}{l}\text { Unimodal, Very Poorly } \\
\text { Sorted }\end{array}$ & $\begin{array}{l}\text { Unimodal, Very Poorly } \\
\text { Sorted }\end{array}$ \\
\hline Sandy Mud & Sandy Mud & Sandy Mud \\
\hline Very Fine Sandy Fine Silt & Very Fine Sandy Fine Silt & Very Fine Sandy Fine Silt \\
\hline 61.93474551 & 58.60549048 & 60.48492448 \\
\hline 211.5481879 & 162.6494564 & 179.6607173 \\
\hline 6.058104562 & 7.21584709 & 6.79963037 \\
\hline 41.88325203 & 63.12147309 & 54.65464254 \\
\hline 11.63647249 & 15.83374595 & 14.92504362 \\
\hline 4.984124115 & 4.893511059 & 4.910947411 \\
\hline 0.677702653 & 0.203030419 & 0.325496363 \\
\hline 3.300567925 & 2.511046323 & 2.694171818 \\
\hline 6.378032601 & 5.963247949 & 6.036548981 \\
\hline 2.346040633 & 2.298459201 & 2.309721719 \\
\hline-0.706307557 & -0.218378349 & -0.349355286 \\
\hline 3.324504042 & 2.53603364 & 2.728916949 \\
\hline 11.3993703 & 15.74571136 & 14.88993221 \\
\hline 4.905942084 & 4.940294546 & 4.935781554 \\
\hline 0.190296821 & 0.038658291 & 0.084319235 \\
\hline 0.963983123 & 0.817920558 & 0.851563731 \\
\hline 6.454902058 & 5.988897252 & 6.069519004 \\
\hline 2.294530203 & 2.304597059 & 2.303278546 \\
\hline-0.190296821 & -0.038658291 & -0.084319235 \\
\hline 0.963983123 & 0.817920558 & 0.851563731 \\
\hline Medium Silt & Coarse Silt & Medium Silt \\
\hline Very Poorly Sorted & Very Poorly Sorted & Very Poorly Sorted \\
\hline Coarse Skewed & Symmetrical & Symmetrical \\
\hline Mesokurtic & Platykurtic & Platykurtic \\
\hline 4.7 & 9.4 & 9.4 \\
\hline 7.754331413 & 6.754331413 & 6.754331413 \\
\hline 1.779381575 & 2.039430602 & 2.019595885 \\
\hline 9.468116775 & 14.96481696 & 13.50126819 \\
\hline 107.9710889 & 123.3060677 & 122.1701597 \\
\hline 60.67899679 & 60.4610265 & 60.49237903 \\
\hline 106.1917073 & 121.2666371 & 120.1505639 \\
\hline 8.932039281 & 11.89010673 & 11.03292721 \\
\hline 28.87274454 & 50.01879004 & 44.65660164 \\
\hline 3.211283037 & 3.019684301 & 3.033036147 \\
\hline 6.722706785 & 6.062281557 & 6.210761263 \\
\hline 9.134408366 & 8.937617869 & 8.951717642 \\
\hline 2.844473147 & 2.95978552 & 2.951404865 \\
\hline 5.923125328 & 5.917933568 & 5.918681495 \\
\hline 1.639102844 & 1.851488487 & 1.796645732 \\
\hline 3.158989596 & 3.571689761 & 3.463743707 \\
\hline 0.161407627 & 0.224404262 & 0.208873974 \\
\hline 0.838592373 & 0.775595738 & 0.791126026 \\
\hline 0.023032566 & 0.011866271 & 0.015603641 \\
\hline 0.009033032 & 0.006366454 & 0.00720168 \\
\hline 0.010132996 & 0.01229959 & 0.012102824 \\
\hline 0.042198593 & 0.067031099 & 0.061447671 \\
\hline 0.077010441 & 0.126840847 & 0.112518157 \\
\hline 0.094349749 & 0.131688913 & 0.121229349 \\
\hline 0.127312491 & 0.135107508 & 0.13814204 \\
\hline 0.165738531 & 0.145432629 & 0.155131335 \\
\hline 0.183375721 & 0.147602067 & 0.155517394 \\
\hline 0.153576831 & 0.122453357 & 0.126429175 \\
\hline 0.11423905 & 0.093311265 & 0.094676734 \\
\hline
\end{tabular}




\begin{tabular}{|c|c|c|}
\hline $\begin{array}{c}\text { 302-2-A-29-X-1 } \\
\text { Cristin Ashmankas }\end{array}$ & $\begin{array}{c}\text { 302-2-A-29-X-1 } \\
\text { Cristin Ashmankas, }\end{array}$ & $\begin{array}{c}\text { 302-2-A-29-X-2 } \\
\text { Cristin Ashmankas, }\end{array}$ \\
\hline $\begin{array}{c}\text { Bimodal, Very Poorly } \\
\text { Sorted }\end{array}$ & $\begin{array}{l}\text { Unimodal, Very Poorly } \\
\text { Sorted }\end{array}$ & $\begin{array}{c}\text { Bimodal, Very Poorly } \\
\text { Sorted }\end{array}$ \\
\hline Sandy Mud & Sandy Mud & Sandy Mud \\
\hline Very Fine Sandy Fine Silt & Very Fine Sandy Fine Silt & Very Fine Sandy Fine Silt \\
\hline 92.59134058 & 58.54942354 & 66.6642035 \\
\hline 201.5271105 & 191.9352858 & 175.6544938 \\
\hline 4.547807929 & 6.576381019 & 6.566871692 \\
\hline 29.3644321 & 49.83212922 & 53.30937769 \\
\hline 19.58287 & 12.8515107 & 16.65783413 \\
\hline 6.248106619 & 4.862297874 & 5.299334507 \\
\hline 0.238010587 & 0.502178383 & 0.198451803 \\
\hline 2.11414806 & 3.012864657 & 2.354636944 \\
\hline 5.646361637 & 6.245711629 & 5.881412126 \\
\hline 2.650559871 & 2.301875096 & 2.415735159 \\
\hline-0.24386284 & -0.53059282 & -0.214420553 \\
\hline 2.120088375 & 3.051124105 & 2.379368969 \\
\hline 19.46289696 & 12.70894235 & 16.59785942 \\
\hline 6.565017343 & 4.807217749 & 5.369122282 \\
\hline 0.141740794 & 0.13628446 & 0.051751093 \\
\hline 0.79206774 & 0.892914113 & 0.791568017 \\
\hline 5.683129725 & 6.298012217 & 5.912858997 \\
\hline 2.714798822 & 2.265202154 & 2.424686263 \\
\hline-0.141740794 & -0.13628446 & -0.051751093 \\
\hline 0.79206774 & 0.892914113 & 0.791568017 \\
\hline Coarse Silt & Medium Silt & Coarse Silt \\
\hline Very Poorly Sorted & Very Poorly Sorted & Very Poorly Sorted \\
\hline Coarse Skewed & Coarse Skewed & Symmetrical \\
\hline Platykurtic & Platykurtic & Platykurtic \\
\hline 4.7 & 6.65 & 4.7 \\
\hline 107.5 & & 107.5 \\
\hline 7.754331413 & 7.254331413 & 7.754331413 \\
\hline 3.236965594 & & 3.236965594 \\
\hline 1.992002828 & 1.885037492 & 1.968320493 \\
\hline 16.12648012 & 10.96871864 & 15.50101341 \\
\hline 252.7589333 & 108.7172547 & 149.239236 \\
\hline 126.8868346 & 57.67378907 & 75.82059759 \\
\hline 250.7669305 & 106.8322172 & 147.2709155 \\
\hline 20.11609878 & 9.77871501 & 14.4842558 \\
\hline 85.00132113 & 34.94907929 & 59.4906423 \\
\hline 1.984166012 & 3.201347163 & 2.744301215 \\
\hline 5.954424609 & 6.51046119 & 6.011493652 \\
\hline 8.971564589 & 9.051191066 & 8.988819137 \\
\hline 4.521579613 & 2.827306944 & 3.27544917 \\
\hline 6.987398577 & 5.849843903 & 6.244517922 \\
\hline 2.243329521 & 1.702470285 & 1.971882415 \\
\hline 4.330278638 & 3.289644898 & 3.856413655 \\
\hline 0.305249565 & 0.17646548 & 0.254068859 \\
\hline 0.694750435 & 0.82353452 & 0.745931141 \\
\hline 0.014032398 & 0.018398773 & 0.014066667 \\
\hline 0.026764882 & 0.008266116 & 0.0077 \\
\hline 0.060262649 & 0.00839944 & 0.020533333 \\
\hline 0.092160523 & 0.046696887 & 0.0821 \\
\hline 0.112029113 & 0.094704264 & 0.129668859 \\
\hline 0.097053737 & 0.109822314 & 0.12328802 \\
\hline 0.102582057 & 0.134389417 & 0.121194491 \\
\hline 0.127558531 & 0.162723629 & 0.132695293 \\
\hline 0.144965493 & 0.171256026 & 0.14431703 \\
\hline 0.125741104 & 0.140334275 & 0.125679451 \\
\hline 0.096849513 & 0.105008859 & 0.098756855 \\
\hline
\end{tabular}




\begin{tabular}{|c|c|c|}
\hline $\begin{array}{c}\text { 302-2-A-29-X-3 } \\
\text { Cristin Ashmankas, }\end{array}$ & $\begin{array}{c}\text { 302-2-A-30-X-1 } \\
\text { Cristin Ashmankas, }\end{array}$ & $\begin{array}{c}\text { 302-2-A-30-X-1 } \\
\text { Cristin Ashmankas, }\end{array}$ \\
\hline $\begin{array}{c}\text { Trimodal, Very Poorly } \\
\text { Sorted }\end{array}$ & $\begin{array}{l}\text { Unimodal, Very Poorly } \\
\text { Sorted }\end{array}$ & $\begin{array}{c}\text { Bimodal, Very Poorly } \\
\text { Sorted }\end{array}$ \\
\hline Sandy Mud & Sandy Mud & Sandy Mud \\
\hline y Fine Sandy Very Coarse & Very Fine Sandy Fine Silt & Very Fine Sandy Fine Silt \\
\hline 75.84386802 & 56.28782141 & 59.82287853 \\
\hline 147.0583369 & 189.4647099 & 193.7117444 \\
\hline 6.580728236 & 6.76197007 & 6.501777718 \\
\hline 62.04498185 & 52.11985541 & 48.71824174 \\
\hline 24.56868513 & 12.56385152 & 12.8347724 \\
\hline 5.267836498 & 4.773720663 & 4.987751915 \\
\hline-0.23868863 & 0.500056815 & 0.498396127 \\
\hline 2.200608274 & 3.057073635 & 2.912088955 \\
\hline 5.33208487 & 6.28003049 & 6.248583691 \\
\hline 2.399433967 & 2.27516099 & 2.337800898 \\
\hline 0.229416346 & -0.529838498 & -0.523317195 \\
\hline 2.214347542 & 3.099882409 & 2.946380429 \\
\hline 24.64810541 & 12.3978911 & 12.78473462 \\
\hline 5.379801566 & 4.704412087 & 4.968969146 \\
\hline-0.212952408 & 0.126817745 & 0.153044861 \\
\hline 0.790083281 & 0.885271364 & 0.869046354 \\
\hline 5.342379432 & 6.333761452 & 6.289433976 \\
\hline 2.42755296 & 2.23401444 & 2.312946584 \\
\hline 0.212952408 & -0.126817745 & -0.153044861 \\
\hline 0.790083281 & 0.885271364 & 0.869046354 \\
\hline Coarse Silt & Medium Silt & Medium Silt \\
\hline Very Poorly Sorted & Very Poorly Sorted & Very Poorly Sorted \\
\hline Fine Skewed & Coarse Skewed & Coarse Skewed \\
\hline Platykurtic & Platykurtic & Platykurtic \\
\hline 107.5 & 6.65 & 6.65 \\
\hline 9.4 & & 76.5 \\
\hline 3.236965594 & 7.254331413 & 7.254331413 \\
\hline 6.754331413 & & 3.731217775 \\
\hline 2.28732037 & 1.867783533 & 1.833328931 \\
\hline 32.15401924 & 10.81634387 & 10.67925111 \\
\hline 177.1380406 & 102.203242 & 114.6197396 \\
\hline 77.44347619 & 54.71899726 & 62.52000811 \\
\hline 174.8507202 & 100.3354585 & 112.7864107 \\
\hline 14.49247488 & 9.616448554 & 10.60044282 \\
\hline 86.93733815 & 33.95719273 & 37.03254998 \\
\hline 2.497054029 & 3.290487134 & 3.125072571 \\
\hline 4.958857105 & 6.530643267 & 6.549045709 \\
\hline 8.772125836 & 9.064457021 & 9.091318631 \\
\hline 3.512990001 & 2.754746229 & 2.909154404 \\
\hline 6.275071807 & 5.773969888 & 5.96624606 \\
\hline 2.127604527 & 1.691590892 & 1.738501937 \\
\hline 3.85723208 & 3.265504191 & 3.406052628 \\
\hline 0.35634555 & 0.169713765 & 0.188000207 \\
\hline 0.64365445 & 0.830286235 & 0.811999793 \\
\hline 0.007967729 & 0.018166061 & 0.018767918 \\
\hline 0.006634218 & 0.007233092 & 0.00810054 \\
\hline 0.035171356 & 0.005899803 & 0.007233816 \\
\hline 0.119549273 & 0.042631912 & 0.053370225 \\
\hline 0.187022973 & 0.095782896 & 0.100527709 \\
\hline 0.149246938 & 0.112725902 & 0.102897473 \\
\hline 0.110845936 & 0.134685174 & 0.126052763 \\
\hline 0.104346159 & 0.163061134 & 0.158401923 \\
\hline 0.105182399 & 0.171994422 & 0.171667864 \\
\hline 0.093128667 & 0.141437821 & 0.14374822 \\
\hline 0.080904351 & 0.106381783 & 0.109231551 \\
\hline
\end{tabular}




\begin{tabular}{|c|c|c|}
\hline $302-2-A-30-X-2$ & $302-2-A-30-X-2$ & $302-2-A-30-X-3$ \\
\hline Cristin Ashmankas, & Cristin Ashmankas, & Cristin Ashmankas, \\
\hline $\begin{array}{c}\text { Unimodal, Very Poorly } \\
\text { Sorted }\end{array}$ & $\begin{array}{c}\text { Unimodal, Very Poorly } \\
\text { Sorted }\end{array}$ & $\begin{array}{c}\text { Unimodal, Very Poorly } \\
\text { Sorted }\end{array}$ \\
\hline Sandy Mud & Sandy Mud & Sandy Mud \\
\hline Very Fine Sandy Fine Silt & Very Fine Sandy Fine Silt & Very Fine Sandy Fine Silt \\
\hline 59.93946283 & 65.36486483 & 59.20304813 \\
\hline 193.4385679 & 196.9077398 & 174.7295578 \\
\hline 6.645995559 & 6.005642976 & 6.775586798 \\
\hline 50.8041175 & 43.19713942 & 55.18670728 \\
\hline 12.98177168 & 13.2821472 & 14.30866791 \\
\hline 5.018312196 & 5.277446033 & 4.983445254 \\
\hline 0.471810882 & 0.507858877 & 0.337499982 \\
\hline 2.853857813 & 2.775093465 & 2.660060237 \\
\hline 6.225180415 & 6.202476225 & 6.102054022 \\
\hline 2.349993743 & 2.416203143 & 2.329278314 \\
\hline-0.501158284 & -0.524769557 & -0.356852182 \\
\hline 2.895021399 & 2.795565878 & 2.690340098 \\
\hline 12.92435663 & 13.09603877 & 14.11835419 \\
\hline 5.048542991 & 5.32196832 & 5.00203049 \\
\hline 0.142368691 & 0.180564115 & 0.086828233 \\
\hline 0.873878657 & 0.878598913 & 0.846750682 \\
\hline 6.273763724 & 6.254725692 & 6.14628427 \\
\hline 2.335867086 & 2.411959923 & 2.322513851 \\
\hline-0.142368691 & -0.180564115 & -0.086828233 \\
\hline 0.873878657 & 0.878598913 & 0.846750682 \\
\hline Medium Silt & Medium Silt & Medium Silt \\
\hline Very Poorly Sorted & Very Poorly Sorted & Very Poorly Sorted \\
\hline Coarse Skewed & Coarse Skewed & Symmetrical \\
\hline Platykurtic & Platykurtic & Platykurtic \\
\hline 4.7 & 4.7 & 4.7 \\
\hline 7.754331413 & 7.754331413 & 7.754331413 \\
\hline 1.820210369 & 1.801257154 & 1.906686468 \\
\hline 11.0344597 & 10.65392397 & 12.84827635 \\
\hline 117.6796761 & 131.0776719 & 117.8841807 \\
\hline 64.65168974 & 72.77010483 & 61.82672542 \\
\hline 115.8594657 & 129.2764148 & 115.9774942 \\
\hline 10.8435617 & 11.65102061 & 11.49778451 \\
\hline 37.79610029 & 40.14497659 & 43.50933535 \\
\hline 3.087062915 & 2.93150614 & 3.084557964 \\
\hline 6.5018402 & 6.5524713 & 6.28228136 \\
\hline 9.101679086 & 9.116780124 & 9.034716656 \\
\hline 2.948329638 & 3.109930421 & 2.929015036 \\
\hline 6.014616172 & 6.185273984 & 5.950158692 \\
\hline 1.749834821 & 1.785595312 & 1.802340064 \\
\hline 3.4387668 & 3.542384433 & 3.523283992 \\
\hline 0.188657265 & 0.200066964 & 0.201899867 \\
\hline 0.811342735 & 0.799933036 & 0.798100133 \\
\hline 0.0194 & 0.017933931 & 0.013899073 \\
\hline 0.005533333 & 0.012033734 & 0.009132724 \\
\hline 0.0118 & 0.01740058 & 0.01409906 \\
\hline 0.055 & 0.057201907 & 0.0539964 \\
\hline 0.096923932 & 0.095496812 & 0.110772609 \\
\hline 0.107581725 & 0.100710951 & 0.125037663 \\
\hline 0.129646131 & 0.120209021 & 0.13318529 \\
\hline 0.154408908 & 0.150662275 & 0.146917279 \\
\hline 0.165687889 & 0.169812754 & 0.156347083 \\
\hline 0.143591453 & 0.146436429 & 0.133281726 \\
\hline 0.110426629 & 0.112101606 & 0.103331091 \\
\hline
\end{tabular}




\begin{tabular}{|c|c|c|}
\hline $302-2-A-31-X-1$ & $302-2-A-32-X-1$ & $302-2-A-32-X-1$ \\
\hline Cristin Ashmankas, & Cristin Ashmankas, & Cristin Ashmankas, \\
\hline $\begin{array}{l}\text { Bimodal, Very Poorly } \\
\text { Sorted }\end{array}$ & $\begin{array}{l}\text { Unimodal, Very Poorly } \\
\text { Sorted }\end{array}$ & $\begin{array}{c}\text { Unimodal, Very Poorly } \\
\text { Sorted }\end{array}$ \\
\hline Sandy Mud & Sandy Mud & Sandy Mud \\
\hline Very Fine Sandy Fine Silt & Very Fine Sandy Fine Silt & Very Fine Sandy Fine Silt \\
\hline 61.94937275 & 46.47953632 & 58.04291883 \\
\hline 173.8990807 & 156.8213248 & 184.6014246 \\
\hline 6.758060564 & 8.035233364 & 6.835492152 \\
\hline 55.11618016 & 74.80099714 & 53.75406809 \\
\hline 15.08641617 & 11.49743515 & 13.64749841 \\
\hline 5.188121302 & 4.578685564 & 4.912190072 \\
\hline 0.277501677 & 0.484061632 & 0.370861638 \\
\hline 2.434448456 & 2.914385421 & 2.770642888 \\
\hline 6.0276817 & 6.418957654 & 6.163329151 \\
\hline 2.385384841 & 2.210437244 & 2.312921325 \\
\hline-0.292846748 & -0.510117524 & -0.396947132 \\
\hline 2.459904612 & 2.966537396 & 2.811246774 \\
\hline 14.99636427 & 11.4877435 & 13.54850887 \\
\hline 5.215243191 & 4.621400028 & 4.86580527 \\
\hline 0.099581495 & 0.149909106 & 0.088702149 \\
\hline 0.780934676 & 0.876272754 & 0.824082511 \\
\hline 6.059243415 & 6.443760747 & 6.20572211 \\
\hline 2.382734528 & 2.208329974 & 2.282678585 \\
\hline-0.099581495 & -0.149909106 & -0.088702149 \\
\hline 0.780934676 & 0.876272754 & 0.824082511 \\
\hline Medium Silt & Medium Silt & Medium Silt \\
\hline Very Poorly Sorted & Very Poorly Sorted & Very Poorly Sorted \\
\hline Symmetrical & Coarse Skewed & Symmetrical \\
\hline Platykurtic & Platykurtic & Platykurtic \\
\hline 4.7 & 4.7 & 4.7 \\
\hline \multicolumn{3}{|l|}{107.5} \\
\hline 7.754331413 & 7.754331413 & 7.754331413 \\
\hline \multicolumn{3}{|l|}{3.236965594} \\
\hline 1.90926453 & 1.800031229 & 1.871801689 \\
\hline 13.07981575 & 9.722070839 & 12.14401406 \\
\hline 131.3298477 & 96.36066705 & 110.3005358 \\
\hline 68.78556931 & 53.53277514 & 58.92746888 \\
\hline 129.4205831 & 94.56063582 & 108.4287341 \\
\hline 14.11221605 & 9.329648041 & 11.4015191 \\
\hline 53.92225362 & 30.34069698 & 41.88820024 \\
\hline 2.928733256 & 3.375411809 & 3.180488296 \\
\hline 6.256513971 & 6.684520638 & 6.363610824 \\
\hline 9.032767282 & 9.117762348 & 9.06135669 \\
\hline 3.084189133 & 2.701229617 & 2.849045759 \\
\hline 6.104034025 & 5.742350539 & 5.880868394 \\
\hline 1.92985786 & 1.660340162 & 1.789932186 \\
\hline 3.818872648 & 3.221822657 & 3.511154152 \\
\hline 0.237387262 & 0.160576747 & 0.195962975 \\
\hline 0.762612738 & 0.839423253 & 0.804037025 \\
\hline 0.013868516 & 0.0120004 & 0.017 \\
\hline 0.008234431 & 0.005233508 & 0.007566667 \\
\hline 0.010934791 & 0.00480016 & 0.004433333 \\
\hline 0.073443126 & 0.042768092 & 0.050866667 \\
\hline 0.130906398 & 0.095774587 & 0.116096308 \\
\hline 0.114344192 & 0.102176965 & 0.121853691 \\
\hline 0.11498991 & 0.128374364 & 0.130406601 \\
\hline 0.138186857 & 0.16302718 & 0.148817758 \\
\hline 0.156860255 & 0.178153507 & 0.160021223 \\
\hline 0.135076988 & 0.155039313 & 0.136925581 \\
\hline 0.103154537 & 0.112651924 & 0.106012171 \\
\hline
\end{tabular}




\begin{tabular}{|c|c|c|}
\hline $\begin{array}{c}302-2-A-32-X-2 \\
\text { Cristin Ashmankas. }\end{array}$ & $\begin{array}{c}\text { 302-2-A-32-X-2 } \\
\text { Cristin Ashmankas, }\end{array}$ & $\begin{array}{c}\text { 302-2-A-32-X-3 } \\
\text { Cristin Ashmankas, }\end{array}$ \\
\hline $\begin{array}{c}\text { Bimodal, Very Poorly } \\
\text { Sorted }\end{array}$ & $\begin{array}{c}\text { Unimodal, Very Poorly } \\
\text { Sorted }\end{array}$ & $\begin{array}{c}\text { Unimodal, Very Poorly } \\
\text { Sorted }\end{array}$ \\
\hline Sandy Mud & Sandy Mud & Sandy Mud \\
\hline Very Fine Sandy Fine Silt & Very Fine Sandy Fine Silt & Very Fine Sandy Fine Silt \\
\hline 70.87122229 & 58.52600213 & 59.59303707 \\
\hline 207.8108436 & 179.2684052 & 202.1701322 \\
\hline 5.88326679 & 6.685598298 & 6.20545192 \\
\hline 40.48439057 & 53.02117397 & 44.35031809 \\
\hline 15.93887972 & 13.62499246 & 11.58633996 \\
\hline 5.212220539 & 4.946603272 & 4.890889877 \\
\hline 0.325389007 & 0.402899791 & 0.683702666 \\
\hline 2.666930386 & 2.776459908 & 3.328826914 \\
\hline 5.934101604 & 6.172022765 & 6.394885206 \\
\hline 2.396998357 & 2.31972898 & 2.312808991 \\
\hline-0.347702167 & -0.422880833 & -0.708291654 \\
\hline 2.692313455 & 2.80689083 & 3.352997851 \\
\hline 15.66865948 & 13.44680584 & 11.27202726 \\
\hline 5.137667337 & 4.946645518 & 4.815531981 \\
\hline 0.058855289 & 0.109441729 & 0.188851049 \\
\hline 0.824457665 & 0.864709374 & 0.998426116 \\
\hline 5.995974433 & 6.216592675 & 6.471109184 \\
\hline 2.361113479 & 2.306450518 & 2.267695184 \\
\hline-0.058855289 & -0.109441729 & -0.188851049 \\
\hline 0.824457665 & 0.864709374 & 0.998426116 \\
\hline Coarse Silt & Medium Silt & Medium Silt \\
\hline Very Poorly Sorted & Very Poorly Sorted & Very Poorly Sorted \\
\hline Symmetrical & Coarse Skewed & Coarse Skewed \\
\hline Platykurtic & Platykurtic & Mesokurtic \\
\hline 4.7 & 6.65 & 6.65 \\
\hline \multicolumn{3}{|l|}{53.5} \\
\hline 7.754331413 & 7.254331413 & 7.254331413 \\
\hline \multicolumn{3}{|l|}{4.247428514} \\
\hline 1.995385599 & 1.876304382 & 1.801758769 \\
\hline 14.74152933 & 11.91400133 & 9.445789959 \\
\hline 129.4151984 & 114.8865057 & 108.2972212 \\
\hline 64.85723788 & 61.230207 & 60.10639329 \\
\hline 127.4198128 & 113.0102013 & 106.4954624 \\
\hline 12.65550695 & 10.79513619 & 8.238065387 \\
\hline 51.60754138 & 39.5373893 & 26.86817037 \\
\hline 2.949921039 & 3.121718743 & 3.20693187 \\
\hline 6.083969988 & 6.391198165 & 6.726112829 \\
\hline 8.969116717 & 9.057890398 & 9.116378418 \\
\hline 3.040459931 & 2.901571584 & 2.84271035 \\
\hline 6.019195679 & 5.936171655 & 5.909446548 \\
\hline 1.880739657 & 1.759294232 & 1.604681052 \\
\hline 3.661693395 & 3.432309539 & 3.042305577 \\
\hline 0.229458181 & 0.190798933 & 0.155535296 \\
\hline 0.770541819 & 0.809201067 & 0.844464704 \\
\hline 0.021265958 & 0.014866171 & 0.020302707 \\
\hline 0.011032966 & 0.009499683 & 0.008967862 \\
\hline 0.010599647 & 0.011066298 & 0.01140152 \\
\hline 0.060931302 & 0.052531582 & 0.045339379 \\
\hline 0.125628308 & 0.102835198 & 0.069523828 \\
\hline 0.129636729 & 0.117547669 & 0.090943133 \\
\hline 0.129587119 & 0.134318484 & 0.130910013 \\
\hline 0.139928465 & 0.152813906 & 0.172927258 \\
\hline 0.148253651 & 0.162187917 & 0.186987872 \\
\hline 0.126581333 & 0.136692288 & 0.150646302 \\
\hline 0.096554522 & 0.105640803 & 0.112050126 \\
\hline
\end{tabular}




\begin{tabular}{|c|c|c|}
\hline $302-2-A-32-X-3$ & 302-2-A-32-X-4 & 302-2-A-33-X-1 \\
\hline $\begin{array}{l}\text { Unimodal, Very Poorly } \\
\text { Sorted }\end{array}$ & $\begin{array}{l}\text { Unimodal, Very Poorly } \\
\text { Sorted }\end{array}$ & $\begin{array}{l}\text { Unimodal, Very Poorly } \\
\text { Sorted }\end{array}$ \\
\hline Sandy Mud & Sandy Mud & Sandy Mud \\
\hline Very Fine Sandy Fine Silt & Very Fine Sandy Fine Silt & Very Fine Sandy Fine Silt \\
\hline 45.6676364 & 51.041571 & 47.95948553 \\
\hline 168.3511058 & 172.880931 & 165.6591899 \\
\hline 7.320901299 & 6.943160294 & 7.523227694 \\
\hline 61.96927159 & 56.38383525 & 65.76541214 \\
\hline 10.10872076 & 11.36267027 & 11.25048526 \\
\hline 4.380526553 & 4.638780886 & 4.565401288 \\
\hline 0.709035643 & 0.604389675 & 0.541534439 \\
\hline 3.627843211 & 3.225271864 & 3.133892443 \\
\hline 6.605668899 & 6.443276829 & 6.44862399 \\
\hline 2.148353446 & 2.224517399 & 2.207711736 \\
\hline-0.735611456 & -0.620087892 & -0.568734364 \\
\hline 3.673287902 & 3.250831516 & 3.183292821 \\
\hline 9.626546212 & 11.07089887 & 10.79808455 \\
\hline 4.225379971 & 4.575663576 & 4.494903828 \\
\hline 0.150744718 & 0.159111738 & 0.129928836 \\
\hline 0.97623731 & 0.949313788 & 0.905410862 \\
\hline 6.698766 & 6.497083828 & 6.533080772 \\
\hline 2.079081083 & 2.193980982 & 2.168290248 \\
\hline-0.150744718 & -0.159111738 & -0.129928836 \\
\hline 0.97623731 & 0.949313788 & 0.905410862 \\
\hline Medium Silt & Medium Silt & Medium Silt \\
\hline Very Poorly Sorted & Very Poorly Sorted & Very Poorly Sorted \\
\hline Coarse Skewed & Coarse Skewed & Coarse Skewed \\
\hline Mesokurtic & Mesokurtic & Mesokurtic \\
\hline 4.7 & 6.65 & 4.7 \\
\hline 7.754331413 & 7.254331413 & 7.754331413 \\
\hline 1.749519166 & 1.804234059 & 1.774162194 \\
\hline 8.571624826 & 9.49309425 & 9.684016927 \\
\hline 70.34297971 & 93.68156855 & 86.52494523 \\
\hline 40.20703578 & 51.9231793 & 48.76946737 \\
\hline 68.59346054 & 91.87733449 & 84.75078304 \\
\hline 7.299660862 & 8.233719619 & 8.935629362 \\
\hline 21.945782 & 26.6726236 & 28.5327972 \\
\hline 3.829449741 & 3.416090958 & 3.530740067 \\
\hline 6.866215579 & 6.718905878 & 6.690178684 \\
\hline 9.158825815 & 9.114397776 & 9.138646378 \\
\hline 2.391681947 & 2.668078189 & 2.588309025 \\
\hline 5.329376074 & 5.698306818 & 5.607906311 \\
\hline 1.54136984 & 1.603278749 & 1.637008626 \\
\hline 2.867829439 & 3.041544322 & 3.159569346 \\
\hline 0.111244061 & 0.147849266 & 0.134609708 \\
\hline 0.888755939 & 0.852150734 & 0.865390292 \\
\hline 0.01313202 & 0.0133 & 0.013065796 \\
\hline 0.00883245 & 0.009433333 & 0.007032864 \\
\hline 0.00826584 & 0.007833333 & 0.008599427 \\
\hline 0.0246642 & 0.0385 & 0.035930938 \\
\hline 0.056349551 & 0.078782599 & 0.069980683 \\
\hline 0.101183625 & 0.09728529 & 0.120700946 \\
\hline 0.136299582 & 0.132665577 & 0.136575929 \\
\hline 0.176320989 & 0.173643745 & 0.160750728 \\
\hline 0.194363484 & 0.184099689 & 0.176469448 \\
\hline 0.162804814 & 0.152449122 & 0.155615439 \\
\hline 0.117783445 & 0.112007312 & 0.115277801 \\
\hline
\end{tabular}




\begin{tabular}{|c|c|c|}
\hline $\begin{array}{c}\text { 302-2-A-33-X-1 } \\
\text { Cristin Ashmankas, }\end{array}$ & $\begin{array}{c}\text { 302-2-A-33-X-2 } \\
\text { Cristin Ashmankas, }\end{array}$ & $\begin{array}{c}\text { 302-2-A-33-X-2 } \\
\text { Cristin Ashmankas, }\end{array}$ \\
\hline $\begin{array}{l}\text { Unimodal, Very Poorly } \\
\text { Sorted }\end{array}$ & $\begin{array}{l}\text { Unimodal, Very Poorly } \\
\text { Sorted }\end{array}$ & $\begin{array}{l}\text { Unimodal, Very Poorly } \\
\text { Sorted }\end{array}$ \\
\hline Sandy Mud & Sandy Mud & Sandy Mud \\
\hline Very Fine Sandy Fine Silt & Very Fine Sandy Fine Silt & Very Fine Sandy Fine Silt \\
\hline 58.69239349 & 60.3290708 & 69.19041747 \\
\hline 211.4375571 & 195.1476061 & 196.5250024 \\
\hline 6.110545296 & 6.400360829 & 5.866269632 \\
\hline 42.13929318 & 47.35182467 & 42.17630969 \\
\hline 10.79511861 & 12.95721298 & 14.72817623 \\
\hline 4.822838307 & 4.961790706 & 5.327656912 \\
\hline 0.742692242 & 0.499755873 & 0.428261311 \\
\hline 3.582444478 & 2.944440521 & 2.665696026 \\
\hline 6.488957323 & 6.234222734 & 6.050731646 \\
\hline 2.299662512 & 2.330484022 & 2.428983323 \\
\hline-0.773421939 & -0.525519366 & -0.446095605 \\
\hline 3.607188989 & 2.978602461 & 2.6857615 \\
\hline 10.46464596 & 12.74283447 & 14.61159981 \\
\hline 4.642020348 & 4.913087534 & 5.442600451 \\
\hline 0.174416176 & 0.132428066 & 0.147990733 \\
\hline 0.97233935 & 0.874103384 & 0.890392579 \\
\hline 6.578332686 & 6.294169968 & 6.096742044 \\
\hline 2.214752847 & 2.296629943 & 2.44429613 \\
\hline-0.174416176 & -0.132428066 & -0.147990733 \\
\hline 0.97233935 & 0.874103384 & 0.890392579 \\
\hline Medium Silt & Medium Silt & Medium Silt \\
\hline Very Poorly Sorted & Very Poorly Sorted & Very Poorly Sorted \\
\hline Coarse Skewed & Coarse Skewed & Coarse Skewed \\
\hline Mesokurtic & Platykurtic & Platykurtic \\
\hline 6.65 & 4.7 & 4.7 \\
\hline 7.254331413 & 7.754331413 & 7.754331413 \\
\hline 1.717735483 & 1.85033351 & 1.912293243 \\
\hline 8.912238887 & 11.09377719 & 12.45516616 \\
\hline 90.0753573 & 111.5205014 & 148.6841802 \\
\hline 52.43843316 & 60.27048682 & 77.75176782 \\
\hline 88.35762182 & 109.6701679 & 146.771887 \\
\hline 8.174390523 & 10.49165141 & 11.90255095 \\
\hline 25.17704605 & 36.50879832 & 44.94676919 \\
\hline 3.47272372 & 3.164619142 & 2.74967694 \\
\hline 6.809996381 & 6.494105534 & 6.327111922 \\
\hline 9.185276394 & 9.077998955 & 9.030480513 \\
\hline 2.644977584 & 2.868591305 & 3.284196911 \\
\hline 5.712552674 & 5.913379813 & 6.280803573 \\
\hline 1.591610372 & 1.73225993 & 1.821607545 \\
\hline 3.031111168 & 3.391169875 & 3.5731989 \\
\hline 0.141203681 & 0.180712866 & 0.2138756 \\
\hline 0.858796319 & 0.819287134 & 0.7861244 \\
\hline 0.022936392 & 0.01890063 & 0.017465502 \\
\hline 0.00990132 & 0.009166972 & 0.013132458 \\
\hline 0.005567409 & 0.008500283 & 0.024698353 \\
\hline 0.030270703 & 0.048368279 & 0.062229185 \\
\hline 0.072527858 & 0.095776702 & 0.096350102 \\
\hline 0.09449594 & 0.11263529 & 0.108551528 \\
\hline 0.127761549 & 0.133378466 & 0.130329206 \\
\hline 0.171188879 & 0.154189254 & 0.150441683 \\
\hline 0.187813242 & 0.165422544 & 0.159183332 \\
\hline 0.157102422 & 0.145660847 & 0.134685467 \\
\hline 0.120434287 & 0.108000732 & 0.102933183 \\
\hline
\end{tabular}




\begin{tabular}{|c|c|c|}
\hline $302-2-A-33-X-3$ & $\frac{302-2-\mathrm{A}-34-\mathrm{X}-1}{}$ & $\frac{302-2-\mathrm{A}-34-\mathrm{X}-1}{}$ \\
\hline $\begin{array}{c}\text { Bimodal, Very Poorly } \\
\text { Sorted }\end{array}$ & $\begin{array}{c}\text { Bimodal, Very Poorly } \\
\text { Sorted }\end{array}$ & $\begin{array}{c}\text { Unimodal, Very Poorly } \\
\text { Sorted }\end{array}$ \\
\hline Sandy Mud & Sandy Mud & Sandy Mud \\
\hline Very Fine Sandy Fine Silt & Very Fine Sandy Fine Silt & Very Fine Sandy Fine Silt \\
\hline 60.76338829 & 58.63290924 & 48.95108341 \\
\hline 178.3473134 & 169.2466436 & 165.8244934 \\
\hline 6.787555051 & 7.231530531 & 7.153907099 \\
\hline 55.03242034 & 61.61459059 & 60.18678636 \\
\hline 14.45419227 & 15.65946247 & 11.20850491 \\
\hline 5.039326881 & 4.887654176 & 4.591831676 \\
\hline 0.360004296 & 0.204273882 & 0.582617617 \\
\hline 2.629581806 & 2.521846005 & 3.196944813 \\
\hline 6.083795808 & 5.971907868 & 6.465641525 \\
\hline 2.346847752 & 2.300015804 & 2.208276666 \\
\hline-0.380593102 & -0.226048631 & -0.596758252 \\
\hline 2.660746098 & 2.557356352 & 3.221810288 \\
\hline 14.50775193 & 15.6210805 & 10.87342203 \\
\hline 5.118442558 & 4.883033994 & 4.529764794 \\
\hline 0.122706564 & 0.028935126 & 0.149481545 \\
\hline 0.85059282 & 0.790984016 & 0.940353105 \\
\hline 6.107032208 & 6.000361943 & 6.52305014 \\
\hline 2.355704893 & 2.287777821 & 2.179436141 \\
\hline-0.122706564 & -0.028935126 & -0.149481545 \\
\hline 0.85059282 & 0.790984016 & 0.940353105 \\
\hline Medium Silt & Medium Silt & Medium Silt \\
\hline Very Poorly Sorted & Very Poorly Sorted & Very Poorly Sorted \\
\hline Coarse Skewed & Symmetrical & Coarse Skewed \\
\hline Platykurtic & Platykurtic & Mesokurtic \\
\hline 6.65 & 6.65 & 6.65 \\
\hline 107.5 & 76.5 & \\
\hline 7.254331413 & 7.254331413 & 7.254331413 \\
\hline 3.236965594 & 3.731217775 & \\
\hline 1.94687576 & 2.02043294 & 1.77677697 \\
\hline 12.49565161 & 14.89271376 & 9.430222013 \\
\hline 130.6909643 & 119.2469059 & 89.82787982 \\
\hline 67.12855899 & 59.02047208 & 50.55664347 \\
\hline 128.7440886 & 117.226473 & 88.05110285 \\
\hline 11.60692014 & 12.35463792 & 8.275092259 \\
\hline 44.63660451 & 51.24568505 & 26.52276449 \\
\hline 2.935768695 & 3.067976262 & 3.476692907 \\
\hline 6.322430055 & 6.069249523 & 6.728492548 \\
\hline 9.004623463 & 8.951119817 & 9.136521686 \\
\hline 3.067211486 & 2.917597482 & 2.627934629 \\
\hline 6.068854768 & 5.883143555 & 5.659828779 \\
\hline 1.812028906 & 1.870895944 & 1.603620463 \\
\hline 3.536913303 & 3.626980825 & 3.048775397 \\
\hline 0.211763971 & 0.227870778 & 0.143082483 \\
\hline 0.788236029 & 0.772129222 & 0.856917517 \\
\hline 0.015202027 & 0.01379954 & 0.011834122 \\
\hline 0.006434191 & 0.006566448 & 0.00960064 \\
\hline 0.015635418 & 0.005599813 & 0.007267151 \\
\hline 0.067775703 & 0.064864505 & 0.036469098 \\
\hline 0.106716632 & 0.137040472 & 0.077911472 \\
\hline 0.110333714 & 0.131852857 & 0.100712515 \\
\hline 0.130179985 & 0.130753831 & 0.134996588 \\
\hline 0.154364997 & 0.14232823 & 0.16989741 \\
\hline 0.160458609 & 0.147960493 & 0.184002485 \\
\hline 0.1324177 & 0.124584095 & 0.152792392 \\
\hline 0.100481023 & 0.094649717 & 0.114516126 \\
\hline
\end{tabular}




\begin{tabular}{|c|c|c|}
\hline $\begin{array}{c}\text { 302-2-A-34-X-2 } \\
\text { Cristin Ashmankas, }\end{array}$ & $\begin{array}{c}\text { 302-2-A-34-X-2 } \\
\text { Cristin Ashmankas, }\end{array}$ & $\begin{array}{c}\text { 302-2-A-35-X-1 } \\
\text { Cristin Ashmankas. }\end{array}$ \\
\hline $\begin{array}{l}\text { Unimodal, Very Poorly } \\
\text { Sorted }\end{array}$ & $\begin{array}{l}\text { Unimodal, Very Poorly } \\
\text { Sorted }\end{array}$ & $\begin{array}{l}\text { Unimodal, Very Poorly } \\
\text { Sorted }\end{array}$ \\
\hline Sandy Mud & Sandy Mud & Sandy Mud \\
\hline Very Fine Sandy Fine Silt & Very Fine Sandy Fine Silt & Very Fine Sandy Fine Silt \\
\hline 70.42026867 & 56.20254517 & 55.1643579 \\
\hline 197.4399097 & 173.3861209 & 187.8228547 \\
\hline 5.800795394 & 7.050020413 & 6.76840194 \\
\hline 41.93115755 & 58.48548989 & 52.49870066 \\
\hline 14.27570815 & 13.74856745 & 11.8350637 \\
\hline 5.429402966 & 4.846618272 & 4.797093027 \\
\hline 0.503503963 & 0.362358358 & 0.565809986 \\
\hline 2.659969555 & 2.737707651 & 3.127977475 \\
\hline 6.091759511 & 6.15932655 & 6.367572759 \\
\hline 2.458539631 & 2.290125411 & 2.282643214 \\
\hline-0.520280364 & -0.384377852 & -0.593242862 \\
\hline 2.676469803 & 2.773621455 & 3.167647155 \\
\hline 14.23803765 & 13.59880328 & 11.7104682 \\
\hline 5.611996606 & 4.830135187 & 4.748413883 \\
\hline 0.209238326 & 0.088437669 & 0.158089494 \\
\hline 0.909319504 & 0.84366466 & 0.914494365 \\
\hline 6.134105869 & 6.200376493 & 6.416057432 \\
\hline 2.488514136 & 2.272063568 & 2.247445689 \\
\hline-0.209238326 & -0.088437669 & -0.158089494 \\
\hline 0.909319504 & 0.84366466 & 0.914494365 \\
\hline Medium Silt & Medium Silt & Medium Silt \\
\hline Very Poorly Sorted & Very Poorly Sorted & Very Poorly Sorted \\
\hline Coarse Skewed & Symmetrical & Coarse Skewed \\
\hline Mesokurtic & Platykurtic & Mesokurtic \\
\hline 6.65 & 4.7 & 6.65 \\
\hline 7.254331413 & 7.754331413 & 7.254331413 \\
\hline 1.911278312 & 1.912500278 & 1.797862192 \\
\hline 11.22594551 & 12.30965916 & 9.877527197 \\
\hline 168.5478014 & 110.8734454 & 102.1950473 \\
\hline 88.18590171 & 57.9730349 & 56.84253652 \\
\hline 166.636523 & 108.9609451 & 100.3971851 \\
\hline 11.88760874 & 10.87905462 & 9.144797419 \\
\hline 43.52063502 & 40.35718959 & 30.54721914 \\
\hline 2.568770287 & 3.173014219 & 3.290602815 \\
\hline 6.477019228 & 6.344065374 & 6.661634371 \\
\hline 9.031246412 & 9.030324327 & 9.119501844 \\
\hline 3.515785922 & 2.845976634 & 2.77137727 \\
\hline 6.462476125 & 5.857310108 & 5.828899029 \\
\hline 1.812530983 & 1.766594155 & 1.656210445 \\
\hline 3.571386633 & 3.443481288 & 3.192951211 \\
\hline 0.213656665 & 0.190340111 & 0.163951335 \\
\hline 0.786343335 & 0.809659889 & 0.836048665 \\
\hline 0.017666667 & 0.014234282 & 0.01759824 \\
\hline 0.011666667 & 0.0075005 & 0.00763257 \\
\hline 0.036266667 & 0.009533969 & 0.00709929 \\
\hline 0.061833333 & 0.051036736 & 0.04269573 \\
\hline 0.086223332 & 0.108034624 & 0.088925504 \\
\hline 0.094908013 & 0.124532562 & 0.100077919 \\
\hline 0.120467594 & 0.135738141 & 0.129110653 \\
\hline 0.157416933 & 0.149370365 & 0.166596236 \\
\hline 0.169160767 & 0.160430521 & 0.180375752 \\
\hline 0.141305142 & 0.136637556 & 0.147602055 \\
\hline 0.103084887 & 0.102950745 & 0.112286051 \\
\hline
\end{tabular}




\begin{tabular}{|c|c|c|}
\hline $\begin{array}{c}\text { 302-2-A-35-X-2 } \\
\text { Cristin Ashmankas, }\end{array}$ & $\begin{array}{c}302-2-\mathrm{A}-35-\mathrm{X}-3 \\
\text { Cristin Ashmankas }\end{array}$ & $302-2-A-35-X-3$ \\
\hline $\begin{array}{l}\text { Unimodal, Very Poorly } \\
\text { Sorted }\end{array}$ & $\begin{array}{l}\text { Unimodal, Very Poorly } \\
\text { Sorted }\end{array}$ & $\begin{array}{l}\text { Unimodal, Very Poorly } \\
\text { Sorted }\end{array}$ \\
\hline Sandy Mud & Sandy Mud & Sandy Mud \\
\hline Very Fine Sandy Fine Silt & Very Fine Sandy Fine Silt & Very Fine Sandy Fine Silt \\
\hline 54.24977568 & 61.71371159 & 54.6010179 \\
\hline 204.6814506 & 184.1784852 & 180.0494425 \\
\hline 6.36129339 & 6.480415342 & 6.99901428 \\
\hline 45.28811691 & 50.07268717 & 56.37917594 \\
\hline 10.52078376 & 14.10783607 & 12.70424452 \\
\hline 4.540108591 & 5.056467672 & 4.747408107 \\
\hline 0.758707441 & 0.4034318 & 0.461186085 \\
\hline 3.871683026 & 2.71616826 & 2.979657111 \\
\hline 6.528760502 & 6.119789307 & 6.269975118 \\
\hline 2.212565939 & 2.351659084 & 2.263625403 \\
\hline-0.796831336 & -0.422595402 & -0.487267573 \\
\hline 3.907920564 & 2.743505923 & 3.020345472 \\
\hline 10.04230753 & 14.05148449 & 12.59337922 \\
\hline 4.270676996 & 5.092454777 & 4.723757535 \\
\hline 0.128147029 & 0.13007616 & 0.121193774 \\
\hline 0.978882396 & 0.861106564 & 0.89145495 \\
\hline 6.637765379 & 6.153133636 & 6.311190732 \\
\hline 2.094464787 & 2.348361263 & 2.239934915 \\
\hline-0.128147029 & -0.13007616 & -0.121193774 \\
\hline 0.978882396 & 0.861106564 & 0.89145495 \\
\hline Medium Silt & Medium Silt & Medium Silt \\
\hline Very Poorly Sorted & Very Poorly Sorted & Very Poorly Sorted \\
\hline Coarse Skewed & Coarse Skewed & Coarse Skewed \\
\hline Mesokurtic & Platykurtic & Platykurtic \\
\hline 6.65 & 6.65 & 6.65 \\
\hline 7.254331413 & 7.254331413 & 7.254331413 \\
\hline 1.764199795 & 1.915776155 & 1.86983666 \\
\hline 9.129031698 & 12.04532586 & 11.01445736 \\
\hline 74.53174808 & 124.8025267 & 104.8303913 \\
\hline 42.2467729 & 65.1446289 & 56.06392984 \\
\hline 72.76754829 & 122.8867505 & 102.9605547 \\
\hline 7.367432259 & 11.29878982 & 9.504451261 \\
\hline 22.94141582 & 42.53376388 & 34.02860043 \\
\hline 3.746001092 & 3.002280952 & 3.253871066 \\
\hline 6.775322441 & 6.375382766 & 6.504457769 \\
\hline 9.14677033 & 9.027855282 & 9.062872036 \\
\hline 2.441742569 & 3.006998821 & 2.785258497 \\
\hline 5.400769238 & 6.02557433 & 5.80900097 \\
\hline 1.550317742 & 1.79114632 & 1.68874157 \\
\hline 2.88116189 & 3.498096353 & 3.248603335 \\
\hline 0.118094 & 0.205013189 & 0.172322806 \\
\hline 0.881906 & 0.794986811 & 0.827677194 \\
\hline 0.021531898 & 0.015832278 & 0.015967731 \\
\hline 0.009832678 & 0.009399373 & 0.007033802 \\
\hline 0.00329978 & 0.013265782 & 0.0060004 \\
\hline 0.021131925 & 0.061262582 & 0.047569838 \\
\hline 0.06229772 & 0.105253173 & 0.095751034 \\
\hline 0.100632701 & 0.109790288 & 0.11042326 \\
\hline 0.144057736 & 0.129718986 & 0.137412926 \\
\hline 0.179313208 & 0.154962604 & 0.165215264 \\
\hline 0.187357126 & 0.163555763 & 0.170454479 \\
\hline 0.154807283 & 0.134294848 & 0.138052314 \\
\hline 0.115737945 & 0.102664322 & 0.106118951 \\
\hline
\end{tabular}




\begin{tabular}{|c|c|c|}
\hline $302-2-A-35-X-4$ & 302-2-A-35-X-4 & 302-2-A-35-X-5 \\
\hline Cristin Ashmankas, & Cristin Ashmankas, & Cristin Ashmankas, \\
\hline $\begin{array}{l}\text { Unimodal, Very Poorly } \\
\text { Sorted }\end{array}$ & $\begin{array}{l}\text { Unimodal, Very Poorly } \\
\text { Sorted }\end{array}$ & $\begin{array}{l}\text { Unimodal, Very Poorly } \\
\text { Sorted }\end{array}$ \\
\hline Sandy Mud & Sandy Mud & Sandy Mud \\
\hline Very Fine Sandy Fine Silt & Very Fine Sandy Fine Silt & Very Fine Sandy Fine Silt \\
\hline 53.042433 & 57.39103794 & 56.93853369 \\
\hline 177.7448974 & 200.714772 & 186.9337932 \\
\hline 7.097505713 & 6.307427288 & 6.641035927 \\
\hline 57.84840731 & 45.56682514 & 51.31591607 \\
\hline 12.4283314 & 11.00833496 & 11.70238536 \\
\hline 4.69492252 & 4.849081816 & 5.045325985 \\
\hline 0.462220592 & 0.699021287 & 0.558849802 \\
\hline 3.019001602 & 3.41477985 & 2.930734924 \\
\hline 6.302649732 & 6.468050601 & 6.387153214 \\
\hline 2.247521996 & 2.302146413 & 2.35305112 \\
\hline-0.488886961 & -0.725430441 & -0.579070882 \\
\hline 3.062016006 & 3.442614171 & 2.961606243 \\
\hline 12.21654933 & 10.57918987 & 11.59721332 \\
\hline 4.640539154 & 4.740059736 & 5.05244044 \\
\hline 0.111300762 & 0.17540882 & 0.190331901 \\
\hline 0.886736144 & 0.988220758 & 0.879926898 \\
\hline 6.355019349 & 6.562627036 & 6.430078006 \\
\hline 2.214292433 & 2.244905241 & 2.33698041 \\
\hline-0.111300762 & -0.17540882 & -0.190331901 \\
\hline 0.886736144 & 0.988220758 & 0.879926898 \\
\hline Medium Silt & Medium Silt & Medium Silt \\
\hline Very Poorly Sorted & Very Poorly Sorted & Very Poorly Sorted \\
\hline Coarse Skewed & Coarse Skewed & Coarse Skewed \\
\hline Platykurtic & Mesokurtic & Platykurtic \\
\hline 6.65 & 4.7 & 4.7 \\
\hline 7.254331413 & 7.754331413 & 7.754331413 \\
\hline 1.847894127 & 1.7200383 & 1.697462237 \\
\hline 10.86730729 & 9.097087209 & 9.301187184 \\
\hline 98.17555749 & 96.67466601 & 110.9134671 \\
\hline 53.12834542 & 56.20494963 & 65.34075671 \\
\hline 96.32766337 & 94.95462771 & 109.2160048 \\
\hline 9.435240205 & 8.313821837 & 10.61842893 \\
\hline 33.15608662 & 25.70530558 & 33.56684474 \\
\hline 3.348492304 & 3.370718315 & 3.172493547 \\
\hline 6.523861677 & 6.780379601 & 6.748369414 \\
\hline 9.079902183 & 9.183343595 & 9.202404805 \\
\hline 2.711638958 & 2.724447058 & 2.900685113 \\
\hline 5.731409878 & 5.81262528 & 6.029911258 \\
\hline 1.681273239 & 1.599483927 & 1.716956432 \\
\hline 3.238059247 & 3.055511832 & 3.40849842 \\
\hline 0.163622896 & 0.143322935 & 0.177577348 \\
\hline 0.836377104 & 0.856677065 & 0.822422652 \\
\hline 0.015501033 & 0.020068674 & 0.016868354 \\
\hline 0.007167144 & 0.009067573 & 0.008234157 \\
\hline 0.005733716 & 0.01040104 & 0.00990099 \\
\hline 0.041202747 & 0.037437077 & 0.049138247 \\
\hline 0.094018255 & 0.066348571 & 0.0934356 \\
\hline 0.116483698 & 0.094751942 & 0.096514739 \\
\hline 0.138421441 & 0.133931918 & 0.114664049 \\
\hline 0.162152585 & 0.166640584 & 0.152750325 \\
\hline 0.170844257 & 0.184263356 & 0.179810945 \\
\hline 0.140583929 & 0.156892498 & 0.15621908 \\
\hline 0.107891194 & 0.120196768 & 0.122463514 \\
\hline
\end{tabular}




\begin{tabular}{|c|c|c|}
\hline $\begin{array}{c}\text { 302-2-A-37-X-1 } \\
\text { Cristin Ashmankas, }\end{array}$ & $\frac{\text { 302-2-A-37-X-1 }}{\text { Cristin Ashmankas, }}$ & $\begin{array}{c}\text { 302-2-A-38-X-1 } \\
\text { Cristin Ashmankas, }\end{array}$ \\
\hline $\begin{array}{l}\text { Unimodal, Very Poorly } \\
\text { Sorted }\end{array}$ & $\begin{array}{l}\text { Unimodal, Very Poorly } \\
\text { Sorted }\end{array}$ & $\begin{array}{c}\text { Bimodal, Very Poorly } \\
\text { Sorted }\end{array}$ \\
\hline Sandy Mud & Sandy Mud & Sandy Mud \\
\hline Very Fine Sandy Fine Silt & Very Fine Sandy Fine Silt & Very Fine Sandy Fine Silt \\
\hline 63.40946265 & 61.53067314 & 83.39433243 \\
\hline 220.0433753 & 199.7960897 & 161.8443204 \\
\hline 5.699908004 & 6.231255393 & 4.975958217 \\
\hline 37.33255599 & 45.160747 & 38.61321913 \\
\hline 10.32615363 & 12.60518487 & 20.61050833 \\
\hline 5.133703691 & 5.051765457 & 6.118347143 \\
\hline 0.829206492 & 0.520141781 & 0.075045117 \\
\hline 3.531675058 & 3.002448771 & 1.915070517 \\
\hline 6.553037902 & 6.268980559 & 5.590509321 \\
\hline 2.389847868 & 2.359521324 & 2.61547744 \\
\hline-0.849122345 & -0.546954891 & -0.077880897 \\
\hline 3.534992939 & 3.034757916 & 1.920229711 \\
\hline 9.904649963 & 12.25679818 & 20.22943255 \\
\hline 5.027675625 & 5.018931264 & 6.294800297 \\
\hline 0.244502975 & 0.134668382 & 0.061837224 \\
\hline 1.023812091 & 0.90391948 & 0.720172528 \\
\hline 6.657678294 & 6.350274034 & 5.627400338 \\
\hline 2.329891573 & 2.327380188 & 2.654160609 \\
\hline-0.244502975 & -0.134668382 & -0.061837224 \\
\hline 1.023812091 & 0.90391948 & 0.720172528 \\
\hline Medium Silt & Medium Silt & Coarse Silt \\
\hline Very Poorly Sorted & Very Poorly Sorted & Very Poorly Sorted \\
\hline Coarse Skewed & Coarse Skewed & Symmetrical \\
\hline Mesokurtic & Mesokurtic & Platykurtic \\
\hline \multirow[t]{2}{*}{4.7} & 4.7 & 107.5 \\
\hline & & 4.7 \\
\hline \multirow[t]{2}{*}{7.754331413} & 7.754331413 & 3.236965594 \\
\hline & & 7.754331413 \\
\hline 1.622156581 & 1.765498315 & 1.970701149 \\
\hline 7.895865791 & 10.80667392 & 18.30966148 \\
\hline 102.4828148 & 108.2037154 & 220.7153811 \\
\hline 63.17689431 & 61.28791769 & 111.9984028 \\
\hline 100.8606583 & 106.4382171 & 218.7446799 \\
\hline 8.492592086 & 10.442568 & 23.05524168 \\
\hline 24.13185898 & 35.30614338 & 98.27734043 \\
\hline 3.286546088 & 3.208178057 & 2.179740924 \\
\hline 6.984686817 & 6.531933632 & 5.771251072 \\
\hline 9.2678712 & 9.145708841 & 8.987075272 \\
\hline 2.819942564 & 2.850748518 & 4.123001579 \\
\hline 5.981325113 & 5.937530784 & 6.807334348 \\
\hline 1.594395165 & 1.723362526 & 2.378918543 \\
\hline 3.086204957 & 3.384404633 & 4.527022884 \\
\hline 0.146763213 & 0.173167702 & 0.342733117 \\
\hline 0.853236787 & 0.826832298 & 0.657266883 \\
\hline 0.024134138 & 0.019666011 & 0.00720072 \\
\hline 0.012133738 & 0.010532982 & 0.01580158 \\
\hline 0.012033734 & 0.013132896 & 0.055605561 \\
\hline 0.034667822 & 0.039698677 & 0.127912791 \\
\hline 0.06379378 & 0.090137136 & 0.136212465 \\
\hline 0.083343386 & 0.115494846 & 0.089446798 \\
\hline 0.11361979 & 0.13297239 & 0.08945379 \\
\hline 0.158923889 & 0.153077148 & 0.116739475 \\
\hline 0.193549003 & 0.165011996 & 0.138477981 \\
\hline 0.17134724 & 0.145048999 & 0.124582718 \\
\hline 0.132453479 & 0.115226919 & 0.098566122 \\
\hline
\end{tabular}




\begin{tabular}{|c|c|c|}
\hline $302-2-A-38-X-2$ & $302-2-A-38-X-2$ & $302-2-A-38-X-3$ \\
\hline Cristin Ashmankas, & Cristin Ashmankas, & Cristin Ashmankas, \\
\hline $\begin{array}{c}\text { Bimodal, Very Poorly } \\
\text { Sorted }\end{array}$ & $\begin{array}{c}\text { Unimodal, Very Poorly } \\
\text { Sorted }\end{array}$ & $\begin{array}{c}\text { Unimodal, Very Poorly } \\
\text { Sorted }\end{array}$ \\
\hline Sandy Mud & Sandy Mud & Sandy Mud \\
\hline Very Fine Sandy Fine Silt & Very Fine Sandy Fine Silt & Very Fine Sandy Fine Silt \\
\hline 80.1290291 & 44.26264526 & 67.9276015 \\
\hline 249.0836661 & 164.311611 & 216.0763068 \\
\hline 4.940523768 & 7.479975814 & 5.784710406 \\
\hline 28.31680156 & 65.02837602 & 38.57119571 \\
\hline 12.94187698 & 9.173996443 & 13.28352823 \\
\hline 5.714319326 & 4.606542109 & 5.317202926 \\
\hline 0.602512607 & 0.708754334 & 0.459600509 \\
\hline 3.000379344 & 3.420631127 & 2.880205898 \\
\hline 6.212020594 & 6.74032695 & 6.187378613 \\
\hline 2.544341106 & 2.226003656 & 2.434408792 \\
\hline-0.619326635 & -0.737049181 & -0.484417345 \\
\hline 2.995769254 & 3.474994955 & 2.906173118 \\
\hline 12.45979817 & 8.849928236 & 12.91480319 \\
\hline 6.022391565 & 4.49347527 & 5.247205137 \\
\hline 0.199109582 & 0.183784864 & 0.101273405 \\
\hline 0.981216784 & 0.945488997 & 0.861278999 \\
\hline 6.326575491 & 6.820118528 & 6.274830532 \\
\hline 2.590336512 & 2.167831662 & 2.391549193 \\
\hline-0.199109582 & -0.183784864 & -0.101273405 \\
\hline 0.981216784 & 0.945488997 & 0.861278999 \\
\hline Medium Silt & Medium Silt & Medium Silt \\
\hline Very Poorly Sorted & Very Poorly Sorted & Very Poorly Sorted \\
\hline Coarse Skewed & Coarse Skewed & Coarse Skewed \\
\hline Mesokurtic & Mesokurtic & Platykurtic \\
\hline 4.7 & 3.35 & 4.7 \\
\hline \multicolumn{3}{|l|}{1200} \\
\hline 7.754331413 & 8.241333809 & 7.754331413 \\
\hline \multicolumn{3}{|l|}{-0.242713414} \\
\hline 1.635952543 & 1.529080952 & 1.691955125 \\
\hline 10.54749977 & 7.493489837 & 11.71004761 \\
\hline 128.0246177 & 75.748359 & 114.895901 \\
\hline 78.2569264 & 49.53848839 & 67.90717985 \\
\hline 126.3886652 & 74.21927805 & 113.2039459 \\
\hline 12.28363444 & 8.136071437 & 12.07161772 \\
\hline 39.69876831 & 21.33310536 & 41.10601406 \\
\hline 2.965506843 & 3.722641555 & 3.121600765 \\
\hline 6.566955134 & 7.060146524 & 6.416109248 \\
\hline 9.255653387 & 9.353119497 & 9.20709298 \\
\hline 3.121103365 & 2.512495323 & 2.949478063 \\
\hline 6.290146543 & 5.630477942 & 6.085492214 \\
\hline 1.798424746 & 1.564076947 & 1.802175152 \\
\hline 3.618665578 & 3.024332347 & 3.593547119 \\
\hline 0.19418376 & 0.119875418 & 0.192282989 \\
\hline 0.80581624 & 0.880124582 & 0.807717011 \\
\hline 0.03159684 & 0.01270127 & 0.0236 \\
\hline 0.01729827 & 0.00950095 & 0.0123 \\
\hline 0.01119888 & 0.00650065 & 0.0081 \\
\hline 0.04169583 & 0.02610261 & 0.0443 \\
\hline 0.092393938 & 0.065069937 & 0.103982989 \\
\hline 0.106822377 & 0.090028599 & 0.122472056 \\
\hline 0.12026201 & 0.120329032 & 0.12854405 \\
\hline 0.144822635 & 0.159025072 & 0.14205901 \\
\hline 0.159663539 & 0.184868181 & 0.153384163 \\
\hline 0.14565403 & 0.178584973 & 0.139166945 \\
\hline 0.128591649 & 0.147288726 & 0.122090788 \\
\hline
\end{tabular}




\begin{tabular}{|c|c|c|}
\hline $\begin{array}{c}\text { 302-2-A-38-X-3 } \\
\text { Cristin Ashmankas }\end{array}$ & $\begin{array}{c}\text { 302-2-A-38-X-3 } \\
\text { Cristin Ashmankas }\end{array}$ & $\begin{array}{c}\text { 302-2-A-38-X-4 } \\
\text { Cristin Ashmankas }\end{array}$ \\
\hline $\begin{array}{c}\text { Bimodal, Very Poorly } \\
\text { Sorted }\end{array}$ & $\begin{array}{l}\text { Unimodal, Very Poorly } \\
\text { Sorted }\end{array}$ & $\begin{array}{c}\text { Bimodal, Very Poorly } \\
\text { Sorted }\end{array}$ \\
\hline Sandy Mud & Sandy Mud & Sandy Mud \\
\hline ry Fine Sandy Very Fine & Very Fine Sandy Fine Silt & lery Coarse Sandy Fine S \\
\hline 92.52587859 & 60.26270123 & 81.03205671 \\
\hline 284.3342622 & 182.2572731 & 288.603733 \\
\hline 4.297186945 & 5.977816591 & 4.439425917 \\
\hline 21.61411687 & 44.34471195 & 22.22193787 \\
\hline 10.86107676 & 11.30151296 & 8.330007087 \\
\hline 6.34952406 & 5.345045114 & 5.500468089 \\
\hline 0.856780111 & 0.644502549 & 1.244805243 \\
\hline 3.219758829 & 2.871046516 & 4.609493429 \\
\hline 6.438974735 & 6.448407171 & 6.820755567 \\
\hline 2.71440144 & 2.429722917 & 2.525005457 \\
\hline-0.854564646 & -0.653499296 & -1.241017588 \\
\hline 3.150089709 & 2.883444589 & 4.440841035 \\
\hline 10.49369457 & 10.99151179 & 7.626588402 \\
\hline 6.8883639 & 5.416332579 & 5.884372822 \\
\hline 0.332598512 & 0.250355828 & 0.356871298 \\
\hline 1.113723524 & 0.926411623 & 1.402233102 \\
\hline 6.574333485 & 6.50746636 & 7.034746443 \\
\hline 2.78416136 & 2.437316328 & 2.556888656 \\
\hline-0.332598512 & -0.250355828 & -0.356871298 \\
\hline 1.113723524 & 0.926411623 & 1.402233102 \\
\hline Medium Silt & Medium Silt & Fine Silt \\
\hline Very Poorly Sorted & Very Poorly Sorted & Very Poorly Sorted \\
\hline Very Coarse Skewed & Coarse Skewed & Very Coarse Skewed \\
\hline Leptokurtic & Mesokurtic & Leptokurtic \\
\hline 3.35 & 3.35 & 3.35 \\
\hline 1200 & & 1200 \\
\hline 8.241333809 & 8.241333809 & 8.241333809 \\
\hline-0.242713414 & & -0.242713414 \\
\hline 1.449384997 & 1.615845126 & 1.440798269 \\
\hline 7.60867939 & 8.345096929 & 6.029135104 \\
\hline 174.2955443 & 125.9307734 & 77.45542741 \\
\hline 120.2548285 & 77.93492791 & 53.75868994 \\
\hline 172.8461593 & 124.3149283 & 76.01462914 \\
\hline 11.61411664 & 10.83772127 & 7.146941416 \\
\hline 30.46347271 & 31.51444361 & 16.54287929 \\
\hline 2.520392406 & 2.989297221 & 3.690489856 \\
\hline 7.038138212 & 6.904855478 & 7.373833226 \\
\hline 9.430343419 & 9.273495358 & 9.438915932 \\
\hline 3.741617137 & 3.102232623 & 2.557632266 \\
\hline 6.909951013 & 6.284198137 & 5.748426076 \\
\hline 1.720989111 & 1.709130276 & 1.497760014 \\
\hline 3.537807523 & 3.437989543 & 2.837325963 \\
\hline 0.179852662 & 0.176343576 & 0.114321796 \\
\hline 0.820147338 & 0.823656424 & 0.885678204 \\
\hline 0.04240424 & 0.01349865 & 0.04490449 \\
\hline 0.02110211 & 0.01459854 & 0.01850185 \\
\hline 0.01880188 & 0.02209779 & 0.00040004 \\
\hline 0.03720372 & 0.050394961 & 0.01120112 \\
\hline 0.060340711 & 0.075753635 & 0.039314295 \\
\hline 0.077907517 & 0.087568105 & 0.069304365 \\
\hline 0.101425606 & 0.107986555 & 0.098355631 \\
\hline 0.134626358 & 0.142891154 & 0.146283273 \\
\hline 0.171737522 & 0.18080646 & 0.203799272 \\
\hline 0.174862592 & 0.170565224 & 0.202297745 \\
\hline 0.159587742 & 0.133838925 & 0.165637919 \\
\hline
\end{tabular}




\begin{tabular}{|c|c|c|}
\hline $302-2-A-38-X-4$ & $302-2-A-38-X-5$ & $302-2-A-38-X-5$ \\
\hline Cristin Ashmankas, & Cristin Ashmankas, & Cristin Ashmankas, \\
\hline $\begin{array}{l}\text { Unimodal, Very Poorly } \\
\text { Sorted }\end{array}$ & $\begin{array}{l}\text { Unimodal, Very Poorly } \\
\text { Sorted }\end{array}$ & $\begin{array}{l}\text { Unimodal, Very Poorly } \\
\text { Sorted }\end{array}$ \\
\hline Sandy Mud & Sandy Mud & Sandy Mud \\
\hline Very Fine Sandy Fine Silt & Very Fine Sandy Fine Silt & Very Fine Sandy Fine Silt \\
\hline 56.6986745 & 58.47252075 & 58.15932357 \\
\hline 215.2684025 & 227.221057 & 204.3117635 \\
\hline 6.023968072 & 5.743757836 & 6.134081087 \\
\hline 40.92024129 & 36.7353716 & 43.13552898 \\
\hline 9.046165604 & 8.999115925 & 11.17803125 \\
\hline 4.773811634 & 4.764695226 & 4.763485068 \\
\hline 0.999393245 & 0.975078214 & 0.719941499 \\
\hline 4.111407007 & 4.274150248 & 3.553998286 \\
\hline 6.735659221 & 6.745180589 & 6.445323883 \\
\hline 2.296434462 & 2.292364844 & 2.276789398 \\
\hline-1.028378895 & -1.004779975 & -0.748124206 \\
\hline 4.111080887 & 4.266904854 & 3.579408985 \\
\hline 8.601150968 & 8.455119183 & 10.64353013 \\
\hline 4.519795406 & 4.373389567 & 4.589660939 \\
\hline 0.243932084 & 0.19175487 & 0.158825583 \\
\hline 1.092346402 & 1.005585565 & 0.988961157 \\
\hline 6.861254557 & 6.885959194 & 6.553879463 \\
\hline 2.176257469 & 2.128751865 & 2.198387579 \\
\hline-0.243932084 & -0.19175487 & -0.158825583 \\
\hline 1.092346402 & 1.005585565 & 0.988961157 \\
\hline Medium Silt & Medium Silt & Medium Silt \\
\hline Very Poorly Sorted & Very Poorly Sorted & Very Poorly Sorted \\
\hline Coarse Skewed & Coarse Skewed & Coarse Skewed \\
\hline Mesokurtic & Mesokurtic & Mesokurtic \\
\hline 4.7 & 3.35 & 4.7 \\
\hline 7.754331413 & 8.241333809 & 7.754331413 \\
\hline 1.613128146 & 1.555155232 & 1.786895244 \\
\hline 7.067717168 & 7.290559147 & 9.418613745 \\
\hline 82.57572229 & 66.74555627 & 87.74579659 \\
\hline 51.18980938 & 42.91890281 & 49.10517104 \\
\hline 80.96259415 & 65.19040103 & 85.95890134 \\
\hline 6.702824348 & 7.332759366 & 8.07337823 \\
\hline 17.49749826 & 19.08903595 & 25.62813365 \\
\hline 3.598138506 & 3.9051844 & 3.510526174 \\
\hline 7.144539977 & 7.099754819 & 6.730269549 \\
\hline 9.275923235 & 9.32872569 & 9.128329225 \\
\hline 2.577978368 & 2.388805427 & 2.600273797 \\
\hline 5.677784729 & 5.42354129 & 5.617803051 \\
\hline 1.489821148 & 1.522649178 & 1.591356767 \\
\hline 2.744769128 & 2.874356196 & 3.013172482 \\
\hline 0.122717023 & 0.105786255 & 0.135136492 \\
\hline 0.877282977 & 0.894213745 & 0.864863508 \\
\hline 0.0241 & 0.02679732 & 0.02049795 \\
\hline 0.0109 & 0.01239876 & 0.01159884 \\
\hline 0.0062 & 0.00079992 & 0.00919908 \\
\hline 0.0273 & 0.0149985 & 0.02919708 \\
\hline 0.054217023 & 0.050791755 & 0.064643541 \\
\hline 0.067832059 & 0.087175182 & 0.102323247 \\
\hline 0.108763521 & 0.123997111 & 0.141357223 \\
\hline 0.171755137 & 0.164387607 & 0.168820235 \\
\hline 0.205545036 & 0.193026665 & 0.183163983 \\
\hline 0.187403934 & 0.182063999 & 0.155496387 \\
\hline 0.135983291 & 0.143563181 & 0.113702433 \\
\hline
\end{tabular}




\begin{tabular}{|c|c|c|}
\hline $302-2-A-39-X-1$ & 302-2-A-39-X-1 & 302-2-A-40-X-1 \\
\hline Cristin Ashmankas, & Cristin Ashmankas, & Cristin Ashmankas, \\
\hline $\begin{array}{l}\text { Unimodal, Very Poorly } \\
\text { Sorted }\end{array}$ & $\begin{array}{l}\text { Unimodal, Very Poorly } \\
\text { Sorted }\end{array}$ & $\begin{array}{l}\text { Unimodal, Very Poorly } \\
\text { Sorted }\end{array}$ \\
\hline Sandy Mud & Sandy Mud & Sandy Mud \\
\hline Very Fine Sandy Fine Silt & Very Fine Sandy Fine Silt & Very Fine Sandy Fine Silt \\
\hline 37.57064006 & 76.95892189 & 65.91211308 \\
\hline 112.7533947 & 255.5609642 & 243.2131903 \\
\hline 8.124090577 & 4.86578144 & 5.282957933 \\
\hline 85.63079458 & 27.30054309 & 31.49243244 \\
\hline 10.05990247 & 10.27996586 & 8.644166116 \\
\hline 4.433004281 & 5.672129624 & 5.195333597 \\
\hline 0.514044221 & 0.886662402 & 1.058444562 \\
\hline 2.876259617 & 3.496332982 & 4.133262701 \\
\hline 6.635239872 & 6.538239962 & 6.794274739 \\
\hline 2.148284756 & 2.545273789 & 2.423078744 \\
\hline-0.514044221 & -0.897066386 & -1.073917847 \\
\hline 2.876259617 & 3.456747556 & 4.087205101 \\
\hline 9.766217066 & 9.823652113 & 8.080136939 \\
\hline 4.487262346 & 5.985983247 & 5.006070694 \\
\hline 0.163401269 & 0.304837208 & 0.289615408 \\
\hline 0.925365184 & 1.116586263 & 1.117070111 \\
\hline 6.677984441 & 6.669524814 & 6.951404541 \\
\hline 2.165835533 & 2.581588241 & 2.323678665 \\
\hline-0.163401269 & -0.304837208 & -0.289615408 \\
\hline 0.925365184 & 1.116586263 & 1.117070111 \\
\hline Medium Silt & Medium Silt & Medium Silt \\
\hline Very Poorly Sorted & Very Poorly Sorted & Very Poorly Sorted \\
\hline Coarse Skewed & Very Coarse Skewed & Coarse Skewed \\
\hline Mesokurtic & Leptokurtic & Leptokurtic \\
\hline 3.35 & 3.35 & 3.35 \\
\hline 8.241333809 & 8.241333809 & 8.241333809 \\
\hline 1.641744117 & 1.517807912 & 1.465332185 \\
\hline 8.36836953 & 7.536089913 & 6.409533989 \\
\hline 82.21899013 & 115.9290484 & 82.16975147 \\
\hline 50.08027091 & 76.37926213 & 56.07585248 \\
\hline 80.57724601 & 114.4112405 & 80.70441929 \\
\hline 8.353287909 & 9.736825824 & 7.656095346 \\
\hline 23.98186452 & 25.99161583 & 18.3952437 \\
\hline 3.604384538 & 3.108685986 & 3.605248787 \\
\hline 6.900837725 & 7.051968107 & 7.285564816 \\
\hline 9.250554999 & 9.363795064 & 9.414556529 \\
\hline 2.566472834 & 3.012139246 & 2.611347257 \\
\hline 5.646170461 & 6.255109078 & 5.809307743 \\
\hline 1.589143729 & 1.642621075 & 1.527921063 \\
\hline 3.062344164 & 3.283451535 & 2.936608797 \\
\hline 0.130732001 & 0.158001534 & 0.121545991 \\
\hline 0.869267999 & 0.841998466 & 0.878454009 \\
\hline 0.00370037 & 0.03350335 & 0.030793841 \\
\hline 0.00780078 & 0.01790179 & 0.013797241 \\
\hline 0.00910091 & 0.01130113 & 0.00639872 \\
\hline 0.03690369 & 0.03080308 & 0.021295741 \\
\hline 0.07322625 & 0.064492183 & 0.049260448 \\
\hline 0.095697981 & 0.081426995 & 0.073779163 \\
\hline 0.12858738 & 0.10584189 & 0.104054123 \\
\hline 0.161939337 & 0.145713493 & 0.147656348 \\
\hline 0.183978339 & 0.181845054 & 0.196057847 \\
\hline 0.168704485 & 0.1783826 & 0.195927991 \\
\hline 0.130360477 & 0.148788433 & 0.160978537 \\
\hline
\end{tabular}




\begin{tabular}{|c|c|c|}
\hline $302-2-A-40-X-1$ & $302-2-A-40-X-2$ & $302-2-A-40-X-2$ \\
\hline Cristin Ashmankas, & Cristin Ashmankas, & Cristin Ashmankas, \\
\hline $\begin{array}{c}\text { Unimodal, Very Poorly } \\
\text { Sorted }\end{array}$ & $\begin{array}{c}\text { Unimodal, Very Poorly } \\
\text { Sorted }\end{array}$ & $\begin{array}{l}\text { Unimodal, Very Poorly } \\
\text { Sorted }\end{array}$ \\
\hline Sandy Mud & Sandy Mud & Sandy Mud \\
\hline Very Fine Sandy Fine Silt & Very Fine Sandy Fine Silt & Very Fine Sandy Fine Silt \\
\hline 56.22596581 & 49.02267746 & 60.27017448 \\
\hline 189.803908 & 175.519793 & 212.9789746 \\
\hline 6.245487517 & 7.278885921 & 5.861018009 \\
\hline 46.44593764 & 60.21877673 & 39.21418728 \\
\hline 9.772849213 & 10.96088223 & 10.38149607 \\
\hline 5.103068688 & 4.598054292 & 4.978653457 \\
\hline 0.824453035 & 0.574748655 & 0.797451339 \\
\hline 3.324293474 & 3.228094744 & 3.553530262 \\
\hline 6.647113678 & 6.48359365 & 6.55297211 \\
\hline 2.372615199 & 2.220139134 & 2.340910116 \\
\hline-0.839538684 & -0.603501008 & -0.818394733 \\
\hline 3.340583228 & 3.277801897 & 3.56652183 \\
\hline 9.585537855 & 10.71414729 & 9.982476424 \\
\hline 5.09661653 & 4.515756838 & 4.782132536 \\
\hline 0.292200058 & 0.140410988 & 0.214784122 \\
\hline 1.01420362 & 0.904323731 & 0.975916202 \\
\hline 6.704924899 & 6.544339155 & 6.646386525 \\
\hline 2.349539809 & 2.174967803 & 2.257654115 \\
\hline-0.292200058 & -0.140410988 & -0.214784122 \\
\hline 1.01420362 & 0.904323731 & 0.975916202 \\
\hline Medium Silt & Medium Silt & Medium Silt \\
\hline Very Poorly Sorted & Very Poorly Sorted & Very Poorly Sorted \\
\hline Coarse Skewed & Coarse Skewed & Coarse Skewed \\
\hline Mesokurtic & Mesokurtic & Mesokurtic \\
\hline 4.7 & 4.7 & 4.7 \\
\hline 7.754331413 & 7.754331413 & 7.754331413 \\
\hline 1.583833683 & 1.741237426 & 1.647243114 \\
\hline 7.064739627 & 9.342021967 & 8.116861815 \\
\hline 107.800424 & 86.41295489 & 95.07151845 \\
\hline 68.06296972 & 49.62732458 & 57.71553553 \\
\hline 106.2165904 & 84.67171747 & 93.42427534 \\
\hline 8.456126915 & 8.765000297 & 8.431426192 \\
\hline 22.7008713 & 27.35095564 & 24.37301736 \\
\hline 3.213565242 & 3.532608575 & 3.394842987 \\
\hline 7.145147894 & 6.742049447 & 6.944862232 \\
\hline 9.302363437 & 9.16567135 & 9.245730789 \\
\hline 2.894717467 & 2.594590133 & 2.723463449 \\
\hline 6.088798195 & 5.633062776 & 5.850887802 \\
\hline 1.583383827 & 1.624166646 & 1.594188361 \\
\hline 3.07999703 & 3.13175414 & 3.075776686 \\
\hline 0.153368485 & 0.140928375 & 0.14371576 \\
\hline 0.846631515 & 0.859071625 & 0.85628424 \\
\hline 0.016296741 & 0.015296941 & 0.02229777 \\
\hline 0.012597481 & 0.00709858 & 0.0129987 \\
\hline 0.015696861 & 0.00389922 & 0.00459954 \\
\hline 0.040991802 & 0.033593281 & 0.03369663 \\
\hline 0.067785602 & 0.081040352 & 0.07012312 \\
\hline 0.072314818 & 0.107005524 & 0.087078591 \\
\hline 0.096606763 & 0.133564675 & 0.11867492 \\
\hline 0.149528026 & 0.162597611 & 0.160079653 \\
\hline 0.202758836 & 0.179238999 & 0.1923272 \\
\hline 0.186071634 & 0.158365822 & 0.168893341 \\
\hline 0.139351438 & 0.118298995 & 0.129230534 \\
\hline
\end{tabular}




\begin{tabular}{|c|c|c|}
\hline $302-2-A-40-X-3$ & $302-2-A-40-X-3$ & $302-2-A-40-X-4$ \\
\hline Cristin Ashmankas, & Cristin Ashmankas, & Cristin Ashmankas, \\
\hline $\begin{array}{l}\text { Bimodal, Very Poorly } \\
\text { Sorted }\end{array}$ & $\begin{array}{l}\text { Unimodal, Very Poorly } \\
\text { Sorted }\end{array}$ & $\begin{array}{l}\text { Unimodal, Very Poorly } \\
\text { Sorted }\end{array}$ \\
\hline Sandy Mud & Sandy Mud & Sandy Mud \\
\hline Very Fine Sandy Fine Silt & Very Fine Sandy Fine Silt & Very Fine Sandy Fine Silt \\
\hline 76.14258174 & 61.04858922 & 53.08425365 \\
\hline 263.1353019 & 231.585689 & 191.0082324 \\
\hline 4.822810037 & 5.565909634 & 6.399037949 \\
\hline 26.40296996 & 34.64024786 & 47.6899558 \\
\hline 10.01820895 & 9.568101607 & 9.147193381 \\
\hline 5.409706288 & 4.799788559 & 4.896365013 \\
\hline 0.971396627 & 0.918077346 & 0.887943274 \\
\hline 3.893056172 & 4.194182323 & 3.625382597 \\
\hline 6.571478068 & 6.657712685 & 6.739574621 \\
\hline 2.481610276 & 2.300100735 & 2.317011477 \\
\hline-0.98494033 & -0.9475561 & -0.907625155 \\
\hline 3.832966236 & 4.186447068 & 3.645800578 \\
\hline 9.515354483 & 8.941788768 & 8.780977839 \\
\hline 5.8098142 & 4.372269726 & 4.755295074 \\
\hline 0.297629873 & 0.152301465 & 0.265565399 \\
\hline 1.240095712 & 0.983027474 & 1.046899314 \\
\hline 6.715526881 & 6.805220819 & 6.831402679 \\
\hline 2.538492026 & 2.128382404 & 2.249534866 \\
\hline-0.297629873 & -0.152301465 & -0.265565399 \\
\hline 1.240095712 & 0.983027474 & 1.046899314 \\
\hline Medium Silt & Medium Silt & Medium Silt \\
\hline Very Poorly Sorted & Very Poorly Sorted & Very Poorly Sorted \\
\hline Coarse Skewed & Coarse Skewed & Coarse Skewed \\
\hline Leptokurtic & Mesokurtic & Mesokurtic \\
\hline 4.7 & 4.7 & 3.35 \\
\hline \multicolumn{3}{|l|}{1200} \\
\hline 7.754331413 & 7.754331413 & 8.241333809 \\
\hline \multicolumn{3}{|l|}{-0.242713414} \\
\hline 1.563939456 & 1.581319045 & 1.558514203 \\
\hline 7.63411084 & 8.010704963 & 6.87325748 \\
\hline 100.8650039 & 67.41888149 & 93.070663 \\
\hline 64.49418713 & 42.63458515 & 59.71755844 \\
\hline 99.30106446 & 65.83756244 & 91.5121488 \\
\hline 8.083651647 & 7.619037638 & 7.472763054 \\
\hline 22.15518245 & 20.99415178 & 19.16213066 \\
\hline 3.309502391 & 3.890703497 & 3.425529705 \\
\hline 7.033324151 & 6.963855076 & 7.184790279 \\
\hline 9.320599622 & 9.304655811 & 9.325612982 \\
\hline 2.816314515 & 2.391509869 & 2.72238567 \\
\hline 6.011097231 & 5.413952314 & 5.900083277 \\
\hline 1.568258332 & 1.545461457 & 1.527730692 \\
\hline 3.015007152 & 2.929608782 & 2.901641778 \\
\hline 0.142509327 & 0.107098169 & 0.134405681 \\
\hline 0.857490673 & 0.892901831 & 0.865594319 \\
\hline 0.03639636 & 0.027505501 & 0.017196561 \\
\hline 0.01689831 & 0.014302861 & 0.01189762 \\
\hline 0.00419958 & 0.00070014 & 0.01009798 \\
\hline 0.02539746 & 0.0115023 & 0.035492901 \\
\hline 0.059617616 & 0.053087367 & 0.059720618 \\
\hline 0.077109995 & 0.095901604 & 0.069186627 \\
\hline 0.111163463 & 0.135633976 & 0.104975349 \\
\hline 0.162857483 & 0.167759024 & 0.156144403 \\
\hline 0.194634423 & 0.187207165 & 0.19997197 \\
\hline 0.171687004 & 0.168524161 & 0.191050909 \\
\hline 0.140038305 & 0.137875901 & 0.144265061 \\
\hline
\end{tabular}




\begin{tabular}{|c|c|c|}
\hline $302-2-A-40-X-4$ & 302-2-A-41-X-1 & 302-2-A-42-X-1 \\
\hline Cristin Ashmankas, & Cristin Ashmankas, & Cristin Ashmankas, \\
\hline $\begin{array}{l}\text { Bimodal, Very Poorly } \\
\text { Sorted }\end{array}$ & $\begin{array}{c}\text { Unimodal, Very Poorly } \\
\text { Sorted }\end{array}$ & Unimodal, Poorly Sorted \\
\hline Sandy Mud & Mud & Mud \\
\hline Very Fine Sandy Fine Silt & Fine Silt & Fine Silt \\
\hline 75.382523 & 66.137304 & 43.94809269 \\
\hline 261.4628959 & 262.5228131 & 190.205195 \\
\hline 4.875691461 & 4.967377567 & 6.873239683 \\
\hline 26.8999653 & 27.47315338 & 52.39280809 \\
\hline 10.48279205 & 7.759266615 & 7.878449441 \\
\hline 5.320318716 & 4.556947661 & 4.184329834 \\
\hline 0.90343193 & 1.507897935 & 1.033728926 \\
\hline 3.852083083 & 6.132031183 & 4.880222182 \\
\hline 6.506072676 & 6.939106917 & 6.953992286 \\
\hline 2.456170911 & 2.251550423 & 2.097360623 \\
\hline-0.92254853 & -1.519931493 & -1.073608495 \\
\hline 3.804065145 & 5.918150495 & 4.920058011 \\
\hline 9.831596142 & 6.873343284 & 7.31229202 \\
\hline 5.685437151 & 4.705360346 & 3.797027661 \\
\hline 0.247237325 & 0.28329883 & 0.140023383 \\
\hline 1.198348013 & 1.590084897 & 1.042289908 \\
\hline 6.66835863 & 7.184772269 & 7.095460598 \\
\hline 2.507271282 & 2.234305212 & 1.924870509 \\
\hline-0.247237325 & -0.28329883 & -0.140023383 \\
\hline 1.198348013 & 1.590084897 & 1.042289908 \\
\hline Medium Silt & Fine Silt & Fine Silt \\
\hline Very Poorly Sorted & Very Poorly Sorted & Poorly Sorted \\
\hline Coarse Skewed & Coarse Skewed & Coarse Skewed \\
\hline Leptokurtic & Very Leptokurtic & Mesokurtic \\
\hline 4.7 & 4.7 & 4.7 \\
\hline \multicolumn{3}{|l|}{1200} \\
\hline 7.754331413 & 7.754331413 & 7.754331413 \\
\hline \multicolumn{3}{|l|}{-0.242713414} \\
\hline 1.590285174 & 1.613480681 & 1.534436872 \\
\hline 8.483709538 & 6.310857059 & 6.78199979 \\
\hline 92.11876868 & 39.92608276 & 44.7635523 \\
\hline 57.92594321 & 24.74531193 & 29.17262555 \\
\hline 90.52848351 & 38.31260208 & 43.22911543 \\
\hline 8.520271413 & 4.983533061 & 5.869534791 \\
\hline 24.28432418 & 11.95440641 & 14.37979675 \\
\hline 3.440361062 & 4.646524657 & 4.481531661 \\
\hline 6.881089057 & 7.307948338 & 7.204073545 \\
\hline 9.296498788 & 9.275607981 & 9.348074991 \\
\hline 2.702186956 & 1.99624637 & 2.085910733 \\
\hline 5.856137726 & 4.629083323 & 4.86654333 \\
\hline 1.596270952 & 1.38216972 & 1.436426173 \\
\hline 3.090899388 & 2.317168899 & 2.553246163 \\
\hline 0.136350111 & 0.071930658 & 0.073036463 \\
\hline 0.863649889 & 0.928069342 & 0.926963537 \\
\hline 0.0361 & 0.0365 & 0.01819818 \\
\hline 0.0164 & 0.0161 & 0.00969903 \\
\hline 0.004 & 0.0011 & 0.00119988 \\
\hline 0.0212 & 0.0033 & 0.01249875 \\
\hline 0.058650111 & 0.014930658 & 0.031440623 \\
\hline 0.09177787 & 0.051017048 & 0.069190598 \\
\hline 0.129251084 & 0.116340209 & 0.12970711 \\
\hline 0.163024541 & 0.18982812 & 0.186261664 \\
\hline 0.179675313 & 0.234133857 & 0.207551763 \\
\hline 0.163781165 & 0.199749112 & 0.187081172 \\
\hline 0.136139917 & 0.137000995 & 0.14717123 \\
\hline
\end{tabular}




\begin{tabular}{|c|c|c|}
\hline $302-2-A-42-X-1$ & 302-2-A-42-X-2 & $302-2-A-42-X-2$ \\
\hline Cristin Ashmankas, & Cristin Ashmankas, & Cristin Ashmankas, \\
\hline $\begin{array}{c}\text { Bimodal, Very Poorly } \\
\text { Sorted }\end{array}$ & Unimodal, Poorly Sorted & $\begin{array}{c}\text { Unimodal, Very Poorly } \\
\text { Sorted }\end{array}$ \\
\hline Sandy Mud & Mud & Sandy Mud \\
\hline Very Fine Sandy Fine Silt & Fine Silt & Very Fine Sandy Fine Silt \\
\hline 80.1410446 & 48.68728423 & 46.3203845 \\
\hline 271.2921623 & 211.2837724 & 154.5412102 \\
\hline 4.698954815 & 6.300174511 & 7.916227759 \\
\hline 24.98361088 & 43.6055357 & 73.3298612 \\
\hline 10.6384587 & 7.714649775 & 11.0725662 \\
\hline 5.62505386 & 4.269749524 & 4.710478939 \\
\hline 0.847805991 & 1.15683525 & 0.486832661 \\
\hline 3.5926823 & 5.21955574 & 2.847542307 \\
\hline 6.478819507 & 6.975326463 & 6.476934998 \\
\hline 2.538063043 & 2.134967713 & 2.249241193 \\
\hline-0.862155615 & -1.195594933 & -0.507154468 \\
\hline 3.543184235 & 5.219827382 & 2.889907732 \\
\hline 10.09891224 & 7.22925694 & 11.03663799 \\
\hline 6.218909737 & 3.760762183 & 4.768978932 \\
\hline 0.269383984 & 0.170710743 & 0.168367818 \\
\hline 1.155752737 & 1.034904289 & 0.863520117 \\
\hline 6.629656281 & 7.111936917 & 6.501555429 \\
\hline 2.636661678 & 1.911025078 & 2.253680409 \\
\hline-0.269383984 & -0.170710743 & -0.168367818 \\
\hline 1.155752737 & 1.034904289 & 0.863520117 \\
\hline Medium Silt & Fine Silt & Medium Silt \\
\hline Very Poorly Sorted & Poorly Sorted & Very Poorly Sorted \\
\hline Coarse Skewed & Coarse Skewed & Coarse Skewed \\
\hline Leptokurtic & Mesokurtic & Platykurtic \\
\hline 3.35 & 4.7 & 4.7 \\
\hline \multicolumn{3}{|l|}{1200} \\
\hline 8.241333809 & 7.754331413 & 7.754331413 \\
\hline \multicolumn{3}{|l|}{-0.242713414} \\
\hline 1.515707876 & 1.536205731 & 1.683649685 \\
\hline 8.374023359 & 6.393772839 & 9.069018047 \\
\hline 102.4486915 & 47.0994708 & 96.87924351 \\
\hline 67.59131695 & 30.65961145 & 57.54121202 \\
\hline 100.9329836 & 45.56326507 & 95.19559383 \\
\hline 10.11787042 & 5.690996498 & 9.999714117 \\
\hline 27.99828422 & 13.72441538 & 30.88981581 \\
\hline 3.287026538 & 4.40814534 & 3.36766859 \\
\hline 6.899863342 & 7.289116796 & 6.784837934 \\
\hline 9.365792557 & 9.346412848 & 9.214192295 \\
\hline 2.84932064 & 2.120259685 & 2.736074542 \\
\hline 6.078766019 & 4.938267509 & 5.846523705 \\
\hline 1.666649326 & 1.424601126 & 1.682853017 \\
\hline 3.338833762 & 2.508681292 & 3.32188685 \\
\hline 0.153256452 & 0.073357657 & 0.162652121 \\
\hline 0.846743548 & 0.926642343 & 0.837347879 \\
\hline 0.03930393 & 0.02310231 & 0.0112 \\
\hline 0.01710171 & 0.01030103 & 0.0066 \\
\hline 0.0010001 & 0.00030003 & 0.0037 \\
\hline 0.02430243 & 0.0040004 & 0.0439 \\
\hline 0.071548281 & 0.035653887 & 0.097252121 \\
\hline 0.09589415 & 0.074484649 & 0.101164392 \\
\hline 0.118796466 & 0.113693189 & 0.117793761 \\
\hline 0.147742576 & 0.175756875 & 0.154007306 \\
\hline 0.171271013 & 0.2213518 & 0.180957147 \\
\hline 0.16597454 & 0.1940463 & 0.159100406 \\
\hline 0.147064803 & 0.14730953 & 0.124324868 \\
\hline
\end{tabular}




\begin{tabular}{|c|c|c|}
\hline $\begin{array}{c}\text { 302-2-A-42-X-3 } \\
\text { Cristin Ashmankas, }\end{array}$ & $\begin{array}{c}\text { 302-2-A-42-X-3 } \\
\text { Cristin Ashmankas, }\end{array}$ & $\begin{array}{c}\text { 302-2-A-42-X-4 } \\
\text { Cristin Ashmankas, }\end{array}$ \\
\hline $\begin{array}{l}\text { Bimodal, Very Poorly } \\
\text { Sorted }\end{array}$ & $\begin{array}{l}\text { Unimodal, Very Poorly } \\
\text { Sorted }\end{array}$ & $\begin{array}{c}\text { Bimodal, Very Poorly } \\
\text { Sorted }\end{array}$ \\
\hline Sandy Mud & Sandy Mud & Sandy Mud \\
\hline Very Fine Sandy Fine Silt & Very Fine Sandy Fine Silt & Very Fine Sandy Fine Silt \\
\hline 81.87631313 & 74.1205014 & 75.8081865 \\
\hline 278.9411164 & 268.8738866 & 261.7319722 \\
\hline 4.575438398 & 4.735245555 & 4.873254771 \\
\hline 23.66781149 & 25.40138377 & 26.87605604 \\
\hline 10.22497058 & 7.93839551 & 10.49087215 \\
\hline 5.645659505 & 5.349511605 & 5.393256649 \\
\hline 0.915628872 & 1.289243418 & 0.882769377 \\
\hline 3.760244267 & 4.700299671 & 3.757314217 \\
\hline 6.530031893 & 6.905197543 & 6.503964502 \\
\hline 2.548585142 & 2.476789723 & 2.476041731 \\
\hline-0.926939873 & -1.288333346 & -0.901039802 \\
\hline 3.687516311 & 4.563313449 & 3.712281349 \\
\hline 9.642598002 & 7.188411466 & 9.91521736 \\
\hline 6.232172857 & 5.525787234 & 5.815507412 \\
\hline 0.28062133 & 0.351966509 & 0.262264475 \\
\hline 1.202567934 & 1.498645497 & 1.174791028 \\
\hline 6.696362381 & 7.120111293 & 6.656139885 \\
\hline 2.639735249 & 2.466180013 & 2.539905075 \\
\hline-0.28062133 & -0.351966509 & -0.262264475 \\
\hline 1.202567934 & 1.498645497 & 1.174791028 \\
\hline Medium Silt & Fine Silt & Medium Silt \\
\hline Very Poorly Sorted & Very Poorly Sorted & Very Poorly Sorted \\
\hline Coarse Skewed & Very Coarse Skewed & Coarse Skewed \\
\hline Leptokurtic & Leptokurtic & Leptokurtic \\
\hline 3.35 & 3.35 & 4.7 \\
\hline 1200 & & 1200 \\
\hline 8.241333809 & 8.241333809 & 7.754331413 \\
\hline-0.242713414 & & -0.242713414 \\
\hline 1.490304308 & 1.432493593 & 1.56859374 \\
\hline 7.990427318 & 5.759594103 & 8.302777042 \\
\hline 98.3485766 & 85.95086204 & 95.22044687 \\
\hline 65.99227825 & 60.00087012 & 60.70433944 \\
\hline 96.85827229 & 84.51836844 & 93.65185313 \\
\hline 9.560105238 & 5.921906554 & 8.992184077 \\
\hline 25.66770577 & 13.10718678 & 25.53422583 \\
\hline 3.345952017 & 3.540344081 & 3.39258479 \\
\hline 6.967511626 & 7.439817141 & 6.912190327 \\
\hline 9.390177337 & 9.447255598 & 9.316312536 \\
\hline 2.806429168 & 2.668456902 & 2.746080971 \\
\hline 6.04422532 & 5.906911517 & 5.923727746 \\
\hline 1.635578893 & 1.428630395 & 1.61871898 \\
\hline 3.257026499 & 2.566061725 & 3.168671569 \\
\hline 0.144893459 & 0.118184717 & 0.142596729 \\
\hline 0.855106541 & 0.881815283 & 0.857403271 \\
\hline 0.04190419 & 0.037892422 & 0.0362 \\
\hline 0.01770177 & 0.017296541 & 0.0167 \\
\hline 0.00040004 & 0.00519896 & 0.003 \\
\hline 0.02050205 & 0.019796041 & 0.0219 \\
\hline 0.064385408 & 0.038000754 & 0.064796729 \\
\hline 0.091397142 & 0.04866494 & 0.093635839 \\
\hline 0.118553294 & 0.084471372 & 0.121967924 \\
\hline 0.150338177 & 0.156883701 & 0.15651243 \\
\hline 0.174270847 & 0.218143648 & 0.182258544 \\
\hline 0.169174766 & 0.206158897 & 0.164288618 \\
\hline 0.151372315 & 0.167492725 & 0.138739917 \\
\hline
\end{tabular}




\begin{tabular}{|c|c|c|}
\hline $\begin{array}{c}\text { 302-2-A-43-X-1 } \\
\text { Cristin Ashmankas, }\end{array}$ & $\begin{array}{c}\text { 302-2-A-43-X-1 } \\
\text { Cristin Ashmankas, }\end{array}$ & $\begin{array}{c}\text { 302-2-A-43-X-2 } \\
\text { Cristin Ashmankas, }\end{array}$ \\
\hline $\begin{array}{l}\text { Unimodal, Very Poorly } \\
\text { Sorted }\end{array}$ & $\begin{array}{l}\text { Unimodal, Very Poorly } \\
\text { Sorted }\end{array}$ & $\begin{array}{l}\text { Bimodal, Very Poorly } \\
\text { Sorted }\end{array}$ \\
\hline Sandy Mud & Sandy Mud & Sandy Mud \\
\hline Very Fine Sandy Fine Silt & Very Fine Sandy Fine Silt & Very Fine Sandy Fine Silt \\
\hline 43.59770373 & 68.55384488 & 82.53835783 \\
\hline 122.0393154 & 227.1124659 & 258.7530503 \\
\hline 6.813132798 & 5.515041107 & 4.716188534 \\
\hline 60.72388186 & 34.85364023 & 25.91027446 \\
\hline 10.68378418 & 12.04993431 & 11.7076132 \\
\hline 4.76583323 & 5.217054972 & 5.834563683 \\
\hline 0.536406933 & 0.670740782 & 0.778513063 \\
\hline 2.729065232 & 3.229225731 & 3.168636432 \\
\hline 6.548433452 & 6.328983716 & 6.351644557 \\
\hline 2.252728468 & 2.40942796 & 2.580039384 \\
\hline-0.536406933 & -0.692446359 & -0.78844971 \\
\hline 2.729065232 & 3.238942024 & 3.14057797 \\
\hline 10.54113039 & 11.69344803 & 11.2974959 \\
\hline 4.874709775 & 5.103666222 & 6.247522786 \\
\hline 0.21656798 & 0.188819297 & 0.306960276 \\
\hline 0.90323087 & 0.928008353 & 1.038531658 \\
\hline 6.567826605 & 6.418155792 & 6.467853156 \\
\hline 2.285316328 & 2.35153398 & 2.643284258 \\
\hline-0.21656798 & -0.188819297 & -0.306960276 \\
\hline 0.90323087 & 0.928008353 & 1.038531658 \\
\hline Medium Silt & Medium Silt & Medium Silt \\
\hline Very Poorly Sorted & Very Poorly Sorted & Very Poorly Sorted \\
\hline Coarse Skewed & Coarse Skewed & Very Coarse Skewed \\
\hline Mesokurtic & Mesokurtic & Mesokurtic \\
\hline 4.7 & 4.7 & 3.35 \\
\hline & & 1200 \\
\hline 7.754331413 & 7.754331413 & 8.241333809 \\
\hline & & -0.242713414 \\
\hline 1.65485949 & 1.742052483 & 1.631310302 \\
\hline 8.265175153 & 9.686381148 & 8.40989336 \\
\hline 101.8009029 & 110.6161101 & 135.6198806 \\
\hline 61.51634234 & 63.49757611 & 83.13555086 \\
\hline 100.1460434 & 108.8740576 & 133.9885703 \\
\hline 9.524366439 & 10.1434845 & 11.725202 \\
\hline 27.90795546 & 32.65531333 & 34.61019292 \\
\hline 3.296177738 & 3.17636658 & 2.882359415 \\
\hline 6.918738892 & 6.689826512 & 6.893696778 \\
\hline 9.239075558 & 9.164996196 & 9.259753052 \\
\hline 2.802966434 & 2.885371057 & 3.21256017 \\
\hline 5.942897821 & 5.988629616 & 6.377393637 \\
\hline 1.649915278 & 1.698270384 & 1.751799819 \\
\hline 3.251623128 & 3.342481428 & 3.551540873 \\
\hline 0.160578451 & 0.171529316 & 0.185377412 \\
\hline 0.839421549 & 0.828470684 & 0.814622588 \\
\hline 0.00419958 & 0.0260026 & 0.034093181 \\
\hline 0.01069893 & 0.01310131 & 0.019596081 \\
\hline 0.01249875 & 0.00770077 & 0.01219756 \\
\hline 0.04729527 & 0.03890389 & 0.039792042 \\
\hline 0.08588592 & 0.085820745 & 0.079698548 \\
\hline 0.089132357 & 0.100880035 & 0.089905604 \\
\hline 0.112174456 & 0.123927515 & 0.101993258 \\
\hline 0.151483308 & 0.154638607 & 0.138967402 \\
\hline 0.187813678 & 0.176483645 & 0.18107994 \\
\hline 0.170183173 & 0.154514392 & 0.170950862 \\
\hline 0.128634577 & 0.118026491 & 0.131725522 \\
\hline
\end{tabular}




\begin{tabular}{|c|c|c|}
\hline 302-2-A-43-X-2 & 302-2-A-43-X-3 & 302-2-A-43-X-3 \\
\hline & Cristin Ashmankas, & Cristin Ashmankas, \\
\hline $\begin{array}{c}\text { Bimodal, Very Poorly } \\
\text { Sorted }\end{array}$ & $\begin{array}{c}\text { Unimodal, Very Poorly } \\
\text { Sorted }\end{array}$ & Unimodal, Poorly Sorted \\
\hline Sandy Mud & Sandy Mud & Mud \\
\hline Very Fine Sandy Fine Silt & Very Fine Sandy Fine Silt & Fine Silt \\
\hline 83.2844335 & 43.4305335 & 35.08465743 \\
\hline 279.4211016 & 174.9294543 & 155.4845458 \\
\hline 4.521736034 & 7.383672627 & 8.618420177 \\
\hline 23.2539365 & 61.03250716 & 83.2419299 \\
\hline 10.25459936 & 8.939778049 & 7.658595293 \\
\hline 5.746725929 & 4.325709267 & 4.024236317 \\
\hline 0.911241201 & 0.810735441 & 0.860853278 \\
\hline 3.686907461 & 3.921908976 & 4.296650684 \\
\hline 6.527858788 & 6.779634232 & 6.993817259 \\
\hline 2.572338138 & 2.135013772 & 2.043639979 \\
\hline-0.919922725 & -0.842075237 & -0.919060674 \\
\hline 3.615919738 & 3.976371423 & 4.420763737 \\
\hline 9.636881851 & 8.555882692 & 7.288612821 \\
\hline 6.300051292 & 4.119865024 & 3.782933017 \\
\hline 0.28527706 & 0.178520928 & 0.147629001 \\
\hline 1.193122257 & 0.975942126 & 0.977844136 \\
\hline 6.697217867 & 6.868867582 & 7.10014002 \\
\hline 2.655363574 & 2.042597072 & 1.919505231 \\
\hline-0.28527706 & -0.178520928 & -0.147629001 \\
\hline 1.193122257 & 0.975942126 & 0.977844136 \\
\hline Medium Silt & Medium Silt & Fine Silt \\
\hline Very Poorly Sorted & Very Poorly Sorted & Poorly Sorted \\
\hline Coarse Skewed & Coarse Skewed & Coarse Skewed \\
\hline Leptokurtic & Mesokurtic & Mesokurtic \\
\hline 3.35 & 4.7 & 3.35 \\
\hline 1200 & & \\
\hline 8.241333809 & 7.754331413 & 8.241333809 \\
\hline-0.242713414 & & \\
\hline 1.473140936 & 1.624521311 & 1.511496715 \\
\hline 7.900463199 & 7.351134475 & 6.575130852 \\
\hline 103.9751956 & 63.48434822 & 45.56954253 \\
\hline 70.58061656 & 39.07880296 & 30.14862163 \\
\hline 102.5020546 & 61.85982691 & 44.05804582 \\
\hline 9.764247252 & 6.924885659 & 6.242055713 \\
\hline 25.91869746 & 18.67700179 & 15.05050355 \\
\hline 3.265688696 & 3.977455244 & 4.455786302 \\
\hline 6.983847045 & 7.087817371 & 7.248764679 \\
\hline 9.406888824 & 9.265769615 & 9.369806442 \\
\hline 2.880522211 & 2.329572314 & 2.102840174 \\
\hline 6.141200128 & 5.288314371 & 4.914020139 \\
\hline 1.642846872 & 1.505979977 & 1.455351646 \\
\hline 3.287508828 & 2.79179025 & 2.642021234 \\
\hline 0.148150111 & 0.101621252 & 0.070068775 \\
\hline 0.851849889 & 0.898378748 & 0.929931225 \\
\hline 0.0416 & 0.0151 & 0.012502501 \\
\hline 0.019 & 0.0078 & 0.00590118 \\
\hline 0.0022 & 0.0015 & 0.00620124 \\
\hline 0.0224 & 0.0205 & 0.01070214 \\
\hline 0.062950111 & 0.056721252 & 0.034761713 \\
\hline 0.089432916 & 0.088748013 & 0.078792189 \\
\hline 0.117129576 & 0.124022376 & 0.129068563 \\
\hline 0.147824541 & 0.168086811 & 0.17293444 \\
\hline 0.173149694 & 0.204538049 & 0.203980708 \\
\hline 0.169853329 & 0.179818796 & 0.193024345 \\
\hline 0.154459833 & 0.133164702 & 0.152130979 \\
\hline
\end{tabular}




\begin{tabular}{|c|c|c|}
\hline $\begin{array}{c}\text { 302-2-A-44-X-1 } \\
\text { Cristin Ashmankas, }\end{array}$ & $\begin{array}{c}\text { 302-2-A-44-X-1 } \\
\text { Cristin Ashmankas, }\end{array}$ & $\begin{array}{c}\text { 302-2-A-44-X-2 } \\
\text { Cristin Ashmankas, }\end{array}$ \\
\hline Unimodal, Poorly Sorted & $\begin{array}{c}\text { Unimodal, Very Poorly } \\
\text { Sorted }\end{array}$ & Unimodal, Poorly Sorted \\
\hline Mud & Sandy Mud & Mud \\
\hline Very Fine Silt & Very Fine Sandy Fine Silt & Fine Silt \\
\hline 26.68546341 & 54.5464405 & 42.59337067 \\
\hline 111.2204538 & 179.4911554 & 173.3920916 \\
\hline 6.196361835 & 6.318380177 & 7.561470158 \\
\hline 41.8789539 & 47.94170894 & 63.47029039 \\
\hline 4.864744739 & 10.83394797 & 9.549787745 \\
\hline 3.809137452 & 4.860149821 & 4.136499107 \\
\hline 1.498362979 & 0.722125172 & 0.764712329 \\
\hline 6.16112385 & 3.255389311 & 3.959964088 \\
\hline 7.683420178 & 6.509362132 & 6.682405839 \\
\hline 1.929464348 & 2.293715439 & 2.071624892 \\
\hline-1.498362979 & -0.735618171 & -0.80491847 \\
\hline 6.16112385 & 3.274201207 & 4.032178652 \\
\hline 4.290335621 & 10.43135892 & 9.262797031 \\
\hline 3.301329661 & 4.78766323 & 3.918275061 \\
\hline 0.247845513 & 0.222430539 & 0.149586933 \\
\hline 1.25204411 & 0.966023837 & 0.91792933 \\
\hline 7.864693774 & 6.582929075 & 6.754336384 \\
\hline 1.723047209 & 2.259321675 & 1.970218678 \\
\hline-0.247845513 & -0.222430539 & -0.149586933 \\
\hline 1.25204411 & 0.966023837 & 0.91792933 \\
\hline Fine Silt & Medium Silt & Medium Silt \\
\hline Poorly Sorted & Very Poorly Sorted & Poorly Sorted \\
\hline Coarse Skewed & Coarse Skewed & Coarse Skewed \\
\hline Leptokurtic & Mesokurtic & Mesokurtic \\
\hline 3.35 & 4.7 & 4.7 \\
\hline 8.241333809 & 7.754331413 & 7.754331413 \\
\hline 1.206400441 & 1.733937785 & 1.797297932 \\
\hline 3.829964215 & 8.416973302 & 8.105695823 \\
\hline 23.48474502 & 99.78001968 & 61.63042023 \\
\hline 19.46679082 & 57.54532863 & 34.29059765 \\
\hline 22.27834458 & 98.04608189 & 59.8331223 \\
\hline 4.076571699 & 8.576380016 & 6.98649832 \\
\hline 6.259525593 & 25.63082188 & 20.47263189 \\
\hline 5.41213226 & 3.325105236 & 4.020213562 \\
\hline 8.028453372 & 6.892482743 & 6.946848247 \\
\hline 9.695075424 & 9.17173215 & 9.119954706 \\
\hline 1.791359664 & 2.758328383 & 2.268524934 \\
\hline 4.282943164 & 5.846626914 & 5.099741144 \\
\hline 1.293237618 & 1.607068381 & 1.520588844 \\
\hline 2.027356389 & 3.100368832 & 2.804569548 \\
\hline 0.052573631 & 0.149750111 & 0.09803621 \\
\hline 0.947426369 & 0.850249889 & 0.90196379 \\
\hline 0 & 0.0135 & 0.015103021 \\
\hline 0.022195561 & 0.0145 & 0.00780156 \\
\hline 0.00319936 & 0.0119 & 0.00030006 \\
\hline 0.00679864 & 0.0376 & 0.01140228 \\
\hline 0.020380069 & 0.072250111 & 0.063429288 \\
\hline 0.028436314 & 0.088553558 & 0.104115229 \\
\hline 0.057502584 & 0.119797754 & 0.132588053 \\
\hline 0.124292083 & 0.160498922 & 0.17522931 \\
\hline 0.228901757 & 0.191546899 & 0.20179937 \\
\hline 0.273254195 & 0.169807971 & 0.174458978 \\
\hline 0.235039437 & 0.120044785 & 0.113772851 \\
\hline
\end{tabular}




\begin{tabular}{|c|c|c|}
\hline $\begin{array}{c}\text { 302-2-A-44-X-2 } \\
\text { Cristin Ashmankas, }\end{array}$ & $\begin{array}{c}\text { 302-2-A-44-X-3 } \\
\text { Cristin Ashmankas, }\end{array}$ & $\begin{array}{c}\text { 302-2-A-44-X-3 } \\
\text { Cristin Ashmankas, }\end{array}$ \\
\hline $\begin{array}{c}\text { Polymodal, Very Poorly } \\
\text { Sorted }\end{array}$ & $\begin{array}{c}\text { Unimodal, Very Poorly } \\
\text { Sorted }\end{array}$ & $\begin{array}{c}\text { Bimodal, Very Poorly } \\
\text { Sorted }\end{array}$ \\
\hline Sandy Mud & Sandy Mud & Sandy Mud \\
\hline Very Fine Sandy Fine Silt & ery Fine Sandy Medium S & ery Fine Sandy Medium S \\
\hline 95.4501495 & 57.41924192 & 75.29182895 \\
\hline 271.6036583 & 166.7682164 & 218.8727215 \\
\hline 4.190259724 & 6.167621741 & 5.185749562 \\
\hline 21.53104121 & 48.61092249 & 32.9214124 \\
\hline 11.22386423 & 13.84929699 & 15.16453724 \\
\hline 6.613119455 & 4.521021713 & 5.100310694 \\
\hline 0.875706723 & 0.640529316 & 0.570622593 \\
\hline 2.998147369 & 3.219464195 & 3.131840187 \\
\hline 6.409519394 & 6.163079986 & 6.001310975 \\
\hline 2.761408827 & 2.182612719 & 2.369014622 \\
\hline-0.869662217 & -0.65089248 & -0.593171277 \\
\hline 2.944058952 & 3.231608552 & 3.137962468 \\
\hline 11.40647121 & 13.31069908 & 14.26681129 \\
\hline 7.11058433 & 4.510584725 & 5.160268298 \\
\hline 0.393995647 & 0.193993235 & 0.144773066 \\
\hline 1.074515351 & 1.066093031 & 1.081105476 \\
\hline 6.454003651 & 6.231269846 & 6.131193269 \\
\hline 2.829968122 & 2.173314468 & 2.367446078 \\
\hline-0.393995647 & -0.193993235 & -0.144773066 \\
\hline 1.074515351 & 1.066093031 & 1.081105476 \\
\hline Medium Silt & Medium Silt & Medium Silt \\
\hline Very Poorly Sorted & Very Poorly Sorted & Very Poorly Sorted \\
\hline Very Coarse Skewed & Coarse Skewed & Coarse Skewed \\
\hline Mesokurtic & Mesokurtic & Mesokurtic \\
\hline 3.35 & 9.4 & 9.4 \\
\hline 107.5 & & 215 \\
\hline 8.241333809 & 6.754331413 & 6.754331413 \\
\hline 3.236965594 & & 2.236965594 \\
\hline 1.512929566 & 2.3641149 & 2.144757819 \\
\hline 7.060536421 & 11.30708561 & 13.20195864 \\
\hline 249.6200759 & 116.4184482 & 141.0635211 \\
\hline 164.9912075 & 49.24398901 & 65.77130521 \\
\hline 248.1071464 & 114.0543333 & 138.9187633 \\
\hline 11.73367748 & 6.96563393 & 8.56813246 \\
\hline 31.33190247 & 28.32424869 & 35.94137954 \\
\hline 2.002194126 & 3.102608403 & 2.825583138 \\
\hline 7.146006489 & 6.466629066 & 6.243104206 \\
\hline 9.36843946 & 8.72448413 & 8.864969533 \\
\hline 4.679086478 & 2.811983659 & 3.13739469 \\
\hline 7.366245334 & 5.621875727 & 6.039386395 \\
\hline 1.729825962 & 1.569361206 & 1.670896032 \\
\hline 3.552583338 & 2.800254656 & 3.098980784 \\
\hline 0.200043767 & 0.161999609 & 0.175581477 \\
\hline 0.799956233 & 0.838000391 & 0.824418523 \\
\hline 0.0353 & 0.00980098 & 0.021393582 \\
\hline 0.028 & 0.01530153 & 0.020393882 \\
\hline 0.0366 & 0.02440244 & 0.031290613 \\
\hline 0.0452 & 0.04380438 & 0.032490253 \\
\hline 0.054943767 & 0.068690278 & 0.070013147 \\
\hline 0.057863572 & 0.096869396 & 0.127317561 \\
\hline 0.079784915 & 0.152484586 & 0.155991589 \\
\hline 0.135950945 & 0.198429012 & 0.173010833 \\
\hline 0.19029473 & 0.191476907 & 0.16190127 \\
\hline 0.185176125 & 0.127194774 & 0.120085429 \\
\hline 0.150885947 & 0.071545716 & 0.086111842 \\
\hline
\end{tabular}




\begin{tabular}{|c|c|c|}
\hline $302-2-A-44-X-4$ & $302-2-A-45-X-1$ & $302-2-A-45-X-1$ \\
\hline Cristin Ashmankas, & Cristin Ashmankas, & Cristin Ashmankas, \\
\hline $\begin{array}{c}\text { Trimodal, Very Poorly } \\
\text { Sorted }\end{array}$ & $\begin{array}{c}\text { Bimodal, Very Poorly } \\
\text { Sorted }\end{array}$ & $\begin{array}{c}\text { Bimodal, Very Poorly } \\
\text { Sorted }\end{array}$ \\
\hline Sandy Mud & Sandy Mud & Sandy Mud \\
\hline Very Fine Sandy Fine Silt & Medium Sandy Fine Silt & Fine Sandy Fine Silt \\
\hline 90.78763674 & 104.2748915 & 122.099865 \\
\hline 255.2795452 & 246.1419792 & 270.4751563 \\
\hline 4.426818889 & 3.575987592 & 3.680086396 \\
\hline 24.15453049 & 17.82867707 & 18.35313486 \\
\hline 12.31286192 & 14.65718282 & 18.70741935 \\
\hline 6.320840671 & 6.763985428 & 7.374782961 \\
\hline 0.788377949 & 0.691413923 & 0.422328777 \\
\hline 2.876253757 & 2.563755432 & 2.105306063 \\
\hline 6.286890767 & 6.066342494 & 5.680456907 \\
\hline 2.688415533 & 2.768153367 & 2.897649717 \\
\hline-0.789170341 & -0.690496557 & -0.419118121 \\
\hline 2.845587465 & 2.550530402 & 2.090027618 \\
\hline 12.62974845 & 16.01394301 & 19.5570997 \\
\hline 6.810150501 & 7.596387717 & 8.053565385 \\
\hline 0.357801237 & 0.342404144 & 0.269982572 \\
\hline 1.027518267 & 1.033579654 & 0.769525716 \\
\hline 6.307030285 & 5.964527613 & 5.676163754 \\
\hline 2.767686681 & 2.925313542 & 3.009627619 \\
\hline-0.357801237 & -0.342404144 & -0.269982572 \\
\hline 1.027518267 & 1.033579654 & 0.769525716 \\
\hline Medium Silt & Coarse Silt & Coarse Silt \\
\hline Very Poorly Sorted & Very Poorly Sorted & Very Poorly Sorted \\
\hline Very Coarse Skewed & Very Coarse Skewed & Coarse Skewed \\
\hline Mesokurtic & Mesokurtic & Platykurtic \\
\hline 4.7 & 4.7 & 3.35 \\
\hline 107.5 & 427.5 & 215 \\
\hline 7.754331413 & 7.754331413 & 8.241333809 \\
\hline 3.236965594 & 1.247054535 & 2.236965594 \\
\hline 1.63775014 & 1.72098183 & 1.790409926 \\
\hline 8.106161593 & 9.699081811 & 12.83293626 \\
\hline 229.5005585 & 375.349778 & 367.7022151 \\
\hline 140.1316067 & 218.1021156 & 205.3731995 \\
\hline 227.8628084 & 373.6287962 & 365.9118051 \\
\hline 11.85945198 & 11.96474123 & 28.71522675 \\
\hline 35.074645 & 38.5694901 & 105.8738929 \\
\hline 2.12343043 & 1.413692465 & 1.443390227 \\
\hline 6.946765349 & 6.687936107 & 6.284004883 \\
\hline 9.254069013 & 9.182552419 & 9.125494345 \\
\hline 4.358074972 & 6.495438467 & 6.322264188 \\
\hline 7.130638582 & 7.768859954 & 7.682104117 \\
\hline 1.758118664 & 1.783444697 & 2.519156035 \\
\hline 3.56796544 & 3.580717289 & 4.843744049 \\
\hline 0.208725114 & 0.218166835 & 0.297871697 \\
\hline 0.791274886 & 0.781833165 & 0.702128303 \\
\hline 0.03049695 & 0.020195961 & 0.03179682 \\
\hline 0.02449755 & 0.050589882 & 0.03769623 \\
\hline 0.03789621 & 0.065486903 & 0.079492051 \\
\hline 0.056994301 & 0.042191562 & 0.088491151 \\
\hline 0.058840103 & 0.039702528 & 0.060395444 \\
\hline 0.060104883 & 0.064982039 & 0.067824761 \\
\hline 0.091793589 & 0.115078959 & 0.099407365 \\
\hline 0.14814498 & 0.152288028 & 0.130517079 \\
\hline 0.188614064 & 0.173232748 & 0.14935013 \\
\hline 0.171278637 & 0.155554646 & 0.141744199 \\
\hline 0.131338733 & 0.120696745 & 0.113284771 \\
\hline
\end{tabular}


302-2-A-46-X-1

Cristin Ashmankas

Bimodal, Very Poorly Sorted

Sandy Mud

Very Fine Sandy Fine Silt 64.18248825

176.9936098

5.502937289 40.57795547

12.01646725

5.460312957

0.659504369

2.799680587

6.360906755

2.459121071

$-0.666498548$

2.807372895

11.67708638

5.662540857

0.261680033

0.988928059

6.420175847

2.501449555

$-0.261680033$

0.988928059

Medium Silt

Very Poorly Sorted Coarse Skewed Mesokurtic

$$
3.35
$$

215

8.241333809

2.236965594

1.693127508

8.90245635

163.8722034

96.78668773

162.1790759

10.33122949

31.20876093

2.609356935

6.811580828

9.206093659

3.528108223

6.596736724

1.693906833

3.36894005

0.18045437

0.81954563

0.01069893

0.01849815

0.04039596

0.04889511

0.061966218

0.082484932

0.114535553

0.153294771

0.177637054

0.166860565

0.124732754 
APENDIX II: Data and statistical variables for IODP Exp. 302, ACEX, samples taken from paleogene sediments. Samples exclusively contained sand, silt, and clay.

Sample identifications are the expedition-site-core-section. The samples are presented in descending order. 


\begin{tabular}{|c|c|c|}
\hline & Sample ID: & 302-2-A-46-X-1 \\
\hline & ANALYST: & Cristin Ashmankas, \\
\hline & SAMPLE TYPE: & Bimodal, Very Poorly Sorted \\
\hline & TEXTURAL GROUP: & Sandy Mud \\
\hline & SEDIMENT NAME: & Very Fine Sandy Fine Silt \\
\hline METHOD OF & MEAN & 73.95 \\
\hline MOMENTS & SORTING & 211.2 \\
\hline Arithmetic (mm) & SKEWNESS & 4.910 \\
\hline & KURTOSIS & 30.92 \\
\hline METHOD OF & MEAN & 11.77 \\
\hline MOMENTS & SORTING & 5.671 \\
\hline Geometric (mm) & SKEWNESS & 0.799 \\
\hline & KURTOSIS & 3.042 \\
\hline METHOD OF & MEAN & 6.380 \\
\hline MOMENTS & SORTING & 2.520 \\
\hline Logarithmic (f) & SKEWNESS & -0.805 \\
\hline & KURTOSIS & 3.036 \\
\hline FOLK AND & MEAN & 11.41 \\
\hline WARD METHOD & SORTING & 5.863 \\
\hline$(\mathrm{mm})$ & SKEWNESS & 0.313 \\
\hline & KURTOSIS & 1.078 \\
\hline FOLK AND & MEAN & 6.454 \\
\hline WARD METHOD & SORTING & 2.552 \\
\hline (f) & SKEWNESS & -0.313 \\
\hline & KURTOSIS & 1.078 \\
\hline FOLK AND & MEAN: & Medium Silt \\
\hline WARD METHOD & SORTING: & Very Poorly Sorted \\
\hline (Description) & SKEWNESS: & Very Coarse Skewed \\
\hline & KURTOSIS: & Mesokurtic \\
\hline & MODE $1(\mathrm{~mm}):$ & 4.700 \\
\hline & MODE $2(\mathrm{~mm}):$ & 215.0 \\
\hline & MODE 1 (f): & 7.754 \\
\hline & MODE 2 (f): & 2.237 \\
\hline & $\mathrm{D} 10(\mathrm{~mm}):$ & 1.707 \\
\hline & D50 (mm): & 8.261 \\
\hline & D90 (mm): & 183.1 \\
\hline & (D90 / D10) (mm): & 107.3 \\
\hline & $(\mathrm{D} 90-\mathrm{D} 10)(\mathrm{mm}):$ & 181.4 \\
\hline & $(\mathrm{D} 75 / \mathrm{D} 25)(\mathrm{mm}):$ & 9.356 \\
\hline & $(\mathrm{D} 75-\mathrm{D} 25)(\mathrm{mm}):$ & 27.90 \\
\hline & D10 (f): & 2.450 \\
\hline & D50 (f): & 6.919 \\
\hline & D90 (f): & 9.194 \\
\hline & $(\mathrm{D} 90 / \mathrm{D} 10)(\mathrm{f}):$ & 3.754 \\
\hline & $(D 90-D 10)(f):$ & 6.745 \\
\hline & $(\mathrm{D} 75$ / D25) (f): & 1.645 \\
\hline & $(D 75-D 25)(f):$ & 3.226 \\
\hline & \% SAND: & $17.8 \%$ \\
\hline & \% MUD: & $82.2 \%$ \\
\hline & \% V COARSE SAND: & $1.7 \%$ \\
\hline & \% COARSE SAND: & $2.5 \%$ \\
\hline & \% MEDIUM SAND: & $3.9 \%$ \\
\hline & \% FINE SAND: & $4.1 \%$ \\
\hline & \% V FINE SAND: & $5.6 \%$ \\
\hline & $\%$ V COARSE SILT: & $7.2 \%$ \\
\hline & \% COARSE SILT: & $10.5 \%$ \\
\hline & $\%$ MEDIUM SILT: & $15.9 \%$ \\
\hline & $\%$ FINE SILT: & $19.2 \%$ \\
\hline & \% V FINE SILT: & $17.1 \%$ \\
\hline & \% CLAY: & $12.3 \%$ \\
\hline
\end{tabular}




\begin{tabular}{|c|c|c|}
\hline $\begin{array}{r}\text { 302-2-A-46-X-2 } \\
\text { Cristin Ashmankas }\end{array}$ & $\begin{array}{r}\text { 302-2-A-46-X-2 } \\
\text { Cristin Ashmankas }\end{array}$ & $\begin{array}{c}\text { 302-2-A-46-X-3 } \\
\text { Cristin Ashmankas }\end{array}$ \\
\hline Bimodal, Very Poorly Sorted & Trimodal, Very Poorly Sorted & Unimodal, Very Poorly Sorted \\
\hline Sandy Mud & Sandy Mud & Mud \\
\hline Very Fine Sandy Fine Silt & Fine Sandy Fine Silt & Fine Silt \\
\hline 87.58 & 103.1 & 58.79 \\
\hline 245.4 & 229.3 & 207.9 \\
\hline 4.357 & 3.711 & 5.274 \\
\hline 24.14 & 19.61 & 34.11 \\
\hline 11.98 & 16.45 & 7.794 \\
\hline 5.986 & 6.918 & 4.674 \\
\hline 0.915 & 0.490 & 1.494 \\
\hline 3.187 & 2.235 & 5.393 \\
\hline 6.335 & 5.908 & 6.977 \\
\hline 2.607 & 2.796 & 2.248 \\
\hline-0.916 & -0.490 & -1.498 \\
\hline 3.150 & 2.231 & 5.340 \\
\hline 12.12 & 16.97 & 6.377 \\
\hline 6.260 & 7.593 & 4.176 \\
\hline 0.360 & 0.299 & 0.266 \\
\hline 1.218 & 0.839 & 1.646 \\
\hline 6.366 & 5.881 & 7.293 \\
\hline 2.646 & 2.925 & 2.062 \\
\hline-0.360 & -0.299 & -0.266 \\
\hline 1.218 & 0.839 & 1.646 \\
\hline Medium Silt & Coarse Silt & Fine Silt \\
\hline Very Poorly Sorted & Very Poorly Sorted & Very Poorly Sorted \\
\hline Very Coarse Skewed & Coarse Skewed & Coarse Skewed \\
\hline Leptokurtic & Platykurtic & Very Leptokurtic \\
\hline 6.650 & 6.650 & 4.700 \\
\hline 427.5 & 215.0 & \\
\hline 7.254 & 7.254 & 7.754 \\
\hline 1.247 & 2.237 & \\
\hline 1.766 & 1.693 & 1.651 \\
\hline 8.119 & 10.73 & 5.986 \\
\hline 259.1 & 328.0 & 42.27 \\
\hline 146.8 & 193.7 & 25.60 \\
\hline 257.4 & 326.3 & 40.62 \\
\hline 7.859 & 20.53 & 4.222 \\
\hline 23.99 & 72.59 & 9.714 \\
\hline 1.948 & 1.608 & 4.564 \\
\hline 6.944 & 6.542 & 7.384 \\
\hline 9.146 & 9.206 & 9.243 \\
\hline 4.694 & 5.725 & 2.025 \\
\hline 7.197 & 7.598 & 4.678 \\
\hline 1.574 & 2.174 & 1.330 \\
\hline 2.974 & 4.360 & 2.078 \\
\hline $18.5 \%$ & $26.8 \%$ & $9.1 \%$ \\
\hline $81.5 \%$ & $73.2 \%$ & $90.9 \%$ \\
\hline $2.6 \%$ & $1.7 \%$ & $1.7 \%$ \\
\hline $3.1 \%$ & $4.2 \%$ & $2.2 \%$ \\
\hline $4.5 \%$ & $6.9 \%$ & $3.1 \%$ \\
\hline $3.7 \%$ & $7.2 \%$ & $1.8 \%$ \\
\hline $4.6 \%$ & $6.8 \%$ & $0.3 \%$ \\
\hline $5.2 \%$ & $6.3 \%$ & $2.3 \%$ \\
\hline $9.1 \%$ & $9.3 \%$ & $8.5 \%$ \\
\hline $18.4 \%$ & $14.9 \%$ & $20.3 \%$ \\
\hline $20.9 \%$ & $16.5 \%$ & $25.9 \%$ \\
\hline $16.4 \%$ & $13.9 \%$ & $20.8 \%$ \\
\hline $11.6 \%$ & $12.2 \%$ & $13.2 \%$ \\
\hline
\end{tabular}




\begin{tabular}{|c|c|c|}
\hline $302-2-A-46-X-3$ & $302-2-A-47-X-1$ & $302-2-A-47-X-2$ \\
\hline Cristin Ashmankas, & Cristin Ashmankas, & Cristin Ashmankas, \\
\hline Unimodal, Poorly Sorted & Unimodal, Poorly Sorted & Unimodal, Poorly Sorted \\
\hline Mud & Mud & Mud \\
\hline Fine Silt & Fine Silt & Fine Silt \\
\hline 51.00 & 54.41 & 39.83 \\
\hline 215.0 & 226.2 & 188.1 \\
\hline 5.959 & 5.726 & 7.102 \\
\hline 39.88 & 36.73 & 55.30 \\
\hline 7.366 & 7.428 & 7.273 \\
\hline 4.198 & 4.281 & 3.660 \\
\hline 1.450 & 1.485 & 1.430 \\
\hline 6.088 & 6.146 & 6.677 \\
\hline 7.044 & 7.023 & 7.069 \\
\hline 2.110 & 2.147 & 1.910 \\
\hline-1.475 & -1.508 & -1.480 \\
\hline 6.022 & 6.039 & 6.692 \\
\hline 6.477 & 6.512 & 6.710 \\
\hline 3.632 & 3.840 & 3.124 \\
\hline 0.194 & 0.219 & 0.167 \\
\hline 1.290 & 1.382 & 1.137 \\
\hline 7.270 & 7.263 & 7.219 \\
\hline 1.861 & 1.941 & 1.643 \\
\hline-0.194 & -0.219 & -0.167 \\
\hline 1.290 & 1.382 & 1.137 \\
\hline Fine Silt & Fine Silt & Fine Silt \\
\hline Poorly Sorted & Poorly Sorted & Poorly Sorted \\
\hline Coarse Skewed & Coarse Skewed & Coarse Skewed \\
\hline Leptokurtic & Leptokurtic & Leptokurtic \\
\hline 4.700 & 4.700 & 4.700 \\
\hline 7.754 & 7.754 & 7.754 \\
\hline 1.613 & 1.620 & 1.810 \\
\hline 6.094 & 6.118 & 6.178 \\
\hline 37.12 & 36.65 & 33.50 \\
\hline 23.01 & 22.63 & 18.51 \\
\hline 35.51 & 35.03 & 31.69 \\
\hline 4.523 & 4.553 & 4.128 \\
\hline 10.50 & 10.62 & 10.02 \\
\hline 4.752 & 4.770 & 4.900 \\
\hline 7.359 & 7.353 & 7.339 \\
\hline 9.276 & 9.270 & 9.110 \\
\hline 1.952 & 1.943 & 1.859 \\
\hline 4.524 & 4.500 & 4.211 \\
\hline 1.350 & 1.353 & 1.328 \\
\hline 2.177 & 2.187 & 2.046 \\
\hline $7.3 \%$ & $7.3 \%$ & $5.4 \%$ \\
\hline $92.7 \%$ & $92.7 \%$ & $94.6 \%$ \\
\hline $2.3 \%$ & $2.6 \%$ & $1.8 \%$ \\
\hline $1.3 \%$ & $1.3 \%$ & $0.9 \%$ \\
\hline $0.6 \%$ & $0.8 \%$ & $0.2 \%$ \\
\hline $0.9 \%$ & $1.0 \%$ & $0.4 \%$ \\
\hline $2.1 \%$ & $1.6 \%$ & $2.1 \%$ \\
\hline $3.9 \%$ & $3.8 \%$ & $5.3 \%$ \\
\hline $10.1 \%$ & $10.4 \%$ & $10.3 \%$ \\
\hline $20.0 \%$ & $19.9 \%$ & $20.1 \%$ \\
\hline $24.6 \%$ & $24.5 \%$ & $27.0 \%$ \\
\hline $20.4 \%$ & $20.4 \%$ & $20.7 \%$ \\
\hline $13.7 \%$ & $13.6 \%$ & $11.3 \%$ \\
\hline
\end{tabular}




\begin{tabular}{|c|c|c|}
\hline $302-2-A-47-X-2$ & $302-2-A-47-X-3$ & $302-2-A-47-X-3$ \\
\hline Cristin Ashmankas, & Cristin Ashmankas, & Cristin Ashmankas, \\
\hline Unimodal, Poorly Sorted & Unimodal, Poorly Sorted & Unimodal, Poorly Sorted \\
\hline Sandy Mud & Mud & Mud \\
\hline Very Fine Sandy Medium Silt & Fine Silt & Fine Silt \\
\hline 61.37 & 43.05 & 7.404 \\
\hline 217.4 & 195.5 & 6.765 \\
\hline 5.767 & 6.872 & 1.938 \\
\hline 37.89 & 51.58 & 7.635 \\
\hline 13.03 & 8.197 & 5.055 \\
\hline 4.142 & 3.842 & 2.399 \\
\hline 0.916 & 1.107 & -0.032 \\
\hline 4.547 & 5.684 & 2.443 \\
\hline 6.220 & 6.893 & 7.628 \\
\hline 2.076 & 1.979 & 1.262 \\
\hline-0.961 & -1.165 & 0.032 \\
\hline 4.553 & 5.727 & 2.443 \\
\hline 12.14 & 7.631 & 5.077 \\
\hline 3.752 & 3.318 & 2.473 \\
\hline 0.115 & 0.060 & 0.000 \\
\hline 1.156 & 0.947 & 0.942 \\
\hline 6.364 & 7.034 & 7.622 \\
\hline 1.908 & 1.730 & 1.306 \\
\hline-0.115 & -0.060 & 0.000 \\
\hline 1.156 & 0.947 & 0.942 \\
\hline Medium Silt & Fine Silt & Fine Silt \\
\hline Poorly Sorted & Poorly Sorted & Poorly Sorted \\
\hline Coarse Skewed & Symmetrical & Symmetrical \\
\hline Leptokurtic & Mesokurtic & Mesokurtic \\
\hline 13.30 & 4.700 & 4.700 \\
\hline 6.254 & 7.754 & 7.754 \\
\hline 2.655 & 1.736 & 1.553 \\
\hline 11.71 & 7.487 & 5.043 \\
\hline 76.18 & 35.26 & 16.28 \\
\hline 28.70 & 20.31 & 10.48 \\
\hline 73.53 & 33.52 & 14.73 \\
\hline 5.169 & 5.531 & 3.546 \\
\hline 21.34 & 14.78 & 6.921 \\
\hline 3.714 & 4.826 & 5.941 \\
\hline 6.416 & 7.061 & 7.632 \\
\hline 8.557 & 9.170 & 9.331 \\
\hline 2.304 & 1.900 & 1.571 \\
\hline 4.843 & 4.344 & 3.390 \\
\hline 1.452 & 1.426 & 1.273 \\
\hline 2.370 & 2.468 & 1.826 \\
\hline $11.7 \%$ & $5.1 \%$ & $0.0 \%$ \\
\hline $88.3 \%$ & $94.9 \%$ & $100.0 \%$ \\
\hline $2.3 \%$ & $2.0 \%$ & $0.0 \%$ \\
\hline $1.5 \%$ & $0.9 \%$ & $0.0 \%$ \\
\hline $0.6 \%$ & $0.0 \%$ & $0.0 \%$ \\
\hline $1.9 \%$ & $0.6 \%$ & $0.0 \%$ \\
\hline $5.4 \%$ & $1.7 \%$ & $0.0 \%$ \\
\hline $9.3 \%$ & $6.5 \%$ & $1.0 \%$ \\
\hline $19.4 \%$ & $17.4 \%$ & $9.8 \%$ \\
\hline $22.5 \%$ & $19.7 \%$ & $21.6 \%$ \\
\hline $19.1 \%$ & $20.8 \%$ & $28.3 \%$ \\
\hline $12.1 \%$ & $18.4 \%$ & $24.2 \%$ \\
\hline $5.8 \%$ & $12.1 \%$ & $15.1 \%$ \\
\hline
\end{tabular}




\begin{tabular}{|c|c|c|}
\hline 302-2-A-47-X-4 & 302-2-A-47-X-4 & 302-2-A-47-X-5 \\
\hline Unimodal, Poorly Sorted & Unimodal, Very Poorly Sorted & Unimodal, Very Poorly Sortec \\
\hline Mud & Sandy Mud & Sandy Mud \\
\hline Very Fine Silt & $\begin{array}{c}\text { very coalse salluy very } \\
\text { Finn cilt }\end{array}$ & Very Fine Sandy Fine Silt \\
\hline 51.83 & 86.46 & 46.83 \\
\hline 215.4 & 275.8 & 158.6 \\
\hline 5.659 & 4.232 & 6.009 \\
\hline 36.75 & 21.46 & 46.48 \\
\hline 5.987 & 7.689 & 7.118 \\
\hline 4.382 & 6.182 & 5.031 \\
\hline 1.768 & 1.364 & 1.101 \\
\hline 6.728 & 4.217 & 3.941 \\
\hline 7.351 & 6.956 & 7.124 \\
\hline 2.168 & 2.679 & 2.340 \\
\hline-1.770 & -1.343 & -1.106 \\
\hline 6.615 & 4.077 & 3.945 \\
\hline 5.021 & 7.192 & 6.485 \\
\hline 3.779 & 6.073 & 4.875 \\
\hline 0.311 & 0.468 & 0.313 \\
\hline 1.617 & 1.572 & 1.293 \\
\hline 7.638 & 7.119 & 7.269 \\
\hline 1.918 & 2.602 & 2.285 \\
\hline-0.311 & -0.468 & -0.313 \\
\hline 1.617 & 1.572 & 1.293 \\
\hline Fine Silt & Fine Silt & Fine Silt \\
\hline Poorly Sorted & Very Poorly Sorted & Very Poorly Sorted \\
\hline Very Coarse Skewed & Very Coarse Skewed & Very Coarse Skewed \\
\hline Very Leptokurtic & Very Leptokurtic & Leptokurtic \\
\hline 3.350 & 3.350 & 4.700 \\
\hline 8.241 & 8.241 & 7.754 \\
\hline 1.459 & 1.398 & 1.265 \\
\hline 4.501 & 4.700 & 5.150 \\
\hline 33.95 & 196.2 & 85.74 \\
\hline 23.27 & 140.4 & 67.78 \\
\hline 32.49 & 194.8 & 84.48 \\
\hline 3.825 & 5.525 & 5.820 \\
\hline 6.907 & 10.71 & 11.22 \\
\hline 4.880 & 2.350 & 3.544 \\
\hline 7.796 & 7.733 & 7.601 \\
\hline 9.421 & 9.483 & 9.627 \\
\hline 1.930 & 4.035 & 2.716 \\
\hline 4.541 & 7.133 & 6.083 \\
\hline 1.287 & 1.394 & 1.409 \\
\hline 1.936 & 2.466 & 2.541 \\
\hline $7.4 \%$ & $14.6 \%$ & $11.9 \%$ \\
\hline $92.6 \%$ & $85.4 \%$ & $88.1 \%$ \\
\hline $2.1 \%$ & $3.7 \%$ & $0.8 \%$ \\
\hline $1.8 \%$ & $2.8 \%$ & $1.8 \%$ \\
\hline $0.9 \%$ & $2.5 \%$ & $2.3 \%$ \\
\hline $0.8 \%$ & $2.7 \%$ & $2.8 \%$ \\
\hline $1.7 \%$ & $2.9 \%$ & $4.1 \%$ \\
\hline $3.0 \%$ & $3.1 \%$ & $4.3 \%$ \\
\hline $5.2 \%$ & $5.0 \%$ & $6.4 \%$ \\
\hline $13.9 \%$ & $11.7 \%$ & $14.6 \%$ \\
\hline $26.4 \%$ & $22.2 \%$ & $21.9 \%$ \\
\hline $26.6 \%$ & $24.7 \%$ & $20.8 \%$ \\
\hline $17.4 \%$ & $18.8 \%$ & $20.2 \%$ \\
\hline
\end{tabular}




\begin{tabular}{|c|c|c|}
\hline 302-2-A-47-X-5 & 302-2-A-48-X-1 & 302-2-A-48-X-1 \\
\hline Cristin Ashmankas, & Cristin Ashmankas, & Cristin Ashmankas, \\
\hline Unimodal, Very Poorly Sorted & Unimodal, Poorly Sorted & Trimodal, Very Poorly Sorted \\
\hline Sandy Mud & Mud & Sandy Mud \\
\hline Very Fine Sandy Fine Silt & Fine Silt & Very Fine Sandy Coarse Silt \\
\hline 52.51 & 47.76 & 83.55 \\
\hline 191.7 & 200.6 & 224.2 \\
\hline 6.439 & 6.253 & 4.851 \\
\hline 48.01 & 44.57 & 29.33 \\
\hline 10.37 & 7.384 & 18.92 \\
\hline 4.398 & 4.088 & 4.955 \\
\hline 0.913 & 1.475 & 0.465 \\
\hline 4.090 & 6.117 & 3.032 \\
\hline 6.559 & 7.046 & 5.686 \\
\hline 2.161 & 2.068 & 2.321 \\
\hline-0.943 & -1.500 & -0.489 \\
\hline 4.115 & 6.073 & 3.036 \\
\hline 9.803 & 6.549 & 17.80 \\
\hline 4.157 & 3.640 & 5.020 \\
\hline 0.200 & 0.234 & 0.085 \\
\hline 1.115 & 1.360 & 1.083 \\
\hline 6.673 & 7.255 & 5.812 \\
\hline 2.056 & 1.864 & 2.328 \\
\hline-0.200 & -0.234 & -0.085 \\
\hline 1.115 & 1.360 & 1.083 \\
\hline Medium Silt & Fine Silt & Coarse Silt \\
\hline Very Poorly Sorted & Poorly Sorted & Very Poorly Sorted \\
\hline Coarse Skewed & Coarse Skewed & Symmetrical \\
\hline Leptokurtic & Leptokurtic & Mesokurtic \\
\hline \multirow{2}{*}{6.650} & 4.700 & 26.50 \\
\hline & & 9.400 \\
\hline \multirow[t]{2}{*}{7.254} & 7.754 & 5.259 \\
\hline & & 6.754 \\
\hline 1.954 & 1.699 & 2.712 \\
\hline 8.558 & 5.994 & 17.80 \\
\hline 76.19 & 36.56 & 166.3 \\
\hline 38.99 & 21.52 & 61.33 \\
\hline 74.24 & 34.86 & 163.6 \\
\hline 5.984 & 4.285 & 8.313 \\
\hline 18.70 & 10.07 & 43.67 \\
\hline 3.714 & 4.774 & 2.588 \\
\hline 6.868 & 7.382 & 5.812 \\
\hline 8.999 & 9.201 & 8.526 \\
\hline 2.423 & 1.928 & 3.295 \\
\hline 5.285 & 4.428 & 5.938 \\
\hline 1.471 & 1.336 & 1.705 \\
\hline 2.581 & 2.099 & 3.055 \\
\hline $11.7 \%$ & $6.9 \%$ & $20.2 \%$ \\
\hline $88.3 \%$ & $93.1 \%$ & $79.8 \%$ \\
\hline $1.7 \%$ & $1.9 \%$ & $2.2 \%$ \\
\hline $1.2 \%$ & $1.4 \%$ & $2.5 \%$ \\
\hline $1.2 \%$ & $1.1 \%$ & $3.4 \%$ \\
\hline $2.3 \%$ & $0.9 \%$ & $3.4 \%$ \\
\hline $5.3 \%$ & $1.6 \%$ & $8.7 \%$ \\
\hline $7.9 \%$ & $4.3 \%$ & $15.8 \%$ \\
\hline $13.3 \%$ & $9.7 \%$ & $17.2 \%$ \\
\hline $19.9 \%$ & $19.2 \%$ & $15.9 \%$ \\
\hline $21.1 \%$ & $26.2 \%$ & $14.6 \%$ \\
\hline $16.1 \%$ & $21.0 \%$ & $10.3 \%$ \\
\hline $10.0 \%$ & $12.6 \%$ & $6.0 \%$ \\
\hline
\end{tabular}




\begin{tabular}{|c|c|c|}
\hline 302-2-A-48-X-2 & 302-2-A-48-X-2 & 302-2-A-48-X-3 \\
\hline Cristin Ashmankas, & Cristin Ashmankas, & Cristin Ashmankas, \\
\hline Unimodal, Very Poorly Sorted & Unimodal, Poorly Sorted & Unimodal, Poorly Sorted \\
\hline Sandy Mud & Mud & Mud \\
\hline Very Coarse Sandy Fine Silt & Fine Silt & Fine Silt \\
\hline 74.70 & 38.63 & 6.227 \\
\hline 257.9 & 182.3 & 6.744 \\
\hline 4.672 & 7.065 & 2.960 \\
\hline 25.69 & 55.90 & 15.14 \\
\hline 7.833 & 5.600 & 4.031 \\
\hline 5.352 & 4.028 & 2.491 \\
\hline 1.431 & 1.523 & 0.110 \\
\hline 4.882 & 6.476 & 2.649 \\
\hline 6.933 & 7.451 & 7.955 \\
\hline 2.471 & 2.047 & 1.317 \\
\hline-1.422 & -1.551 & -0.110 \\
\hline 4.735 & 6.462 & 2.649 \\
\hline 6.651 & 4.856 & 3.976 \\
\hline 4.951 & 3.444 & 2.547 \\
\hline 0.353 & 0.189 & 0.010 \\
\hline 1.616 & 1.282 & 0.975 \\
\hline 7.232 & 7.686 & 7.974 \\
\hline 2.308 & 1.784 & 1.349 \\
\hline-0.353 & -0.189 & -0.010 \\
\hline 1.616 & 1.282 & 0.975 \\
\hline Fine Silt & Fine Silt & Fine Silt \\
\hline Very Poorly Sorted & Poorly Sorted & Poorly Sorted \\
\hline Very Coarse Skewed & Coarse Skewed & Symmetrical \\
\hline Very Leptokurtic & Leptokurtic & Mesokurtic \\
\hline 4.700 & 4.700 & 3.350 \\
\hline 7.754 & 7.754 & 8.241 \\
\hline 1.515 & 1.289 & 1.199 \\
\hline 5.510 & 4.643 & 3.990 \\
\hline 105.7 & 28.15 & 13.46 \\
\hline 69.80 & 21.84 & 11.23 \\
\hline 104.2 & 26.86 & 12.26 \\
\hline 4.891 & 4.276 & 3.612 \\
\hline 10.67 & 7.484 & 5.460 \\
\hline 3.241 & 5.151 & 6.215 \\
\hline 7.504 & 7.751 & 7.970 \\
\hline 9.367 & 9.599 & 9.704 \\
\hline 2.890 & 1.864 & 1.561 \\
\hline 6.125 & 4.449 & 3.489 \\
\hline 1.368 & 1.314 & 1.263 \\
\hline 2.290 & 2.096 & 1.853 \\
\hline $11.5 \%$ & $6.3 \%$ & $0.0 \%$ \\
\hline $88.5 \%$ & $93.7 \%$ & $100.0 \%$ \\
\hline $3.2 \%$ & $1.6 \%$ & $0.0 \%$ \\
\hline $2.2 \%$ & $1.0 \%$ & $0.0 \%$ \\
\hline $2.4 \%$ & $0.5 \%$ & $0.0 \%$ \\
\hline $1.7 \%$ & $1.0 \%$ & $0.0 \%$ \\
\hline $1.8 \%$ & $2.2 \%$ & $0.0 \%$ \\
\hline $3.3 \%$ & $3.0 \%$ & $1.4 \%$ \\
\hline $7.2 \%$ & $5.7 \%$ & $5.8 \%$ \\
\hline $16.4 \%$ & $16.3 \%$ & $16.6 \%$ \\
\hline $24.0 \%$ & $25.0 \%$ & $27.1 \%$ \\
\hline $22.0 \%$ & $23.3 \%$ & $26.5 \%$ \\
\hline $15.5 \%$ & $20.2 \%$ & $22.7 \%$ \\
\hline
\end{tabular}




\begin{tabular}{|c|c|c|}
\hline $\begin{array}{c}\text { 302-2-A-48-X-3 } \\
\text { Cristin Ashmankas, }\end{array}$ & $\begin{array}{c}\text { 302-2-A-48-X-4 } \\
\text { Cristin Ashmankas, }\end{array}$ & $\begin{array}{c}\text { 302-2-A-48-X-4 } \\
\text { Cristin Ashmankas, }\end{array}$ \\
\hline Unimodal, Poorly Sorted & Unimodal, Very Poorly Sorted & Unimodal, Poorly Sorted \\
\hline Mud & Mud & Mud \\
\hline Fine Silt & Very Fine Silt & Very Fine Silt \\
\hline 12.43 & 59.13 & 8.390 \\
\hline 21.38 & 244.6 & 9.956 \\
\hline 5.385 & 5.207 & 2.294 \\
\hline 43.41 & 30.55 & 8.655 \\
\hline 6.097 & 5.964 & 4.865 \\
\hline 3.076 & 4.548 & 2.747 \\
\hline 0.374 & 1.777 & 0.308 \\
\hline 2.831 & 6.925 & 2.449 \\
\hline 7.358 & 7.335 & 7.683 \\
\hline 1.621 & 2.244 & 1.458 \\
\hline-0.374 & -1.772 & -0.308 \\
\hline 2.831 & 6.687 & 2.449 \\
\hline 6.021 & 5.118 & 4.875 \\
\hline 3.119 & 4.313 & 2.872 \\
\hline 0.118 & 0.325 & 0.149 \\
\hline 0.966 & 1.708 & 0.969 \\
\hline 7.376 & 7.610 & 7.680 \\
\hline 1.641 & 2.109 & 1.522 \\
\hline-0.118 & -0.325 & -0.149 \\
\hline 0.966 & 1.708 & 0.969 \\
\hline Fine Silt & Fine Silt & Fine Silt \\
\hline Poorly Sorted & Very Poorly Sorted & Poorly Sorted \\
\hline Coarse Skewed & Very Coarse Skewed & Coarse Skewed \\
\hline Mesokurtic & Very Leptokurtic & Mesokurtic \\
\hline 4.700 & 3.350 & 3.350 \\
\hline 7.754 & 8.241 & 8.241 \\
\hline 1.493 & 1.393 & 1.387 \\
\hline 5.492 & 4.572 & 4.376 \\
\hline 28.79 & 30.34 & 21.97 \\
\hline 19.28 & 21.79 & 15.84 \\
\hline 27.30 & 28.95 & 20.58 \\
\hline 4.737 & 4.166 & 4.157 \\
\hline 10.20 & 7.545 & 7.299 \\
\hline 5.118 & 5.043 & 5.508 \\
\hline 7.509 & 7.773 & 7.836 \\
\hline 9.387 & 9.488 & 9.494 \\
\hline 1.834 & 1.882 & 1.723 \\
\hline 4.269 & 4.445 & 3.985 \\
\hline 1.358 & 1.309 & 1.307 \\
\hline 2.244 & 2.059 & 2.056 \\
\hline $2.4 \%$ & $6.6 \%$ & $0.0 \%$ \\
\hline $97.6 \%$ & $93.4 \%$ & $100.0 \%$ \\
\hline $0.0 \%$ & $3.0 \%$ & $0.0 \%$ \\
\hline $0.0 \%$ & $1.8 \%$ & $0.0 \%$ \\
\hline $0.0 \%$ & $0.6 \%$ & $0.0 \%$ \\
\hline $0.8 \%$ & $0.6 \%$ & $0.0 \%$ \\
\hline $1.6 \%$ & $0.7 \%$ & $0.0 \%$ \\
\hline $6.3 \%$ & $3.2 \%$ & $4.6 \%$ \\
\hline $12.1 \%$ & $6.9 \%$ & $11.0 \%$ \\
\hline $17.5 \%$ & $14.3 \%$ & $14.3 \%$ \\
\hline $24.1 \%$ & $25.2 \%$ & $24.5 \%$ \\
\hline $21.9 \%$ & $25.2 \%$ & $26.3 \%$ \\
\hline $15.8 \%$ & $18.6 \%$ & $19.2 \%$ \\
\hline
\end{tabular}




\begin{tabular}{|c|c|c|}
\hline $302-2-A-49-X-1$ & $302-2-A-49-X-2$ & $302-2-A-49-X-2$ \\
\hline Cristin Ashmankas, & Cristin Ashmankas, & Cristin Ashmankas, \\
\hline Unimodal, Very Poorly Sorted & Unimodal, Poorly Sorted & Unimodal, Poorly Sorted \\
\hline Mud & Mud & Mud \\
\hline Fine Silt & Very Fine Silt & Very Fine Silt \\
\hline 67.34 & 7.614 & 6.659 \\
\hline 271.1 & 9.581 & 9.022 \\
\hline 4.752 & 2.870 & 3.567 \\
\hline 25.28 & 13.07 & 18.93 \\
\hline 6.031 & 4.400 & 3.895 \\
\hline 4.654 & 2.739 & 2.644 \\
\hline 1.889 & 0.286 & 0.374 \\
\hline 7.304 & 2.652 & 2.992 \\
\hline 7.302 & 7.828 & 8.004 \\
\hline 2.293 & 1.454 & 1.402 \\
\hline-1.866 & -0.286 & -0.374 \\
\hline 6.914 & 2.652 & 2.992 \\
\hline 5.085 & 4.315 & 3.778 \\
\hline 4.633 & 2.826 & 2.680 \\
\hline 0.341 & 0.092 & 0.082 \\
\hline 1.899 & 1.021 & 1.075 \\
\hline 7.619 & 7.856 & 8.048 \\
\hline 2.212 & 1.499 & 1.422 \\
\hline-0.341 & -0.092 & -0.082 \\
\hline 1.899 & 1.021 & 1.075 \\
\hline Fine Silt & Fine Silt & Very Fine Silt \\
\hline Very Poorly Sorted & Poorly Sorted & Poorly Sorted \\
\hline Very Coarse Skewed & Symmetrical & Symmetrical \\
\hline Very Leptokurtic & Mesokurtic & Mesokurtic \\
\hline 3.350 & 3.350 & 3.350 \\
\hline 8.241 & 8.241 & 8.241 \\
\hline 1421 & 1912 & 1140 \\
\hline 4.622 & 4.126 & 3.679 \\
\hline 29.35 & 18.34 & 14.27 \\
\hline 20.66 & 15.12 & 12.52 \\
\hline 27.93 & 17.12 & 13.13 \\
\hline 4.096 & 3.967 & 3.584 \\
\hline 7.487 & 6.302 & 5.096 \\
\hline 5.091 & 5.769 & 6.131 \\
\hline 7.757 & 7.921 & 8.086 \\
\hline 9.459 & 9.688 & 9.777 \\
\hline 1.858 & 1.679 & 1.595 \\
\hline 4.368 & 3.919 & 3.646 \\
\hline 1.306 & 1.288 & 1.258 \\
\hline 2.034 & 1.988 & 1.842 \\
\hline $6.8 \%$ & $0.2 \%$ & $0.2 \%$ \\
\hline $93.2 \%$ & $99.8 \%$ & $99.8 \%$ \\
\hline $3.8 \%$ & $0.0 \%$ & $0.0 \%$ \\
\hline $1.9 \%$ & $0.0 \%$ & $0.0 \%$ \\
\hline $0.1 \%$ & $0.0 \%$ & $0.0 \%$ \\
\hline $0.1 \%$ & $0.0 \%$ & $0.0 \%$ \\
\hline $0.9 \%$ & $0.2 \%$ & $0.2 \%$ \\
\hline $2.7 \%$ & $3.7 \%$ & $3.0 \%$ \\
\hline $6.6 \%$ & $8.2 \%$ & $5.5 \%$ \\
\hline $15.1 \%$ & $14.9 \%$ & $13.0 \%$ \\
\hline $25.4 \%$ & $25.2 \%$ & $25.6 \%$ \\
\hline $25.3 \%$ & $25.7 \%$ & $28.0 \%$ \\
\hline $18.1 \%$ & $22.2 \%$ & $24.6 \%$ \\
\hline
\end{tabular}




\begin{tabular}{|c|c|c|}
\hline $\begin{array}{c}\text { 302-2-A-49-X-3 } \\
\text { Cristin Ashmankas, }\end{array}$ & $\begin{array}{c}\text { 302-2-A-49-X-3 } \\
\text { Cristin Ashmankas, }\end{array}$ & $\begin{array}{c}\text { 302-2-A-49-X-4 } \\
\text { Cristin Ashmankas, }\end{array}$ \\
\hline Unimodal, Poorly Sorted & Unimodal, Very Poorly Sorted & Unimodal, Poorly Sorted \\
\hline Mud & Sandy Mud & Mud \\
\hline Fine Silt & Very Fine Sandy Fine Silt & Fine Silt \\
\hline 6.271 & 76.05 & 42.79 \\
\hline 6.676 & 247.4 & 184.1 \\
\hline 2.849 & 4.959 & 6.545 \\
\hline 13.98 & 28.58 & 49.37 \\
\hline 4.109 & 11.17 & 6.205 \\
\hline 2.453 & 5.455 & 4.250 \\
\hline 0.123 & 0.881 & 1.422 \\
\hline 2.677 & 3.474 & 5.835 \\
\hline 7.927 & 6.426 & 7.309 \\
\hline 1.294 & 2.482 & 2.113 \\
\hline-0.123 & -0.894 & -1.439 \\
\hline 2.677 & 3.445 & 5.823 \\
\hline 4.049 & 10.85 & 5.452 \\
\hline 2.504 & 5.669 & 3.746 \\
\hline 0.018 & 0.309 & 0.225 \\
\hline 0.987 & 1.113 & 1.327 \\
\hline 7.948 & 6.526 & 7.519 \\
\hline 1.324 & 2.503 & 1.905 \\
\hline-0.018 & -0.309 & -0.225 \\
\hline 0.987 & 1.113 & 1.327 \\
\hline Fine Silt & Medium Silt & Fine Silt \\
\hline Poorly Sorted & Very Poorly Sorted & Poorly Sorted \\
\hline Symmetrical & Very Coarse Skewed & Coarse Skewed \\
\hline Mesokurtic & Leptokurtic & Leptokurtic \\
\hline 3.350 & 4.700 & 4.700 \\
\hline 8.241 & 7.754 & 7.754 \\
\hline 1.257 & 1.728 & 1.356 \\
\hline 4.054 & 8.147 & 4.982 \\
\hline 13.50 & 124.5 & 33.83 \\
\hline 10.74 & 72.02 & 24.94 \\
\hline 12.24 & 122.7 & 32.47 \\
\hline 3.490 & 8.841 & 4.457 \\
\hline 5.388 & 26.31 & 8.490 \\
\hline 6.211 & 3.006 & 4.886 \\
\hline 7.946 & 6.939 & 7.649 \\
\hline 9.635 & 9.177 & 9.526 \\
\hline 1.551 & 3.053 & 1.950 \\
\hline 3.424 & 6.170 & 4.640 \\
\hline 1.256 & 1.620 & 1.331 \\
\hline 1.803 & 3.144 & 2.156 \\
\hline $0.0 \%$ & $16.7 \%$ & $6.9 \%$ \\
\hline $100.0 \%$ & $83.3 \%$ & $93.1 \%$ \\
\hline $0.0 \%$ & $3.1 \%$ & $1.5 \%$ \\
\hline $0.0 \%$ & $1.8 \%$ & $1.4 \%$ \\
\hline $0.0 \%$ & $1.3 \%$ & $0.9 \%$ \\
\hline $0.0 \%$ & $3.8 \%$ & $1.2 \%$ \\
\hline $0.0 \%$ & $6.7 \%$ & $1.9 \%$ \\
\hline $1.4 \%$ & $7.6 \%$ & $3.6 \%$ \\
\hline $5.9 \%$ & $11.0 \%$ & $7.7 \%$ \\
\hline $16.4 \%$ & $15.8 \%$ & $16.2 \%$ \\
\hline $27.9 \%$ & $19.7 \%$ & $24.7 \%$ \\
\hline $27.0 \%$ & $17.3 \%$ & $22.5 \%$ \\
\hline $21.5 \%$ & $12.1 \%$ & $18.4 \%$ \\
\hline
\end{tabular}




\begin{tabular}{|c|c|c|}
\hline $302-2-A-49-X-4$ & $302-2-A-49-X-5$ & $302-2-A-49-X-5$ \\
\hline Cristin Ashmankas, & Cristin Ashmankas, & Cristin Ashmankas, \\
\hline Unimodal, Poorly Sorted & Bimodal, Very Poorly Sorted & Unimodal, Poorly Sorted \\
\hline Mud & Mud & Mud \\
\hline Very Fine Silt & Fine Silt & Very Fine Silt \\
\hline 6.706 & 80.27 & 5.298 \\
\hline 8.488 & 295.1 & 6.059 \\
\hline 3.059 & 4.348 & 3.839 \\
\hline 14.08 & 21.29 & 24.22 \\
\hline 4.014 & 7.579 & 3.520 \\
\hline 2.603 & 5.084 & 2.359 \\
\hline 0.375 & 1.585 & 0.267 \\
\hline 2.844 & 5.865 & 2.932 \\
\hline 7.961 & 6.951 & 8.150 \\
\hline 1.380 & 2.424 & 1.238 \\
\hline-0.375 & -1.566 & -0.267 \\
\hline 2.844 & 5.538 & 2.932 \\
\hline 3.888 & 6.611 & 3.454 \\
\hline 2.654 & 5.188 & 2.370 \\
\hline 0.100 & 0.351 & 0.030 \\
\hline 1.058 & 1.709 & 0.985 \\
\hline 8.007 & 7.241 & 8.177 \\
\hline 1.408 & 2.375 & 1.245 \\
\hline-0.100 & -0.351 & -0.030 \\
\hline 1.058 & 1.709 & 0.985 \\
\hline Very Fine Silt & Fine Silt & Very Fine Silt \\
\hline Poorly Sorted & Very Poorly Sorted & Poorly Sorted \\
\hline Coarse Skewed & Very Coarse Skewed & Symmetrical \\
\hline Mesokurtic & Very Leptokurtic & Mesokurtic \\
\hline \multirow[t]{2}{*}{3.350} & 4.700 & 3.350 \\
\hline & 1200.0 & \\
\hline \multirow[t]{2}{*}{8.241} & 7.754 & 8.241 \\
\hline & -0.243 & \\
\hline 1.199 & 1.541 & 1.154 \\
\hline 3.755 & 5.676 & 3.435 \\
\hline 14.97 & 49.13 & 10.64 \\
\hline 12.49 & 31.88 & 9.217 \\
\hline 13.77 & 47.59 & 9.485 \\
\hline 3.579 & 4.995 & 3.261 \\
\hline 5.220 & 11.23 & 4.309 \\
\hline 6.062 & 4.347 & 6.554 \\
\hline 8.057 & 7.461 & 8.185 \\
\hline 9.704 & 9.342 & 9.759 \\
\hline 1.601 & 2.149 & 1.489 \\
\hline 3.643 & 4.994 & 3.204 \\
\hline 1.259 & 1.377 & 1.233 \\
\hline 1.840 & 2.321 & 1.705 \\
\hline $0.0 \%$ & $8.8 \%$ & $0.0 \%$ \\
\hline $100.0 \%$ & $91.2 \%$ & $100.0 \%$ \\
\hline $0.0 \%$ & $4.7 \%$ & $0.0 \%$ \\
\hline $0.0 \%$ & $2.0 \%$ & $0.0 \%$ \\
\hline $0.0 \%$ & $0.1 \%$ & $0.0 \%$ \\
\hline $0.0 \%$ & $0.4 \%$ & $0.0 \%$ \\
\hline $0.0 \%$ & $1.6 \%$ & $0.0 \%$ \\
\hline $3.0 \%$ & $4.7 \%$ & $1.1 \%$ \\
\hline $6.4 \%$ & $9.4 \%$ & $3.6 \%$ \\
\hline $13.1 \%$ & $16.6 \%$ & $12.5 \%$ \\
\hline $25.8 \%$ & $23.9 \%$ & $26.7 \%$ \\
\hline $28.1 \%$ & $21.6 \%$ & $30.3 \%$ \\
\hline $23.7 \%$ & $15.0 \%$ & $25.8 \%$ \\
\hline
\end{tabular}




\begin{tabular}{|c|c|c|}
\hline $302-2-A-50-X-1$ & $302-2-A-50-X-1$ & $302-2-A-50-X-2$ \\
\hline Cristin Ashmankas, & Cristin Ashmankas, & Cristin Ashmankas, \\
\hline Unimodal, Poorly Sorted & Unimodal, Poorly Sorted & Unimodal, Poorly Sorted \\
\hline Mud & Mud & Mud \\
\hline Fine Silt & Fine Silt & Fine Silt \\
\hline 38.67 & 6.430 & 26.66 \\
\hline 167.1 & 6.932 & 96.98 \\
\hline 6.553 & 2.773 & 7.568 \\
\hline 50.53 & 14.12 & 73.84 \\
\hline 6.036 & 4.073 & 6.022 \\
\hline 4.008 & 2.574 & 3.811 \\
\hline 1.493 & 0.078 & 1.311 \\
\hline 6.315 & 2.496 & 5.002 \\
\hline 7.362 & 7.940 & 7.375 \\
\hline 2.015 & 1.364 & 1.930 \\
\hline-1.504 & -0.078 & -1.311 \\
\hline 6.314 & 2.496 & 5.002 \\
\hline 5.286 & 4.025 & 5.246 \\
\hline 3.346 & 2.646 & 3.479 \\
\hline 0.187 & 0.007 & 0.268 \\
\hline 1.211 & 0.940 & 1.386 \\
\hline 7.563 & 7.957 & 7.575 \\
\hline 1.742 & 1.404 & 1.799 \\
\hline-0.187 & -0.007 & -0.268 \\
\hline 1.211 & 0.940 & 1.386 \\
\hline Fine Silt & Fine Silt & Fine Silt \\
\hline Poorly Sorted & Poorly Sorted & Poorly Sorted \\
\hline Coarse Skewed & Symmetrical & Coarse Skewed \\
\hline Leptokurtic & Mesokurtic & Leptokurtic \\
\hline 3.350 & 3.350 & 3.350 \\
\hline 8.241 & 8.241 & 8.241 \\
\hline 1.404 & 1.151 & 1481 \\
\hline 4.918 & 4.034 & 4.702 \\
\hline 28.46 & 14.38 & 36.01 \\
\hline 20.27 & 12.49 & 24.31 \\
\hline 27.06 & 13.23 & 34.52 \\
\hline 4.293 & 3.941 & 3.981 \\
\hline 8.151 & 5.967 & 7.470 \\
\hline 5.135 & 6.120 & 4.796 \\
\hline 7.668 & 7.954 & 7.733 \\
\hline 9.476 & 9.763 & 9.399 \\
\hline 1.846 & 1.595 & 1.960 \\
\hline 4.341 & 3.643 & 4.603 \\
\hline 1.321 & 1.284 & 1.300 \\
\hline 2.102 & 1.979 & 1.993 \\
\hline $5.6 \%$ & $0.0 \%$ & $7.7 \%$ \\
\hline $94.4 \%$ & $100.0 \%$ & $92.3 \%$ \\
\hline $1.0 \%$ & $0.0 \%$ & $0.2 \%$ \\
\hline $1.8 \%$ & $0.0 \%$ & $0.9 \%$ \\
\hline $0.9 \%$ & $0.0 \%$ & $1.3 \%$ \\
\hline $0.2 \%$ & $0.0 \%$ & $2.5 \%$ \\
\hline $1.7 \%$ & $0.0 \%$ & $2.9 \%$ \\
\hline $3.6 \%$ & $1.3 \%$ & $3.0 \%$ \\
\hline $7.6 \%$ & $7.0 \%$ & $5.8 \%$ \\
\hline $16.9 \%$ & $17.4 \%$ & $15.1 \%$ \\
\hline $24.9 \%$ & $25.6 \%$ & $26.0 \%$ \\
\hline $23.4 \%$ & $25.0 \%$ & $25.6 \%$ \\
\hline $17.9 \%$ & $23.7 \%$ & $16.9 \%$ \\
\hline
\end{tabular}




\begin{tabular}{|c|c|c|}
\hline 302-2-A-50-X-2 & $\begin{array}{c}\text { 302-2-A-51-X-1 } \\
\text { Cristin Ashmankas }\end{array}$ & $\begin{array}{c}\text { 302-2-A-51-X-1 } \\
\text { Cristin Ashmankas }\end{array}$ \\
\hline Cristin Ashmankas, & Cristin Ashmankas, & Cristin Ashmankas, \\
\hline Unimodal, Very Poorly Sorted & Unimodal, Poorly Sorted & Unimodal, Poorly Sorted \\
\hline Sandy Mud & Mud & Sandy Mud \\
\hline very coarsise sallay very & Fine Silt & Very Fine Sandy Coarse Silt \\
\hline 85.38 & 16.25 & 59.20 \\
\hline 285.7 & 81.58 & 208.8 \\
\hline 4.194 & 8.431 & 6.356 \\
\hline 20.74 & 76.41 & 44.93 \\
\hline 6.837 & 4.550 & 14.61 \\
\hline 5.944 & 2.847 & 4.248 \\
\hline 1.531 & 1.604 & 0.455 \\
\hline 4.972 & 8.989 & 3.730 \\
\hline 7.117 & 7.780 & 6.045 \\
\hline 2.635 & 1.509 & 2.114 \\
\hline-1.501 & -1.604 & -0.521 \\
\hline 4.747 & 8.989 & 3.791 \\
\hline 5.478 & 4.244 & 14.18 \\
\hline 5.280 & 2.430 & 3.890 \\
\hline 0.370 & 0.040 & -0.071 \\
\hline 1.763 & 1.012 & 0.899 \\
\hline 7.512 & 7.880 & 6.140 \\
\hline 2.400 & 1.281 & 1.960 \\
\hline-0.370 & -0.040 & 0.071 \\
\hline 1.763 & 1.012 & 0.899 \\
\hline Fine Silt & Fine Silt & Medium Silt \\
\hline Very Poorly Sorted & Poorly Sorted & Poorly Sorted \\
\hline Very Coarse Skewed & Symmetrical & Symmetrical \\
\hline Very Leptokurtic & Mesokurtic & Platykurtic \\
\hline 3.350 & 3.350 & 26.50 \\
\hline 8.241 & 8.241 & 5.259 \\
\hline 1.279 & 1.411 & 2.324 \\
\hline 4.599 & 4.208 & 15.32 \\
\hline 169.2 & 13.66 & 76.56 \\
\hline 132.3 & 9.678 & 32.94 \\
\hline 167.9 & 12.25 & 74.24 \\
\hline 4.777 & 3.297 & 7.227 \\
\hline 8.543 & 5.348 & 32.92 \\
\hline 2.563 & 6.194 & 3.707 \\
\hline 7.765 & 7.892 & 6.028 \\
\hline 9.611 & 9.469 & 8.749 \\
\hline 3.750 & 1.529 & 2.360 \\
\hline 7.048 & 3.275 & 5.042 \\
\hline 1.345 & 1.245 & 1.606 \\
\hline 2.256 & 1.721 & 2.853 \\
\hline $12.0 \%$ & $1.8 \%$ & $13.3 \%$ \\
\hline $88.0 \%$ & $98.2 \%$ & $86.7 \%$ \\
\hline $4.1 \%$ & $0.0 \%$ & $2.3 \%$ \\
\hline $2.7 \%$ & $1.2 \%$ & $1.0 \%$ \\
\hline $2.1 \%$ & $0.4 \%$ & $0.4 \%$ \\
\hline $1.8 \%$ & $0.1 \%$ & $0.8 \%$ \\
\hline $1.4 \%$ & $0.1 \%$ & $8.8 \%$ \\
\hline $1.9 \%$ & $0.9 \%$ & $17.1 \%$ \\
\hline $5.1 \%$ & $4.8 \%$ & $19.1 \%$ \\
\hline $13.7 \%$ & $16.8 \%$ & $16.9 \%$ \\
\hline $23.1 \%$ & $29.0 \%$ & $14.7 \%$ \\
\hline $23.7 \%$ & $27.9 \%$ & $11.3 \%$ \\
\hline $20.4 \%$ & $18.8 \%$ & $76 \%$ \\
\hline
\end{tabular}




\begin{tabular}{|c|c|c|}
\hline 302-2-A-51-X-2 & 302-2-A-51-X-2 & 302-2-A-52-X-1 \\
\hline Cristin Ashmankas, & Cristin Ashmankas, & Cristin Ashmankas, \\
\hline Unimodal, Poorly Sorted & Unimodal, Poorly Sorted & Unimodal, Poorly Sorted \\
\hline Mud & Sandy Mud & Sandy Mud \\
\hline Coarse Silt & Very Fine Sandy Coarse Silt & Very Fine Sandy Medium Sil \\
\hline 45.42 & 53.27 & 49.35 \\
\hline 160.8 & 185.5 & 146.7 \\
\hline 7.533 & 6.891 & 6.649 \\
\hline 65.33 & 53.55 & 55.69 \\
\hline 13.82 & 14.40 & 14.15 \\
\hline 3.770 & 4.146 & 4.141 \\
\hline 0.348 & 0.356 & 0.418 \\
\hline 3.992 & 3.602 & 3.418 \\
\hline 6.168 & 6.085 & 6.137 \\
\hline 1.920 & 2.069 & 2.053 \\
\hline-0.368 & -0.404 & -0.427 \\
\hline 4.021 & 3.663 & 3.432 \\
\hline 13.13 & 13.96 & 13.49 \\
\hline 3.412 & 3.861 & 3.992 \\
\hline-0.202 & -0.095 & 0.023 \\
\hline 0.905 & 0.892 & 1.020 \\
\hline 6.251 & 6.163 & 6.211 \\
\hline 1.771 & 1.949 & 1.997 \\
\hline 0.202 & 0.095 & -0.023 \\
\hline 0.905 & 0.892 & 1.020 \\
\hline Medium Silt & Medium Silt & Medium Silt \\
\hline Poorly Sorted & Poorly Sorted & Poorly Sorted \\
\hline Fine Skewed & Symmetrical & Symmetrical \\
\hline Mesokurtic & Platykurtic & Mesokurtic \\
\hline 26.50 & 26.50 & 18.80 \\
\hline 5.259 & 5.259 & 5.754 \\
\hline 2296 & 2220 & 2370 \\
\hline 15.74 & 15.28 & 13.61 \\
\hline 54.70 & 72.94 & 77.96 \\
\hline 23.83 & 32.85 & 32.90 \\
\hline 52.41 & 70.72 & 75.59 \\
\hline 5.892 & 7.135 & 6.478 \\
\hline 27.06 & 32.59 & 29.00 \\
\hline 4.192 & 3.777 & 3.681 \\
\hline 5.990 & 6.032 & 6.200 \\
\hline 8.767 & 8.815 & 8.721 \\
\hline 2.091 & 2.334 & 2.369 \\
\hline 4.575 & 5.038 & 5.040 \\
\hline 1.518 & 1.600 & 1.554 \\
\hline 2.559 & 2.835 & 2.696 \\
\hline $7.0 \%$ & $12.7 \%$ & $12.8 \%$ \\
\hline $93.0 \%$ & $87.3 \%$ & $87.2 \%$ \\
\hline $1.1 \%$ & $1.7 \%$ & $0.7 \%$ \\
\hline $1.0 \%$ & $1.0 \%$ & $1.6 \%$ \\
\hline $0.9 \%$ & $0.5 \%$ & $1.6 \%$ \\
\hline $0.2 \%$ & $0.4 \%$ & $1.9 \%$ \\
\hline $3.8 \%$ & $9.0 \%$ & $7.0 \%$ \\
\hline $19.4 \%$ & $17.5 \%$ & $14.4 \%$ \\
\hline $23.8 \%$ & $19.3 \%$ & $19.0 \%$ \\
\hline $17.6 \%$ & $17.5 \%$ & $19.1 \%$ \\
\hline $13.6 \%$ & $14.0 \%$ & $16.4 \%$ \\
\hline $10.8 \%$ & $10.9 \%$ & $10.8 \%$ \\
\hline $7.8 \%$ & $8.2 \%$ & $7.5 \%$ \\
\hline
\end{tabular}




\begin{tabular}{|c|c|c|}
\hline 302-2-A-52-X-1 & 302-2-A-52-X-2 & 302-2-A-53-X-1 \\
\hline & & \\
\hline Bimodal, Poorly Sorted & Unimodal, Poorly Sorted & Unimodal, Poorly Sorted \\
\hline Mud & Sandy Mud & Mud \\
\hline Coarse Silt & Very Fine Sandy Coarse Silt & Coarse Silt \\
\hline 17.37 & 41.48 & 29.02 \\
\hline 17.85 & 134.3 & 106.5 \\
\hline 1.526 & 9.421 & 12.72 \\
\hline 5.163 & 102.5 & 178.1 \\
\hline 9.607 & 16.09 & 12.55 \\
\hline 3.180 & 3.438 & 3.260 \\
\hline-0.172 & 0.155 & -0.044 \\
\hline 2.060 & 3.741 & 3.517 \\
\hline 6.702 & 5.935 & 6.303 \\
\hline 1.669 & 1.794 & 1.716 \\
\hline 0.172 & -0.224 & -0.016 \\
\hline 2.060 & 3.849 & 3.657 \\
\hline 9.735 & 15.97 & 12.58 \\
\hline 3.313 & 3.271 & 3.200 \\
\hline-0.067 & -0.120 & -0.201 \\
\hline 0.794 & 0.958 & 0.888 \\
\hline 6.683 & 5.969 & 6.313 \\
\hline 1.728 & 1.710 & 1.678 \\
\hline 0.067 & 0.120 & 0.201 \\
\hline 0.794 & 0.958 & 0.888 \\
\hline Medium Silt & Coarse Silt & Medium Silt \\
\hline Poorly Sorted & Poorly Sorted & Poorly Sorted \\
\hline Symmetrical & Fine Skewed & Fine Skewed \\
\hline Platykurtic & Mesokurtic & Platykurtic \\
\hline 26.50 & 26.50 & 26.50 \\
\hline 4.700 & & \\
\hline 5.259 & 5.259 & 5.259 \\
\hline 7.754 & & \\
\hline 1.950 & 3.145 & 2.375 \\
\hline 10.19 & 17.50 & 14.61 \\
\hline 42.61 & 66.55 & 48.86 \\
\hline 21.85 & 21.16 & 20.57 \\
\hline 40.66 & 63.40 & 46.48 \\
\hline 6.654 & 5.178 & 5.436 \\
\hline 21.53 & 29.80 & 24.50 \\
\hline 4.553 & 3.909 & 4.355 \\
\hline 6.616 & 5.836 & 6.097 \\
\hline 9.002 & 8.313 & 8.718 \\
\hline 1.977 & 2.126 & 2.002 \\
\hline 4.449 & 4.403 & 4.363 \\
\hline 1.516 & 1.499 & 1.483 \\
\hline 2.734 & 2.372 & 2.443 \\
\hline $2.7 \%$ & $11.0 \%$ & $4.6 \%$ \\
\hline $97.3 \%$ & $89.0 \%$ & $95.4 \%$ \\
\hline $0.0 \%$ & $0.9 \%$ & $0.6 \%$ \\
\hline $0.0 \%$ & $0.6 \%$ & $0.3 \%$ \\
\hline $0.0 \%$ & $0.6 \%$ & $0.1 \%$ \\
\hline $0.0 \%$ & $0.7 \%$ & $0.0 \%$ \\
\hline $2.7 \%$ & $8.3 \%$ & $3.7 \%$ \\
\hline $15.9 \%$ & $19.2 \%$ & $18.9 \%$ \\
\hline $20.5 \%$ & $23.5 \%$ & $24.5 \%$ \\
\hline $17.6 \%$ & $19.2 \%$ & $19.1 \%$ \\
\hline $17.6 \%$ & $13.8 \%$ & $14.8 \%$ \\
\hline $15.6 \%$ & $8.5 \%$ & $10.8 \%$ \\
\hline $10.0 \%$ & $4.7 \%$ & $7.4 \%$ \\
\hline
\end{tabular}




\begin{tabular}{|c|c|c|}
\hline $302-2-A-53-X-2$ & $302-2-A-53-X-2$ & $302-2-A-53-X-3$ \\
\hline Cristin Ashmankas, & Cristin Ashmankas, & Cristin Ashmankas, \\
\hline Unimodal, Poorly Sorted & Unimodal, Poorly Sorted & Trimodal, Very Poorly Sorted \\
\hline Mud & Sandy Mud & Sandy Mud \\
\hline Coarse Silt & very rille salluy very & Very Fine Sandy Coarse Silt \\
\hline 43.35 & 44.64 & 71.19 \\
\hline 172.1 & 152.1 & 213.6 \\
\hline 7.530 & 9.000 & 4.938 \\
\hline 63.00 & 89.12 & 30.01 \\
\hline 12.94 & 16.66 & 13.83 \\
\hline 3.388 & 3.595 & 4.926 \\
\hline 0.668 & 0.010 & 0.682 \\
\hline 5.343 & 3.629 & 3.458 \\
\hline 6.248 & 5.873 & 6.156 \\
\hline 1.778 & 1.863 & 2.311 \\
\hline-0.735 & -0.102 & -0.694 \\
\hline 5.425 & 3.763 & 3.461 \\
\hline 12.53 & 16.68 & 12.37 \\
\hline 2.960 & 3.422 & 4.935 \\
\hline-0.098 & -0.213 & 0.109 \\
\hline 1.015 & 0.920 & 1.138 \\
\hline 6.318 & 5.905 & 6.337 \\
\hline 1.566 & 1.775 & 2.303 \\
\hline 0.098 & 0.213 & -0.109 \\
\hline 1.015 & 0.920 & 1.138 \\
\hline Medium Silt & Coarse Silt & Medium Silt \\
\hline Poorly Sorted & Poorly Sorted & Very Poorly Sorted \\
\hline Symmetrical & Fine Skewed & Coarse Skewed \\
\hline Mesokurtic & Mesokurtic & Leptokurtic \\
\hline 18.80 & 37.50 & 26.50 \\
\hline & & 6.650 \\
\hline 5.754 & 4.759 & 5.259 \\
\hline & & 7.254 \\
\hline 2.895 & 2.850 & 2.039 \\
\hline 13.34 & 19.71 & 12.63 \\
\hline 45.56 & 69.22 & 87.24 \\
\hline 15.73 & 24.29 & 42.78 \\
\hline 42.66 & 66.37 & 85.20 \\
\hline 4.309 & 5.728 & 7.948 \\
\hline 20.34 & 33.93 & 29.89 \\
\hline 4.456 & 3.853 & 3.519 \\
\hline 6.228 & 5.665 & 6.307 \\
\hline 8.432 & 8.455 & 8.938 \\
\hline 1.892 & 2.195 & 2.540 \\
\hline 3.976 & 4.602 & 5.419 \\
\hline 1.402 & 1.547 & 1.614 \\
\hline 2.107 & 2.518 & 2.991 \\
\hline $5.4 \%$ & $12.1 \%$ & $13.0 \%$ \\
\hline $94.6 \%$ & $87.9 \%$ & $87.0 \%$ \\
\hline $1.4 \%$ & $1.3 \%$ & $1.8 \%$ \\
\hline $0.9 \%$ & $0.4 \%$ & $2.8 \%$ \\
\hline $0.4 \%$ & $0.2 \%$ & $2.4 \%$ \\
\hline $0.2 \%$ & $0.2 \%$ & $1.4 \%$ \\
\hline $2.5 \%$ & $10.0 \%$ & $4.5 \%$ \\
\hline $13.9 \%$ & $22.5 \%$ & $14.2 \%$ \\
\hline $24.9 \%$ & $22.3 \%$ & $18.0 \%$ \\
\hline $24.1 \%$ & $16.4 \%$ & $15.8 \%$ \\
\hline $16.9 \%$ & $12.1 \%$ & $16.2 \%$ \\
\hline $9.1 \%$ & $8.7 \%$ & $13.5 \%$ \\
\hline $5.7 \%$ & $5.8 \%$ & $9.3 \%$ \\
\hline
\end{tabular}




\begin{tabular}{|c|c|c|}
\hline 302-2-A-53-X-3 & 302-2-A-53-X-4 & 302-2-A-53-X-4 \\
\hline & Cristin Ashmankas, & \\
\hline Unimodal, Poorly Sorted & Unimodal, Poorly Sorted & Unimodal, Poorly Sorted \\
\hline Mud & Mud & Mud \\
\hline Coarse Silt & Coarse Silt & Medium Silt \\
\hline 45.19 & 26.10 & 21.76 \\
\hline 156.2 & 105.2 & 63.38 \\
\hline 7.564 & 12.50 & 11.40 \\
\hline 66.22 & 175.0 & 157.5 \\
\hline 14.91 & 10.65 & 10.05 \\
\hline 3.506 & 3.136 & 3.126 \\
\hline 0.407 & 0.236 & 0.068 \\
\hline 4.473 & 4.092 & 3.585 \\
\hline 6.060 & 6.540 & 6.636 \\
\hline 1.815 & 1.661 & 1.645 \\
\hline-0.429 & -0.298 & -0.068 \\
\hline 4.502 & 4.255 & 3.585 \\
\hline 14.20 & 10.52 & 9.997 \\
\hline 3.120 & 3.008 & 3.033 \\
\hline-0.180 & -0.130 & -0.115 \\
\hline 1.002 & 0.905 & 0.934 \\
\hline 6.138 & 6.571 & 6.644 \\
\hline 1.642 & 1.589 & 1.601 \\
\hline 0.180 & 0.130 & 0.115 \\
\hline 1.002 & 0.905 & 0.934 \\
\hline Medium Silt & Medium Silt & Medium Silt \\
\hline Poorly Sorted & Poorly Sorted & Poorly Sorted \\
\hline Fine Skewed & Fine Skewed & Fine Skewed \\
\hline Mesokurtic & Mesokurtic & Mesokurtic \\
\hline 26.50 & 18.80 & 18.80 \\
\hline 5.259 & 5.754 & 5.754 \\
\hline & & \\
\hline 2.923 & 2.317 & 2.135 \\
\hline 16.46 & 11.59 & 10.74 \\
\hline 52.90 & 39.83 & 38.17 \\
\hline 18.10 & 17.19 & 17.88 \\
\hline 49.97 & 37.51 & 36.03 \\
\hline 4.681 & 4.950 & 4.832 \\
\hline 24.63 & 18.86 & 17.84 \\
\hline 4.241 & 4.650 & 4.712 \\
\hline 5.925 & 6.431 & 6.541 \\
\hline 8.418 & 8.754 & 8.872 \\
\hline 1.985 & 1.882 & 1.883 \\
\hline 4.178 & 4.104 & 4.160 \\
\hline 1.446 & 1.427 & 1.415 \\
\hline 2.227 & 2.308 & 2.272 \\
\hline $6.8 \%$ & $3.1 \%$ & $2.5 \%$ \\
\hline $93.2 \%$ & $96.9 \%$ & $97.5 \%$ \\
\hline $1.0 \%$ & $0.6 \%$ & $0.1 \%$ \\
\hline $1.0 \%$ & $0.3 \%$ & $0.4 \%$ \\
\hline $0.9 \%$ & $0.3 \%$ & $0.5 \%$ \\
\hline $0.9 \%$ & $0.2 \%$ & $0.3 \%$ \\
\hline $3.0 \%$ & $1.7 \%$ & $1.2 \%$ \\
\hline $18.3 \%$ & $12.8 \%$ & $12.1 \%$ \\
\hline $26.9 \%$ & $24.0 \%$ & $22.7 \%$ \\
\hline $19.7 \%$ & $22.4 \%$ & $23.1 \%$ \\
\hline $13.9 \%$ & $17.6 \%$ & $18.9 \%$ \\
\hline $8.9 \%$ & $12.7 \%$ & $11.9 \%$ \\
\hline $5.5 \%$ & $7.4 \%$ & $8.7 \%$ \\
\hline
\end{tabular}




\begin{tabular}{|c|c|c|}
\hline 302-2-A-54-X-1 & 302-2-A-54-X-1 & 302-2-A-55-X-1 \\
\hline & Cristin Ashmankas, & Cristin Ashmankas, \\
\hline Unimodal, Poorly Sorted & Unimodal, Poorly Sorted & Unimodal, Poorly Sorted \\
\hline Sandy Mud & Mud & Mud \\
\hline Very Fine Sandy Coarse Silt & Coarse Silt & Coarse Silt \\
\hline 44.26 & 50.82 & 39.55 \\
\hline 103.7 & 192.9 & 164.6 \\
\hline 6.427 & 6.667 & 8.709 \\
\hline 52.87 & 49.61 & 81.70 \\
\hline 16.68 & 13.54 & 11.80 \\
\hline 3.878 & 3.689 & 3.595 \\
\hline 0.060 & 0.637 & 0.509 \\
\hline 2.959 & 4.900 & 4.249 \\
\hline 5.906 & 6.174 & 6.357 \\
\hline 1.955 & 1.904 & 1.882 \\
\hline-0.060 & -0.704 & -0.626 \\
\hline 2.959 & 4.959 & 4.449 \\
\hline 16.16 & 12.90 & 11.54 \\
\hline 3.782 & 3.211 & 3.370 \\
\hline-0.142 & -0.134 & -0.042 \\
\hline 0.927 & 0.996 & 0.932 \\
\hline 5.951 & 6.276 & 6.437 \\
\hline 1.919 & 1.683 & 1.753 \\
\hline 0.142 & 0.134 & 0.042 \\
\hline 0.927 & 0.996 & 0.932 \\
\hline Coarse Silt & Medium Silt & Medium Silt \\
\hline Poorly Sorted & Poorly Sorted & Poorly Sorted \\
\hline Fine Skewed & Fine Skewed & Symmetrical \\
\hline Mesokurtic & Mesokurtic & Mesokurtic \\
\hline 26.50 & 18.80 & 18.80 \\
\hline 5.259 & 5.754 & 5.754 \\
\hline & & \\
\hline 2.603 & 2.599 & 2.362 \\
\hline 18.61 & 14.46 & 12.13 \\
\hline 80.27 & 51.34 & 52.53 \\
\hline 30.83 & 19.75 & 22.24 \\
\hline 77.67 & 48.74 & 50.16 \\
\hline 6.645 & 4.883 & 5.692 \\
\hline 35.50 & 23.08 & 22.76 \\
\hline 3.639 & 4.284 & 4.251 \\
\hline 5.748 & 6.112 & 6.365 \\
\hline 8.585 & 8.588 & 8.726 \\
\hline 2.359 & 2.005 & 2.053 \\
\hline 4.946 & 4.304 & 4.475 \\
\hline 1.596 & 1.448 & 1.484 \\
\hline 2.732 & 2.288 & 2.509 \\
\hline $14.5 \%$ & $6.7 \%$ & $7.3 \%$ \\
\hline $85.5 \%$ & $93.3 \%$ & $92.7 \%$ \\
\hline $0.2 \%$ & $1.8 \%$ & $1.6 \%$ \\
\hline $1.2 \%$ & $1.1 \%$ & $0.2 \%$ \\
\hline $1.5 \%$ & $0.5 \%$ & $0.3 \%$ \\
\hline $1.7 \%$ & $0.1 \%$ & $1.1 \%$ \\
\hline $9.8 \%$ & $3.2 \%$ & $4.2 \%$ \\
\hline $19.6 \%$ & $15.7 \%$ & $13.9 \%$ \\
\hline $20.9 \%$ & $25.1 \%$ & $21.4 \%$ \\
\hline $15.8 \%$ & $21.1 \%$ & $19.9 \%$ \\
\hline $13.1 \%$ & $15.0 \%$ & $17.8 \%$ \\
\hline $9.7 \%$ & $10.0 \%$ & $12.5 \%$ \\
\hline $6.5 \%$ & $6.5 \%$ & $7.1 \%$ \\
\hline
\end{tabular}




\begin{tabular}{|c|c|c|}
\hline 302-2-A-55-X-2 & 302-2-A-55-X-2 & 302-2-A-55-X-3 \\
\hline Bimodal, Very Poorly Sorted & Unimodal, Very Poorly Sorted & Unimodal, Poorly Sorted \\
\hline Sandy Mud & Sandy Mud & Mud \\
\hline Very Fine Sandy Medium Silt & Very Fine Sandy Coarse Silt & Coarse Silt \\
\hline 66.88 & 65.02 & 33.61 \\
\hline 220.4 & 232.6 & 113.7 \\
\hline 5.493 & 5.460 & 9.179 \\
\hline 35.39 & 33.71 & 99.28 \\
\hline 13.20 & 12.40 & 12.98 \\
\hline 4.617 & 4.454 & 3.308 \\
\hline 0.774 & 0.812 & 0.256 \\
\hline 3.860 & 4.291 & 4.097 \\
\hline 6.198 & 6.281 & 6.268 \\
\hline 2.232 & 2.187 & 1.726 \\
\hline-0.807 & -0.857 & -0.256 \\
\hline 3.863 & 4.290 & 4.097 \\
\hline 12.02 & 11.46 & 12.61 \\
\hline 4.508 & 4.188 & 3.070 \\
\hline 0.121 & 0.065 & -0.185 \\
\hline 1.187 & 1.098 & 0.927 \\
\hline 6.378 & 6.447 & 6.309 \\
\hline 2.172 & 2.066 & 1.618 \\
\hline-0.121 & -0.065 & 0.185 \\
\hline 1.187 & 1.098 & 0.927 \\
\hline Medium Silt & Medium Silt & Medium Silt \\
\hline Very Poorly Sorted & Very Poorly Sorted & Poorly Sorted \\
\hline Coarse Skewed & Symmetrical & Fine Skewed \\
\hline Leptokurtic & Mesokurtic & Mesokurtic \\
\hline 18.80 & 18.80 & 26.50 \\
\hline 9.400 & & \\
\hline 5.754 & 5.754 & 5.259 \\
\hline 6.754 & & \\
\hline 2.189 & 2.095 & 2.623 \\
\hline 11.93 & 11.82 & 14.51 \\
\hline 84.79 & 64.78 & 46.49 \\
\hline 38.74 & 30.92 & 17.73 \\
\hline 82.60 & 62.68 & 43.87 \\
\hline 6.551 & 6.564 & 4.930 \\
\hline 25.52 & 24.63 & 22.53 \\
\hline 3.560 & 3.948 & 4.427 \\
\hline 6.389 & 6.403 & 6.107 \\
\hline 8.836 & 8.899 & 8.575 \\
\hline 2.482 & 2.254 & 1.937 \\
\hline 5.276 & 4.950 & 4.148 \\
\hline 1.537 & 1.532 & 1.447 \\
\hline 2.712 & 2.715 & 2.301 \\
\hline $12.2 \%$ & $10.4 \%$ & $5.1 \%$ \\
\hline $87.8 \%$ & $89.6 \%$ & $94.9 \%$ \\
\hline $2.3 \%$ & $2.7 \%$ & $0.4 \%$ \\
\hline $1.6 \%$ & $1.6 \%$ & $0.8 \%$ \\
\hline $2.1 \%$ & $0.6 \%$ & $0.5 \%$ \\
\hline $2.1 \%$ & $0.7 \%$ & $0.5 \%$ \\
\hline $4.1 \%$ & $4.7 \%$ & $2.8 \%$ \\
\hline $11.8 \%$ & $12.7 \%$ & $16.1 \%$ \\
\hline $18.7 \%$ & $19.4 \%$ & $26.5 \%$ \\
\hline $18.7 \%$ & $18.6 \%$ & $20.1 \%$ \\
\hline $17.5 \%$ & $17.0 \%$ & $15.3 \%$ \\
\hline $12.8 \%$ & $13.2 \%$ & $10.6 \%$ \\
\hline $8.2 \%$ & $8.8 \%$ & $6.3 \%$ \\
\hline
\end{tabular}




\begin{tabular}{|c|c|c|}
\hline 302-2-A-55-X-3 & 302-2-A-55-X-4 & 302-2-A-55-X-4 \\
\hline & Cristin Ashmankas, & Cristin Ashmankas, \\
\hline Unimodal, Poorly Sorted & Unimodal, Poorly Sorted & Bimodal, Poorly Sorted \\
\hline Mud & Mud & Sandy Mud \\
\hline Medium Silt & Coarse Silt & Very Fine Sandy Coarse Silt \\
\hline 59.82 & 24.38 & 43.76 \\
\hline 227.3 & 45.18 & 137.4 \\
\hline 5.715 & 13.25 & 7.600 \\
\hline 36.46 & 248.9 & 71.67 \\
\hline 12.15 & 13.01 & 13.12 \\
\hline 4.014 & 3.170 & 3.987 \\
\hline 0.947 & -0.276 & 0.439 \\
\hline 5.207 & 2.747 & 3.348 \\
\hline 6.311 & 6.264 & 6.244 \\
\hline 2.040 & 1.664 & 2.000 \\
\hline-1.010 & 0.276 & -0.453 \\
\hline 5.197 & 2.747 & 3.374 \\
\hline 11.27 & 13.09 & 12.45 \\
\hline 3.566 & 3.200 & 3.765 \\
\hline 0.015 & -0.215 & -0.001 \\
\hline 1.144 & 0.906 & 0.891 \\
\hline 6.472 & 6.256 & 6.328 \\
\hline 1.834 & 1.678 & 1.912 \\
\hline-0.015 & 0.215 & 0.001 \\
\hline 1.144 & 0.906 & 0.891 \\
\hline Medium Silt & Medium Silt & Medium Silt \\
\hline Poorly Sorted & Poorly Sorted & Poorly Sorted \\
\hline Symmetrical & Fine Skewed & Symmetrical \\
\hline Leptokurtic & Mesokurtic & Platykurtic \\
\hline \multirow[t]{2}{*}{18.80} & 26.50 & 26.50 \\
\hline & & 6.650 \\
\hline \multirow[t]{2}{*}{5.754} & 5.259 & 5.259 \\
\hline & & 7.254 \\
\hline 2.372 & 2.483 & 2.294 \\
\hline 11.89 & 15.50 & 12.74 \\
\hline 49.06 & 50.57 & 64.69 \\
\hline 20.68 & 20.37 & 28.20 \\
\hline 46.69 & 48.08 & 62.39 \\
\hline 5.028 & 5.355 & 7.189 \\
\hline 20.43 & 24.85 & 28.88 \\
\hline 4.349 & 4.306 & 3.950 \\
\hline 6.394 & 6.012 & 6.295 \\
\hline 8.720 & 8.654 & 8.768 \\
\hline 2.005 & 2.010 & 2.220 \\
\hline 4.370 & 4.348 & 4.818 \\
\hline 1.440 & 1.481 & 1.581 \\
\hline 2.330 & 2.421 & 2.846 \\
\hline $7.1 \%$ & $5.6 \%$ & $10.5 \%$ \\
\hline $92.9 \%$ & $94.4 \%$ & $89.5 \%$ \\
\hline $2.7 \%$ & $0.0 \%$ & $0.7 \%$ \\
\hline $1.3 \%$ & $0.2 \%$ & $1.1 \%$ \\
\hline $0.6 \%$ & $0.1 \%$ & $1.5 \%$ \\
\hline $0.5 \%$ & $0.5 \%$ & $1.3 \%$ \\
\hline $2.1 \%$ & $4.7 \%$ & $5.9 \%$ \\
\hline $11.7 \%$ & $18.6 \%$ & $16.5 \%$ \\
\hline $22.2 \%$ & $25.6 \%$ & $18.4 \%$ \\
\hline $22.3 \%$ & $18.3 \%$ & $16.4 \%$ \\
\hline $17.8 \%$ & $14.6 \%$ & $17.7 \%$ \\
\hline $11.5 \%$ & $10.5 \%$ & $13.1 \%$ \\
\hline $7.3 \%$ & $6.9 \%$ & $7.5 \%$ \\
\hline
\end{tabular}




\begin{tabular}{|c|c|c|}
\hline 302-2-A-55-X-5 & 302-2-A-55-X-5 & 302-2-A-56-X-1 \\
\hline Cristin Ashmankas, & Cristin Ashmankas, & Cristin Ashmankas, \\
\hline Unimodal, Poorly Sorted & Unimodal, Poorly Sorted & Unimodal, Poorly Sorted \\
\hline Mud & Mud & Mud \\
\hline Coarse Silt & Coarse Silt & Coarse Silt \\
\hline 47.30 & 32.52 & 42.16 \\
\hline 154.1 & 87.41 & 158.3 \\
\hline 7.390 & 11.68 & 8.440 \\
\hline 65.70 & 177.5 & 77.96 \\
\hline 14.72 & 14.61 & 15.15 \\
\hline 3.794 & 3.407 & 3.345 \\
\hline 0.370 & -0.153 & 0.218 \\
\hline 3.887 & 3.256 & 4.565 \\
\hline 6.070 & 6.091 & 6.020 \\
\hline 1.933 & 1.772 & 1.756 \\
\hline-0.403 & 0.131 & -0.297 \\
\hline 3.932 & 3.301 & 4.677 \\
\hline 13.89 & 14.37 & 14.91 \\
\hline 3.433 & 3.273 & 3.072 \\
\hline-0.165 & -0.285 & -0.216 \\
\hline 0.971 & 0.910 & 0.992 \\
\hline 6.169 & 6.121 & 6.068 \\
\hline 1.779 & 1.710 & 1.619 \\
\hline 0.165 & 0.285 & 0.216 \\
\hline 0.971 & 0.910 & 0.992 \\
\hline Medium Silt & Medium Silt & Medium Silt \\
\hline Poorly Sorted & Poorly Sorted & Poorly Sorted \\
\hline Fine Skewed & Fine Skewed & Fine Skewed \\
\hline Mesokurtic & Mesokurtic & Mesokurtic \\
\hline 26.50 & 26.50 & 26.50 \\
\hline 5.259 & 5.259 & 5.259 \\
\hline & & \\
\hline 2.574 & 2.533 & 2.967 \\
\hline 16.45 & 18.23 & 17.45 \\
\hline 57.62 & 54.37 & 54.32 \\
\hline 22.38 & 21.46 & 18.31 \\
\hline 55.04 & 51.83 & 51.36 \\
\hline 5.630 & 5.538 & 4.579 \\
\hline 27.40 & 28.09 & 25.85 \\
\hline 4.117 & 4.201 & 4.202 \\
\hline 5.926 & 5.777 & 5.841 \\
\hline 8.602 & 8.625 & 8.397 \\
\hline 2.089 & 2.053 & 1.998 \\
\hline 4.484 & 4.424 & 4.194 \\
\hline 1.508 & 1.507 & 1.446 \\
\hline 2.493 & 2.469 & 2.195 \\
\hline $8.3 \%$ & $6.5 \%$ & $6.8 \%$ \\
\hline $91.7 \%$ & $93.5 \%$ & $93.2 \%$ \\
\hline $1.0 \%$ & $0.3 \%$ & $1.3 \%$ \\
\hline $1.1 \%$ & $0.3 \%$ & $0.6 \%$ \\
\hline $1.7 \%$ & $1.1 \%$ & $0.0 \%$ \\
\hline $0.9 \%$ & $0.5 \%$ & $0.0 \%$ \\
\hline $3.7 \%$ & $4.3 \%$ & $4.8 \%$ \\
\hline $18.9 \%$ & $22.1 \%$ & $20.3 \%$ \\
\hline $24.5 \%$ & $26.6 \%$ & $27.1 \%$ \\
\hline $17.3 \%$ & $15.3 \%$ & $19.3 \%$ \\
\hline $14.3 \%$ & $12.9 \%$ & $12.8 \%$ \\
\hline $10.1 \%$ & $9.7 \%$ & $8.4 \%$ \\
\hline $6.6 \%$ & $6.9 \%$ & $5.5 \%$ \\
\hline
\end{tabular}




\begin{tabular}{|c|c|c|}
\hline $302-2-A-56-X-1$ & $302-2-A-56-X-2$ & $302-2-A-56-X-2$ \\
\hline Cristin Ashmankas, & Cristin Ashmankas, & Cristin Ashmankas, \\
\hline Unimodal, Poorly Sorted & Unimodal, Poorly Sorted & Unimodal, Poorly Sorted \\
\hline Sandy Mud & Sandy Mud & Mud \\
\hline Very Fine Sandy Coarse Silt & Very Fine Sandy Coarse Silt & Coarse Silt \\
\hline 47.84 & 48.23 & 26.47 \\
\hline 145.1 & 174.4 & 29.13 \\
\hline 8.479 & 7.751 & 3.870 \\
\hline 83.78 & 65.81 & 30.92 \\
\hline 18.38 & 15.60 & 15.43 \\
\hline 3.595 & 3.697 & 3.082 \\
\hline-0.015 & 0.219 & -0.482 \\
\hline 3.691 & 3.958 & 2.723 \\
\hline 5.745 & 5.971 & 6.018 \\
\hline 1.854 & 1.903 & 1.624 \\
\hline-0.037 & -0.290 & 0.482 \\
\hline 3.757 & 4.052 & 2.723 \\
\hline 18.18 & 15.39 & 15.51 \\
\hline 3.384 & 3.431 & 3.119 \\
\hline-0.232 & -0.184 & -0.258 \\
\hline 1.009 & 0.925 & 0.944 \\
\hline 5.782 & 6.022 & 6.010 \\
\hline 1.759 & 1.779 & 1.641 \\
\hline 0.232 & 0.184 & 0.258 \\
\hline 1.009 & 0.925 & 0.944 \\
\hline Coarse Silt & Medium Silt & Medium Silt \\
\hline Poorly Sorted & Poorly Sorted & Poorly Sorted \\
\hline Fine Skewed & Fine Skewed & Fine Skewed \\
\hline Mesokurtic & Mesokurtic & Mesokurtic \\
\hline 26.50 & 26.50 & 26.50 \\
\hline 5.259 & 5.259 & 5.259 \\
\hline 3.078 & 2.683 & 2.982 \\
\hline 21.90 & 17.82 & 18.93 \\
\hline 72.65 & 64.35 & 56.29 \\
\hline 23.60 & 23.98 & 18.87 \\
\hline 69.58 & 61.66 & 53.30 \\
\hline 5.080 & 5.750 & 4.944 \\
\hline 33.89 & 31.14 & 28.26 \\
\hline 3.783 & 3.958 & 4.151 \\
\hline 5.513 & 5.810 & 5.723 \\
\hline 8.344 & 8.542 & 8.389 \\
\hline 2.206 & 2.158 & 2.021 \\
\hline 4.561 & 4.584 & 4.238 \\
\hline 1.513 & 1.534 & 1.478 \\
\hline 2.345 & 2.524 & 2.306 \\
\hline $12.9 \%$ & $10.6 \%$ & $7.2 \%$ \\
\hline $87.1 \%$ & $89.4 \%$ & $92.8 \%$ \\
\hline $1.0 \%$ & $1.6 \%$ & $0.0 \%$ \\
\hline $0.7 \%$ & $0.6 \%$ & $0.0 \%$ \\
\hline $0.9 \%$ & $0.1 \%$ & $0.2 \%$ \\
\hline $0.6 \%$ & $0.1 \%$ & $0.9 \%$ \\
\hline $9.7 \%$ & $8.1 \%$ & $6.2 \%$ \\
\hline $23.5 \%$ & $20.7 \%$ & $22.7 \%$ \\
\hline $24.4 \%$ & $22.8 \%$ & $26.7 \%$ \\
\hline $15.5 \%$ & $17.3 \%$ & $16.7 \%$ \\
\hline $10.8 \%$ & $13.1 \%$ & $12.8 \%$ \\
\hline $7.5 \%$ & $9.2 \%$ & $8.6 \%$ \\
\hline $5.4 \%$ & $6.3 \%$ & $5.3 \%$ \\
\hline
\end{tabular}




\begin{tabular}{|c|c|c|}
\hline $302-2-A-56-X-3$ & 302-2-A-56-X-3 & $302-2-A-57-X-1$ \\
\hline Cristin Ashmankas, & Cristin Ashmankas, & Cristin Ashmankas, \\
\hline Unimodal, Poorly Sorted & Unimodal, Poorly Sorted & Unimodal, Poorly Sorted \\
\hline Mud & Mud & Mud \\
\hline Coarse Silt & Coarse Silt & Coarse Silt \\
\hline 39.08 & 19.93 & 52.16 \\
\hline 138.4 & 20.28 & 190.4 \\
\hline 9.085 & 2.157 & 6.510 \\
\hline 93.18 & 10.78 & 48.37 \\
\hline 14.65 & 11.41 & 12.49 \\
\hline 3.391 & 3.151 & 4.053 \\
\hline 0.166 & -0.408 & 0.668 \\
\hline 4.094 & 2.485 & 4.211 \\
\hline 6.087 & 6.454 & 6.292 \\
\hline 1.766 & 1.656 & 2.039 \\
\hline-0.186 & 0.408 & -0.713 \\
\hline 4.128 & 2.485 & 4.257 \\
\hline 14.28 & 11.66 & 11.72 \\
\hline 3.182 & 3.218 & 3.659 \\
\hline-0.206 & -0.184 & -0.032 \\
\hline 0.965 & 0.884 & 0.971 \\
\hline 6.130 & 6.423 & 6.415 \\
\hline 1.670 & 1.686 & 1.872 \\
\hline 0.206 & 0.184 & 0.032 \\
\hline 0.965 & 0.884 & 0.971 \\
\hline Medium Silt & Medium Silt & Medium Silt \\
\hline Poorly Sorted & Poorly Sorted & Poorly Sorted \\
\hline Fine Skewed & Fine Skewed & Symmetrical \\
\hline Mesokurtic & Platykurtic & Mesokurtic \\
\hline 26.50 & 26.50 & 18.80 \\
\hline 5.259 & 5.259 & 5.754 \\
\hline 2.742 & 2.215 & 2.228 \\
\hline 16.77 & 13.32 & 12.59 \\
\hline 54.76 & 44.62 & 58.65 \\
\hline 19.97 & 20.14 & 26.32 \\
\hline 52.01 & 42.40 & 56.42 \\
\hline 4.949 & 5.601 & 6.177 \\
\hline 26.10 & 22.99 & 24.07 \\
\hline 4.191 & 4.486 & 4.092 \\
\hline 5.898 & 6.230 & 6.311 \\
\hline 8.510 & 8.818 & 8.810 \\
\hline 2.031 & 1.966 & 2.153 \\
\hline 4.320 & 4.332 & 4.718 \\
\hline 1.468 & 1.482 & 1.513 \\
\hline 2.307 & 2.486 & 2.627 \\
\hline $7.0 \%$ & $3.8 \%$ & $9.0 \%$ \\
\hline $93.0 \%$ & $96.2 \%$ & $91.0 \%$ \\
\hline $0.8 \%$ & $0.0 \%$ & $1.7 \%$ \\
\hline $0.6 \%$ & $0.0 \%$ & $1.4 \%$ \\
\hline $0.4 \%$ & $0.0 \%$ & $0.6 \%$ \\
\hline $0.0 \%$ & $0.2 \%$ & $0.9 \%$ \\
\hline $5.1 \%$ & $3.5 \%$ & $4.5 \%$ \\
\hline $19.5 \%$ & $17.2 \%$ & $13.4 \%$ \\
\hline $26.0 \%$ & $24.5 \%$ & $21.5 \%$ \\
\hline $19.0 \%$ & $18.8 \%$ & $18.6 \%$ \\
\hline $13.2 \%$ & $16.1 \%$ & $16.5 \%$ \\
\hline $9.2 \%$ & $11.2 \%$ & $13.0 \%$ \\
\hline $6.1 \%$ & $8.3 \%$ & $7.9 \%$ \\
\hline
\end{tabular}




\begin{tabular}{|c|c|c|}
\hline 302-2-A-57-X-2 & 302-2-A-57-X-2 & 302-2-A-57-X-3 \\
\hline Cristin Ashmankas, & Cristin Ashmankas, & Cristin Ashmankas, \\
\hline Unimodal, Poorly Sorted & Unimodal, Poorly Sorted & Unimodal, Poorly Sorted \\
\hline Mud & Mud & Mud \\
\hline Coarse Silt & Coarse Silt & Coarse Silt \\
\hline 49.33 & 49.92 & 40.29 \\
\hline 187.1 & 176.7 & 157.2 \\
\hline 7.006 & 6.378 & 8.681 \\
\hline 54.18 & 48.14 & 81.84 \\
\hline 14.61 & 12.52 & 13.80 \\
\hline 3.544 & 3.822 & 3.451 \\
\hline 0.492 & 0.810 & 0.255 \\
\hline 4.919 & 4.731 & 4.262 \\
\hline 6.065 & 6.305 & 6.153 \\
\hline 1.844 & 1.945 & 1.804 \\
\hline-0.570 & -0.835 & -0.334 \\
\hline 4.998 & 4.755 & 4.390 \\
\hline 13.96 & 11.51 & 13.49 \\
\hline 3.132 & 3.438 & 3.245 \\
\hline-0.200 & -0.010 & -0.196 \\
\hline 1.012 & 1.105 & 0.946 \\
\hline 6.162 & 6.441 & 6.212 \\
\hline 1.647 & 1.782 & 1.698 \\
\hline 0.200 & 0.010 & 0.196 \\
\hline 1.012 & 1.105 & 0.946 \\
\hline Medium Silt & Medium Silt & Medium Silt \\
\hline Poorly Sorted & Poorly Sorted & Poorly Sorted \\
\hline Fine Skewed & Symmetrical & Fine Skewed \\
\hline Mesokurtic & Mesokurtic & Mesokurtic \\
\hline 26.50 & 18.80 & 26.50 \\
\hline 5.259 & 5.754 & 5.259 \\
\hline & & \\
\hline 2.826 & 2.481 & 2.556 \\
\hline 16.55 & 12.31 & 15.90 \\
\hline 52.47 & 49.31 & 53.79 \\
\hline 18.57 & 19.87 & 21.05 \\
\hline 49.65 & 46.83 & 51.24 \\
\hline 4.573 & 4.948 & 5.155 \\
\hline 23.84 & 20.51 & 25.16 \\
\hline 4.252 & 4.342 & 4.216 \\
\hline 5.917 & 6.344 & 5.975 \\
\hline 8.467 & 8.655 & 8.612 \\
\hline 1.991 & 1.993 & 2.043 \\
\hline 4.215 & 4.313 & 4.396 \\
\hline 1.436 & 1.437 & 1.473 \\
\hline 2.193 & 2.307 & 2.366 \\
\hline $6.8 \%$ & $7.2 \%$ & $6.9 \%$ \\
\hline $93.2 \%$ & $92.8 \%$ & $93.1 \%$ \\
\hline $1.8 \%$ & $1.2 \%$ & $1.3 \%$ \\
\hline $1.0 \%$ & $1.7 \%$ & $0.5 \%$ \\
\hline $0.1 \%$ & $1.3 \%$ & $0.0 \%$ \\
\hline $0.1 \%$ & $0.7 \%$ & $0.1 \%$ \\
\hline $3.8 \%$ & $2.3 \%$ & $5.0 \%$ \\
\hline $17.3 \%$ & $11.7 \%$ & $18.1 \%$ \\
\hline $28.2 \%$ & $23.1 \%$ & $25.7 \%$ \\
\hline $19.6 \%$ & $22.3 \%$ & $19.2 \%$ \\
\hline $12.8 \%$ & $17.4 \%$ & $13.3 \%$ \\
\hline $9.6 \%$ & $11.6 \%$ & $10.4 \%$ \\
\hline $5.6 \%$ & $6.7 \%$ & $6.5 \%$ \\
\hline
\end{tabular}




\begin{tabular}{|c|c|c|}
\hline 302-2-A-57-X-3 & 302-2-A-57-X-4 & 302-2-A-57-X-4 \\
\hline Cristin Ashmankas, & Cristin Ashmankas, & Cristin Ashmankas, \\
\hline Unimodal, Poorly Sorted & Unimodal, Poorly Sorted & Unimodal, Poorly Sorted \\
\hline Mud & Mud & Sandy Mud \\
\hline Coarse Silt & Coarse Silt & Very Fine Sandy Coarse Silt \\
\hline 44.43 & 35.85 & 42.68 \\
\hline 154.6 & 104.9 & 137.2 \\
\hline 7.946 & 8.798 & 9.895 \\
\hline 72.61 & 97.27 & 108.1 \\
\hline 14.74 & 13.95 & 18.35 \\
\hline 3.527 & 3.417 & 3.300 \\
\hline 0.412 & 0.285 & -0.104 \\
\hline 4.272 & 3.720 & 3.857 \\
\hline 6.065 & 6.164 & 5.742 \\
\hline 1.830 & 1.773 & 1.734 \\
\hline-0.461 & -0.285 & 0.014 \\
\hline 4.341 & 3.720 & 3.983 \\
\hline 14.17 & 13.45 & 18.46 \\
\hline 3.207 & 3.228 & 3.148 \\
\hline-0.109 & -0.074 & -0.248 \\
\hline 1.002 & 1.003 & 0.979 \\
\hline 6.141 & 6.216 & 5.759 \\
\hline 1.681 & 1.691 & 1.654 \\
\hline 0.109 & 0.074 & 0.248 \\
\hline 1.002 & 1.003 & 0.979 \\
\hline Medium Silt & Medium Silt & Coarse Silt \\
\hline Poorly Sorted & Poorly Sorted & Poorly Sorted \\
\hline Fine Skewed & Symmetrical & Fine Skewed \\
\hline Mesokurtic & Mesokurtic & Mesokurtic \\
\hline 26.50 & 18.80 & 26.50 \\
\hline 5.259 & 5.754 & 5.259 \\
\hline & & \\
\hline 2.967 & 2.892 & 3.424 \\
\hline 15.63 & 14.46 & 22.19 \\
\hline 57.88 & 56.37 & 67.45 \\
\hline 19.51 & 19.49 & 19.70 \\
\hline 54.92 & 53.47 & 64.03 \\
\hline 4.874 & 4.940 & 4.734 \\
\hline 25.21 & 23.99 & 32.59 \\
\hline 4.111 & 4.149 & 3.890 \\
\hline 5.999 & 6.112 & 5.494 \\
\hline 8.397 & 8.434 & 8.190 \\
\hline 2.043 & 2.033 & 2.105 \\
\hline 4.286 & 4.285 & 4.300 \\
\hline 1.459 & 1.456 & 1.488 \\
\hline 2.285 & 2.304 & 2.243 \\
\hline $8.5 \%$ & $8.2 \%$ & $11.5 \%$ \\
\hline $91.5 \%$ & $91.8 \%$ & $88.5 \%$ \\
\hline $1.1 \%$ & $0.3 \%$ & $1.0 \%$ \\
\hline $0.9 \%$ & $0.7 \%$ & $0.4 \%$ \\
\hline $0.7 \%$ & $1.0 \%$ & $0.1 \%$ \\
\hline $1.1 \%$ & $1.7 \%$ & $0.4 \%$ \\
\hline $4.8 \%$ & $4.5 \%$ & $9.7 \%$ \\
\hline $16.9 \%$ & $15.5 \%$ & $24.7 \%$ \\
\hline $24.6 \%$ & $23.8 \%$ & $25.3 \%$ \\
\hline $20.7 \%$ & $21.2 \%$ & $15.7 \%$ \\
\hline $14.9 \%$ & $16.2 \%$ & $11.0 \%$ \\
\hline $9.1 \%$ & $9.7 \%$ & $7.5 \%$ \\
\hline $5.2 \%$ & $5.4 \%$ & $4.1 \%$ \\
\hline
\end{tabular}




\begin{tabular}{|c|c|c|}
\hline $\begin{array}{c}\text { 302-2-A-57-X-5 } \\
\text { Cristin Ashmankas }\end{array}$ & $\begin{array}{c}\text { 302-2-A-57-X-5 } \\
\text { Cristin Ashmankas }\end{array}$ & 302-2-A-58-X-1 \\
\hline Cristin Ashmankas, & Cristin Ashmankas, & Cristin Ashmankas, \\
\hline Unimodal, Poorly Sorted & Unimodal, Poorly Sorted & Unimodal, Poorly Sorted \\
\hline Mud & Sandy Mud & Sandy Mud \\
\hline Coarse Silt & Very Fine Sandy Coarse Silt & Very Fine Sandy Coarse Silt \\
\hline 21.41 & 49.16 & 39.32 \\
\hline 18.40 & 147.7 & 110.3 \\
\hline 1.415 & 7.666 & 9.745 \\
\hline 5.460 & 71.66 & 115.4 \\
\hline 13.63 & 16.76 & 17.32 \\
\hline 2.837 & 3.694 & 3.257 \\
\hline-0.565 & 0.339 & 0.026 \\
\hline 2.647 & 3.708 & 3.776 \\
\hline 6.198 & 5.884 & 5.847 \\
\hline 1.505 & 1.892 & 1.705 \\
\hline 0.565 & -0.371 & -0.041 \\
\hline 2.647 & 3.750 & 3.800 \\
\hline 13.90 & 16.08 & 17.09 \\
\hline 2.898 & 3.536 & 3.090 \\
\hline-0.257 & -0.044 & -0.160 \\
\hline 0.922 & 1.069 & 1.017 \\
\hline 6.169 & 5.959 & 5.870 \\
\hline 1.535 & 1.822 & 1.628 \\
\hline 0.257 & 0.044 & 0.160 \\
\hline 0.922 & 1.069 & 1.017 \\
\hline Medium Silt & Coarse Silt & Coarse Silt \\
\hline Poorly Sorted & Poorly Sorted & Poorly Sorted \\
\hline Fine Skewed & Symmetrical & Fine Skewed \\
\hline Mesokurtic & Mesokurtic & Mesokurtic \\
\hline 26.50 & 26.50 & 26.50 \\
\hline 5.259 & 5.259 & 5.259 \\
\hline 2.966 & 3.180 & 3.538 \\
\hline 16.64 & 17.35 & 19.24 \\
\hline 45.45 & 75.66 & 62.95 \\
\hline 15.32 & 23.79 & 17.79 \\
\hline 42.48 & 72.48 & 59.41 \\
\hline 4.528 & 5.224 & 4.520 \\
\hline 23.42 & 29.78 & 28.93 \\
\hline 4.460 & 3.724 & 3.990 \\
\hline 5.909 & 5.849 & 5.700 \\
\hline 8.397 & 8.297 & 8.143 \\
\hline 1.883 & 2.228 & 2.041 \\
\hline 3.937 & 4.573 & 4.153 \\
\hline 1.431 & 1.501 & 1.458 \\
\hline 2.179 & 2.385 & 2.176 \\
\hline $3.3 \%$ & $12.3 \%$ & $10.2 \%$ \\
\hline $96.7 \%$ & $87.7 \%$ & $89.8 \%$ \\
\hline $0.0 \%$ & $0.9 \%$ & $0.5 \%$ \\
\hline $0.0 \%$ & $1.0 \%$ & $0.6 \%$ \\
\hline $0.0 \%$ & $1.5 \%$ & $0.7 \%$ \\
\hline $0.0 \%$ & $2.4 \%$ & $1.4 \%$ \\
\hline $3.3 \%$ & $6.6 \%$ & $7.0 \%$ \\
\hline $20.0 \%$ & $17.6 \%$ & $21.0 \%$ \\
\hline $29.2 \%$ & $23.5 \%$ & $26.3 \%$ \\
\hline $19.0 \%$ & $19.2 \%$ & $18.7 \%$ \\
\hline $14.0 \%$ & $14.2 \%$ & $12.5 \%$ \\
\hline $9.4 \%$ & $8.5 \%$ & $7.2 \%$ \\
\hline $5.1 \%$ & $4.6 \%$ & $4.1 \%$ \\
\hline
\end{tabular}




\begin{tabular}{|c|c|c|}
\hline 302-2-A-58-X-1 & 302-2-A-58-X-2 & $302-2-A-58-X-2$ \\
\hline Cristin Ashmankas, & Cristin Ashmankas, & Cristin Ashmankas, \\
\hline Bimodal, Poorly Sorted & Unimodal, Poorly Sorted & Unimodal, Poorly Sorted \\
\hline Mud & Mud & Mud \\
\hline Coarse Silt & Coarse Silt & Medium Silt \\
\hline 45.09 & 44.53 & 39.05 \\
\hline 174.9 & 172.7 & 164.7 \\
\hline 7.425 & 7.504 & 8.375 \\
\hline 61.34 & 62.97 & 76.39 \\
\hline 12.44 & 12.29 & 11.30 \\
\hline 3.785 & 3.747 & 3.517 \\
\hline 0.495 & 0.535 & 0.611 \\
\hline 4.253 & 4.393 & 4.789 \\
\hline 6.303 & 6.319 & 6.435 \\
\hline 1.939 & 1.925 & 1.841 \\
\hline-0.551 & -0.592 & -0.697 \\
\hline 4.334 & 4.474 & 4.928 \\
\hline 11.90 & 11.69 & 10.97 \\
\hline 3.426 & 3.373 & 3.208 \\
\hline-0.157 & -0.140 & -0.034 \\
\hline 0.897 & 0.935 & 0.990 \\
\hline 6.393 & 6.419 & 6.510 \\
\hline 1.776 & 1.754 & 1.682 \\
\hline 0.157 & 0.140 & 0.034 \\
\hline 0.897 & 0.935 & 0.990 \\
\hline Medium Silt & Medium Silt & Medium Silt \\
\hline Poorly Sorted & Poorly Sorted & Poorly Sorted \\
\hline Fine Skewed & Fine Skewed & Symmetrical \\
\hline Platykurtic & Mesokurtic & Mesokurtic \\
\hline 26.50 & 26.50 & 13.30 \\
\hline 4.700 & & \\
\hline 5.259 & 5.259 & 6.254 \\
\hline 7.754 & & \\
\hline 2.200 & 2.247 & 2.398 \\
\hline 13.95 & 13.54 & 11.35 \\
\hline 51.17 & 48.53 & 46.04 \\
\hline 23.26 & 21.59 & 19.20 \\
\hline 48.97 & 46.28 & 43.64 \\
\hline 6.092 & 5.695 & 4.960 \\
\hline 24.18 & 22.83 & 19.67 \\
\hline 4.289 & 4.365 & 4.441 \\
\hline 6.163 & 6.207 & 6.462 \\
\hline 8.828 & 8.798 & 8.704 \\
\hline 2.059 & 2.015 & 1.960 \\
\hline 4.540 & 4.433 & 4.263 \\
\hline 1.510 & 1.485 & 1.432 \\
\hline 2.607 & 2.510 & 2.310 \\
\hline $6.7 \%$ & $6.4 \%$ & $6.1 \%$ \\
\hline $93.3 \%$ & $93.6 \%$ & $93.9 \%$ \\
\hline $1.5 \%$ & $1.5 \%$ & $1.5 \%$ \\
\hline $0.9 \%$ & $0.8 \%$ & $0.4 \%$ \\
\hline $0.3 \%$ & $0.6 \%$ & $0.3 \%$ \\
\hline $0.5 \%$ & $0.9 \%$ & $1.0 \%$ \\
\hline $3.5 \%$ & $2.6 \%$ & $3.0 \%$ \\
\hline $15.5 \%$ & $14.2 \%$ & $12.0 \%$ \\
\hline $24.6 \%$ & $25.1 \%$ & $21.3 \%$ \\
\hline $17.6 \%$ & $18.8 \%$ & $22.8 \%$ \\
\hline $14.7 \%$ & $15.2 \%$ & $18.8 \%$ \\
\hline $12.7 \%$ & $12.4 \%$ & $11.8 \%$ \\
\hline $8.1 \%$ & $7.8 \%$ & $7.2 \%$ \\
\hline
\end{tabular}




\begin{tabular}{|c|c|c|}
\hline 302-2-A-58-X-3 & $302-2-A-58-X-3$ & $302-2-A-58-X-4$ \\
\hline Cristin Ashmankas, & Cristin Ashmankas, & Cristin Ashmankas, \\
\hline Unimodal, Poorly Sorted & Unimodal, Poorly Sorted & Unimodal, Poorly Sorted \\
\hline Mud & Sandy Mud & Mud \\
\hline Coarse Silt & very rille samay very & Coarse Silt \\
\hline 37.94 & 32.22 & 22.20 \\
\hline 92.49 & 24.21 & 20.05 \\
\hline 5.829 & 1.073 & 1.526 \\
\hline 41.94 & 4.134 & 5.776 \\
\hline 14.00 & 21.75 & 13.55 \\
\hline 3.710 & 2.756 & 2.994 \\
\hline 0.242 & -0.993 & -0.548 \\
\hline 3.333 & 3.648 & 2.572 \\
\hline 6.159 & 5.523 & 6.206 \\
\hline 1.891 & 1.463 & 1.582 \\
\hline-0.242 & 0.993 & 0.548 \\
\hline 3.333 & 3.648 & 2.572 \\
\hline 13.33 & 22.97 & 13.70 \\
\hline 3.555 & 2.726 & 3.082 \\
\hline-0.073 & -0.306 & -0.270 \\
\hline 1.007 & 1.187 & 0.935 \\
\hline 6.230 & 5.444 & 6.189 \\
\hline 1.830 & 1.447 & 1.624 \\
\hline 0.073 & 0.306 & 0.270 \\
\hline 1.007 & 1.187 & 0.935 \\
\hline Medium Silt & Coarse Silt & Medium Silt \\
\hline Poorly Sorted & Poorly Sorted & Poorly Sorted \\
\hline Symmetrical & Very Fine Skewed & Fine Skewed \\
\hline Mesokurtic & Leptokurtic & Mesokurtic \\
\hline 26.50 & 37.50 & 26.50 \\
\hline 5.259 & 4.759 & 5.259 \\
\hline 2.548 & 4.641 & 2.621 \\
\hline 14.65 & 26.87 & 16.79 \\
\hline 60.67 & 64.82 & 48.75 \\
\hline 23.81 & 13.97 & 18.60 \\
\hline 58.12 & 60.18 & 46.13 \\
\hline 5.677 & 3.307 & 4.828 \\
\hline 26.42 & 30.89 & 24.44 \\
\hline 4.043 & 3.947 & 4.358 \\
\hline 6.093 & 5.218 & 5.896 \\
\hline 8.616 & 7.751 & 8.575 \\
\hline 2.131 & 1.964 & 1.968 \\
\hline 4.574 & 3.804 & 4.217 \\
\hline 1.505 & 1.384 & 1.452 \\
\hline 2.505 & 1.726 & 2.271 \\
\hline $9.4 \%$ & $11.0 \%$ & $4.6 \%$ \\
\hline $90.6 \%$ & $89.0 \%$ & $95.4 \%$ \\
\hline $0.0 \%$ & $0.0 \%$ & $0.0 \%$ \\
\hline $1.2 \%$ & $0.0 \%$ & $0.0 \%$ \\
\hline $1.8 \%$ & $0.0 \%$ & $0.0 \%$ \\
\hline $1.7 \%$ & $0.1 \%$ & $0.0 \%$ \\
\hline $4.8 \%$ & $10.9 \%$ & $4.6 \%$ \\
\hline $16.3 \%$ & $31.8 \%$ & $19.9 \%$ \\
\hline $22.4 \%$ & $28.7 \%$ & $28.3 \%$ \\
\hline $19.1 \%$ & $13.2 \%$ & $18.3 \%$ \\
\hline $15.6 \%$ & $6.9 \%$ & $12.7 \%$ \\
\hline $10.4 \%$ & $5.2 \%$ & $9.8 \%$ \\
\hline $6.7 \%$ & $3.3 \%$ & $6.4 \%$ \\
\hline
\end{tabular}




\begin{tabular}{|c|c|c|}
\hline 302-2-A-58-X-4 & 302-2-A-59-X-1 & 302-2-A-59-X-1 \\
\hline Cristin Ashmankas, & Cristin Ashmankas, & Cristin Ashmankas, \\
\hline Unimodal, Poorly Sorted & Unimodal, Poorly Sorted & Trimodal, Very Poorly Sortec \\
\hline Mud & Mud & Sandy Mud \\
\hline Coarse Silt & Coarse Silt & Very Fine Sandy Fine Silt \\
\hline 20.28 & 34.04 & 72.12 \\
\hline 15.40 & 93.68 & 233.7 \\
\hline 0.895 & 6.892 & 5.074 \\
\hline 3.495 & 57.74 & 30.16 \\
\hline 13.46 & 11.87 & 12.13 \\
\hline 2.768 & 3.772 & 5.265 \\
\hline-0.755 & 0.299 & 0.669 \\
\hline 2.787 & 3.287 & 3.432 \\
\hline 6.215 & 6.396 & 6.324 \\
\hline 1.469 & 1.915 & 2.419 \\
\hline 0.755 & -0.299 & -0.687 \\
\hline 2.787 & 3.287 & 3.431 \\
\hline 13.71 & 11.37 & 11.16 \\
\hline 2.835 & 3.620 & 5.380 \\
\hline-0.342 & -0.057 & 0.135 \\
\hline 0.954 & 0.941 & 1.103 \\
\hline 6.188 & 6.459 & 6.485 \\
\hline 1.503 & 1.856 & 2.428 \\
\hline 0.342 & 0.057 & -0.135 \\
\hline 0.954 & 0.941 & 1.103 \\
\hline Medium Silt & Medium Silt & Medium Silt \\
\hline Poorly Sorted & Poorly Sorted & Very Poorly Sorted \\
\hline Very Fine Skewed & Symmetrical & Coarse Skewed \\
\hline Mesokurtic & Mesokurtic & Mesokurtic \\
\hline 26.50 & 18.80 & 4.700 \\
\hline & & 26.50 \\
\hline 5.259 & 5.754 & 7.754 \\
\hline & & 5.259 \\
\hline 2.836 & 2.075 & 1.663 \\
\hline 17.33 & 12.22 & 10.82 \\
\hline 41.43 & 56.28 & 93.83 \\
\hline 14.61 & 27.12 & 56.43 \\
\hline 38.60 & 54.21 & 92.17 \\
\hline 4.181 & 6.228 & 9.082 \\
\hline 22.17 & 23.78 & 29.26 \\
\hline 4.593 & 4.151 & 3.414 \\
\hline 5.851 & 6.354 & 6.531 \\
\hline 8.462 & 8.913 & 9.232 \\
\hline 1.842 & 2.147 & 2.704 \\
\hline 3.869 & 4.761 & 5.818 \\
\hline 1.405 & 1.513 & 1.646 \\
\hline 2.064 & 2.639 & 3.183 \\
\hline $0.9 \%$ & $8.4 \%$ & $13.9 \%$ \\
\hline $99.1 \%$ & $91.6 \%$ & $86.1 \%$ \\
\hline $0.0 \%$ & $0.1 \%$ & $2.6 \%$ \\
\hline $0.0 \%$ & $1.2 \%$ & $2.1 \%$ \\
\hline $0.0 \%$ & $1.0 \%$ & $1.3 \%$ \\
\hline $0.0 \%$ & $1.4 \%$ & $2.1 \%$ \\
\hline $0.9 \%$ & $4.7 \%$ & $5.8 \%$ \\
\hline $20.6 \%$ & $13.8 \%$ & $12.1 \%$ \\
\hline $33.1 \%$ & $20.9 \%$ & $16.0 \%$ \\
\hline $18.3 \%$ & $19.1 \%$ & $15.1 \%$ \\
\hline $12.2 \%$ & $16.3 \%$ & $16.1 \%$ \\
\hline $9.2 \%$ & $12.5 \%$ & $14.3 \%$ \\
\hline $5.7 \%$ & $9.1 \%$ & $12.4 \%$ \\
\hline
\end{tabular}




\begin{tabular}{|c|c|c|}
\hline 302-2-A-59-X-2 & 302-2-A-59-X-2 & 302-2-A-59-X-3 \\
\hline Cristin Ashmankas, & Cristin Ashmankas, & Cristin Ashmankas, \\
\hline Unimodal, Very Poorly Sorted & Unimodal, Poorly Sorted & Unimodal, Poorly Sorted \\
\hline Mud & Mud & Sandy Mud \\
\hline Coarse Silt & Coarse Silt & Very Fine Sandy Coarse Silt \\
\hline 66.67 & 31.00 & 49.42 \\
\hline 231.7 & 77.22 & 156.1 \\
\hline 5.319 & 10.33 & 8.334 \\
\hline 32.42 & 130.5 & 77.91 \\
\hline 12.66 & 14.44 & 18.73 \\
\hline 4.527 & 3.287 & 3.619 \\
\hline 0.782 & -0.094 & -0.050 \\
\hline 4.219 & 3.356 & 3.729 \\
\hline 6.256 & 6.114 & 5.712 \\
\hline 2.206 & 1.717 & 1.867 \\
\hline-0.820 & 0.094 & -0.017 \\
\hline 4.216 & 3.356 & 3.812 \\
\hline 11.55 & 14.23 & 18.53 \\
\hline 4.497 & 3.231 & 3.460 \\
\hline 0.062 & -0.166 & -0.225 \\
\hline 1.205 & 1.035 & 1.049 \\
\hline 6.436 & 6.135 & 5.754 \\
\hline 2.169 & 1.692 & 1.791 \\
\hline-0.062 & 0.166 & 0.225 \\
\hline 1.205 & 1.035 & 1.049 \\
\hline Medium Silt & Medium Silt & Coarse Silt \\
\hline Very Poorly Sorted & Poorly Sorted & Poorly Sorted \\
\hline Symmetrical & Fine Skewed & Fine Skewed \\
\hline Leptokurtic & Mesokurtic & Mesokurtic \\
\hline 18.80 & 26.50 & 26.50 \\
\hline 5.754 & 5.259 & 5.259 \\
\hline 2.063 & 2804 & 2989 \\
\hline 12.49 & 16.31 & 22.25 \\
\hline 61.47 & 56.81 & 77.34 \\
\hline 29.79 & 20.26 & 25.88 \\
\hline 59.40 & 54.01 & 74.35 \\
\hline 6.573 & 4.713 & 4.915 \\
\hline 24.79 & 24.87 & 34.39 \\
\hline 4.024 & 4.138 & 3.693 \\
\hline 6.323 & 5.938 & 5.490 \\
\hline 8.921 & 8.478 & 8.386 \\
\hline 2.217 & 2.049 & 2.271 \\
\hline 4.897 & 4.341 & 4.694 \\
\hline 1.533 & 1.449 & 1.507 \\
\hline 2.716 & 2.237 & 2.297 \\
\hline $9.8 \%$ & $8.2 \%$ & $14.3 \%$ \\
\hline $90.2 \%$ & $91.8 \%$ & $85.7 \%$ \\
\hline $2.6 \%$ & $0.2 \%$ & $1.2 \%$ \\
\hline $1.9 \%$ & $0.5 \%$ & $0.6 \%$ \\
\hline $0.9 \%$ & $0.1 \%$ & $0.1 \%$ \\
\hline $0.9 \%$ & $1.7 \%$ & $1.2 \%$ \\
\hline $3.5 \%$ & $5.7 \%$ & $11.1 \%$ \\
\hline $13.3 \%$ & $17.1 \%$ & $22.5 \%$ \\
\hline $20.9 \%$ & $26.3 \%$ & $25.2 \%$ \\
\hline $18.1 \%$ & $20.1 \%$ & $15.2 \%$ \\
\hline $15.9 \%$ & $13.4 \%$ & $9.6 \%$ \\
\hline $13.0 \%$ & $8.7 \%$ & $7.6 \%$ \\
\hline $9.1 \%$ & $6.1 \%$ & $5.6 \%$ \\
\hline
\end{tabular}




\begin{tabular}{|c|c|c|}
\hline 302-2-A-59-X-3 & $302-2-A-60-X-1$ & $302-2-A-60-X-1$ \\
\hline Cristin Ashmankas, & Cristin Ashmankas, & Cristin Ashmankas, \\
\hline Unimodal, Poorly Sorted & Unimodal, Poorly Sorted & Bimodal, Very Poorly Sorted \\
\hline Sandy Mud & Mud & Sandy Mud \\
\hline Very Fine Sandy Coarse Silt & Coarse Silt & Very Fine Sandy Coarse Silt \\
\hline 35.89 & 36.85 & 58.69 \\
\hline 86.19 & 109.1 & 148.0 \\
\hline 14.20 & 9.380 & 5.477 \\
\hline 241.1 & 116.2 & 41.51 \\
\hline 19.28 & 13.63 & 16.11 \\
\hline 3.023 & 3.612 & 4.474 \\
\hline-0.374 & 0.223 & 0.420 \\
\hline 3.613 & 3.504 & 3.062 \\
\hline 5.692 & 6.179 & 5.951 \\
\hline 1.598 & 1.864 & 2.164 \\
\hline 0.350 & -0.270 & -0.425 \\
\hline 3.653 & 3.596 & 3.068 \\
\hline 19.57 & 13.23 & 15.20 \\
\hline 2.978 & 3.455 & 4.488 \\
\hline-0.209 & -0.088 & 0.068 \\
\hline 1.107 & 1.000 & 1.120 \\
\hline 5.675 & 6.240 & 6.040 \\
\hline 1.574 & 1.789 & 2.166 \\
\hline 0.209 & 0.088 & -0.068 \\
\hline 1.107 & 1.000 & 1.120 \\
\hline Coarse Silt & Medium Silt & Medium Silt \\
\hline Poorly Sorted & Poorly Sorted & Very Poorly Sorted \\
\hline Fine Skewed & Symmetrical & Symmetrical \\
\hline Mesokurtic & Mesokurtic & Leptokurtic \\
\hline \multirow[t]{2}{*}{26.50} & 18.80 & 18.80 \\
\hline & & 215.0 \\
\hline \multirow[t]{2}{*}{5.259} & 5.754 & 5.754 \\
\hline & & 2.237 \\
\hline 3.953 & 2.538 & 2.534 \\
\hline 22.37 & 14.48 & 15.19 \\
\hline 68.14 & 60.75 & 128.0 \\
\hline 17.24 & 23.93 & 50.50 \\
\hline 64.19 & 58.22 & 125.4 \\
\hline 3.874 & 5.365 & 6.674 \\
\hline 29.96 & 25.06 & 31.81 \\
\hline 3.875 & 4.041 & 2.966 \\
\hline 5.482 & 6.110 & 6.041 \\
\hline 7.983 & 8.622 & 8.624 \\
\hline 2.060 & 2.134 & 2.907 \\
\hline 4.107 & 4.581 & 5.658 \\
\hline 1.422 & 1.483 & 1.578 \\
\hline 1.954 & 2.424 & 2.739 \\
\hline $11.6 \%$ & $9.5 \%$ & $16.2 \%$ \\
\hline $88.4 \%$ & $90.5 \%$ & $83.8 \%$ \\
\hline $0.3 \%$ & $0.4 \%$ & $0.5 \%$ \\
\hline $0.1 \%$ & $0.9 \%$ & $1.9 \%$ \\
\hline $0.1 \%$ & $1.2 \%$ & $3.3 \%$ \\
\hline $1.4 \%$ & $1.1 \%$ & $4.4 \%$ \\
\hline $9.6 \%$ & $5.9 \%$ & $6.1 \%$ \\
\hline $23.6 \%$ & $15.1 \%$ & $12.8 \%$ \\
\hline $28.9 \%$ & $23.0 \%$ & $20.2 \%$ \\
\hline $16.6 \%$ & $20.3 \%$ & $18.1 \%$ \\
\hline $9.4 \%$ & $15.0 \%$ & $15.3 \%$ \\
\hline $6.2 \%$ & $10.4 \%$ & $10.6 \%$ \\
\hline $3.6 \%$ & $6.7 \%$ & $6.7 \%$ \\
\hline
\end{tabular}




\begin{tabular}{|c|c|c|}
\hline $\begin{array}{c}\text { 302-2-A-60-X-2 } \\
\text { Cristin Ashmankas, }\end{array}$ & $\begin{array}{c}\text { 302-2-A-60-X-2 } \\
\text { Cristin Ashmankas, }\end{array}$ & $\begin{array}{c}\text { 302-2-A-60-X-3 } \\
\text { Cristin Ashmankas, }\end{array}$ \\
\hline Unimodal, Poorly Sorted & Unimodal, Poorly Sorted & Unimodal, Poorly Sorted \\
\hline Sandy Mud & Mud & Sandy Mud \\
\hline Very Fine Sandy Coarse Silt & Coarse Silt & Very Fine Sandy Coarse Silt \\
\hline 31.75 & 26.53 & 50.85 \\
\hline 27.96 & 26.24 & 183.8 \\
\hline 1.736 & 1.918 & 7.144 \\
\hline 7.018 & 7.850 & 56.49 \\
\hline 20.15 & 15.60 & 14.86 \\
\hline 2.905 & 3.069 & 3.842 \\
\hline-0.769 & -0.464 & 0.373 \\
\hline 3.256 & 2.624 & 3.887 \\
\hline 5.633 & 6.002 & 6.042 \\
\hline 1.538 & 1.618 & 1.958 \\
\hline 0.769 & 0.464 & -0.431 \\
\hline 3.256 & 2.624 & 3.961 \\
\hline 20.57 & 15.69 & 14.46 \\
\hline 2.937 & 3.173 & 3.493 \\
\hline-0.270 & -0.202 & -0.169 \\
\hline 1.170 & 0.969 & 0.839 \\
\hline 5.603 & 5.994 & 6.112 \\
\hline 1.554 & 1.666 & 1.805 \\
\hline 0.270 & 0.202 & 0.169 \\
\hline 1.170 & 0.969 & 0.839 \\
\hline Coarse Silt & Coarse Silt & Medium Silt \\
\hline Poorly Sorted & Poorly Sorted & Poorly Sorted \\
\hline Fine Skewed & Fine Skewed & Fine Skewed \\
\hline Leptokurtic & Mesokurtic & Platykurtic \\
\hline 26.50 & 26.50 & 37.50 \\
\hline 5.259 & 5.259 & 4.759 \\
\hline 3.940 & 3.018 & 2.584 \\
\hline 24.43 & 18.36 & 16.90 \\
\hline 67.34 & 60.04 & 62.66 \\
\hline 17.09 & 19.89 & 24.25 \\
\hline 63.40 & 57.02 & 60.08 \\
\hline 3.556 & 4.815 & 6.752 \\
\hline 30.06 & 28.37 & 31.67 \\
\hline 3.892 & 4.058 & 3.996 \\
\hline 5.355 & 5.767 & 5.887 \\
\hline 7.987 & 8.372 & 8.596 \\
\hline 2.052 & 2.063 & 2.151 \\
\hline 4.095 & 4.314 & 4.600 \\
\hline 1.400 & 1.472 & 1.580 \\
\hline 1.830 & 2.268 & 2.755 \\
\hline $11.5 \%$ & $9.0 \%$ & $10.1 \%$ \\
\hline $88.5 \%$ & $91.0 \%$ & $89.9 \%$ \\
\hline $0.0 \%$ & $0.0 \%$ & $1.7 \%$ \\
\hline $0.0 \%$ & $0.0 \%$ & $0.8 \%$ \\
\hline $0.0 \%$ & $0.0 \%$ & $0.2 \%$ \\
\hline $1.1 \%$ & $0.7 \%$ & $0.1 \%$ \\
\hline $10.4 \%$ & $8.2 \%$ & $7.2 \%$ \\
\hline $26.6 \%$ & $20.7 \%$ & $20.8 \%$ \\
\hline $30.1 \%$ & $26.2 \%$ & $21.3 \%$ \\
\hline $13.7 \%$ & $18.2 \%$ & $15.3 \%$ \\
\hline $8.2 \%$ & $12.0 \%$ & $14.8 \%$ \\
\hline $6.3 \%$ & $8.9 \%$ & $11.6 \%$ \\
\hline $3.6 \%$ & $5.0 \%$ & $6.1 \%$ \\
\hline
\end{tabular}




\begin{tabular}{|c|c|c|}
\hline $\begin{array}{c}\text { 302-2-A-60-X-3 } \\
\text { Cristin Ashmankas }\end{array}$ & 302-2-A-60-X-4 & 302-2-A-61-X-1 \\
\hline Unimodal, Poorly Sorted & Bimodal, Poorly Sorted & Unimodal, Poorly Sorted \\
\hline Sandy Mud & Mud & Mud \\
\hline Very Fine Sandy Coarse Silt & Coarse Silt & Coarse Silt \\
\hline 40.03 & 48.15 & 42.98 \\
\hline 85.34 & 187.8 & 154.8 \\
\hline 7.565 & 7.278 & 8.027 \\
\hline 77.13 & 57.40 & 72.76 \\
\hline 17.66 & 14.09 & 13.83 \\
\hline 3.525 & 3.736 & 3.658 \\
\hline-0.087 & 0.280 & 0.299 \\
\hline 3.175 & 4.337 & 4.087 \\
\hline 5.823 & 6.111 & 6.162 \\
\hline 1.818 & 1.925 & 1.880 \\
\hline 0.087 & -0.367 & -0.334 \\
\hline 3.175 & 4.445 & 4.140 \\
\hline 17.36 & 13.58 & 13.39 \\
\hline 3.476 & 3.343 & 3.342 \\
\hline-0.137 & -0.310 & -0.176 \\
\hline 1.036 & 0.883 & 0.960 \\
\hline 5.848 & 6.202 & 6.223 \\
\hline 1.797 & 1.741 & 1.741 \\
\hline 0.137 & 0.310 & 0.176 \\
\hline 1.036 & 0.883 & 0.960 \\
\hline Coarse Silt & Medium Silt & Medium Silt \\
\hline Poorly Sorted & Poorly Sorted & Poorly Sorted \\
\hline Fine Skewed & Very Fine Skewed & Fine Skewed \\
\hline Mesokurtic & Platykurtic & Mesokurtic \\
\hline \multirow[t]{2}{*}{26.50} & 26.50 & 26.50 \\
\hline & 3.350 & \\
\hline \multirow[t]{2}{*}{5.259} & 5.259 & 5.259 \\
\hline & 8.241 & \\
\hline 3.163 & 2.314 & 2.550 \\
\hline 19.72 & 17.95 & 15.76 \\
\hline 79.15 & 52.15 & 54.33 \\
\hline 25.02 & 22.53 & 21.31 \\
\hline 75.98 & 49.83 & 51.78 \\
\hline 5.124 & 5.897 & 5.469 \\
\hline 32.00 & 27.21 & 25.54 \\
\hline 3.659 & 4.261 & 4.202 \\
\hline 5.664 & 5.800 & 5.988 \\
\hline 8.304 & 8.755 & 8.615 \\
\hline 2.269 & 2.055 & 2.050 \\
\hline 4.645 & 4.494 & 4.413 \\
\hline 1.507 & 1.519 & 1.490 \\
\hline 2.357 & 2.560 & 2.451 \\
\hline $13.6 \%$ & $6.0 \%$ & $7.4 \%$ \\
\hline $86.4 \%$ & $94.0 \%$ & $92.6 \%$ \\
\hline $0.1 \%$ & $1.9 \%$ & $1.1 \%$ \\
\hline $0.7 \%$ & $0.7 \%$ & $0.8 \%$ \\
\hline $0.9 \%$ & $0.0 \%$ & $0.3 \%$ \\
\hline $2.9 \%$ & $0.0 \%$ & $1.4 \%$ \\
\hline $8.9 \%$ & $3.5 \%$ & $3.8 \%$ \\
\hline $19.3 \%$ & $20.8 \%$ & $17.6 \%$ \\
\hline $25.1 \%$ & $28.3 \%$ & $25.3 \%$ \\
\hline $16.8 \%$ & $14.2 \%$ & $17.7 \%$ \\
\hline $12.2 \%$ & $12.0 \%$ & $15.1 \%$ \\
\hline $7.9 \%$ & $11.0 \%$ & $10.2 \%$ \\
\hline $5.0 \%$ & $7.6 \%$ & $6.8 \%$ \\
\hline
\end{tabular}




\begin{tabular}{|c|c|c|}
\hline $302-4-A-4-X-1$ & $302-2-A-61-X-1$ & 302-2-A-61-X-2 \\
\hline Cristin Ashmankas, & Cristin Ashmankas, & Cristin Ashmankas, \\
\hline Unimodal, Poorly Sorted & Unimodal, Poorly Sorted & Unimodal, Poorly Sorted \\
\hline Mud & Mud & Mud \\
\hline Coarse Silt & Coarse Silt & Coarse Silt \\
\hline 44.76 & 51.99 & 24.40 \\
\hline 172.0 & 185.6 & 16.82 \\
\hline 7.767 & 6.856 & 0.790 \\
\hline 65.89 & 53.15 & 3.426 \\
\hline 15.07 & 14.07 & 17.09 \\
\hline 3.351 & 3.953 & 2.626 \\
\hline 0.325 & 0.448 & -1.023 \\
\hline 4.988 & 4.111 & 3.503 \\
\hline 6.025 & 6.121 & 5.870 \\
\hline 1.761 & 2.000 & 1.393 \\
\hline-0.413 & -0.499 & 1.023 \\
\hline 5.095 & 4.168 & 3.503 \\
\hline 14.63 & 13.39 & 17.47 \\
\hline 2.996 & 3.605 & 2.629 \\
\hline-0.249 & -0.125 & -0.394 \\
\hline 1.019 & 1.007 & 1.157 \\
\hline 6.095 & 6.223 & 5.839 \\
\hline 1.583 & 1.850 & 1.394 \\
\hline 0.249 & 0.125 & 0.394 \\
\hline 1.019 & 1.007 & 1.157 \\
\hline Medium Silt & Medium Silt & Coarse Silt \\
\hline Poorly Sorted & Poorly Sorted & Poorly Sorted \\
\hline Fine Skewed & Fine Skewed & Very Fine Skewed \\
\hline Mesokurtic & Mesokurtic & Leptokurtic \\
\hline 26.50 & 26.50 & 26.50 \\
\hline 5.259 & 5.259 & 5.259 \\
\hline & & \\
\hline 2.955 & 2.463 & 3.739 \\
\hline 17.55 & 15.69 & 22.15 \\
\hline 50.79 & 57.36 & 46.89 \\
\hline 17.19 & 23.29 & 12.54 \\
\hline 47.84 & 54.89 & 43.15 \\
\hline 4.233 & 5.903 & 3.121 \\
\hline 23.97 & 27.08 & 23.12 \\
\hline 4.299 & 4.124 & 4.414 \\
\hline 5.832 & 5.994 & 5.497 \\
\hline 8.403 & 8.665 & 8.063 \\
\hline 1.954 & 2.101 & 1.827 \\
\hline 4.103 & 4.541 & 3.649 \\
\hline 1.417 & 1.519 & 1.337 \\
\hline 2.082 & 2.561 & 1.642 \\
\hline $5.7 \%$ & $8.3 \%$ & $2.4 \%$ \\
\hline $94.3 \%$ & $91.7 \%$ & $97.6 \%$ \\
\hline $1.5 \%$ & $1.7 \%$ & $0.0 \%$ \\
\hline $0.7 \%$ & $0.9 \%$ & $0.0 \%$ \\
\hline $0.0 \%$ & $0.8 \%$ & $0.0 \%$ \\
\hline $0.0 \%$ & $1.5 \%$ & $0.0 \%$ \\
\hline $3.4 \%$ & $3.4 \%$ & $2.4 \%$ \\
\hline $19.4 \%$ & $18.1 \%$ & $27.0 \%$ \\
\hline $29.7 \%$ & $23.7 \%$ & $36.4 \%$ \\
\hline $19.2 \%$ & $16.9 \%$ & $14.5 \%$ \\
\hline $11.9 \%$ & $15.4 \%$ & $9.2 \%$ \\
\hline $8.7 \%$ & $10.5 \%$ & $6.7 \%$ \\
\hline $5.4 \%$ & $7.1 \%$ & $3.8 \%$ \\
\hline
\end{tabular}




\begin{tabular}{|c|c|c|}
\hline 302-2-A-61-X-2 & $302-2-A-62-X-1$ & 302-4-A-5-X-1 \\
\hline Cristin Ashmankas, & Cristin Ashmankas, & Cristin Ashmankas, \\
\hline Unimodal, Poorly Sorted & Unimodal, Poorly Sorted & Unimodal, Poorly Sorted \\
\hline Sandy Mud & Mud & Mud \\
\hline Very Fine Sandy Coarse Silt & Coarse Silt & Coarse Silt \\
\hline 48.94 & 43.70 & 21.74 \\
\hline 110.9 & 135.0 & 16.87 \\
\hline 8.365 & 8.145 & 0.979 \\
\hline 95.71 & 79.13 & 3.734 \\
\hline 21.65 & 17.70 & 14.20 \\
\hline 3.433 & 3.271 & 2.844 \\
\hline-0.050 & 0.076 & -0.786 \\
\hline 3.412 & 4.485 & 2.885 \\
\hline 5.525 & 5.819 & 6.138 \\
\hline 1.781 & 1.710 & 1.508 \\
\hline 0.038 & -0.079 & 0.786 \\
\hline 3.425 & 4.489 & 2.885 \\
\hline 20.94 & 16.88 & 14.45 \\
\hline 3.355 & 2.936 & 2.903 \\
\hline-0.143 & -0.316 & -0.349 \\
\hline 1.123 & 1.078 & 0.980 \\
\hline 5.577 & 5.889 & 6.113 \\
\hline 1.746 & 1.554 & 1.537 \\
\hline 0.143 & 0.316 & 0.349 \\
\hline 1.123 & 1.078 & 0.980 \\
\hline Coarse Silt & Coarse Silt & Medium Silt \\
\hline Poorly Sorted & Poorly Sorted & Poorly Sorted \\
\hline Fine Skewed & Very Fine Skewed & Very Fine Skewed \\
\hline Leptokurtic & Mesokurtic & Mesokurtic \\
\hline 26.50 & 26.50 & 26.50 \\
\hline 5.259 & 5.259 & 5.259 \\
\hline 4.083 & 3.322 & 2.877 \\
\hline 24.33 & 21.28 & 18.44 \\
\hline 87.85 & 54.81 & 43.90 \\
\hline 21.52 & 16.50 & 15.26 \\
\hline 83.77 & 51.49 & 41.02 \\
\hline 4.577 & 3.916 & 4.200 \\
\hline 35.55 & 26.55 & 23.50 \\
\hline 3.509 & 4.189 & 4.510 \\
\hline 5.361 & 5.554 & 5.761 \\
\hline 7.936 & 8.234 & 8.441 \\
\hline 2.262 & 1.965 & 1.872 \\
\hline 4.427 & 4.045 & 3.931 \\
\hline 1.492 & 1.409 & 1.413 \\
\hline 2.194 & 1.969 & 2.070 \\
\hline $15.7 \%$ & $6.6 \%$ & $2.2 \%$ \\
\hline $84.3 \%$ & $93.4 \%$ & $97.8 \%$ \\
\hline $0.4 \%$ & $0.6 \%$ & $0.0 \%$ \\
\hline $0.6 \%$ & $1.2 \%$ & $0.0 \%$ \\
\hline $1.7 \%$ & $0.9 \%$ & $0.0 \%$ \\
\hline $3.8 \%$ & $0.2 \%$ & $0.0 \%$ \\
\hline $9.2 \%$ & $3.8 \%$ & $2.2 \%$ \\
\hline $24.2 \%$ & $24.3 \%$ & $22.2 \%$ \\
\hline $25.0 \%$ & $31.6 \%$ & $32.7 \%$ \\
\hline $14.9 \%$ & $15.3 \%$ & $16.8 \%$ \\
\hline $10.9 \%$ & $10.2 \%$ & $11.6 \%$ \\
\hline $6.1 \%$ & $7.4 \%$ & $8.7 \%$ \\
\hline $3.3 \%$ & $4.6 \%$ & $5.8 \%$ \\
\hline
\end{tabular}




\begin{tabular}{|c|c|c|}
\hline $\begin{array}{c}\text { 302-2-A-62-X-1 } \\
\text { Cristin Ashmankas }\end{array}$ & $\begin{array}{c}\text { 302-4-A-5-X-1 } \\
\text { Cristin Ashmankas }\end{array}$ & $\begin{array}{c}\text { 302-2-A-62-X-2 } \\
\text { Cristin Ashmankas }\end{array}$ \\
\hline Unimodal, Poorly Sorted & Unimodal, Poorly Sorted & Unimodal, Poorly Sorted \\
\hline Mud & Mud & Mud \\
\hline Coarse Silt & Coarse Silt & Coarse Silt \\
\hline 40.37 & 20.76 & 38.37 \\
\hline 140.1 & 21.32 & 151.6 \\
\hline 8.402 & 2.043 & 8.740 \\
\hline 82.35 & 9.360 & 83.81 \\
\hline 13.39 & 11.69 & 13.51 \\
\hline 3.624 & 3.205 & 3.274 \\
\hline 0.330 & -0.389 & 0.341 \\
\hline 3.992 & 2.447 & 4.804 \\
\hline 6.217 & 6.418 & 6.191 \\
\hline 1.861 & 1.680 & 1.724 \\
\hline-0.345 & 0.389 & -0.409 \\
\hline 4.019 & 2.447 & 4.915 \\
\hline 12.86 & 11.93 & 13.23 \\
\hline 3.354 & 3.267 & 2.977 \\
\hline-0.124 & -0.181 & -0.222 \\
\hline 0.992 & 0.866 & 0.954 \\
\hline 6.281 & 6.389 & 6.240 \\
\hline 1.746 & 1.708 & 1.574 \\
\hline 0.124 & 0.181 & 0.222 \\
\hline 0.992 & 0.866 & 0.954 \\
\hline Medium Silt & Medium Silt & Medium Silt \\
\hline Poorly Sorted & Poorly Sorted & Poorly Sorted \\
\hline Fine Skewed & Fine Skewed & Fine Skewed \\
\hline Mesokurtic & Platykurtic & Mesokurtic \\
\hline 26.50 & 26.50 & 26.50 \\
\hline 5.259 & 5.259 & 5.259 \\
\hline & & \\
\hline 2.508 & 2.239 & 2.800 \\
\hline 14.47 & 13.65 & 15.56 \\
\hline 54.15 & 47.65 & 45.44 \\
\hline 21.59 & 21.28 & 16.23 \\
\hline 51.64 & 45.41 & 42.64 \\
\hline 5.276 & 5.864 & 4.552 \\
\hline 24.11 & 24.21 & 22.41 \\
\hline 4.207 & 4.391 & 4.460 \\
\hline 6.111 & 6.195 & 6.006 \\
\hline 8.639 & 8.803 & 8.480 \\
\hline 2.054 & 2.005 & 1.902 \\
\hline 4.432 & 4.412 & 4.021 \\
\hline 1.473 & 1.501 & 1.427 \\
\hline 2.399 & 2.552 & 2.187 \\
\hline $7.6 \%$ & $4.6 \%$ & $4.6 \%$ \\
\hline $92.4 \%$ & $95.4 \%$ & $95.4 \%$ \\
\hline $0.8 \%$ & $0.0 \%$ & $1.1 \%$ \\
\hline $0.8 \%$ & $0.0 \%$ & $0.6 \%$ \\
\hline $0.6 \%$ & $0.0 \%$ & $0.1 \%$ \\
\hline $1.5 \%$ & $0.3 \%$ & $0.3 \%$ \\
\hline $3.9 \%$ & $4.3 \%$ & $2.4 \%$ \\
\hline $15.7 \%$ & $18.0 \%$ & $17.0 \%$ \\
\hline $24.4 \%$ & $23.8 \%$ & $28.3 \%$ \\
\hline $19.5 \%$ & $18.0 \%$ & $20.5 \%$ \\
\hline $15.5 \%$ & $16.0 \%$ & $14.2 \%$ \\
\hline $10.3 \%$ & $11.5 \%$ & $9.8 \%$ \\
\hline $6.9 \%$ & $8.1 \%$ & $5.7 \%$ \\
\hline
\end{tabular}




\begin{tabular}{|c|c|c|}
\hline $302-4-A-5-X-2$ & $302-4-A-5-X-2$ & $302-2-A-62-X-2$ \\
\hline Cristin Ashmankas, & Cristin Ashmankas, & Cristin Ashmankas, \\
\hline Unimodal, Poorly Sorted & Unimodal, Poorly Sorted & Unimodal, Poorly Sorted \\
\hline Mud & Mud & Mud \\
\hline Coarse Silt & Coarse Silt & Coarse Silt \\
\hline 21.65 & 34.63 & 46.33 \\
\hline 17.35 & 112.6 & 140.1 \\
\hline 0.989 & 10.04 & 6.742 \\
\hline 3.652 & 118.8 & 57.15 \\
\hline 13.80 & 13.33 & 15.42 \\
\hline 2.914 & 3.568 & 3.624 \\
\hline-0.694 & 0.034 & 0.376 \\
\hline 2.647 & 3.533 & 4.153 \\
\hline 6.180 & 6.229 & 6.019 \\
\hline 1.543 & 1.835 & 1.858 \\
\hline 0.694 & -0.034 & -0.376 \\
\hline 2.647 & 3.533 & 4.153 \\
\hline 14.05 & 13.12 & 14.25 \\
\hline 2.987 & 3.403 & 3.218 \\
\hline-0.338 & -0.188 & -0.230 \\
\hline 0.914 & 0.936 & 1.031 \\
\hline 6.153 & 6.252 & 6.133 \\
\hline 1.579 & 1.767 & 1.686 \\
\hline 0.338 & 0.188 & 0.230 \\
\hline 0.914 & 0.936 & 1.031 \\
\hline Medium Silt & Medium Silt & Medium Silt \\
\hline Poorly Sorted & Poorly Sorted & Poorly Sorted \\
\hline Very Fine Skewed & Fine Skewed & Fine Skewed \\
\hline Mesokurtic & Mesokurtic & Mesokurtic \\
\hline 26.50 & 26.50 & 26.50 \\
\hline 5.259 & 5.259 & 5.259 \\
\hline 2.730 & 2.344 & 2.791 \\
\hline 18.02 & 15.40 & 17.69 \\
\hline 44.99 & 54.90 & 52.00 \\
\hline 16.48 & 23.42 & 18.63 \\
\hline 42.26 & 52.55 & 49.21 \\
\hline 4.746 & 5.701 & 4.738 \\
\hline 24.62 & 26.11 & 24.81 \\
\hline 4.474 & 4.187 & 4.265 \\
\hline 5.794 & 6.021 & 5.821 \\
\hline 8.517 & 8.737 & 8.485 \\
\hline 1.904 & 2.087 & 1.989 \\
\hline 4.043 & 4.549 & 4.220 \\
\hline 1.449 & 1.504 & 1.450 \\
\hline 2.247 & 2.511 & 2.244 \\
\hline $2.4 \%$ & $7.3 \%$ & $6.7 \%$ \\
\hline $97.6 \%$ & $92.7 \%$ & $93.3 \%$ \\
\hline $0.0 \%$ & $0.5 \%$ & $0.5 \%$ \\
\hline $0.0 \%$ & $0.6 \%$ & $1.6 \%$ \\
\hline $0.0 \%$ & $0.4 \%$ & $1.8 \%$ \\
\hline $0.0 \%$ & $0.8 \%$ & $0.9 \%$ \\
\hline $2.4 \%$ & $5.1 \%$ & $1.9 \%$ \\
\hline $22.5 \%$ & $18.1 \%$ & $18.5 \%$ \\
\hline $30.7 \%$ & $24.2 \%$ & $29.8 \%$ \\
\hline $16.2 \%$ & $17.9 \%$ & $16.9 \%$ \\
\hline $12.5 \%$ & $14.6 \%$ & $12.7 \%$ \\
\hline $9.6 \%$ & $10.2 \%$ & $9.5 \%$ \\
\hline $6.1 \%$ & $7.7 \%$ & $5.9 \%$ \\
\hline
\end{tabular}




\begin{tabular}{|c|c|c|}
\hline 302-2-A-62-X-3 & $\begin{array}{c}\text { 302-2-A-62-X-3 } \\
\text { Cristin Ashmankas }\end{array}$ & $\begin{array}{c}\text { 302-4-A-6-X-1 } \\
\text { Cristin Ashmankas }\end{array}$ \\
\hline Cristin Ashmankas, & Cristin Ashmankas, & Cristin Ashmankas, \\
\hline Unimodal, Poorly Sorted & Unimodal, Poorly Sorted & Unimodal, Poorly Sorted \\
\hline Mud & Mud & Mud \\
\hline Coarse Silt & Coarse Silt & Coarse Silt \\
\hline 52.67 & 52.10 & 23.56 \\
\hline 167.0 & 197.9 & 18.35 \\
\hline 7.060 & 6.687 & 1.069 \\
\hline 58.36 & 49.28 & 4.283 \\
\hline 18.62 & 14.35 & 15.36 \\
\hline 3.442 & 3.692 & 2.861 \\
\hline 0.287 & 0.488 & -0.811 \\
\hline 4.640 & 4.862 & 2.931 \\
\hline 5.729 & 6.089 & 6.025 \\
\hline 1.791 & 1.905 & 1.516 \\
\hline-0.337 & -0.561 & 0.811 \\
\hline 4.683 & 4.925 & 2.931 \\
\hline 17.51 & 13.70 & 15.54 \\
\hline 2.981 & 3.114 & 2.907 \\
\hline-0.266 & -0.282 & -0.369 \\
\hline 1.132 & 0.942 & 0.990 \\
\hline 5.836 & 6.190 & 6.008 \\
\hline 1.576 & 1.639 & 1.540 \\
\hline 0.266 & 0.282 & 0.369 \\
\hline 1.132 & 0.942 & 0.990 \\
\hline Coarse Silt & Medium Silt & Medium Silt \\
\hline Poorly Sorted & Poorly Sorted & Poorly Sorted \\
\hline Fine Skewed & Fine Skewed & Very Fine Skewed \\
\hline Leptokurtic & Mesokurtic & Mesokurtic \\
\hline 26.50 & 26.50 & 26.50 \\
\hline 5.259 & 5.259 & 5.259 \\
\hline & & \\
\hline 3.533 & 2.611 & 3.027 \\
\hline 21.55 & 17.11 & 20.16 \\
\hline 57.86 & 47.90 & 48.24 \\
\hline 16.37 & 18.34 & 15.94 \\
\hline 54.32 & 45.29 & 45.22 \\
\hline 3.839 & 4.950 & 4.155 \\
\hline 26.96 & 24.50 & 25.35 \\
\hline 4.111 & 4.384 & 4.374 \\
\hline 5.536 & 5.869 & 5.632 \\
\hline 8.145 & 8.581 & 8.368 \\
\hline 1.981 & 1.957 & 1.913 \\
\hline 4.033 & 4.197 & 3.994 \\
\hline 1.406 & 1.459 & 1.419 \\
\hline 1.941 & 2.307 & 2.055 \\
\hline $8.1 \%$ & $5.2 \%$ & $3.4 \%$ \\
\hline $91.9 \%$ & $94.8 \%$ & $96.6 \%$ \\
\hline $1.2 \%$ & $2.0 \%$ & $0.0 \%$ \\
\hline $1.1 \%$ & $0.9 \%$ & $0.0 \%$ \\
\hline $1.4 \%$ & $0.4 \%$ & $0.0 \%$ \\
\hline $0.8 \%$ & $0.6 \%$ & $0.0 \%$ \\
\hline $3.5 \%$ & $1.4 \%$ & $3.4 \%$ \\
\hline $23.6 \%$ & $19.0 \%$ & $24.6 \%$ \\
\hline $31.4 \%$ & $29.2 \%$ & $32.4 \%$ \\
\hline $15.5 \%$ & $16.9 \%$ & $15.1 \%$ \\
\hline $10.2 \%$ & $13.4 \%$ & $11.0 \%$ \\
\hline $7.1 \%$ & $9.7 \%$ & $8.2 \%$ \\
\hline $4.2 \%$ & $6.6 \%$ & $5.3 \%$ \\
\hline
\end{tabular}




\begin{tabular}{|c|c|c|}
\hline 302-4-A-6-X-2 & 302-4-A-6-X-2 & 302-4-A-6-X-3 \\
\hline Cristin Ashmankas, & Cristin Ashmankas, & Cristin Ashmankas, \\
\hline Unimodal, Poorly Sorted & Bimodal, Poorly Sorted & Unimodal, Poorly Sorted \\
\hline Mud & Mud & Mud \\
\hline Coarse Silt & Coarse Silt & Coarse Silt \\
\hline 37.51 & 41.90 & 26.95 \\
\hline 140.5 & 160.1 & 20.56 \\
\hline 9.376 & 8.411 & 1.276 \\
\hline 96.66 & 76.83 & 5.226 \\
\hline 13.95 & 14.83 & 18.45 \\
\hline 3.401 & 3.442 & 2.653 \\
\hline 0.138 & 0.107 & -0.889 \\
\hline 3.985 & 4.326 & 3.480 \\
\hline 6.148 & 6.053 & 5.760 \\
\hline 1.776 & 1.797 & 1.408 \\
\hline-0.188 & -0.178 & 0.889 \\
\hline 4.076 & 4.434 & 3.480 \\
\hline 13.75 & 14.48 & 19.04 \\
\hline 3.195 & 3.134 & 2.626 \\
\hline-0.248 & -0.350 & -0.310 \\
\hline 0.876 & 0.882 & 1.116 \\
\hline 6.184 & 6.110 & 5.714 \\
\hline 1.676 & 1.648 & 1.393 \\
\hline 0.248 & 0.350 & 0.310 \\
\hline 0.876 & 0.882 & 1.116 \\
\hline Medium Silt & Medium Silt & Coarse Silt \\
\hline Poorly Sorted & Poorly Sorted & Poorly Sorted \\
\hline Fine Skewed & Very Fine Skewed & Very Fine Skewed \\
\hline Platykurtic & Platykurtic & Leptokurtic \\
\hline \multirow[t]{2}{*}{26.50} & 26.50 & 26.50 \\
\hline & 4.700 & \\
\hline \multirow[t]{2}{*}{5.259} & 5.259 & 5.259 \\
\hline & 7.754 & \\
\hline 2.610 & 2.618 & 4.303 \\
\hline 16.84 & 19.14 & 22.65 \\
\hline 52.27 & 50.61 & 54.57 \\
\hline 20.03 & 19.33 & 12.68 \\
\hline 49.66 & 47.99 & 50.26 \\
\hline 5.580 & 5.327 & 3.310 \\
\hline 26.68 & 27.46 & 25.80 \\
\hline 4.258 & 4.305 & 4.196 \\
\hline 5.892 & 5.707 & 5.464 \\
\hline 8.582 & 8.577 & 7.860 \\
\hline 2.016 & 1.993 & 1.873 \\
\hline 4.324 & 4.273 & 3.665 \\
\hline 1.502 & 1.494 & 1.363 \\
\hline 2.480 & 2.413 & 1.727 \\
\hline $5.9 \%$ & $4.7 \%$ & $5.8 \%$ \\
\hline $94.1 \%$ & $95.3 \%$ & $94.2 \%$ \\
\hline $1.0 \%$ & $1.3 \%$ & $0.0 \%$ \\
\hline $0.5 \%$ & $0.6 \%$ & $0.0 \%$ \\
\hline $0.1 \%$ & $0.0 \%$ & $0.0 \%$ \\
\hline $0.0 \%$ & $0.0 \%$ & $0.1 \%$ \\
\hline $4.3 \%$ & $2.8 \%$ & $5.8 \%$ \\
\hline $20.6 \%$ & $23.7 \%$ & $27.3 \%$ \\
\hline $26.2 \%$ & $28.8 \%$ & $32.6 \%$ \\
\hline $16.3 \%$ & $14.1 \%$ & $16.2 \%$ \\
\hline $14.1 \%$ & $12.3 \%$ & $9.2 \%$ \\
\hline $10.7 \%$ & $10.0 \%$ & $5.6 \%$ \\
\hline $6.2 \%$ & $6.4 \%$ & $3.3 \%$ \\
\hline
\end{tabular}




\begin{tabular}{|c|c|c|}
\hline 302-4-A-6-X-3 & 302-4-A-6-X-4 & 302-4-A-6-X-4 \\
\hline Cristin Ashmankas, & Cristin Ashmankas, & Cristin Ashmankas, \\
\hline Unimodal, Poorly Sorted & Unimodal, Poorly Sorted & Unimodal, Poorly Sorted \\
\hline Mud & Mud & Mud \\
\hline Coarse Silt & Coarse Silt & Coarse Silt \\
\hline 33.24 & 33.58 & 27.40 \\
\hline 125.8 & 111.9 & 29.72 \\
\hline 10.54 & 10.91 & 13.29 \\
\hline 121.0 & 134.0 & 489.1 \\
\hline 13.84 & 14.60 & 17.00 \\
\hline 3.179 & 3.243 & 2.904 \\
\hline 0.012 & -0.023 & -0.600 \\
\hline 4.146 & 3.649 & 2.999 \\
\hline 6.166 & 6.097 & 5.879 \\
\hline 1.675 & 1.697 & 1.538 \\
\hline-0.052 & 0.023 & 0.600 \\
\hline 4.224 & 3.649 & 2.999 \\
\hline 13.77 & 14.48 & 17.46 \\
\hline 3.012 & 3.115 & 2.931 \\
\hline-0.297 & -0.238 & -0.227 \\
\hline 0.887 & 0.875 & 1.000 \\
\hline 6.182 & 6.109 & 5.840 \\
\hline 1.591 & 1.639 & 1.551 \\
\hline 0.297 & 0.238 & 0.227 \\
\hline 0.887 & 0.875 & 1.000 \\
\hline Medium Silt & Medium Silt & Coarse Silt \\
\hline Poorly Sorted & Poorly Sorted & Poorly Sorted \\
\hline Fine Skewed & Fine Skewed & Fine Skewed \\
\hline Platykurtic & Platykurtic & Mesokurtic \\
\hline 26.50 & 26.50 & 26.50 \\
\hline 5.259 & 5.259 & 5.259 \\
\hline & & \\
\hline 2.757 & 2.867 & 3.682 \\
\hline 17.25 & 17.41 & 20.25 \\
\hline 46.18 & 53.74 & 58.79 \\
\hline 16.75 & 18.74 & 15.97 \\
\hline 43.43 & 50.87 & 55.11 \\
\hline 5.017 & 5.403 & 4.278 \\
\hline 24.72 & 27.71 & 28.46 \\
\hline 4.437 & 4.218 & 4.088 \\
\hline 5.857 & 5.844 & 5.626 \\
\hline 8.503 & 8.446 & 8.085 \\
\hline 1.917 & 2.002 & 1.978 \\
\hline 4.066 & 4.228 & 3.997 \\
\hline 1.464 & 1.499 & 1.441 \\
\hline 2.327 & 2.434 & 2.097 \\
\hline $3.6 \%$ & $6.1 \%$ & $8.3 \%$ \\
\hline $96.4 \%$ & $93.9 \%$ & $91.7 \%$ \\
\hline $0.8 \%$ & $0.5 \%$ & $0.0 \%$ \\
\hline $0.4 \%$ & $0.4 \%$ & $0.0 \%$ \\
\hline $0.0 \%$ & $0.1 \%$ & $0.0 \%$ \\
\hline $0.0 \%$ & $0.0 \%$ & $0.5 \%$ \\
\hline $2.5 \%$ & $5.0 \%$ & $7.7 \%$ \\
\hline $20.9 \%$ & $22.1 \%$ & $23.6 \%$ \\
\hline $29.3 \%$ & $25.3 \%$ & $27.6 \%$ \\
\hline $16.4 \%$ & $16.8 \%$ & $17.9 \%$ \\
\hline $13.8 \%$ & $14.4 \%$ & $11.9 \%$ \\
\hline $10.2 \%$ & $9.9 \%$ & $6.7 \%$ \\
\hline $5.8 \%$ & $5.4 \%$ & $4.0 \%$ \\
\hline
\end{tabular}




\begin{tabular}{|c|c|c|}
\hline 302-4-A-6-X-5 & 302-4-A-7-X-1 & 302-4-A-7-X-1 \\
\hline Cristin Ashmankas, & Cristin Ashmankas, & Cristin Ashmankas, \\
\hline Unimodal, Poorly Sorted & Bimodal, Poorly Sorted & Unimodal, Poorly Sorted \\
\hline Mud & Mud & Sandy Mud \\
\hline Coarse Silt & Coarse Silt & very rille-3aniquy very \\
\hline 53.56 & 20.54 & 32.97 \\
\hline 199.4 & 15.57 & 25.95 \\
\hline 6.588 & 0.896 & 1.307 \\
\hline 47.79 & 3.613 & 5.145 \\
\hline 15.33 & 13.52 & 21.96 \\
\hline 3.598 & 2.821 & 2.779 \\
\hline 0.537 & -0.793 & -0.925 \\
\hline 4.928 & 2.823 & 3.559 \\
\hline 5.992 & 6.208 & 5.509 \\
\hline 1.867 & 1.496 & 1.475 \\
\hline-0.618 & 0.793 & 0.925 \\
\hline 4.992 & 2.823 & 3.559 \\
\hline 14.68 & 13.75 & 22.82 \\
\hline 3.120 & 2.877 & 2.755 \\
\hline-0.187 & -0.375 & -0.292 \\
\hline 0.982 & 0.943 & 1.164 \\
\hline 6.090 & 6.184 & 5.453 \\
\hline 1.642 & 1.525 & 1.462 \\
\hline 0.187 & 0.375 & 0.292 \\
\hline 0.982 & 0.943 & 1.164 \\
\hline Medium Silt & Medium Silt & Coarse Silt \\
\hline Poorly Sorted & Poorly Sorted & Poorly Sorted \\
\hline Fine Skewed & Very Fine Skewed & Fine Skewed \\
\hline Mesokurtic & Mesokurtic & Leptokurtic \\
\hline \multirow[t]{2}{*}{26.50} & 26.50 & 37.50 \\
\hline & 4.700 & \\
\hline \multirow[t]{2}{*}{5.259} & 5.259 & 4.759 \\
\hline & 7.754 & \\
\hline 2.991 & 2.771 & 4.664 \\
\hline 17.13 & 17.94 & 26.87 \\
\hline 55.35 & 41.47 & 67.69 \\
\hline 18.50 & 14.96 & 14.52 \\
\hline 52.36 & 38.70 & 63.03 \\
\hline 4.767 & 4.326 & 3.358 \\
\hline 25.88 & 22.59 & 31.39 \\
\hline 4.175 & 4.592 & 3.885 \\
\hline 5.868 & 5.801 & 5.218 \\
\hline 8.385 & 8.495 & 7.744 \\
\hline 2.008 & 1.850 & 1.993 \\
\hline 4.210 & 3.903 & 3.859 \\
\hline 1.457 & 1.415 & 1.390 \\
\hline 2.253 & 2.113 & 1.747 \\
\hline $7.4 \%$ & $1.1 \%$ & $11.9 \%$ \\
\hline $92.6 \%$ & $98.9 \%$ & $88.1 \%$ \\
\hline $2.0 \%$ & $0.0 \%$ & $0.0 \%$ \\
\hline $1.0 \%$ & $0.0 \%$ & $0.0 \%$ \\
\hline $0.0 \%$ & $0.0 \%$ & $0.0 \%$ \\
\hline $0.1 \%$ & $0.0 \%$ & $0.5 \%$ \\
\hline $4.3 \%$ & $1.1 \%$ & $11.5 \%$ \\
\hline $19.2 \%$ & $20.6 \%$ & $30.8 \%$ \\
\hline $26.8 \%$ & $34.5 \%$ & $28.8 \%$ \\
\hline $18.9 \%$ & $16.3 \%$ & $12.5 \%$ \\
\hline $13.6 \%$ & $12.0 \%$ & $7.8 \%$ \\
\hline $8.9 \%$ & $9.4 \%$ & $5.1 \%$ \\
\hline $5.2 \%$ & $6.0 \%$ & $3.0 \%$ \\
\hline
\end{tabular}




\begin{tabular}{|c|c|c|}
\hline $302-4-A-7-X-2$ & 302-4-A-7-X-2 & $302-4-A-7-X-3$ \\
\hline Cristin Ashmankas, & Cristin Ashmankas, & Cristin Ashmankas, \\
\hline Unimodal, Poorly Sorted & Bimodal, Poorly Sorted & Unimodal, Poorly Sorted \\
\hline Mud & Mud & Sandy Mud \\
\hline Coarse Silt & Coarse Silt & Very Fine Sandy Coarse Silt \\
\hline 25.94 & 20.99 & 42.51 \\
\hline 27.47 & 15.31 & 112.0 \\
\hline 1.851 & 0.775 & 8.822 \\
\hline 7.081 & 3.288 & 96.36 \\
\hline 14.01 & 14.06 & 18.55 \\
\hline 3.331 & 2.776 & 3.354 \\
\hline-0.309 & -0.854 & -0.028 \\
\hline 2.264 & 2.910 & 3.624 \\
\hline 6.158 & 6.152 & 5.751 \\
\hline 1.736 & 1.473 & 1.746 \\
\hline 0.309 & 0.854 & 0.025 \\
\hline 2.264 & 2.910 & 3.628 \\
\hline 14.19 & 14.20 & 18.35 \\
\hline 3.462 & 2.835 & 3.217 \\
\hline-0.169 & -0.393 & -0.166 \\
\hline 0.850 & 0.978 & 1.019 \\
\hline 6.139 & 6.138 & 5.768 \\
\hline 1.792 & 1.503 & 1.686 \\
\hline 0.169 & 0.393 & 0.166 \\
\hline 0.850 & 0.978 & 1.019 \\
\hline Medium Silt & Medium Silt & Coarse Silt \\
\hline Poorly Sorted & Poorly Sorted & Poorly Sorted \\
\hline Fine Skewed & Very Fine Skewed & Fine Skewed \\
\hline Platykurtic & Mesokurtic & Mesokurtic \\
\hline \multirow[t]{2}{*}{26.50} & 26.50 & 26.50 \\
\hline & 4.700 & \\
\hline \multirow[t]{2}{*}{5.259} & 5.259 & 5.259 \\
\hline & 7.754 & \\
\hline 2.537 & 2.861 & 3.545 \\
\hline 16.41 & 18.68 & 20.85 \\
\hline 61.36 & 41.65 & 72.86 \\
\hline 24.19 & 14.56 & 20.55 \\
\hline 58.83 & 38.79 & 69.31 \\
\hline 6.525 & 4.021 & 4.724 \\
\hline 30.68 & 22.50 & 32.08 \\
\hline 4.026 & 4.586 & 3.779 \\
\hline 5.929 & 5.742 & 5.584 \\
\hline 8.623 & 8.449 & 8.140 \\
\hline 2.142 & 1.843 & 2.154 \\
\hline 4.596 & 3.864 & 4.361 \\
\hline 1.565 & 1.397 & 1.485 \\
\hline 2.706 & 2.008 & 2.240 \\
\hline $9.5 \%$ & $0.9 \%$ & $12.7 \%$ \\
\hline $90.5 \%$ & $99.1 \%$ & $87.3 \%$ \\
\hline $0.0 \%$ & $0.0 \%$ & $0.4 \%$ \\
\hline $0.0 \%$ & $0.0 \%$ & $0.9 \%$ \\
\hline $0.0 \%$ & $0.0 \%$ & $0.5 \%$ \\
\hline $0.9 \%$ & $0.0 \%$ & $1.4 \%$ \\
\hline $8.6 \%$ & $0.9 \%$ & $9.5 \%$ \\
\hline $20.3 \%$ & $21.8 \%$ & $21.8 \%$ \\
\hline $21.5 \%$ & $35.6 \%$ & $25.4 \%$ \\
\hline $16.2 \%$ & $16.0 \%$ & $17.3 \%$ \\
\hline $14.7 \%$ & $11.0 \%$ & $11.6 \%$ \\
\hline $11.2 \%$ & $9.2 \%$ & $7.1 \%$ \\
\hline $6.4 \%$ & $5.6 \%$ & $4.1 \%$ \\
\hline
\end{tabular}




\begin{tabular}{|c|c|c|}
\hline 302-4-A-7-X-3 & $302-4-A-7-X-4$ & 302-4-A-7-X-4 \\
\hline Cristin Ashmankas, & Cristin Ashmankas, & Cristin Ashmankas, \\
\hline Unimodal, Poorly Sorted & Unimodal, Poorly Sorted & Unimodal, Poorly Sorted \\
\hline Sandy Mud & Mud & Mud \\
\hline Very Fine Sandy Coarse Silt & Coarse Silt & Coarse Silt \\
\hline 44.36 & 34.39 & 43.68 \\
\hline 139.1 & 102.6 & 165.8 \\
\hline 9.133 & 10.56 & 8.108 \\
\hline 94.01 & 133.2 & 71.80 \\
\hline 17.89 & 14.93 & 14.63 \\
\hline 3.485 & 3.355 & 3.508 \\
\hline-0.067 & -0.076 & 0.239 \\
\hline 3.678 & 3.556 & 4.327 \\
\hline 5.796 & 6.066 & 6.067 \\
\hline 1.805 & 1.747 & 1.827 \\
\hline 0.041 & 0.076 & -0.317 \\
\hline 3.717 & 3.556 & 4.439 \\
\hline 17.50 & 14.64 & 14.23 \\
\hline 3.374 & 3.240 & 3.226 \\
\hline-0.240 & -0.222 & -0.239 \\
\hline 1.009 & 0.969 & 0.943 \\
\hline 5.836 & 6.094 & 6.135 \\
\hline 1.755 & 1.696 & 1.690 \\
\hline 0.240 & 0.222 & 0.239 \\
\hline 1.009 & 0.969 & 0.943 \\
\hline Coarse Silt & Medium Silt & Medium Silt \\
\hline Poorly Sorted & Poorly Sorted & Poorly Sorted \\
\hline Fine Skewed & Fine Skewed & Fine Skewed \\
\hline Mesokurtic & Mesokurtic & Mesokurtic \\
\hline 26.50 & 26.50 & 26.50 \\
\hline 5.259 & 5.259 & 5.259 \\
\hline 3.026 & 2.773 & 2.667 \\
\hline 21.52 & 17.58 & 17.40 \\
\hline 70.74 & 56.91 & 54.54 \\
\hline 23.37 & 20.53 & 20.45 \\
\hline 67.71 & 54.14 & 51.87 \\
\hline 4.973 & 5.081 & 5.183 \\
\hline 32.26 & 27.15 & 26.64 \\
\hline 3.821 & 4.135 & 4.196 \\
\hline 5.538 & 5.830 & 5.845 \\
\hline 8.368 & 8.495 & 8.550 \\
\hline 2.190 & 2.054 & 2.038 \\
\hline 4.547 & 4.359 & 4.354 \\
\hline 1.500 & 1.480 & 1.482 \\
\hline 2.314 & 2.345 & 2.374 \\
\hline $12.2 \%$ & $7.9 \%$ & $7.0 \%$ \\
\hline $87.8 \%$ & $92.1 \%$ & $93.0 \%$ \\
\hline $0.9 \%$ & $0.3 \%$ & $1.4 \%$ \\
\hline $0.6 \%$ & $0.7 \%$ & $0.6 \%$ \\
\hline $0.0 \%$ & $0.1 \%$ & $0.0 \%$ \\
\hline $1.2 \%$ & $0.8 \%$ & $0.2 \%$ \\
\hline $9.5 \%$ & $6.0 \%$ & $4.7 \%$ \\
\hline $22.5 \%$ & $19.9 \%$ & $20.0 \%$ \\
\hline $26.3 \%$ & $26.5 \%$ & $27.0 \%$ \\
\hline $14.6 \%$ & $17.6 \%$ & $17.2 \%$ \\
\hline $10.7 \%$ & $12.9 \%$ & $12.9 \%$ \\
\hline $8.4 \%$ & $9.1 \%$ & $9.8 \%$ \\
\hline $5.2 \%$ & $6.1 \%$ & $6.2 \%$ \\
\hline
\end{tabular}




\begin{tabular}{|c|c|c|}
\hline 302-4-A-8-X-1 & 302-4-A-9-X-1 & $302-4-A-10-X-1$ \\
\hline Cristin Ashmankas, & Cristin Ashmankas, & Cristin Ashmankas, \\
\hline Unimodal, Poorly Sorted & Unimodal, Poorly Sorted & Bimodal, Poorly Sorted \\
\hline Mud & Mud & Mud \\
\hline Coarse Silt & Coarse Silt & Coarse Silt \\
\hline 31.81 & 25.82 & 15.95 \\
\hline 73.45 & 23.59 & 13.78 \\
\hline 9.869 & 2.521 & 1.136 \\
\hline 122.2 & 13.82 & 4.098 \\
\hline 14.83 & 16.71 & 9.809 \\
\hline 3.384 & 2.785 & 2.957 \\
\hline-0.147 & -0.695 & -0.482 \\
\hline 3.106 & 3.161 & 2.346 \\
\hline 6.075 & 5.903 & 6.672 \\
\hline 1.759 & 1.478 & 1.564 \\
\hline 0.147 & 0.695 & 0.482 \\
\hline 3.106 & 3.161 & 2.346 \\
\hline 14.80 & 16.65 & 10.11 \\
\hline 3.332 & 2.793 & 2.989 \\
\hline-0.177 & -0.312 & -0.247 \\
\hline 0.937 & 1.089 & 0.815 \\
\hline 6.078 & 5.909 & 6.628 \\
\hline 1.737 & 1.482 & 1.580 \\
\hline 0.177 & 0.312 & 0.247 \\
\hline 0.937 & 1.089 & 0.815 \\
\hline Medium Silt & Coarse Silt & Medium Silt \\
\hline Poorly Sorted & Poorly Sorted & Poorly Sorted \\
\hline Fine Skewed & Very Fine Skewed & Fine Skewed \\
\hline Mesokurtic & Mesokurtic & Platykurtic \\
\hline \multirow[t]{2}{*}{26.50} & 26.50 & 26.50 \\
\hline & & 4.700 \\
\hline \multirow{2}{*}{5.259} & 5.259 & 5.259 \\
\hline & & 7.754 \\
\hline 2.816 & 3.543 & 2.061 \\
\hline 17.15 & 20.64 & 12.07 \\
\hline 60.68 & 51.72 & 35.41 \\
\hline 21.55 & 14.60 & 17.18 \\
\hline 57.87 & 48.18 & 33.35 \\
\hline 5.529 & 3.593 & 5.563 \\
\hline 28.65 & 24.32 & 19.53 \\
\hline 4.043 & 4.273 & 4.820 \\
\hline 5.866 & 5.599 & 6.373 \\
\hline 8.472 & 8.141 & 8.922 \\
\hline 2.096 & 1.905 & 1.851 \\
\hline 4.430 & 3.868 & 4.102 \\
\hline 1.510 & 1.377 & 1.459 \\
\hline 2.467 & 1.845 & 2.476 \\
\hline $9.3 \%$ & $5.7 \%$ & $0.4 \%$ \\
\hline $90.7 \%$ & $94.3 \%$ & $99.6 \%$ \\
\hline $0.1 \%$ & $0.0 \%$ & $0.0 \%$ \\
\hline $0.6 \%$ & $0.0 \%$ & $0.0 \%$ \\
\hline $0.2 \%$ & $0.0 \%$ & $0.0 \%$ \\
\hline $1.2 \%$ & $0.8 \%$ & $0.0 \%$ \\
\hline $7.3 \%$ & $5.0 \%$ & $0.4 \%$ \\
\hline $19.4 \%$ & $22.5 \%$ & $13.1 \%$ \\
\hline $24.3 \%$ & $34.3 \%$ & $28.9 \%$ \\
\hline $17.4 \%$ & $15.7 \%$ & $18.3 \%$ \\
\hline $14.3 \%$ & $10.5 \%$ & $16.6 \%$ \\
\hline $9.3 \%$ & $7.4 \%$ & $13.7 \%$ \\
\hline $6.0 \%$ & $3.9 \%$ & $9.1 \%$ \\
\hline
\end{tabular}




\begin{tabular}{|c|c|c|}
\hline $302-4-A-10-X-1$ & $302-4-A-10-X-2$ & $302-4-A-10-X-2$ \\
\hline Cristin Ashmankas, & Cristin Ashmankas, & Cristin Ashmankas, \\
\hline Bimodal, Poorly Sorted & Bimodal, Poorly Sorted & Unimodal, Poorly Sorted \\
\hline Mud & Mud & Mud \\
\hline Coarse Silt & Coarse Silt & Coarse Silt \\
\hline 42.63 & 48.73 & 43.56 \\
\hline 172.8 & 190.6 & 167.3 \\
\hline 7.798 & 7.024 & 8.025 \\
\hline 66.06 & 53.91 & 70.41 \\
\hline 13.52 & 13.79 & 14.35 \\
\hline 3.407 & 3.657 & 3.443 \\
\hline 0.367 & 0.438 & 0.373 \\
\hline 4.975 & 4.724 & 4.524 \\
\hline 6.180 & 6.144 & 6.095 \\
\hline 1.788 & 1.894 & 1.801 \\
\hline-0.455 & -0.522 & -0.453 \\
\hline 5.094 & 4.815 & 4.637 \\
\hline 13.08 & 13.09 & 13.93 \\
\hline 3.040 & 3.215 & 3.152 \\
\hline-0.310 & -0.298 & -0.194 \\
\hline 0.921 & 0.924 & 0.952 \\
\hline 6.257 & 6.255 & 6.165 \\
\hline 1.604 & 1.685 & 1.656 \\
\hline 0.310 & 0.298 & 0.194 \\
\hline 0.921 & 0.924 & 0.952 \\
\hline Medium Silt & Medium Silt & Medium Silt \\
\hline Poorly Sorted & Poorly Sorted & Poorly Sorted \\
\hline Very Fine Skewed & Fine Skewed & Fine Skewed \\
\hline Mesokurtic & Mesokurtic & Mesokurtic \\
\hline 26.50 & 26.50 & 26.50 \\
\hline 4.700 & 3.350 & \\
\hline 5.259 & 5.259 & 5.259 \\
\hline 7.754 & 8.241 & \\
\hline 2.561 & 2.428 & 2.847 \\
\hline 16.76 & 17.18 & 16.54 \\
\hline 43.36 & 46.41 & 53.62 \\
\hline 16.93 & 19.11 & 18.84 \\
\hline 40.80 & 43.98 & 50.78 \\
\hline 4.846 & 5.308 & 4.988 \\
\hline 22.93 & 24.00 & 24.80 \\
\hline 4.528 & 4.430 & 4.221 \\
\hline 5.899 & 5.863 & 5.918 \\
\hline 8.609 & 8.686 & 8.457 \\
\hline 1.901 & 1.961 & 2.003 \\
\hline 4.081 & 4.256 & 4.236 \\
\hline 1.445 & 1.474 & 1.463 \\
\hline 2.277 & 2.408 & 2.318 \\
\hline $3.9 \%$ & $5.6 \%$ & $7.1 \%$ \\
\hline $96.1 \%$ & $94.4 \%$ & $92.9 \%$ \\
\hline $1.6 \%$ & $1.9 \%$ & $1.4 \%$ \\
\hline $0.7 \%$ & $0.8 \%$ & $0.6 \%$ \\
\hline $0.0 \%$ & $0.0 \%$ & $0.0 \%$ \\
\hline $0.0 \%$ & $0.6 \%$ & $0.3 \%$ \\
\hline $1.7 \%$ & $2.3 \%$ & $4.7 \%$ \\
\hline $17.4 \%$ & $16.9 \%$ & $17.6 \%$ \\
\hline $31.7 \%$ & $31.6 \%$ & $27.4 \%$ \\
\hline $17.1 \%$ & $15.3 \%$ & $18.0 \%$ \\
\hline $12.7 \%$ & $12.3 \%$ & $14.2 \%$ \\
\hline $10.8 \%$ & $11.4 \%$ & $10.3 \%$ \\
\hline $6.4 \%$ & $6.9 \%$ & $5.3 \%$ \\
\hline
\end{tabular}




\begin{tabular}{|c|c|c|}
\hline $\begin{array}{c}\text { 302-4-A-10-X-3 } \\
\text { Cristin Ashmankas, }\end{array}$ & $\begin{array}{c}\text { 302-4-A-10-X-3 } \\
\text { Cristin Ashmankas, }\end{array}$ & $\begin{array}{c}\text { 302-4-A-10-X-4 } \\
\text { Cristin Ashmankas, }\end{array}$ \\
\hline Bimodal, Poorly Sorted & Unimodal, Poorly Sorted & Bimodal, Poorly Sorted \\
\hline Mud & Mud & Mud \\
\hline Coarse Silt & Coarse Silt & Coarse Silt \\
\hline 18.47 & 20.46 & 18.69 \\
\hline 15.28 & 16.52 & 15.14 \\
\hline 1.081 & 1.026 & 1.002 \\
\hline 4.026 & 3.840 & 3.766 \\
\hline 11.68 & 13.00 & 11.92 \\
\hline 2.883 & 2.921 & 2.874 \\
\hline-0.552 & -0.675 & -0.595 \\
\hline 2.387 & 2.591 & 2.432 \\
\hline 6.419 & 6.266 & 6.391 \\
\hline 1.528 & 1.546 & 1.523 \\
\hline 0.552 & 0.675 & 0.595 \\
\hline 2.387 & 2.591 & 2.432 \\
\hline 11.96 & 13.21 & 12.21 \\
\hline 2.953 & 3.006 & 2.946 \\
\hline-0.315 & -0.342 & -0.335 \\
\hline 0.839 & 0.905 & 0.849 \\
\hline 6.385 & 6.242 & 6.356 \\
\hline 1.562 & 1.588 & 1.559 \\
\hline 0.315 & 0.342 & 0.335 \\
\hline 0.839 & 0.905 & 0.849 \\
\hline Medium Silt & Medium Silt & Medium Silt \\
\hline Poorly Sorted & Poorly Sorted & Poorly Sorted \\
\hline Very Fine Skewed & Very Fine Skewed & Very Fine Skewed \\
\hline Platykurtic & Mesokurtic & Platykurtic \\
\hline 26.50 & 26.50 & 26.50 \\
\hline 4.700 & & 4.700 \\
\hline 5.259 & 5.259 & 5.259 \\
\hline 7.754 & & 7.754 \\
\hline 2.423 & 2.526 & 2.442 \\
\hline 15.16 & 17.09 & 15.69 \\
\hline 39.55 & 42.59 & 39.71 \\
\hline 16.32 & 16.86 & 16.26 \\
\hline 37.12 & 40.06 & 37.26 \\
\hline 5.205 & 4.834 & 5.096 \\
\hline 21.84 & 23.39 & 22.01 \\
\hline 4.660 & 4.553 & 4.655 \\
\hline 6.043 & 5.870 & 5.994 \\
\hline 8.689 & 8.629 & 8.678 \\
\hline 1.864 & 1.895 & 1.864 \\
\hline 4.029 & 4.075 & 4.023 \\
\hline 1.457 & 1.447 & 1.453 \\
\hline 2.380 & 2.273 & 2.349 \\
\hline $1.0 \%$ & $1.8 \%$ & $0.9 \%$ \\
\hline $99.0 \%$ & $98.2 \%$ & $99.1 \%$ \\
\hline $0.0 \%$ & $0.0 \%$ & $0.0 \%$ \\
\hline $0.0 \%$ & $0.0 \%$ & $0.0 \%$ \\
\hline $0.0 \%$ & $0.0 \%$ & $0.0 \%$ \\
\hline $0.0 \%$ & $0.0 \%$ & $0.0 \%$ \\
\hline $1.0 \%$ & $1.8 \%$ & $0.9 \%$ \\
\hline $17.2 \%$ & $20.4 \%$ & $17.8 \%$ \\
\hline $30.9 \%$ & $31.5 \%$ & $31.5 \%$ \\
\hline $17.4 \%$ & $16.8 \%$ & $17.3 \%$ \\
\hline $14.7 \%$ & $12.5 \%$ & $14.1 \%$ \\
\hline $12.0 \%$ & $10.3 \%$ & $11.6 \%$ \\
\hline $6.9 \%$ & $6.7 \%$ & $6.8 \%$ \\
\hline
\end{tabular}




\begin{tabular}{|c|c|c|}
\hline 302-4-A-10-X-4 & 302-4-A-11-X-1 & 302-4-A-11-X-1 \\
\hline Cristin Ashmankas, & Cristin Ashmankas, & Cristin Ashmankas, \\
\hline Bimodal, Poorly Sorted & Unimodal, Poorly Sorted & Unimodal, Poorly Sorted \\
\hline Mud & Mud & Mud \\
\hline Coarse Silt & Coarse Silt & Coarse Silt \\
\hline 20.68 & 36.48 & 19.88 \\
\hline 16.53 & 130.5 & 15.60 \\
\hline 0.876 & 10.22 & 1.038 \\
\hline 3.458 & 114.2 & 3.970 \\
\hline 12.80 & 16.08 & 13.09 \\
\hline 3.056 & 3.049 & 2.764 \\
\hline-0.678 & -0.042 & -0.669 \\
\hline 2.402 & 4.641 & 2.651 \\
\hline 6.288 & 5.944 & 6.255 \\
\hline 1.612 & 1.617 & 1.467 \\
\hline 0.678 & -0.029 & 0.669 \\
\hline 2.402 & 4.757 & 2.651 \\
\hline 12.97 & 16.00 & 13.31 \\
\hline 3.138 & 2.827 & 2.831 \\
\hline-0.403 & -0.288 & -0.326 \\
\hline 0.827 & 1.004 & 0.913 \\
\hline 6.269 & 5.966 & 6.232 \\
\hline 1.650 & 1.499 & 1.501 \\
\hline 0.403 & 0.288 & 0.326 \\
\hline 0.827 & 1.004 & 0.913 \\
\hline Medium Silt & Coarse Silt & Medium Silt \\
\hline Poorly Sorted & Poorly Sorted & Poorly Sorted \\
\hline Very Fine Skewed & Fine Skewed & Very Fine Skewed \\
\hline Platykurtic & Mesokurtic & Mesokurtic \\
\hline 26.50 & 26.50 & 26.50 \\
\hline 3.350 & & \\
\hline 5.259 & 5.259 & 5.259 \\
\hline 8.241 & & \\
\hline 2.273 & 3.412 & 2.840 \\
\hline 18.09 & 19.33 & 16.76 \\
\hline 42.62 & 51.08 & 41.02 \\
\hline 18.75 & 14.97 & 14.44 \\
\hline 40.35 & 47.67 & 38.18 \\
\hline 5.757 & 4.014 & 4.392 \\
\hline 25.00 & 25.05 & 21.94 \\
\hline 4.552 & 4.291 & 4.608 \\
\hline 5.789 & 5.693 & 5.899 \\
\hline 8.781 & 8.195 & 8.460 \\
\hline 1.929 & 1.910 & 1.836 \\
\hline 4.229 & 3.904 & 3.852 \\
\hline 1.500 & 1.409 & 1.416 \\
\hline 2.525 & 2.005 & 2.135 \\
\hline $1.5 \%$ & $5.2 \%$ & $1.3 \%$ \\
\hline $98.5 \%$ & $94.8 \%$ & $98.7 \%$ \\
\hline $0.0 \%$ & $0.9 \%$ & $0.0 \%$ \\
\hline $0.0 \%$ & $0.4 \%$ & $0.0 \%$ \\
\hline $0.0 \%$ & $0.0 \%$ & $0.0 \%$ \\
\hline $0.0 \%$ & $0.0 \%$ & $0.0 \%$ \\
\hline $1.5 \%$ & $3.9 \%$ & $1.3 \%$ \\
\hline $21.9 \%$ & $22.5 \%$ & $19.0 \%$ \\
\hline $32.7 \%$ & $31.0 \%$ & $32.8 \%$ \\
\hline $12.8 \%$ & $17.7 \%$ & $18.2 \%$ \\
\hline $11.6 \%$ & $11.9 \%$ & $13.1 \%$ \\
\hline $11.8 \%$ & $7.4 \%$ & $10.1 \%$ \\
\hline $7.7 \%$ & $4.4 \%$ & $5.4 \%$ \\
\hline
\end{tabular}




\begin{tabular}{|c|c|c|}
\hline $\begin{array}{c}\text { 302-4-A-11-X-2 } \\
\text { Cristin Ashmankas, }\end{array}$ & $\begin{array}{c}\text { 302-4-A-11-X-2 } \\
\text { Cristin Ashmankas. }\end{array}$ & $\begin{array}{c}\text { 302-4-A-11-X-3 } \\
\text { Cristin Ashmankas }\end{array}$ \\
\hline Unimodal, Poorly Sorted & Bimodal, Poorly Sorted & Unimodal, Poorly Sorted \\
\hline Mud & Mud & Mud \\
\hline Coarse Silt & Coarse Silt & Coarse Silt \\
\hline 45.08 & 18.07 & 20.34 \\
\hline 175.1 & 16.62 & 16.34 \\
\hline 7.500 & 1.257 & 1.066 \\
\hline 61.79 & 4.245 & 3.968 \\
\hline 13.84 & 10.80 & 13.16 \\
\hline 3.531 & 2.986 & 2.828 \\
\hline 0.416 & -0.319 & -0.654 \\
\hline 4.621 & 2.154 & 2.636 \\
\hline 6.150 & 6.533 & 6.248 \\
\hline 1.836 & 1.578 & 1.500 \\
\hline-0.482 & 0.319 & 0.654 \\
\hline 4.708 & 2.154 & 2.636 \\
\hline 13.41 & 11.02 & 13.44 \\
\hline 3.146 & 3.081 & 2.896 \\
\hline-0.244 & -0.151 & -0.317 \\
\hline 0.886 & 0.803 & 0.905 \\
\hline 6.220 & 6.503 & 6.217 \\
\hline 1.653 & 1.623 & 1.534 \\
\hline 0.244 & 0.151 & 0.317 \\
\hline 0.886 & 0.803 & 0.905 \\
\hline Medium Silt & Medium Silt & Medium Silt \\
\hline Poorly Sorted & Poorly Sorted & Poorly Sorted \\
\hline Fine Skewed & Fine Skewed & Very Fine Skewed \\
\hline Platykurtic & Platykurtic & Mesokurtic \\
\hline \multirow[t]{2}{*}{26.50} & 26.50 & 26.50 \\
\hline & 4.700 & \\
\hline \multirow[t]{2}{*}{5.259} & 5.259 & 5.259 \\
\hline & 7.754 & \\
\hline 2.620 & 2.314 & 2.811 \\
\hline 16.39 & 12.26 & 16.89 \\
\hline 49.92 & 41.44 & 42.27 \\
\hline 19.05 & 17.91 & 15.04 \\
\hline 47.30 & 39.13 & 39.46 \\
\hline 5.373 & 5.912 & 4.608 \\
\hline 25.18 & 22.37 & 22.81 \\
\hline 4.324 & 4.593 & 4.564 \\
\hline 5.931 & 6.350 & 5.888 \\
\hline 8.576 & 8.755 & 8.475 \\
\hline 1.983 & 1.906 & 1.857 \\
\hline 4.252 & 4.163 & 3.910 \\
\hline 1.484 & 1.492 & 1.432 \\
\hline 2.426 & 2.564 & 2.204 \\
\hline $5.5 \%$ & $1.8 \%$ & $1.8 \%$ \\
\hline $94.5 \%$ & $98.2 \%$ & $98.2 \%$ \\
\hline $1.5 \%$ & $0.0 \%$ & $0.0 \%$ \\
\hline $0.9 \%$ & $0.0 \%$ & $0.0 \%$ \\
\hline $0.0 \%$ & $0.0 \%$ & $0.0 \%$ \\
\hline $0.0 \%$ & $0.0 \%$ & $0.0 \%$ \\
\hline $3.1 \%$ & $1.8 \%$ & $1.8 \%$ \\
\hline $19.2 \%$ & $17.5 \%$ & $19.8 \%$ \\
\hline $27.1 \%$ & $24.6 \%$ & $31.7 \%$ \\
\hline $16.9 \%$ & $17.1 \%$ & $17.5 \%$ \\
\hline $14.3 \%$ & $18.0 \%$ & $13.5 \%$ \\
\hline $11.0 \%$ & $13.7 \%$ & $10.0 \%$ \\
\hline $6.1 \%$ & $7.2 \%$ & $5.7 \%$ \\
\hline
\end{tabular}




\begin{tabular}{|c|c|c|}
\hline $\begin{array}{c}\text { 302-4-A-11-X-3 } \\
\text { Cristin Ashmankas. }\end{array}$ & $\begin{array}{c}\text { 302-4-A-11-X-4 } \\
\text { Cristin Ashmankas }\end{array}$ & $\begin{array}{c}\text { 302-4-A-11-X-4 } \\
\text { Cristin Ashmankas }\end{array}$ \\
\hline Unimodal, Poorly Sorted & Bimodal, Poorly Sorted & Unimodal, Poorly Sorted \\
\hline Sandy Mud & Mud & Mud \\
\hline Very Fine Sandy Coarse Silt & Coarse Silt & Coarse Silt \\
\hline 51.33 & 26.72 & 32.48 \\
\hline 165.1 & 84.95 & 89.78 \\
\hline 7.397 & 14.82 & 13.73 \\
\hline 64.01 & 246.7 & 215.5 \\
\hline 15.36 & 13.72 & 16.36 \\
\hline 3.991 & 3.013 & 3.190 \\
\hline 0.371 & -0.329 & -0.358 \\
\hline 3.490 & 3.574 & 3.286 \\
\hline 6.003 & 6.188 & 5.930 \\
\hline 2.008 & 1.591 & 1.676 \\
\hline-0.408 & 0.329 & 0.340 \\
\hline 3.539 & 3.574 & 3.321 \\
\hline 14.62 & 13.63 & 16.26 \\
\hline 3.876 & 2.971 & 3.184 \\
\hline-0.063 & -0.352 & -0.303 \\
\hline 1.011 & 0.908 & 0.944 \\
\hline 6.096 & 6.197 & 5.943 \\
\hline 1.955 & 1.571 & 1.671 \\
\hline 0.063 & 0.352 & 0.303 \\
\hline 1.011 & 0.908 & 0.944 \\
\hline Medium Silt & Medium Silt & Coarse Silt \\
\hline Poorly Sorted & Poorly Sorted & Poorly Sorted \\
\hline Symmetrical & Very Fine Skewed & Very Fine Skewed \\
\hline Mesokurtic & Mesokurtic & Mesokurtic \\
\hline 26.50 & 26.50 & 26.50 \\
\hline & 4.700 & \\
\hline 5.259 & 5.259 & 5.259 \\
\hline & 7.754 & \\
\hline 2.577 & 2.675 & 2.946 \\
\hline 16.42 & 17.82 & 20.81 \\
\hline 78.26 & 43.07 & 58.50 \\
\hline 30.37 & 16.10 & 19.86 \\
\hline 75.68 & 40.39 & 55.55 \\
\hline 6.330 & 4.718 & 4.966 \\
\hline 30.38 & 23.64 & 29.90 \\
\hline 3.676 & 4.537 & 4.095 \\
\hline 5.929 & 5.811 & 5.587 \\
\hline 8.600 & 8.546 & 8.407 \\
\hline 2.340 & 1.884 & 2.053 \\
\hline 4.924 & 4.009 & 4.312 \\
\hline 1.555 & 1.442 & 1.488 \\
\hline 2.662 & 2.238 & 2.312 \\
\hline $12.5 \%$ & $2.3 \%$ & $8.1 \%$ \\
\hline $87.5 \%$ & $97.7 \%$ & $91.9 \%$ \\
\hline $1.3 \%$ & $0.3 \%$ & $0.4 \%$ \\
\hline $0.8 \%$ & $0.2 \%$ & $0.2 \%$ \\
\hline $1.3 \%$ & $0.1 \%$ & $0.0 \%$ \\
\hline $2.9 \%$ & $0.1 \%$ & $0.2 \%$ \\
\hline $6.4 \%$ & $1.6 \%$ & $7.3 \%$ \\
\hline $16.6 \%$ & $20.7 \%$ & $24.5 \%$ \\
\hline $22.4 \%$ & $32.6 \%$ & $27.5 \%$ \\
\hline $16.8 \%$ & $15.8 \%$ & $14.4 \%$ \\
\hline $14.4 \%$ & $12.2 \%$ & $11.3 \%$ \\
\hline $11.0 \%$ & $10.4 \%$ & $9.0 \%$ \\
\hline $6.3 \%$ & $6.0 \%$ & $5.2 \%$ \\
\hline
\end{tabular}




\begin{tabular}{|c|c|c|}
\hline 302-4-A-15-X-1 & 302-4-A-19-X-1 & 302-4-A-19-X-1 \\
\hline Cristin Ashmankas, & Cristin Ashmankas, & Cristin Ashmankas, \\
\hline Unimodal, Poorly Sorted & Unimodal, Very Poorly Sorted & Bimodal, Poorly Sorted \\
\hline Sandy Mud & Muddy Sand & Sandy Mud \\
\hline Very Fine Sandy Coarse Silt & Fine Silty Very Coarse Sand & Very Fine Sandy Fine Silt \\
\hline 38.26 & 678.9 & 24.94 \\
\hline 34.02 & 577.8 & 33.50 \\
\hline 1.486 & 0.427 & 2.149 \\
\hline 5.138 & 1.934 & 8.111 \\
\hline 23.86 & 223.2 & 10.87 \\
\hline 2.970 & 9.522 & 3.704 \\
\hline-0.777 & -1.276 & 0.216 \\
\hline 3.387 & 3.355 & 2.036 \\
\hline 5.390 & 1.516 & 6.524 \\
\hline 1.571 & 2.549 & 1.889 \\
\hline 0.777 & 1.523 & -0.216 \\
\hline 3.387 & 4.363 & 2.036 \\
\hline 25.36 & 416.7 & 11.02 \\
\hline 2.980 & 5.352 & 3.889 \\
\hline-0.183 & -0.615 & 0.184 \\
\hline 1.194 & 1.322 & 0.788 \\
\hline 5.302 & 1.263 & 6.504 \\
\hline 1.575 & 2.420 & 1.960 \\
\hline 0.183 & 0.615 & -0.184 \\
\hline 1.194 & 1.322 & 0.788 \\
\hline Coarse Silt & Medium Sand & Medium Silt \\
\hline Poorly Sorted & Very Poorly Sorted & Poorly Sorted \\
\hline Fine Skewed & Very Fine Skewed & Coarse Skewed \\
\hline Leptokurtic & Leptokurtic & Platykurtic \\
\hline \multirow[t]{2}{*}{26.50} & 1200.0 & 4.700 \\
\hline & & 53.50 \\
\hline \multirow[t]{2}{*}{5.259} & -0.243 & 7.754 \\
\hline & & 4.247 \\
\hline 4.659 & 15.65 & 2.135 \\
\hline 27.31 & 728.1 & 8.951 \\
\hline 86.85 & 1825.2 & 72.10 \\
\hline 18.64 & 116.7 & 33.77 \\
\hline 82.19 & 1809.6 & 69.97 \\
\hline 3.647 & 6.022 & 8.633 \\
\hline 37.35 & 1057.0 & 29.34 \\
\hline 3.525 & -0.868 & 3.794 \\
\hline 5.194 & 0.458 & 6.804 \\
\hline 7.746 & 5.998 & 8.871 \\
\hline 2.197 & -6.910 & 2.338 \\
\hline 4.221 & 6.866 & 5.078 \\
\hline 1.436 & -6.575 & 1.633 \\
\hline 1.867 & 2.590 & 3.110 \\
\hline $18.7 \%$ & $84.1 \%$ & $12.6 \%$ \\
\hline $81.3 \%$ & $15.9 \%$ & $87.4 \%$ \\
\hline $0.0 \%$ & $36.5 \%$ & $0.0 \%$ \\
\hline $0.0 \%$ & $25.0 \%$ & $0.0 \%$ \\
\hline $0.0 \%$ & $11.5 \%$ & $0.0 \%$ \\
\hline $2.6 \%$ & $6.8 \%$ & $1.9 \%$ \\
\hline $16.1 \%$ & $4.2 \%$ & $10.6 \%$ \\
\hline $25.2 \%$ & $3.0 \%$ & $13.6 \%$ \\
\hline $28.7 \%$ & $2.9 \%$ & $11.9 \%$ \\
\hline $12.7 \%$ & $3.0 \%$ & $15.4 \%$ \\
\hline $6.2 \%$ & $3.3 \%$ & $21.1 \%$ \\
\hline $5.2 \%$ & $2.5 \%$ & $17.3 \%$ \\
\hline $3.3 \%$ & $1.2 \%$ & $8.2 \%$ \\
\hline
\end{tabular}




\begin{tabular}{|c|c|}
\hline $302-4-A-19-X-2$ & $302-4-A-19-X-2$ \\
\hline Cristin Ashmankas, & Cristin Ashmankas, \\
\hline Unimodal, Very Poorly Sorted & Bimodal, Very Poorly Sorted \\
\hline Sandy Mud & Sandy Mud \\
\hline Coarse Sandy Fine Silt & Very Fine Sandy Fine Silt \\
\hline 59.06 & 46.79 \\
\hline 184.7 & 131.9 \\
\hline 4.923 & 7.233 \\
\hline 30.41 & 69.21 \\
\hline 10.43 & 12.26 \\
\hline 4.651 & 4.567 \\
\hline 1.093 & 0.531 \\
\hline 4.162 & 2.698 \\
\hline 6.584 & 6.349 \\
\hline 2.217 & 2.192 \\
\hline-1.093 & -0.532 \\
\hline 4.162 & 2.701 \\
\hline 8.974 & 11.90 \\
\hline 4.416 & 4.524 \\
\hline 0.251 & 0.228 \\
\hline 1.310 & 0.814 \\
\hline 6.800 & 6.393 \\
\hline 2.143 & 2.178 \\
\hline-0.251 & -0.228 \\
\hline 1.310 & 0.814 \\
\hline Medium Silt & Medium Silt \\
\hline Very Poorly Sorted & Very Poorly Sorted \\
\hline Coarse Skewed & Coarse Skewed \\
\hline Leptokurtic & Platykurtic \\
\hline \multirow[t]{2}{*}{4.700} & 4.700 \\
\hline & 53.50 \\
\hline \multirow{2}{*}{7.754} & 7.754 \\
\hline & 4.247 \\
\hline 1.985 & 2.048 \\
\hline 8.076 & 9.249 \\
\hline 81.34 & 96.32 \\
\hline 40.98 & 47.03 \\
\hline 79.36 & 94.27 \\
\hline 5.693 & 10.58 \\
\hline 16.86 & 35.94 \\
\hline 3.620 & 3.376 \\
\hline 6.952 & 6.756 \\
\hline 8.977 & 8.932 \\
\hline 2.480 & 2.646 \\
\hline 5.357 & 5.556 \\
\hline 1.447 & 1.731 \\
\hline 2.509 & 3.403 \\
\hline $11.0 \%$ & $17.1 \%$ \\
\hline $89.0 \%$ & $82.9 \%$ \\
\hline $1.0 \%$ & $0.5 \%$ \\
\hline $2.9 \%$ & $1.1 \%$ \\
\hline $2.4 \%$ & $1.7 \%$ \\
\hline $2.2 \%$ & $3.3 \%$ \\
\hline $2.5 \%$ & $10.6 \%$ \\
\hline $6.0 \%$ & $11.7 \%$ \\
\hline $14.3 \%$ & $10.5 \%$ \\
\hline $19.6 \%$ & $14.6 \%$ \\
\hline $21.5 \%$ & $19.9 \%$ \\
\hline $17.9 \%$ & $17.2 \%$ \\
\hline $9.6 \%$ & $9.0 \%$ \\
\hline
\end{tabular}




\section{BIBLIOGRAPHY}

Aagaard, K., 1981. "On the Deep Circulation in the Arctic Ocean.” Deep-Sea Research, Vol. 28, No. 3, pp. 251-268.

Aagaard, K., E.C. Carmack, 1989. "The Role of Sea Ice and Other Fresh Water in the Arctic Circulation.” Journal of Geophysical Research, Vol. 94, No. C10, pp. 14485-14498.

Alley, R.B., K.M. Cuffey, E.B. Evenson, J.C. Strasser, D.E. Lawsons, and G.J. Larson, 1997. "How Glaciers Entrain and Transport Basal Sediment: Physical Constraints." Quaternary Science Reviews, Vol. 16, pp. 1017-1038.

Bachman, R.T., 1985. "Acoustic and Physical Property Relationships in Marine Sediments." Journal of Accoust. Soc. Am., Vol. 78, No. 2, pp. 616-621.

Backman, J., M. Jakobsson, M. Frank, F. Sangiorgi, H. Brinkhuis, C. Stickley, M. O'Regan, R. Lovlie, H. Palike, D. Spofforth, J. Gattacecca, K. Moran, and C. Heil, 2008. "Age Model and Core-Seismic Integration for the Cenozoic ACEX Sediments from the Lomonosov Ridge." Paleoceanography, Vol. 23.

Backman, J., M. Jakobsson, R. Lovlie, L. Polyak, and L.A. Febo, 2004. "Is the Central Arctic Ocean a Sediment Starved Basin?" Quaternary Science Reviews, Vol. 23, pp. 1435-1454.

Backman, J., K. Moran, and D. Evans, 2004. "ACEX Arctic Coring Expedition: Paleoceanographic and tectonic evolution of the central Arctic Ocean." IODP Expedition 302 Scientific Prospectus, Edinburgh (Integrated Ocean Drilling Program Management International, Inc.).

Backman, J., K. Moran, D.B. McInroy, L.A. Mayer, 2006. Proceedings of the Integrated Ocean Drilling Program, 302, Edinburg (Integrated Ocean Drilling Program Management International, Inc.).

Barrett, L., and S.B. Treves, 1981. "Sedimentology and Petrology of Core from DVDP-15, Western McMurdo Sound." Antarctic Research Series, Vol. 33, pp. 281-314.

Bendat, J.S., and A.G. Piersol, 2000. Random Data: Analysis and Measurement Procedures. John Wiley \& Sons Inc., NY.

Betzer, P.R., K.I. Carder, R.A. Duce, J.T. Merrill, et al., 1988. "Long-range Transport of Giant Mineral Aerosol Particles.” Nature, Vol. 336, pp. 568-571.

Bischof, J., 2000. Ice Drift, Ocean Circulation, and Climate Change. Springer, NY. 
Bischof, J., D.L. Clark, and J.S. Vincent, 1996. "Origin of Ice-Rafted Debris: Pleistocene paleoceanography in the western Arctic Ocean."

Paleoceanography, Vol. 11, No. 6, pp. 743-756.

Bischof, J.F. and D.A. Darby, 1997. "Mid- to Late Pleistocene Ice Drift in the Western Arctic Ocean: Evidence for a different circulation in the past." Science, Vol. 277, pp. 74-77.

Bischof, J.F. and D.A. Darby, 1999. "Quaternary Ice Transport in the Canadian Arctic and Extent of Late Wisconsinan Glaciation in the Queen Elizabeth Islands." Canadian Journal of Earth Science, Vol. 36, pp. 2007-2022.

Bischof, J.F., D.A. Darby, and C. Majer, 1999. "Very High Resolution Record of Late Pleistocene to Holocene Ice Rafting and Glacio-Fluvial Meltwater Discharge from the Northern Chukchi Sea." EOS, AGU, Vol. 80, No. 46.

Bjork, G., Jakobsson, M., Rudels, B., et al., 2007. "Bathymetry and Deep-Water Exchange Across the Central Lomonosov Ridge at 88-89² N." Deep-Sea Research I, Vol. 54, pp. 1197-1208.

Boggs, S., 1995. Principles of Sedimentology and Stratigraphy. Prentice-Hall Inc., NJ.

Bouyoucos, G.J., 1962. "Hydrometer Method Improved for Making Particle Size Analysis of Soils.” Agronomy Journal, Vol. 54, pp. 464-465.

Boyce, R. E., 1976. "Definitions and Laboratory Techniques of Compressional Sound Velocity Parameters and Wet-Water Content, Wet-Bulk Density, and Porosity Parameters by Gravimetric and Gamma Ray Attenuation Techniques." Initial Report of the Deep Sea Drilling Program, Vol. 33, pp. 931-958.

Broecker, W.S., 1997. "Thermohaline Circulation, the Achilles Heel of our Climate System: Will man-made CO2 upset the current balance?" Science, Vol. 278, pp. $1582-1588$.

Clark, D.L., 1996. "The Pliocene Record in the Central Arctic." Marine Micropaleontology, Vol. 27, pp. 157-164.

Clark, D.L., Hanson, A., 1983. "Central Arctic Ocean Sediment Texture: a key to icetransport mechanisms." In: B. Molnia (Ed.), Glacial-Marine Sedimentation, Plenum, New York, pp. 301-330.

Clark, P.U., N.G. Pisias, T.F. Stocker, and A.J. Weavers, 2002. "The Role of the Thermohaline Circulation in Abrupt Climate Change." Nature, Vol. 415, pp. 863-869. 
Coachman, L.K. and K. Aagaard, 1974. Physical Oceanography of Arctic and Subarctic Seas. Marine Geology and Oceanography of the Arctic Seas, Springer-Veriag, NY.

Curry, J.A., J. Schramm, and E.E. Ebert, 1995. "On the Sea-Ice Albedo Climate Feedback Mechanism.” Journal of Climate, Vol. 8, pp. 240-247.

Darby, D.A., 2008. “Arctic Perennial Ice Cover Over the Last 14 Million Years.” Paleoceanography, Vol. 23, PA1S07. doi:10.1029/2007PA001479.

Darby, D.A., Naidu, S.A., Mowatt, T.C., Jones, G.A., 1989. "Sediment Composition and Sedimentary Processes in the Arctic Ocean." In: Herman, Y. (Ed.), The Arctic Seas: Climatology, Oceanography, Geology, and Biology, Van Nostrand Reinhold Co., New York, pp. 657-720.

Darby, D.A., Bischof, J.F., Jones, G.A., 1997. "Radiocarbon Chronology of Depositional Regimes in the Western Arctic Ocean." Deep-Sea Research I, Vol. 44, pp. 1745-1757.

Darby, D.A., J.F. Bischof, R.F. Spielhagen, S.A. Marshall, and S.W. Herman, 2002. "Arctic Ice Export Events and their Potential Impact on Global Climate during the Late Pleistocene." Paleoceanography, Vol. 17, No. 2.

Dethloff, K, et al., 2006. "A Dynamical Link Between the Arctic and the Global Climate System.” Geophysical Research Letters, Vol. 33, L03703.

Dreimanis A., and V.J. Vagners, 1971. "Bimodal Distribution of Rock and Mineral Fragments in Basal Tills." In: R.P. Goldthwait (ed) A Symposium on Till, Univ. Press, Ohio, pp. 237-250.

Eicken, H., J. Kolatschek, F. Lindemann, I. Dmitrenko, J. Freitag, and H. Kassens, 2000. "A Key Source Area and Constraints on Entrainment for Basin-Scale Sediment Transport by Arctic Sea Ice." Geophysical Research Letters, Vol. 27, pp. 1919-1922.

Eldrett, J.S., I.C. Harding, P.A. Wilson, E. Butler, and A.P. Roberts, 2007. "Continental Ice in Greenland during the Eocene and Oligocene." Nature.

Evans, H.B., 1965. "GRAPE-A Device for Continuous Determination of Material Density and Porosity." Transactions $6^{\text {th }}$ Annual SPWIA Logging Symposium, Dallas, TX. Vol. 2, pp. B1-B25.

Fahl, K., and E.-M. Nothig, 2007. "Lithogenic and Biogenic Particle Fluxes on the Lomonosov Ridge (central Arctic Ocean) and their Relevance for Sediment Accumulation: Vertical vs. Lateral Transport." Deep-Sea Research I, Vol. 54, pp. 1256-1272. 
Fetter, C.W., 2001. Applied Hydrogeology. Prentice-Hall Inc., NJ.

Frank, M., J. Backman, M. Jakobsson, K. Moran, M. O’Regan, J. King, B.A. Haley, P.W. Kubik, and D. Garbe-Schonberg, 2008. "Beryllium Isotopes in Central Arctic Ocean Sediments Over the Past 12.3 Million Years: Stratigraphic and Paleoclimatic Implications.” Paleoceanography, Vol. 23.

Goldstein, R.H., 1983. "Stratigraphy and Sedimentology of Ice-Rafted and Turbidite Sediment, Canadian Basin, Arctic Ocean." In: B Molnia (ed) Glacial Marine Sedimentation. Plenum Press, New York, pp. 367-401.

Goossens, D., 2008. "Techniques to Measure Grain-Size Distributions of Loamy Sediments: a comparative study of ten instruments for wet analysis." Sedimentology, Vol. 55, pp. 65-96.

Grosswald, M.G., Hughes, T.J., 1999. “The Case for an Ice Shelf in the Pleistocene Arctic Ocean.” Polar Geography, Vol. 23, pp. 23-54.

Gyllencreutz, R., 2005. "Late Glacial and Holocene Paleoceanography in the Skagerrak from High-Resolution Grain Size Records.” Paleogeography, Paleoclimatology, Paleoecology, Vol. 222, pp. 344-369.

Hald, M., H. Ebbesen, M. Forwick, F. Goftliebsen, L. Khomenko, S. Korsun, L.R. Olsen, and T.O. Vorren, 2004. "Holocene Paleoceanography and Glacial History of the West Spitsbergen Area, Euro-Arctic Margin." Quaternary Science Reviews, Vol. 23, pp. 2075-2088.

Haley, A.B., Frank, M., Spielhagen, R.F., Eisenhauer, A., 2008. "Influence of Brine Formation on Arctic Ocean Circulation Over the Past 15 Million Years." Nature Geoscience, Vol. 1, pp. 68-72.

Haley, B.A., M. Frank, R.F. Spielhagen, and J. Fietzke, 2008. "The Radiogenic Isotope Record of Arctic Ocean Circulation and Weathering Inputs of the Past 15 Million Years.” Paleoceanography, Vol. 23.

Hall, I.R., McCave, I.N., M.R. Chapman, and Shackleton, N.J., 1998. "Coherent Deep Flow Variation in the Iceland and American Basins during the Last Interglacial." Earth and Planetary Science Letters, Vol. 164, pp. 15-21.

Hall, I.R., McCave, I.N., Shackleton, N.J., Weedon, and G.P., Harris, S.E., 2001. "Intensified Deep Pacific Inflow and Ventilation in Pleistocene Glacial Times." Nature, Vol. 412, pp. 809-811. 
Hamilton, E.L., 1970. "Sound Velocity and Related Properties of Marine Sediments, North Pacific." Journal of Geophysical Research, Vol. 75, No. 23, pp. 44234446.

Hamilton, E.L., 1971. "Elastic Properties of Marine Sediments." Journal of Geophysical Research, Vol. 76, No. 2, pp. 579-604.

Hein, F.J., 991. "The Need for Grain Size Analyses in Marine Geotechnical Studies." In Syvitski, J.P.M. (Ed.), Principles, Methods, and Applications of Particle Size Analysis, Cambridge Univ. Press, NY.

Heinrich, H., 1988. "Origin and Consequences of Cyclic Ice Rafting in the Northeast Atlantic Ocean during the Past 130,000 Years." Quaternary Research, Vol. 29, pp. 142-152.

Herman, Y., 1974. Topography of the Arctic Ocean. Marine Geology and Oceanography of the Arctic Seas, Springer-Veriag, NY.

Hodell, D.A., Woodruff, F., 1994. "Variation in the Strontium Isotope Ratio of Seawater during the Miocene: stratigraphic and geochemical implications." Paleoceanography, Vol. 9, pp. 405-426.

Holland, M.M., et al., 2001. "The Role of Ice-Ocean Interactions in the Variability of the North Atlnatic Thermohaline Circulation." Journal of Climate, Vol. 14, pp. 656-675.

Holland, M.M., and C.M. Bitz, 2003. "Polar Amplification of Climate Change in Coupled Models." Climate Dynamics, Vol. 21, pp. 221-232.

Honjo, S., 1980. "Material Fluxes and Mode of Sedimentation in Mesopelagic and Bathypelagic Zones.” Journal of Marine Research, Vol. 38, pp. 53-97.

Hughes, T.J., Denton, G.H., Grosswald, M.G., 1977. "Was There a Late Wurm Ice Sheet?" Nature, Vol. 266, pp. 596-602.

Hunt, A.G, and P.E. Malin, 1998. Possible Triggering of Heinrich Events by IceLoad-Induced Earthquakes." Nature, Vol. 393, pp. 155-158.

Iverson, N.R., and D.J. Semmens, 1995. "Intrusion of Ice into Porous Media by Regelation: A mechanism of sediment entrainment by glaciers. ” Journal of Geophysical Research, Vol. 100, pp. 10219-10230.

Jakobsson, M., R. Lovlie, H. Al-Hanbali, et al., 2000. "Manganese and Color Cycles in Arctic Ocean Sediments Constrain Pleistocene Chronology." Geology, Vol. 28, No. 1, pp. 23-26. 
Jakobsson, M., R. Lovlie, E.M. Arnold, J. Backman, L. Polyak, J.O. Knutsen, and E. Musatov, 2001. "Pleistocene Stratigraphy and Paleoenvironmental Variation from Lomonosov Ridge Sediments, Central Arctic Ocean." Global and Planetary Change, Vol. 31, pp. 1-22.

Jokat, W., G. Uenseimann-Neben, Y. Kristoffersen, and T.M. Rasmussen, 1992. "Lomonosov Ridge- A Double-sided Continental Margin." Geology, Vol. 20, pp. 887-890.

Jonkers, L., Prins, M.A., Brummer, G.-J.A., Koner, M., Lougheed, B.C., 2009. "Experimental Insights into Laser Diffraction Particle Sizing of Fine-Grained Sediments for Use in Paleoceanography." Sedimentology, Vol. 56, pp. 21922206.

Knies, J., Gaina, C., 2008. "Middle Miocene Ice Sheet Expansion in the Arctic: views from the Barents Sea". Geochemistry, Geophysics, and Geosystems, Vol. 9, Q02015. doi:10.1029/2007GC001824.

Knight, P.G., R.I. Waller, C.J. Patterson, A.P. Jones, and Z.P. Robinson, 2002. "Discharge of Debris from Ice at the Margin of the Greenland Ice Sheet." Journal of Glaciology, Vol. 48, No. 161, pp. 192-198.

Kotlyakov, V.M., and F.G. Gordienko, 1982. "Isotopic and Geochemical Glaciology." Gidrometeoizdat, Moscow.

Krissek, L.A., 1989. "Late Cenozoic Records of Ice-Rafting at ODP Sites 642, 643, and 644, Norwegian Sea: onset, chronology, and characteristics of glacial/interglacial fluctuations." Proceedings of ODP, Scientific Results, Edinburgh (Ocean Drilling Program Management International, Inc.).

Kristoffersen, Y., M.Y. Sorokin, W. Jokat, and O. Svendsen, 2004. A Submarine Fan in the Amundsen Basin, Arctic Ocean." Marine Geology, Vol. 204, pp. 317324.

Krylov, A.A., Andreeva, I.A., Vogt, C., Backman, J., Krupskaya, V.V., Grikurov, G.E., Moran, K., Shoji, H., 2008. "A Shift in Heavy and Clay Mineral Provenance Indicates a Middle Miocene Onset of a Perennial Sea Ice Cover in the Arctic Ocean." Paleoceanography, Vol. 23, PA1S06. doi:10.1029/2007PA001497.

Lisiecki, L.E., Raymo, M.E., 2005. "A Pliocene-Pleistocene Stack of 57 Globally Distributed Benthic $\delta 180$ Records.” Paleoceanography, Vol. 20, PA 1003. doi:10.1029/2004PA001071.

Lisitzin, A.P., 2002. Sea-Ice and Iceberg Sedimentation in the Ocean. Springer, NY. 
Lisitzin, A.P., 1961. "Ice-Rafted Deposits and Glacial Epochs on the Polar Areas and their Importance for Paleogeography." International Geography Congress in Stockholm, pp. 33-43.

Lisitzin, A.P., and V.I. Chernyshova, 1970. "Rock Material from Bottom Sediments of the North Pacific.” In: The Pacific Ocean, Nauka, Moscow, pp. 237-296.

Lisitzin, A.P., V.P. Shevchenko, M.E. Vinogradov, O.V. Severina, V.V. Vavilova, I.N. Mitzkevich, 1994. "Particle Fluxes in the Kara Sea and Ob and Yenisei Estuaries.” Oceanology, Vol. 34, pp. 748-759.

Madureira, L.A.S., S.A. Kreveld, G. Eglington, H. Maureen, G. Ganssen, J.E. Hinte, J.J. Ottens, 1997. "Late Quaternary High-Resolution Biomarker and other Sedimentary Climate Proxies in a Northeast Atlantic Core."

Paleoceanography, Vol. 12, pp. 255-269.

Maslin, M.A., X.S. Li, M.F. Loutre, and A. Berger, 1998. "The Contribution of Orbital Forcing to the Progressive Intensification of Northern Hemisphere Glaciation." Quaternary Science Reviews, Vol. 17, pp. 411-426.

McCave, I.N., 2008. "Size Sorting During Transport and Deposition of fine Sediments: Sortable Silt and Flow Speed." In: M. Rebesco, A. Camerlenghi (eds) Contourites. Developments in Sedimentology, Vol. 57.

McCave, I.N., and I.R. Hall, 2006. "Size Sorting in Marine Muds:Processes, pitfalls, and prospects for paleoflow-speed proxies." Geochem. Geophys. Geosyst., Vol. 7.

McCave, I.N., I.R. Hall, and G.G. Bianchi, 2006. "Laser vs. Settling Velocity Differences in Silt Grainsize Measurements: estimation of palaeocurrent vigour." Sedimentology, Vol. 53, pp. 919-928.

McCave, I.N., Manighetti, B., Robinson, S.G., 1995a. "Sortable Silt and Fine Sediment Size/Composition Slicing; Parameters for Paleocurrent Speed and Paleoceanography." Paleoceanography, Vol. 10, pp. 593-610.

McCave, I.N., Manighetti, B., Beveridge, N.A.S., 1995b. "Circulation in the Glacial North Atlantic Inferred from Grain Size Measurements." Nature, Vol. 374, pp. 149-152.

Mercer, J.H., 1970. "A Former Ice Sheet in the Arctic Ocean.” Palaeogeography, Palaeoclimatology, Palaeoecology, Vol. 8, pp. 19-27.

Moran, K., V. Altmann, M. O’Regan, and C. Ashmankas, 2007. “Acoustic Compressional Wave Velocity as a Predictor of Glacio-marine Sediment Grain Size.” Geotechnical Testing Journal, Vol. 30, No. 4. 
Moran, K., J. Backman, H. Brinkhuis, S.C. Clemens, T. Cronin, G.R., Dickens, et al., 2006. "The Cenozoic Palaeoenvironment of the Arctic Ocean." Nature, Vol. 441, pp. 601-605.

Moros, M., Kuijpers, A., Snowball, I., Lassens, S., Backstrom, D., Gingele, F., McManus, J., 2002. "Were Glacial Iceberg Surges in the North Atlantic Triggered by Climatic Warming?” Marine Geology, Vol.192, pp. 393-417.

Mortlock, R.A., and P.N. Froelich, 1989. "A Simple Method for the Rapid Determination of Biogenic Opal in Pelagic Marine Sediments." Deep-Sea Research, Vol. 36, No. 9, pp. 1415-1426.

Mulholland, J.W., 1976. "Texture of Tills, Central Massachusetts." Journal of Sedimentary Petrology, Vol. 46, pp. 778-787.

Nam, S.I., R. Stein, H. Grobe, and H. Hubberten, 1995. "Late Quaternary GlacialInterglacial Changes in Sediment Composition at the East Greenland Continental Margin and their Paleoceanographic Implications." Marine Geology, Vol. 122, pp. 243-262.

NECP, 2008. "Real-time , Global, Sea Surface Temperature Experimental Analysis: Arctic SST." < polar.ncep.noaa.gov/sst/ophi > (July 30, 2008).

Norgaard-Pedersen, N., R.F. Spielhagen, J. Thiede, and H. Kassens, 1998. "Central Arctic Surface Ocean Environment during the Past 80,000 Years." Paleoceanography, Vol. 13, No. 2, pp. 193-204.

Nurnberg, D., I. Wollenburg, D. Dethleff, H. Eicken, H. Kassens, T. Letzig, E. Reimnnitz, and J. Thiede, 1994. "Sediments in the Arctic Sea Ice: Implications for entrainment, transport, and release." Marine Geology, Vol. 119, pp. 185-214.

O'Regan, M.A., 2007. A Cenozoic History of the Central Arctic Ocean. University of Rhode Island Doctorate Dissertation.

O’Regan, M., St. John, K., Moran, K., Backman, J., King, J., Haley, B.A., Jakobsson, M., Frank, M., Rohl, U., 2010. "Plio-Pleistocene Trends in Ice Rafted Debris on the Lomonosov Ridge." Quaternary International, Vol. 219, pp. 168-176.

Pagani, M., Arthur, M.A., Freeman, K.H., 2000. "Variations in Miocene Phytoplankton Growth Rates in the Southwest Atlantic: Evidence for changes in ocean circulation." Paleoceanography, Vol. 15, pp. 486-496. 
Pffirman, S.L., R. Colony, D. Nurnberg, H. Eicken, and I. Rigor, 1997. "Reconstructing the Origin and Trajectory of Drifting Arctic Sea Ice." Journal of Geophysical Research, Vol. 102, pp. 12575-12586.

Phillips, R.L., and A. Grantz, 1997. "Quaternary History of Sea Ice and Paleoclimate in the Amerasia Basin, Arctic Ocean, as Recorded in the Cyclical Strata of Northwind Ridge." GSA Bulletin, Vol. 109, No. 9, pp. 1101-1115.

Polyak, L., Darby, D.A., Bischof, J.F., Jakobsson, M., 2007. "Stratigraphic Constraints on Late Pleistocene Glacial Erosion and Deglaciation of the Chukchi Margin, Arctic Ocean." Quaternary Research, Vol. 67, pp. 234-245.

Poore, R.Z., R.L. Phillips, and H.J. Rieck, 1993. "Paleoclimate Record for Northwind Ridge, Western Arctic Ocean.” Paleoceanography, Vol. 8, No. 2, pp. 149159.

Prins, M.A., L.M. Bouwer, C.J. Beets, S.R. Troelstra, G.J. Weltje, R.W. Kruk, A. Kuijpers, and P.Z. Vroon, 2002. "Ocean Circulation and Iceberg Discharge in the Glacial North Atlantic: Inferences from unmixing of sediment size distributions." Geology, Vol. 30, No. 6, pp. 555-558.

Raymo, M.E., L.E. Lisiecki, and K.H. Nisancioglu, 2006. "Pli-Peistocene Ice Volume, Antarctic Climate, and the Global $\delta^{18} \mathrm{O}$ Record." Science,

Reeh, N., 2004. "Holocene Climate and Fjord Glaciations in Northeast Greenland: implications for IRD deposition in the North Atlantic." Sedimentary Geology, Vol. 165, pp. 333-342.

Reimnitz, E., M. McCormick, K. McDougall, and E. Brouwers, 1993a. "Sediment Export by Ice-Rafting from Coastal Polynya, Arctic, Alaska, USA." Arctic and Alpine Research, Vol. 25, pp. 83-89.

Reimnitz, E., J.R. Clayton, E.W. Kempema, J.R. Payne, W.S. Wefer, 1993b. "Interaction of Rising Frazil with Suspended Particles: Tank experiments with application to nature." Cold Regions Science and Technology, Vol. 21, pp. 117-135.

Reimnitz, E., M. McCormick, J. Bischof, D.A. Darby, 1998. "Comparing Sea-Ice Sediment Load with Beaufort Sea Shelf Deposits: Is entrainment selective?" Journal of Sedimentary Research, Vol. 68, pp. 777-787.

Rennermalm, A.K., E.F. Wood, S.J. Dery, A.J. Weaver, and M. Eby, 2006. Sensitivity of the Thermohaline Circulation to Arctic Runoff. Geophysical Research Letters, Vol. 33, L12703. 
Ruddiman, W.F., 1977a. "Late Quaternary Deposition of Ice Rafted Sand in the Subpolar North Atlantic (Lat. $40^{\circ}$ to $65^{\circ} \mathrm{N}$ )." Geological Society of America Bulletin, Vol. 88, pp. 1813-1827.

Ruddiman, W.F., 1977b. "North Atlantic Ice Rafting: a major change at 75000 years before present." Science, Vol. 196, pp. 1208-1211.

Ruddiman, W.F., and L.K. Glover, 1972. "Vertical Mixing of Ice-Rafted Volcanic Ash in North Atlantic Sediments." Geological Society of America Bulletin, Vol. 83, pp. 2817-2836.

Ruddiman, W.F., and JOIDES NAAG-DPG, 1991. "North Atlantic-Arctic Gateways." JOIDES Journal, Vol. 17, pp. 38-50.

Ruddiman, W.F., and A. McIntyre, 1976. "Northeast Atlantic Paleoclimatic Changes over the Past 60000 Years." Geological Society of America Mem, Vol. 145, pp. 111-146.

Ruddiman, W.F., and A. McIntyre, 1977. "Late Quaternary Surface Ocean Kinematics and Climatic Change in the High-Latitude North Atlantic." Journal of Geophysical Research, Vol, 82, pp. 3877-3887.

Ruddiman, W.F., and A. McIntyre, 1981. "The North Atlantic Ocean during the Last Deglaciation.” Palaeogeography Palaeoclimatology Palaeoecology, Vol. 35, pp. 145-214.

Ruddiman, W.F., and A. McIntyre, 1984. "Ice-Age Thermal Response and Climatic Role of the Surface Atlantic Ocean, $40^{\circ} \mathrm{N}$ to $63^{\circ} \mathrm{N}$." Geological Society of America Bulletin, Vol. 95, pp. 381-396.

Ruddiman, W.F., N.J. Shackleton, and A. McIntyre, 1986. "North Atlantic SeaSurface Temperatures for the Last 1.1 Million Years." In: M. Smmaerhayes, N.J. Shackleton (eds) North Atlantic Palaeoceanography. Geological Society Special Publications, Vol. 21, pp. 155-173.

Rutherford, S., and S. D'Hondt, 2000. "Early Onset and Tropical Forcing of 100,000year Pleistocene Glacial Cycles.” Nature, Vol. 408, pp. 72-75.

Sakamoto, T., M. Ikehara, K. Aoki, K. Iijima, N. Kimura, T. Nakatsuka, and M. Wakatsuchi, 2005. "Ice-Rafted Debris (IRD)- Based Sea-Ice Expansion Events during the Past 100 kyrs in the Okhotsk Sea." Deep-Sea Research, Vol. 52, pp. 2275-2301.

Schreiber, B.C., 1968. "Sound Velocity in Deep Sea Sediments." Journal of Geophysical Research, Vol. 73, pp. 1259-1268. 
Schultheiss, P.J., and S.D. McPhail, 1989. “An Automated P-Wave Logger for Recording Fine-Scale Compressional Wave Velocity Structures in Sediments." Proc. ODP Sci. Results, Vol. 108, pp. 407-413.

Shackleton, N.J., J. Imbrie, and N.G. Pisias, 1988. "The Evolution of Oceanic Oxygen-Isotope Variability in the North Atlantic Over the Past Three Million Years.” Phil. Trans. R. Soc. Lond. B, Vol. 318, pp. 679-688.

Singarayer, J.S., J.L. Bamber, and P.J. Valdes, 2006. "Twenty-First Century Climate Impacts from a Declining Arctic Sea Ice Cover." Journal of Climate, Vol. 19, pp. 1109-1124.

Smythe, F.W., W.F. Ruddiman, and D.N. Lumsden, 1985. "Ice-Rafted Evidence of Long-term North Atlantic Circulation.” Marine Geology, Vol. 64, pp. 131141.

Goossens, D., 2008. "Techniques to Measure Grain-Size Distributions of Loamy Sediments: a comparative study of ten instruments for wet analysis." Sedimentology, Vol. 55, pp. 65-96.

Steurer, J.F., and M.B. Underwood, 2003. "Data Report: The Relation Between Physical Properties and Grain-Size Variations in Hemipelagic Sediments from Nankai Trough.” In Mikada, H., G.F. Moore, et al. (Eds.), Proc. ODP Sci. Results, Vol. 190/196.

Stickley, C.E., K. St John, N. Koc, et al., 2009. "Evidence for Middle Eocene Arctic Sea Ice from Diatoms and Ice-Rafted Debris." Nature, Vol. 460, pp. 376-390.

St. John, K., 2008. "Cenozoic Ice-Rafting History of the Central Arctic Ocean: Terrigenous Sands on the Lomonosov Ridge." Paleoceanography, Vol. 23.

Svendsen, J.I., Alexanderson, H., Astakhov, V.I.,, et al., 2004. "Late Quaternary Ice Sheet History of Northern Euraisa." Quaternary Science Reviews, Vol. 23, pp. 1229-1271.

Thiede, J., O. Eldholm, E. Taylor, 1989. "Variability of Cenozoic NorwegianGreenland Sea Paleoceanography and Northern Hemisphere Paleoclimate." Proceedings of ODP, Scientific Results, Vol. 104.

Tripati, A., J. Backman, H. Elderfield, and P. Ferretti, 2005. "Eocene Bipolar Glaciation Associated with Global Carbon Cycle Changes." Nature, Vol. 436, pp. 341-346.

Vanney, J., and L. Dangeard, 1976. "Les deposits glacio-marins actuels et anciens." Rev Geogr Montr, Vol. 30, pp. 9-50. 
Vorren, T.O., and J. Thiede, 1994. "The Marine Geology of the Arctic Ocean." Marine Geology, Vol. 119, pp. 357-361.

Wefer, G., E. Suess, W. Balzer, et al., 1982. "Fluxes of Biogenic Components from Sediment Trap Deployment in Circumpolar waters of the Antarctic sector." In: U. Bleil and J. Thiede (eds) Geological History of the Polar Oceans: Arctic versus Antarctic, Kluwer Academic Publishing, Dordrecht, pp. 245-254.

Wefer, G., G. Fisher, D. Futterer, R. Gersonde, S. Honjo, D. Osterman, 1990. "Particle Sedimentation and Productivity in Atlantic waters of the Atlantic sector." In: U. Bleil and J. Thiede (eds) Geological History of the Polar Oceans: Arctic versus Antarctic, Kluwer Academic Publishing, Dordrecht, pp. 363-380.

Weller, P., and R. Stein, 2008. "Paleogene Biomarker Records from the Central Artic Ocean (IODP Exp. 302): Organic Carbon Sources, Anoxia, and Sea Surface Temperatures. "Paleoceanography, Vol. 23.

Wen, B., Aydin, A., Duzgoren-Aydin, N.S., 2002. "A Comparative Study of Particle Size Analyses by Sieve-Hydrometer and Laser Diffraction Methods." ASTM Geotechnical Testing Journal, Vol. 25, pp. 434-442.

Winter, B.L., C.M. Johnson, and D.L. Clark, 1997. "Strontium, Neodymium, and Lead Isotope Variations of Authigenic and Silicate Sediment Components from the Late Cenozoic Arctic Ocean: Implications for Sediment Provenance and the Source of Trace Metals in Seawater." GSA, Vol. 61, No. 19, pp. 41814200 .

Winton, M., 2006. “Amplified Arctic Climate Change: What does surface albedo feedback have to do with it?" Geophysical Research Letters, Vol. 33, L03701.

Wolf-Welling, T.C.W., M. Cremer, S. O’Connell, A. Winkler, and J. Thiede, 1996. "Cenozoic Arctic Gateway Paleoclimate Variablity Indications from Changes in Coarse-Fraction Composition." Proceedings of the Ocean Drilling Program, Scientific Results, Vol. 151, pp. 515-567.

Woodruff, F., Savin, S.M., 1989. "Miocene Deepwater Oceanography." Paleoceanography, Vol. 4, pp. 87-140.

Woods Hole Oceanographic Institution, 2008. "Image: Arctic Ocean Circlation Primer." Polar Research, $<$ www.whoi.edu/page.do?pid $=12317 \&$ tid $=441 \&$ cid $=41043 \& \mathrm{ct}=61 \&$ article $=23$ 446>. (March 3, 2008). 
Zachos, J., M. Pagani, L. Sloan, E. Thomas, and K. Billups, 2001. “Trends, Rhythms, and Aberrations in Global Climate 65 Ma to Present." Science, Vol. 292, pp. 686-693. 